


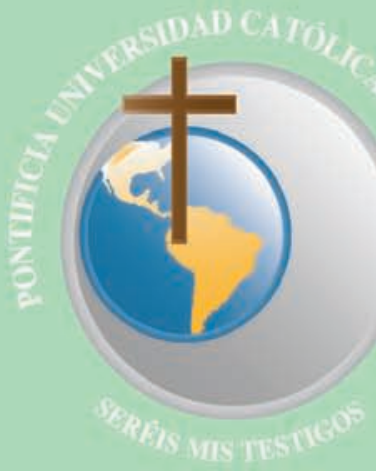

PONTIFICIA

UNIVERSIDAD

CATÓLICA

\section{DEL ECUADOR}

NÚMERO GENERAL

3 DE NOVIEMBRE 2015-3 DE MAYO 2016 QUITO, ECUADOR 


\section{PONTIFICIA UNIVERSIDAD CATÓLICA DEL ECUADOR}

\section{Centro de Publicaciones}

Revista PUCE

Número General

Quito, Ecuador

\section{Rector}

Dr. Fernando Ponce León, S. J.

\section{Vicerrector}

Dr. Fernando Barredo Heinert, S. J.

\section{Directora General Académica}

Dra. Graciela Monesterolo Lencioni

\section{Director del Centro de Publicaciones}

Mtr. César Eduardo Carrión

\section{Comité Ejecutivo del Centro de Publicaciones} (Comité Editorial):

Dra. Mercedes Mafla Simon

Dr. León Espinosa O.

Dr. Álvaro Mejía S.

Mtr. César Eduardo Carrión

\section{Presidente (Editor en Jefe)}

Dr. Alberto Rengifo A.

Secretario (Coordinador del Comité Editorial)

Lic. Walter Jiménez S.

\section{Autores que pertenecen a la PUCE}

Andrade Susana

Argüello Susana

Buitrón María Elena

Cagigal José Luis

Dávila Ana Gabriela

De la Torre David

Díaz Ana

Estrella Ana

García María Verónica

Gea-Izquierdo Enrique

Gordillo Ruth

Granja Jorge

Lyco Halina

Maldonado Priscila

Nicolalde Damián

Paredes Ana

Pareja Daniela

Robayo Aníbal

Sarmiento Marisol

Segovia Fausto

Schweider Peter

Stefos Efstathios

Wong María Belén 


\section{Autores externos a la PUCE}

Estrella Andrés

Gavidia José (Ministerio del Interior, Comandancia General de Policía Nacional, Quito, Ecuador).

Gea-Izquierdo Enrique (Universidad de Málaga, Málaga, España).

Nicolalde Daniel

Ortega José Luis (Universidad de Granada, Facultad de Ciencias de la Educación, Granada, España).

Palacios Teresa (Universidad Central del Ecuador, Facultad de Ingeniería, Minas, Petróleos y Ambiental, Quito, Ecuador).

Peña Sonia (Universidad de Granada, Facultad de Ciencias de la Educación, Granada, España).

Valencia Mónica (Universidad de Carabobo, Facultad de Ciencias de la Educación, Carabobo, Venezuela).

\section{Corrector de estilo y ortografía}

Alfonso Sánchez

Colección n. ${ }^{\circ} 102$

3 de mayo de 2016

Publicación semestral

ISSN: 13907719

Registro de Derecho Autoral: 010645

Ingresada al Catálogo Latindex. Folio: 21880

La Revista de la Pontificia Universidad Católica del Ecuador es una publicación semestral (mayo y noviembre) de su Centro de Publicaciones. Difunde trabajos académicos y científicos, estrictamente originales en español, en las área de Leyes, Pedagogía, Ingeniería, Economía, Biología, Química, Historia, Geografía, Antropología, Sociología, Filosofía, Teología, Comunicación, Lingüística, Literatura, Medicina, Administración, Arquitectura, Gestión Social, Psicología y Diseño. El propósito de la Revista PUCE es difundir conocimientos, intercambiar experiencias e incentivar la producción del pensamiento especializado. El contenido de esta revista está dirigido a docentes, investigadores, estudiantes universitarios y público en general. Esta revista es arbitrada por especialistas de indiscutible valor, cuyos nombres se mantienen en absoluta confidencialidad.

Los artículos son de responsabilidad exclusiva de sus autores.

Los derechos de autor son exclusivos de la PUCE.

Se prohíbe la reimpresión parcial o total con cualquier finalidad sin el previo consentimiento por escrito del Centro de Publicaciones de la PUCE.

Editorial (Punto de venta)

Centro de Publicaciones PUCE

Av. 12 de Octubre y Robles

Apartado n. ${ }^{\circ} 1701-2184$

Teléf:: 593-02-291700

2991700 (Troncal). Extensiones: 1013, 1711, 1122

Teléf.: 593-02-2991711, ext.: 1927

arengifo@puce.edu.ec

Quito, Ecuador

\section{Impresión}

PPL Impresores. 2529762

Quito, Ecuador

pplimpresores@gmail.com 



\section{EDITORIAL}

La palabra, ayer, hoy y mañana, seguirá teniendo un grandísimo poder, pues una sola basta para herir o curar, mancillar o enaltecer, ofender o perdonar.

Por esto, alguien decía que una buena palabra dicha en el momento justo, con el tono adecuado, a la persona indicada, puede constituir ese aliento que se necesitaba para retomar los ideales y volver a vivir a plenitud.

Esperamos, sinceramente, que las palabras que aparecen en este nuevo número general de la Revista PUCE, el 102, constituyan las puertas para entender, más y mejor, las diferentes disciplinas que de un modo u otro interactúan en la vida del ser humano.

Deseamos que los aportes interdisciplinarios que se mueven por los caminos de la Antropología, Bioacústica, Comunicación, Economía, Educación, Filosofía, Medicina, Psicología, Sociología y Teología, escritos por connotados profesionales de la PUCE y de otras universidades nacionales y extranjeras, nos hagan reflexionar acerca del compromiso que todos tenemos, sin excepción, y desde el lugar donde ejerzamos nuestro trabajo, de unir nuestros anhelos y esperanzas en la búsqueda de un desarrollo sostenible integral que nos permita vislumbrar un mundo en el cual podamos amar y ser felices.

Con beneplácito, entonces, ponemos en sus manos, amable lector, esta revista que es el resultado de un trabajo solidario, de una esperanza compartida. Disfrútela y corra la voz.

Agradecemos a las autoridades de la PUCE y a todos cuantos han colaborado para que la Revista PUCE n. 102 salga a luz y continúe alumbrando no solo las faenas académicas sino también la lucha diaria por compartir una vida solidaria y justa.

\section{Alberto B. Rengifo A}

Editor 



\section{CONTENIDO}

\section{ANTROPOLOGÍA}

LA CONSTRUCCIÓN DEL DISCURSO SOBRE PATRIMONIO INMATERIAL

\section{Y LAS POLÍTICAS CULTURALES EN EL ECUADOR}

BUILDING THE INMATERIAL HERITAGE DISCOURSE

AND CULTURAL POLICIES IN ECUADOR

Susana Andrade

BIOACÚSTICA

SELECCIÓN, ANOTACIÓN

Y ETIQUETADO DE LOS CANTOS

DE LAS RANAS DEL ECUADOR

SELECTION, ANNOTATION AND LABELING

OF ECUADORIAN FROG CALLS

Andrés Estrella, Daniel Nicolalde, Damián Nicolalde, Daniela Pareja

COMUNICACIÓN

LA CRISIS DE LAS EMPRESAS INFORMATIVAS REPLANTEA EL PERFIL DEL PERIODISTA ACTUAL

THE CRISIS IN THE MASS MEDIA COMPANIES

REQUIRES A REDEFINITION OF THE PROFILE

OF THE JOURNALIST NOWADAYS

Ana Gabriela Dávila J.

ECONOMÍA

PERSPECTIVAS COMERCIALES DEL ECUADOR CON LOS PAÍSES

DE EUROPA DEL ESTE: BULGARIA, ESLOVAQUIA, HUNGRÍA, POLONIA, REPÚBLICA CHECA Y RUMANÍA, MIEMBROS DE LA UNIÓN EUROPEA

ECUADOR'S TRADE PERSPECTIVES WITH EASTERN EUROPE COUNTRIES:

BULGARIA, HUNGARY, POLAND, CZECH REPUBLIC AND ROMANIA, MEMBERS OF THE EUROPEAN UNION

Halina Lyko Marczak, Aníbal Robayo Lemarié, María Belén Wong 
INTERSUBJETIVIDAD ORIENTATIVA NUEVA ÉTICA EN QUE LA ACCIÓN INDIVIDUAL Y EL COMPROMISO PERSONAL NO ESTÉN DESVINCULADOS DE LOS INTERESES COLECTIVOS

APPROXIMATE INTERSUBJECTIVITY NEW ETHICS IN INDIVIDUAL ACTION AND PERSONAL COMMITMENT ARE NOT UNRELATED TO COLLECTIVE INTERESTS

Mónica Valencia Bolaños

\section{MÁS ALLÁ DE LAS FRONTERAS}

BEYOND BORDERS

Jorge Granja E.

LA ENSEÑANZA Y APRENDIZAJE DEL INGLÉS COMO LENGUA AÑADIDA: ESTUDIO DE CASO DE LA COMUNIDAD INMIGRANTE EN BRADFORD TEACHING AND LEARNING ENGLISH AS AN ADDITIONAL LANGUAGE: CASE STUDY OF THE IMMIGRANT COMMUNITY IN BRADFORD

Sonia Peña, José Luis Ortega

APROXIMACIÓN AL ESTUDIO DE LA NEUROEDUCACIÓN: EL ENCUENTRO DE LAS CIENCIAS CON LA ESCUELA

AN APPROACHTOTHE STUDY OF NEUROEDUCATION: THE MEETING BETWEEN SCIENCE AND EDUCATION

Fausto Segovia Baus

RELACIONES ENTRE NOTAS DEL ALUMNO Y EVALUACIONES AL PROFESOR RELATIONSHIP BETWEEN STUDENT GRADES AND TEACHER EVALUATIONS

José Luis Cagigal G.

FILOSOFÍA

SOBRE LA CONCEPCIÓN BERGSONIANA DE "INTUICIÓN" Y LAS CONSECUENCIAS PARA LA COMPRENSIÓN DE LA CIENCIA Y LA METAFÍSICA (UNA COMPARACIÓN CON KANT)

ABOUT THE BERGSONIAN CONCEPT OF "INTUITION"AND THE CONSEQUENCES FOR THE UNDERSTANDING OF SCIENCE AND METAPHYSICS (A COMPARISON WITH KANT) Ruth Gordillo R.

LA ARQUEOLOGÍA BÍBLICA: UNA CIENCIA HERMENÉUTICA ENTRE HISTORIA Y TOLDOT

BIBLICAL ARCHAEOLOGY: A QUEST OF HISTORY BETWEEN HISTORIA AND TOLDOT

Stéphane Vinolo 
LENGUA Y LITERATURA

¡FULL LINDO!: ACERCA DEL USO DE FULL EN EL HABLA DE ECUADOR

FULL LINDO!: THE USE OF FULL

IN ECUADORIAN SPANISH

Ana Estrella-Santos

MEDICINA

APLICACIÓN DEL TEST DE FUKUDA PARA IDENTIFICACIÓN DE ALTERACIONES PROPIOCEPTIVAS EN PACIENTES PRE Y POSQUIRÚRGICOS DE EXTRACCIÓN DEL TERCER MOLAR, EN EL HOSPITAL "PABLO ARTURO SUÁREZ”

FUKUDA TEST APPLICATION FOR PROPRIOCEPTIVE ALTERATIONS IDENTIFICATION

IN PATIENTS BEFORE AND AFTER EXTRACTION OF THIRD MOLAR SURGERY,

IN THE HOSPITAL PABLO ARTURO SUAREZ

Susana Argüello P.,Cristina Díaz C., Adrián Rubio

TECNOLOGÍAS EN INFORMACIÓN Y COMUNICACIÓN SANITARIA

SANITARY INFORMATION AND COMMUNICATION TECHNOLOGIES

Miriam Elena Buitrón, Enrique Gea, María Verónica García

SOCIOLOGÍA

LA ARQUITECTURA DE LAS ORGANIZACIONES EN EL SIGLO XXI

ARCHITECTURE OF THE ORGANIZATIONS IN THE CENTURY XXI

Peter José Schweizer

SEGURIDAD ALIMENTARIA Y SU RELACIÓN CON FACTORES SOCIECONÓMICOS: CASO FAMILIA DE PRODUCTORES DE QUINUA DE LA PARROQUIA SAN ISIDRO, CANTÓN ESPEJO, PROVINCIA DEL CARCHI

FOOD SECURITY RELATED FACTORS SOCIOECONOMIC: CASE FAMILY QUINOA PRODUCERS PARISH SAN ISIDRO, CANTON ESPEJO, CARCHI

Priscila Maldonado $\mathrm{P}$.

PERFIL DE LOS DESEMPLEADOS ECUATORIANOS

UN ANÁLISIS MULTIDIMENSIONAL

PROFILE OF THE UNEMPLOYED ECUADORIANS A MULTIDIMENSIONAL ANALYSIS

Ana Paredes, Marisol Sarmiento, Efstathios Stefos

DISEÑO METODOLÓGICO PARA LA VALORACIÓN ECONÓMICA

DE LOS SERVICIOS AMBIENTALES DE LA RESERVA ECOLÓGICA "HOLA VIDA" METHODOLOGICAL DESIGN FORTHE ECONOMIC VALUATION 
OF THE ENVIRONMENTAL SERVICES "HOLA VIDA" ECOLOGICAL RESERVE

José Gavidia B., Teresa Palacios C., Carmen Yauri B.

TEOLOGÍA

LA TEOLOGÍA DE LA LIBERACIÓN DEL ECUADOR LÍDERES, PRINCIPIOS Y ESTILO DE IGLESIAS

ECUADORIAN LIBERATION THEOLOGY

LEADERS, PRINCIPLES AND STYLE OF THE CHURCHES

Boris Tobar Solano

LOGOS Y VERDAD

INTRODUCCIÓN A LA PERSPECTIVA CRISTOLÓGICA DE LA VERDAD

LOGOS AND TRUTH INTRODUCTION TO THE CHRISTOLOGICAL PERSPECTIVE OF TRUTH

Agustín Garcells Suárez

405

LA VERDAD DE LA ESCRITURA: ENTRE TEOLOGIA DOGMÁTICA Y EXÉGESIS

THE TRUTH OF THE SCRIPTURE: BETWEEN DOGMATIC THEOLOGY AND EXEGESIS

David de la Torre

429

INSTRUCTIVO PARA PUBLICAR ARTÍCULOS EN LA REVISTA PUCE

INSTRUCTIONS FOR PUBLISHING ARTICLES IN THE "REVISTA PUCE" (PUCE JOURNAL) 
ANTROPOLOGÍA 


\section{LA CONSTRUCCIÓN DEL DISCURSO SOBRE PATRIMONIO INMATERIAL Y LAS POLÍTICAS CULTURALES EN EL ECUADOR}

\section{BUILDING THE INMATERIAL HERITAGE DISCOURSE AND CULTURAL POLICIES IN ECUADOR}





\title{
LA CONSTRUCCIÓN DEL DISCURSO SOBRE PATRIMONIO INMATERIAL Y LAS POLÍTICAS CULTURALES EN EL ECUADOR ${ }^{1}$
}

\author{
Susana Andrade*
}

\section{RESUMEN}

El artículo aborda los procesos de pensar y gestionar la cultura cuando manifestaciones culturales que antes no fueron consideradas expresiones de la memoria y la identidad nacional, hoy son reconocidas como parte de los inventarios y declaraciones del patrimonio inmaterial.

El artículo explora procesos de construcción del discurso sobre el patrimonio cultural desde la política cultural de UNESCO hasta las declaratorias patrimoniales del gobierno nacional.

Al analizar algunos efectos de la política cultural observaremos el debilitamiento que afecta las identidades y culturas locales cuando se convierten en fichas de inventarios o de listas representativas.

Palabras clave: patrimonio inmaterial, políticas culturales, identidad nacional, UNESCO

\section{ABSTRACT}

This article reflects on new ways of thinking and managing culture. Cultural expressions that historically have not been given value or considered part of the national identity have begun to be recognized and declared as Inmaterial Heritage of humanity and Ecuador.

This article explores how the discourse of Cultural heritage is built by in-

\footnotetext{
* Pontificia Universidad Católica del Ecuador, Facultad de CC.HH, Quito, Ecuador ( andrades@hotmail.com). 'Agradezco a las estudiantes Natalia Breilh, María José Arellano y Alejandra Atiencia por su participación en el taller y proyecto de investigación sobre patrimonio inmaterial durante los años 2011 y 2012. Una versión de este artículo fue presentado en el XIV Congreso Colombiano de Antropología, Medellín, octubre, 2013. Los resultados de la investigación serán publicados próximamente.
} 
ternational politics (UNESCO) and applied by local governments like Ecuador.

The politics and practices of cultural heritage will paradoxically show how local cultures and identities are threatened and more vulnerable now than ever.

Key words: World Heritage, cultural policies, national identity, UNESCO

\section{ASPECTOS METODOLÓGICOS}

En este artículo reflexionamos sobre la investigación realizada por un equipo de tres estudiantes y una profesora de la Escuela de Antropología de la Universidad Católica del Ecuador en el año 2012. El proyecto se enfocó en cuatro casos de intervención de la política patrimonial pública en igual número de provincias del Ecuador: el complejo turístico "Aldea Colorada" (Santo Domingo de los Tsáchilas); el proceso de declaratoria patrimonial de la danza ritual la Yumbada (Pichincha); la declaratoria de patrimonio inmaterial del ídolo prehispánico San Biritute (Santa Elena); y emprendimientos culinarios de la chicha de jora (Imbabura). Por limitaciones de espacio nos referiremos con más detalle, exclusivamente a los dos primeros estudios de caso.

Evaluamos el carácter de las intervenciones ejecutadas por el Instituto Nacional de Patrimonio Cultural (INPC) y el Ministerio Coordinador de Patrimonio², reconocibles tanto en el discurso como en la implementación y consecuencias de estas acciones sobre las comunidades involucradas. ${ }^{3}$

El proyecto reunió entrevistas a funcionarios públicos de nivel alto y medio del Ministerio Coordinador de Patrimonio, Instituto Nacional de Patrimonio Cultural (INPC), el área de gestión patrimonial del Municipio de Quito y gobiernos locales y provinciales. Organizamos un taller en la provincia de Chimborazo, con representantes de comunidades indígenas, universidades, INPC y ONG's, con el fin de evaluar los resultados de las políticas patrimoniales ejecutadas a nivel provincial y nacional. Pobladores, protagonistas directos de los proyectos de declaratorias patrimoniales, compartieron generosamente sus experiencias.

En el presente artículo presentamos una mirada general sobre la política

\footnotetext{
${ }^{2}$ El Ministerio de Coordinación de Patrimonio Cultural fue eliminado en el 2014 y algunas de sus funciones fueron absorbidas por el Ministerio de Cultura y Patrimonio.

${ }^{3}$ Para un mayor detalle de cada estudio de caso remitirse al informe final del proyecto: "Patrimonio Cultural Inmaterial, entre el discurso oficial y la realidad social: tres estudios de caso", Dirección de investigación de la PUCE, diciembre del 2012.
} 
relativa al patrimonio cultural inmaterial que tiene como referencia los casos del complejo turístico "Aldea Colorada" (provincia de Santo Domingo de los Tsáchilas) y el proceso de declaratoria patrimonial de la danza ritual la Yumbada (provincia de Pichincha).
La investigación completa y los análisis pormenorizados se presentarán en una publicación de próxima aparición.

\section{ANTECEDENTES}

El discurso y la gestión del patrimonio cultural han sido influenciadas, no solo por las políticas y directrices que emanan de la UNESCO sino también por las nociones trabajadas por la teoría social contemporánea y por las demandas que surgen de los movimientos sociales e indígenas de América Latina.

Las reivindicaciones incluyen el reconocimiento de las diversidades culturales, la lucha contra el racismo y la discriminación, la vitalidad de las lenguas, saberes e identidades, la construcción de un Estado Plurinacional e Intercultural, como lo reconoce la Constitución del Ecuador del 2008. ${ }^{4}$

Los movimientos sociales cuestionaron y redefinieron los conceptos de cultura, identidad, multiculturalidad, sumak kausay, plurinacionalidad, interculturalidad, entre otras nociones. Por ello,
Stuart Hall señala la necesidad de pensar con los movimientos sociales y teorizar desde la práctica. "La emergencia de los márgenes", a la que hace referencia, es justamente la lucha de los movimientos sociales por disputar el poder cultural, alrededor de la pluralización de la sociedad, el reconocimiento de la diversidad cultural y de la interculturalidad (Hall, 2013: 12). ${ }^{5}$ Revisemos brevemente el uso que se ha dado a algunos de estos conceptos.

En Ecuador, las visiones sobre Patrimonio Cultural Inmaterial (PCl) desarrolladas por UNESCO confluyen con el discurso oficial del Buen Vivir o sumak kausay promovido por el gobierno del presidente Rafael Correa. Se plantea un nuevo modelo de desarrollo inspirado en la cosmovisión de los pueblos andinos. El Buen Vivir promete justicia social, reducción de la pobreza, redistribución

\footnotetext{
${ }^{4}$ Recordemos los sucesivos levantamientos indígenas en Ecuador a partir de 1990. Fueron protestas masivas que lograron cambios políticos decisivos a favor de los derechos colectivos, el reconocimiento de la interculturalidad y la plurinacionalidad.

${ }^{5}$ En Ecuador varios autores han trabajado sobre la historia del movimiento indígena, sus luchas y aportes teóricos: Becker (2015), Tuaza (2011) Martínez (2009), Ospina (2010).
} 
de la riqueza, derechos de la naturaleza; todo dentro de un Estado plurinacional e intercultural. ${ }^{6}$

Pero, ¿qué es el sumak kausay? El Buen Vivir es un concepto de la filosofía andina que supone respetar y vivir en equilibrio con el cosmos, la naturaleza, los seres humanos y las divinidades. El deterioro de este tejido de relaciones puede ocasionar enfermedad, desastres naturales y otros males. El sumak kausay no busca únicamente la prosperidad económica sino un bienestar que integra lo social, lo espiritual y lo material. La noción remite a una visión del mundo, un estilo de vida, una conducta apropiada entre los miembros de una comunidad y abarca los legados ancestrales, la cultura material entrelazada con poderosos simbolismos y formas de organización y redistribución económica y social.?

El sumak, es la plenitud, lo sublime, excelente, magnifico, hermoso, superior. El kawsay, es la vida, es ser estando pero es dinámico, cambiante, no es una cuestión pasiva. Por lo tanto sumak kawsay sería la vida en plenitud. La vida en excelencia material y espiritual". (Dirigente indígena Luis Macas en Schavelzon, 2015:209)
El uso del término por los gobiernos de Ecuador y Bolivia, ha sido muy criticado por ser "el Estado quien determina en términos tecnocráticos, economicistas y humanistas lo que es Buen vivir y desarrollo" (Walsh en Schavelzon, 2015:186). El Buen Vivir se ha convertido, en palabras de Curbelo, en un eslogan, una cultura light, un sombrero expuesto en un maniquí desnudo. Sin contenido y sin repercusiones reales en la vida cotidiana. $^{8}$

La noción de plurinacionalidad, también impulsada desde las luchas indígenas, demanda reconocer y legitimar a las nacionalidades y pueblos del país y rechaza la visión de una sola cultura, una sola lengua, una sociedad y un estado-nación.

Tanto en Bolivia como en Ecuador, la idea de lo plurinacional surge de la fuerza política e intelectual quechua y aymara, con su crítica de la república liberal construida por una élite criolla que obtuvo la independencia política, pero mantuvo la admiración y dominancia de la cultura europea. Son estas poblaciones de alta densidad demográfica las que emprenden la lucha anticolonial asociándose a minorías étnicas y también cuestionando

\footnotetext{
${ }^{6}$ Según algunos autores, gobiernos latinoamericanos de 'izquierda' como el de Rafael Correa, se han convertido en regímenes neoextractivistas por su dependencia del petróleo, gas, minerales, y por sus acuerdos con grandes corporaciones de Estados Unidos, Canadá, China. (Ver Escobar, 2012, Acosta, 2012, Gudynas, 2009).

'Para recientes análisis sobre los conceptos de plurinacionalidad y Sumak Kausay ver: Sánchez Parga, 2014, Schavelzon, 2015; Gudynas, Eastermann et al, 2014, Pilataxi, 2014.

${ }^{8}$ Diario El Universo, artículo de opinión, Guayaquil,17 de junio del 2015.
} 
el nacionalismo, la bandera política que negaba sus orígenes. (Schavelzon, 2015:73)

En cuanto al Estado plurinacional, este es definido por la presencia de diversas nacionalidades e identidades, alimentadas por la riqueza de culturas diferentes. ${ }^{9}$

El país intenta marcar la diferencia y ejercita soberanía patrimonial frente a procesos de globalización, proponiendo el patrimonio inmaterial como elemento diferenciador. Visualizamos el patrimonio inmaterial como el elemento que configura personalidad al Ecuador en su diversidad y multiplicidad de culturas. (Entrevista a funcionario del Ministerio de Patrimonio, 12 de agosto del 2012)

El paradigma intercultural, incorporado a las políticas públicas, postula la inclusión y reconocimiento de las culturas indígenas, afroecuatorianas y montubias. ${ }^{10}$ Se presenta como un espacio de diálogo entre las diversas culturas para construir una nueva relación social, más igualitaria, inclusiva y sin discrimi- nación. A nivel político, la interculturalidad se plantea como una herramienta de transformación del Estado y la sociedad, que obliga a efectuar cambios al conjunto de las políticas públicas.

Los pueblos y nacionalidades del Ecuador conservaban su representación en organismos públicos como una manera de asegurar los procesos de inclusión social y política, hasta la llegada a la presidencia de Rafael Correa. ${ }^{11}$ A partir de entonces, objetan la interculturalidad retórica del gobierno: simples enunciados que no producen un cambio estructural ni instaurar la justicia social. ${ }^{12}$ Esta interculturalidad 'políticamente correcta' no cuestiona las relaciones de poder ni los patrones de dominación social vigentes.

No se trata de asumir que los proyectos interculturales sirven solamente para promover el mayor conocimiento de fiestas y danzas que hay en el país, ni para aprender a cocinar los distintos ingredientes regionales. Menos aún se trata de valorar la "diversidad cultural" como un simple particularismo estético o como una pieza de museo car-

\footnotetext{
${ }^{9}$ Agenda del Consejo Sectorial de Patrimonio 2011-2013.

${ }^{10}$ Existen 14 nacionalidades y 18 pueblos en el Ecuador que representan aproximadamente el 20\% de la población. http://www.codenpe.gob.ec/index.php?option=com_content\&view=article\&id=125\&catid=96 Según el censo del 2010 la población afroecuatoriana representa el 7.2\%; la población montubia el 7.4\% y la población indígenas alrededor del 7.3\%. https://redciecuador.wordpress.com/2012/03/02/como-estamoslos-pueblos-indigenas-segun-el-censo-2010.

${ }^{11}$ Desde 1990, a raíz de la protesta social, se creó el Proyecto de Educación Bilingüe Intercultural (EBI), la Dirección Nacional de Salud Intercultural (DINAIB), el Consejo de Nacionalidades y Pueblos del Ecuador (CODENPE), con representación de las diferentes nacionalidades.

${ }^{12}$ Ver Andrade, 2009.
} 
gada de un esencialismo nostálgico (Vich, 2014:49).

Chaves (2010) se pregunta si los discursos y marcos ideológicos de las políticas patrimoniales, como el Buen Vivir, la plurinacionalidad, la interculturalidad así como las iniciativas de patrimonialización, no se encuentran en sintonía con un proyecto de nación 'incluyente y multicultural'afín al neoliberalismo e interesado en la capitalización de los recursos culturales. Cuestiona además, si estas políticas son eficaces en la generación de inclusión social y horizontes político plurales (2010:10).

En el caso ecuatoriano, hay que subrayar que las nociones de interculturalidad y plurinacionalidad se gestan desde la resistencia de los pueblos indígenas, por lo que sus significados superan los reduccionismos y esencialismos del que son objeto $y$, por tanto, se distinguen en su génesis y desarrollo, del multiculturalismo asociado a la lógica economicista neoliberal. "Es el espacio abierto por el multiculturalismo el que ha permitido pensar (y usar) la diversidad cultural como recurso económico. Y como un recurso que exige ser gestionado y administrado." (Montenegro, 2013:42)

A pesar de la elocuencia del gobierno ecuatoriano en el uso continuo de estas nociones, las comunidades indígenas, las organizaciones y movimientos sociales y ambientales, están excluidos de la política cultural, económica y social de la revolución ciudadana. No forman parte de las discusiones del plan nacional del Buen Vivir ni de los proyectos de patrimonialización. Hay organizaciones indígenas que condenan la apropiación gubernamental de dichas nociones, mientras reclaman por el desmantelamiento de programas que estaban en manos de las organizaciones sociales. ${ }^{13}$

\section{ALGUNOS ENFOQUES SOBRE PCI EN LA LITERATURA SOCIAL}

Antes de abordar el proceso seguido en la configuración del concepto de $\mathrm{PCl}$ y algunas repercusiones de su aplicación para el caso ecuatoriano, nos detendremos brevemente en algunos ejes de análisis abordados por la literatura sobre $\mathrm{PCl}$.
Estas tesis, que presentamos de modo resumido, tienen en común una crítica al enfoque multicultural concebido desde un marco ideológico neoliberal:

1. Un primer eje es el análisis crí-

\footnotetext{
${ }^{13}$ Los proyectos e instituciones con representación indígena y afroecuatoriana, citados en la nota n. 11 fueron eliminados por el gobierno del presidente Correa.
} 
tico de los estudios sobre el PCl como política cultural aislada de determinaciones políticas y económicas. Se señala que la diversidad, la identidad y las demandas culturales podrían distraer el debate por los derechos sociales y políticos.

Al giro cultural ha seguido, casi de inmediato, el multicultural. Esto ha significado el desplazamiento de intereses sociales como la representación política hacia la reivindicación de la diversidad; es decir, hacia la esfera de la "identidad" y el reemplazo de las demandas sociales por las demandas culturales (Chaves, 2010:17).

Otros autores hablan de un adelgazamiento de la categoría de cultura y su inutilidad política (Comaroff, Brown en Montenegro, 2013:48 )

2. Otro reparo se refiere a los problemas de conceptualización de las políticas del PCl pues se refieren a esencialismos locales, identidades cerradas y diferencias culturales irreductibles, que esconden la dimensión histórica de las prácticas culturales y los dinámicos procesos de transformación de las identidades.

... aparecen como indisociablemente ligados a una localidad, una esencia y una identidad, se invisibiliza, si no se niega, su constante transformación. (Chaves, 2010:14).

3. Se señala también al marco institucional como un inconveniente en los procesos de patrimonialización. Existe una variedad de actores y gestiones en la política patrimonial así como inestabilidad, duplicidad e incompetencia de las instituciones encargadas de la política cultural.

4. El uso de categorías de la economía de mercado -recursos, capital, valor-, en el análisis de la política cultural (y su producción, distribución y consumo), privilegia la relación con los mercados turísticos y la activación económica de lo cultural. Como lo explica Montenegro:

Esta lógica del valor puede derivar en una búsqueda compulsiva de diferencias, e incluso en su impostura. No la identificación de lo diverso sino su producción. En efecto, la diversidad cultural no solamente se identifica, también se produce, y esta producción muchas veces se pone al servicio de intereses económicos. (2013:46)

Veremos más adelante cómo algunos datos de nuestra investigación, concuerdan con los ejes analíticos aquí descritos. 


\section{CONFIGURACIÓN DEL DISCURSO DE PATRIMONIO CULTURAL INMATERIAL}

La UNESCO ha diseñado su discurso y sus políticas de acción global en torno al patrimonio cultural, en medio de tensiones derivadas de demandas sociales, intereses hegemónicos en competencia y contando también con los aportes de los estudios sobre la cultura. ${ }^{14}$

Durante el siglo XIX y mediados del XX, las nociones de cultura y patrimonio nacional se asociaban a la herencia colonial y prehispánica de carácter material: pinturas, monumentos, sitios arqueológicos, bienes arquitectónicos y demás objetos con trascendencia histórica, estética, arqueológica y científica. Las culturas indígenas vivas carecían de valoración pues estaban destinadas a asimilarse a los patrones culturales blanco-mestizos.

El legado cultural indígena sería reconocido tardíamente durante el siglo XIX, con la formación de los estados-nación, que buscaron "la reconstrucción del pasado nacional, la reintegración de su historia desmembrada, el rescate de su raíz más antigua y la creación de museos que atesoren sus monumentos" (Florescano, 1997: 154).
José Carlos Mariátegui describió el interés de los criollos independentistas peruanos de revalorizar un pasado grandioso de los incas, al mismo tiempo que rechazaban la cultura y las tradiciones de los descendientes de esos pueblos. De manera parecida en Ecuador, el estadonación se constituyó sobre una memoria histórica y una identidad nacional imaginada, sin lugar para las diversas culturas indígenas. Hobsbawm explica el uso, en muchas sociedades, de un bagaje cultural de antiguas prácticas que puede ser modificado, ritualizado e institucionalizado para los propósitos nacionales nuevos; proceso que supone una manipulación consciente de símbolos. (2008:6)

Podemos encontrar ciertas similitudes en los países andinos donde el rescate del patrimonio y la movilización de formas culturales tuvieron fines esencialmente ideológicos; como lo explica Hall"Ios Estados-naciones nunca fueron solamente entidades políticas sino, además, formaciones simbólicas que produjeron una idea de la nación como una comunidad imaginada siempre bajo un presupuesto homogenizante" (Hall, 2013:11).

\footnotetext{
${ }^{14}$ UNESCO se fundó en 1945 con "el objetivo de contribuir a la paz y a la seguridad en el mundo mediante la educación, la ciencia, la cultura y las comunicaciones". Tiene representación de más de 195 países y ha contado con la asesoría de académicos en la elaboración de un instrumental teórico sobre el patrimonio cultural.
} 
Carlos de la Torre expone con claridad los mecanismos de la discriminación basados en la ideología del "blanqueamiento" racial y cultural."La ideología del mestizaje anula la posibilidad de incorporar a los indígenas con su propia identidad a la sociedad nacional"15 (De la Torre, 1997:97)

La institucionalidad cultural que se crea a mediados del siglo XX, reafirma la distancia con el patrimonio inmaterial. En Ecuador, el Instituto Nacional de Patrimonio Cultural (INPC) asume la conservación del patrimonio material sin preguntarse sobre el uso o significado de los lugares, objetos, y rituales que proponía preservar. El valor espiritual, histórico, la memoria o la identidad de lo material, permanecen ausente.

En los años 40, los "usos y costumbres", se sumaron a la definición y gestión del patrimonio. Los estudios del folclore se adjudican la recuperación y recreación de las expresiones materiales de las culturas indígenas por parte de los no indígenas. Bailes, cantos, disfraces, símbolos, son sacados de contexto y llevados a escenarios urbanos, tarimas de eventos patrios o museos y colecciones. La reinvención de tradiciones que se encontraban vivas constituyó un contrasentido histórico y cultural;" Il fuerza y la adaptabilidad de tradiciones genuinas no se las debe confundir con la invención de tradiciones. Donde los modos de vida antiguos están vivos, las tradiciones no necesitan ser revividas ni inventadas". (Hobsbawm, 2008: 8, traducción propia).

En los años 70, mientras UNESCO consolida políticas con ámbitos de aplicación global, la concepción del patrimonio cultural se amplía, considerando no solo el legado arqueológico, de la arquitectura monumental o las "Bellas Artes", sino además la cultura inmaterial o intangible comprendida en la clasificación de PCl que llega con la Convención para la Salvaguarda del Patrimonio Cultural Inmaterial, (2003), cuya ruta revisamos brevemente a continuación.

\section{La construcción del concepto de PCI de UNESCO}

La significación de Patrimonio Cultural Inmaterial (PCI), inscrito en las convenciones, recomendaciones y declaraciones de UNESCO, es producto de un largo camino de debates, tensiones, resistencias y confrontaciones académicas, económicas y sobre todo, políticas.

La firma en 1972, de la 'Convención para la Protección del Patrimonio Mundial, Cultural y Natural', que creó la lista para preservar sitios culturales y naturales de "valor excepcional", 16 originó

\footnotetext{
${ }^{15}$ Traducción propia del inglés.

${ }^{16}$ Para el año 2012 esta lista incluía 922 bienes patrimoniales.
} 
críticas al desbalance geográfico pues la mayoría de lugares patrimoniales se encontraba en Europa, en desmedro de los países periféricos.

En 1989 UNESCO aprueba la recomendación sobre la 'Salvaguarda de la Cultura tradicional y el folclore', la cual no fue bien recibida pues apelaba a nociones obsoletas de cultura y folclore."El término folclore estuvo muy orientado al producto, dejando de lado los símbolos, los valores y los procesos" anota Aikawa, responsable del programa de Patrimonio Cultural Inmaterial de UNESCO (2009: 21).

La cumbre de Río de Janeiro de 1992, reconoció los saberes de los pueblos indígenas y denunció las amenazas culturales y ambientales de las que son objeto. Se sumaría en 1995 el reporte de Pérez de Cuéllar: 'Nuestra diversidad creativa', que impulsó la revisión del patrimonio cultural para incluir los aspectos inmateriales.

Dos años después, en el 'Foro mun- dial sobre la protección del folclore' se buscó la protección de los derechos de propiedad intelectual vinculados al folclore. "Esta iniciativa halló una fuerte oposición de los países que se estaban benefi ciando del uso libre de las expresiones tradicionales", rememora Aikawa, (2009:15).

En la reunión de Marrakech (1997), se introdujo el concepto de "espacio cultural", ${ }^{17}$ con el cual algunos países impulsaron el proyecto "Proclamación de Obras Maestras del patrimonio oral de la humanidad". Se debatió intensamente sobre las ideas de 'obra maestra', 'valor universal', 'participación comunitaria', y 'procesos de selección', entre otras. ${ }^{18}$

En la mesa redonda 'Patrimonio Cultural Inmaterial' (Turín, 2001), los expertos definieron las nociones de cultura tradicional, patrimonio cultural, folclore, tesoros, patrimonio oral. El concepto de cultura adquirió una dimensión procesual, relievando el proceso antes que el producto. El término salvaguarda prevaleció sobre el de protección. ${ }^{19}$ Se destacó

\footnotetext{
${ }^{17}$ Definido como "los lugares donde existe actividad cultural, teniendo la característica de cambiar en el tiempo y cuya existencia depende de la presencia de estas formas de expresión cultural". Los criterios guía fueron: 1) el valor universal excepcional y 2) los criterios organizativos (participación comunitaria). Buscaba que los gobiernos, ONG's y comunidades locales iniciaran actividades de identificación, preservación y promoción del patrimonio oral. (Aikawa, 2009:18).

${ }^{18}$ Hasta el 2013 se habían declarado 48 obras maestras a nivel mundial, entre ellas, el patrimonio oral y las manifestaciones culturales del pueblo Zápara de Ecuador, y el tejido tradicional del sombrero de paja toquilla. En América Latina, existen obras maestras, entre las cuales se encuentran: la cosmovisión de los Kallawayas (Bolivia, 2003); el carnaval de Oruro (Bolivia, 2001) y el de Barranquilla (Colombia, 2003); las expresiones de los Wajapi (Brasil, 2003).

19 "La protección supone erigir barreras en torno a una expresión determinada, aislándola de su contexto y su pasado y reduciendo su función o su valor social. Salvaguarda significa mantenerla viva, conservando su valor y su función" (Bokova, 2010).
} 
el rol participativo de las comunidades locales en la transmisión, aprendizaje, creación y cooperación del patrimonio inmaterial. Finalmente se estableció la necesidad de crear un instrumento jurídico internacional (Convención) para su salvaguarda. En Turín se esbozaron las dimensiones que debían cubrir dicho ins- trumento: patrimonio oral, lenguas, artes performativas y eventos festivos, rituales y prácticas sociales, cosmologías y sistemas de conocimiento, creencias y prácticas acerca de la naturaleza. (Aikawa, 2009:13) El Plan de Acción incluyó siete objetivos. ${ }^{20}$

\section{LA CONVENCIÓN PARA LA SALVAGUARDA DEL PATRIMONIO CULTURAL INMATERIAL (PCI) DEL 2003}

La conferencia general n. 31 de UNESCO, en octubre del 2001, luego de revisar la documentación de Turín, crea la Convención para la Salvaguarda del Patrimonio Cultural Inmaterial. Aprobada el 2003, entra en vigencia en abril del 2006 y es ratificada el 2008 por más de 120 Estados. Finalmente se contaba con un instrumento legal para promover la diversidad cultural y proteger al patrimonio inmaterial de las amenazas de la globalización y las transformaciones sociales.

La Convención define al PCl como: "Los usos, representaciones, expresiones, conocimientos y técnicas -junto con los instrumentos, objetos, artefactos y espacios culturales que les son inherentesque las comunidades, los grupos y los individuos reconozcan como parte integrante de su patrimonio cultural". "Este patrimonio cultural inmaterial, que se transmite de generación en generación, es recreado constantemente por las comunidades y grupos en función de su entorno, su interacción con la naturaleza y su historia, infundiéndoles un sentimiento de identidad y continuidad" (artículo 2.1 de la Convención)

La Convención enfatiza en el reconocimiento y promoción del PCl, históricamente desconocido y desestimado. Se afirma que, si bien el concepto de'Patrimonio Inmaterial' era nuevo, su idea era "tan antigua como la propia humanidad".21 (Queda sin embargo, pendiente identificar las nociones propias que utiliza la población para referirse a sus legados inmateriales. En esta línea, el concepto de sumak kausay pudiera constituir una versión emic de patrimo-

\footnotetext{
20 1. Conservar las creaciones del ser humano que podrían desaparecer para siempre, 2. Darles un reconocimiento mundial, 3. Fortalecer la identidad, 4. Posibilitar la cooperación social dentro de los grupos y entre ellos, 5. Garantizar la continuidad histórica, 6. Promover la diversidad creativa de la humanidad, 7. Fomentar el disfrute de este patrimonio. Ver: unesdoc.unesco.org/images/0012/001225/122585s.pd

${ }^{21}$ Bokova, I. Directora General de Unesco 2010.
} 


\section{LA CONSTRUCCIÓN DEL DISCURSO SOBRE PATRIMONIO INMATERIAL \\ Y LAS POLIITICAS CULTURALES EN EL ECUADOR}

nio inmaterial, con un contenido que trasciende la definición de UNESCO.22)

El instrumento aporta también a la legitimación y valoración de los conocimientos ancestrales como posibles respuestas a problemas contemporáneos. "Los conocimientos tradicionales y la sabiduría ancestral nos pueden dar muchas lecciones valiosas en ámbitos como la seguridad alimentaria, la salud o la ordenación de los recursos naturales y, en términos más generales, pueden contribuir a mantener la cohesión social y una convivencia pacífica"23

La Convención afirma la interdependencia entre patrimonio inmaterial y patrimonio material cultural y natural. ${ }^{24}$ Sostiene además el rol decisivo de la participación ciudadana para el éxito de los programas de salvaguarda:25 y pide aplicar "los derechos de propiedad intelectual, el derecho al respeto de la vida privada y cualquier otra forma apropiada de protección jurídica", de las comunidades, los grupos y los individuos. ${ }^{26}$

\section{Listas, inventarios, declaratorias}

Los países que han ratificado la Convención, se obligan a"identificar y definir los distintos elementos del PCl con participación de las comunidades, los grupos y las ONG's pertinentes", a través de la elaboración de inventarios, los mismos que se "actualizarán regularmente" (art. 11 y 12). Estos registros deben seguir la metodología diseñada por UNESCO a partir de una clasificación del patrimonio inmaterial en ámbitos y sub ámbitos. ${ }^{27}$

Son tres las listas obligatorias que estableció la Convención para los países firmantes:

1. Listas representativas del $\mathrm{PCl}$ de la humanidad

2. Listas del PCl en necesidad de salvaguardia urgente

3. Inventarios nacionales del PCI

\footnotetext{
${ }^{22}$ Arispe ha intentado encontrar una definición más apropiada para el patrimonio inmaterial:"Hay un patrimonio en las formas inmateriales, que nos permiten saber lo que otros piensan, sentir lo que sienten e intercambiar lo que necesitamos. Aquel que damos por sentado porque lo aprendimos como la forma en que se expresa nuestro propio mundo. Es un legado que se absorbe de manera inconsciente y se repite como parte de nuestras vidas. Y lo más importante, es que nos abre la posibilidad de saber quiénes somos ante los otros, ante la tierra y el cosmos" (Arispe, 2009:8).

${ }^{23}$ Bokova, l., 2010.

${ }^{24}$ Esta interdependencia está basada en los estudios sociales que describen cómo los sistemas de creencias y prácticas indígenas revelan un pensamiento relacional donde lo onírico, lo espiritual, lo material y la naturaleza se encuentran estrechamente vinculados.

${ }^{25}$ Artículo 15 de la Convención, 2003.

${ }^{26}$ Artículos 103 y 104 de la Convención, 2003.

${ }^{27}$ Ecuador ratifica la convención en el 2008. Los ámbitos del Patrimonio Inmaterial son: 1.Tradiciones y expresiones orales, incluido el idioma; 2. Artes del espectáculo; 3. Usos sociales, rituales y actos festivos; 4. Conocimientos y usos relacionados con la naturaleza y el universo; 5 . Técnicas artesanales tradicionales.
} 
La definición de las listas, sin embargo, provocó inconformidad. El principal desacuerdo fue que, al ser concebidas para preservar el patrimonio material de sitios culturales y naturales de "valor excepcional", resultaban inadecuadas para reconocer la cultura inmaterial viva. Además, nociones como "valor universal", "tesoros","obras maestras", sugerían jerarquías discutibles, puesto que al seleccionar y enlistar un elemento patrimonial, se excluía a otros; todo lo cual desató en muchos países -Ecuador incluido-, conflictos y división social. Los esfuerzos de salvaguarda, se argumentó, no debían orientarse a promover competencias o convertirse en concursos "de belleza" (Valdimar, 2009:102).

La pugna sobre las listas tuvo también su trasfondo político; según Hafstein, servían para canalizar fondos y obtener prestigio y publicidad para UNESCO. “... el gobierno de Estados Unidos amenazó con quitar su apoyo a la Convención si no se establecía una lista mundial de Patrimonio" (Titchen, 1995:150-1; Schuster 2002:2 en Hafstein: 95).

Listas, declaratorias, inventarios y demás instrumentos para promover la diversidad cultural y proteger el $\mathrm{PCl}$, si bien han contribuido a su reconocimiento, conllevan el riesgo de no comprender las culturas y sus dinámicas internas. El mal uso de los instrumentos de selección, la pérdida del sigilo cultural y la mercantilización de las prácticas culturales o su folclorización, ${ }^{28}$ son un peligro real.

\section{LA APLICACIÓN EN ECUADOR DE LAS OBLIGACIONES DE LA CONVENCIÓN}

El compromiso de elaborar y administrar las listas e inventarios de bienes culturales públicos y privados, así como las declaratorias patrimoniales, atañe directamente a la gestión pública del patrimonio. Es allí donde se origina buena parte de los conflictos y desencuentros que encontramos en nuestra investigación, entre la política cultural y las comunidades locales.
El actor ejecutante del Estado ecuatoriano es el Instituto Nacional de Patrimonio Cultural (INPC), quien desde 1973 se encarga de"investigar, preservar, conservar, restaurar, exhibir y promocionar" el patrimonio cultural en el Ecuador. ${ }^{29}$ Sin embargo, la Ley de Patrimonio vigente, expedida en 1979 y todavía no sustituida por la Ley de Cultura aún en trámite legislativo, mantiene una clasifi-

\footnotetext{
${ }^{28}$ Término usado por la UNESCO -en publicaciones, discursos y documentos internos-, para caracterizar la mercantilización de prácticas tradicionales dirigidas a audiencias foráneas (Hafstein, 2009: 106).

${ }^{29}$ Artículo 4 de la Ley de Patrimonio Cultural, sobre funciones y atribuciones.
} 
cación elitista de los bienes patrimoniales sujetos a protección, que soslaya las formas culturales cotidianas de la mayoría de la población.

En el 2008 se crean el Ministerio de Cultura y el Ministerio Coordinador del Patrimonio cultural y natural (institución suprimida el 2014). Con este andamiaje institucional se buscó fortalecer el diseño y la gestión descentralizada del patrimonio cultural.

\section{Decreto de emergencia, inventario y declaratorias}

El 2008, que coincidió con el robo de una valiosa pieza religiosa de un museo de Riobamba, el gobierno expidió el 'Decreto de emergencia del patrimonio cultural e inmaterial'con vigencia de un año. Su objetivo, rescatar bienes patrimoniales en peligro y establecer un inventario nacional de bienes patrimoniales, según el compromiso asumido al ratificar la Convención de UNESCO.

Entre el 2001 y el 2007, constaban como declarados apenas 13 bienes patrimoniales inmateriales; a partir del de- creto de emergencia fueron más de 4.500 los bienes inmateriales inventariados. En el 2008, por primera vez, se efectuó un registro de bienes inmateriales, posteriormente informatizado y subido a la red como herramienta para los gobiernos locales, quienes según la Ley de Descentralización, tienen la competencia para gestionar el patrimonio cultural en sus territorios. ${ }^{30}$

Para inventariar los bienes culturales inmateriales, se aplicó la ficha de registro con los criterios de identificación diseñados por UNESCO. ${ }^{31}$ Sin embargo, el proceso fue cuestionado por las omisiones, criterios de selección obsoletos y falta de capacitación de quienes levantaron la información. También se observó una escasa participación ciudadana pues muchos datos no fueron completados ni cotejados con las poblaciones locales. El Ministerio Coordinador de Patrimonio y el INPC intentaron remediar los problemas; depuraron fichas y promovieron la participación ciudadanía. Aseguran haber capacitado al 70\% del personal de los 221 municipios del país y al $50 \%$ de las juntas parroquiales.

\footnotetext{
${ }^{30}$ El Código de ordenamiento territorial, autonomías y descentralización (COOTAD) establece la conformación del sistema nacional de competencias, que regula la organización político-administrativa del Estado en el territorio, el régimen de los diferentes niveles de gobierno y de los regímenes especiales, propende a la autonomía política, administrativa y financiera (Introducción al Patrimonio Cultural, 2011: 49).

${ }^{31}$ Las tres categorías con sus criterios son: 1. Manifestaciones vigentes. Criterios: representatividad y reconocimiento comunitario, transmisión intergeneracional y vigencia; 2. Manifestaciones vigentes vulnerables. Criterios: representatividad en el proceso de transmisión; 3. Manifestaciones vigentes en la memoria colectiva pero no practicadas en la actualidad. Criterios: representatividad y reconocimiento comunitario y memoria (Instructivo para fichas de registro e inventario. PCI, 2011:13).
} 
La segunda lista comisionada por UNESCO debía incluir las declaratorias de bienes patrimoniales inmateriales. En ellas, el patrimonio no siempre fue reconocido y gestionado por los propios portadores, tal como lo exige el procedimiento. Hubo declaratorias impuestas a las comunidades por gobiernos locales, el INPC, el Ministerio de Cultura y ONG's, mientras que otras solicitudes de declaratoria de bien patrimonial, carecían de estudios serios que las justificaran. Encontramos incluso, declaratorias sin el conocimiento ni el consentimiento de los pobladores y sus autoridades. El pueblo de San Gabriel (provincia del Carchi), rechazó la declaratoria por considerarla restrictiva para sus aspiraciones urbanísticas. En San Miguel (provincia de Bolívar), la declaración patrimonial de su centro histórico, impidió a migrantes retornados de Estados Unidos construir"la casa de sus sueños".
Una funcionaria del INPC admitía, luego de un proceso de autocrítica: "la nueva directriz debe seguir un proceso de registro, diagnóstico e inventario y elaboración de un plan de salvaguarda bajo perspectiva participativa". Las entidades de gobierno reconocieron errores de gestión, suspendieron las declaratorias y convocaron mesas de discusión con el fin de lograr mayor participación ciudadana, mejorar la investigación y enfocarse en planes de acción integrales. La formula revisada consistió en 1) registrar ;2) diagnosticar e inventariar; 3) realizar planes de salvaguardia. ${ }^{32}$

A pesar que el gobierno insiste en un cambio de enfoque a favor del reconocimiento del valor simbólico e identitario de las culturas, en el 2014 se inventariaron apenas 705 bienes inmateriales, mientras que en el mismo período, se registraron 3.512 bienes inmuebles y 23.471 bienes muebles.

\section{ALGUNAS REFLEXIONES SOBRE LA INTERVENCIÓN PATRIMONIAL PÚBLICA}

Los objetivos y metas del Plan Nacional para el Buen Vivir son el norte de la política pública que impone la Secretaría Nacional de Planificación, SENPLADES. Sus diagnósticos, lineamientos, indicadores, metas, acciones, cuadros y estadísticas, se presentan bellamente impresos en libros e informes.
El discurso gubernamental sobre el Patrimonio en Ecuador, muestra sintonía con la teoría social contemporánea y las demandas indígenas. Propone la inclusión y la valoración de la diversidad, supera la concepción fragmentada entre naturaleza y cultura; y publicita un enfoque intercultural con voces diversas.

\footnotetext{
${ }^{32}$ Ver: "Proceso e instrumentos de salvaguardia del patrimonio inmaterial" en Instructivo para fichas, registro e
} inventario, 2011:25. 
Sin embargo, la parafernalia discursiva se estrella contra la realidad. "Hablamos los mismos términos pero comprendemos de diferentes formas", precisa un indígena de Chimborazo para expresar el desencuentro entre el discurso y la gestión patrimonial; "solo está en papeles y no hay nada en la práctica" concluye otro.

Estas palabras evidencian que en las comunidades no se gestiona, ni se clasifica, ni se vende la memoria o la identidad porque el patrimonio es aquello que une y confiere significado a la vida, más aún en situaciones de exclusión. "La cultura tiene una dimensión política pues dichos significados son motivo de disputa semiótica y política, son un campo de batalla ideológico por el control de significados y significaciones sociales". (Guerrero, 2009: 32). Como ejemplo, los eventos folclóricos organizados por las oficinas regionales del INPC, son percibidos por los actores sociales, como una grosera apropiación de su cultura; que imita o se burla de los indios, al mezclar las vestimentas y distintivos de cada grupo cultural. "Los mestizos se visten de nosotros, nosotros no ponemos lo de ellos, eso molesta", reclama una mujer indígena; lo que recuerda el contrasentido de reinventar culturas que se encuentran vivas (Hobsbawm 2008:8).

En un contexto de intervenciones estatales inconsultas, también las decla- ratorias patrimoniales producen recelo: "mejor no decir, han de llevar a destruir", comenta un indígena en relación con ciertos objetos de su comunidad, identificados como patrimoniales. En la misma línea, lugares sagrados que durante siglos pasaron desapercibidos para los extraños, ahora son "puestos en valor" y negociados, luego de ser declarados patrimoniales. "Ya no podemos entrar a estos lugares, a hacer curaciones, ofrendas, no dejan pasar los que ahora han comprado", se lamentan los comuneros de San Juan en Chimborazo.

El resultado de la política cultural dista mucho de sus enunciados. Durante la investigación, practicamos la exigencia antropológica que postula García Canclini (2012) "de escuchar a los diversos actores, detenerse en lo cualitativo, en la "densidad intranquilizante de los hechos" para revelar la retórica del patrimonio.

Las políticas culturales del gobierno ecuatoriano se ofrecen ahora, no en términos de progreso o desarrollo sino de sumak kawsay, plurinacionalidad e interculturalidad; y paradójicamente atentan contra aquello que pretendían proteger. La cultura transformada en mercancía, es despojada de su capacidad regeneradora. "Existe un empobrecimiento, vaciamiento, degradación de sentidos de los símbolos usurpados para ser instrumentalizados al sentido que les 
da el poder para su legitimación". (Guerrero, 2009: 45)

\section{Declaratorias patrimoniales versus comunidades}

Se hace necesario indagar en la relación entre los intereses de la industria del turismo y la preservación de las manifestaciones culturales tradicionales. Montenegro afirma que las políticas patrimoniales propician la mercantilización de los bienes culturales.

Las declaratorias patrimoniales no son únicamente instrumentos políticos de reconocimiento cultural, sino que cada vez con más frecuencia se integran en las dinámicas económicas y participan activamente en los mercados abiertos por su influencia. (Montenegro, 2013:37)

El proceso de las declaratorias está acompañado por intereses económicos y turísticos a pesar de existir una visión ambigua sobre el uso económico del patrimonio. El discurso oficial declara no ser intervencionista o invasivo, "queremos establecer limitacio- nes de la inferencia del Estado sobre la dinámica de las manifestaciones culturales", explica una funcionaria del INPC. Sin embargo, existe urgencia para vincular patrimonio con desarrollo local, sin respetar los ritmos y las lógicas comunitarias.

El patrimonio se ha convertido en una herramienta poderosa para mejorar la calidad de vida; el patrimonio dinamiza las economías locales, genera empleo... (exministra de coordinación del patrimonio, informe a la nación, 08-10-2012)

Esta lógica económica se refleja en los planes y proyectos patrimoniales que estimulan, y financian "emprendimientos", o iniciativas con ingredientes "culturales". Las rutas turísticas del patrimonio gastronómico son un ejemplo de ello. "Se intenta crear certificaciones de platos que cumplan condiciones de memoria social, paso de generación y sean representativos de la cultura" (entrevista a funcionario del Ministerio de Patrimonio, mayo del 2012); pero ¿cuánto de estos planes afectan a las dinámicas internas de quienes preparan estos platos y tienen su clientela y producción limitada? ${ }^{33}$

Al develar las buenas intenciones con las que están empedrados ciertos caminos, encontramos ejemplos del desencuentro entre los enunciados y la gestión oficial del patrimonio en Ecuador.

Algunas fiestas tradicionales, luego de ser declaradas por mandato legal, pa-

\footnotetext{
${ }^{33}$ Ciudades patrimoniales, ciudades del buen vivir, salvaguarda del patrimonio culinario, SOS patrimonio, plan vive patrimonio, vivienda patrimonial privada, etc. La idea detrás de estos planes fue crear políticas de financiamiento para dinamizar los bienes patrimoniales.
} 
trimonio inmaterial, quedan a cargo de gobiernos locales descentralizados, quienes norman, financian y reforman las celebraciones sin entender el complejo entramado social ni la ritualidad involucradas. La"Mama Negra"en Latacunga, la 'diablada' de Píllaro en Tungurahua o las fiestas de san Pedro de Cayambe en Imbabura, ${ }^{34}$ muestran como los verdaderos actores fueron excluidos, se alteró el significado de los ritos y se transgredió el sistema de cargos, al igual que el sentido religioso de la fiesta.

En el caso del ídolo prehispánico conocido como San Biritute, el gobierno apoyó el retorno de la imagen a la comuna de Sacachún en la provincia de Santa Elena, que lo había reclamado durante más de cincuenta años a la ciudad de Guayaquil..$^{35}$ El retorno se acompañó de la declaratoria patrimonial y más de veinte proyectos de desarrollo transformaron la pacífica vida de las familias del sector, despertando la envidia de las comunidades vecinas, que no accedieron a estas dádivas. ${ }^{36}$

El INPC capacitó a los pobladores de Sacachún con información sobre la identidad del ídolo para que pudieran "explicar bien" a la prensa y a los turistas que llegarían con la declaratoria. San Biritute es un monolito fálico perteneciente a la cultura Manteño-Huancavilca (500 a.C -1500 d.C). a quien se le ofrecían ofrendas con azotes para propiciar la fecundidad de las mujeres y la fertilidad de la tierra. Ahora encontramos turistas que llegan a probar el antiguo rito sin consultar siquiera a los pobladores locales. (Figura 1)

\footnotetext{
${ }^{34}$ Para un análisis de estos cambios en la fiesta de la Mama Negra en Latacunga, ver la tesis de licenciatura de Silvana Cárate, Dinámicas simbólicas en una fiesta popular andina, el caso de la Mama Negra de Latacunga, PUCE, 2011.

${ }^{35}$ En la década de 1950, arqueólogos guayaquileños desenterraron varios ídolos prehispánicos en la península de Santa Elena, a quienes la población local rendía culto. Uno de estos -San Biritute-, fue llevado a Guayaquil e instalado en una calle central y luego en el museo municipal donde permaneció por más de medio siglo.

${ }^{36} \mathrm{El}$ camino asfaltado solo llegó hasta el pueblo de Sacachún al igual que los demás proyectos sociales.
} 


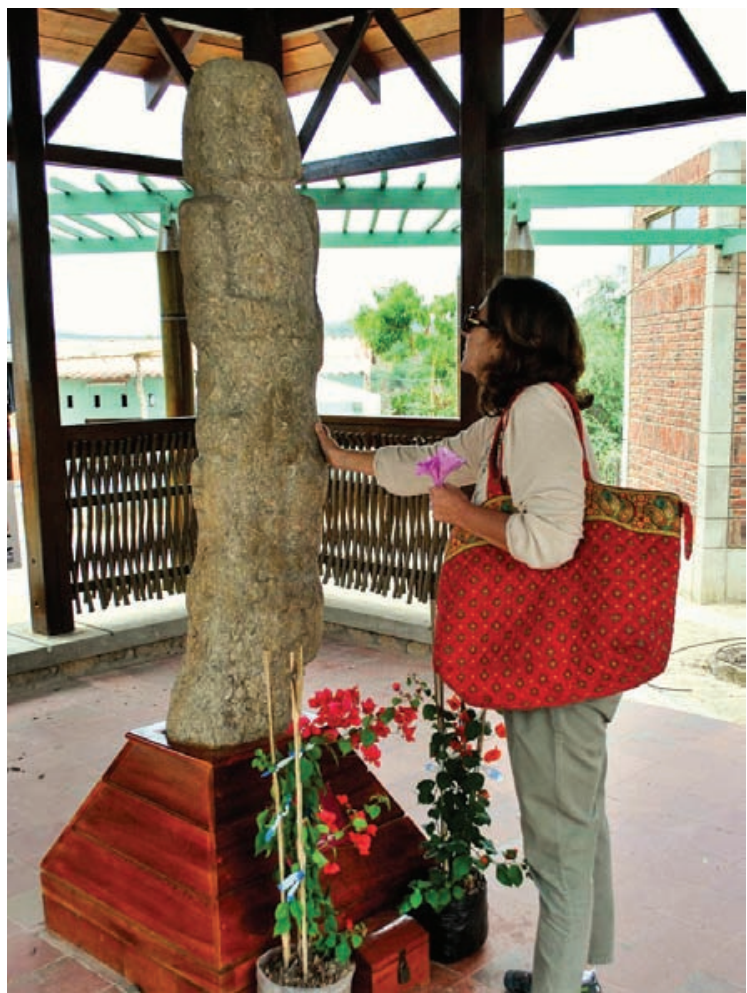

Figura 1. San Biritute

Revisamos a continuación dos casos que muestran, con mayor detalle, la discrepancia que se produce entre una política cultural patrimonial no consultada ni consensuada con las comunidades y las distorsiones que estas acciones producen en el tejido social.

\section{Proyecto Aldea Colorada}

\section{El contexto}

La nacionalidad indígena Tsáchila se concentra en la provincia de Santo Domingo de los Tsáchilas. En sus siete comunidades, se destacan los curanderos o ponés, reconocidos por su conocimiento de las plantas medicinales. Su jerarquía, que va desde simples vegetalistas hasta los más prestigiosos shama- 
nes, depende del número y el poder de los espíritus guardianes con que cuentan para sanar; los cuales provienen de piedras, animales, plantas y objetos sagrados que se ven representados en la mesa o altar. Un poné se forma en un largo y riguroso proceso de aprendizaje que comprende la toma de ayahuasca, la práctica de dietas y ayunos, la búsqueda de conocimiento a través de la vía onírica y el intercambio de saberes con otros ponés.

La transmisión del conocimiento del maestro al aprendiz dependerá del interés de este último."Son los aprendices quienes deben prepararse y tener verdadero interés y sacrificio, no todos (los maestros) avisan, unos enseñan otros no", explica un joven poné. Mientras otro curandero explica la razón para restringir el acceso al conocimiento: "Para los ancianos, el miedo está en dejar los conocimientos a los jóvenes, pero no por mezquinar el conocimiento, sino por lo que ellos ven ahora en la juventud. Don Audón reclama que hoy en día él conoce a muchos curanderos tsáchilas que hacen los 'trabajos' sin tener conocimiento; él dice que a ellos nadie les ha enseñado, que estos nuevos curanderos no han tenido el proceso de aprendizaje necesario para poder hacer los rituales, para ver a las personas y curarlas" (AreIlano, 2012:76)
Para el tsáchila, debe existir una relación equilibrada entre la comunidad, el entorno y los espíritus que lo habitan, para lo cual celebran elaborados rituales como la Jampeka. ${ }^{37}$ Los saberes sobre plantas, usos, manipulación de elementos, energías y espíritus constituye su patrimonio cultural. Como guardianes, su función es proteger y reproducir este conocimiento que, según relatan, tiene su origen en los comienzos del tiempo y es lo que permite el orden del universo y la comunidad.

La capital provincial, Santo Domingo, es una de las ciudades de más acelerado crecimiento en el país. Su expansión absorbió las comunas tsáchilas, con su secuela de deforestación y aculturación, mientras poderosas agroempresas contaminan los lugares sagrados destinados para los rituales de curación. "Las plantas han perdido el aroma y con ello el poder de curar"revela un poné. La mercantilización de su cultura es estimulada por un turismo de exotismo que busca indios brujos, desnudos y pintados; imagen que muchos han explotado abriendo un sinfín de falsos centros curativos. El gobernador tsáchila, con carácter vitalicio, ha sido reemplazado por nuevas autoridades bajo la forma de elección "democrática", lo que ha instalado la intriga de intereses políticos y económicos y la consecuente división interna.

\footnotetext{
${ }^{37}$ Para un amplio estudio sobre la Jampeka como ritual de purificación, protección y sanación ver el capítulo desarrollado por María José Arellano, 2012.
} 


\section{La intervención cultural}

En este contexto se presenta el INPC con el proyecto turístico'Aldea Colorada', y el "propósito de rescatar y revalorizar las tradiciones y costumbres milenarias de la nacionalidad Tsáchila que constituye la identidad cultural de Santo Domingo" (lbid:86)

El proyecto fue propuesto por una familia notable de la comuna Peripa; el padre fue gobernador tsáchila además de concejal municipal, y un conocido poné. Gracias a sus influencias, reformularon un antiguo proyecto ofrecido al Banco Mundial en 1997 y lo plantearon ante al INPC. 'Aldea Colorada' no fue acordada ni discutida con la población ni con las organizaciones culturales tsáchilas formadas para regular el turismo comunitario. (Arellano, 2012:86). El proyecto incluía un conjunto de edificios modernos y tradicionales provistos de hospedaje, mirador y restaurante.

Se alcanzó a levantar la primera parte: una enorme instalación con diseños y materiales incompatibles con la vida comunitaria tsáchila. Después, la construcción se paralizó por falta de financiamiento mientras lo ya edificado comenzó a deteriorase: espacios para encuentros festivos, otros para practicar ritos de curación, un museo de dos pisos con unas pocas fotos y objetos tradicionales y un salón de uso múltiple que se arrienda a instituciones de la ciudad.
Pocos turistas llegan a la comuna Peripa a conocer esta cultura-objeto tsáchila, donde un shamán realiza una ceremonia light; luego los guías del museo disfrazados de indios conducen un recorrido por las instalaciones semivacías y concluyen tocando, por unos minutos, la tradicional marimba.

El proyecto, financiado por el INPC, provocó malestar entre las comunidades tsáchila, que denunciaron la falta de participación de la nacionalidad, el derroche de recursos públicos y la incongruencia de una propuesta que ahondó la descomposición grupal. Según Arellano "el apoyo y la gestión del proyecto fue cosa de un momento, para cumplir con los objetivos de una política cultural determinada." (Ibid: 88)

'Revitalización cultural,'rescate,',revalorización'; son solo formas retóricas para instrumentalizar una política de patrimonio que no se interesa por entender las dinámicas culturales ni la riqueza de los saberes para salvaguardarlos.

\section{Los Yumbos de Cotocollao}

La primera declaratoria de patrimonio inmaterial en Ecuador, la obtuvo el ballet folclórico "Jacchigua", grupo de bailarines profesionales mestizos, que representa bailes indígenas con vestimentas estilizadas e inventadas. ¿No argüían los pomposos enunciados de la 
política cultural que el patrimonio debía ser algo vivo, dinámico y complejo, que tenía que ver con el valor simbólico, identitario y espiritual de los pueblos?

Escuchemos a los yumbos, danzantes indígenas del barrio de Cotocollao en Quito, sus opiniones sobre el grupo folclórico:

Jacchiwa es un apoderamiento de todas las culturas quitadas su propia esencia y hablada por ellos. Si hubiéramos desaparecido estaría bien pero las culturas están vivas, los Otavalos, los Saraguros, y no hay un solo actor en el grupo que sea del sitio. Es un trabajo para hacer dinero, es una empresa. (Yumbo mayor, Taita Pedro Morales+)

\section{Fiesta y rito}

La Yumbada de Cotocollao tiene lugar en junio y corresponde al tiempo de cosecha y el solsticio de verano. Con ella se agradece a la tierra por su fertilidad y abundancia.

El rito comprende diversos personajes: yumbos, molecañas, capariches, así como música, juegos, disfraces, pirotecnia, comida, bebida, cantos y sobre todo, danzas.

Históricamente se conocía de modo genérico como yumbos, a los pueblos que llegaban desde la selva subtropical a la Sierra para intercambiar productos de las tierras bajas, así como saberes, plantas e informaciones. La fiesta los recuerda con sus vestimentas: coronas de plumas, collares y bolsos de semillas, máscaras, pañuelos; y con su principal arma, la lanza hecha de dura madera de chonta.

La Yumbada dura tres días y se inicia con un baño de purificación y la recogida de todos los participantes casa por casa, donde comen, beben y danzan desde que anochece hasta el amanecer. Luego viene el antialbazo, la visita a los priostes, la noche de castillos, los juegos varios como la muerte del yumbo y por último, el canto de despedida. ${ }^{38}$ El baile, dos pasos adelante y uno atrás, como lo explica un yumbo "son pasos que nos conectan con la tierra, la danza lleva a un trance, los movimientos están cargados de energía". Se llaman a sí mismos con nombre de cerros o de santos ya que de ellos proviene el vigor del baile. El bien más preciado, heredado de sus padres, es este nombre secreto, junto con la lanza de chonta de sus ancestros yumbos.

La yumbada, explican, es la 'unión de uniones', la integración de las familias y la comunidad. El ciclo ritual restaura el vínculo con los espíritus de los cerros, con San Sebastián y el Divino Niño. Es

\footnotetext{
${ }^{38}$ El material sobre la Yumbada de Cotocollao fue recogido por Nathalia Breilh en el marco del proyecto de investigación de la PUCE, 2012.
} 
una fiesta que se organiza al detalle, sin dejar nada al azar pues de ella dependerá la fecundidad, la sabiduría y la prosperidad del pueblo de Cotocollao.

La yumbada es también la representación del shamanismo. Un momento crucial del ritual es 'la muerte del yumbo', que ejemplifica el poder del shamán que da muerte y resucita a un hombre que se convertirá en cerdo. El rito/ juego tiene momentos burlescos, dramáticos, eróticos y siempre simbólicos.

"La Yumbada es herencia, el espíritu de la Yumbada ha quedado en mí; mi papá me entregó la chonta del abuelo, esa es la esencia de la Yumbada. Esto no es un grupo folclórico que sale a hacer un baile". (Yumbo mayor).

\section{La intervención cultural}

Al observar con recelo la experiencia comercial del ballet folclórico "Jacchigua", los yumbos de Cotocollao solicitaron la declaratoria patrimonial de sus danzas ante el temor que "venga un señor que tiene dinero, tome fotos, haga video, cree una escuela de danza y luego diga, esta es la Yumbada del Ecuador, ni siquiera de Cotocollao" (Yumbo Mayor). La solicitud de declaratoria llegó en un momento oportuno para el INPC, que era objeto de críticas por la ausencia de participación ciudadana en la implementación de sus políticas.
El año 2009, los habitantes de Cotocollao completaron los requisitos para la declaratoria; buscaban proteger y conservar ("escondiéndose, no desapareciendo", en palabras del Yumbo mayor) un rito al que veían debilitarse. Los requerimientos del INPC de investigar, justificar y realizar un plan de gestión demoraron varios años, en medio de interminables trámites burocráticos.

En el 2010, como paso previo a la declaratoria, la Yumbada de Cotocollao pasó a formar parte del inventario de bienes inmateriales, lo cual se reflejó en una ficha de 20 líneas que resumía toda la complejidad del ritual esbozado anteriormente.

Finalmente, mientras esperaban la declaratoria, los yumbos pudieron reflexionar acerca de la conveniencia o no, de formar parte de la lista del patrimonio nacional. Decidieron entonces dar marcha atrás con la solicitud de declaratoria.

Entre las razones para este repliegue estuvieron, el largo y engorroso trámite que los fue desanimando; y la presión que sintieron del INPC, que reclamaba un origen inca del rito, lo cual fue descartado de plano por los pobladores de Cotocollao. Chaves, lo explica:

Las comunidades pueden postular prácticas, bienes, saberes susceptibles de patrimonialización; sin embargo, sus demandas solo se materializan 


\section{LA CONSTRUCCIÓN DEL DISCURSO SOBRE PATRIMONIO INMATERIAL}

Y LAS POLITICAS CULTURALES EN EL ECUADOR

cuando atienden a criterios esencialistas de una diferencia cultural domesticada, dictada por normas de UNESCO y los ministerios" (Chaves: 2010:9)

Los yumbos también sintieron temor de perder control sobre el ritual y tener que lidiar con una masiva llegada de turistas y la previsible mercantilización de su danza.

Finalmente reconocen que los resultados de nuestra investigación fueron claves para conocer documentadamente otros casos de malas prácticas patrimoniales. (figura 2.)

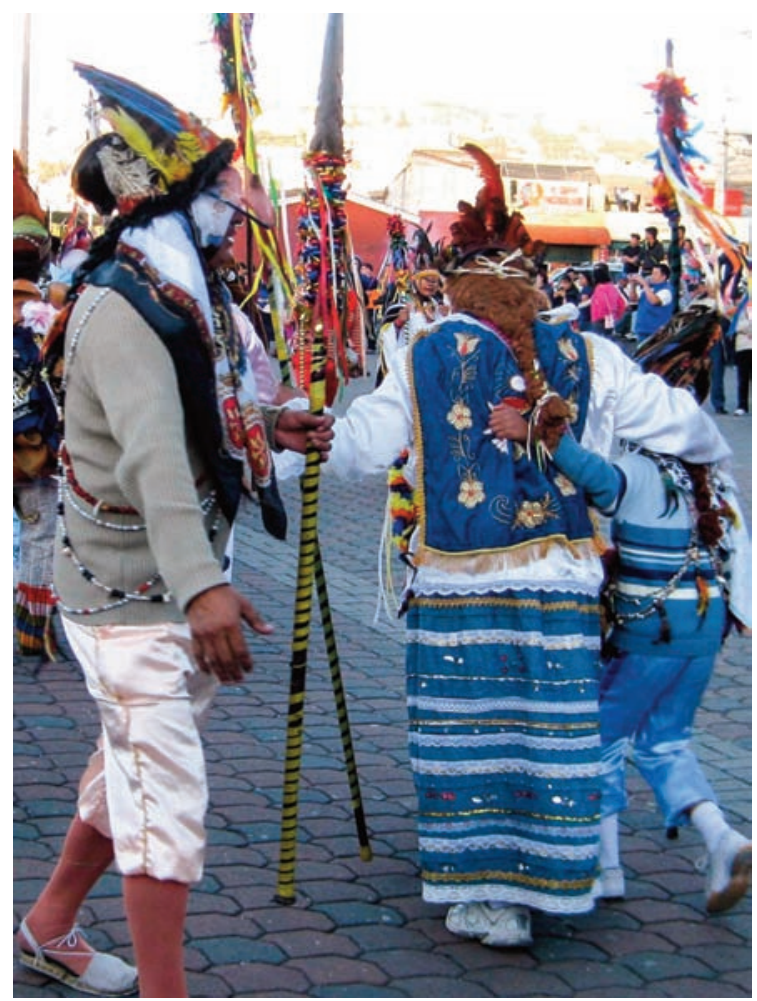

Figura 2. Los Yumbos de Cotocollao 
REVISTA PUCE，ISSN 1012-389X, NÚM, 102

\section{CONCLUSIONES}

El concepto de patrimonio, estuvo y continúa asociado a las identidades, al sentido de pertenencia, la memoria histórica y el ejercicio del poder. Las élites republicanas seleccionaron, elaboraron y difundieron imaginarios y tradiciones para construir el estado- nación. De modo análogo, el gobierno de la 'revolución ciudadana' elabora una argumentación a partir del patrimonio, la cultura y el buen vivir para proyectar un Estado plurinacional e intercultural.

Al revisar el proceso de construcción de las formulaciones de UNESCO sobre patrimonio cultural inmaterial, encontramos profundas discrepancias entre su aplicación en la política cultural del Ecuador, con las necesidades y expectativas de las poblaciones. Se registra y se celebra la diversidad cultural pero las complejas dinámicas y transformaciones de la cultura viva son desconocidas y desvaloradas.

Nos preguntamos, ¿por qué, políticas culturales como las declaratorias patrimoniales no han logrado promover la protección del patrimonio inmaterial y el empoderamiento de sus protagonis- tas? En los casos que dejamos registrados hallamos visiones enfrentadas respecto de las nociones de cultura, patrimonio y gestión cultural; y desacuerdos en los ámbitos de expresión que las comunidades se empeñan en conservar bajo su control. Al fin y al cabo estas últimas viven su tradición y sus costumbres como una posibilidad de sostener la cohesión social y resolver conflictos internos. Su patrimonio es también la posibilidad de transmitir a las nuevas generaciones los códigos necesarios que aseguren la continuidad de un ethos percibido como una condición de sobrevivencia, resistencia y afirmación de identidad, sin la cual la comunidad se disuelve, sus referentes se difuminan y son presa fácil de la codicia del mercado y de la manipulación ideológica y política del Estado.

No se pueden gestionar políticas interculturales exitosas sin la participación de las comunidades, los barrios y los ciudadanos; con roles activos que busquen cambiar las relaciones de poder e incorporar las transformaciones culturales. 


\section{BIBLIOGRAFÍA}

ACOSTA, Alberto (2009). Derechos de la naturaleza, Abya-Yala, Quito, Ecuador.

ACOSTA, Alberto; SACHER, William, (2012). La minería a gran escala, Abya-yala, Quito, Ecuador.

AIKAWA-FAURE, Noriko. (2009). From the proclamation of masterpieces to the convention for the safeguarding of intangible cultural Heritage, en Intangible Heritage, Routledge, New York, pp. 13-44.

ANDRADE, Susana, ARELLANO, MJ, ATIENCIA, A, BREILH, N,. (2012). Patrimonio Cultural Intangible: entre el discurso oficial y la realidad social, Quito, Dirección de Investigaciones, Pontificia Universidad Católica del Ecuador.

ANDRADE, Susana (2009). “El reto de la interculturalidad: Interculturalidad, plurinacionalidad y ciencias sociales en el Ecuador". Quito, Revista Cuadernos de Antropología, \#8, Pontificia Universidad Católica del Ecuador.

ARELLANO, María José, (2012) La Jampeka: saberes ancestrales medicinales, en Andrade, et-al, Patrimonio Cultural Intangible: entre el discurso oficial y la realidad social, Quito, Dirección de Investigaciones, Pontificia Universidad Católica del Ecuador.

ARISPE, Lourdes (2009). El patrimonio cultural inmaterial de México, editor Miguel Ángel Porrúa, México.

BECKER, Marc (2015). Pachakutik, movimientos indígenas, proyectos políticos y dis- putas electoral en el Ecuador, Quito, Abya-Yala.

BENDIX, Regina (2009). Heritage between economy and politics, en Intangible Heritage, Routledge, New York, pp.253-269.

BOKOVA, Irina, (2011). Prólogo de los Textos fundamentales de la Convención para la salvaguarda del Patrimonio cultural inmaterial de 2003, UNESCO, París, Francia.

BREILH, Natalia (2012). "La Yumbada de Cotocollao como Patrimonio Cultural Intangible" en Andrade, S et-al. En Patrimonio Cultural Intangible: entre el discurso oficial y la realidad social, Proyecto de investigación:, Quito, Dirección de Investigaciones, Pontificia Universidad Católica del Ecuador.

BRETON, Víctor, CORTEZ D (2014). "En busca del Sumak Kawsay" en revista Iconos, Flacso, Num. 48, Quito, pp. 9-24.

BURGOS, Hugo. (2008). Siete claves para describir y analizar un elemento cultural en una sociedad dada, INPC, Quito, Ecuador

BYRNE, Denis (2009). A critique of unfeeling Heritage, en Intangible Heritage, Routledge, New York, pp. 229-269.

CARATE, Silvana (2011). Dinámicas simbólicas en una fiesta popular andina: el caso de la mama negra de Latacunga, (Quito, Pontificia Universidad Católica del Ecuador).

CHAVES, Margarita, MONTENEGRO M y ZAMBRANO M (Eds.). 2014. El valor del patrimonio: mercado, políticas culturales y agenciamientos sociales, Instituto Colombiano de 
Antropología e Historia (Icanh), Bogotá, Colombia.

CURBELO, Nelsa, (2015) "Siembra vientos y cosecha...". En: diario El Universo, Artículo de opinión, Guayaquil, edición del 17 de junio del 2015.

DE LA TORRE, Carlos. (1999), “Everyday forms of racism in contemporary Ecuador", en Ethnic and Racial Studies, Volume 22, Number 1, January, Routledge.

DE LA CRUZ, Pedro (2009). Conferencia presentada en el seminario sobre políticas públicas e interculturalidad, Organizado por la Organización de Estados Americanos, Quito, 25-26 de junio del 2009.

ESCOBAR, Arturo. (2012). Encountering development, Princeton University Press, New Jersey, Estados Unidos.

FLORESCANO, Enrique. (1997). El patrimonio cultural de México, FCE, México.

GARCÍA CANCLINI, Néstor. (2010). La sociedad sin relato, Katz editores, México.

GUERRERO, Patricio (2009). Escenarios de lucha de sentidos: entre la usurpación y la insurgencia simbólica en Revista del patrimonio cultural, INPC. Quito, Ecuador.

GEERTZ, Clifford, (1973). The interpretation of cultures, , Basic Books, Estados Unidos.

GUDYNAS, Eduardo (2003). Ecología, economía y ética del desarrollo sostenible, Abya-Yala, Quito, Ecuador.

GUDYNAS, Eduardo, (2009). El man- dato ecológico, Abya-Yala, Quito, Ecuador.

GUDYNAS, Eduardo, ESTERMAN, J, Etal compiladores (2014). Bifurcación del Buen Vivir y el Sumak Kawsay, Ediciones Sumak, Quito, Ecuador.

HAFSTEIN, Valdimar (2009). Intangible Heritage as a list, en Intangible Heritage, Routledge, New York, pp. 93-111.

HALL, Stuart (2013) Sin Garantías, en Restrepo, E., Walsh, C, Vich, V., editores, Corporación Editora Nacional, Quito, Ecuador.

HERNÁNDEZ GONZÁLEZ, Edna (2010). Sobre patrimonio cultural y participación ciudadana en Patrimonio Cultural, identidades y ciudadanía, Abya-Yala, Quito, Ecuador.

HOBSBAWM, Eric, ((1983]2008). The invention of Tradition, Cambridge University Press, Londres, Inglaterra.

INPC. 2009. Revista del patrimonio cultural del Ecuador, \#1, Quito, INPC.

INPC, (2010). Revista del patrimonio cultural del Ecuador, \#2, Quito, INPC.

INPC, (2010.) Revista del patrimonio cultural del Ecuador, \#3, Quito, INPC.

INPC, (2010). Revista del patrimonio cultural del Ecuador, \#4, Quito, INPC.

INPC, (2014). Revista del patrimonio cultural del Ecuador, \#5, Quito, INPC.

INPC, (2014). Revista PCl, \# 12, eneroabril, Quito, INPC. 


\section{LA CONSTRUCCIÓN DEL DISCURSO SOBRE PATRIMONIO INMATERIAL

INPC, (2014). Revista PCI, \# 13, mayoagosto, Quito, INPC.

INPC, (2014). Revista PCI, \# 14, sept-diciembre, Quito, INPC.

INPC, (2010). Informe de gestión, Quito, INPC.

INPC, (2012). Informe de gestión, Quito, INPC.

INPC, (2013). Rendición de Cuentas, enero-diciembre del 2013, INPC, Quito, Ecuador.

INPC, (2014). Rendición de Cuentas, enero-diciembre del 2014, INPC, Quito, Ecuador.

INPC, (2011), Introducción al patrimonio cultural, MCP, Quito, Ecuador.

INPC . (2011). Instructivo para fichas de registro e inventario: patrimonio cultural intangible, INPC, Quito, Ecuador.

INPC, Abaco: Manual de uso para el manejo del sistema de información patrimonial.

Ley de Patrimonio Cultural del Ecuador, (1978), en http://www.unesco.org/culture/natlaws/media/pdf/ecuador/ec_codific acion_27_ley_de_patrimonio_cultural_spao rof.pdf

Ley orgánica de cultura (2011). Archivo Asamblea Nacional, Quito, Ecuador.

MARIATEGUI, José Carlos, (2009). Siete ensayos de interpretación de la realidad peruana, Red Ediciones, Lima, Perú.
MARTÍNEZ, Carmen. (2009). Repensando los movimientos indígenas. FLACSO, Quito, Ecuador.

MINISTERIO COORDINADOR DEL PATRIMONIO. (2011). Un aporte a la construcción de políticas públicas sobre el patrimonio cultural inmaterial. Reflexiones y resultados de la mesa-taller. UNESCO, IPHAN (Brasil), INPC, IAPH (España).

MINISTERIO COORDINADOR DEL PATRIMONIO.(2011). Agenda del consejo sectorial de patrimonio, 2011-2013.

MINISTERIO COORDINADOR DEL PATRIMONIO. (2011). Introducción al Patrimonio Cultural, MCP Quito, Ecuador.

MINISTERIO COORDINADOR DEL PATRIMONIO. (2011). Políticas públicas sobre el patrimonio cultural inmaterial, MCP, Quito, Ecuador.

MINISTERIO COORDINADOR DEL PATRIMONIO. (2009). Decreto de emergencia del patrimonio cultural, MCP, Quito, Ecuador.

MINISTERIO COORDINACIÓN DEL PATRIMONIO. (2013). Política sectorial de género e interculturalidad 2011-2013, Consejo sectorial de patrimonio, Quito, Ecuador.

MONTENEGRO, Mauricio. (2013). "Articulaciones entre políticas económicas y políticas culturales en Colombia, el patrimonio cultural, el sector artesanal y las nuevas formas del valor y la propiedad" en Boletín del Antropología, Vol. 28, Núm. 46, Medellín, pp. 35-52. 
OLLERO, Francisco Coord. (2010). Patrimonio cultural, Identidad y Ciudadanía, Abya-Yala, Quito, Ecuador.

OSPINA, Pablo. (2010). Estado plurinacional y autogobierno territorial, demandas indígenas en Ecuador en La Autonomía a debate: autogobierno indígena y estado plurinacional en América Latina, FLACSO, Quito, Eucador.

PECKHAM, R.S. (2003). The politics of Heritage and public culture, en Rethinking Heritage: cultures and politics in Europe, I. B. Tauris.

PILATAXI, Cesar. (2014). Sumak Kawsay, organización comunitaria y emprendimiento productive, Abya-Yala, Quito, Ecuador.

PRATS, Loren. (1997). Antropologíay Patrimonio, Ariel Editorial, Madrid, España.

RESTREPO, Adriana Maya. (2011). Conclusiones balance y perspectivas premio $\mathrm{CAB}$, en Somos patrimonio, IPANC, Quito, Ecuador.

RIVAS, Alex. (2011). Políticas públicas para la gestión del patrimonio cultural inmaterial, en Un aporte para la construcción de políticas públicas sobre el patrimonio cultural inmaterial, Ministerio coordinador de patrimonio, Quito, Ecuador.

ROEL MENDIZÁBAL, Pedro, (2005). De Folklore a culturas híbridas, en No Hay país más diverso, , Instituto de Estudios peruanos, Lima, Perú.

SALOMON, Frank (1997). Los Yumbos, Niguas, y Tsáchila o "Colorados" durante la coIonia española: Etnohistoria del Noroccidente de Pichincha . Ediciones Abya-Yala. Quito, Ecuador.

(1981) "Killing the Yumbo: A Ritual Drama of Northern Quito". En:WHITTEN, N.E. (ed.) Cultural Transformations and Ethnicity in Modern Ecuador. University of IIlinois Press, Urbana Illinois. p. 161-208.

SANCHEZ PARGA, José, (2014). Alternativas virtuales vs. Cambios reales, Centro andino de acción popular, Quito, Ecuador (CAAP).

SCHAVELZON, Salvador, (2015). Plurinacionalidady Vivirbien/Buen vivir, Quito, Ediciones Abya-Yala y FLACSO.

SMITH, Laurajane, AKAGAWA, Natsuko (2009). Intangible Heritage, , Routledge, Londres, Inglaterra.

TUAZA, Luis Alberto. (2011). La Crisis del movimiento indígena ecuatoriano, FLACSO, Quito, Ecuador.

UNESCO. (1986). Recommendation on safeguarding traditional culture and folklore.

UNESCO. (1989). Actas de la Conferencia General, Reunión París.

UNESCO. (2003). Convención para la salvaguardia del patrimonio cultural inmaterial, París.

UNESCO. (2005). Declaratoria para la Protección y Promoción de las Diversidad y Expresiones Culturales.

UNESCO . (2006). Proyecto de Turismo Cultural para América Latina y el Caribe. 
UNESCO. (2011). Textos fundamentales de la Convención para la salvaguarda del Patrimonio cultural inmaterial de 2003, UNESCO, París.

UNESCO. WWw.unesco.org/new/en/ cairo/.../intangible-cultural-heritage/

UNESCO. wWw.unesco.org/archives/ multimedia/index.php?pg...heritage

UNESCO. wWw.unesco.org/.../worldday-for-audiovisual-heritage-2014/
UNESCO. www.unesco.org/culture/ich /index.php?pg=00002

VICH, Víctor (2014) Desculturizar la cultura, Siglo veintiuno editores, Buenos Aires.

WALSH, Catherine (2009), Interculturalidad, Estado Sociedad. Luchas (de)coloniales de nuestra época, Universidad Andina Simón Bolívar, Abya-Yala, Quito, Ecuador. 
BIOACÚSTICA 


\section{SELECCIÓN, ANOTACIÓN \\ Y ETIQUETADO DE LOS CANTOS DE LAS RANAS DEL ECUADOR}

\section{SELECTION, RECORDING AND LABELING OF ECUADORIAN FROG CALLS}

ANDRÉS ESTRELLA DANIEL NICOLALDE DAMIÁN NICOLALDE DANIELA PAREJA

Recibido 15 de marzo de 2016 Aceptado 8 de abril de 2016 



\title{
SELECCIÓN, ANOTACIÓN Y ETIQUETADO DE LOS CANTOS DE LAS RANAS DEL ECUADOR
}

\author{
Andrés Estrella', Daniel Nicolalde², Damián Nicolalde³ ${ }^{3}$ Daniela Pareja ${ }^{4}$
}

\section{RESUMEN}

El presente trabajo explica el estándar y prácticas de selección, anotación y etiquetado del material bioacústico para grabaciones que contengan cantos de ranas. El objetivo es disponer de una base de datos de señales acústicas de cantos de ranas presentes en el Parque Nacional Yasuní en Ecuador considerando que los cantos anotados son una valiosa fuente de información para investigación de reconocimiento automático de especies. Este documento explica el procedimiento de selección de audio en buen estado, así como el procedimiento de anotación. En la selección de audio se evitarán sonidos con baja relación-señala-ruido, con presencia de voz humana, con ruidos mecánicos y señales satura- das. En el procedimiento de anotación, se usan etiquetas estándar para marcar el intervalo de anotación, los cantos de rana por especie y cada nota. Esta base de datos servirá como referencia para desarrollo de aplicaciones bioacústicas, bioinformáticas y de procesamiento digital de señales en tareas que requieran reconocimiento automático de cantos de rana.

Palabras clave: cantos de ranas; bioacústica; anotar cantos; etiquetar cantos; procesamiento digital de señal

\section{ABSTRACT}

The present work explains the standards and practices of selection, recording and labeling of bioacoustic

\footnotetext{
1 (andrew srocks@yahoo.com).

2 (danielnicolalde@gmail.com).

${ }_{3}^{3}$ Pontificia Universidad Católica del Ecuador, Facultad de Ingeniería, Quito, Ecuador (danicolalde@puce.edu.ec).

${ }^{4}$ Pontificia Universidad Católica del Ecuador, Facultad de Ciencias Exactas y Naturales, Quito, Ecuador (dparejamejia@gmail.com).
} 
material found in recordings of frog calls in the wild. The goal is to have a consistent audio database of annotated frog calls found in Yasuní National Park in the eastern region of Ecuador for development and testing of automatic recognition algorithms. This document describes the procedure for audio selection as well as the recording procedure. Signals with low signal-to-noise-ratio, presence of human voice, mechanical noises, and clipped are discarded during the selection step. In the annotation task, standard labels are chosen to mark the annotation interval, a frog call, and each note. This database is expected to serve as ground-truth for the development of automatic species recognition applications in bioacoustics, bioinformatics, and digital signal processing.

Key words: songs of frogs; bioacoustics; record songs; tag songs; digital signal processing

\section{INTRODUCCIÓN}

Ecuador es hábitat de 566 especies de ranas conocidas (Ron, S. R., Guayasamín, J. M., Yánez-Muñoz, M. H., Merino-Viteri, A. Ortiz, D. A. y Nicolalde, 2016). Sin embargo, nuevas especies se van descubriendo constantemente. Los machos cantan para atraer a las hembras con fines reproductivos y también para defender su territorio. Los cantos son compuestos de una o varias notas como se observa en Figura 1. Por sus características particulares, los investigadores consideran los cantos de rana como una valiosa fuente de información para identificación y clasificación de especies. Específicamente, se ha reportado el uso de características del canto discriminatorias entre diferentes especies. Estas características son: frecuencia fundamental y dominante, número de pulsos, número de armónicas, duración del canto, tiempo de subida, etc (Duellman, W. E., 1986).
En general, el procedimiento de obtención de características de canto de rana se realiza de forma manual y con auxiliares de software que permiten extraer las características de cada canto, que serán usadas por un clasificador estadístico. En muchos casos, la complejidad del hábitat de las ranas permite registrar únicamente el canto de las especies.

Este trabajo brindará un protocolo que les permita a los investigadores extraer las características de los cantos de las ranas para futuros análisis, por ejemplo: investigar el desempeño de modelos de combinación de gaussianas (GMM) (Reynolds \& Rose, 1995), un método clásico de reconocimiento de locutor, para reconocimiento de especies de rana.

Para el proceso de reconocimiento de las especies de ranas, se consideran 
dos fases: entrenamiento y pruebas. En la fase de entrenamiento se estiman los parámetros de los modelos de cada rana en base a su registro acústico anotado, y en la fase de pruebas se evalúa el desempeño del algoritmo a través de métricas (Jaafar \& Ramli, 2013). En ambos casos es necesario contar con un corpus de evaluación anotado y etiquetado cuidadosamente.

El objetivo de este documento es proveer instrucciones detalladas para anotar un archivo de audio que contiene el canto de rana y producir un corpus de evaluación (ground truth) consistente y acertado para investigación. Este documento también va a servir como referencia a investigadores usando los datos anotados. Los procedimientos mostrados de aquí en adelante fueron desarrollados usando como referencia los métodos propuestos en (Kasturi et al., 2009) (Jaafar \& Ramli, 2013) y recogiendo la experiencia de los investigadores en el proyecto.

El documento está organizada de la siguiente forma. En la sección II se analiza la selección de audio que se usará para la anotación. Posteriormente, en la sección III (A, B, C, D, E, F, G, H, I, J, K, L) se explica el procedimiento de anotación y etiquetado de audio. Finalmente, en la sección IV se emitirán las conclusiones.

\section{MATERIALES Y MÉTODOS}

\section{Selección de audio}

El hábitat de la rana es un ambiente acústico muy complejo y diverso donde varias especies compiten por ser escuchadas con fines reproductivos y territoriales (Duellman, W. E., 1986). Además, las ranas cantan en coros compuestos de varios individuos de la misma especie y durante la caída de lluvia (Jaafar \& Ramli, 2013)(Taylor, Watson, Grigg, \& McCallum, 1996). También existen diferencias en las prácticas de grabación seguidas por cada investigador. Algunas veces se pueden introducir ruidos mecánicos en el procedimiento de graba- ción. En otras palabras, existen fuentes de ruido que degradan la calidad del audio grabado en campo.

Debido a esto, es necesario realizar una selección del material acústico que se va a usar para entrenar el sistema automático antes de realizar la anotación y etiquetado del mismo. La selección se hace en base al análisis visual del espectrograma y escuchando cada segmento para asegurar buena calidad del corpus de evaluación. 


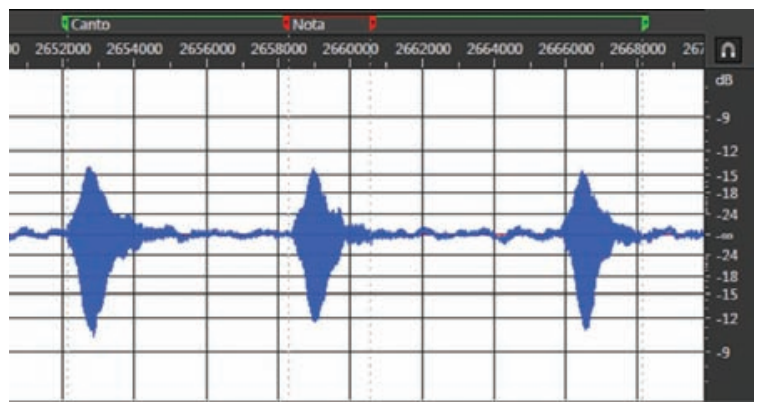

Figura 1: Un canto de $\mathrm{H}$. lanciformis compuesto de 3 notas (sílabas)

\section{a. Registro acústico de cantos de ranas}

Es importante seguir un método sistemático de grabación de audio en el campo para generar muestras homogéneas y de calidad suficiente para análisis e inventario de material bioacústico (Brandes, 2008). Un manual de grabación bioacústica propuesto por Obritzet al. está disponible en («Bioacoustic approaches in biodiversity inventories», 2010).

\section{b. Herramientas de software}

Para selección, anotación y etiquetado de los cantos de ranas se ha escogido usar el software Adobe Audition 6.0 en combinación con la herramienta de edición CueListTool 1.7 («CueListTool $1.7 »$, s. f.) para generar el archivo de intercambio.

\section{c. Formato de audio}

Para inventario y análisis de material bioacústico es necesario usar audio digital de alta calidad sin pérdidas («Bioacoustic approaches in biodiversity inventories», 2010). En particular, se van a usar archivos en formato Waveform Audio File Format WAVE («Multimedia Programming Interface and Data Specifications 1.0», 1991) con extensión. WAV. La frecuencia de muestreo a partir de 44100 Hz y con resolución de 16-bits en adelante. No usar archivos en MP3.

\section{d. Tipos de ruido por evitar en archivo de audio}

En el audio seleccionado para entrenar el sistema automático, es importante evitar perturbaciones que introduzcan errores en los modelos estocásticos. Primero, impedir grabaciones de rana con conversación de fondo. En Figura 2 
se puede ver un segmento de espectrograma típico de voz humana. La voz concentra energía en una zona del espectro típicamente usada por las ranas por lo que es necesario seleccionar archivos sin esta clase de interferencia.

Segundo, omitir archivos con zumbido en $60 \mathrm{~Hz}$ o con sonido de motores. Las harmónicas de estas señales pueden también interferir en los cantos. En la figura 3 se puede ver un espectrograma típico de un generador AC de fondo con sus armónicas durante la grabación. Ruido de este tipo puede ser tratado con filtros de audio. Sin embargo, el foco de este trabajo es en análisis sin profundizar en restauración. Evitar archivos con este ruido porque introduce tendencias erróneas en los modelos de rana.

Tercero, no escoger grabaciones con baja relación de señal a ruido (SNR). Esta situación se genera cuando el canto de rana ha sido grabado a distancia y es apenas perceptible por sobre el ruido de fondo. Para entrenar los modelos de rana se busca segmentos donde el canto de rana sea claramente más fuerte que el ruido de fondo. En lo posible usar SNR $>20$.

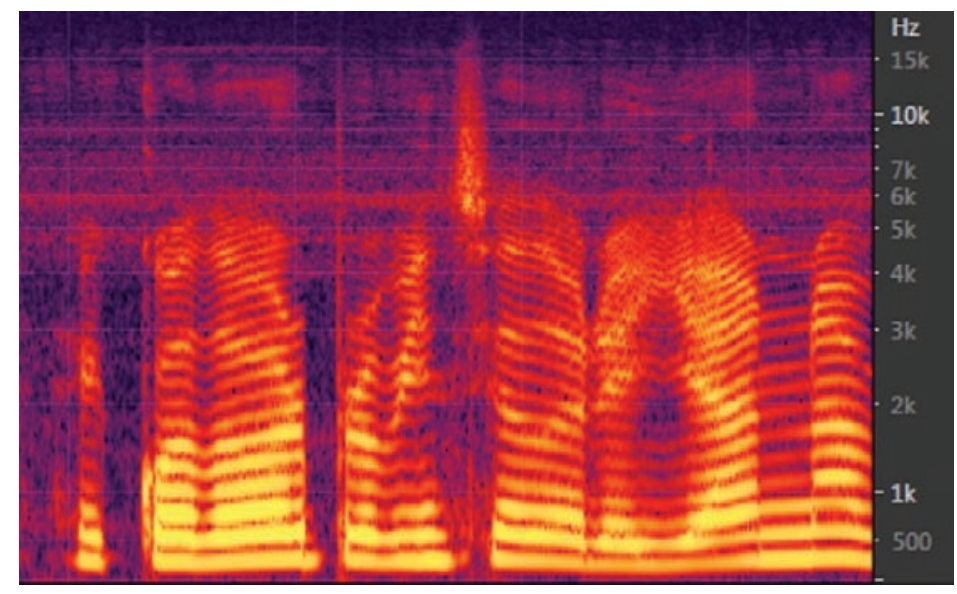

Figura 2: Espectrograma típico de voz humana 


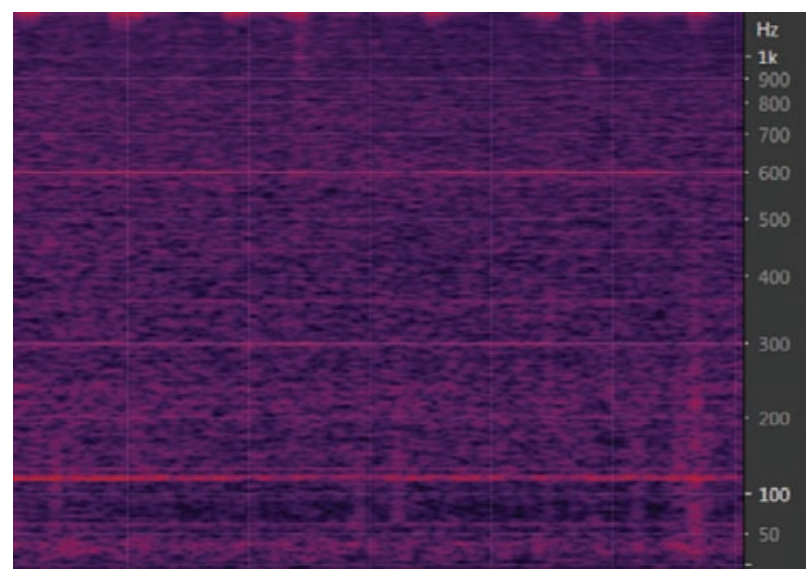

Figura 3: Espectrograma de un generador $A C$ en $60 \mathrm{~Hz}$ con sus armónicas

Cuarto, evitar grabaciones que presenten artefactos mecánicos como golpes en el micrófono, fricción o mala conexión del cable. En la figura 4 se presenta el espectrograma de golpe y fricción en el micrófono. Su espectro interfiere con los cantos de rana por lo que su presencia degrada significativamente la calidad del material.

Finalmente, no escoger archivos que presenten clipping. Descartar grabaciones que presenten saturación que produce distorsión del canto. La figura 5 muestra un ejemplo de canto saturado. Se recomienda escoger cantos que no sobrepasen el nivel -6dB que es la pérdida esperada de presión acústica a 1 metro de distancia de la rana con un micrófono correctamente calibrado («Bioacoustic approaches in biodiversity inventories», 2010).

El material seleccionado se anota y etiqueta siguiendo el procedimiento detallado en la siguiente sección. 


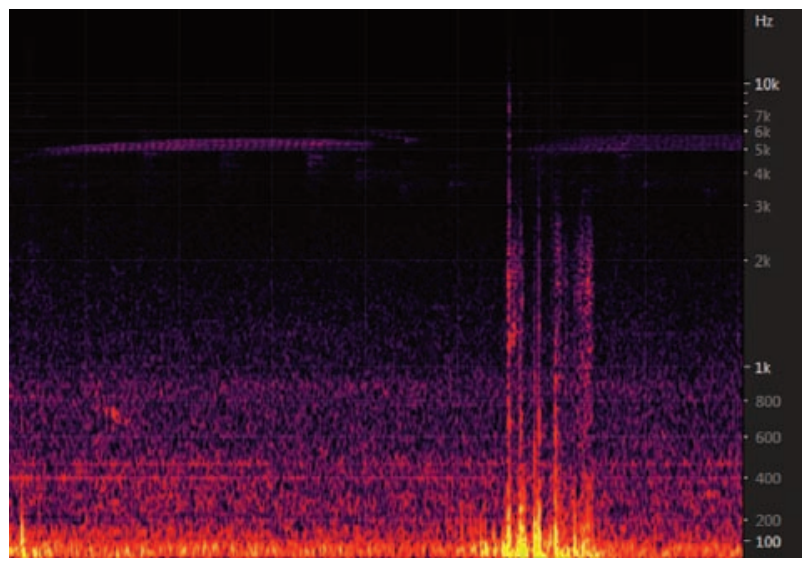

Figura 4: Allobates Insperatus con ruido de golpes en micrófono y generador AC de fondo

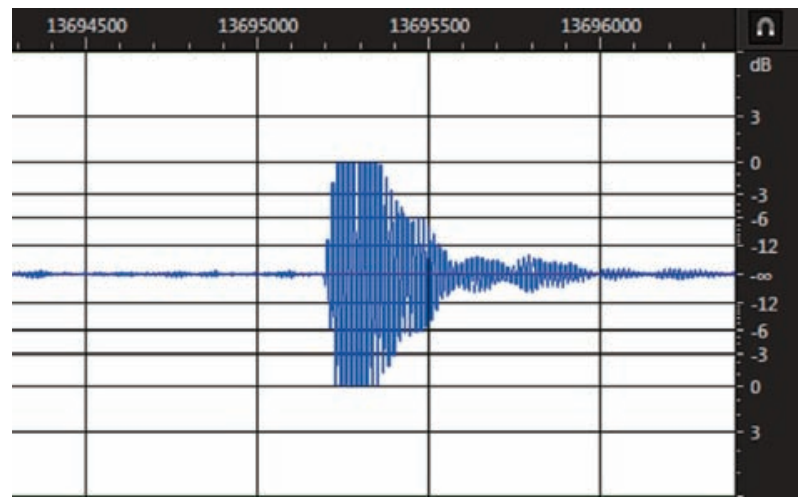

Figura 5: Canto de rana con clipping

\section{Anotación y Etiquetado de Audio}

Una vez que el corpus de evaluación ha sido seleccionado es necesario anotar y etiquetar los cantos de acuerdo con las características de cada especie. El corpus se anota entre 5 especialistas en identificación manual con un cross- 
check del 10\% del material anotado por cada uno. A continuación se define el dominio y la identificación única por cada especie de rana. Después se introducen la nomenclatura y el procedimiento de anotación e intercambio.

\section{e. Matriz de Anotación}

Se define un dominio "Yasuní" con 128 especies de ranas. Para el estudio de reconocimiento automático de especie de ranas se escogen inicialmente 10 especies que se muestran en tabla 1.

\section{Tabla 1: Lista de ranas escogidas}

\begin{tabular}{|ccc|}
\hline FAMILIA & GÉNERO & CÓDIGO \\
\hline Bufonidae & Rhinella margaritifera & R0009 \\
Craugastoridae & Pristimantis conspicillatus & R0023 \\
Hylidae & Dendropsophus bifurcus & R0056 \\
Hylidae & Dendropsophus triangulum & R0068 \\
Hylidae & Hypsiboas alfaroi & R0070 \\
Hylidae & Hypsiboas calcaratus & R0072 \\
Hylidae & Hypsiboas cinerascens & R0073 \\
Hylidae & Osteocephalus fuscifacies & R0084 \\
Leptodactylidae & Engystomops petersi & R0105 \\
Leptodactylidae & Leptodactylus discodactylus & R0106 \\
\hline
\end{tabular}

\section{f. Elementos de anotación}

Se definen tres elementos para anotar en una grabación: intervalo de anotación, canto de rana y nota. Primero, el intervalo de anotación se escoge siguiendo los criterios de selección y debe contener la mayor cantidad de cantos posible. Marcar inicio y final de cada intervalo en el archivo. Segundo, un canto de rana está formado por una o más notas. La figura 1 muestra un canto compuesto de tres notas. Marcar como segmentos la extensión del canto y cada nota individualmente.

\section{g. Nomenclatura}

Para anotar los segmentos seleccionados en cada archivo se usan marcadores de cue list. Usar en la etiqueta las palabras en mayúsculas INICIO para el punto inicial y FINAL para el punto final del intervalo de anotación tal como se muestra en la figura 7. Solo anotar los cantos entre un INICIO y FINAL. Para marcar todo el canto de rana se usa la etiqueta RXXXXA en canto de apareamiento y RXXXXXT en canto territorial. Para marcar cada sílaba componente de un canto se etiqueta con RXXXXAYY en 
canto de apareamiento y RXXXXTYY en canto territorial. Donde XXXX representa la Identificación numérica única de cada especie de rana en la TABLA 1, y YY es un número de dos dígitos que indica el orden de ocurrencia de cada sílaba en un mismo canto. Cada canto YY inicia en 01.

\section{h. Procedimiento de anotación}

En cada especie de rana se dispone de una lista de archivos *.WAV que contienen grabaciones de cantos de rana. Identificar en cada archivo intervalos de anotación que contengan la mayor cantidad de cantos de rana posible. Puede existir uno o más intervalos de anotación por archivo. Estos intervalos deben limitarse a condiciones libre de ruido descritos en la sección II. En cada intervalo de anotación se seleccionan los cantos a anotar siguiendo el flujo de la figura 6 con ayuda de la forma de onda y el espectrograma. Primero identificar un canto que pertenezca a la especie buscada. Si el canto tiene suficiente volumen para estar en primer plano, comprobar que no se encuentre saturado. Si el canto, además, no está superpuesto con cantos de la misma u otra especie, anotar y etiquetar. Si alguna de las condiciones anteriores no se cumple, no anotar, y continuar al siguiente canto hasta llegar al final del intervalo de anotación.

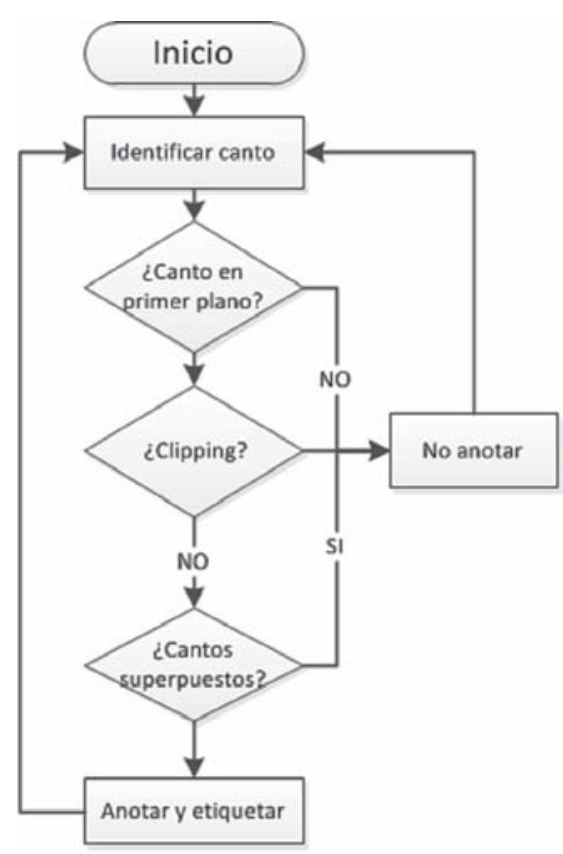

Figura 6. Flujo de anotación de un canto de rana 


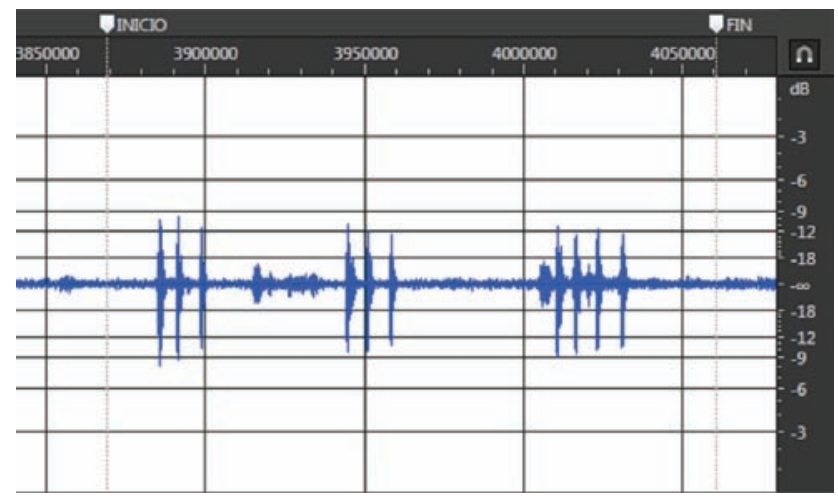

Figura 7. Inicio y final de un intervalo de anotación

Con Adobe Audition 6.0 el procedimiento de anotación y etiquetado se realiza de la siguiente forma:

1. Seleccionar con el "mouse" el elemento de anotación a marcar.

2. Presionar ' $M$ ' o en el menú principal dar click en "Edición->Marcador-> Añadir Marcador. Escoger marcador de señal (cue).

3. Editar el marcador con la nomenclatura correspondiente.

4. Continuar al siguiente elemento de anotación y repetir los pasos 13 de ser el caso.

5. Guardar al culminar la anotación.

\section{i. Marcar el Intervalo de Anotación}

Los intervalos de anotación deben contener a todos los cantos anotados en una grabación. Marcar más de un intervalo de anotación por archivo de ser necesario. Posicionar siempre el INICIO en una zona con ruido de fondo estable y localizado al menos unos 200 milisegundos antes del primer canto en el intervalo ya que este marcador se usa también para estimar la potencia del ruido de fondo. Usar el mismo criterio para posicionar el FINAL. La figura 7 presenta un ejemplo de selección de un intervalo de anotación con las etiquetas INICIO y FIN colocadas adecuadamente. 
ReVista PUCE， ISSN 1012-389X. Núm. 102

3 nov 2015-3 mayo 2016. Estrella, Nicolalde, Nicolalde, Pareja, Pp. $37-54$

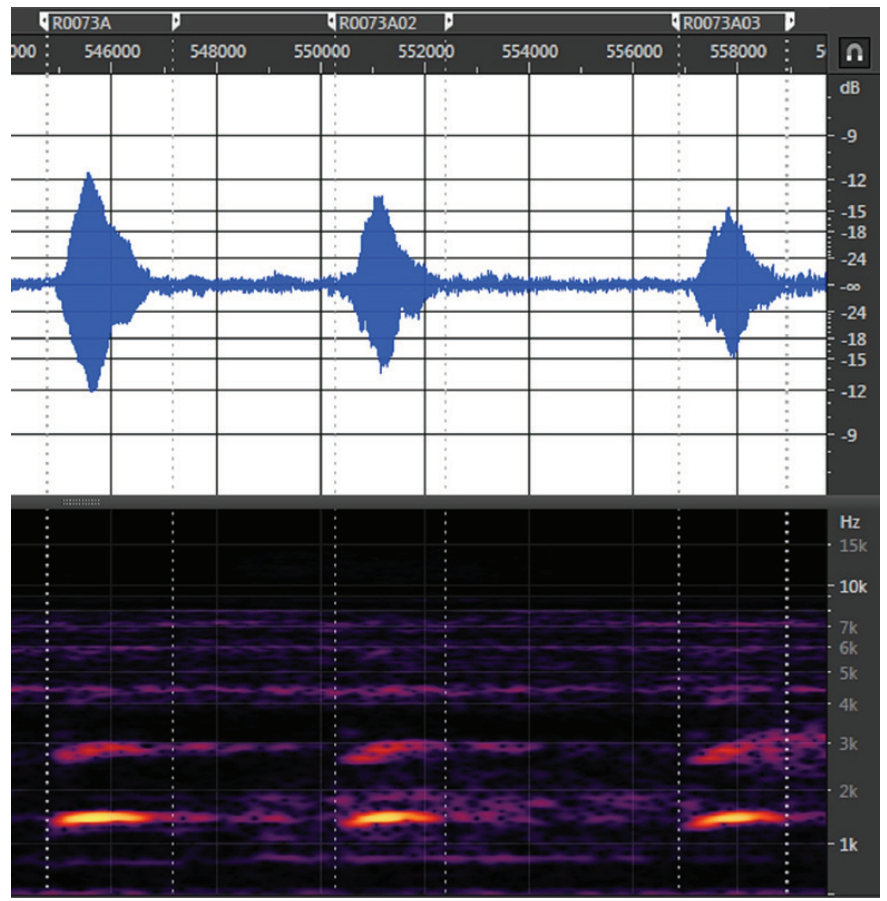

Figura 8. Marcado de un canto con tres notas de Hypsiboas cinerascens 


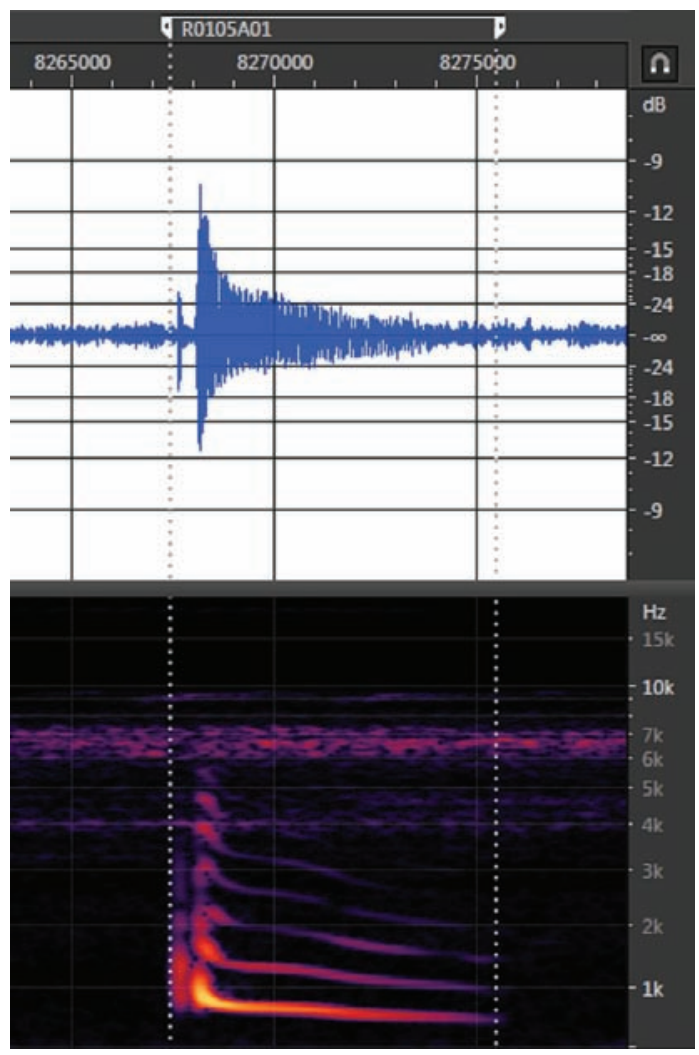

Figura 9. Marcado de un canto de Engystomops Petersi

\section{j. Marcar el canto de rana}

Seleccionar los cantos de acuerdo con el flujo de la figura 6. Usar el espectrograma como guía para reconocer superposición de cantos. Al anotar, marcar los límites del segmento en la forma de onda. Las figuras 8 y 9 muestran un ejemplo de anotado de cantos de cor- tejo compuestos de una nota y varias notas. Las etiquetas se asignan R0073A y $\mathrm{R} 0105 \mathrm{~A}$ respectivamente.

\section{k. Marcar las notas del canto de rana}

Las notas del canto de rana se marcarán de manera secuencial en el canto de acuerdo con su su orden de 
ocurrencia. Por ejemplo, el canto de Hypsiboas Cinerascens en la figura 8 tiene 3 notas. Se asigna el nombre para el marcador de la siguiente forma:

1. Nota 1: R0073A01

2. Nota 2: R0073A02

3. Nota 3: R0073A03

Las notas de un canto se encuentran separadas por silencios. Como regla general se registran las notas de un canto si los silencios intermedios son de duración igual o mayor a la notas. En caso que no exista una separación obvia, marcar todo el canto como una sola nota como se muestra en la figura 9.

\section{Generar el archivo de intercambio con CueListTool}

Debido a que los marcadores creados con Adobe Audition 6.0 se guardan directamente en el archivo.WAV, se usa CueList Tool 7.0 para generar una lista de marcadores en texto simple para intercambio. El archivo generado debe tener el mismo nombre del archivo.WAV, pero con extensión .RTF.
El procedimiento para generar los archivos es el siguiente:

1. Abrir el archivo. WAV con CueListTool:

File > Open Wav File o click en

$$
\text { EWWAV }
$$

2. Aplicar el botón "Read Cue list file from Wav File" dar click en

\section{\& WAV}

3. Guardar por defecto con el mismo nombre del archivo y en la misma carpeta. Aplicar el botón "Save Cue list file to disk"

回 CLT

4. Guardar también el archivo de texto .RTF aplicando el botón "Save text window to disk" dando click en

\section{Text}

\section{RESULTADOS Y DISCUSIÓN}

Lista de especies de ranas seleccionadas, anotadas y etiquetadas

El número de cantos seleccionados, anotados y etiquetados bajo el pro- tocolo desarrollado en el presente trabajo fue de 67; en la TABLA 2 se puede observar el número de cantos por especie. 
TABLA 2. Número de cantos por especie

\begin{tabular}{|cccc|}
\hline FAMILIA & GÉNERO & CÓDIGO & NO. CANIOS \\
\hline Bufonidae & Rhinella margaritifera & R0009 & 6 \\
Craugastoridae & Pristimantis conspicillatus & R0023 & 8 \\
Hylidae & Dendropsophus bifurcus & R0056 & 8 \\
Hylidae & Dendropsophus triangulum & R0068 & 4 \\
Hylidae & Hypsiboas alfaroi & R0070 & 5 \\
Hylidae & Hypsiboas calcaratus & R0072 & 8 \\
Hylidae & Hypsiboas cinerascens & R0073 & 9 \\
Hylidae & Osteocephalus fuscifacies & R0084 & 5 \\
Leptodactylidae & Engystomops petersi & R0105 & 11 \\
Leptodactylidae & Leptodactylus discodactylus & R0106 & 3 \\
\hline
\end{tabular}

\section{Cross-check}

Para realizar el cross-check de los cantos anotados el procedimiento a seguir es:

Aleatoriamente se redistribuirán los cantos anotados entre personas diferentes a las que realizaron la anotación del canto. Estas personas deben revisar todos los cantos anotados y de ser el caso, corregir si alguno presenta alguna falla en la anotación.

Por cada especie, quién esté realizando el cross-check anota nuevamente un canto -aleatoriamente-, escogiendo el mismo punto de inicio y fin.

Luego de realizar un estudio en la literatura, no se encontró un protocolo para la selección, anotación y etiquetado de material bioacústico, específica- mente para el canto de las ranas y que permita intercambio. El presente trabajo sugiere un protocolo y se propone usar un archivo de texto simple generado con el software CueListTool para intercambio.

El uso de este protocolo con un archivo de intercambio permite la automatización de los procesos de entrenamiento y testeado a través de software especializado sin necesidad de analizar el archivo digital de audio que podría ser demasiado grande. Además, permite el fácil intercambio de información de contenido de bioacústica en archivos que son generalmente de larga duración entre los interesados sin enviar el audio digital cada vez.

Un archivo de CueList ofrece un detalle del contenido de la grabación como referencia para una rápida extrac- 
ción de información sin necesidad de dría llevar mucho tiempo. escuchar toda la grabación, lo que po-

\section{CONCLUSIONES}

El presente documento propone un estándar de selección de material acústico, explica como marcar los cantos de rana con sus respectivas notas usando etiquetas predefinidas. Es importante tener una base de datos consistente con cantos de ranas de diferentes especies. La presencia de ranas es un indicador muy importante del buen estado del ambiente en regiones como la selva amazónica. Esta base de datos será base para investigadores en áreas de bioacústica, bioinformática, procesamiento digital de señales, entre otras.
Se sugiere instrucciones detalladas de selección, anotación y etiquetado de los cantos para generar un corpus de evaluación y archivo de material bioacústico que servirá como referencia para investigaciones futuras.

Una aplicación específica de la base da datos de cantos de rana, con sus respectivas anotaciones, es para el reconocimiento automático de especies de rana a base de sus cantos. Aquí es muy importante un modelo estocástico por especie, donde se requieren cantos de rana previamente identificados. 


\section{BIBLIOGRAFÍA}

Bioacoustic approaches in biodiversity inventories. (2010). En Manual on Field Recording Techniques and Protocols for All Taxa Biodiversity Inventories (Vol. 8, pp. 68-99). Abc Taxa.

Brandes, T. S. (2008). Feature vector selection and use with hidden Markov models to identify frequency-modulated bioacoustic signals amidst noise. Audio, Speech, and Language Processing, IEEE Transactions on, 16(6), 1173-1180.

CueListTool 1.7. (s. f.). [Software Documentation].

Duellman, W. E., and L. T. (1986). Biology of Amphibians. (McGraw-Hill Book, Ed.). New York.

Jaafar, H., \& Ramli, D. A. (2013). Automatic syllables segmentation for frog identification system. En Signal Processing and its Applications (CSPA), 2013 IEEE 9th International Colloquium on (pp. 224-228). http:// doi.org/10.1109/CSPA.2013.6530046

Kasturi, R., Goldgof, D., Soundararajan, P., Manohar, V., Garofolo, J., Bowers, R., ... Zhang, J. (2009). Framework for Performance Evaluation of Face, Text, and Vehicle Detection and Tracking in Video: Data, Metrics, and Protocol. Pattern Analysis and Machine Intelligence, IEEE Transactions on, 31(2), 319-336. http://doi.org/10.1109/TPAMI.2008.57
Multimedia Programming Interface and Data Specifications 1.0. (1991, agosto).

Reynolds, D. A., \& Rose, R. C. (1995). Robust text-independent speaker identification using Gaussian mixture speaker models. IEEE Transactions on Speech and Audio Processing, 3(1), 72-83. http://doi.org/10.1109/89. 365379

Ron, S. R., Guayasamín, J. M., YánezMuñoz, M. H., Merino-Viteri, A. Ortiz, D. A. y Nicolalde, D. A. (2016). AmphibiaWebEcuador. Recuperado 20 de febrero de 2016, a partir de http://zoologia.puce.edu.ec/vertebrados/anfibios/EspeciesEstadisticas.aspx

Taylor, A., Watson, G., Grigg, G., \& McCallum, H. (1996). Monitoring Frog Communities: An Application of Machine Learning. En W. J. Clancey \& D. S. Weld (Eds.), AAAI/IAAI, Vol. 2 (pp. 1564-1569). AAAI Press / The MIT Press. 
COMUNICACIÓN 


\section{LA CRISIS DE LAS EMPRESAS INFORMATIVAS REPLANTEA EL PERFIL DEL PERIODISTA ACTUAL}

THE CRISIS IN THE MASS MEDIA COMPANIES REQUIRES A REDEFINITION OF THE PROFILE OF THE JOURNALIST NOWADAYS

ANA GABRIELA DÁVILA J. 



\section{LA CRISIS DE LAS \\ EMPRESAS INFORMATIVAS \\ REPLANTEA EL PERFIL \\ DEL PERIODISTA ACTUAL}

Ana Gabriela Dávila J. ${ }^{1}$

\section{RESUMEN}

La revolución digital, a nivel global, y varios factores propios del contexto local, han transformado a las empresas informativas en todos los ámbitos que las componen. Uno de los cambios más importantes, involucra directamente al periodista, quien ha debido enfrentarse a nuevos escenarios en cuanto a la producción de contenidos, rutinas de trabajo y preferencias de las audiencias.

Este artículo expondrá y analizará los elementos que, a la luz del despunte tecnológico y del contexto nacional, han impulsado el pensar en un nuevo perfil profesional del periodista y, en ese sentido, se enfocará en delinear un perfil que abarque nuevas competencias y conocimientos.
Además, analizará la formación que históricamente han brindado las facultades de comunicación y/o periodismo del país y que definirá la convergencia y sus niveles como concepto fundamental para entender las transformaciones que han experimentado los medios de comunicación.

Palabras clave: medios de comunicación, convergencia, perfil del periodista, contenidos periodísticos.

\section{ABSTRACT}

The digital revolution, at a global level, and other factors belonging to the local context have transformed the mass media companies in all the fields they are a part of. One of the most important changes involves the journalists directly as they have had to face new scenarios

\footnotetext{
'Pontificia Universidad Católica del Ecuador, Facultad de Comunicación, Lingüística y Literatura, Quito, Ecuador (anagadavila@gmail.com).
} 
in which they deal with the production of contents, working routines and audience preferences.

This article will present and analyze the elements which, in light of technological advancement and the national context, have fostered the thought about finding a new professional profile. That is to say, it will focus on proposing a profile which encompasses new competencies and knowledge.
In addition, it will analyze the formation that has been offered by the schools of communication and/or journalism in the country for years and will define the convergence and its levels as a fundamental concept in order to understand the transformation that mass media has experienced.

Key words: mass media, convergence, journalist profile, journalistic contents

\section{INTRODUCCIÓN}

Los cambios y las transformaciones nunca han sido desconocidos para el periodismo. Su concepto, en sí mismo, se ha definido en función de la evolución de la historia del mundo. Basado en esto, se identifican tres etapas que tienen lugar en contextos específicos. La primera es la del periodismo ideológico, misma que llegó hasta el fin de la Primera Guerra Mundial; esta se caracterizó por impulsar un periodismo al servicio de ideas políticas y religiósas. Hacia 1870 nace la etapa del periodismo informativo, la que se destacó por el relato de los hechos más que por la difusión de comentarios. A través de esta, se daba cuenta de los principales acontecimientos que empezaron a transformar el mundo. A partir de 1945, cuando termina la Segunda Guerra Mundial, se gesta el periodismo interpretativo, caracterizado por una profundización de las informaciones, combinado con el punto de vista del periodista. Es durante este período cuando desde los medios se empezó a contribuir con elementos que permitían no solo conocer la realidad sino comprenderla.

Estas etapas trajeron consigo cambios tanto en el manejo de la información y del desarrollo del oficio periodístico, como en la forma del consumo de los productos periodísticos por parte de las audiencias. De ser un público que únicamente conocía el hecho o el qué, pasó a conocer las razones y los contextos, en otras palabras, el porqué de los acontecimientos.

Así se puede resumir, brevemente, las principales transformaciones que el periodismo ha experimentado a lo largo de su historia, hasta llegar a la revolución 
digital; para muchos la etapa que más cambios ha traído a los profesionales de la comunicación, principalmente, por el aparecimiento de las nuevas tecnologías de la información y comunicación.

En el mundo entero se habla de una crisis de la profesión, provocada por los cambios que están enfrentando las empresas informativas y que acarrea consigo la imperiosa necesidad de generar variados perfiles que puedan desenvolverse en una nueva realidad comunicativa e informativa, que plantea como cambio transcendental un nuevo modelo de comunicación.

\section{LA CRISIS DE LA PROFESIÓN}

Para entender la crisis de la profesión es preciso referirse a la crisis de las empresas informativas. Fruto de la revolución digital, los medios de comunicación han experimentado una serie de transformaciones que les han afectado tanto en su parte comercial como en la editorial. Los cambios en los contenidos, en las rutinas de producción, en los comportamientos de las audiencias, en la publicidad y en los modelos de negocios, han roto los esquemas tradicionales de manejo de los medios, lo cual también ha afectado a los periodistas. Para comprender lo apuntado cabe ir analizando cada uno de estos elementos relacionándolos con la actividad y función del periodista.

\section{Cambios en los contenidos}

Trabajar contenidos multiplataforma y multimediales requiere el conocimiento de las nuevas tecnologías. Ya no basta con escribir adecuadamente un texto y escoger una fotografía o ima- gen para acompañarlo. Se requiere manejar programas de edición de audio, video, fotografía, saber construir contenidos específicos para un teléfono o una tableta, por ejemplo. Se necesita, además, dotar a estos textos de elementos que generen interactividad y tengan hipertextos. También se deben trabajar contenidos de alta calidad informativa y contar buenas historias que atraigan a los lectores y sobresalgan dentro del océano de información que es la web. Es decir, se requieren conocimientos sólidos en varias herramientas digitales y nuevas narrativas, entre otros, los mismos que muchos periodistas no los tienen. Es ahí donde surge el primer inconveniente para el periodista, si no posee estos conocimientos podrá ser desplazado por quien tenga un perfil polivalente que es el que demandan los medios hoy.

\section{Rutinas de producción}

Los entornos digitales requieren 
un trabajo de 24/7; actualizar permanentemente la información y producir contenidos que serán distribuidos a través de distintos canales. Eso implica adaptar el mismo contenido al canal, con todo el esfuerzo que eso supone; algo parecido a trabajar tres y cuatro veces más. "El cambio en la estructura externa de los escenarios productivos tiene prolongación a los ciclos de organización del trabajo periodístico: los temarios se renuevan o actualizan en ciclos cada vez más cortos imbuidos de las dinámicas de actualización constante en Internet." (Tuñez, Martínez, Abejón 2010).

Antes, el reportaje sobre la delincuencia en la ciudad se lo trabajaba para publicarse en el periódico impreso, ahora ese contenido debe adaptarse, además, para aparecer en el periódico virtual, en la revista del grupo, en el video que se colgará en Facebook y en la galería de fotos que se publicará en Instagram. Cada producto debe ser elaborado tomando en cuenta las características propias del canal, es decir, es como crear un nuevo y diferente contenido cada vez. Si antes el trabajo del periodista era extenuante, ahora lo es más por la transformación de las rutinas de producción. En las redacciones actuales no se puede hablar de que la información es un producto terminado; hoy la información es un insumo para un producto que está en constante construcción (Franco, Pellicer 2014).

\section{Comportamiento de las audiencias}

Los periodistas ya no son los únicos que generan contenido para los medios, ahora son los públicos quienes también pueden contribuir con información, alterando así la dinámica de construcción de la información en la que solo había espacio para el periodista."Internet ha democratizado la posibilidad de convertirse en emisor para una audiencia transnacional que ha alimentado el papel de la audiencia como proveedor de productos propios y de productos elaborados a partir de lo transmitido por otros medios" (Tuñez et al 2010). En ese sentido, el papel de mediadores de la realidad puede haberse debilitado. ¿Cómo actuar frente al hecho que personas sin preparación específica, puedan también informar? De ahí surge el cuestionamiento sobre la formación que debe recibir un periodista. No es lo mismo publicar una foto y escribir un texto, con lo que de alguna manera se informa, que hacer un trabajo metodológico de búsqueda y procesamiento de información, de selección cuidadosa de fuentes, de análisis de contenidos, de reflexión de contextos, tareas indispensables del oficio periodístico y que deben seguir aprendiéndose en las escuelas de comunicación. A esto se suma, el enfrentarse a audiencias cada vez más heterogéneas, con amplio acceso a la información y saturadas de mensajes, que demandan información con valor agregado. 


\section{Publicidad y modelos de negocio}

Históricamente el sustento de los medios de comunicación ha sido la publicidad. La cantidad de usuarios que han sumado los medios digitales los han transformado en espacios atractivos para la publicidad, por lo que un gran porcentaje de esta se trasladó a ellos, dejando a los medios tradicionales sin piso sobre el cual sostenerse. Es pertinente también referirse, en este punto, a la crisis económica mundial que ha reducido los gastos en publicidad." EI descenso en las inversiones publicitarias es consecuencia directa de la situación mundial de crisis económica, pero en el ámbito de las empresas de comunicación coincide con la multiplicación de las plataformas de emisión que suponen los nuevos canales de televisión digital y con un constante desvío de recursos de los soportes tradicionales en papel a los soportes masivos on-line". (Tuñez et al 2010).

Internet trajo consigo la cultura de la gratuidad y con ella un cambio de paradigma en torno al consumo de productos informativos. ¿Por qué pagar por consumir un contenido si se puede hacerlo gratuitamente? De este cuestionamiento nace uno de los traspiés que han tenido que afrontar las empresas informativas: reformular su modelo de negocio. Tomemos el ejemplo de los medios impresos, su modelo de negocio tradi- cional planteaba tres vías por las que obtenían ingresos: la publicidad, las suscripciones y la venta de ejemplares. Si la publicidad se ha reducido y la venta de ejemplares también, ya que las audiencias prefieren consumir información a través de los soportes digitales en los que no pagan por informarse, ¿qué ingresos están recibiendo los medios impresos? El camino más inmediato para afrontar esta realidad ha sido poner en marcha nuevos modelos de negocio que aún no terminan de cuajar del todo. Uno de los más usados es cobrar por el acceso a cierto contenido con valor agregado. Otro modelo plantea acceder a un número limitado de información, y a partir de una cantidad específica de artículos leídos, cobrar para continuar consumiendo otros. Hay modelos que plantean, incluso, cobrar por otro tipo de servicios relacionados con el entorno digital, pero que no tienen que ver necesariamente con la producción de información periodística, sino más bien con la creación de contenido de otra especie.

Para los medios aplicar estos modelos de negocio ha significado una apuesta a ciegas, ya que ha sido muy difícil prever si van a ser efectivos o no. Al respecto, los empresarios de los medios reconocen que nadie tiene la receta del modelo perfecto; todo ha sido una experimentación a prueba y a error. 
La falta de ingresos, ineludiblemente, pone al medio en una situación de inestabilidad, misma que gatilla decisiones muchas veces extremas como la disminución de personal o la reducción en gastos de producción. En el Ecuador muchos periodistas se han visto afectados por esta situación y ahora se encuentran engordando las listas del desempleo. A diciembre del 2015 el porcentaje de desempleo en Ecuador fue de $4,77 \%$, de esa cifra, una parte corresponde a los periodistas despedidos de los medios de comunicación, dato que todavía no se ha contabilizado (www. periodismoecuador.com).

A estos elementos analizados, y que pueden ser extrapolados para entender la realidad de las empresas informativas en otros rincones del mundo, se suman otros propios del contexto local. Desde el 2007, año en que Rafael Correa asumió la presidencia del Ecuador, se han generado varios hechos que han marcado la relación prensa-poder, la misma que se ha desgastado al punto de afectar a la estabilidad de las empresas informativas. El juicio en contra de diario El Universo por el editorial No a las mentiras de Emilio Palacios; el juicio en contra de los periodistas Juan Carlos Calderón y Christian Zurita, autores del libro El gran hermano, investigación periodística en la que se develaba la supuesta participación de Fabricio Correa, hermano del Presidente de la República, en contratos millonarios con el gobierno; la creación de la Ley de Comunicación; la conformación de instancias reguladoras de la comunicación e información como la Secretaría de Comunicación (SECOM), la Superintendencia de la Información y Comunicación (SUPERCOM) y el Consejo de Regulación y Desarrollo de la Información y Comunicación (CORDICOM) y las permanentes acusaciones por parte del Presidente de la República en contra de los medios de comunicación cuestionando su manejo editorial y su función social. Todos estos estos hechos han generado un contexto complejo para ejercer la profesión en el país. Como hitos dentro de esta etapa se pueden mencionar el cierre de diario Hoy, el cambio de dueños de diario El Comercio, uno de los diarios referentes del país-actualmente está en manos de un empresario mexicano propietario de varios medios en Latinoamérica-y el despido de periodistas quienes han optado por crear sus propios medios. En la búsqueda de una salida para continuar ejerciendo la profesión y hacer frente al desempleo, varios periodistas han mirado en los medios digitales una alternativa. Según un estudio realizado por CIESPAL, en el 2012 existían 34 medios digitales en el país. Tres años más tarde, un mapeo desarrollado por Fundamedios, reveló que hasta abril del 2015, de los 34 medios solo quedaban 15. "Se hace periodismo en internet desde las cuatro regiones del país, con equipos mínimos o que pasan 
la docena, con recursos ajustados y deudas, pero con esfuerzos extraordinarios: más de uno ha pasado por la tentación de cerrar" (www.planv.com). De esta manera, los estudios muestran que algunos medios han logrado sobrevivir, pero otros no han tenido la misma suerte.

Este panorama local, además, ha llamado la atención de los organismos internacionales defensores de la libertad de expresión, quienes se han referido al país como un territorio complejo para ejercer el periodismo libremente. Con todos estos antecedentes, cabe la pregunta, ¿será el periodismo una buena profesión para ejercer en Ecuador?
"El momento de crisis que viven las empresas informativas, se suma a crisis de credibilidad de la profesión y al debilitamiento del papel de los periodistas en nuestra sociedad. El papel de mediadores de la realidad se está agotando tal como lo entendíamos décadas atrás. El retroceso de la profesión tal y como la vemos actualmente es triple: económico, de prestigio y de rol en la sociedad" (Franco, Pellicer 2014). Con todo lo expuesto se explica por qué la crisis de las empresas informativas es también la crisis del periodismo.

\section{LA CONVERGENCIA: CONCEPTO TEÓRICO PARA COMPRENDER LOS CAMBIOS EN LAS EMPRESAS INFORMATIVAS}

Desde la perspectiva teórica existe un concepto fundamental para comprender las transformaciones que han experimentado los medios de comunicación, a partir de la revolución digital, se trata de la convergencia. Esta no es consecuencia del surgimiento de Internet, pero es indiscutible que su aparición ha dado un impulso al concepto. Aunque ya existían diferentes formas de convergencia en los medios tradicionales, es innegable que el nuevo medio potenció y enriqueció el fenómeno. (Irigaray, Ceballos, Manna 2013). Existen varias definiciones del concepto de convergencia, una de ellas es la introducida por Henry Jenkins -investigador que más ha teorizado sobre este concepto- mencionada en el artículo Contenidos periodísticos en el ecosistema líquido, entre la convergencia y la divergencia, publicado en el libro Webperiodismo en un ecosistema líquido, quien la define como: "the flow of content across multiple media platforms, the cooperation between multiple media industries, and the migratory behavior of media audiences who will go almost anywhere in search the kind of entertainment they want". Con esta definición, el autor identifica tres 
grandes áreas en la convergencia: la distribución de información multiplataforma, la cooperación entre empresas y el comportamiento migratorio de las audiencias (Irigaray et al. 2013). Otro concepto abanderado por el investigador de nuevos medios, el español Ramón Salavarría, por su parte, apunta que la convergencia es un proceso multifactorial, e identifica cuatro componentes fundamentales que definen su marco estructural: convergencia tecnológica, profesional, empresarial y de contenidos (Irigaray et al. 2013).

\section{Convergencia empresarial}

Se deriva de la evolución del modelo de negocio de las empresas periodísticas. A partir de un determinado momento, la evolución tecnológica obligó a las empresas a un replanteamiento de sus estrategias, buscando rentabilizar sus inversiones en tecnología y recursos humanos en un escenario donde Internet emergía como medio del futuro. Las fusiones entre empresas y la estrategia de los grupos de comunicación de ampliar su oferta a todas las áreas - prensa, radio, televisión e Internet- generó grandes conglomerados mediáticos que buscaron en la cross-promotion formas de rentabilizar sus inversiones.

Este proceso es facilitado por la conexión que siempre existe entre nue- vos medios y sus antecesores, porque los nuevos medios renuevan los anteriores en un proceso de remediación. El nuevo medio es siempre una mejora, más o menos profunda, de los precedentes y, por ello, hay una dependencia entre los dos y existe un conjunto de características comunes que facilitan el proceso de convergencia en las empresas (Irigaray et al. 2013).

\section{Convergencia profesional}

Es consecuencia directa de la convergencia empresarial. Esta ya ocurría anteriormente, sobre todo, entre los periodistas que trabajan en radio y televisión, pero ganó más visibilidad con la digitalización. La simplificación técnica y la aceleración del proceso de producción periodística fueron aprovechados por las empresas para unir funciones: los fotógrafos, tal como los editores de sonido y de video, han visto desaparecer muchos puestos de trabajo porque las empresas imputaron esas ocupaciones a los periodistas. Cuánto más evolucionan los medios, mayor es la tendencia para que se establezca la polivalencia de los profesionales, que van acumulando funciones anteriores con las nuevas. (Irigaray et al. 2013).

\section{Convergencia tecnológica}

Los medios han sido empujados hacia un modelo de producción multi- 
plataforma porque los usuarios consumen cada vez más los contenidos en diferentes soportes o canales. Las nuevas demandas de los nativos digitales $y$, simultáneamente, de una audiencia móvil, han fragmentado el consumo, exigiendo a las empresas un reposicionamiento capaz de responder a los nuevos desafíos generados por esta audiencia liquida caracterizada por una conexión a la red permanente, universal y dinámica (Irigaray et al. 2013).

\section{Convergencia de contenidos}

Involucra a la producción de información multimedia que explota las características de las nuevas plataformas de recepción. En este caso se entiende la multimedialidad en su concepto más amplio, no solo la utilización de contenidos de diferentes tipologías -texto, sonido y video- en una unidad informativa homogénea y coherente, sino también en su mezcla con la hipertextualidad e interactividad (Irigaray et al. 2013).

El concepto de convergencia es uno de los más estudiados dentro del campo de las investigaciones sobre los medios. Relacionados con este concepto están el transmedia y el crossmedia, otros fenómenos propios de la cultura digital desde los que también se puede entender el rol actual del periodista como un creador de historias concebidas para ser expuestas a través de múltiples canales.

\section{LA FORMACIÓN DEL PERIODISTA}

Los cambios que se han suscitado en las empresas informativas, traen consigo, inevitablemente, un replanteamiento del perfil profesional del periodista. Antes de esbozar ideas que intenten construir ese perfil, conviene referirse a la formación que los periodistas han recibido, históricamente, en el país.

Primero cabe señalar que el proceso de profesionalización del periodista ecuatoriano se inició de manera formal dentro de las aulas universitarias en la década del 40, con la creación de la primera Facultad de Comunicación Social de la Universidad Central del Ecuador (1943) en Quito, y luego, con la formación de la Escuela de Información de la Universidad Estatal de Guayaquil, en Guayaquil (1945). Actualmente, se estima que en el país existen, aproximadamente, 26 escuelas y facultades de Comunicación Social.

María Isabel Punín, profesora investigadora de la Universidad Técnica Particular de Loja, señala en su trabajo titulado Los estudios de Comunicación Social/Periodismo en el Ecuador. Una visión crítica al rol de la universidad y la acade- 
mia que la enseñanza del periodismo en el país ha vivido dos momentos. El primero estuvo marcado por la ideología de izquierda, bajo la que los periodistas se formaban desde una óptica marxista. "Dentro de esa formación existió la idea de usar los medios desde la visión de la comunicación contestataria que combatió al sistema dominante" (Punín, 2012).

El segundo momento habría estado marcado por la tendencia neoliberal que dominó al mundo; es dentro de esta etapa cuando se estudian las relaciones públicas, la comunicación organizacional y el periodista recibe una formación apolítica (Punín, 2012). En el mismo estudio se señala que hasta la década del 60 existió una titulación pura en periodismo, la misma que luego cambió a partir de un proyecto realizado por el Centro Internacional de Estudios Superiores de Comunicación para América Latina, CIESPAL, el cual planteaba la formación polivalente del periodista, lo que permitió ampliar el perfil profesional y motivar la creación de más facultades y escuelas de comunicación en distintos países de la Región.

El periodismo desde sus inicios, ha sido una disciplina ecléctica que se ha nutrido de un sinnúmero de perspectivas teóricas y metodológicas. Esta posición multidisciplinaria, sumada a las tendencias del mercado, ha provocado que la formación de los comuni- cadores tenga dos tendencias limitadas. La primera, una formación de corte humanística, que considera al periodista un intelectual, y la segunda, la formación técnica sobre temáticas relacionadas con la producción audiovisual, el marketing y la comunicación organizacional (Punín, Martínez, 2013).

En América Latina, en tanto, el origen de la formación universitaria de comunicadores sociales puede situarse entre 1934 y 1935, cuando se empezaron a impartir cursos de periodismo a nivel superior en la Universidad de La Plata (Argentina); fue esta la primera universidad de la Región en ofertar la carrera. Las escuelas que nacieron durante este tiempo imitaron el modelo clásico que se estaba aplicando en las escuelas de periodismo de Estados Unidos y Europa. Según la Federación de Facultades Latinoamericanas de Comunicación, FELAFACS, existen 295 escuelas y facultades de comunicación en Latinoamérica (Punín et al. 2013).

Según el estudio de Punín, la formación de comunicadores en América Latina ha tenido tres momentos:

- Entre 1930 y 1960 corresponde el período en el cual los académicos se centran en el análisis de los medios, la producción informativa y el comportamiento de las audiencias. 
- Entre 1945 y 1969 se crea y se consolida CIESPAL, cuyo aporte fue proponer la formación polivalente de los comunicadores y plantear que las escuelas deberían tener un nivel académico, que la carrera debería tener una duración mínima de cuatro años e incluir en su programa de estudio enfoques humanísticos y técnico-profesionales.

- La década de los setenta es la etapa en la que los centros de for- mación universitaria trabajan en especializaciones y en la consolidación de los centros dedicados a la investigación (Punín et al. 2013).

En los últimos años la formación de los comunicadores ha tenido distintos enfoques, según la universidad. A nivel de las universidades que ofrecen la carrera en Quito, la clasificación es la siguiente:

\section{Tabla 1: Enfoques formativos de las carreras de Comunicación en las universidades que ofrecen la carrera en Quito}

\begin{tabular}{|c|c|}
\hline UNIVERSIDAD & ENFOQUE \\
\hline Universidad Central del Ecuador & Hacia el campo teórico de la comunicación. \\
\hline $\begin{array}{l}\text { Pontificia Universidad Católica } \\
\text { del Ecuador }\end{array}$ & $\begin{array}{l}\text { Hacia la literatura y la división clásica de los } \\
\text { medios: prensa, radio y televisión. También } \\
\text { cuenta con una mención en Comunicación } \\
\text { Organizacional. }\end{array}$ \\
\hline Universidad Politécnica Salesiana & Hacia la comunicación para el desarrollo social. \\
\hline Universidad de las Américas & $\begin{array}{l}\text { Hacia el campo organizacional de la } \\
\text { comunicación. }\end{array}$ \\
\hline $\begin{array}{l}\text { Universidad Internacional } \\
\text { del Ecuador }\end{array}$ & $\begin{array}{l}\text { Hacia el campo organizacional de la } \\
\text { comunicación. }\end{array}$ \\
\hline $\begin{array}{l}\text { Universidad Tecnológica } \\
\text { Equinoccial }\end{array}$ & Hacia las relaciones públicas y la publicidad. \\
\hline Universidad San Francisco de Quito & Hacia la comunicación multimedia. \\
\hline Universidad Internacional SEK & $\begin{array}{l}\text { Hacia los medios y la comunicación } \\
\text { organizacional. }\end{array}$ \\
\hline
\end{tabular}

Fuente: Ana Gabriela Dávila

Cabe anotar que en Quito la Universidad de los Hemisferios y la Universidad Técnica Particular de Loja también ofrecen una carrera en Comunicación, cuyo enfoque no difiere mayormente de los de las otras universidades citadas. 
De esta manera, al revisar lo que ofrecen las facultades de comunicación ubicadas en Quito, se puede resumir, a breves rasgos, la formación que han recibido los periodistas ecuatorianos en los últimos setenta años, tomando en cuenta que la mayoría de ellos se han formado en estas facultades, al ser las más representativas del país. Es preciso recordar que la facultad más antigua de comunicación del Ecuador tiene 73 años.

A partir de los cambios que han experimentado la comunicación y los medios, fruto de la revolución digital, en la mayoría de universidades a los planes de estudio que están basados en los en- foques descritos, se han incorporado materias relacionadas con las nuevas tecnologías. Sin embargo, como reconocen los docentes de varias universidades, en el escenario actual es inviable seguir sosteniendo el modelo de formación que planteaba el estudio desde la división clásica de los medios: prensa, radio, televisión. Hoy, es necesario pensar en otros ámbitos de acción para el periodista que están mucho más allá de los medios. Las facultades de comunicación, en la actualidad, tiene el reto de formar a los periodistas que deben conservar el ADN de la profesión, combinándolo con las nuevas herramientas y lenguajes que ofrece el campo digital.

\section{EL NUEVO PERFIL PROFESIONAL}

En las facultades de comunicación del país y del mundo se encuentra instaurado el debate en torno a cómo debería ser el perfil del periodista actual. El problema que se enfrenta desde la academia es que existe una brecha entre lo que se imparte y lo que el campo laboral demanda. La revolución digital ha traído consigo nuevos perfiles que fusionan el conocimiento técnico de las herramientas digitales, con el manejo de las prácticas del oficio periodístico tradicional, entre otros saberes; perfiles que hace cinco años no existían en los medios y que no están contemplados en ningún plan de estudio de las facultades que ofertan la carrera.
Uno de los grandes problemas de las facultades de Comunicación actuales es que se enfrentan a una brecha casi insalvable con la realidad. Se enseña mucho para los problemas del pasado pero se aprende poco de los desafíos del futuro. Y no se debe a una especial incompetencia educativa, simplemente es complicado que propuestas docentes y planes de estudio vayan al ritmo de las tecnologías de la comunicación. En otras palabras y bajo la perspectiva más pragmática (no útil) de la universidad, esta tiene el difícil reto de preparar a los futuros profesionales de la comunicación para muchas profesiones que aún no existen". (Noguera, Martínez, Grandío, 2011) 
Prueba de esto son los anuncios que se publican requiriendo personal en los que aparecen cargos como editor web, periodista de datos, estratega de medios digitales, especialista en narrativas digitales, consultor digital, periodista multimedia, entre otros. Aunque no se detalle, específicamente, los conocimientos que deben tener, se sabe que debe ser alguien que conozca bien las herramientas digitales y la cultura digital. Es decir, no basta con manejar bien Facebook, Twitter o Instagram, sino que entienda las dinámicas que rigen el espacio digital, los intereses de las audiencias, la lógica y códigos de la comunicación digital. Al no encontrar profesionales que integren en su perfil estos conocimientos, ya que las universidades no los ofrecen, se buscan personas que, por ejemplo, sean curiosas, les guste experimentar en nuevos ámbitos, estén interesados en explorar a través de Internet, disfruten compartiendo contenidos en redes sociales, generen con frecuencia contenidos para sus "blogs", es decir, que tengan una actitud positiva frente a la tecnología más que conocimientos específicos. En ese sentido, en esos perfiles se estaría haciendo más hincapié en las actitudes que en las aptitudes. Es preciso señalar, además, que estos perfiles podrían estar en cualquier facultad, sin embargo, el mercado los busca en las facultades de comunicación ya que el componente básico de los procesos que se desarrollan desde estos cargos, es la comunicación (Franco, Pellicer 2014).
Ser una persona versátil, que se adapte fácilmente a distintos entornos y que esté abierta a los cambios, es una de las actitudes que puede ser más útil para desempeñarse en los medios de hoy en donde los cambios transcurren vertiginosamente. En el libro Optimismo para periodistas: claves para entender los nuevos medios en la era digital, se recoge lo que señala que Steve Hermann, editor de la web de la BBC NEWS, quien manifiesta que los periodistas deben "amar" el cambio. "Si no te gusta el cambio vas a ser una persona muy estresada e infeliz, porque las cosas cambian muy rápidamente, ya sea las herramientas que utilizamos o en la forma en la que el público se informa" (Franco, Pellicer 2014). Además, resalta las principales habilidades que deben tener los periodistas en las redacciones de hoy.

1. Velocidad y precisión para organizar los pensamientos de forma rápida y precisa.

2. Narración visual para contar historias usando varios canales de comunicación.

3. Saber usar los medios y las redes sociales para recopilar noticias, averiguar datos, ponerse en contacto con personas y detectar tendencias, así como para distribuir el trabajo periodístico.

4. Saber valorar los datos y cómo utilizarlos para contar historias, no solo con textos, sino a través de 
gráficos y de otros recursos interactivos (Franco, Pellicer 2014).

Hoy más que nunca, el periodista debe ofrecer contenidos con valor agregado, que sobresalgan del resto de informaciones similares que se pueden encontrar en la web. Debe destacarse en ello e ir ganando el territorio que ha perdido; para esto es fundamental el desarrollo de buenas prácticas. "Evitar convertir nuestras informaciones en algo previsible, excusándose en "lo que la audiencia quiere"; evitar la observación constante de la competencia en detrimento de la realidad; evitar ser meros transmisores de la voz de los poderes fácticos; ganar el prestigio perdido con buenas prácticas y entendiendo la sociedad que nos toca vivir, así como de qué forma se ha transformado la profesión. La esencia periodística es la misma. Los instrumentos y las competencias han cambiado" (Franco, Pellicer, 2014).

Dentro del nuevo perfil se deben ir incorporando competencias multidisciplinares que abarquen el campo de lo digital y del periodismo tradicional. En lo que concierne a lo digital, como primer requisito se requiere que el periodista domine el mundo multimedia y entienda las dinámicas de la comunicación digital. Los conocimientos más técnicos también son importantes; debe entender de analítica web y algunos principios básicos de código HTML. Además, debe saber manejar su identidad digital, cómo promocionar sus contenidos en la red, filtrar la información que circula a borbotones, evaluar y verificar las fuentes digitales de valor que va a utilizar en su relato. En ese sentido, el periodista vendría a ser una especie de curador de contenidos. Es preciso mencionar también que es necesario que sepa manejar las redes sociales, tratar con un público participativo y gestionar instrumentos como microbloggins, fuentes RSS, weblogs, gestores de imágenes, archivos compartidos y visualización de datos. Para facilitar estas tareas, es necesario que el periodista cuente con una amplia cultura visual y tenga conocimientos de diseño, programación, edición y conozca sobre el tratamiento de bases de datos y de nuevos dispositivos móviles (Franco, Pellicer, 2014).

En lo que respecta a las herramientas clásicas del oficio periodístico, primero, es importante aclarar que aunque el periodismo se ha transformado, estas no han cambiado ya que son el ADN de la profesión. El olfato periodístico para detectar dónde puede estar una historia, la curiosidad y persistencia para investigar hasta encontrar lo que se busca, la sensibilidad para llegar hasta el lado humano de los hechos y conmover al público, la sagacidad y perspicacia para relacionar los rastros que van dejando los acontecimientos. A esto se suma la capacidad de análisis de los contextos y de lectura de los hechos, el manejo de fuentes, la contrastación de información; 
el tener criterio y capacidad de discernimiento para seleccionar la información. El atreverse a innovar, a plantear temas diferentes y a abordarlos desde múltiples miradas y tener una amplia cultura. Ser creativo, versátil, crítico, ético, imparcial, comprometido, actuar siempre con la verdad, ser valiente y amar lo que se hace, ante todo.

Cuando empezó el auge de los medios digitales hace más de diez años, y a la luz de los cambios producidos en torno a la producción de contenidos, se planteaba que el periodista debía ser un "hombre orquesta". En otras palabras, debía conocer un poco de todo y fusionar eficientemente sus capacidades de recolección, procesamiento y redacción de información con el manejo de herramientas digitales para elaborar contenidos multimediales y multiplataforma; ya no solo debía saber desarrollar un texto de alta calidad, con valor periodístico, sino también, tomar fotografías, grabar videos y editar audios, entre otras tareas.

Aunque, actualmente, esta realidad no ha cambiado, hoy se plantea la especialización del periodista. En estos días, el campo del conocimiento es tan amplio que es posible prepararse en un área específica para rendir con mayor eficiencia en la esfera laboral. Es así que fruto de la fusión de saberes tecnológicos y del oficio periodístico han nacido varios puestos de trabajo en las redacciones, además de los que ya existían desde algunos años como los comunity manager y analistas de tráfico. Algunos de estos son:

- Especialista en narrativas digitales: es el encargado de pensar y desarrollar nuevas maneras de contar historias, sobre todo, centradas en el campo visual.

- Periodista multimedia: es el responsable de crear piezas audiovisuales y de las posibilidades interactivas del video y la fotografía.

- Equipo de tabletas y celulares: integrado por un trío de funciones en el que se une un editor, un diseñador y un programador. Son los encargados de hacer piezas para estos dispositivos o adaptar los contenidos que ya están producidos para estos soportes.

- Periodista de datos: es una persona capaz de encontrar historias dentro de las grandes bases de datos.

En seguimiento de la clasificación que se presenta en el libro Optimismo para periodistas: claves para entender los nuevos medios de comunicación en la era digital, basado en lo que señala la periodista Lina María Aguirre Jaramillo, en la revista Capcalera, del Colegio de Periodistas de Catalunya, otros cargos presentes en varios medios internacionales son: estratega de redes sociales, optimizador de titulares, agregador de medios sociales, especialista en presentaciones digitales, curador de contenidos, reali- 
zadores y controladores virales. Estos periodistas son los encargados de crear y difundir los contenidos de una manera más efectiva en las redes sociales, gestionar los grandes archivos digitales, analizar datos, filtrar información, en definitiva, ser capaces de contar buenas historias interconectando contenidos y tecnología (Franco, Pellicer, 2014).

Otro campo que se abre para el periodista actual es el del emprendimiento. La crisis que enfrenta el sectory que fue analizada en puntos anteriores, ha llevado a que muchos periodistas emprendan su propio proyecto. El amplio campo digital ha desplegado un abanico de posibilidades en torno a la comunicación y al periodismo; proyectos creativos e innovadores a los que se les conoce como medios alternativos, los mismos que intentan recoger todo aquello que no está presente en los medios tradicionales y que se plantean como una salida a la crisis que viven las empresas informativas. Tomando en cuenta lo dicho, el periodista actual también debería fortalecer sus habilidades de emprendedor y desprenderse de la idea que las plazas de trabajo están, solamente, en los medios tradicionales.

Décadas atrás era imposible que alguien, totalmente independizado de los grandes monopolios mediáticos, pudiese tener un medio de comunicación, una voz periodística propia más allá del medio, sin embargo, hoy sí es posible.
Antes el medio era la marca, ahora lo es el periodista. Ese es, precisamente, uno de los retos para los que deben estar formados los periodistas actualmente, para trabajar alejados de las estructuras tradicionales y convertirse en una marca de calidad informativa e independencia." En la actualidad ya no existe claramente el binomio medio de comunicación-periodista. La crisis arranca a muchos periodistas de las redacciones. En otros casos, muchos profesionales entienden que trabajar para un medio de masas no es sinónimo ni de estabilidad ni de excelencia" (Franco, Pellicer, 2014).

La crisis que atraviesan las empresas informativas y que ha afectado a los periodistas es innegable; la profesión está en crisis. Para muchos esta situación está limitando el campo de acción de los periodistas e, incluso, está poniendo en duda el sentido de la profesión; sin embargo, ocurre todo lo contrario. Ahora más que nunca las posibilidades para los periodistas y comunicadores se han ampliado, la radio, la prensa, la televisión y las empresas ya no son el único lugar en los que pueden desempañarse. Desde los espacios comunitarios hasta los más avanzados proyectos transmedia necesitan periodistas y/o comunicadores. La clave para enfrentar estos nuevos escenarios está en la formación, en la construcción de un nuevo perfil multidisciplinario que integre los conocimientos y herramientas clásicas de la profesión con las nuevas tecnologías. La forma- 
ción basada en el trinomio prensa, radio y televisión hoy resulta insuficiente para abarcar todos los conocimientos y saberes que circundan el ámbito de la información y la comunicación. Es preciso pensar en un perfil más global, más integrador, que combine áreas del conocimiento que sirvan para formar profesionales que respondan a las ver- daderas necesidades de las sociedades de hoy, cambiantes, complejas, hiperinformadas pero poco formadas, y que ante todo, comprendan que aunque los años pasen y los procesos se transformen, la esencia de la vida no ha cambiado, como tampoco la esencia del periodismo. Los periodistas seguirán siendo periodistas. Punto.

\section{CONCLUSIONES}

Las empresas informativas se encuentran, permanentemente, replanteando su modelo de negocio. Las estrategias que se planifican son solo de mediano plazo, ya que no se pueden proyectar al futuro, debido a que el mercado de la información es muy cambiante. El dinamismo del entorno digital ha hecho replantear no solo la forma de producir los contenidos, sino también, las formas de monetizarlos.

Los planes de estudio de las universidades deberían estar alineados con lo que demanda el mercado laboral. Actualmente, existe una brecha entre la academia y las empresas que no permite que se puedan generar los perfiles que se requieren hoy: más amplios, versátiles y que combinen varias áreas de la profesión e, incluso, de otras. La formación ya no debería plantearse desde el trinomio prensa, radio, televisión, sino desde una perspectiva global que integre múltiples saberes relacionados con la comunicación, en la que no se pierda de vista al emprendimiento.

El nuevo perfil del periodista no solo debería contemplar conocimientos en torno a distintas áreas, sino también, integrar herramientas relacionadas al ámbito personal, life skills, que son fundamentales para el oficio periodístico. En un entono que se transforma cada día, no es suficiente requerir un profesional con unas aptitudes específicas, sino también, con unas actitudes que le permitan relacionarse adecuadamente en espacios cambiantes y complejos.

La esencia del periodismo no ha cambiado, son las herramientas las que se han transformado. Eso significa que las prácticas tradicionales del oficio siguen vigentes y continúan siendo la base de cualquier trabajo periodístico, independientemente del canal a través del que circulen los contenidos. 


\section{BIBLIOGRAFÍA}

Franco Marta, Pellicer Miquel (2014). Optimismo para periodistas: claves para entender los nuevos medios de comunicación en la era digital. Barcelona. Editorial UOC.

Noguera José Manuel, Martínez Josep, Grandío María del Mar (2011). Redes sociales para estudiantes de comunicación: 50 ideas para comprender el escenario online. Barcelona. Editorial UOC.

Canavilhas Joao (2012). Contenidos periodísticos en un ecosistema líquido: entre la convergencia y divergencia. En Irigay Fernando, Dardo Ceballos, Matías Manna (Ed.) Webperiodismo en un ecosistema líquido (pp. 11-22). Rosario: Laborde Libros Editor.

Tuñez, M., Martínez, Y., Abejón, P. (2010). Nuevos entornos, nuevas demandas, nuevos periodistas http://revistas.ucm.es/index.php /ESMP/article/view/ESMP1010110079A/11358
Punín, M.l., Martínez, A. (2013). La profesionalización periodística en Ecuador: ¿la experiencia de las calles o el conocimiento de las aulas? http://revistas.ucm.es/index.php/ ESMP/article/viewFile/42535/40444

Punín, M.I. (2012). Los estudios de comunicación social/periodismo en el Ecuador. Una visión crítica al rol de la universidad y la academia http://www.razonypalabra.org.mx /N/N79/N79/66_Punin_V79.pdf

El desempleo en el Ecuador. En sección Economía del portal Periodismo Ecuador http://periodismoecuador.com/2016/01 /19/ecuador-registra-un-desempleo-de-477en-diciembre-de-2015/

El auge de los medios nativos digitales en Ecuador. En sección Sociedad del portal PlanV http://www.planv.com.ec/historias/sociedad/el-auge-medios-nativos-digitalesecuador 
ECONOMÍA 


\section{PERSPECTIVAS COMERCIALES DEL ECUADOR CON LOS PAÍSES DE EUROPA DEL ESTE: BULGARIA, ESLOVAQUIA, HUNGRÍA, POLONIA, REPÚBLICA CHECA Y RUMANÎA, MIEMBROS DE LA UNIÓN EUROPEA}

ECUADOR'S TRADE PERSPECTIVES WITH EASTERN EUROPE COUNTRIES: BULGARIA, HUNGARY, POLAND, CZECH REPUBLIC AND ROMANIA, MEMBERS OF THE EUROPEAN UNION

HALINA LYKO MARCZAK ANÎBAL ROBAYO LEMARIÉ MARÍA BELÉN WONG 



\title{
PERSPECTIVAS COMERCIALES DEL ECUADOR CON LOS PAIISES DE EUROPA DEL ESTE: BULGARIA, ESLOVAQUIA, HUNGRÍA, POLONIA, REPÚBLICA CHECA Y RUMANÍA, MIEMBROS DE LA UNIÓN EUROPEA
}

\author{
Halina Lyko Marczak' \\ Aníbal Robayo Lemarié2 \\ María Belén Wong 3
}

\section{RESUMEN}

El presente artículo pretende establecer las perspectivas comerciales del Ecuador con los países de Europa del Este: Bulgaria, Eslovaquia, Hungría, Polonia, República Checa y Rumanía, miembros de la Unión Europea; en función del análisis previo de la estructura del comercio exterior del Ecuador y de los citados países en el periodo 2007-2014, investigación en la que participó activamente la Ing. María Belén Wong Flores en su Tra- bajo de Titulación de la Facultad de Ciencias Administrativas y Contables de la Pontificia Universidad Católica del Ecuador.

Este Trabajo de Titulación, a su vez, fue parte de la Investigación intitulada: "Fomento de las exportaciones ecuatorianas de productos de emprendimientos populares y solidarios hacia países de Europa del Este, integrantes de la Unión Europea", el proyecto de investigación que fue financiado por la PUCE -Convo-

\footnotetext{
1 Pontificia Universidad Católica del Ecuador, Facultad de Ciencias Administrativas y Contables, Quito, Ecuador (HLYKOM@puce.edu.ec).

2 Pontificia Universidad Católica del Ecuador, Facultad de Ciencias Administrativas y Contables, Quito, Ecuador (NAROBAYO@puce.edu.ec).

${ }^{3}$ Pontificia Universidad Católica del Ecuador, Facultad de Ciencias Administrativas y Contables, Quito, Ecuador (MABELENWONG@hotmail.com).
} 
catoria 2015- y fue realizado por un equipo de los Investigadores de la PUCE, bajo la Dirección de la Master Halina Lyko Marczak.

La metodología aplicada en este trabajo es de tipo cuantitativo y cualitativo. Se incluyeron tanto fuentes primarias como secundarias, y técnicas como la observación, entrevista, análisis de los indicadores económicos publicados por el Banco Central del Ecuador en el periodo 2007-2014; Acuerdos Comerciales del periodo analizado; asimismo, se revisó publicaciones, artículos y revistas relacionadas. Además, se recopiló y se analizó la normativa oficial aplicable y vigente en el periodo, emitida por los Ministerios de Comercio Exterior, Relaciones Exteriores y Movilidad Humana, entre otras instituciones.

En cuanto a los resultados obtenidos, se demostró que la economía ecuatoriana es complementaria con cada una de las economías de estos países de Europa del Este, y que todavía el volumen del comercio exterior entre el Ecuadory los países mencionados, es realmente incipiente, por lo que se determinó que existen enormes perspectivas de mejoramiento y diversificación del intercambio comercial entre el Ecuador y los citados países.

Palabras clave: Ecuador, Unión Europea, Europa de Este, Intercambio Comercial,
Perspectivas de Comercio Exterior, Diversificación de Mercados, Complementariedad.

\section{ABSTRACT}

This article aims to establish Ecuador's trade perspectives with Eastern Europe countries: Bulgaria, Slovakia, Hungary, Poland, Czech Republic and Romania, members of the European Union; based on the preliminary analysis of Ecuador's foreign trade structure and those countries during the 2007-2014 period; the analysis was done by María Belén Wong Flores (Eng.) in her degree work for the School of Accounting and Administrative Sciences at Catholic University of Ecuador.

This work was part of the research entitled: "Promotion of Ecuadorian exports of popular and solidary enterprises to Eastern Europe countries, members of the European Union." The research project was financed by Catholic University, and was conducted by a team of researchers from this institution, under the direction of Master Halina Lyko Marczak.

The methodology used in this study is quantitative and qualitative, both primary and secondary sources were used such as: observation, interview, analysis of economic indicators published by the Central Bank of Ecuador during the 2007-2014 period; trade agreements of 
the reviewed period; besides, publications, articles and related magazines were revised. In addition, the current and applicable official regulations of the period, issued by the Foreign Trade, Foreign Affairs and Human Mobility Ministry, among others were analyzed.

The results obtained showed that the Ecuadorian economy is complementary to each of the economies of these countries in Eastern Europe, and that foreign trade volume between Ecuador and those countries is emerging, these findings determined that there are huge perspectives to improve and diversify trade.

Key words: Ecuador, European Union, Eastern Europe, Commercial Exchange, Foreign Trade Perspectives, Market Diversification, Complementarity

\section{INTRODUCCIÓN}

Para alcanzar el objetivo de establecer las perspectivas comerciales del Ecuador con los países de Europa del Este: Bulgaria, Eslovaquia, Hungría, Polonia, República Checa y Rumanía, miembros de la Unión Europea, se analizó el entorno económico nacional e internacional, lo que permitió identificar las opciones y, asimismo, proyectar la potencial expansión y buen posicionamiento de las exportaciones ecuatorianas en el mercado internacional, especialmente en los países de Europa del Este, miembros de la Unión Europea; como también permitió la generación de las propuestas de emprendimiento e investigación para mejorar y/o ampliar acuerdos comerciales que respondan a los actuales desafíos de eficiencia, globalización, innovación y responsabilidad social.

Si bien el Ecuador exporta muchos productos no petroleros como el ba- nano, café, cacao, piña, maracuyá, brócoli, flores, camarones, ciertos productos industrializados, entre otros; estos rubros en su conjunto no tienen el mismo peso que el petróleo.

El Ecuador ha concentrado en buena parte sus exportaciones de productos no petroleros en mercados correspondientes a América y Europa Occidental; lo mismo ha sucedido a nivel de sus importaciones; es decir, de los mercados y proveedores que los llamaríamos tradicionales.

Se debe señalar que hay un potencial mercado en los países emergentes de Europa del Este que tenían, después de la II guerra mundial y por aproximadamente cinco décadas, una economía, que fue relativamente restringida al comercio exterior. Estos países, en la última década, se han abierto mucho al inter- 
cambio comercial; sin embargo, el Ecuador tiene muy pocas relaciones comerciales y diplomáticas con dichos países, y eso se evidencia en que los mismos ni siquiera tienen Embajadas en el Ecuador y solamente cuentan con consulados honoríficos.

Varios de los países considerados en el presente análisis formaron parte del bloque socialista liderado por la URSS (Unión de Repúblicas Socialistas Soviéticas). Este bloque se constituyó al finalizar la Segunda Guerra Mundial, y su disolución fue a raíz de la caída del Muro del Berlín en noviembre de 1989. Característica principal de estos países consiste en que sus economías fueron centralmente planificadas, tenían comercio exterior muy restringido hacia los países capitalistas; se puede decir que no existía libre mercado.

Actualmente, sus economías se orientan hacia el libre mercado ya que son de perspectiva capitalista. Estos seis países forman parte de la OTAN y de la Unión Europea.

A continuación, se muestra algunas breves referencias productivas y comerciales de los mismos:

Bulgaria es miembro de la Unión Europea desde el primero de enero de 2007. La economía búlgara es un mercado abierto al sector privado y se carac- teriza por una estabilidad política y económica. Bulgaria es reconocida a nivel mundial por la excelente calidad de derivados lácteos como el yogur, así como de productos elaborados con aceite de rosa, vinos y licores.

Hungría es un país que pudo afrontar la caída del bloque mejor que el resto de los países que tenían sistema político-económico comunista en Europa del Este. Forma parte de la Unión Europea desde el año 2004. Las exportaciones de este país se centran en tecnología como telecomunicaciones, productos eléctricos y partes de vehículos. Las importaciones de este país son gas natural en estado gaseoso y circuitos integrados.

Polonia ingresa a formar parte de la Unión Europea en el 2004. Las importaciones principales de Polonia son el trigo, granos, aceite vegetal y alimentos de proteína, y las exportaciones en su mayoría son dulces, frutas manufacturadas, verduras y productos lácteos.

En cuanto a la ex Checoslovaquia debemos señalar que el 1 de enero de 1993 se dividió en 2 países: República Checa y Eslovaquia.

República Checa es miembro de la Unión Europea desde el 2004. Su principal mercado es Alemania, sus exportaciones en su mayoría son productos 
industriales, unidades de procesamiento y automóviles y el rubro de importación más importante es el aceite de crudo de petróleo y de mineral bituminoso.

Eslovaquia se integra a la Unión Europea en el 2004 y adopta al euro como su moneda en el año 2009. La principal industria es la automotriz, por lo que su economía se basa en la producción de automóviles y de sus componentes, los que representan un tercio de sus exportaciones. El rubro de importaciones principalmente consiste en las máquinas, aparatos y material eléctrico, sus partes y aparatos de grabación.

A partir del 2007, Rumanía forma parte de la Unión Europea. Es un país que se dedica a la producción y exportación de productos agrícolas, especialmente a los mercados de Alemania e Italia. Importa fundamentalmente aceites crudos de petróleo o de mineral, como también el gas natural en estado gaseoso.

Considerando que los seis países de Europa del Este son miembros de la Unión Europea, creemos necesario hacer una vinculación con el SGP y sus proyecciones hasta en la actualidad, a fin de relievar las derivaciones de este beneficio que es vinculante para todo el bloque y que por muchos años ha sido aprovechado por el Ecuador para el ingreso de gran cantidad de productos a
Europa en condiciones de mayor competitividad; situación que ha determinado que la UE se convierta en el segundo socio comercial del Ecuador y en el primero en cuanto a la demanda de productos no petroleros.

\section{Sistema Generalizado de Preferen- cias de la Unión Europea}

El Ecuador fue beneficiario del Sistema Generalizado de Preferencias Arancelarias (Plus) con la Unión Europea desde el año 2005, y a partir de esta fecha el país ha registrado un incremento importante de sus relaciones comerciales con este bloque. La Unión Europea otorga preferencias arancelarias en el marco del Sistema Generalizado de Preferencias (SGP Plus) a los países en vías de desarrollo. Debido a que el Ecuador fue calificado como país de renta media alta por el Banco Mundial durante, 3 años consecutivos dejó de ser beneficiario del SGP-Plus a partir del 2015; sin embargo, el 18 de diciembre del 2014 el Parlamento y el Consejo de la Unión Europea emitieron el Reglamento 1384/ 2014, a través del cual la UE se compromete a mantener las preferencias arancelarias hasta el 31 de diciembre de 2016.

\section{Acuerdo Comercial entre Ecuador y Unión Europea}

Debemos destacar que el Ecuador negoció con la Unión Europea un 
Acuerdo Comercial que permitirá la liberalización paulatina del comercio bilateral conforme a las condiciones establecidas. La negociación de este Acuerdo concluyó el 17 de julio de 2014, pero es necesario atravesar un proceso interno en la Unión Europea para la aprobación del mismo. Este proceso requerirá también, a su debido tiempo, el análisis y aprobación de los textos negociados, tanto por parte del Parlamento Europeo como de la Asamblea Nacional del Ecuador. Solo una vez que se cuente con su aprobación, el Acuerdo podrá entrar en vigencia.
Los países Bulgaria, Eslovaquia, Hungría, Polonia, República Checa y Rumanía por ser miembros de la Unión Europea se rigen bajo las leyes y normas del comercio exterior establecidas dentro del bloque de la Unión Europea, por lo que al firmar el Acuerdo Comercial entre Ecuador y Unión Europea, en el futuro también se nos abrirán mayores posibilidades de dinamizar el comercio exterior con estos países de Europa del Este que son tan atractivos para nosotros dentro de la perspectiva de diversificación de mercados.

\section{MARCO TEÓRICO}

El sustento teórico de nuestra investigación es bastante amplio; sin embargo, queremos mencionar algunas teorías que fueron referentes para el presente trabajo:

- Teoría Mercantilista: destaca la importancia de la intervención del gobierno quien promueve las exportaciones y/o restringe o limita las importaciones con el fin de mantener siempre una balanza comercial positiva.

\section{- Teoría de Ventaja Absoluta de} Adam Smith: propone la liberalización del comercio exterior y determinó que al producir un bien de manera más eficiente que otro país se lo debe exportar, mientras que el bien que se produce de manera menos eficiente se lo debe importar.

\section{- Teoría de Ventaja Comparativa de David Ricardo: establece que} el país que tiene desventaja absoluta en sus 2 bienes, debe especializarse en la producción del bien en el que tiene menor desventaja absoluta ya que en ese tendrá ventaja comparativa; en consecuencia, deberá exportar el bien en el que tiene ventaja comparativa e importar el bien en el que tiene desventaja comparativa o que se produce con mayor desventaja absoluta. 
- Teoría Heckscher-Ohlin: establece que el país debe exportar el bien que para producirse utiliza en forma intensiva los factores de producción que en ese país son abundantes, por lo cual son baratos. Mientras que se debe importar el bien que para producirse se utiliza de forma intensiva los factores de producción que en ese país son escasos, por lo que son caros.

\section{- Teoría de la Dependencia de} Prebisch: exhorta a los países en vías de desarrollo a implementar políticas que permitan generar productos con mayor valor agregado, a sustituir paulatinamente importaciones y, asimismo, aplicar estrategias o medidas de protección como aranceles y cuotas que permitan amparar la producción nacional.

\section{METODOLOGÍA}

En la presente investigación se utilizó, en primera instancia, el estudio exploratorio con el fin de conocer más sobre el tema y contar con una visión general sobre la situación del comercio exterior y las relaciones comerciales entre Ecuador y los países de Europa del Este en el periodo de estudio.

Una vez obtenido el conocimiento general, se utilizó el estudio descriptivo para comprobar e identificar la asociación entre las variables que intervienen en el estudio como tipo de producto, precio, calidad, volumen, destinatario para así determinar su incidencia en las importaciones y exportaciones ecuatorianas. Este análisis permitió determinar las perspectivas del comercio exterior ecuatoriano y acuerdos comerciales con los mercados de Bulgaria, Eslovaquia, Hungría, Polonia, República Checa y Rumanía.
En el desarrollo de la presente investigación se utilizó la fuente primaria de obtención de la información, que es la Entrevista, la cual fue aplicada a los funcionarios públicos que trabajan en los Ministerios de Comercio Exterior, Relaciones Exteriores y Movilidad Humana.

Fue necesario también recurrir a otro tipo de fuentes que son de fácil acceso y proporcionan información que se constituye en el punto de partida para el desarrollo de la investigación. Estas fuentes fueron:

- Resoluciones aplicables emitidas por el Ministerio de Comercio Exterior.

- Acuerdos comerciales entre Ecuador y los países de Europa del Este.

- Boletines emitidos por el Banco Central del Ecuador.

- Libros, revistas periódicos, enciclo- 
pedias, estudios anteriores y trabajos de titulación que proporcionen información que aporte o contribuya al tema de estudio.

- Estadísticas obtenidas de "Trade
Map" (Centro de Comercio Internacional).

- Estadísticas del Banco Mundial y Estadísticas e información de la legislación de la Unión Europea.

\section{ANÁLISIS DE RESULTADOS}

A continuación, se muestran los principales resultados de nuestra investigación:

\section{Balanza comercial bilateral Ecuador-Bulgaria}

\section{Tabla n. ${ }^{\circ}$ 1. Balanza Comercial Ecuador-Bulgaria (en miles de dólares americanos)}

\begin{tabular}{|lrrrrrrrrrr|}
\hline Descripción & 2007 & 2008 & 2009 & 2010 & 2011 & 2012 & 2013 & 2014 & $\begin{array}{c}\text { Acumulado } \\
\mathbf{2 0 0 7 - 2 0 1 4}\end{array}$ \\
\hline Exportaciones & 2941 & 2188 & 4073 & 5346 & 3589 & 11236 & 10021 & 12994 & 52388 \\
\hline Importaciones & 478 & 792 & 468 & 1221 & 10640 & 1449 & 2797 & 2977 & 20822 \\
\hline $\begin{array}{l}\text { Balanza } \\
\text { Comercial }\end{array}$ & 2463 & 1396 & 3605 & 4125 & -7051 & 9787 & 7224 & 10017 & 31566 \\
\hline
\end{tabular}

Fuente: Trade Map.

Elaboración: Halina Lyko/Aníbal Robayo/María Belén Wong

De los ocho años analizados, siete presentaron un superávit para Ecuador y solamente en el año 2011 el saldo comercial para Ecuador fue negativo. Cabe señalar que el comportamiento de la balanza comercial a lo largo de los ocho años de análisis fue irregular. Ecuador por concepto de exportaciones totalizó 52 millones 388 mil dólares, mientras que sus importaciones alcanzaron 20 millones 822 mil dólares, por lo que el saldo comercial con Bulgaria para Ecuador fue positivo y sumó 31 millones 566 mil dólares de superávit. 


\section{Balanza comercial bilateral Ecuador-Eslovaquia}

Tabla n. ${ }^{\circ} 2$. Balanza Comercial Ecuador-Eslovaquia (en miles de dólares americanos)

\begin{tabular}{|lrrrrrrrrr|}
\hline Descripción & 2007 & 2008 & 2009 & 2010 & 2011 & 2012 & 2013 & 2014 & $\begin{array}{r}\text { Acumulado } \\
\text { 2007-2014 }\end{array}$ \\
\hline Exportaciones & 3341 & 181 & 296 & 2233 & 3535 & 3329 & 678 & 106 & 13699 \\
\hline $\begin{array}{l}\text { Importaciones } \\
172\end{array}$ & 754 & 178 & 980 & 5049 & 568 & 3263 & 3459 & 14423 \\
\hline $\begin{array}{l}\text { Balanza } \\
\text { Comercial }\end{array}$ & 3169 & -573 & 118 & 1253 & -1514 & 2761 & -2585 & -3353 & -724 \\
\hline
\end{tabular}

Fuente: Trade Map.-

Elaboración: Halina Lyko/Aníbal Robayo/María Belén Wong

Los saldos comerciales para Ecuador en los cuatro años fueron negativos y en otros cuatro años positivos. El 2014 fue el año con mayor déficit comercial para Ecuador alcanzando 3 millones 353 mil dólares de déficit, mientras que el año 2007 fue el año que registró una balanza comercial positiva, más alta, para Ecuador con 3 millones 169 mil dólares.
Ecuador por concepto de exportaciones a Eslovaquia totalizó 13 millones 699 mil dólares, mientras que sus importaciones alcanzaron 14 millones 423 mil dólares, por lo que el saldo comercial con Eslovaquia para Ecuador fue negativo y sumó 724 mil dólares EE.UU de déficit.

\section{Balanza comercial bilateral Ecuador-Hungría}

\section{Tabla n. ${ }^{\circ}$ 3. Balanza Comercial Ecuador-Hungría}

(en miles de dólares americanos)

\begin{tabular}{|lrrrrrrrrr|}
\hline Descripción & 2007 & 2008 & 2009 & 2010 & 2011 & 2012 & 2013 & 2014 & $\begin{array}{r}\text { Acumulado } \\
\mathbf{2 0 0 7 - 2 0 1 4}\end{array}$ \\
\hline Exportaciones & 47 & 110 & 66 & 145 & 372 & 391 & 765 & 882 & 2778 \\
\hline $\begin{array}{l}\text { Importaciones } \\
\text { Balanza } \\
\text { Comercial }\end{array}$ & -1059 & 369 & 747 & 1193 & 6534 & 2827 & 7193 & 14008 & 33930 \\
\hline
\end{tabular}

Fuente: Trade Map.

Elaboración: Halina Lyko/Aníbal Robayo/María Belén Wong. 
Conforme podemos apreciar, los saldos comerciales en todos los años analizados fueron negativos para Ecuador. El 2008 fue el año con menor déficit comercial alcanzando solo 259 mil dólares, mientras que el año 2011 fue el año que registró el mayor déficit con 13 millones 126 mil dólares. A partir del año 2008 el saldo comercial fue cada año más deficitario para Ecuador, exceptuando el 2012 que evidenció una mejora.

\section{Balanza comercial bilateral Ecuador-Polonia}

\section{Tabla n. ${ }^{\circ}$ 4. Balanza Comercial Ecuador-Polonia} (en miles de dólares americanos)

\begin{tabular}{|lrrrrrrrrrr|}
\hline Descripción & 2007 & 2008 & 2009 & 2010 & 2011 & 2012 & 2013 & 2014 & $\begin{array}{c}\text { Acumulado } \\
\text { 2007-2014 }\end{array}$ \\
\hline Exportaciones & 24174 & 36394 & 41041 & 58178 & 56612 & 70990 & 90964 & 68556 & 446909 \\
\hline $\begin{array}{l}\text { Importaciones } \\
60082\end{array}$ & 7911 & 4195 & 11276 & 13382 & 12785 & 14631 & 15556 & 85818 \\
\hline $\begin{array}{l}\text { Balanza } \\
\text { Comercial }\end{array}$ & 18092 & 28483 & 36846 & 46902 & 43230 & 58205 & 76333 & 53000 & 361091 \\
\hline
\end{tabular}

Fuente: Trade Map

Elaboración: Halina Lyko/Aníbal Robayo/María Belén Wong

En los años analizados, los saldos de la balanza fueron positivos para Ecuador. El 2007 fue el año con menor superávit alcanzando 18 millones 92 mil dólares, mientras que el año 2013 fue el mejor año ya que evidenció un saldo comercial positivo de 76 millones 333 mil dólares.
Ecuador por concepto de exportaciones a Hungría totalizó 2 millones 778 mil dólares, mientras que sus importaciones alcanzaron 33 millones 930 mil dólares, por lo que el saldo comercial con Hungría para Ecuador fue negativo y sumó 31 millones 152 mil dólares de déficit. 


\section{Balanza comercial bilateral Ecuador-República Checa}

\section{Tabla n. ${ }^{\circ}$ 5. Balanza Comercial Ecuador-República Checa}

(en miles de dólares americanos)

\begin{tabular}{|lrrrrrrrrr|}
\hline Descripción & 2007 & 2008 & 2009 & 2010 & 2011 & 2012 & 2013 & 2014 & $\begin{array}{r}\text { Acumulado } \\
\text { 2007-2014 }\end{array}$ \\
\hline Exportaciones & 575 & 446 & 702 & 539 & 881 & 2182 & 2546 & 5181 & 13052 \\
\hline Importaciones & 3757 & 4460 & 1679 & 3873 & 16266 & 3716 & 20584 & 17306 & 71641 \\
\hline $\begin{array}{l}\text { Balanza } \\
\text { Comercial }\end{array}$ & -3182 & -4014 & -977 & -3334 & -15385 & -1534 & -18038 & -12125 & -58589 \\
\hline
\end{tabular}

Fuente: Trade Map

Elaboración: Halina Lyko/Aníbal Robayo/María Belén Wong

Del cuadro precedente se deriva que los saldos comerciales en todos los años analizados fueron negativos para Ecuador. En el año 2009, el déficit comercial fue menor alcanzando 977 mil dólares y el 2013 fue el año que registró el déficit mayor con 18 millones 38 mil dólares. El comportamiento de la balanza comercial entre Ecuador y Republica Checa presentó importantes irregularidades, ha sido fluctuante y no ha tenido un comportamiento estable.
Ecuador por concepto de exportaciones a República Checa totalizó 13 millones 52 mil dólares, mientras que sus importaciones alcanzaron 71 millones 641 mil dólares, por lo que el saldo comercial con Republica Checa para Ecuador fue muy negativo y sumó 58 millones 589 mil dólares de déficit. 


\section{Balanza comercial bilateral Ecuador-Rumanía}

Tabla n. ${ }^{\circ}$ 6. Balanza Comercial Ecuador-Rumanía

(en miles de dólares americanos)

\begin{tabular}{|lrrrrrrrrrr|}
\hline Descripción & 2007 & 2008 & 2009 & 2010 & 2011 & 2012 & 2013 & 2014 & $\begin{array}{r}\text { Acumulado } \\
\mathbf{2 0 0 7}-2014\end{array}$ \\
\hline Exportaciones & 482 & 2682 & 8393 & 10702 & 2392 & 3221 & 3622 & 5566 & 37060 \\
\hline Importaciones & 866 & 1134 & 10371 & 20249 & 11821 & 27642 & 35551 & 67736 & 175370 \\
\hline $\begin{array}{l}\text { Balanza } \\
\text { Comercial }\end{array}$ & -384 & 1548 & -1978 & -9547 & -9429 & -24421 & -31929 & -62170 & -138310 \\
\hline
\end{tabular}

Fuente: Trade Map

Elaboración: Halina Lyko/Aníbal Robayo/María Belén Wong

En el período analizado, los saldos de la balanza comercial entre Ecuadory Rumanía fueron negativos exceptuando el año 2008 que experimentó un superávit de 1 millón 548 mil dólares. El año 2007, fue el año con menor déficit alcanzando 384 mil dólares de déficit, mientras que el año 2014 fue el peor año en cuanto al saldo de la balanza comercial bilateral para Ecuador, ya que en este año se totalizaron 62 millones 170 mil dólares de déficit.

Ecuador por concepto de exportaciones a Rumanía totalizó 37,060 mil dó- lares EE.UU., mientras que sus importaciones alcanzaron 175,370 miles de dólares EE.UU, por lo que el saldo comercial con Rumanía para Ecuador fue muy negativo y sumó 138,310 mil dólares EE.UU. de déficit.

A continuación, se resalta el comportamiento y la proyección para los siguientes tres años (2015, 2016 y 2017) de los productos más importantes de las exportaciones ecuatorianas hacia cada uno de estos 6 países de Europa del Este, miembros de la Unión Europea. 


\section{Proyecciones de las exportaciones ecuatorianas hacia Bulgaria}

\begin{tabular}{|l|c|c|c|c|}
\hline \multirow{2}{*}{ Producto 1 } & \multirow{2}{*}{ Capítulo } & \multicolumn{3}{|c|}{ Proyección (miles de USD) } \\
\cline { 3 - 5 } & $\mathrm{Y} \mathrm{(2015)}$ & $\mathrm{Y}$ (2016) & $\mathrm{Y}$ (2017) \\
\hline $\begin{array}{l}\text { Frutos comestibles, cortezas } \\
\text { de agrios o de melones }\end{array}$ & 08 & 12009 & 13420 & 14832 \\
\hline
\end{tabular}

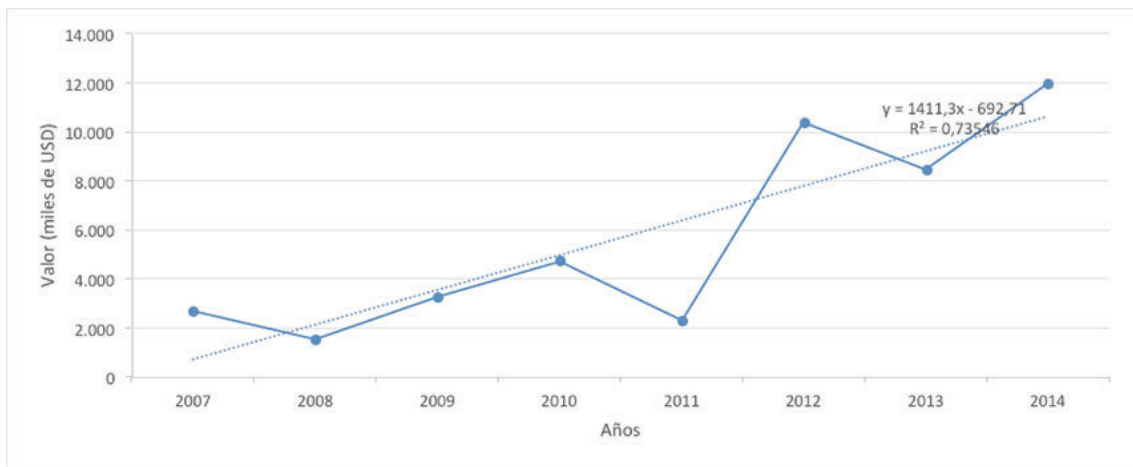

Se identifican como los más importantes productos exportados por Ecuador hacia Bulgaria los siguientes: frutos comestibles, cortezas de agrios o de melones, los cuales muestran la tendencia de crecimiento muy pronunciada, especialmente en los últimos tres años de análisis.
Otras exportaciones ecuatorianas, de menor volumen, hacia el mercado de Bulgaria son: plantas vivas y productos de la floricultura; preparados de legumbres, hortalizas, frutos o de otras partes de plantas; pescados y crustáceos moluscos y otros invertebrados acuáticos, también cacao, entre otros. 


\section{Proyecciones de las exportaciones ecuatorianas hacia Eslovaquia}

\begin{tabular}{|l|c|c|c|c|}
\hline \multirow{2}{*}{ Producto 1 } & \multirow{2}{*}{ Capítulo } & \multicolumn{3}{|c|}{ Proyección (miles de USD) } \\
\cline { 3 - 5 } & $\mathrm{Y} \mathrm{(2015)}$ & $\mathrm{Y} \mathrm{(2016)}$ & $\mathrm{Y}$ (2017) \\
\hline $\begin{array}{l}\text { Plantas vivas y productos } \\
\text { de la floricultura }\end{array}$ & 06 & 4101 & 4852 & 5603 \\
\hline
\end{tabular}

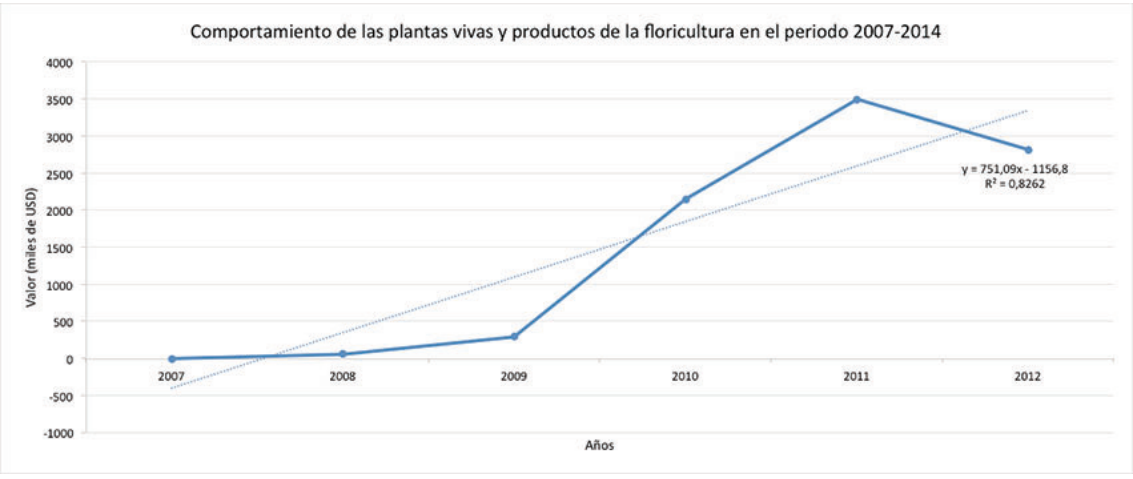

Los productos más importantes de las exportaciones ecuatorianas hacia Eslovaquia son: plantas vivas y productos de la floricultura. En el análisis, originalmente, se observó que el coeficiente de determinación obtenido sin aislar dato alguno fue bajo, por lo que se decidió aislar los dos datos atípicos. Después de aislar los datos de los años 2013 y 2014, el resultado obtenido del coeficiente de determinación permitió realizar una proyección confiable y válida sobre el comportamiento del producto. Se evidencia que en los años 2010, 2011 y 2012 se ex- perimentó un crecimiento mayor de las exportaciones ecuatorianas del producto: plantas vivas y productos de la floricultura.

Otras exportaciones ecuatorianas, de menor volumen, hacia el mercado de Eslovaquia son preparaciones de carne, de pescado o de crustáceos y de moluscos; combustibles minerales, aceites minerales y productos de su destilación; los azúcares y artículos de confitería, como también los productos de origen animal, entre otros. 


\section{Proyecciones de las exportaciones ecuatorianas hacia Hungría}

\begin{tabular}{|l|c|c|c|c|}
\hline \multirow{2}{*}{ Producto 1} & \multirow{2}{*}{ Capítulo } & \multicolumn{3}{|c|}{ Proyección (miles de USD) } \\
\cline { 3 - 5 } & $Y$ (2015) & $Y$ (2016) & $Y$ (2017) \\
\hline $\begin{array}{l}\text { Plantas vivas y productos } \\
\text { de la floricultura }\end{array}$ & 06 & 722 & 826 & 931 \\
\hline
\end{tabular}

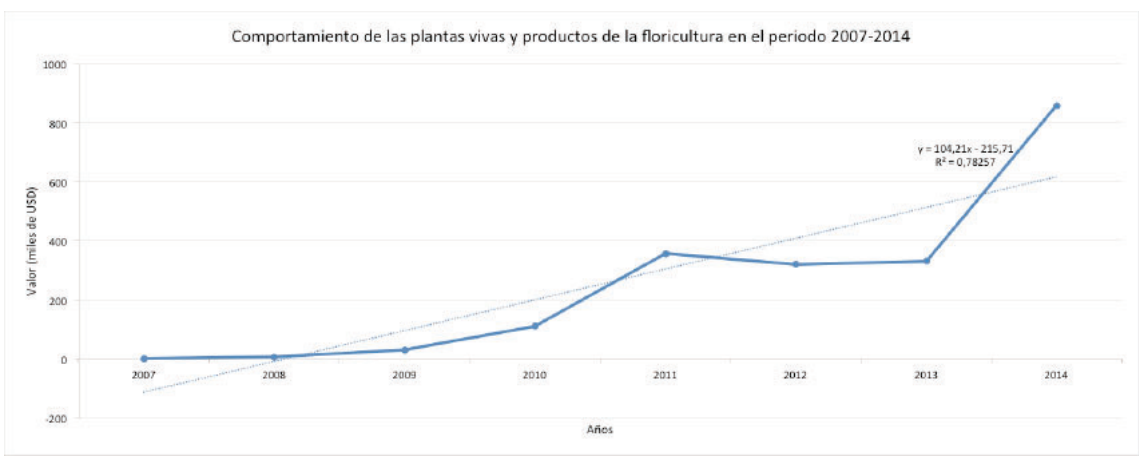

Los productos más importantes de las exportaciones ecuatorianas hacia Hungría son: plantas vivas y productos de la floricultura. Cabe señalar que el resultado obtenido en el análisis del coeficiente de determinación permitió realizar una proyección confiable y válida sobre el comportamiento del producto, por lo que no fue necesario aislar ningún dato. Se evidencia que en los últimos cuatro años las exportaciones ecuatorianas del producto: plantas vivas y productos de la floricultura experimentaron un crecimiento mayor que en años anteriores.
Con relación a los restantes productos de exportación del Ecuador a Hungría podemos anotar que, en cuanto al monto total de exportación, fueron muy insignificantes, por lo que no fue viable realizar la proyección para años posteriores debido a que la mayoría de datos registrados para el periodo 20072014 fueron cero. Solamente podemos mencionar que estos productos fueron las preparaciones de carne, pescado o crustáceos, moluscos; azúcares y artículos de confitería; frutos comestibles, cortezas de agrios o de melones. 


\section{Proyecciones de las exportaciones ecuatorianas hacia Polonia}

\begin{tabular}{|l|c|c|c|c|}
\hline \multirow{2}{*}{ Producto 1 } & Capítulo & \multicolumn{3}{|c|}{ Proyección (miles de USD) } \\
\cline { 3 - 5 } & $\mathrm{Y} \mathrm{(2015)}$ & $\mathrm{Y}$ (2016) & $\mathrm{Y}$ (2017) \\
\hline $\begin{array}{l}\text { Preparaciones alimenticias } \\
\text { diversas }\end{array}$ & 21 & 62877 & 68458 & 74038 \\
\hline
\end{tabular}

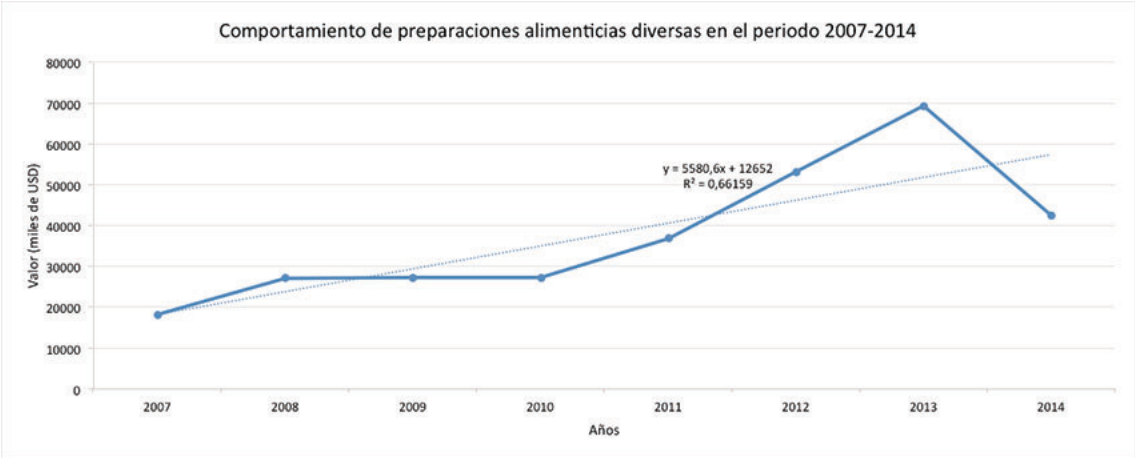

Los productos más significativos de las exportaciones ecuatorianas hacia Polonia son preparaciones alimenticias diversas. El resultado obtenido del coeficiente de determinación permitió realizar una proyección confiable y válida sobre el comportamiento del producto, por lo que no fue necesario aislar ningún dato. Se evidencia que en los últimos cuatro años las exportaciones del producto: preparaciones alimenticias diversas, experimentó un crecimiento mayor que en años anteriores.
Otras exportaciones ecuatorianas, de menor volumen, hacia el mercado de Polonia son frutos comestibles, cortezas de agrios o de melones; tabaco y sucedáneos del tabaco elaborados; la preparación de legumbres, hortalizas, frutos o de otras partes de plantas y, además azúcares y productos de confitería, entre otros. 


\section{Proyecciones de las exportaciones ecuatorianas hacia la República Checa}

\begin{tabular}{|l|c|c|c|c|}
\hline \multirow{2}{*}{$\begin{array}{l}\text { Producto 1 } \\
\begin{array}{l}\text { Preparaciones de carne, } \\
\text { de pescado o de crustáceos } \\
\text { y de moluscos. }\end{array}\end{array}$} & Capítulo & Y (2015) & Y (2016) & Y (2017) \\
\cline { 2 - 5 } & 16 & 2225 & 2537 & 2848 \\
\hline
\end{tabular}

Comportamiento de las preparaciones de carne, de pescado o de crustáceos y de moluscos en el periodo 2007-2014

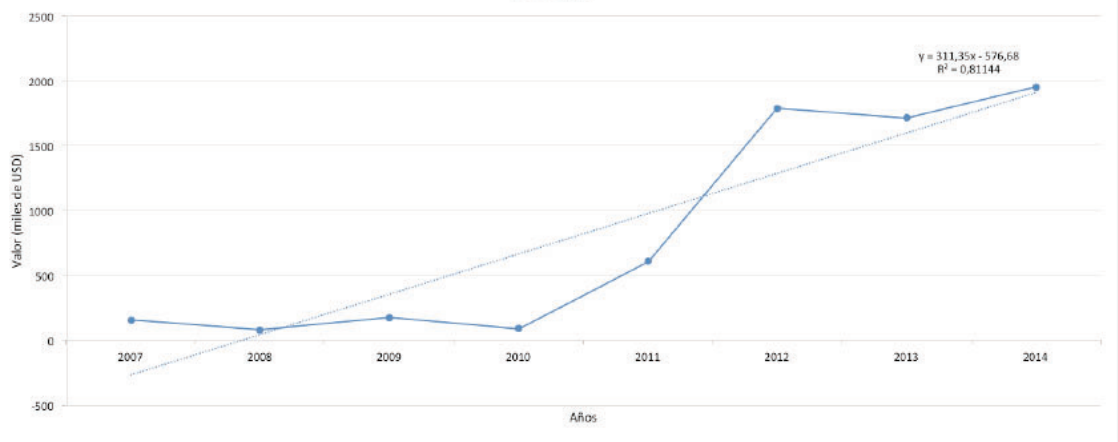

Los productos más representatipescado o de crustáceos y de moluscos, vos de las exportaciones ecuatorianas hacia la República Checa son: preparaciones de carne, de pescado o de crustáceos y de moluscos. Podemos colegir que el resultado obtenido del coeficiente de determinación permitió realizar una proyección confiable y válida sobre el comportamiento del producto, por lo que no fue necesario aislar ningún dato. Se evidencia que en los últimos cuatro años el producto: preparaciones de carne, de

experimentó un crecimiento mayor que en años anteriores

Otras exportaciones ecuatorianas, de menor volumen, hacia el mercado de Republica Checa son plantas vivas y productos de la floricultura; madera, carbón vegetal y manufacturas de madera y, en menor grado, el tabaco, tabaco elaborado y las preparaciones alimenticias diversas. 


\section{Proyecciones de las exportaciones ecuatorianas hacia Rumanía}

\begin{tabular}{|l|c|c|c|c|}
\hline \multirow{2}{*}{ Producto 1 } & Capítulo & \multicolumn{3}{|c|}{ Proyección (miles de USD) } \\
\cline { 3 - 5 } & $\mathrm{Y} \mathrm{(2015)}$ & $\mathrm{Y}$ (2016) & $\mathrm{Y}$ (2017) \\
\hline $\begin{array}{l}\text { Preparaciones de carne, } \\
\text { de pescado 0 de crustáceos } \\
\text { y de moluscos. }\end{array}$ & 16 & 1794 & 2058 & 2322 \\
\hline
\end{tabular}

Comportamiento de las preparaciones de carne, de pescado o de crustáceos y de moluscos en el periodo 2007-2014

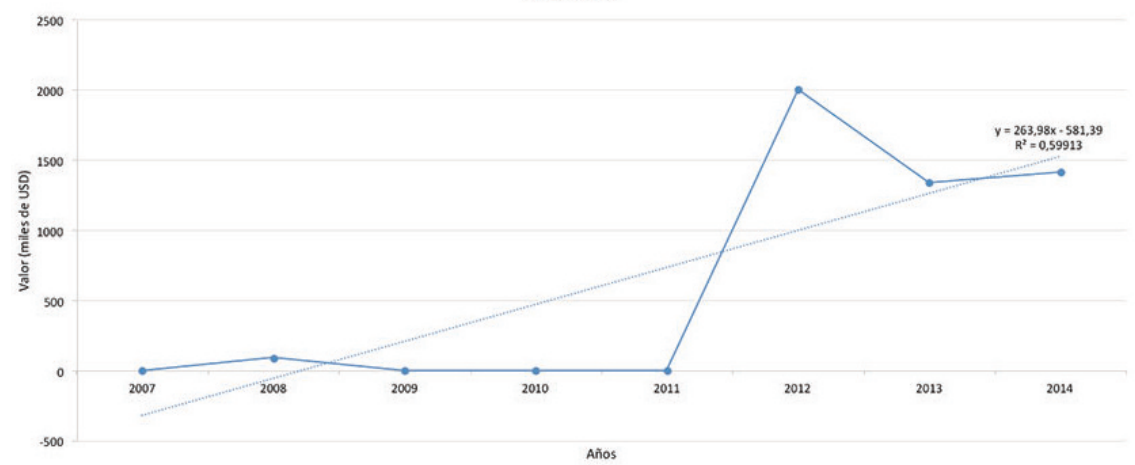

Los productos más importantes de las exportaciones ecuatorianas hacia Rumania son preparaciones de carne, de pescado o de crustáceos y de moluscos. El resultado obtenido del coeficiente de determinación permitió realizar una proyección confiable y válida sobre el comportamiento del producto, por lo que no fue necesario aislar ningún dato. Asimismo, se observa que en los últimos tres años, el producto preparaciones de carne, de pescado o de crustáceos y de moluscos, experimentó mayor crecimiento que en años anteriores.

Otras exportaciones ecuatorianas, de menor volumen, hacia el mercado de Rumanía son pescados y crustáceos, moluscos y otros invertebrados acuáticos; frutos comestibles, cortezas de agrios o de melones; plantas vivas y productos de la floricultura; aceites esenciales, preparaciones de perfumería y de tocador, entre otros. 


\section{CONCLUSIONES}

- La producción exportable del Ecuador, en su mayor porcentaje, está constituida por los productos del sector primario, es decir de "commodities" como el petróleo crudo, banano, café y elaborados, camarón, cacao y elaborados, atún y pescado; situación que conlleva una vulnerabilidad implícita, al estar expuestos a la volatilidad de los precios de estos bienes dentro del mercado mundial.

- El sector camaronero ha tenido un crecimiento importante en los últimos años gracias al precio internacional y a la disminución de producción de países competidores. En el 2014 el monto total de exportaciones de camarón estuvo muy próximo al valor del mayor bien de exportación no petrolero, el banano.

- Las exportaciones petroleras en el Ecuador representaron más de la mitad de las exportaciones totales en los años de análisis. El 2009 y el 2014 fueron años atípicos en cuanto la dependencia en términos porcentuales fue menor; en el primer año las exportaciones disminuyeron por la crisis mundial y en el segundo debido al precio en el mercado internacional.

- En términos de intercambio comercial se considera que las economías de Europa del Este con la ecuatoriana son complementarias en cuanto Ecuador exporta bienes primarios; y Bulgaria,
Eslovaquia, Hungría, Polonia, República Checa y Rumanía exportan maquinaria que puede ser utilizada para procesar los "commodities".

- Se resalta que los productos ecuatorianos exportados hacia los seis países de Europa del Este corresponden casi su totalidad a productos del sector primario y en algunos casos estos han experimentado algún tipo de procesamiento adicional.

- Ecuador tiene saldo positivo y bien pronunciado en el comercio exterior con Polonia, y se quiere anotar que las relaciones comerciales entre estos dos países son mucho más dinámicas que con el resto de los países analizados en esta investigación.

- Ecuador tiene saldo positivo en el comercio exterior con Bulgaria; sin embargo, las relaciones comerciales entre estos dos países son de poca importancia si se refiere al volumen del comercio exterior.

- Ecuador tiene saldo negativo en el comercio exterior con Eslovaquia, Republica Checa, Hungría y Rumanía y los volúmenes del comercio exterior entre Ecuador y estos cuatro países de Europa del Este son realmente pequeños, un poco mayores con Republica Checa y Rumanía, y realmente insignificantes con Eslovaquia y Hungría. 


\section{PERSPECTIVAS COMERCIALES DE ECUADOR VERSUS PAÍSES DE EUROPA DEL ESTE}

- En cuanto a las perspectivas a corto plazo de los principales grupos de productos ecuatorianos exportados hacia Bulgaria se prevé un comportamiento favorable para el Ecuador en los siguientes bienes: frutos comestibles, cortezas de agrios o de melones; plantas vivas y productos de la floricultura; preparados de legumbres, hortalizas, frutos o de otras partes de plantas; y en menor volumen pescados y crustáceos moluscos y otros invertebrados acuáticos, como también cacao, entre otros.

- Los productos ecuatorianos de mayor demanda en Eslovaquia son: plantas vivas y productos de la floricultura; preparaciones de carne, de pescado o de crustáceos y de moluscos; otros productos, y de menor volumen combustibles minerales, aceites minerales y productos de su destilación, los azúcares y artículos de confitería, como también los productos de origen animal, entre otros.

- Las proyecciones de las exportaciones ecuatorianas a Hungría son positivas ya que denotan un crecimiento en los bienes plantas vivas y productos de la floricultura; otros productos. En el caso de las preparaciones de carne, de pescado o de crustáceos, de moluscos; los azúcares y artículos de confitería; los frutos comestibles, cortezas de agrios o de melones, entre otros, presenta una relación poco definida entre el tiempo y la demanda.

- Las perspectivas a corto plazo con PoIonia son positivas en los siguientes productos: preparaciones alimenticias diversas; frutos comestibles; cortezas de agrios o de melones; otros productos; tabaco y sucedáneos del tabaco elaborados; la preparación de legumbres, hortalizas, frutos o de otras partes de plantas; sin embargo, no existe un patrón de demanda con tendencia para los azúcares y productos de confitería, entre otros.

- Los productos ecuatorianos de mayor demanda en República Checa son: preparaciones de carne, de pescado o de crustáceos y de moluscos; plantas vivas y productos de la floricultura; otros productos; madera, carbón vegetal y manufacturas de madera; y en menor grado el tabaco, tabaco elaborado y preparaciones alimenticias diversas.

- Las tendencias de las exportaciones del Ecuador hacia Rumanía son optimistas en los productos: plantas vivas y productos de la floricultura; pescados y crustáceos, moluscos y otros invertebrados acuáticos; las preparaciones de 
carne, de pescado o de crustáceos y de moluscos; frutos comestibles, cortezas de agrios o de melones; y otros productos. No obstante, la tendencia poco definida del bien aceites esenciales y resinoides, preparaciones de perfumería y de tocador no permitió realizar una proyección confiable.

- Ecuador exporta sus productos a un universo de cerca de 190 países, de los cuales 28 forman parte de la Unión Europea que se ha convertido en el segundo socio más importante para el Ecuador después de los Estados Unidos.

- Cabe señalar que el Ecuador mantiene relaciones comerciales con cada uno de los países miembros por lo que el acuerdo comercial con la Unión Europea favorecería al país en cuanto se eliminan parcial o totalmente los aranceles en ciertos productos y permitiría que los productos ecuatorianos sean más competitivos en el mercado europeo.
- El mercado europeo normalmente ha sido muy exigente; sin embargo, muchos países desean tener a la Unión Europea como socio comercial ya que la introducción de los productos a este bloque comunitario abre las puertas hacia veintiocho países miembros. En tal sentido, el beneficio radica en que el país exportador simplemente realiza el procedimiento común establecido por la Unión Europea para la exportación hacia cualquier país integrante del bloque.

- La supresión de restricciones arancelarias negociadas sería beneficioso para el país en cuanto se eliminan barreras comerciales que pueden ser aprovechadas satisfactoriamente, ya que no se pagaría aranceles tan elevados; por ejemplo, el 38\% en la partida del chocolate y demás preparaciones alimenticias que contengan cacao; o se beneficiaría de reducciones arancelarias que incluso podrían llegar a cero en ciertas partidas.

\section{RECOMENDACIONES}

- El Ecuador debe diversificar su oferta exportable ya que el $91 \%$ de las exportaciones totales corresponden a seis productos que son el petróleo, el banano y el plátano, café y elaborados, camarón, cacao y elaborados, y atún y pescado. Entre los bienes que son apreciados en los países del Este Europeo están bolsos, sombreros, quinua, artesanías, productos textiles, entre otros.

- Exportar los productos primarios con valor agregado, es decir, con un procesamiento adicional ya que de esta manera se genera inversión y empleos en el país y se obtienen mayores ga- 
nancias que al exportar el producto en estado natural.

- Los empresarios ecuatorianos deben estar atentos al comportamiento y tendencias de los productos no petroleros tradicionales y no tradicionales en el mercado internacional para enfocarse en la producción de aquellos bienes con mayor precio y demanda a nivel mundial.

- El comercio exterior del Ecuador con varios de los países de la Unión Europea es casi nulo, por lo que consideramos que se puede aprovechar esta situación para promover y consolidar vínculos comerciales con cada uno de los miembros de este mercado común y así diversificar sus socios comerciales, maximizar beneficios y evitar la dependencia en uno o en pocos países.

- El Acuerdo Comercial -no vigente aún- firmado por el Ecuador con la Unión Europea en julio de 2014, es una oportunidad y un reto; a su vez, el país se ve obligado a ser más competitivo si desea consolidarse en el mercado europeo. Consideramos que se debe trabajar eficientemente en mejorar la calidad de los productos ya que la dolarización en el Ecuador es vista como una barrera que no permite igualar en precios a los países vecinos como Colombia y Perú.

- Se debería gestionar acuerdos comer- ciales bilaterales complementarios entre el Ecuador y cada uno de los seis países de Europa del Este ya que se podrían obtener mayores beneficios que los negociados en el Acuerdo Comercial con la Unión Europea.

- Tomando en cuenta que la Unión Europea es el mayor socio no petrolero del Ecuador, se debe enfocar esfuerzos en mantener buenas relaciones con el bloque europeo y fomentar el comercio exterior a través de la promoción planificada de productos ecuatorianos en ferias, rondas de negocios, entre otros.

- Con el fin de promover las exportaciones, el gobierno ecuatoriano debería encargarse de facilitar capacitaciones, crédito y financiamiento para los pequeños empresarios ecuatorianos que buscan exportar sus productos hacia la Unión Europea; puesto que no cuentan con la tecnología, recursos humanos y financieros suficientes.

- De igual manera, el cambio de la matriz productiva propuesta por el gobierno ecuatoriano actual se ha conver- tido en uno de los motores para lograr el desarrollo del país por lo que se debe fomentar la exportación de productos que cuenten con un mayor procesamiento y valor agregado. 


\section{BIBLIOGRAFÍA}

Bravo Chuquillanque, E. (2009). Documentos utilizados en el comercio exterior. Buenos Aires: El Cid Editor | apuntes.

Carrera Galicia, O., Nicolás Huerta, S., \& Pérez Torres, M. (Diciembre de 2009). Tesis IPN México. Recuperado el 17 de marzo de 2015, de Tesis IPN México: http://tesis.ipn.mx/bitstream/handle/123456789/6622/CP2009\%20 C343o.pdf?sequence $=1$

Coral, M. L. (September de 2013). Universidad Andina Simón Bolívar. Obtenido de Universidad Andina Simón Bolívar: http:// www.uasb.edu.ec/UserFiles/372/File/pdfs/N OTICIASYSUCESOS/2013/Ecuador\%20UE\%20 logicas\%20negociacion\%20inconclusa\%20 M\%20LEVI\%20FES\%20Ecuador\%20vdef\%20। X13.pdf

European Commission. (13 de Novemeber de 2015). Trade Export Helpdesk. Obtenido de Trade Export Helpdesk: http://exporthelp.europa.eu/thdapp/display.htm?page=cd\%2fcd_SistemaDePreferenciasGeneralizadas.html\&docType=main\&l anguageld=es

González Lanzarote, R. (2013). Manual Negociación y compraventa internacional. Madrid: Editorial CEP.

González López, I., Martínez Senra, A. I., Otero Neira, M. C., \& González Vasquéz , E. (2014). Gestión del Comercio Exterior de la empresa. Madrid: Esic Editorial.

Lafuente, F. (2012). Aspectos de comercio exterior. Madrid: B - EUMED.
Lluc López, V. (2010). La política exterior y de seguridad japonesa. Barcelona: Editorial UOC.

Martín Martín, M., \& Martínez Gormaz, R. (2014). Manual Práctico de Comercio Exterior. Madrid, España: FC Editorial.

Ministerio de Comercio Exterior. (31 de December de 2014). Comercio Exterior. Obtenido de Comercio Exterior: http://www.comercioexterior.gob.ec/wp-content/uploads/ downloads/2015/04/CARTILLA-UNION-EUROPEA-1.pdf

Parlamento y Consejo Europeo. (2012 de October de 2012). Trade Export Helpdesk. Obtenido de Trade Export Helpdesk: http://eur-lex.europa.eu/LexUriServ/LexUriServ.do?uri=OJ:L:2012:303:FULL:ES:PDF

Secretaría de Estado de Comercio. (s.f.). Secretaría de Estado de Comercio. Obtenido de Secretaría de Estado de Comercio: http://www.comercio.gob.es/es-es/comercio-exterior/politica-comercial/medidasarancelarias/paginas/sistema-de-preferencia s-generalizadas-spg.aspx

Subdirección de Política Arancelaria y de Instrumentos de Defensa Comercial. (31 de December de 2012). Revistas ICE. Obtenido de Revistas ICE: http://www. revistasice.com/CachePDF/BICE_3034_3-16_2332 EF5E0C216AC61C28A3642D284D81.pdf

Unión Europea. (18 de August de 2015). Delegación de la Unión Europea para Ecuador. Obtenido de Delegación de la 
Unión Europea para Ecuador: http://ec.europa.eu/trade/policy/countries-and-regions/development/generalised-scheme-ofpreferences/index_en.htm

Unión Europea. (s.f.). Unión Europea Acción Exterior. Obtenido de Unión Europea Acción Exterior: http://www.eeas.europa.eu/ ecuador/index_es.htm 


\section{EDUCACIÓN}




\title{
INTERSUBJETIVIDAD ORIENTATIVA NUEVA ÉTICA
}

EN QUE LA ACCIÓN INDIVIDUAL Y EL COMPROMISO PERSONAL NO ESTÉN DESVINCULADOS DE LOS INTERESES COLECTIVOS

\author{
APPROXIMATE INTERSUBJECTIVITY \\ NEW ETHICS IN INDIVIDUAL ACTION AND \\ PERSONAL COMMITMENT ARE NOT UNRELATED \\ TO COLLECTIVE INTERESTS
}

MÓNiCA VALENCIA BOLAÑOS

Recibido 16 de febrero de 2016 Aceptado 15 de marzo de 2016 



\section{INTERSUBJETIVIDAD ORIENTATIVA NUEVA ÉTICA EN QUE LA ACCIÓN INDIVIDUAL Y EL COMPROMISO PERSONAL NO ESTÉN DESVINCULADOS DE LOS INTERESES COLECTIVOS}

Mónica Valencia Bolaños ${ }^{1}$

\section{RESUMEN}

La investigación se centra en quienes dirigen el proceso orientativo, su accionar en el orientado como los resultados alcanzados. Desde la premisa que la orientación es una acción social, se dirige la intención investigativa a descubrir esos episodios que hacen de ella un proceso esencialmente humano. El propósito central es desvelar un constructo teórico que constituya un nuevo episteme orientativo para el ejercicio de la carrera fundamentado en la intersubjetividad. El proceso investigativo toma cuerpo en seis puntos de inflexión: El primero, describe la realidad social del acto de la orientación tal cual como es. En un segundo, una revisión exhaustiva de la Orientación como ciencia y acción social. Tercer punto, detalla las ilaciones teóricas de la Sociología Comprensiva de Schutz (1932), el mundo de vida de
Husserl (1973) y la Acción Comunicativa de Habermas (1999). Un cuarto punto, aborda el marco metodológico estipulado en el paradigma cualitativo, desde la fenomenología como matriz epistemológica y metodológica. Además, contiene las técnicas para la obtención de las evidencias fenomenológica como la entrevista en profundidad tipo libre. Seguidamente está el quinto punto en donde se muestra el análisis de los hallazgos a través de dos vías para encontrar el significado de los datos cualitativos. Finalmente, el sexto punto de inflexión, que muestra las aproximaciones e interpretaciones realizadas para la construcción de un "Novum Corpus Teórico" en el campo de la Orientación.

Palabras clave: acción social, acción orientadora, intersubjetividad, actos de habla, cuidado de sì.

\footnotetext{
${ }^{1}$ Universidad de Carabobo, Facultad de Ciencias de la Educación, Dto. de Orientación, Valencia, Venezuela (mvalenci10@gmail.com/).
} 


\section{A MANERA DE INTRODUCCIÓN}

A partir del surgimiento de la corriente humanista SXV, la mirada investigativa se dirige hacia los factores internos de la persona, a saber: sentimientos, valores ideales, esperanzas y otros. A partir de estas premisas, se busca orientar, asistir y apoyar a los individuos a dirigir su propio desarrollo a través de capacidades característicamente humanas como la selección, la creatividad, la voluntad y la autorrealización a partir del descubrimiento y promoción de un "sí mismo".

Esta intención investigativa logró acercarse a ese cúmulo de experiencias vividas de los orientadores, sus percepciones, habilidades sociales, actitudes y aptitudes para interpretarlas y descifrarlas en relación con posturas teóricas actuales, como base para construir aportes enriquecedores de la función de ayuda y asesoramiento en el proceso de orientación educativa, con miras a responder de forma efectiva y con pertinencia social en el actual contexto riquísimo en retos, tendencias, cambios y sobre todo, incertidumbres.

Si se parte del reconocimiento del poder social del orientador y su correspondiente influencia, no queda duda al autor que esta posición privilegiada de este profesional del campo del desarrollo humano, pudiera ser maximizada, a través de la aproximación teórica de esa base de poder acercándolo a un desempeño con pericia, confiabilidad, efectividad, funcionalidad logrando con esto dar el carácter de acción a la orientación.

Es por ello que, en el marco de la composición del estudio, la investigación doctoral consta de seis partes denominadas Puntos de Inflexión (punto de no retorno), organizados de la siguiente manera:

El primero está relacionado con la presentación del hecho científico mediante la argumentación, describe la realidad social determinada tal cual, un segundo y tercer punto de inflexión, se presentan las columnas teórico-conceptuales, todo sobre la intersubjetividad, y la orientación, respectivamente. El cuarto punto, describe la vía metodológica y metódica asumidas por el autor, desde los marcos de la investigación cualitativa, con orientaciones de la Fenomenología. El quinto punto contiene el análisis de los hallazgos o evidencias fenomenológicas, con rigurosidad y exhaustividad requeridas en este tipo de investigación cualitativa basándose en la entrevista a profundidad y análisis de narrativas dialógicas. Finalmente, el sexto punto de inflexión, contiene el aporte teórico. 


\section{PRIMER PUNTO DE INFLEXIÓN: DESCRIPCIÓN DE UNA REALIDAD SOCIAL LA ORIENTACIÓN, UNA NUEVA FILOSOFÍA PARA LA RELACIONALIDAD HUMANA}

El proceso educativo en la actualidad representa un verdadero reto tanto para las comunidades gubernamentales como las civiles, el mismo está permanentemente sujeto a críticas, evaluaciones, transformaciones y al parecer, ningún cambio responde a las necesidades de la época. En la presente, la sociedad del conocimiento y la era de la información ha sido mucho más desvalorizada; se ha intentado incluso sustituir la misma naturaleza humana de la educación, por la virtualidad y la poderosa influencia de las tecnologías de información.

Sin duda, la educación tiene un fin social, la escuela no termina en sí misma (Alonso: 2006-44), sino que funciona como un trampolín para la vida. Es para ella que se enseña, se forma, se aconseja, e incluso se yerra. Esta realidad obliga a estudiar la vida, la sociedad, la cultura y principalmente al individuo.

Sin embargo para nuestros tiempos, los episodios citados son juzgados duramente por un incisivo Savater (2000:13), quien toma las angustias de Juan Carlos Tedesco, sobre la crisis de la educación. Él afirma que ya no es lo que era esta crisis, considera que no proviene de la deficiente forma en que la educa- ción cumple con los objetivos sociales que tiene asignados, sino que, es más grave aún, no se sabe qué finalidades debe cumplir y hacia dónde efectivamente debe orientar sus acciones. Probablemente ya no solo se reduce esta problemática al fracaso de un puñado de estudiantes, ni tampoco los innumerables conflictos socio-educativos propios en los contextos actuales, sino que al parecer, es mucho más siniestro: se visualiza el desdibujamiento de la naturaleza de sus fines.

Así, dentro de la cosmovisión educativa, está imbricada la Orientación. Luego, ¿quién orienta a quién, la escuela solo educa y no orienta o sí lo hace? ¿La construcción de la persona es obra solamente de la educación? ¿Las corrientes educativas deben contener visiones integrales donde vinculen el conocer con el ser, el convivir y la participación? ¿Los agentes socializadores qué tan responsables son del hombre actual? ¿La orientación es un proceso de humanización dentro del de socialización?

La orientación es una de las Ciencias de la Educación en donde el conocimiento del otro es esencial, la realidad de nuestros semejantes, la percepción al considerarles sujetos y no objetos, pro- 
tagonistas de su vida y no meros títeres de las circunstancias (Rogers 1902-1987) constituye una misión en sí misma y una tarea. El orientador requiere comprender que el destino de cada ser humano, incluso el suyo mismo, no es solamente la cultura, ni siquiera estrictamente la sociedad, en cuanto a institución, sino los semejantes. "Solamente en el comercio intersubjetivo con los semejantes se aprende significados" Sabater (2000:31).

El ser humano, enfrentado a una realidad impresionantemente diversa, compleja y dinámica, con avances y miserias de dimensiones nunca vistas, con realidades sociales conflictivas y con deslumbrantes hiperrealidades simuladas desde los medios audiovisuales constituye un laberinto en medio del cual las personas circulan en estados de confusión, bloqueo, faltas o carencias, abandono o locura social. Desde estos horizontes, cabe indagar ¿cómo se desarrolla la orientación?, probablemente hay nuevas formas de construirse y precisamente este, como otros especialistas del comportamiento humano, está sujeto a desplazar sus estrategias de intervención y/o medición en este nuevo hombre.

En este sentido, para Foucault (1994:3) esta construcción tiene que ver con una actitud en general de estar en el mundo, realizar acciones, tener relaciones con el prójimo. Él inserta la "epimeleia heautou" (término estonio sin traducción al español) que es una actitud: con respecto a sí mismo, con respecto a los otros, con respecto al mundo. Esa actitud parte de una serie de fórmulas como "ocuparse de sí mismo", "cuidar de sí," "retirarse hacia sí mismo", "retrotraerse en sí mismo", "complacerse en sí mismo", "no buscar otra voluptuosidad que la que hay en uno mismo", "permanecer en compañía de sí mismo", "ser amigo de sí mismo", "estar en sí mismo como en una fortaleza", "cuidarse" o"rendirse culto", "respetarse", entre otros. Con esto carga una gran preponderancia de la propia subjetividad para pasar inmediatamente a la intersubjetividad.

\section{SEGUNDO PUNTO DE INFLEXIÓN: ILACIONES TEÓRICAS. LA ORIENTACIÓN EDUCATIVA PERSPECTIVAS EN EL TIEMPO Y EN EL ESPACIO}

Con el fin de comprender, los fundamentos contextuales de la Orientación, se hace necesario identificar los antecedentes históricos de esta práctica socioeducativa en aquellas latitudes donde se institucionalizó: Estados Unidos y Europa. La práctica de la Orientación se establece debido a unas condiciones contextuales específicas que la convierten en un área educativa nece- 
saria, útil y pertinente. Según Álvarez y Bisquerra (2005) en un breve recorrido sobre su historia reseña a varios autores entre los cuales están: Parsons (1909) concibió la Orientación como la adecuación del sujeto al trabajo. Proctor (1925) la define como proceso de distribución (formular metas, conocimiento propio y del entorno) y ajuste. Según Brewer (1932) la Orientación se identifica con la educación. Williamson (1939) pone el énfasis en las bases diagnósticas de la Orientación. Shoben (1962) la planteó como una reforma social, con el orientador como líder de esta «reconstrucción». Para Miller (1971) la Orientación es el proceso por el que se ayuda a los individuos a lograr la autocomprensión y autodirección necesarias para conseguir el máximo ajuste a la escuela, al hogar y a la comunidad. Mathewson (1962) concibe la Orientación como proceso de desarrollo. Adschuier (1969), Mosher y Sprinthall (1970, 197l), Cottinghan (1973) e Ivey y Alschuler (1973), entre otros, la denominan educación psicológica.

En virtud de ello, Álvarez y Bisquerra (Cit.Ob.) citan además a Hoyt, (1978, 1985) que a partir de los años setenta ha tenido una especial relevancia el movimiento de Educación para la Carrera. Estos autores citados, afirman que muchos autores actuales tienden a poner el énfasis en la prevención como: (Baker y Shaw, 1987; Botvin y Dusenbury, 1987; Conyne, 1987) o en el desarrollo (Hayes y Aubrey, 1988; Myrick, 1987). De esta forma, los autores concluyen que la multiplicidad de teorías a veces ha provocado disputas partidistas entre los respectivos militantes. De allí la importancia que tiene el último criterio de Beck (1973), el cual afirma que todos los autores citados anteriormente parecen coincidir en que el fin de la orientación no solo es la solución de problemas, sino la ayuda para lograr la autoorientación y el desarrollo personal, premisa que coincide con esta investigación.

Centrados en este enfoque, durante el siglo XX, el dinamismo cultural, social y sobre todo los avances de la ciencia, la tecnología y la comunicación marcaron pautas paradigmáticas para el ejercicio docente. Así en Orientación, se asume el paradigma del Desarrollo Humano como el medio para el desarrollo de las potencialidades de la persona, en su plenitud, tanto en su dimensión personal, como familiar, social. A finales de este siglo, la Organización de las Naciones Unidas, para la Educación, la Ciencia y la Cultura (UNESCO, 1998), formaliza este paradigma como elemento fundamental para la Educación Superior del Siglo XXI. 


\section{TERCER PUNTO DE INFLEXIÓN: ILACIONES TEÓRICAS. LA ACCIÓN COMUNICATIVA Y LA INTERSUBJETIVIDAD. EL HORIZONTE DE LA OTREDAD}

Para el abordaje de la acción comunicativa y la intersubjetividad, se hace perentorio un paso primero en la subjetividad del ser humano, tomando una premisa base, la que afirma: el hombre es un ser humano, y todo ser como tal posee una lógica propia de existencia: nace, se alimenta, crea un medio propio de reproducción como de mantenimiento y muere. Logra así su propio criterio de existencia, o de realidad. El hombre es un ser corporal, la vida, su contexto; las circunstancias, el libreto y sus vivencias, sentimientos, sensaciones, el mundo interno o subjetivo.

Este ser protagonista, tiene un elemento que lo hace único en este contexto, su corporalidad, ésta tiene un centro nervioso que le permite experimentar estímulos, sensaciones o impresiones de fuera hacia adentro. Es decir, que a través de su piel, este sujeto siente dolor, placer, sensaciones, emociones y un sinnúmero de vivencias internas que salen de él, provocando todo tipo de expresiones que pueden ser incluso adversas a sí mismo. Al respecto Dusser (1999) describe a ese mundo subjetivo de la siguiente manera:

La subjetividad es un momento de la corporalidad humana. Es el momento en el que toda la corporalidad hu-

\begin{abstract}
mana es considerada desde la indicada perspectiva "interior" no es una metáfora, ya que la "interioridad" de la corporalidad humana es todo lo que acontece "desde debajo de la piel"; lo demás es el campo de lo real (omnitudo realitatis) que se presenta "afuera" bajo la luz en el "estado de vigilia"La subjetividad es más que consciencia, pero dice referencia a ella. Es el "vivenciar" lo que acontece (físicamente transmitido por el sistema nervioso) en la realidad (págs. 3/18).
\end{abstract}

De tal forma que, una referencia básica al hablar de subjetividad es la interioridad, relativa al mundo vivido desde adentro hacia afuera, desde lo físico (piel, músculos, células, glándulas, órganos, y demás) generando no solamente, respuestas orgánicas funcionales, sino sensaciones, sentimientos, ideas, pulsiones que a su vez generan otras vivencias.

En este preciso episodio, cuando surge y se reconocen esas nuevas vivencias, también aparece el "Otro", como un hecho interior por excelencia (visión fenomenológica), por el que la corporalidad se sitúa como una experiencia vivida en donde surgen las vivencias en sí, las cosas, los objetos. Dusser (Cit.Ob.) lo explica así: 
La corporalidad de cada ser humano es un momento de la comunidad humana. La comunidad humana constituye en cada nivel una referencia necesaria y coimplicante. Mi propia corporalidad ha nacido dentro de la especie humana, dentro de un pueblo, una familia; mi madre me ha parido. Esto indica todo el problema genético, la referencia ecológica terrestre, la historia biológica de una especie. Pero, además, mi subjetividad está constituida intersubjetivamente, desde el punto de vista lingüístico, cultural (valores), social (instituciones), histórico (tradiciones), etc (pags. 5/18).

Desde este contexto, el ser humano individual es a la vez plural, se constituye un ser solamente con el otro, es decir, mantiene una suerte de referencia existencial con una comunidad de pares. Es por ello que al hablar de subjetividad está implícita la intersubjetividad. Esta situación de relacionalidad eminentemente social, se puede enfocar desde varias corrientes filosóficas, a saber:

Edmundo Husserl (1859-1938) en la primera mitad del pasado siglo XX y aún vigente en el interés de los estudiosos. El citado por Derridá (1967) el cual adelanta la tesis central de la Fenomenología: "La filosofía de Husserl es el verdadero positivismo que vuelve a las cosas mismas y desaparece ante las originalidades, pues en efecto la Fenomenología busca captar los objetos (las cosas mismas) como son dados directa- mente a la conciencia por la experiencia sin implicarse en la conceptualización. El observador se propone como un ente pasivo que se suspende (epogé) se abstiene de ir más allá del acto de captar en la conciencia, de tender hacia un objeto, acción que en Fenomenología se denomina Intencionalidad (concepto que Husserl toma de Franz Brentano que fue profesor suyo). Toda conciencia es siempre conciencia de algo. La presencia de un objeto en la conciencia implica que ese algo está presente en ella aunque tal presencia no se conceptualice. A ese acto de captación directa del objeto sin posterior conceptualización, le llama Husserl, Reducción Eidética.

En síntesis la intersubjetividad es posible en los contextos orientativos porque el mundo del sentido común permite anticipar ciertas conductas para desarrollar la vida social, la misma que se puede evidenciar cuando el asesor se dirige a un orientado y le pregunta sobre algún tema, él estaría suponiendo una estructura social en la que reconoce al otro, y asume que comparte ciertos códigos, se une a ellos en alguna actividad común, influiría y el otro se dejaría influir, es decir un intercambio de actitudes, búsquedas y posiciones de intenciones de aprendizaje e interaprendizaje.

En lo referente a la teoría Acción Comunicativa de Habermas (1999) propone un modelo teórico que permite 
analizar la sociedad con dos formas de racionalidad que están en juego simultáneamente: la racionalidad sustantiva del mundo, de la vida y la racionalidad formal del sistema; la primera, es donde se representa una perspectiva interna como el punto de vista de los sujetos que actúan sobre la sociedad, mientras que en la segunda representa la perspectiva externa, como la estructura sistémica (la racionalidad técnica, burocratizada-weberiana, de las instituciones).

Estos postulados de Habermas (Cit.Ob.) como la racionalidad, la acción comunicativa, racionalidad moral, la in- tersubjetividad, mundo de vida entre otros son aristas que dirigieron las respectivas interpretaciones y análisis de la modernidad en la que se desenvuelve el orientador educativo, en la cual, "habermasianamente" hablando, se dan tipos de patologías sociales que actualmente se van tornando cada vez más comunes y a las que se enfrenta y debe abordarlas, intervenirlas, orientarlas y reorientarlas. En mis términos, la teoría de la acción comunicativa permitió una minuciosa categorización del plexo de la vida socioeducativa, con la que se podrá dar alguna razón de las paradojas de la modernidad.

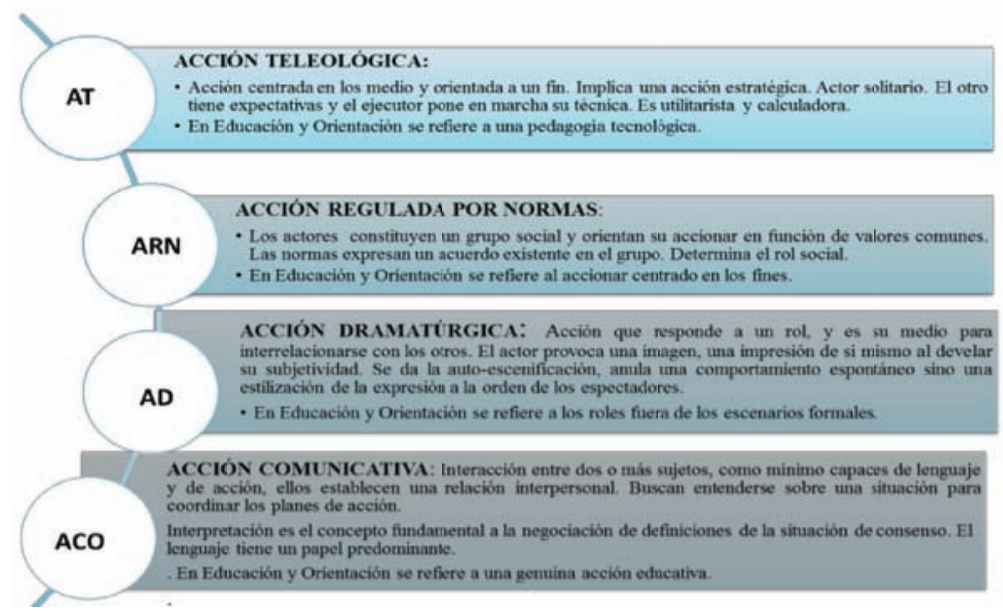

\section{Gráfico n. ${ }^{\circ}$ 1-Tipos de Acciones Sociales según Habermas (1999)}

Fuente: Habermas (1999) Adatado por Valencia, M. (2013). 


\section{CUARTO PUNTO DE INFLEXIÓN: LA METODOLOGÍA Y METÓDICA INVESTIGATIVA. UNA VÍA PARA LA CIENTIFICIDAD DE DATOS CUALITATIVOS}

a. Exploración inicial del problema a estudiar

\begin{tabular}{|c|c|c|c|}
\hline $\begin{array}{c}\text { Descripción de la realidad } \\
\text { social }\end{array}$ & $\begin{array}{c}\text { Exploración contextual e } \\
\text { intertextual de los hechos socio } \\
\text { educativos tal comoson }\end{array}$ & $\begin{array}{c}\text { Captación de los enfoques } \\
\text { de las realidades sociales }\end{array}$ & $\begin{array}{c}\text { Especificidad de la realidad } \\
\text { social como fenómeno social }\end{array}$ \\
\hline
\end{tabular}

b. Participación del investigador en el medio social a investigar

Determinación de la realidad mental o constituyente

Exploración de la realidad social, actores sociales,

con marco referencial para una interacción dialéctica actos sociales posibles sujetos a interpretación.

\section{c. Uso de técnicas propias de la investigación cualitativa}

\begin{tabular}{|l|c|}
\hline Definición metodológica del enfoque cualitativo investigativo & $\begin{array}{c}\text { Definición de técnicas base: } \\
\text { la entrevista a profundidad y análisis del relato }\end{array}$
\end{tabular}

\section{d. Marco interpretativo}

Seleccionar las estructruras teóricas adecuadas para crear epistemes significantes en el ámbito socio - educativo - orientativo

\section{e. Resultados escritos}

Proceso de decantación del material obtenido para detectar realidades, matices, acentos, versiones, actitudes, percepciones. Ubicación de los verbos, adjetivos, adverbios que den la significatividad contextual e intracontextual

\section{f. Teorización}

Crear ciencia, ver el hecho socioeducativo desde la percepción cualitativa fenomenológica por medio de un arte constructivista logrando un todo coherente, lógico, que sintetice los referentes teóricos, las experiencias vividas contrastando y pariendo posturas científicas.

\section{Cuadro $n .^{\circ}$ 1. Pasos de la metódica cualitativa-fenomenológica}

Fuente: Martínez (2004) Adaptado por Valencia M. (2013). 


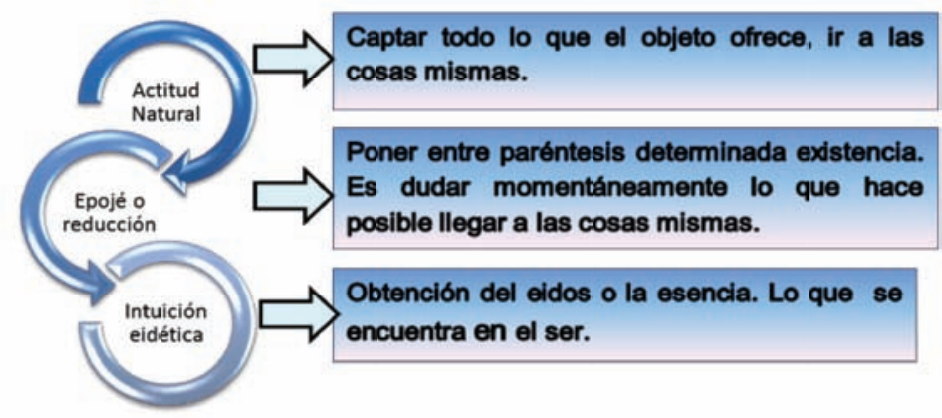

Gráfico n. ${ }^{\circ}$ 2. Pasos del método fenomenológico según Husserl Fuente: Chávez (2004) Adaptado por Valencia, M. (2013).

Técnicas de investigación cualitativa

Son dos técnicas que se aplican con una visión de complementariedad: a. Entrevista en profundidad libre: Claret 2008.

b. Análisis dialógico: Mayring (1983), Riessman (2008), Labov citado por Coffey (2003).

\section{Cuadro n. ${ }^{\circ}$ 2. Guía proceso para la entrevista en profundidad libre}

\section{GUÍA PROCESO PARA LA ENTREVISTA EN PROFUNDIDAD LIBRE}

\section{Elaboración del guión:}

- Longitud de la entrevista: libre

- Naturaleza de las preguntas: inicial-generadora a la conversación

- Naturaleza de la investigación: cualitativa- indagatoria

- Tipo de hallazgos: narrativa dialógica

\section{Fase Introductoria:}

- Fin de la entrevista: contacto con orientadores y sus experiencias desde su propia vida académica universitaria

- Carácter: confidencial

- Modalidad de colaboración: solicitada por la investigadora previa cita

\section{Desarrollo}

- Dar a conocer la intencionalidad investigativa

- Dirigir la conversación de forma libre y direccionada a la vez

- Aprovechar el discurso para afianzar temas de interés

- Cerrar de forma grata, elegante y cordial

- Dejar la posibilidad de nuevas entrevistas 
Dentro de este orden, la segunda técnica, tanto Mayring (1983) como Riessman (2008) señalan al análisis narrativo desde términos cualitativos como la historia en sí, es decir, el relato de una secuencia de acontecimientos que tienen especial importancia para el narrador, como para el investigador. Dicho relato tiene una estructura determinada, un comienzo, una mitad y un final, con una lógica para el narrador. Visto desde esta perspectiva, la narración de hechos vividos por sus propios actores, para su respectivo análisis fenomenológico, es lo que Riessman (Ob.Cit) denomina el "giro interpretativo" en la investigación cualitativa y lo que fundamentalmente la autora aplica con una visión social tan profunda, que logra aportar una etnometodología.

Así mismo, se toman las consideraciones de Coffey (2003), cuando cita a Labov quien sostiene que las narrativas y relatos tienen funciones sociales con propiedades estructurales y formales en donde se identifican patrones recurrentes que se pueden interpretar a través de las formas cómo cuenta la gente sus historias, del modo en que lo hacen, cuando dan forma a los acontecimientos que relatan, cómo hacen para mostrar sus ideas, cómo empacan los eventos narrados, y sus reacciones a ellos, y cómo articulan las narrativas con el investigador.

\section{QUINTO PUNTO DE INFLEXIÓN: \\ ANÁLISIS DE LA INFORMACIÓN, TRATAMIENTO Y SIGNIFICADO FENOMENOLÓGICO. ANÁLISIS DE CONTENIDO Y NARRATIVA, UNA VÍA DE TRATAMIENTO EN PROFUNDIDAD}

\section{Cuadro n. ${ }^{\circ}$ 3- Protocolización y organización del contenido de entrevistas según Mayring (1983)}

\begin{tabular}{|ll|}
\hline FASES & \multicolumn{1}{c|}{ DESCRIPCIÓN } \\
\hline Primera & $\begin{array}{l}\text { Seleccionar las entrevistas o las partes relevantes para responder a los objetivos } \\
\text { de la investigación. }\end{array}$ \\
\hline Segunda & $\begin{array}{l}\text { Analizar la situación de recogida de datos, es decir cómo se generó el material, } \\
\text { quién o quiénes estuvieron implicados, de dónde proceden los hechos. }\end{array}$ \\
\hline Tercera & Caracterizar el material o diseñar el modelo de análisis formal de información. \\
\hline Cuarta & $\begin{array}{l}\text { Direccionar el análisis de los textos o párrafos de las entrevistas, los cuales deben } \\
\text { hacerse en función de los propósitos de la investigación. }\end{array}$ \\
\hline
\end{tabular}

Fuente: Mayring (1993). Adaptado por Valencia, M. (2013) 


\section{Cuadro n. ${ }^{\circ}$ 4-Modelo de Evaluación de Labov (2003)}

\begin{tabular}{|ll|}
\hline $\begin{array}{l}\text { UNIDADES DE ANÁLISIS } \\
\text { (ESTRUCTURA }\end{array}$ & $\begin{array}{l}\text { PREGUNTAS DETECTORAS } \\
\text { DE SIGNIFICADOS) }\end{array}$ \\
\hline Resumen & ¿De qué trata? \\
\hline Orientación & ¿Quién? ¿qué? cuándo? ¿cómo? \\
\hline Complicación & ¿Entonces qué sucedió? \\
\hline Evaluación & ¿Y entonces qué? \\
\hline Resultado & ¿Finalmente qué pasó? \\
\hline Coda & ¿Cómo termina la narrativa? \\
\hline
\end{tabular}

Fuente: Coffe y Atkinson (2003:69) adaptado por Valencia, M. (2013)

\section{Cuadro . $^{\circ}$ 5-Unidades de análisis.- Definición}

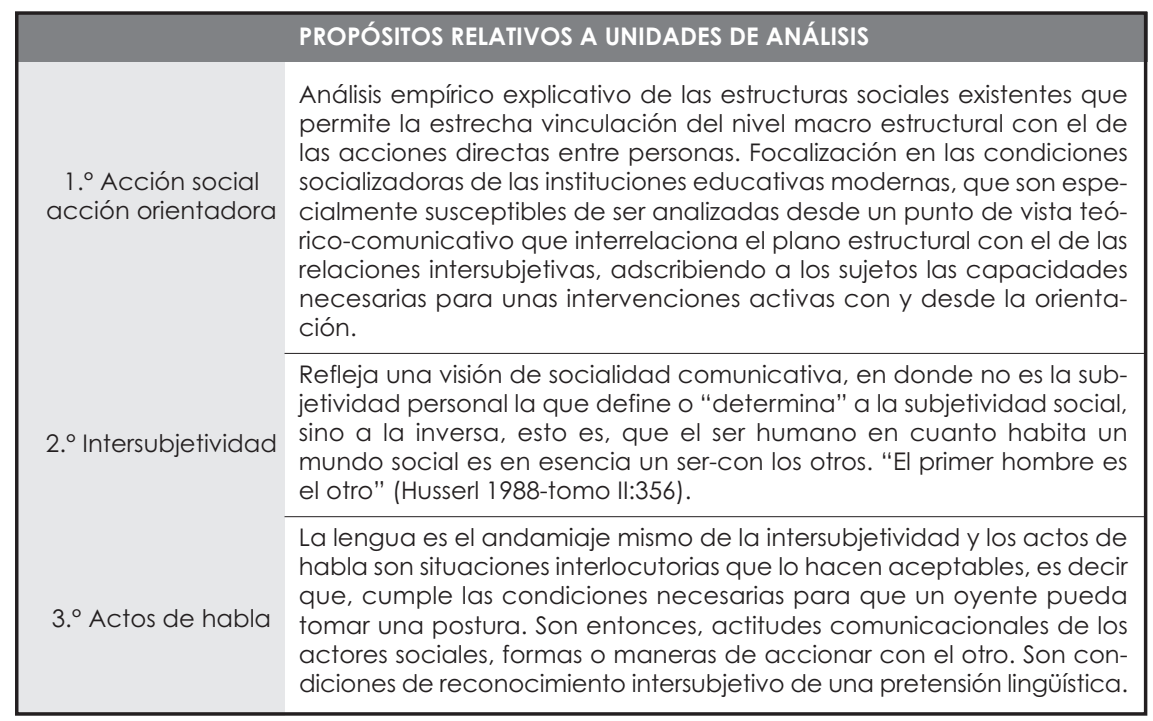

Fuente: Valencia, M. (2013). 


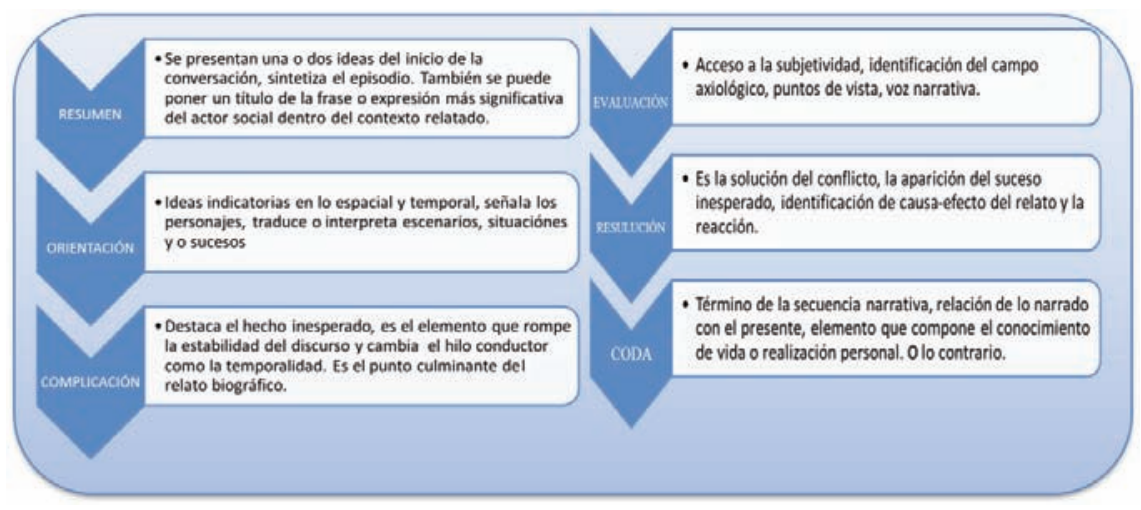

\section{GRÁFICO n. ${ }^{\circ}$ 3. SEGUNDO NIVEL DE ANÁLISIS SEGÚN RIESSMAN Y LABOV}

Fuente: Riessman y otros (2003) Adaptado por Valencia, M. (2013)

Este análisis se desarrolló con cada uno de los informantes claves, obteniendo sistemática y producativamente las dimensiones dialógicas más ricas en las narraciones de cada uno de ellos, así. relaciones de poder, niveles de racionalidad, roles, episiodios significativos, entre lo más resaltante, se resume la frase que de su propio discurso se ob- tuvo con la que se identifican en su existencia:

DOR: "NACI CON LA NECESIDAD DE AYUDAR"

DFA: "EPA...LÍDER..YA VIENE EL LÍDER"

DLFS: "NO SOY YO...SOY EL COLECTIVO"

\section{SEXTO PUNTO DE INFLEXIÓN: NOVUM CORPUS TEÓRICO}

\section{EL"Novum Corpus" (Cuerpo Nuevo)} teórico para la intermediación de una comunidad intersubjetiva, es preciso reflexionar sobre las bases de una nueva ética en la que la acción individual y el compromiso personal no estén desvinculados de los intereses colectivos. En este orden, se construye el establecimiento de otros modos de pensar, poder, saber, ser, sentir, comunicar, escuchar para una sociedad de convivencia del buen vivir, que libere al hombre de esos contenidos que los ata a cadenas mezquinas, dándole la dirección justa a 
sus potencialidades, para ello, se demarcan varias inspiraciones tomadas del análisis en profundidad de las evidencias fenoménicas presentadas en los partes anteriores, y son (en documento doctoral están presentadas y desarrolladas):

\section{La"epimeleia heautou". El compro-} miso personal vinculado al colectivo.

2. La búsqueda del buey. Vías para la comprensión de la individuación.

3. El diálogo que somos. El orientador hermeneuta en la formación de seres dialógicos, un desafío en los procesos de vinculación actuales.

En fin... la Orientación universitaria bajo estas aristas, implica la libación de la particularidad a favor de la generalidad, más bien, de la otredad. Los agentes sociales que forman para y por el diálogo, padres, escuela, docentes, orientadores se enfrentan a esta realidad cruda en donde el principio de la individualidad es lo que prima, el reto es recuperar el humanismo gadameriano, es aprender a escuchar, en contra del ensimismamiento; es eliminar el personalismo y el afán de imposición de todo impulso vanidoso que genera el intelecto egoico.

Para finalizar, en la ostentación vanidosa de educadores y orientadores, al creer que somos capaces de educar a otros, es obligante apropiarse de las tesis gamerianas, ya que en el trato con las personas hay que mantenerse abierto al entendimiento, y eso implica consideración, tolerancia, respeto y humildad frente al otro; sin estos elementos la maravillosa aventura del interaprendizaje se convierte en una quimera. Lo planteado nos lleva a afirmar que todos educamos a todos, y aun sin quererlo lo hacemos, lo importante es asumir como orientadores responsablemente y con conocimiento, este rol de humanizadores en la comunidad, parroquia, institución educativa, familia, para dar cuenta de ello a las generaciones presentes y a futuro.

Tanto es así, que el hombre es definido como ser dialógico, un ser capaz de entrar en conversación, sobre todo un ser lingüístico, por estar provisto de la lengua como auténtico vínculo de comunicación con los demás. Para Gadamer, existe una "lingüisticidad" original de nuestra experiencia hermenéutica, experiencia interpretativa-del mundo, por ende, suscribimos la experiencia como la del dios griego Hermes, mediar entre los seres humanos para no olvidarnos que lo somos. 


\section{BIBLIOGRAFÍA}

Alonso, J. (2007). Manual de Orientación Educativa y Tutoría. Tercera Edición. Universidad La Salle y Plaza y Valdés, S.A. de Madrid, España.

Alvarez, M. y Bisquerra, R. (2005). Manual de Orientación y Tutoría. Barcelona: Praxis.

Aristóteles, (1973). Obras completas. Madrid (nemo compilación) Documento www. Disponible [www.aristoteles/obrascompletas.com]

Asamblea Nacional Constituyente (2009). Ley Orgánica de Educación. Gaceta Oficial n. 5929 del 15 de agosto de 2009. Editorial La Piedra Caracas, Venezuela.

Asamblea Nacional Constituyente (1999). Constitución de la República Bolivariana de Venezuela. Gaceta Oficial 36.860 Del 30 de diciembre de 1999. Editorial Nabriel Caracas, Venezuela.

Bisquerra, R. (2002). Modelos de Orientación e Intervención Psicopedagógica. BarceIona: Praxis Universidad.

Claret, A. (2008). Proyectos Comunitarios e Investigación Cualitativa. Segunda Edición. Editorial Texto, C.A. Caracas, Venezuela.

Chávez, P. (2004). Historia de las doctrinas filosóficas. Tercera Edición. Editorial Pearson Educación. México.

Derridá, J (1967). Génesis y estructura y la fenomenología. Conferencia pronunciada en Cerisy La Salle en 1959. Publicada en el volumen Genesys y estructura dirigido por MM de Gandillac, L. Goldmann y J. Piaget, Mounton 1964. Publicada por último en Lécriture et la Difference. Colección Criteque, Paris, Minuit, 1967. Documento web disponible en (http://www.jacquesderrida.com.ar/ index.htm]

Dussel, E. (1999). Sobre el sujeto y la intersubjetividad: el agente histórico como actor en los movimientos sociales. Publicado en Revista Pasos n. ${ }^{\circ}$ 84-Segunda Época 1999: julio-agosto. [Documento WWW] Disponible en www.intersubjetividad.com.ar Consulta: 16-06-2012

Egan, G. (1994). El orientador experto: un modelo para la ayuda sistemática y la relación interpersonal. Grupo Editorial iberoamericana, S.A. de C.V. Versión español. Distrito Federal, México

Estrada, M. (1995). Participación política, actores colectivos. Primera edición. Editorial universidad iberoamericana. México. DF. Gadamer, H.G. (1993) Verdad y Método I. Fundementos de una hermenútica Filosófica. Hermeneia. Quinta Edición. Ediciones Sígueme. Salamanca España. Gadamer, H.G. (2000) Educar es Educarse. Editorial Paidos. BarceIona, España.

Habermas, J (1999). Teoría de la Acción Comunicativa, I. Racionalidad de la Acción Y Racionalización Social. Cuarta Edición. Grupo Santillana de Ediciones S.A. Editorial TaurusSantafé de Bogotá, Colombia 
Husserl, E. (1973). El Problema de la Realidad Social. Buenos Aires: Amorrortu, 1973, Traducción del libro original Collected Papers: The Problem Of Social Reality, de 1962).

Mayring. F. (1993). Análisis social del contenido cualitativo. [Documento WWW] Disponible en: http://www.qualitative-research.net/index.php/fqs/article/vie

Ministerio del Poder Popular para la Educación Superior (2009) Mesa Técnica Nacional. Proyecto: Sistema Nacional de Orientación. Documento Oficial DOP-2009-01. [Documento WWW] Disponible en: www.mes.gov.ve/documentos/descarga/pd f18-12-2009_11:28:58.pdf
Riessman, C. (2008). Métodos narrativos para las Ciencias Humanas. CA, EE.UU.: SAGE Publications, 244 páginas, ISBN: 978-0-76192998-7, EE.UU.[DocumentoWeb] Disponible en http://www.qualitative-research.net/in dex.php/fqs/article/view/1418/2906

Rogers, C. (1969). Psicoterapia centrada en el cliente. Buenos Aires: Paidós.

Savater, F. (2000). El Valor de Educar. Décima primera reimpresión. Bogotá, Colombia. Editorial Ariel S.A.

Schültz, A. (1993). La Construcción significativa del Mundo Social. Introducción a La Sociología Comprensiva, Ediciones Paidós 


\section{MÂS ALLÁ DE LAS FRONTERAS}

\section{BEYOND BORDERS}

JORGE GRANJA E.

Recibido 15 de marzo de 2016

Aceptado 8 de abril de 2016 



\section{MÁS ALLÁ DE LAS FRONTERAS}

Jorge Granja E. ${ }^{1}$

\section{RESUMEN}

El presente trabajo pretende dar una visión sobre la dimensión que la Educación Global tiene en el mundo contemporáneo y su alcance a nivel internacional. La tendencia que están teniendo los estudiantes jóvenes por un aprendizaje global tratando de optar por una internalización o ciudadanía global. Se concluye con resultados de una investigación que ayuda a entender por qué esta educación está siendo aceptada y promocionada por los países desarrollados.

Palabras clave: educación global, internalización, aprendizaje global, perspectiva global

\section{ABSTRACT}

The present work tries to provide a vision of the dimension that Global Education is taking in the contemporary world and its potential scope of international education. The trend that young students are taking for global learning is trying to opt for an internalization or global citizenship. It was concluded with results of a research that helps to understand why this education is being accepted and promoted by developed countries.

Key words: global education, internalization, global learning, global perspective

\section{INTRODUCCIÓN}

La Educación Global, en la actualidad, se ha convertido en un tema de mucho interés para los estudiantes jóvenes, porque esta les ofrece oportu- nidades que les permite insertarse en un mundo intercultural. El crecimiento para esta perspectiva global se atribuye a su enfoque de dar u optar por una in-

\footnotetext{
1 Pontificia Universidad Católica del Ecuador, Facultad de Comunicación, Lingüística y Literatura, Quito, Ecuador (jorgevge@hotmail.com).
} 
ternalización o ciudadanía global que les permita crecer y enrolarse con el resto del mundo y a la vez ser parte de las amenazas y conflictos que el planetay sus habitantes enfrentan. Larry Braskamp describe la internalización, término utilizado en 1980, como una "comunicación intercultural" en donde los estudiantes puedan aprender a pensar y actuar con quienes son diferentes, refiriéndose a los distintos aspectos de cultura, hábitos, creencias religiosas, etc. Sin embargo el concepto más reciente acerca de la internalización el cual ha permitido la creación de programas in- ternacionales y ha alentado a crear los últimos programas on line que están ofreciendo muchas universidades internacionales está dado por Jane Knight quién define la internalización como "process of integrating an international dimension into the teaching/ learning, research, and service functions of the university or college. An international dimension means a perspective, activity or service which introduces or integrates an international/ intercultural/global outlook into the major functions of an institution of higher education" (Knight, 2015)2.

\section{EL APRENDIZAJE GLOBAL}

Una de la investigaciones basada en niños determina que la creatividad propia de un niño para construir su propio lenguaje no se basa solo en la imitación de los sonidos o modelos que tiene a su rededor. Hoy en día, el concepto de adquisición de una nueva lengua o cualquier otro conocimiento debe ser visto desde una perspectiva global. Por ejemplo, la teoría de Noam Chomsky explica que los niños están dotados con un aparato natural para la adquisición de la lengua, este aparato se activa por ciertas experiencias lingüísticas y el crecimiento de la misma depende en gran parte de la influencia del medio en el cual se desenvuelve o crece. Esto implica que los estudiantes deben ser provistos no solo de habilidades cognitivas sino también de habilidades sociales y proporcionar el medio adecuado para su desarrollo. Chomsky da una visión en la que se involucra al individuo más allá de lo aprendido, para ser parte de algo más.

¿Por qué utilizar o considerar contenidos que surgen de la problemática global? ¿Por qué deben los educandos relacionarse con este tipo de contenido? Aparte que el hemisferio derecho de

\footnotetext{
(jorgevge@hotmail.com)

2"el proceso de integración de una dimensión internacional en la enseñanza-aprendizaje, investigación y funciones de servicio de la Universidad o el colegio. Una dimensión internacional significa una perspectiva, actividad o servicio la cual introduce o integra una representación internacional- intercultural
} 
nuestro cerebro es "global", y adquiere información de aspectos globales tanto concretos como abstractos, muchos de los planes y programas de la nueva educación en países desarrollados están considerando la incorporación de la diversidad en lengua y cultura que existe en el mundo. Por ejemplo, profesionales de la educación de instituciones con altos estándares en educación en los Estados Unidos han creado una serie de rúbricas (conjunto de criterios y estándares, generalmente relacionados con objetivos de aprendizaje, que se utilizan para evaluar un nivel de desempeño o una tarea). Una que llama la atención es la que está relacionada con el aprendizaje global; esta evalúa la interdependencia natural, cultural, económica y política de los estudiantes.

Kitty Johnson vocera oficial de la Embajada Americana, Quito, PUCE (2008), manifiesta que si incorporamos en los planes de clase y currículos, aspectos como simulación de resolución de problemas, comités de trabajo sobre proyectos reales y aprendizaje por descubrimiento, estaríamos involucrando en el sistema educativo a un mayor número de estudiantes con distintos estilos de aprendizaje. Una de las ventajas de este tipo de currículos tendría un impacto positivo en la enseñanza de los conceptos, impartiéndolos con mayor claridad e inspirando a los estudiantes a indagar más allá de sus propias fronteras y fomentar una inclusión y cooperación positiva con otras culturas.

Ernesto Santos (2007), en su tesis basada en "Las percepciones que los educadores de lenguas tienen acerca de la Educación Global" demuestra que tanto los docentes como los estudiantes concuerdan en que los problemas globales deberían ser incluidos en los contenidos a ser enseñados. Además, su estudio argumenta que la inserción de temas globales contribuiría a expandir el conocimiento de la diversidad humana y así lograr que los estudiantes tengan un acercamiento a los problemas del mundo junto al compromiso de velar por sus soluciones. La inserción de los problemas del planeta en temas de estudio abre la puerta para conectar dominios cognitivos, afectivos y participativos junto con la capacidad de ser parte de una solución.

¿Por qué los estudiantes deben aprender sobre los problemas y desafíos que son causados por aspectos globales? Existen varias tendencias a lo global que las nuevas generaciones están considerando. Una de ellas es la posibilidad de educarse fuera de los países de origen, tendencia que ha sido percibida por los jóvenes y en la cual la tecnología ha sido la mejor herramienta para que la lengua y la cultura no sean un impedimento para desarrollarse más allá de las propias fronteras. Una segunda tenden- 
cia que está tomando fuerza es la necesidad de pertenencia. El pertenecer y ser aceptado ha dado lugar al aprendizaje de nuevos idiomas dando sentido a que la migración se convierta hoy en una necesidad por la búsqueda de pertenencia y la noción de igualdad.

\section{TENDENCIA DE LA EDUCACIÓN INTERNACIONAL}

En las últimas décadas ha existido un movimiento global de estudiantes que son auspiciados por sus gobiernos para estudiar en el extranjero. Muchos países a nivel mundial han sido beneficiados por este fenómeno migratorio estudiantil. Asia, Estados Unidos y Europa han atraído a miles de estudiantes a sus universidades basados en una idea global. Así lo demuestran los registros de suscripción de estudiantes extranjeros, en donde podemos apreciar que en el caso de Asia creció en un porcentaje de 133\%, de 214.744 a 500.947, en Europa fue del $121 \%$, de 920.140 a 2.033,082 y en los Estados Unidos fue del $60 \%$, de 569.640 a 913.464 estudiantes (OECD, 2013a; p169). Cabe mencionar que para el año 2025, el número de estudiantes preparándose en universidades extranjeras se incrementará de 4.6 a 8 millones. (Goddard, 2012; OECD, 2009).

En una investigación llevada a cabo en una institución educativa en la ciudad de Quito se compararon dos tipos de contenidos. La hipótesis consistía en probar que los contenidos globales en la enseñanza del idioma Inglés, en séptimo grado de educación básica son más efectivos y significativos que los contenidos enseñados tradicionalmente y que por consiguiente son asimilados de mejor manera. Por contenidos tradicionales entendemos los que están relacionados con la moda, el espectáculo y la farándula, por contenidos globales se entienden todos aquellos que son causados por el ser humano y que tienen incidencia en los aspectos social y ambiental.

Esta investigación expone algunas razones que ayudan a entender por qué la enseñanza de contenidos globales parece ser más atractiva y por qué las instituciones educativas internacionales están proponiendo perspectivas globales a más de enseñar contenidos tradicionales. Las razones son presentadas en el orden en el cual fueron impartidas a los estudiantes en la clase. Se debe aclarar que aun cuando estamos hablando de contenidos para los niños, este tipo de contenidos resultaron interesantes para la edad de un séptimo grado. Sin embargo, los mismos temas se pueden presentar para estudiantes de un nivel universitario ya que el problema es el 
mismo. Se detectó que los estudiantes cuando utilizan contenidos globales desarrollan estrategias de curiosidad y se empoderan de un sentido de responsabilidad frente al problema e intentan, de alguna manera, buscar una solución.

\section{CONCLUSIÓN}

De la investigación realizada se pudo llegar a comprobar que los contenidos que surgen de los problemas globales se convierten en más que una simple actividad en la clase, se pudo observar la participación grupal así como la creación de posibles soluciones. Estos contenidos fomentan la participación y la disminución del temor en algunos niños ya que los contenidos trabajados eran cercanos a su realidad como ¿Quién no ha comido un hot dog? El vocabulario, aun cuando fue en inglés, dio mayor facilidad para trabajar en un contexto más amplio. Los proyectos presentados a los estudiantes permitieron dar experiencia y habilidades sociales y cognitivas para involucrarse en los problemas de su comunidad. Se percibió que existe una afinidad entre los contenidos globales, la ciencia y los estudios sociales.
La dirección que está tomando la educación por causa de la influencia tecnológica y ambiental impulsa a esta, a anclarse en una perspectiva global para enfrentar los retos de una globalización que no solamente abarca problemas ambientales sino que está involucrando a la lengua, cultura, y a la manera de sentir y pensar. Probablemente los hechos globales cambien de manera drástica la manera de vivir en el planeta y modifiquen el proceso de enseñar y aprender en el futuro, pero es claro que de alguna manera la internalización está enfocándose en aspectos que involucren a áreas lingüísticas, psicológicas, filosóficas, científicas y naturales como un solo cuerpo. 


\section{BIBLIOGRAFÍA}

Anderson, Tim (2015). Seeking Internationalization, Canadian Journal of Higher Education.

Whitehead, Michele (2015). Global Learning, Liberal Education, Vol. 101 issue3, p6-13.

Anderson, Charles (1995). Language Test Construction and Evaluation, Cambridge University Press.

Anderson, Gregory G. (1996). Global Issue in the University ESL Clasroom. Kansai Gaidai University. Recuperado /http://www.jalt-publications .org/.

Applebee (1974). The Basis of the particular needs manifested by the class.

Bartelson (2000). Globalization has destabilized the foundations of the nature of being as a new object of thought and action.

Cates, Kip A. (1991). Recuperado /http: //www.jalt-publications.org/

Cromer (1974). Relaltionships between cognitive factors and language.

Drayton, George. Education is only worth it makes in the activities of the individual who has been educated.
Freeman (1989). Applied linguistics and methodology, should not be the primary subjects matter of Language Teacher Education.

Hanvey, Robert (1976). An Attainable Global Perspective, the American Forum for Global Education. New York.

Kniep, W. (1985). A Critical Review of the Short History of Global Education. New York.

Littlewood, William T. (1984). Foreign and Second Language Teaching. Cambridge University.

Pike and Selby (1988). Phenomenon that is affecting the lives of people and of the planet.

Ramírez, Franking (1979). The most important thing in education is providing students with attitudes and capacities to solve world problems.

Santos, Ernesto (2007). Perceptions of Language Educators about Global Education...

Smith Glenda and Mike (1990). A Study Skills Handbook. Oxford University Press. 
ReVista PUCE, ISSN 1012-389X. NúM. 102

Wen-chung, Liu (2006). Memorization and Improvisation: a Comparison of Two Strategies in the Oral Acquisition of English as a Second Language.

Widdonson (1976). Foreign Language can be associated with other subjects.

Van, Ek and Alexander (1975). Whole con- text and learning and teaching and the need to consider societal and learner's needs.

Yakovchuk, Nadezhda (2001). Global Issues and Values in Foreign Language Education. Belarus. 



\title{
LA ENSEÑANZA Y APRENDIZAJE DEL INGLÉS COMO LENGUA AÑADIDA: ESTUDIO DE CASO \\ DE LA COMUNIDAD INMIGRANTE EN BRADFORD
}

TEACHING AND LEARNING ENGLISH AS AN ADDITIONAL LANGUAGE: CASE STUDY OF THE IMMIGRANT COMMUNITY IN BRADFORD

\author{
SONIA PEÑA \\ JOSÉ LUIS ORTEGA
}





\section{LA ENSEÑANZA Y APRENDIZAJE DEL INGLÉS COMO LENGUA AÑADIDA: ESTUDIO DE CASO DE LA COMUNIDAD INMIGRANTE EN BRADFORD}

Sonia Peña', José Luis Ortega²

\section{RESUMEN}

Hasta la fecha, numerosas investigaciones se han llevado a cabo sobre la enseñanza del inglés como lengua añadida (EAL en inglés). Sin embargo, parecen no haber sido suficientes para cubrir las necesidades que este tipo de alumnado y profesorado requiere. Este estudio trata de analizar lo que está sucediendo actualmente en las aulas. Se llevó a cabo en varios colegios de secundaria en Bradford (GB), donde más de la mitad del centro son alumnos EAL, con una participación de 117 sujetos. El principal objetivo es el de analizar qué métodos se utilizan en la enseñanza del inglés como lengua añadida y realizar una propuesta de mejora.

Palabras clave: inmigración, integración, EAL, minorías étnicas, diversidad.

\section{ABSTRAC}

To date, several investigations have been carried out about teaching English as an additional language (EAL). However, they have not been enough to cover the needs that this type of students and teachers require. This study attempts to analyze what is currently happening in the classroom. This study took place in several secondary schools in Bradford (UK), where more than half of the population are EAL students and a total of 117 people participated in the study. The main objective is to analyze what methods are used in teaching EAL and suggest an improvement proposal.

Key words: immigration, integration, $E A L$, ethnic minority groups, diversity.

\footnotetext{
${ }^{1}$ Universidad de Granada, Facultad Ciencias de la Educación, Granada, España (soniapg85@gmail.com). 2 Universidad de Granada, Facultad Ciencias de la Educación, Granada, España (joseluisortegamartin@gmail.com).
} 


\section{INTRODUCCIÓN}

... Si tú no emigraste, emigró tu padre, y si tu padre no necesitó mudar de sitio fue tu abuelo, antes, no tuvo otro remedio que ir, cargando la vida sobre la espalda, en busca de la comida que su propia tierra le negaba.

\section{José Saramago}

Según los datos publicados por la Oficina Nacional de Estadística (ONS) ${ }^{3}$ en el (Annual Mid-year Population Estimates, 2013), Inglaterra es un país que ha registrado el fenómeno de la inmigración durante siglos, pero ha sido en las últimas décadas donde ha ejercido como puerta principal de entrada para la inmigración procedente de Europa y Asia principalmente. En la actualidad, estos movimientos migratorios se ven reflejados en la población escolar en una diversidad social y cultural creciente. Estos cambios significativos, han motivado que durante los últimos años, en el sistema educativo hayan surgido nuevas necesidades a las que atender y respuestas que ofrecer a dichas circunstancias. En este sentido, el centro educativo es el lugar que debemos usar para llevar a cabo una integración entre las diversas procedencias y culturas, que permita cruzar lazos de confianza, respeto e igualdad por encima de las diferencias. Para el gobierno británico, apoyar a los estudiantes que tienen inglés como lengua añadida es un área de trabajo de la máxima prioridad (EAL Nexus Website, British (ouncil ${ }^{4}$ ). Su objetivo central es ayudar a que los estudiantes inmigrantes puedan acceder y aprender positivamente en las escuelas, en la comunidad y en la sociedad, promoviendo así el diálogo intercultural y la cohesión social.

\section{MARCO TEÓRICO}

En Inglaterra, es habitual encontrar aulas de primaria y de secundaria donde son muy pocos los alumnos que tienen el inglés como primera lengua en casa. Por las cifras tan altas que han alcanzado en los últimos años, el gobierno se ha visto en la necesidad de apoyar y atender a aquellos alumnos que se encuentran en esa situación. La gestión en las aulas de inclusión en los colegios públi-

\footnotetext{
${ }^{3}$ La Oficina Nacional de Estadísticas (ONS) es una autoridad británica que se encarga de la creación y publicación de estadísticas en los cambios de la economía, población y sociedad a diferentes niveles nacionales y locales.

${ }^{4}$ El Consejo Británico (en inglés British Council ) es un instituto cultural público equivalente al Instituto Cervantes, cuya misión es difundir el conocimiento de la lengua inglesa y su cultura mediante la formación y otras actividades educativas. La EAL Nexus website, es una plataforma que da apoyo exclusivamente al profesorado y alumnos EAL, con una gran variedad de recursos y materiales a disponibilidad pública.
} 
cos tanto de primaria como de secundaria, se lleva a cabo por medio del English as an Additional Language Programme (EAL), que tiene como objetivo lograr que este alumnado, los new-to-English students, pueda seguir de manera normal el National Curriculum en el menor tiempo posible. En el apartado de inglés como lengua añadida en Inglaterra, analizaremos en detalle el programa EAL. Hasta la fecha autores como Stephen Talmy (2011), Angela Creese (2005) y Jean Conteh (2012), han llevado a cabo investigaciones sobre la enseñanza y aprendizaje del inglés como lengua añadida. Muchas de sus investigaciones son guías dirigidas al profesorado que hablan de diferentes estrategias de enseñanza (Conteh, 2015), de la formación necesaria del profesorado (Conteh, 2012), de criterios de evaluación (Creese, 2012) y de las necesidades del alumnado EAL (Leung y Creese, 2010). Además existen dos importantes entidades en Reino Unido que ofrecen apoyo escolar, formación, opciones de investigación y una variedad de recursos "online": Naldic (National Association for Language Development in the Curriculum) y EAL Nexus Website de la British Council.

No obstante, parece que estos recursos no son suficientes para cubrir todas la necesidades que este tipo de profesorado y alumnado requiere. Con este estudio, intentamos analizar lo que sucede actualmente en las aulas EAL, e intenta dar respuestas a cuestiones aún sin resolver como podrían ser las siguientes: ¿Hasta qué punto el programa EAL implementado actualmente en Inglaterra puede integrar al alumnado inmigrante en el currículo nacional de manera eficaz y eficiente? Si es así, ¿cuáles son las claves de su éxito? y si no, ¿Cuáles son algunas de las áreas que se podrían mejorar?

Con el presente estudio, proponemos analizar qué métodos se usan para la enseñanza del inglés como lengua añadida, estudiar en profundidad el programa de adaptación, el nivel de importancia que se da a las raíces culturales y realizar una propuesta de mejora para que el alumnado inmigrante se sienta parte de la nueva cultura, respetando y manteniendo la de origen. La investigación fue llevada a cabo en las aulas EAL en varios colegios de secundaria en Bradford, donde más de la mitad del centro son alumnos EAL. El diseño del estudio es mixto, cualitativo y cuantitativo, no experimental, basado en el estudio de caso descriptivo como metodología de investigación. 


\section{LA INMIGRACIÓN EN EL REINO UNIDO}

El Reino Unido ha sido un punto de llegada de inmigrantes durante siglos y, especialmente, en las últimas décadas. Durante los años 1960 y 1970 hubo más personas que emigraban desde el Reino Unido a diferencia de los que llegaban para vivir en él. Según los datos publicados el 26 de junio de 2014 por la ONS en el Annual Mid-year Population Estimates 2013, refleja que la migración neta se mantuvo en un nivel relativamente bajo durante la década de 1980 y principios de 1990.

Desde 1994, la inmigración al Reino Unido se mantuvo estable, pero después de 1997 creció bruscamente. Durante la primera década del siglo XXI, la inmigración neta tuvo un aumento significativo de 150.000 a 300.000 personas aproximadamente. Este crecimiento se produjo por la incorporación de diez nuevos países miembros a la Unión Europea el 1 de mayo de 2004: República Checa, Chipre, Eslovaquia, Eslovenia, Estonia, Hungría, Letonia, Lituania, Malta y Polonia.

La Oficina Nacional de Estadísticas (ONS) en colaboración con el Ministerio del Interior (Home Office en inglés) y el Departamento de Trabajo y Pensiones (en inglés Department for Work and Pensions ) publica el informe Migration Statistic Quartely Report (MSQR) con las estimaciones anuales de la migración internacional a largo plazo en el Reino Unido.

La ONS define a "long- term International Migration" como:

A person who moves to a country other than that of his or her usual residence for a period of at least a year (12 months), so that country of destination effectively becomes his or her new country of usual residence.

\section{Inmigración por áreas}

En el Reino Unido, la inmigración internacional a largo plazo puede producirse por diferentes motivos: inmigración por estudios, trabajo, familias, amigos o refugio. La tercera o cuarta parte del total de la inmigración en Gran Bretaña, es producida por motivos de trabajo o estudios principalmente, según afirman los datos facilitados por la MSQR en febrero de 2015.

El último informe de Migration Statistic Quartely Report (MSQR) publicado el 26 de febrero de 2015, refleja un crecimiento estadísticamente significativo de 624.000 personas inmigradas al Reino Unido respecto a las 530.000 en el año anterior (2014), cifras recogidas hasta septiembre con el cierre de cada año. Como se ha mencionado previamente este crecimiento fue producido por la in- 
corporación de nuevos países miembros a la Unión Europea. Como detalla International Passenger Survey (IPS) en el último informe de MSQR febrero de 2015, se estima que el $51 \%$, 30\% y el $16 \%$ del total de los inmigrantes Europeos en el Reino Unido pertenecen a los primeros 15 países de la Unión Europea (EU15), a los 8 países de Europa de Este que se incorporaron en 2004 (EU8) y a Bulgaria y Rumania que se unieron en 2007 (EU2).

En relación con los inmigrantes no europeos, también se produjo, hasta septiembre 2013/2014 un crecimiento respecto al año anterior de 243.000 a 292.000. De los Estados que forman el Reino Unido, Inglaterra es el que acoge el mayor número de inmigrantes llegados al país. El Migration Statistic Quartely Report del 27 de noviembre de 2014, afirmaba que 462.000 inmigrantes llegaron a Inglaterra en el 2013, lo que representa un $88 \%$ del total de la población extranjera (530.000) en Gran Bretaña hasta junio de 2014 con el cierre del año. Las proporciones respecto a los inmigrantes que llegaron a Gales, Escocia e Irlanda del Norte eran del 4\%, $6 \%$ y $2 \%$ respectivamente. Dentro de Inglaterra, 140.000 personas inmigraron a Londres, cifra que no representa un crecimiento estadísticamente significativo en comparación con 2012, (MSQR noviembre 2014). La International Passenger Survey indica que Londres es la puerta de entrada internacional al Reino Unido y, por tanto, es un punto de transición previo al fijar una residencia en cualquier otra parte del Reino Unido, (Long-Term International Migration Methodology Document, febrero de 2015). El Sureste de Inglaterra (a las afueras de Londres) recibió el mayor número de inmigrantes, 62.000 en el 2013. En total, Londres y el Sureste recibieron el $38 \%$ del total de los inmigrantes llegados al Reino Unido en 2013, cifra similar a años anteriores. Las regiones del Este y Nordeste recibieron el mayor número de inmigrantes a las afueras de Londres y del sureste del país, con 56.000 y 51.000 respectivamente. En 2013, Inglaterra también obtuvo el mayor número de emigrantes, 272.000 personas emigraron de Inglaterra a países fuera del Reino Unido, lo que representa el $86 \%$ de todos los emigrantes procedentes de UK. Gales, Escocia y el Norte de Irlanda representan el 3\%, 8\% y $3 \%$, (MSQR, noviembre 2014). En Inglaterra, la gran diversidad de minorías étnicas es considerable. Leicester acoge el mayor número de residentes nacidos en India; Ealing en el sur de Londres tiene la cifra más alta de inmigrantes polacos; Slough y Bradford tienen el número más alto de residentes nacidos en Pakistán. Existe una gran cantidad de residentes con pasaportes europeos en Boston Lincolnshire, Peterborough y en otros muchos distritos de Londres. 


\section{Lenguas de Inglaterra}

Es evidente que el uso de otras lenguas distintas al inglés es una parte del patrimonio cultural de un porcentaje importante y creciente de la población británica. El Centre of Dynamics of Ethnicity (CODE) de la Universidad de Manchester, publicó un informe con los datos recopilados en el censo de 2011 sobre las principales lenguas de Inglaterra. 138.000 residentes entre Inglaterra y el País de Gales declararon no hablar inglés, la lengua principal más representada fue con diferencia el polaco con 546.000 hablantes, seguida por el panjabi $6,6 \%$ y el urdu 6,5\% del total de los ciudadanos que representaron hablar otra lengua distinta al inglés.

De los grupos más numerosos de lenguas diferentes al inglés se encuentran su mayoría dentro de Londres, con un 22\% o 1.7 millones de residentes. Fuera de la capital, los porcentajes más altos se encuentran en áreas como Leicester (28\%), Manchester (17\%), Peterborough (16\%), Birmingham (15\%) y Bradford (15\%). Según el CODE las principales 20 lenguas habladas en Inglaterra y Gales por número de hablantes en 2011, fueron:

$\begin{array}{ll}\text { Polaco: } & 546.174 \\ \text { Urdu: } & 268.680 \\ \text { Panyabi: } & 273.231 \\ \text { Bengali: } & 221.403\end{array}$

$\begin{array}{lr}\text { Árabe: } & 231.094 \\ \text { Francés: } & 159.290 \\ \text { Chino: } & 147.099 \\ \text { Portugués: } & 141.052 \\ \text { Español: } & 133.453 \\ \text { Tamil: } & 120.222 \\ \text { Turco: } & 100.689 \\ \text { Italiano: } & 99.423\end{array}$

Más del 50\% de los siguientes distritos, no representaron el inglés como lengua principal en el Censo 2011, (CODE): Latimern, Spinney Hills y Belgrave en Leicester; Southall Broadway y Southall verde en Ealing; Green Street Oriente y Wall End en Newham; Alperton y Wembley en el centro de Brent; Peterborough central; Green Street West y East Ham Norte.

Estas áreas se ubican en algunas de las zonas con mayor diversidad étnica de Inglaterra y Gales. La mayoría de ellos acogen grandes grupos de personas del sur de Asia: en Latimer (Leicester), el 74\% de los residentes declararon el Hindi como lengua principal en el Censo de 2011. Las principales lenguas agrupadas a nivel de distrito con más de 600 hablantes fueron:

- Yiddish, el 75\% se declaró en los barrios londinenses de Hackney, $12 \%$ en Salford y $10 \%$ en Haringey.

- Pahari / Mirpuri / Potwari : el 50\% de todos los que la hablan viven en Birmingham, el 6,4\% en Roch- 
dale y 4,8\% en Bradford.

- Hebreo: el 25\% vive en Barnet, en Hackney y Camden, un 10\% en Westminster y Haringey 4,3\%.

- La categoría que combina todas las lenguas de Australia y Oceanía se encuentran en Wiltshire 17\% y en Richmondshire 6\%.

Otros grandes grupos de lenguas incluyen: krio, turco, gujarati y bengalí. Las lenguas menos agrupadas, es decir, lenguas cuyos hablantes son los que más dispersos están en los distritos de Inglaterra y Gales son tailandés, holandés y polaco, junto con la lengua de señas británicas (Sign Language en inglés), CoDE 2013.

\section{Un país multicultural}

La rica diversidad de culturas, sociedad y lenguas que se ha desarrollado durante siglos en Inglaterra se ve reflejada en las escuelas. Hay más de un millón de niños entre los 5 y 18 años de edad que hablan más de 360 lenguas entre ellos. Más del 25 por ciento de los alumnos pertenece a una minoría étnica y casi uno de cada seis alumnos habla inglés como lengua añadida. Cada mes de enero, se realiza el Censo escolar en Inglaterra, de donde se desprenden datos fundamentales para realizar los cálculos de financiación escolar, que incluyen: Dedicated Schools Grand Funding; Funding Academies; Pupil Premium Funding y Capital Funding Allocations. Los datos aportados por el último Censo escolar se detallan en el informe publicado por el Departamento de Educación de Reino Unido, Schools, pupils and their characteristic: January 2014 y refleja lo siguiente:

En las escuelas de secundaria financiadas por el Estado (state-funded schools en inglés) un 14,3\% de los alumnos representaron otra lengua distinta al inglés, lo que muestra un aumento respecto a enero de 2013 (13,6\%).

Más de la mitad de las escuelas financiadas por el Estado se convirtieron en Academy $^{5}$, en enero de 2014, representaban un $57 \%$, lo que muestra un pequeño crecimiento de menos del 50 por ciento respecto a 2013. 29,5\% de los alumnos en las escuelas de primaria financiadas por el estado, fueron clasificados en un grupo étnico, lo que muestra un aumento respecto a enero de 2013 (28,5\%). Los alumnos pertenecientes a minorías étnicas forman el 60\% del crecimiento total de las escuelas de primaria.

\footnotetext{
${ }^{5}$ Las academies son escuelas independientes, que reciben la financiación directa del gobierno en lugar de las autoridades locales. El funcionamiento de la escuela recae en el director/a, son supervisadas por organismos individuales denominados "Academy trust" que le ofrecen apoyo y sugerencias. Las academies tienen más libertad que otras escuelas estatales sobre su financiación y planes de estudios. El profesorado no necesita seguir las condiciones nacionales de pago.
} 
Los grupos étnicos con el mayor crecimiento hasta enero de 2014 fueron: White British subió a 43.000, other White background 21.000, Mixed 13.600, Asian 13.300 y Chinese 9.000. En las escuelas de secundarias financiadas por el Estado, $25,3 \%$ de los alumnos fueron clasificados en un grupo étnico, con un aumento respecto a enero de 2013 (24,2\%). Desde el 2009, un poco menos del $20 \%$ de los alumnos de state-funded secondary schools eran de orígenes étnicos minoritarios, por lo que en 5 años ha tenido un crecimiento de más del 25\%. Según los datos publicado por Naldic (EAL statistic), los alumnos que tienen el inglés como lengua añadida, conocidos como EAL learners en las escuelas de primaria y secundaria financiadas por el Estado ha tenido un incremento anual y constante que se ha producido desde 1997 hasta la fecha. En 1997 se calculó 257.000 alumnos en las escuelas de primaria y 225.000 en las escuelas de secundaria, hoy día llegan a 665.000 alumnos de primaria y 460.000 de secundaria. Desde enero de 2013 a 2014 se produjo un aumento de $0,6 \%$ en las escuelas de primaria y $0,7 \%$ en las escuelas de secundaria. El número y el porcentaje de alumnos bilingües o EAL, varía significativamente por todo el país según el tipo de escuela.
En las escuelas rurales son muy pocos los alumnos EAL escolarizados, la gran mayoría se encuentra en las escuelas urbanas llegando casi al 100\% (EAL Nexus, British Council).

En los datos recogidos por el informe Schools, pupis and their characteristic de 2014, las 5 localidades con el mayor número de alumnos EAL de primaria y secundaria fueron:

\section{Escuelas financiadas por el Estado}

\section{Primaria}

Birmingham: $\quad 37.605$

Newham: $\quad 20.122$

Ealing: $\quad 15.207$

Tower Hamlets: 14.458

Bradbord: $\quad 13.788$

\section{Secundaria}

Birmingham: 25.589

Newham: $\quad 13.127$

Redbridge: 13.079 Bradford: $\quad 12.846$ Brent: $\quad 10.350$
Además, el menor número de alumnos EAL en las escuelas de primaria y secundaria de Inglaterra se encuentran en Redcar y Cleveland con 93 alumnos en primaria y 118 en secundaria; Halton con 114 en primaria y 75 en secundaria y Rutland con 72 en primaria y 50 en secundaria. El condado de Rutland acoge el menor número de alumnos EAL de toda Inglaterra.

\section{EL INGLÉS COMO LENGUA AÑADIDA EN INGLATERRA}

Como hemos mencionado al principio del estudio, la enseñanza del inglés como lengua añadida conocida en inglés como English as an Additional Language program es impartida en los colegios de Primaria y Secundaria finan- 
ciados por el Estado. Este programa tiene como objetivo lograr que alumnado EAL pueda incorporarse al plan nacional de estudios con total normalidad y en igualdad de condiciones al alumnado local.

El Ministerio de Educación, (en inglés Department of Education (DFE)) define la primera lengua como:

as the language to which a child was initially exposed during early development and continues to be exposed in the home or in the community.

Para la gran mayoría de los alumnos EAL esto significa que si comienzan la escuela a los 3-5 años de edad como alumnos EAL, serán estudiantes de EAL a lo largo de toda su etapa escolar.

No existe ningún plan de estudios acordado a nivel nacional para los alumnos EAL. Desde mediados de 1980, la ley inglesa señalaba que los aprendices EAL junto con los demás alumnos deben tener el mismo acceso al plan de estudios nacional sin ningún currículo específico. En Inglaterra, las segundas lenguas son reconocidas con éxito, sin embargo la lengua predilecta en las escuelas y para todo alumnado es el inglés, a través de él se alcanzará el logro académico. La política de alumnos que estudia a los EAL en el aula ordinaria a través del Plan Na- cional de Estudios, plantea cuestiones no solo de lengua y de pedagogía, sino también de los derechos y beneficios de la integración social y la igualdad de acceso al sistema educativo (EAL Nexus, British (ouncil).

A través del Plan Nacional de Estudios, el DFE espera una enseñanza eficaz para los alumnos EAL, que se lleve a cabo dentro del plan de estudios y que el profesorado tenga presente lo siguiente:

1. Las necesidades de los alumnos cuya lengua materna no es el inglés. En este seguimiento, se considerará la edad del alumno, el tiempo que lleva en el país, la experiencia educativa previa y la habilidad en otros idiomas.

2. Planificar las clases de tal modo que puedan ayudar a los alumnos a desarrollar su inglés y dar el apoyo que necesiten para participar en las demás materias.

En septiembre de 2013, el DFE planteó para el nuevo curso escolar 2014/2015 no ofrecer apoyo específico para los alumnos EAL, sino que propusieron desarrollar lo siguiente:

1. Tener altas expectativas de todos los estudiantes, independientemente de sus antecedentes o necesidades.

2. Dar plena libertad a las escuelas 
para implementar las medidas necesarias.

3. Tener un nivel alto de responsabilidades a través de la Office for Standards in Education, Children's Services and Skills (Ofsted).

\section{Cómo evaluar a los alumnos de inglés como lengua añadida}

No existe un sistema nacional de evaluación para medir el desarrollo y aprendizaje de los alumnos EAL. La guía más reciente publicada por Ofsted ${ }^{6}$ declaró que la escuela debe supervisar el logro y el progreso de los alumnos que pueden estar en la primera etapa del aprendizaje del inglés. Para ello, se sugiere utilizar los descriptores de nivel que incluye el Currículo Nacional 2000 (en inglés A language in common: assessing English as an additional language,). Aunque dicha escala no está oficialmente legalizada, fue plenamente recomendada por el Department for children, schools and families (dcfs). Además, la escuela también deberá tomar medidas para evaluar las competencias y la alfabetización de los alumnos en su lengua materna y haber comprobado los conocimientos previos y la experiencia en otras materias.

\section{Fondos para el alumnado inmigrante}

Desde abril de 2013, un factor EAL podría incluirse en las fórmulas de financiación de las escuelas inglesas para satisfacer las necesidades de los alumnos bilingües. Este factor se limita a los alumnos bilingües que han estado escolarizados por un período máximo de tres años. The local schools Forum puede decidir si debe o no incluir un factor EAL en su fórmula, si este factor incluye a los alumnos bilingües que han estado escolarizados por uno, dos o tres años y el valor en efectivo de este factor para los alumnos de primaria y de secundaria.

Las autoridades locales no están obligadas a incluir este factor, ni tampoco existe un mecanismo que delegue sobre el uso de la financiación EAL en las escuelas. Estas no están obligadas a utilizar estos fondos para satisfacer las necesidades de los alumnos bilingües, lo que contrasta con la exigencia de dar cuenta sobre el uso de sus fondos y sus efectos. Para el curso escolar 2014/15, el $87 \%$ de todas las autoridades locales optaron por incluir el factor EAL en su fórmula de financiación. Un 23\% de las autoridades locales optaron por incluir a los alumnos que habían estado escolarizados por solo uno o dos años, en lugar de los tres años completos. El valor que

\footnotetext{
${ }^{6}$ Ofsted, se encarga de realizar inspecciones regulares de cada escuela en Inglaterra, lo que deriva a desarrollar un informe de la eficacia del centro y será libremente publicado. Un informe desfavorable puede incluir una recomendación para mejorar el funcionamiento del centro y cómo poder llegar al éxito. El objetivo principal es lograr la excelencia en la educación para todos los estudiantes en general.
} 
se asigna al factor EAL es de 250 hasta 1.000 libras por alumno. Por lo general, todas las autoridades locales están asignando menos del $5 \%$ de financiación a este factor, con un promedio de 0,9\%. En el curso escolar 2014/15, un total de 243 millones de libras se delegó a las escuelas a través del factor EAL,(Naldic, EAL Funding). Para el siguiente curso escolar 2015/16, el gobierno ha establecido un nivel mínimo que será de 466 libras para Primaria y 1.130 libras para Secundaria. Este nivel mínimo de financiación se destinará a los alumnos que entraron en el sistema escolar en los últimos tres años.

\section{Los alumnos de inglés como lengua añadida en Bradford}

Bradford es el cuarto distrito metropolitano más grande en términos de población en Inglaterra, después de Birmingham, Sheffield y Leeds. En los dos últimos años, la población ha crecido un $0,6 \%$, lo que es más lento que el promedio regional de $0,9 \%$ y la media nacional de 1,4\%. El crecimiento de la población en Bradford es inferior a otras ciudades como Birminghan, Manchester o Londres, (Bradford Metropolitan District Counci).La población de Bradford es totalmente multicultural, un 63,9\% de la población se identifica como White British.

Bradford cuenta con la mayor cifra de origen étnico paquistaní de Inglate- rra con un 20,3\%. Uno de los grupos étnicos más reciente llegados a Bradford pertenece a Europa Central y Oriental, concretamente de Eslovaquia, República Checa y Polonia. Por lo general, son familias de origen de etnia gitana, de Eslovaquia y República Checa. Los gitanos polacos, rumanos y húngaros son menores en número. El estado social de Bradford es de inmigrantes con motivos económicos (en inglés Economic Migrants), pero se estima que gran parte de ellos se van a afincar allí y a formar parte de la comunidad, (Bradford Metropolitan District Council).

Bradford a su vez, cuenta con familias de refugiados que se han trasladado a la zona buscando un asilo, seguridad y mejor calidad de vida, debido a una persecución por motivos de raza, religión, nacionalidad y opinión política en su país de origen, (Bradford Metropolitan District Council). Según el Censo Escolar de 2014, la ciudad de Bradford cuenta con 36.485 alumnos escolarizados en las escuelas de secundaria financiadas por el Estado, de los cuales 19.230 pertenecen a minorías étnicas. Esta cifra está formada por los alumnos que pertenecen a uno de los cinco principales grupos étnicos según las categorías del Censo: white, mixed, asian, black, chinese y any other ethnic group. Como muestran los datos recogidos en el Censo, el grupo que acoge el mayor número de alumnos respecto a las otras minorías étnicas 
es el asiático con 15.665 alumnos. De esta cifra cabe destacar los 12.911 que pertenecen al grupo pakistaní. Estos datos ratifican lo que hemos mencionado anteriormente, que el distrito de Bradford recibe el mayor número de ciudadanos pakistaníes. Además, solo 349 alumnos corresponden al grupo Gypsy/
Roma (gitanos) lo que certifica que muchas familias gitanas no declaran su grupo étnico en las escuelas ni en otras entidades públicas por miedo a la discriminación, National Association of Teachers of Travellers + Other Professionals (Natt+).

\section{METODOLOGÍA}

\section{Muestra}

La muestra ha sido seleccionada según un tipo de muestreo, no probabilístico de sujetos voluntarios, puesto que la elección de ellos dependió del criterio de posibilidad de acceder al alumnado y al profesorado. Un total de 117 participantes han colaborado, lo que corresponde a 101 alumnos y 16 profesores. La recogida de datos se llevó a cabo durante la primavera de 2014 en 4 colegios públicos de secundaria en Bradford (Inglaterra). La elección de dichos centros se tomó tras analizar el total de alumnos EAL escolarizados y seleccionar los centros con el mayor número.

\section{Instrumentos}

Para la toma de datos, se aplicaron observaciones participativas en el aula, las personas encargadas de pasar los cuestionarios se identificaron de antemano y participaban en la clase, a la vez que realizaban las observaciones e inter- pretaciones. También se elaboraron dos cuestionaros cerrados, tanto para el profesorado como para el alumnado, con el fin de analizar qué materiales y recursos utilizan los docentes en las aulas EAL. En la primavera de 2013, se realizó la prueba piloto de la encuesta para consolidar y probar su funcionamiento en el campo. Dichas encuestas fueron modificadas, debido a que las preguntas no eran adecuadas para una buena comprensión de los encuestados. El cuestionario usado, fue validado siguiendo el método de triangulación de expertos.

\section{Procedimiento}

Individualmente, cada participante completó la encuesta en el mismo aula de inclusión. A aquellos alumnos que ya estaban integrados en el aula ordinaria, se les pidió que fueran a la misma. A los alumnos que necesitaron apoyo para la comprensión, se les ofreció ayuda con profesores asistentes que les traducían a su lengua materna 
para obtener resultados más precisos. El profesorado optó por realizar la encuesta fuera del centro para dedicarle el tiempo requerido.

\section{Variables empleadas}

Hemos analizado qué nivel de la cultura de origen tienen los encuestados. Para ello, hemos realizado correlaciones de las variables culturales con otras cuestiones que podían influir de manera positiva o negativa en este conocimiento. En este caso, se confeccionó una variable nueva a partir de las preguntas que tenía acerca de diferen- tes aspectos culturales y otras varias que se detallan en el cuestionario. A partir de estas, se creó una variable que mide de forma más certera el conocimiento cultural de los encuestados. Se asignó una puntuación ponderada sobre cada ítem, de forma que al final se obtenga un sumatorio ponderado de las respuestas correctas que indique un nivel de conocimiento cultural, categorizada de la siguiente forma: fail (0 a 4,99), pass (5-5.99), pass + (6-6.99), outstanding (7$7,99)$ outstanding + $(8-8,99)$. En la encuesta del profesorado se empleó el valor de la moda.

\section{ESTUDIO ESTADÍSTICO}

Se trata de una investigación mixta cualitativa y cuantitativa no experimental, basada en un estudio de caso descriptivo como método de investigación. Se ha utilizado el Alfa de Cronbach estandarizado para medir la fiabilidad de las correlaciones de los ítems, habiéndose obtenido un índice de fiabilidad de 0,742 (George y Mallery, 2003: 231).

\section{Resultados}

Respecto al funcionamiento de las aula EAL, cada centro desarrolla su propio programa de adaptación, que puede tener un período de duración, comprendido entre 2 semanas hasta 1, 2 o 3 años. Los alumnos continuarán con clases de apoyo una vez finalizado el período de adaptación, pero siempre dependerá del progreso del alumno. La mayoría de los profesores de EAL solo imparten inglés y solo un $43,8 \%$ de los encuestados han recibido formación específica para impartir en dichas aulas. Una vez más, según el centro, la elección de enseñar en las aulas EAL puede ser obligatoria $u$ opcional. Al respecto, un 50\% de los encuestados confiesa que fue opcional, frente a un $25 \%$ que afirma que fue obligatoria. El resto de participantes (25\%) optaron por no contestar.

Se estudió si los materiales más utilizados en la aulas EAL eran los mismos que los alumnos habían conside- 
rado muy apropiados o apropiados para el aprendizaje de la lengua. Tras el análisis se observó que de los materiales más utilizados, entre ellos fotocopias, pizarra digital, libros de lecturas, ordenadores y videos por lo general, los alumnos lo vaIoran como muy apropiados para el aprendizaje. Además, el material utilizado en menor frecuencia por el profesorado, en este caso el libro de texto, es valorado por el alumnado como muy apropiado. Esta opinión nos hace pensar, que al día de hoy, los alumnos optan por el método tradicional, y no asimilan que sin el uso constante del libro de texto, también se puede alcanzar el éxito y aprender la lengua.

En relación con el nivel de conocimiento de lo cultural que tienen los alumnos sobre el país en el que viven se desvela que el nivel de conocimiento acerca del país en el que residen es escaso: un $81,2 \%$ del total de los encuestados no alcanzan un conocimiento mínimo de aspectos culturales. Cabe destacar que, en un porcentaje muy alto de los casos recogidos en esta población, ninguno de los progenitores trabaja; en el $44,6 \%$ de los casos, no trabaja ni el padre ni la madre. Sobre este mismo ítem, evaluamos si el nivel cultural estaba quizás influenciado por el tiempo que llevaban viviendo en Inglaterra. Los datos obtenidos mostraron que el nivel de cultura no varía en función del tiempo, pues no influye si han vivido en Inglaterra uno o diez años según se desprende de los resultados obtenidos

\section{CONCLUSIONES GENERALES}

Tras las observaciones en las aulas, se puede constatar que el objetivo principal del programa profundización en la integración del alumnado inmigrante de manera eficazy en igualdad de condiciones al alumnado local, no se está llevando a cabo, puesto que se hace una segregación al alumnado extranjero desde su ingreso en el centro. Con ello, solo se puede conseguir que los estudiantes se sientan diferentes a los demás, ya que llevan la etiqueta de EAL students nada más llegar.
El alumnado inmigrante permanece semanas, meses, e incluso años en las aulas EAL hasta llegar a alcanzar el nivel correspondiente al currículum nacional, y con ello poder acceder a las aulas ordinarias. El hecho que los alumnos de distintas nacionalidades que comparten una misma lengua (caló) permanezcan en una misma aula, como es el caso de los alumnos eslovacos y checos estudiados, concluimos que no es la manera más adecuada para el aprendizaje de la lengua de acogida. Es fundamental que el alumnado extran- 
jero se relacione con el resto de compañeros, no solo por la adquisición lingüística, sino para la construcción de valores de buena convivencia en el ámbito escolar y social.

El apoyo al alumnado inmigrante dentro y fuera del aula ordinaria es la cuestión clave ya que hay cierto debate sobre si la separación de los estudiantes es la opción correcta o no. Llegados a este punto, cabe reflexionar sobre la manera en que reciben dicho apoyo. Como pudimos comprobar a través de las observaciones en las aulas ordinarias, el alumnado extranjero que observamos estaba ubicado al final de la clase con el profesor de apoyo sin tener relación con el resto de compañeros y ni siquiera son tenidos en cuenta para trabajos grupales.

Con el fin de fomentar la cultura y la lengua de origen, los centros ofrecen clases extraescolares en su lengua materna y organizan actividades de ocio fuera del centro. La participación de sus familias en el ámbito escolar es escasa, ya que la mayoría de ellas no han tenido buenas experiencias en el ámbito social y escolar, debido a que muchas veces se han visto discriminados a la hora de representar su nacionalidad. Estos hechos, juntos con la falta de asistencia escolar, nos llevan a pensar que los problemas que aparecen en la educación de los niños inmigrantes no son atribuidos únicamente a los propios sujetos, sino en gran parte a factores externos. Un ejemplo es la falta de integración social de sus familias o el tener que trabajar siendo menores de edad. Como dice Miller (2000), el contexto social y educativo son dos factores determinantes en el proceso de aprendizaje del alumnado inmigrante, reflejado en la autoimagen que tiene el propio extranjero de sí mismo y la figura que la escuela construye de él.

En relación con el profesorado, se debería requerir una formación especifica, puesto que la metodología que se usa en la enseñanza de inglés como lengua añadida es diferente a la empleada en la del inglés como lengua materna. En definitiva, se debería formar al profesorado en general, puesto que la mayoría de los profesores no saben adaptar sus materias para la comprensión de todo el alumnado. A continuación se plantean una serie de propuestas de mejora del programa EAL, que consideramos que debieran llevarse a cabo procurando así que la integración del alumnado inmigrante se desarrollará de manera más eficaz.

1. Recibir apoyo dentro del aula ordinaria (el permanecer en contacto con alumnos nativos aseguraría una adquisición natural de la lengua, una integración en vez de aislamiento).

2. Procurar que ningún estudiante 
sea excluido de la acción que se esté desarrollando en clase (utilizando estrategias de enseñanza inclusiva el alumno extranjero manifestará mayor interés por participar y aprender la lengua).

3. Situar al alumnado EAL con otros compañeros nativos del país de origen o que están totalmente adaptados a la lengua y la cultura potenciando así la cooperación entre todos y la implicación del grupo en su proceso de adaptación.

Con este trabajo hemos obtenido un diagnóstico de la situación actual en las aulas EAL, que ya está siendo utilizado en otras investigaciones para el diseño de intervenciones pedagógicas destinadas a mejorar la adaptación del alumnado inmigrante al currículo nacional. 


\section{BIBLIOGRAFÍA}

Constant, L. and Creese, A. (eds.)(2010). English as an additional language: Aprroaches to teaching linguistic minoriy students. Reading: University of Reading.

Conteh, J. (2012). Teaching bilingual and EAL learners in primary schools. Transforming Primary QTS. London: Sage.

Conteh, J. (2015). The EAL teaching book Promoting success for multilingual learners in primary and secondary schools. London: Sage.

Creese, A. (eds.)(2012). "Multilingual teaching and learning (online)" in NALDIC Quarterly 10.1, ISSN 1751-2190

available from www.naldic.org.uk/eal-publica tions-resources/Shop/shop-products/nq 1010, accessed 19 April

George, D. y Mallery, P. (2003). SPSS for Windows step by step: A Simple Guide and Reference. 11.0 Update (4⿳a . ed.). Boston: Allyn \& Bacon.

Miller, J. (2000). Language use, identity, and social interaction: Migrant students in Australia, Research on Language \& Social Interaction, 33, 1: 66-100.

http://www.bradford.gov.uk/bmdc/co mmunity_and_living/population, accessed 6 March, 2015.

http://www.eal.britishcouncil.org/ealsector/education-policy-eal-england, accessed 6 February, 2015. http:// www.ethnicity.ac.uk/research /outputs/briefings/dynamics-of-diversity/, accessed 10 March, 2015.

http:// www.gov.uk/government/statistics/schools-pupils-and-their-characteristics-january-2014 accessed 3 April, 2015.

http://www.migrationobservatory.ox.a c.uk/briefings/long-term-international-migration-flows-and-uk, accessed 25

March, 2015.

http://www.naldic.org.uk/researchand-information/, accessed 3 April, 2014.

http://www.naldic.org.uk/researchand-information/eal-funding, accessed 2 April, 2015.

http://www.natt.org.uk, accessed 10 April, 2015.

http://www.ons.gov.uk/ons/rel/popestimate/population-estimates-for-uk-england-and-wales-scotland-and-northern-irel and/2013/stb--mid-2013-uk-populationestimates.html, accessed 10 March, 2015. 


\section{APROXIMACIÓN AL ESTUDIO \\ DE LA NEUROEDUCACIÓN: \\ EL ENCUENTRO DE LAS CIENCIAS \\ CON LA ESCUELA}

AN APPROACH TO THE STUDY OF NEUROEDUCATION:

THE MEETING BETWEEN SCIENCE AND EDUCATION

FAUSTO SEGOVIA BAUS

Recibido 15 de marzo de 2016 Aceptado 8 de abril de 2016 



\title{
APROXIMACIÓN AL ESTUDIO DE LA NEUROEDUCACIÓN: EL ENCUENTRO DE LAS CIENCIAS CON LA ESCUELA
}

\author{
Fausto Segovia Baus ${ }^{1}$
}

\section{RESUMEN}

Las neurociencias son las nuevas disciplinas que inciden poderosamente en el conocimiento del funcionamiento del cerebro para enseñar y aprender mejor. En el presente ensayo se pretende conectar la escuela con las neurociencias para incidir en la educación de calidad, y específicamente los aprendizajes.

Palabras clave: neuroeducación, neurodidáctica, ciencias, escuela, investigación.

Una de las debilidades del sistema educativo ecuatoriano es la ausencia de políticas y líneas de investigación, en los ámbitos de la educación, la pedagogía y

\section{ABSTRACT}

Neurosciences are new disciplines deeply involved in our knowledge about brain function and teaching and learning processes. This essay provides a connection between school and neuroscience to improve education, specifically the learning processes.

Key words: neuroscience, neuroeducation, neurodidactic, science, school, research.

la didáctica. Si bien las inversiones en la educación en los últimos años son ostensibles por el financiamiento que ha incrementado la cobertura escolar, la ca-

\footnotetext{
1 Universidad Andina Simón Bolívar, Quito, Ecuador (faustosegovia@cablemodem.com.ec).
} 
lidad constituye una debilidad de origen estructural por los factores complejos que entran en juego.

Los datos oficiales demuestran avances cuantitativos importantes, especialmente en cobertura, pero en los cualitativos -asociados a la calidad- to- davía se reconocen falencias. Informes de la UNESCO pueden ilustrar sobre la situación del país en el concierto internacional, en el ámbito de la educación. El Ecuador se ubicó en la media regional en los resultados TERCE, según la última medición de la UNESCO denominada LLECE (SERCE y TERCE). ${ }^{2}$

\section{Cuadro 1: Distribución de los países según sus resultados y su comparación con la media regional}

\begin{tabular}{|c|c|c|c|c|}
\hline ÁREAS & GRADOS & $\begin{array}{l}\text { POR DEBAJO DE LA } \\
\text { MEDIA REGIONAL }\end{array}$ & $\begin{array}{l}\text { IGUAL QUE LA } \\
\text { MEDIA REGIONAL }\end{array}$ & $\begin{array}{l}\text { POR SOBRE LA } \\
\text { MEDIA REGIONAL }\end{array}$ \\
\hline Lectura & $3^{\circ}$ & $\begin{array}{l}\text { Guatemala, Honduras, } \\
\text { Nicaragua, Panamá, } \\
\text { Paraguay y Rep. } \\
\text { Dominicana }\end{array}$ & $\begin{array}{l}\text { Argentina, Brasil } \\
\text { Colombia y Ecuador }\end{array}$ & $\begin{array}{l}\text { Chile, Costa Rica, } \\
\text { México, Perú, Uruguay, } \\
\text { y el estado mexicanor } \\
\text { de Nuevo León }\end{array}$ \\
\hline Lectura & $6^{\circ}$ & $\begin{array}{l}\text { Ecuador, Guatemala, } \\
\text { Honduras, Nicaragua, } \\
\text { Panamá, Paraguay } \\
\text { y Rep. Dominicana }\end{array}$ & Argentina y Perú & $\begin{array}{c}\text { Brasil, Chile, } \\
\text { Colombia, Costa Rica, } \\
\text { México, Uruguay } \\
\text { y el estado de } \\
\text { Nuevo León (Mex.) }\end{array}$ \\
\hline Matemática & $3^{\circ}$ & $\begin{array}{l}\text { Guatemala, Honduras, } \\
\text { Nicaragua, Panamá, } \\
\text { Paraguay y Rep. } \\
\text { Dominicana }\end{array}$ & Colombia y Ecuador & $\begin{array}{c}\text { Argentina, Brasil, } \\
\text { Chile, Costa Rica, } \\
\text { México, Perú, Uruguay } \\
\text { y el estado de Nuevo } \\
\text { León (Mex.) }\end{array}$ \\
\hline Matemática & $6^{\circ}$ & $\begin{array}{l}\text { Guatemala, Honduras, } \\
\text { Nicaragua, Panamá, } \\
\text { Paraguay y Rep. } \\
\text { Dominicana }\end{array}$ & $\begin{array}{c}\text { Brasil, Colombia } \\
\text { y Ecuador }\end{array}$ & $\begin{array}{c}\text { Argentina, Chile, } \\
\text { Costa Rica, México, } \\
\text { Perú, Uruguay y el estado } \\
\text { de Nuevo León (Mex.) }\end{array}$ \\
\hline $\begin{array}{l}\text { Ciencias } \\
\text { naturales }\end{array}$ & $6^{\circ}$ & $\begin{array}{l}\text { Guatemala, Honduras, } \\
\text { Nicaragua, Panamá, } \\
\text { Paraguay y Rep. } \\
\text { Dominicana }\end{array}$ & $\begin{array}{l}\text { Argentina, Brasil, } \\
\text { Ecuador y Perú }\end{array}$ & $\begin{array}{c}\text { Chile, Colombia, } \\
\text { Costa Rica, México, } \\
\text { Uruguay y el estado } \\
\text { de Nuevo León (Mex.) }\end{array}$ \\
\hline Escritura & $3^{\circ}$ & $\begin{array}{l}\text { Guatemala, Honduras, } \\
\text { Nicaragua, Paraguay } \\
\text { y Rep. Dominicana }\end{array}$ & $\begin{array}{l}\text { Brasil, Colombia, } \\
\text { Ecuador, Panamá } \\
\text { y est. Nuevo León }\end{array}$ & $\begin{array}{l}\text { Argentina, Chile, } \\
\text { Costa Rica, México, } \\
\text { Perú y Uruguay }\end{array}$ \\
\hline Escritura & $6^{\circ}$ & $\begin{array}{l}\text { Colombia, Ecuador, } \\
\text { Honduras, Paraguay } \\
\text { y Rep. Dominicana }\end{array}$ & $\begin{array}{l}\text { Brasil, Nicaragua, } \\
\text { Panamá, Perú y } \\
\text { Uruguay }\end{array}$ & $\begin{array}{l}\text { Argentina, Chile, } \\
\text { Costa Rica, Guatemala, } \\
\text { México y Nuevo León }\end{array}$ \\
\hline
\end{tabular}

Fuente: http://www.unesco.org/new/fileadmin/MULTIMEDIA/FIELD/pdf/TERCE-distribucion-paises-por-resultados.pdf 
Según el Instituto Nacional de Evaluación (INEVAL), si se comparan los resultados entre las pruebas TERCE ejecutadas en 2013 por el LLECE de la UNESCO, y también la prueba precedente -SERCE 2006- "el Ecuador se encuentra entre los países con más avances en los aprendizajes". Y subraya que "es importante destacar que el incremento de los puntajes en el desempeño educativo de Ecuador va acompañado de una mejor distribución de la riqueza, lo cual se evidencia con el índice Gini que pasó de 0,53 en el 2006 a 0,46 en el 2011; y de un incremento en el gasto público destinado a la educación que pasó de 2,6 \% en el 2006 a $5 \%$ en el 2013. En el caso del Índice de Desarrollo Humano (IDH) de 0,687 (2005) a 0,711 (2013). Lo que significa que se ha alcanzado un desarrollo humano medio alto".3
Un punto importante digno de mencionarse es la ejecución de las ocho políticas educativas de Estado contenidas en el Plan Decenal de Educación 2006-2015, que fueron aprobadas en referendo por el pueblo ecuatoriano, que constituyeron una guía significativa para el desarrollo de los planes, programas y proyectos en marcha.

La información anterior establece -en resumen- que el Ecuador en los últimos diez años ha realizado esfuerzos importantes en el sector educativo gracias a algunos factores: voluntad política, altas inversiones, reformas legales y la creación de cuatro nuevas universidades: UNAE, Universidad Nacional de Educación; IKIAM, Universidad Amazónica; UNIARTES, Universidad de las Artes; y YACHAY, Universidad de Investigación y Tecnología Experimental.

\section{PARADOJAS}

Estos emprendimientos se inscribieron en el Plan de Desarrollo del "Buen Vivir", que ubicó a la reforma educativa en uno de los cinco ejes de la denominada Revolución Ciudadana, y donde los actores directos e indirectos del sistema educativo tuvieron escasa participación.
Prueba de lo mencionado es la no convocatoria, por ejemplo, al Consejo Nacional de Educación, según el Art. 23 de la Ley Orgánica de Educación Intercultural, cuya disposición es mandataria u obligatoria y no facultativa. ${ }^{4}$

2 LLECE es el Laboratorio Latinoamericano de Evaluación de la Calidad de la Evaluación, coordinado por la Oficina Regional de la UNESCO. EI TERCE se aplicó en 15 países de América Latina: Argentina, Brasil, Chile, Colombia, Costa Rica, Ecuador, Guatemala, Honduras, México, Nicaragua, Panamá, Paraguay, Perú, República Dominicana y Uruguay, y en el estado mexicano de Nuevo León.

${ }^{3}$ SÁNCHEZ, Harvey. Director Ejecutivo de INEVAL. En documento electrónico TERCE -INEVAL-UNESCO. Disponible en: http://www.unesco.org/new/fileadmin/MULTIMEDIA/FIELD/Santiago/pdf/TERCE-distribucion-paises-por-resultados.pdf

${ }^{4}$ REGISTRO OFICIAL DE LA REPÚBLICA DEL ECUADOR. n. 417, de 31 de marzo de 2011. Disponible en: http://planipolis.iiep.unesco.org/upload/Ecuador/Ecuador_Ley_organica_educacion_intercultural.pdf 
Pero lo paradójico del proceso estriba no solo en la poca o escasa participación de los actores sociales, especialmente de los profesores; por ejemplo, en validaciones técnicas y consensos cardinales, sino en la ausencia de las universidades y sus centros de investigación, en el diseño y ejecución de las políticas públicas en educación y en la fundamentación científica de las reformas.
En esa línea de pensamiento, un punto en discusión -todavía intocado en el Ecuador- es la necesaria conexión de la escuela con las ciencias, como núcleo central de la educación inicial y continua de los docentes y específicamente de los sistemas neurolingüísticos asociados a la lectura, que es el tema que motiva este artículo.

\section{NECESIDAD DE INTERCONEXIONES}

En el Ecuador existen pocos estudios sobre las neurociencias y sus relaciones con las escuelas y los procesos de aprendizaje de los estudiantes. Las escuelas -salvo excepciones- actúan sobre sistemas formales, anclados a modelos tradicionales, donde la gestión del currículo -lo administrativo- supera a las teorías pedagógicas, así como a los fundamentos curriculares, que deberían formar parte de la actualización de los docentes, y a los estándares de aprendizaje de los estudiantes, sobre la base de sistemas de evaluación y calidad sustentados en parámetros científicos.

Tracey Tokuhama-Espinosa ${ }^{5}$ ha identificado las interconexiones entre la psicología, el cerebro y la educación como ejes de sus investigaciones y publicaciones, que tienden a fortalecer la calidad de la educación desde perspec- tivas científicas. Sus trabajos han sido reconocidos por la comunidad educativa internacional.

Y si nos referimos a la escuela, los vacíos son evidentes tanto en lo conceptual y pedagógico. La escuela del Ecuador responde a sistemas tradicionales de enseñanza y aprendizaje, y su estructura reproduce un sistema social de carácter piramidal y paternalista, cuya cultura organizacional privilegia la memorización de cantidades de "materia", en nombre de un currículo inflexible, y donde los modelos de evaluación fomentan la calificación y generan incertidumbres. A lo anterior se une la falta de programas de investigación asociados a la educación, la pedagogía y la didáctica para la toma de decisiones estratégicas y la construcción de políticas públicas. Y si existen, la mayoría de las investigacio-

${ }^{5}$ Dra. Tracey Tokuhama-Espinosa, Ph.D. Director of IDEA (Instituto de Enseñanza y Aprendizaje or Teaching and Learning Institute), and Professor of Education and Neuropsychology at the of the University of San Francisco in Quito, Ecuador. 
nes (las tesis de grado y posgrado son ejemplos) quedan en los archivos de las bibliotecas de las universidades. La Ley Orgánica de Educación Intercultural menciona a la escuela, pero con énfasis en la gestión, mas no en lo pedagógico y cualitativo.
Las neurociencias y la programación neurolingüística, en este contexto, no pasan de ser temas que se estudian en cursos especiales, sin mayor incidencia en las políticas públicas.

\section{LA NEUROEDUCACIÓN}

La pedagogía, la psicología y las neurociencias -entre las que se destacan la neuroeducación y la neurodidáctica- son nuevos enfoques y corrientes de investigación que, en su conjunto, tienen como objeto de estudio la formación integral de los seres humanos, de manera especial en conexión con los aprendizajes, el funcionamiento del cerebro y los comportamientos.

En la actualidad la neuroeducación es considerada una disciplina -o mejor, una transdisciplina- que integra varias ciencias de la educación, cuyo núcleo central es el estudio del cerebro como constructo interdisciplurocognitivo de los seres humanos. Su vigencia es reciente. En 1971, Arthur Benton publicó el libro Introducción a la neuropsicología. De ahí surgieron otras investigaciones sobre neuropsicología infantil y sus derivaciones: la neuropsicología del aprendizaje, la neuropsicología escolar, la neuropedagogía y la neurodidáctica. En 1988, Gerhard Preiss, investigador de la Universidad de Friburgo, intro- dujo la neurodidáctica como ciencia autónoma encargada del estudio de las relaciones entre el cerebro y la pedago gía ${ }^{6}$.

Los recursos de alta tecnología han permitido el desarrollo extraordinario de la neuroeducación en los últimos años, a saber: las imágenes cerebrales, las pruebas genéticas, las simulaciones computacionales, entre otras, cuya utilización va más allá de los trastornos del aprendizaje, discapacidades, dislexia, autismo y defectos de atención. La neuroeducación intenta articular las ciencias del cerebro -conocidas como neurociencias- con las ciencias de la educación.

Tracey Tokuhama-Espinosa concibe así la neuroeducación, según el libro Ciencias de la educación, mentey cerebro: una guía completa a la nueva enseñanza basada en el cerebro (W.W. Norton), basado en más de 4.500 estudios y contribuciones de los líderes del mundo, en la nueva educación centrada en el estudio del cerebro:

\footnotetext{
${ }^{6}$ Neuroeducación. Disponible en: https://es.wikipedia.org/wiki/Neuroeducaci\%C3\%B3n
} 


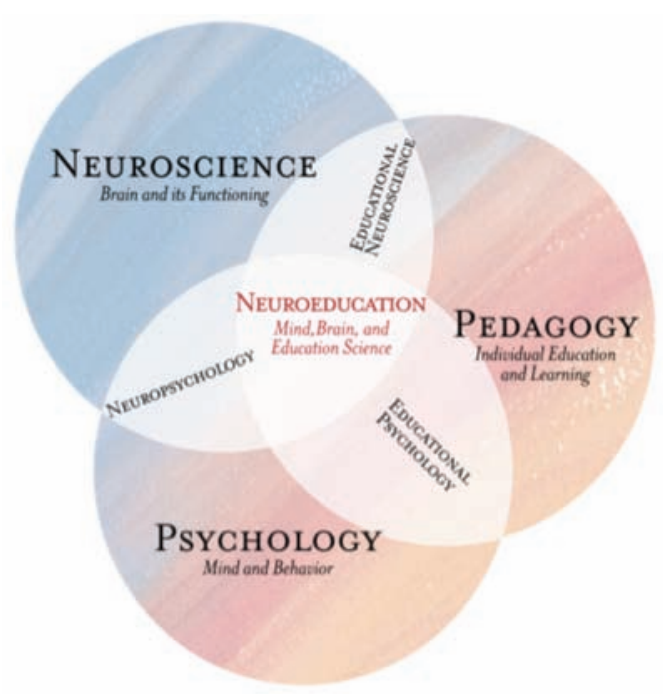

Fuente: MBE Science as a Multidisciplinary Field. Interpretación en línea transdisciplinaria, por TokuhamaEspinosa Nakagawa, (2008), redibujado por Bramwell, (2010).

La neuroeducación se nutre de las neurociencias, que explican las conexiones y funciones del cerebro; de la psicología o ciencia de los comportamientos humanos asociados a la mente y el pensamiento crítico o cognición; y a la pedagogía, cuyo centro de atención son los aprendizajes.

\section{EL CEREBRO LECTOR}

El ser humano tiene entre 12 y 15 mil millones de células nerviosas o neuronas, aproximadamente. Cada neurona, a su vez, puede construir millones de conexiones, que se forman al usarse el cerebro. Así, cuando son más estimuladas se construyen más conexiones y más capacidades del ser humano para pensar. Por eso la lectura es considerada pensamiento en acción.
El cerebro humano, en efecto, es un órgano maravilloso dotado de una complejidad impresionante. Sus funciones neurocognitivas retratan la historia evolutiva de las personas y de las diferentes especies mediante estudios comparados.

Las neurociencias, en este sentido, recién comienzan a investigarse, y en el 
caso de la neuroeducación su interdisciplinariedad es indispensable, así como una rigurosa confirmación experimental, junto con la'neuroética', que permita evitar falsificaciones o manipulaciones inaceptables.

Uno de los puntos relevantes que se debe considerar, en el ámbito de la neurodidáctica, es la enseñanza y aprendizaje de la lectura. En este contexto, los trabajos de Stanislas Dehaene ${ }^{7}$ son relevantes. En esta investigación, el autor da a conocer las últimas noticias de las neurociencias sobre la lectura, la enseñanza, el aprendizaje y la dislexia.

La arquitectura cerebral es similar en todos los miembros de la familia de los Homo Sapiens, y se diferencia muy poco de la de otros primates. A lo largo y a lo ancho del mundo, las mismas regiones cerebrales se activan para decodificar una palabra escrita. Ya se trata de francés o de chino, el aprendizaje de la lectura recorre un circuito genéticamente condicionado (Dehaene, 2014).

La importancia de la lectura -como sabemos- va mucho más allá de enseñar a leer. El reduccionismo, a veces, ha matado la lectura y por extensión a la calidad de la educación. Los educadores enseñamos a leer -y es un mérito relevante- bajo sistemas que aprendimos en los normales y en las universidades. Pero hoy, en el siglo XXI, el tema de la lectura ha superado los modelos tradicionales que están centrados en la lectura mecánica, orientados a adquirir una serie de automatismos que permiten a los estudiantes a interpretar signos gráficos, mediante una percepción visual y darles una identidad oral. Se insiste más en la lectura comprensiva, que tiende a asociar las letras con los sonidos y las palabras con su significado, y lograr, en última instancia, la lectura crítica.

Existen varios métodos de enseñanza de la lectura. Los más conocidos son el método fónico, el método global y el método constructivista. El primero se fundamenta en el principio alfabético, que implica la asociación entre fonemas y grafemas, y de las vocales a las consonantes. El segundo se centra en las palabras, que deben ser memorizadas inicialmente, como base de la creación de los primeros enunciados, cuyos significados son aprendidos con la ayuda de dibujos, conocimientos previos y más. De esta manera, las palabras antes desconocidas cobran sentido. Por último, el método constructivista, creado por Jean Piaget, sugiere la enseñanza de la lectura a partir de las hipótesis implícitas que el niño desarrolla del aspecto fonológico. Pero el debate entre estos modelos de enseñanza de la lectura no

\footnotetext{
${ }^{7}$ Stanislas Dehaene es uno de los científicos más representativos, que ha estudiado con rigor el tema del "cerebro lector", en el ámbito de las neurociencias.
} 
ha terminado, porque existen evidencias empíricas que muestran la importancia de la conciencia fonológica en el proceso de alfabetización, y que es posible integrar los métodos fónico y global.

Lo anterior sería imposible entender sin considerar la existencia de un cerebro lector, de acuerdo con la terminología de Stanislas Dehaene; es decir, de la arquitectura cerebral que hace posible las relaciones entre las neuronas que explican las neurociencias, y permiten, según Max Weber:"saber pronunciar las palabras escritas; saber identificar las palabras y el significado de cada una de ellas; y, saber extraer y comprender el significado de un texto".

El tema es complejo y fascinante. Para algunos investigadores estamos todavía en la "madrugada" de la palabra es- crita, porque recién comienza a descifrarse en el ADN de la lectura y algunos campos específicos de la neuro educación: el aprendizaje, la memoria, la atención, la dislexia, entre otros asuntos, donde la bioingeniería, la computación y la biología molecular se han unido para cambiar para siempre a la pedagogía y la medicina.

Las ciencias aplicadas a los aprendizajes están, por lo tanto, en "pañales". Pese a ello, en los últimos veinte años, la pedagogía y la psicología, con el apoyo de las neurociencias, han podido generar mapas preliminares del cerebro, en los cuales se identifican los circuitos cerebrales de la lectura, a través de neuro imágenes o imágenes cerebrales, que revelan las áreas que se activan cuando desciframos palabras escritas.

\section{¿LA CIENCIA DE LA LECTURA?}

Stanislas Dehaene -ya mencionado- considera que 'una persona promedio sabe más sobre su auto, que sobre el funcionamiento de su cerebro's.

La nueva ciencia de la lectura es desconocida en varias partes del mundo, y peor aplicada. Las razones son obvias: la mayoría de los modelos de enseñanza y aprendizaje -y en general de las cienciasson lineales, mecanicistas-funcionalistas, que reducen los fenómenos a mecanismos limitados o reduccionistas; por ejemplo, células, moléculas o modelos de conducta de los seres vivientes. Cuando el enfoque dinámico de los sistemas considera al mundo a partir de vínculos e integración.

\footnotetext{
${ }^{8}$ Neuroeducación. Disponible en: https://es.wikipedia.org/wiki/Neuroeducaci\%C3\%B3n

${ }^{9}$ Es una aseveración muy cierta: la mayoría de las personas sabe muy poco sobre su propio cuerpo, mientras domina ciertas herramientas de uso diario. El cerebro, en este contexto, es casi desconocido.
} 
En otras palabras, todo es sistémico y sus estructuras específicas resultan de las relaciones entre las partes o subsistemas. En este contexto, la lectura es un sistema complejo cuyo eje es el cerebro, que es la central de manejo, que actúa también como centro de la memoria.

\section{LA NEUROEDUCACIÓN EN LA ESCUELA}

No se trata de convertir a los médicos neurólogos en neuropedagogos; tampoco a los pedagogos en médicos especialistas en neurología. La idea central es crear espacios académicos interdisciplinares para investigar el cerebro que aprende... matemáticas o física, el cerebro bilingüe o el cerebro que aprende las artes o las ciencias sociales.

Hoy en día las investigaciones se realizan fuera de las escuelas, en los laboratorios; es decir, en ambientes controlados, por ejemplo, los hospitales. No obstante, se pretende a futuro llevar la neuroeducación a las aulas, al identificar los procesos neurocognitivos de ense- ñanza y aprendizaje, mediante sistemas de información y comunicación de alta tecnología, que ayuden a contar, por ejemplo, con imágenes cerebrales de profesores y estudiantes en interacción. Para ello-sugieren los especialistas- es necesario crear comités de neuroética en las escuelas, así como existen comités de bioética en los hospitales.

El camino está abierto. La Escuela de Educación de la Universidad de Harvard ofrece cursos anuales sobre mente, cerebro y educación. En el Ecuador, el Instituto IDEA, de la Universidad de San Francisco de Quito, ejecuta cursos de alta calidad sobre estos temas.

\section{APUNTES PARA UNA INVESTIGACIÓN INTERDISCIPLINAR}

El tema planteado lleva a un propósito central: articular la ciencias -las neurociencias con la escuela-, a través de modelos de investigación aplicada en los que se integren la pedagogía, la psicología y las neurociencias, y dentro de este esquema analizar los problemas recurrentes de la lectura y la escritura, que son, en su conjunto, situaciones estructurales de la educación ecuatoriana.
Recuérdese que, pese a los esfuerzos realizados en inversiones y equipamiento, la calidad de la educación es todavía una asignatura pendiente. Los estudios de neuroeducación asociados a la calidad, y en este contexto, de manera específica, a la lectura y escritura, podrían ayudar a descifrar los problemas de los estudiantes que, en el nivel básico, tienen dificultades de compresión 
lectora. Y también en el proceso de selección y formación inicial y continua de los docentes.

La receta no es la neuroeducación; tampoco la neurodidáctica. Es importante incorporar la investigación -rigurosamente concebida y aplicada-, con la participación activa de las universidades, en la construcción de nuevas teorías y métodos que acompañen los procesos de cambio educativo. Lo hecho hasta aquí es relevante, en cuanto a infraestructura y equipamiento, pero falta dar fundamento teórico-epistemo- lógico-metodológico a los procesos de reforma del currículo de los estudiantes y de la formación de los profesores.

El nuevo Plan Decenal de Educación 2016-2026 debería incorporar la investigación educativa de carácter interdisciplinaria, que integre las neurociencias, la pedagogía y la psicología, en la formación del profesorado y como parte esencial de una nueva política pública con el compromiso de la academia. Y que el encuentro de las ciencias con la escuela no sea una utopía más. 


\section{BIBLIOGRAFÍA}

Dehaene, S. (2014) El cerebro lector. Siglo XXI Editores. Ciencia que labra. Serie Mayor. Buenos Aires, Argentina. pp 9-45.

Tokuhama-Espinosa, T. (2008) http:// education.jhu.edu/PD/newhorizons/Journals/Winter2011/Tokuhama1

Sánchez, Harvey. Director Ejecutivo de INEVAL. http://www.unesco.org/new/fileadmin/MULTIMEDIA/FIELD/Santiago/pdf/TERC E-distribucion-paises-por-resultados.pdf

Registro Oficial del Ecuador. n. ${ }^{\circ} 417$, de 31 de marzo de 2011. http://planipolis.iiep .unesco.org/upload/Ecuador/Ecuador_Ley_ organica_educacion_intercultural.pdf http://www.unesco.org/new/fileadmin/MULTIMEDIA/FIELD/Santiago/pdf/TERC E-distribucion-paises-por-resultados.pdf

http://my.gse.harvard.edu/icb/icb.do? course $=$ gse-ht100

http://www.znl-ulm.de

http://www.tc.umn.edu/ athe0007/B NEsig/ http://w3.cnice.mec.es/oecd/department/cerebro.html

http://my.gse.harvard.edu/icb/icb.do? course $=$ gse $-\mathrm{ht} 100$

https://es.wikipedia.org/wiki/Neuroeducaci\%C3\%B3n 


\section{RELACIONES ENTRE NOTAS DEL ALUMNO Y EVALUACIONES AL PROFESOR}

\section{RELATIONSHIP BETWEEN STUDENT GRADES AND TEACHER EVALUATIONS}

JOSÉ LUIS CAGIGAL G. 



\section{RELACIONES ENTRE NOTAS DEL ALUMNO Y EVALUACIONES AL PROFESOR}

José Luis Cagigal G. ${ }^{1}$

\section{RESUMEN}

Para definir si existe reciprocidad entre notas que da el profesor y evaluaciones que sus alumnos le conceden, se compararon estas variables con muestras independientes de tres semestres. A pesar que algunos docentes piensan que las calificaciones dadas a los estudiantes del curso inciden en su evaluación, este estudio muestra que no existe dicha reciprocidad.

Sin embargo, sí existe reciprocidad entre la expectativa que tiene el estudiante de sus notas y la evaluación que da al profesor, definida esa expectativa como la diferencia entre la nota en la materia evaluada y el promedio de sus notas en la carrera.

El estudio descubre una implícita aceptación, por parte de los alumnos, que se prefiere la dispersión en las notas y no la uniformidad. Del análisis de las distribuciones de las Evaluaciones al Docente (EAD), se sugieren algunas medidas para mejorar su aplicación.

Palabras clave: evaluaciones a docentes, notas, calidad docente, gestión académica

\section{ABSTRACT}

To determine whether there is reciprocity between grades and the student evaluations to teachers, both variables were compared with independent samples over three semesters. Although some teachers think that the course grades given to the students influence their assessment, this study shows that there is no such reciprocity.

However, this reciprocity exists between the expectation that the student

\footnotetext{
${ }^{1}$ Pontificia Universidad Católica del Ecuador, Facultad de Ciencias Administrativas, Quito, Ecuador (jlcagigal@hotmail.com).
} 
has on his grades and the assessment given to the teacher, expectations defined as the difference between the grade on the subject tested and the average of his grades in the school have been witnessed.

The study finds an implicit acceptance by the students for dispersion in the grades and not for uniformity. From the analysis of the distributions of the EAD some measures are suggested to improve its implementation

Key words: student evaluations, grades, quality of teaching, academic management

\section{INTRODUCCIÓN}

Las evaluaciones de los estudiantes a los docentes (EAD), introducidas en las universidades norteamericanas en la segunda década del siglo pasado, como mecanismo de medición de la calidad de la docencia, se generalizaron rápidamente en ese país (Seldim, 1993) y han sido utilizadas como un instrumento para impulsar el mejoramiento de la calidad docente, particularmente en las universidades.

El concepto de calidad de la docencia, en sí mismo, es una idea abstracta bastante ambigua, por sus variadas percepciones, y por ello el uso de las EAD, como instrumento de mejoramiento de la calidad docente, puede ser ineficaz. Para ello, las EAD deben ajustarse a procesos correctos y ser usadas cuidadosamente.

Han trascurrido casi nueve décadas desde que Remmers y Brandenburg (1927) publicaron la primera investiga- ción sobre el tema, sin que se haya podido establecer conclusiones definitivas sobre la validez y confiabilidad de las EAD para el fin esperado de medir la calidad profesional de los docentes. Sin embargo, ninguna otra modalidad de evaluación a los docentes, tales como las visitas al aula, las autoevaluaciones, el análisis de la distribución de notas, el análisis del portafolio, ha sido usada y analizada con tal esmero como el procedimiento de encuestas a los alumnos, sobre todo en el ámbito universitario.

A medida que el uso de los puntajes resultantes de las EAD, sobrepasaron los fines primarios relacionados con el monitoreo administrativo y de retroalimentación al docente, para convertirse en indicadores orientados al reconocimiento, selección, promoción o asignación de cursos a los docentes; la controversia en torno a la validez de los instrumentos y de los resultados de estas evaluaciones ha ido creciendo y 
ello ha generado una polémica en la que las EAD son cuestionadas por unos y defendidas por otros, a través de investigaciones que intentan probar una posición a favor o en contra de su uso, como instrumento de medición de la calidad docente. La principal objeción en contra de los resultados de las evaluaciones asocia una posible reciprocidad entre las notas que el docente entrega a los alumnos y las evaluaciones que el alumno otorga al profesor. Los estudios presentados se muestran contradictorios en sus conclusiones $y, a$ pesar de la cantidad de datos acumulados y analizados durante años por diversos investigadores, aún se mantiene el debate y el cuestionamiento, probablemente intuitivo, a su significado y a su uso, particularmente para los fines de reconocimiento de méritos académicos.

La falta de acuerdos en las conclusiones generales ha originado nuevas investigaciones posteriores derivadas de la diversidad de los resultados presentados, en las que se analizan algunos de los diversos factores adicionales que pueden incidir en las EAD, tales como la dificultad del contenido de las materias, el tamaño de clases, el nivel del curso, el tipo de curso (obligatorio u optativo), el interés del tema, la carga de trabajo para el estudiante, las formas de evaluación en la materia y otras variables que diferencian los cursos y los grupos de materias, al igual que el análisis del contenido de los instrumentos de medición y sus características en los que puede darse una sensibilidad considerable de las respuestas a la formulación del texto, como también al momento de aplicación del cuestionario y la forma de implementación. La variedad de estudios realizados en torno a las EAD y los factores que en ellas inciden, solo resaltan la complejidad del tema, pues su análisis sobrepasa a la simple asociación de una potencial entrega recíproca de facilidades entre los profesores y los estudiantes.

Es importante destacar que, en cualquier evaluación, sea la de estudiantes a docentes, o la recíproca, de profesores a alumnos, el propósito de la misma y su forma de implementación son elementos claves que inciden tanto en los enfoques usados, como en los resultados que muestran. En el proceso educativo, la evaluación se orienta a la búsqueda del mejoramiento de la persona evaluada (evaluación formativa). Sin embargo, las evaluaciones terminan en una calificación del desempeño (evaluación sumativa), que se utiliza para comparaciones entre los evaluados o también con respecto a un estándar predefinido (evaluación basada en criterios).

Mientras las EAD se limiten a su carácter formativo, como un instrumento para que el profesor, gracias a una retroalimentación de parte de sus alumnos, le permita mejorar sus formas de enseñar, 
es más fácil que los resultados puedan ser aceptados por el docente y que pueda acoger las sugerencias sin asumir una posición defensiva frente a los mismos.

La polémica sobre las EAD se agudiza aún más cuando los directivos de la universidad, recogen estos resultados y establecen comparaciones con los otros docentes o realizan la divulgación de los resultados, tratando con ello de impulsar el mejoramiento de la eficacia y la eficiencia de la función docente, y, peor aún si se establecen normas en las que los resultados de las evaluaciones sirven para fines administrativos de escalafón docente, lo que afecta a los programas establecidos de carrera universitaria de los docentes y, a la larga, a sus remuneraciones. En este entorno de estímulorespuesta, es probable que los docentes quieran buscar las formas de mejorar estos resultados e intenten ajustar sus prácticas en el aula, no necesariamente hacia un mejoramiento del proceso de enseñanza-aprendizaje, sino a lo que ellos creen que puedan ser factores que incidan en una mejor o peor evaluación por parte de los educandos.

La idea primaria de explicar las diferencias, entre otras causas, bajo el supuesto no probado que los alumnos otorgan a sus profesores mejores evaluaciones cuando estos conceden en sus cursos altas calificaciones, puede re- flejarse en menor exigencia en el trabajo de clase, lo cual ocasiona un ascenso general de las notas asignadas a los alumnos, sin que con ello mejore ni el nivel de aprendizaje en el curso ni la pedagogía empleada.

En la línea de la reciprocidad - del "toma y daca"o del "quid pro quo" - varios autores (Baldwin \& Blattner, 2003; Krautmann \& Sander, 1999; Sojka, Gupta, \& Deeter-Schmelz, 2002) infieren la existencia de la reciprocidad entre notas y EAD, al probar que hay una correlación positiva entre las evaluaciones docentes con las notas de los alumnos.

Más allá de ello, hay investigadores que asocian este posible trueque de altas notas con una degradación de la calidad denominada "inflación de las notas" (Rosovsky y Hartley, 2002); (McDonald y Johnson, 2003), esto es, un aumento sistemático de los puntajes promedios de los estudiantes en las universidades, bajo el supuesto de que la presunta reciprocidad incentiva a los profesores a ajustar las calificaciones dadas a los alumnos con el fin de mejorar sus evaluaciones como maestros.

Otras investigaciones, en un sentido paralelo al de la reciprocidad, asocian los resultados de mejores evaluaciones a una aceptación y a una supuesta búsqueda de un mayor facilismo en las notas, por parte de los alumnos. (Rodin 
y Rodin, 1972; Greenwald y Gillmore, 1997) o también la preferencia del alumno por menores cargas de trabajo en las materias (Miron y Segal, 1986).

En otra línea de investigación experimental, se intenta relacionar el grado de aceptación alcanzado ante los estudiantes, con los factores que demuestran una agradable personalidad (Cabezas, Christian y Mancheno Paulina, 2008)², o el uso del entretenimiento en el aula y otros similares, lo que puede inducir un tipo de diversión en el aula orientada a generar un efecto de espectáculo o efecto "payaso", denominado "Dr. Fox efect"3 (Naftulin, Ware, y Donnelly, 1973).

En contraposición con los estudios citados, otros autores (Centra, 2003; Cashin, 1995), sostienen que numerosas investigaciones sobre EAD, demuestran que las evaluaciones de los alumnos a los profesores son confiables, válidas y útiles para mejorar la enseñanza, además de ser multidimensionales en lo que miden.
Dada la complejidad real de medir la calidad de la docencia, los académicos han elaborado variados cuestionarios para realizar las EAD y han incorporado la ponderación de diversos factores asociados a las percepciones variadas sobre el concepto de calidad en la enseñanza. March (1987) y Feldman (1997) y otros, identificaron múltiples dimensiones de la calidad en la docencia, entre ellos el valor de lo aprendido, la organización, el entusiasmo, la interacción del grupo, la relación con el docente, la cobertura y profundidad de lo enseñado, las formas de calificación, la carga de trabajo y su dificultad, como variables que han servido para el diseño de estos cuestionarios. Pocos estudios se han realizado sobre la elevada colinearidad entre las variables utilizadas, aunque en su formulación, las afirmaciones dadas parecen independientes entre sí. ${ }^{4}$

Para algunos, el criterio esencial de calidad de la docencia debería ser el aprendizaje logrado por el alumno. Sin embargo, si se intentase medir la calidad de un docente por el grado de aprendi-

\footnotetext{
${ }^{2}$ Christian Cabezas señala que los docentes de alto rendimiento en la PUCE presentan un pensamiento abstracto, son más aventureros (extrovertidos) que conservadores, y son más emotivos que prácticos; en cambio, los de bajo rendimiento presentan un pensamiento concreto, son más conservadores que aventureros y son más prácticos que emotivos.

${ }^{3}$ http://www.er.uqam.ca/nobel/r30034/PSY4180/Pages/Naftulin.html

${ }^{4}$ En un estudio anterior realizado por el autor se puede observar que las correlaciones entre los promedios en las preguntas evaluadas en un grupo de alumnos, con inclusión de aquellas cuestiones relativas a variables objetivas como asistencia y puntualidad, comparadas con preguntas sobre metodología, presentaban coeficientes de correlación superiores a 0,76 en casi todos los grupos. Esto apunta a que la percepción sobre la calidad del docente frente a la que el grupo evaluador tiende a ser global y no diferencia mucho el significado específico de cada pregunta, por lo que evalúa todas las facetas de la actividad del docente bajo un prisma común de bueno, mediocre o malo, independientemente de su realidad.
} 
zaje alcanzado por el curso, se da el caso, que el temor generado por un profesor muy exigente logra mejores resultados de aprendizaje, debido al gran esfuerzo de los alumnos, sin que medie una forma de enseñanza que facilite en forma efectiva dicho aprendizaje.

Fuera de las universidades norteamericanas, el tema de las EAD ha sido poco estudiado. Sin embargo, las políticas de calidad centradas en las evaluaciones a los docentes se han generalizado en las universidades del mundo y se ha enfocado su uso para la promoción del profesorado y, no tanto para el mejoramiento de calidad, pues existe el riesgo que su uso indiscriminado pueda contribuir a una disminución de la misma en el largo plazo.

\section{ANTECEDENTES DE LA INVESTIGACIÓN}

La presente investigación que se realiza con datos obtenidos de la Facultad de Ciencias Administrativas y Contables (FCAC) de la PUCE en los años 2006 y 2007. Esta facultad introdujo las EAD en 1986.

El Dr. Jaime Moreno, al recoger opiniones de docentes y alumnos en grupos focales de varias facultades, realiza un análisis estadístico de los resultados de las evaluaciones y construye instrumentos de evaluación docente que se incorporan a la web para su aplicación general en la PUCE, basados en grupos de preguntas asociadas a varias áreas de competencias pedagógicas, según puede observarse en el Cuadro n. 1 . El alumno califica al docente contestando el cuestionario según una es- cala de Likert de 5 a 0, según su acuerdo o desacuerdo con las afirmaciones dadas, todas expresadas en positivo, lo cual puede inducir a una calificación uniforme por columnas. En ese momento solo conoce notas parciales. La nota obtenida por el docente es el promedio simple de los puntajes recibidos.

Desde el año 2002, para el ascenso de categoría de los profesores, consta en el capítulo seis del Reglamento General Académico, como uno de los requisitos el haber obtenido puntajes por lo menos iguales al promedio de la respectiva unidad académica en la evaluación del desempeño, la cual incluye como parte de la misma las evaluaciones de los estudiantes. 


\section{METODOLOGÍA DEL ESTUDIO}

El estudio recoge los datos de las EAD y de las notas de la población de estudiantes de la FCAC durante tres semestres y cada uno se analiza en forma independiente, para que se pueda verificar la consistencia de resultados en distintos períodos.

Se asume como hipótesis inicial la no dependencia entre las dos variables indicadas, notas de los alumnos en una materia y evaluaciones recibidas por el docente de parte de los alumnos en esa materia. El análisis inicial relaciona indicadores estadísticos de las notas globales en cada materia con el promedio de notas obtenido por el docente en la evaluación de cada curso, considerada la variable dependiente. Como variables dependientes se usan los indicadores de notas de alumnos, tales como el promedio del curso en la materia, pero se amplían a medidas de la distribución de notas, tal como se describen a continuación, en la definición de indicadores estadísticos utilizados. Las variables independientes se obtienen de las distribuciones de notas publicadas que el profesor ha asignado a los alumnos del curso, en la nota parcial sobre 30 (S30) antes del examen final y próxima a la evaluación al docente, nota del examen final sobre 20 (\$20), cuando la evaluación al docente ya se ha realizado y la suma de notas anteriores (S50), sobre las cuales se calculan los indicadores estadísticos del Cuadro n. 2.

Para evitar la incidencia del tamaño de los grupos y de la posible deserción de alumnos, que no completan el curso, se realiza una depuración de datos. Se eliminaron los cursos con un número de alumnos inferior a 12, para excluir el posible impacto del tamaño del curso en los resultados y se eliminaron también de las listas de notas, aquellas de valor nulo en alguno de los datos, y se asumió el retiro de la materia. Sin embargo, esto no garantiza que algunos de estos alumnos eliminados en la lista de notas no hayan participado en la evaluación al profesor. ${ }^{5}$

Para establecer la relación de asociación, sea positiva, nula o negativa, entre la variable dependiente (promedio de la evaluación dada por el curso al do-

\footnotetext{
${ }^{5}$ La eliminación de las notas con valor nulo, incide también en los resultados obtenidos de las distribuciones, medidas de tendencia central y de dispersión. Se asume para justificar esta decisión en la investigación que una nota nula sobre 20 o sobre 30, más se debe al retiro del estudiante de la materia y no a una nota real dada por el docente. Sin embargo, si aquel alumno que se ha retirado realiza la evaluación al docente y lo califica superficialmente, sus notas totales bajas, asociadas a una evaluación al profesor recíproca, aumentaría el valor de los coeficientes de correlación entre notas y evaluaciones, más aún considerando el efecto en el promedio de ambas variables.
} 
cente) y cada una de las distintas variables independientes anteriormente indicadas se calcula el coeficiente de correlación, esto es un número entre-1 y +1 , expresado en tanto por ciento. Por ello, el coeficiente de correlación mide la variación conjunta de datos, esto es el grado en el que la variable dependiente es mayor o menor en similar proporción a la variable independiente.

En cada semestre, después de depurar los datos, las muestras selecciona- das son superiores a los 294 docentes, lo que les hace suficientemente amplias para realizar inferencias estadísticamente válidas con un nivel de confianza de 95\%, para coeficientes de correlación superiores a 9,64\% y para aquellas muestras de la tercera parte, alrededor de cien datos, se debe superar el 16,9\% como coeficiente de correlación, basados en la fórmula ${ }^{6}$ del valor $t$ correspondiente al nivel de confianza esperado

$$
t=r /\left[\left(1-r^{2}\right) /(n-2)\right]^{1 / 2}
$$

\section{HIPÓTESIS SOBRE LOS RESULTADOS ESPERADOS}

De conformidad con la relación esperada entre las variables estadísticas escogidas con la variable independiente que es el valor de la evaluación obtenida por el docente, se asume que a un mayor valor en las notas promedio de los grupos de alumnos debería corresponder a una mejor evaluación a los docentes, esto es, debería obtenerse un valor significativo de correlación positiva; por ello, todas las medidas de posición, promedio, cuartiles, Q1 (cuarti1 1), Q2 (mediana) y Q3 (cuartil3) deberían tener una correlación positiva con la evaluación dada a los docentes. Esto es, cuanto mayor sea el valor de la nota promedio del curso, en la media, mediana y cuartiles, en las notas de los alumnos, se espera una mayor "generosidad" de los estudiantes en la evaluación al docente.
Igualmente, si las notas de los alumnos se agrupan en mayor proporción (\%) por encima de los parámetros fijos establecidos como porcentaje del límite superior M, (sea este 30, 20 o 50, respectivamente), $P>0,6 \mathrm{M}$ ( $M=$ Máxima), $P>0,7 M, P>0,8 M, P>0,9 M$, en particular los más altos, se esperaría una correlación significativamente positiva, pues mayor número de alumnos se agrupan en los intervalos superiores. Estos supuestos se resumen en el Cuadro n. ${ }^{\circ} 3$.

A pesar de ser muestras independientes para cada semestre, se pudiera asumir la consistencia en los signos de los valores de la correlación obtenida.

${ }^{6}$ Ver Downie N. y Heath, R. Métodos estadísticos aplicados, p. 249. 
No se asumen supuestos previos referentes a las medidas de dispersión, como son la desviación estándar y la desviación intercuartílica, ni tampoco para los coeficientes de asimetría y la curtosis, indicadores utilizados para el análisis descriptivo de las distribuciones de notas y de las EAD.

\section{ANÁLISIS DE LOS RESULTADOS}

\section{Características de las distribuciones de las notas}

Los indicadores de tendencia central, dispersión y momentos de la distribución de notas S30, S20 y S50 dadas por los profesores a los alumnos, presentan valores y características comunes, tal como puede verse en la Tabla n. ${ }^{\circ} 1$. El promedio y la mediana (cuartil 2) de las notas con valores de 39,4 y 45,0 respectivamente, se ubican por encima del $79 \%$ de la escala del rango de las notas (entre 0 y la máxima) y notablemente por encima de la nota mínima de pase que es 30 sobre 50 en la nota final. El $92 \%$ de las calificaciones finales se ubican por encima de la nota de pase (30/50), y el $62 \%$ de las notas finales están entre 40 y 50 puntos. Lo anterior muestra una asimetría hacia notas altas, -mediana superior al promedio- y una distribución inclinada hacia la derecha respecto a la curva normal (curtosis positiva), tal como puede observarse en los gráficos 1 y 2 anexos.

Por ello, todas las distribuciones de notas tienen valores negativos en los coeficientes de asimetría, lo que muestra una acumulación de puntajes en las notas altas, si se compara la distribución con la curva normal centrada en el rango de pase, tal como se puede apreciar en los gráficos de las notas de uno de los semestres.

\section{Predictibilidad entre las notas de los alumnos}

Al disponer de la nota parcial (S30) y la nota (S20) del examen final se realizó un análisis del índice de predictibilidad entre ambas mediante la correlación entre ellas. Esta se ubica consistentemente entre $42 \%$ y $43 \%$ en cada uno de los tres períodos académicos examinados. Pudiera esperarse que la nota del examen final (\$20) está asociada más estrechamente con la nota previa acumulada (S30). Una correlación de $43 \%$ significaría que la nota anterior S30 apenas explica un $18 \%$ de la nota del examen final, lo que implica que el $82 \%$ restante corresponde a otros factores y no se relaciona con el trabajo valorado en las tres primeras notas sobre diez, que corresponden a las mediciones del aprendizaje y el esfuerzo durante el semestre. Puede contribuir a ello, el hecho 
frecuente que los estudiantes pueden concentrar más su esfuerzo en el examen final en aquellas materias en las que tienen notas bajas y pueden descuidar aquellas en las que ya están seguros. También puede contribuir a ello el hecho que la nota S20 suele ser fundamentalmente un examen escrito y no tiene componentes de trabajos colectivos.

Si se comparan los datos que constan en la Tabla n. ${ }^{\circ} 2$, se observa que los indicadores de posición, promedio y mediana, se mantienen en similares niveles, en ambas notas sobre 30 y sobre 20. Sin embargo, en forma consistente los dos indicadores de dispersión relativa, el coeficiente de variación y la razón de desviación intercuartílica/mediana, en la nota del examen final S20, son superiores a los de la nota S30, lo cual indica que los docentes dispersan más las notas en el examen final que en la nota S30. Esto puede deberse a que, en la nota S30, por las formas de evaluar, tales como notas de grupo y talleres, las calificaciones se hacen más homogéneas la nota única del examen final o también pudiera ser resultante del menor condicionamiento del docente, al final del semestre, cuando ya han sido realizadas las EAD.

\section{Características de las distribuciones de las EAD}

Los indicadores de tendencia central, dispersión y momentos de las EAD en los tres semestres analizados presentan valores y características comunes y consistentes, tal como puede verse en la Tabla n. ${ }^{\circ}$ 3. El promedio de las EAD está cercano a 90/100 en la escala total; más de las tres cuartas partes de los docentes reciben notas superiores a 86/100, una cuarta parte de los docentes supera el $95,7 / 100$ y un $4 \%$ recibe notas máximas superiores de 99/100. El $25 \%$ de los peores evaluados recibe notas entre 38 y 86 sobre 100, con una amplia dispersión entre ellos. Existe una elevada asimetría (entre -1,52 y-1,94) en la distribución de las EAD, como consta en la tabla n. 3 y se ve en el gráfico n. ${ }^{\circ} 3$. La concentración de las EAD en puntajes altos incide mucho en el grupo asignado al docente según cuartiles. Por ejemplo, una nota nula en un grupo de 20 alumnos, baja en 5 puntos porcentuales la calificación promedio del profesor, pasándolo al grupo siguiente inferior.?

\section{Relación entre las EAD y las notas del curso}

Los resultados obtenidos de la aplicación del coeficiente de correlación

\footnotetext{
7 El impacto de la incidencia de las evaluaciones extremas debería ser filtrado como "outliers"- fuera de rangopor el sistema informático, eliminando calificaciones uniformes en el último rango. Puede darse, entre otros motivos, por problemas de relación, disciplina, copia en pruebas, hechos no académicos, y deberían eliminarse del cálculo del promedio por su marcado sesgo emocional.
} 
de Pearson aplicada al promedio de todas las EAD para cada docente con cada uno de los indicadores de las distribuciones de las tres notas, S20, S30 y S50 en cada semestre consta en la tabla No 4 muestran que las correlaciones no son consistentes ni en valores ni en el signo esperado de la correlación, en las tres muestras semestrales independientes analizadas, por lo cual puede concluirse que la relación entre EAD y notas promedio de los cursos, es claramente aleatoria.

En contraste, las EAD en el examen final S20, llevan signos contrarios a los esperados en 22 de 24 datos, -aunque sin valores significativos- esto es, mayores EAD corresponden a menores notas en esa última nota. Si se considera que la nota S20 es posterior a la fecha de realización de las EAD, la contradicción puede sugerir que el docente actúa con más independencia en el examen final o puede deberse a las formas de calificación, examen versus trabajos. Ya se mencionó que las notas S20 del examen final, muestran mayor dispersión que las S30 y tienen baja correlación entre ellas.

Por último, dado que las distribuciones de EAD y de notas no tienen las características de una distribución normal, para completar el análisis de resul- tados se verificó, por técnicas no paramétricas, la consistencia de signos y valores con lo esperado, y para ello se hizo el análisis de correlaciones mediante el coeficiente de correlación de Spearman, denominado correlación de puestos, en vez de coeficiente de correlación de Pearson, utilizado antes. En los resultados se mantiene la inconsistencia citada en los signos y valores, por lo que se mantienen las conclusiones anteriores.

Del análisis se concluye que no hay evidencia estadística para inferir que en las EAD exista una asociación positiva entre las notas del curso y las EAD. Esto no descarta que a nivel individual puedan existir casos aislados de reciprocidad, pero su incidencia no es general en el conjunto de notas impartidas.

En la tabla n. ${ }^{\circ}$, aparece un resultado interesante al relacionar el promedio de las EAD con las dos medidas de dispersión, la desviación intercuartílica (DIQ) y la desviación estándar (SIGMA), pues aparece una consistencia completa en los signos en todos los nueve casos de notas y semestres, aunque solo en tres valores en la DIQ y uno en la SIGMA los valores son significativos a un $95 \%$ de confianza. La interpretación de esta consistencia apunta a que en la evaluación a los docentes los alumnos pre-

\footnotetext{
${ }^{8}$ El coeficiente $\rho$ de Spearman -estadístico no paramétrico- no requiere que la distribución de las variables sea normal y que la relación entre ellas sea lineal. Mide la existencia de una tendencia monótona creciente o decreciente entre las variables al ordenarlas por puestos.
} 
fieren dispersión en las notas de los alumnos del grupo más que notas altas uniformes e indiferenciadas, lo que de alguna manera indica un reconocimiento a una diferencia equitativa en las notas del docente.

\section{Análisis de las EAD según grupos de docentes}

Se investigó también si las EAD mantenían sus relaciones por grupos de docentes, los mejor calificados (SUP), los intermedios (MED) y los peor calificados (INF).

En las notas del examen final S20 (Tabla n.0 5) de grupo INF -profesores con menores evaluaciones- aparece claramente una consistencia en la correlación negativa entre EAD y notas en los tres semestres con la mayoría de los valores significativos al $95 \%$. Esta consistencia especial no ocurre en el grupo medio ni en el superior. Este grupo INF representa una tercera parte de los docentes. Es el grupo en el que más se dispersan los puntajes de las EAD, entre $90 \%$ y $37 \%$ de la escala. Este resultado contradice en el supuesto de una reciprocidad entre notas dadas y evaluaciones recibidas y plantea un interrogante complejo, pues significaría que, en el grupo inferior, los profesores que tienen una mejor evaluación han otorgado notas finales S20 más bajas. Esta paradoja plantea un interrogante: ¿La mayor dispersión y exigencia en notas es percibida antes y valorada por los alumnos?

Del análisis de grupos se mantiene que no hay existencia de reciprocidad entre las EAD y las notas. tanto para el grupo general de todos los docentes (TT) como para los grupos mejor, medio y peor evaluados, aunque aparece un interrogante sobre exigencia y EAD.

\section{Opiniones de los alumnos y de los docentes $^{9}$}

En la marcha de la investigación, se hizo un sondeo a docentes (20) y estudiantes (72) sobre su percepción del valor de las EAD, como instrumento válido y relevante para medir la calidad docente, la objetividad de las respuestas de alumnos y la supuesta reciprocidad.

Los resultados de esta encuesta (Tabla No 6), indican la duda de alumnos y de los docentes sobre la reflexividad y validez de las EAD. Un $64 \%$ de los alumnos encuestados considera que las EAD rara vez son válidas para medir la calidad del docente y un $50 \%$ de los profesores opina lo mismo. El $64 \%$ de los alumnos y el $75 \%$ de los docentes cree que rara

\footnotetext{
${ }^{9}$ Como mencionan los autores Miron, Mordechai y Segal, Esther, en su artículo "Opinión de los estudiantes sobre la validez de las EAD", poca investigación se ha hecho de las percepciones de los que evalúan. Ver http://www.jstor.org/stable/3446689
} 
vez se realizan en forma objetiva y reflexiva. Este resultado se relaciona con las inconsistencias en los resultados estadísticos analizados.

En el tema de reciprocidad entre notas y evaluaciones, difiere la posición de los alumnos y docentes. Los estudiantes niegan que esta exista en la mayoría de los casos (46\%), aunque un $47 \%$ de los alumnos aceptan que hay bastante reciprocidad. En contraste, un $50 \%$ de los profesores considera que hay un exceso de reciprocidad y un $35 \%$ considera que hay bastante reciprocidad. La percepción de exceso o bastante reciprocidad suma $54 \%$ en alumnos y $85 \%$ en profesores.

Conocer las causas del pobre significado dado por los alumnos a las EAD permitiría enfocar las razones de las dudas de su validez y, a la par, saber lo que lo ellos realmente evalúan y por qué lo hacen así y definir qué se requiere para que este importante insumo de información a docentes y autoridades se realice con la debida reflexión y criterio por parte de los alumnos.

\section{Ampliación del estudio}

Para contrastar los resultados globales obtenidos, se obtuvo información adicional sobre las EAD individuales de los alumnos en el segundo semestre de 2008 y de sus notas (6145 asignaturaalumno) tanto en la materia en ese semestre y como del promedio de la carrera, con el fin de confirmar o no la relación de reciprocidad y analizar la incidencia que pudiera tener la expectativa de la nota por parte del alumno y su evaluación al docente.

Los resultados generales de correlación entre notas y las EAD confirmó lo anteriormente dicho, esto es, que no hay una correlación significativa entre las notas que el alumno recibe y las evaluaciones de los alumnos al docente.

Para analizar la expectativa de nota, se introdujo una nueva variable en el análisis que fue la diferencia entre la nota del alumno en la materia y su promedio en la carrera. ${ }^{10}$ Esta variable denominada diferencia en expectativas, arroja un resultado interesante de una correlación positiva $(13,6 \%)$ consistente en todos los niveles entre esta variable y las EAD, estadísticamente significativa. Esto representaría que si el alumno espera lograr en la materia una nota superior a su promedio en la carrera tiende a calificar mejor al profesor y si este alumno prevé en ese curso una nota inferior a su promedio general, tiende a calificar peor al profesor, al considerar que la realización de las EAD precede a la nota final completa.

\footnotetext{
${ }^{10}$ Cabe destacar la alta correlación entre las notas de los alumnos en las materias del semestre analizado y la nota promedio de la carrera que es de $70,9 \%$.
} 
La información recopilada permitió analizar el nivel de homogeneidad o de dispersión en las notas por preguntas o ítem dadas a los docentes por cada alumno. En un cuestionario de 15 ítem evaluados, un $60,2 \%$ de los alumnos asignó una única calificación al profesor en la escala de 1 a 5 . En esta homogeneidad destaca la asignación de la nota más alta (5) a todas las preguntas por parte del $57,0 \%$ de los alumnos y de la nota mínima (1) a todas las preguntas por parte de un 1,2\% de los alumnos. Este resultado indica que la percepción del alumno hacia su profesor tiende a ser holística y que al contestar el cuestionario rara vez discrimina entre distintas preguntas al hacer su evaluación. Dada la escasa diferenciación en las respuestas y la percepción holística de su calidad se pueden acortar los cuestionarios o deben ser estructurados de modo que no todas las afirmaciones concuerden con la escala de mejor a peor.

\section{CONCLUSIONES Y RECOMENDACIONES}

Las EAD se establecen hace más de ocho décadas, en las universidades, como un instrumento para el mejoramiento de la calidad de la docencia. Su finalidad primaria de mejoramiento o información al docente, pero desde que las EAD se usan para las decisiones de promoción de los profesores, surgen numerosos estudios que cuestionan los resultados y los usos de las mismas. En la literatura investigativa sobre este tema existe una alta contradicción entre quienes objetan la validez de las EAD y los que la defienden.

Las opiniones de alumnos y docentes revelan coincidencias al cuestionar la validez y la seriedad en la realización de las EAD - aspecto que requiere ser investigado en sus razones pero señalan posiciones distintas en el tema de la reciprocidad, aunque la ma- yoría de docentes y de alumnos reconoce la existencia de cierta reciprocidad entre las notas y las EAD.

Sin embargo, del análisis de los indicadores y notas en este estudio se concluye que no hay evidencia estadística para inferir que en las EAD exista una asociación positiva con las notas otorgadas a los alumnos del curso. Esto no descarta que a nivel individual puedan existir casos de reciprocidad, pero su incidencia no se refleja en los indicadores estadísticos generales, sino en la evaluación a docentes, en los que se da una calificación mínima a todas las preguntas, sesgo del resentimiento, que debe ser eliminado en el procesamiento de datos.

Un 60,2 \% de los alumnos usa un solo número de la escala de 1 a 5 para las 15 preguntas del cuestionario. Dada 
la percepción holística que predomina en los alumnos con relación a sus docentes, la amplitud del cuestionario es poco relevante. Existen factores más allá de las notas entregadas, tales como la simpatía, personalidad, dinamismo, tipo de asignatura que inciden en los resultados de las EAD y en esa percepción global que el alumno construye de su profesor.

Gracias a los sistemas informáticos actuales se puede mejorar tanto la presentación de la encuesta como su procesamiento para aumentar la calidad de la información que se genera. Así, para incitar a la reflexión sobre las preguntas del cuestionario, estas deben presentarse en forma aleatoria al alumno, una por una, que varíen la posición en la escala de calificación, repetición para in- citar la consistencia y la reflexión. Debe haber una introducción que motive la reflexión, la objetividad y la diferenciación en las respuestas dadas. En el procesamiento, además de eliminar el sesgo del resentimiento, se puede ponderar las evaluaciones con el rendimiento global del estudiante en la carrera.

Las EAD constituyen un instrumento eficaz que debe mantenerse como medio para que el propio docente, si se hacen bien. Es un criterio parcial de la calidad de un docente y requiere ser complementada con otros indicadores de la calidad, como el nivel de aprendizaje alcanzado en valores, conocimientos, actitudes y destrezas, resultado que es altamente complejo evaluar. 


\title{
ANEXOS: \\ CUADROS , TABLAS Y GRÁFICOS CITADOS
}

\author{
CUADRO n. ${ }^{\circ}$ 1: CUESTIONARIO DE EVALUACIÓN A LOS PROFESORES \\ Preguntas por tipo de competencia \\ COMPETENCIA SOCIABILIDAD PEDAGÓGICA \\ 1. Asiste a la actividad académica en los horarios previstos \\ 2. Empieza la actividad académica con puntualidad \\ 3. Trata a los estudiantes con cortesia y respeto \\ 4. Aprovecha el tiempo sin extenderse más allá del término estipulado para la \\ actividad académica \\ 5. Hay un clima de confianza propicio a la comunicación \\ COMPETENCIA GESTIÓN DE CLASES \\ 1. Estimula la participación de los estudiantes \\ 2. Desarrolla de manera coherente las actividades académicas \\ 3. Explica los criterios de evaluación que se emplean (pruebas, exámenes y otros) \\ 4. Analiza con los estudiantes las calificaciones asignadas en las evaluaciones \\ (pruebas, exámenes y otros)
}

\section{COMPETENCIA IMPACTO EMOCIONAL}

1. Promueve un ambiente de trabajo favorable al aprendizaje

2. Promueve actividades académicas como: consultas, investigación, salidas de campo, observaciones u otras

3. Su nivel de exigencia incentiva mi aprendizaje

4. Me gustaría volver a trabajar con este(a) profesor(a) en el futuro

COMPETENCIA REFUERZO DE HABILIDADES BÁSICAS

1. Estimula el análisis y la reflexión

2. Propicia la generación de nuevas ideas, enfoques, alternativas, opciones, soluciones, innovaciones.

3. Adquiero nuevos conocimientos o habilidades 


\section{CUADRO n. ${ }^{\circ}$ 2: INDICADORES DE LAS VARIABLES INDEPENDIENTES} UTILIZADOS EN LA INVESTIGACIÓN

\begin{tabular}{|c|c|c|c|}
\hline \multicolumn{4}{|c|}{ Medidas de posición } \\
\hline NOMBRE & SÍMBOLO & \multicolumn{2}{|c|}{ CONCEPTO } \\
\hline MEDIA & MEAN & \multicolumn{2}{|c|}{ Promedio de notas de los alumnos del curso } \\
\hline MEDIANA & Q2 & \multicolumn{2}{|c|}{ Nota que separa el $50 \%$ inferior en el curso } \\
\hline CUARTIL1 & Q1 & \multicolumn{2}{|c|}{ Nota que separa el $25 \%$ inferior en el curso } \\
\hline CUARTIL3 & Q3 & \multicolumn{2}{|c|}{ Nota que separa el $25 \%$ superior en el curso } \\
\hline $\mathrm{P}>.6$ & $\mathrm{P}>.6$ & \multirow{2}{*}{\multicolumn{2}{|c|}{$\begin{array}{l}\text { \% de alumnos con nota superior al } 60 \% \text { de la nota total. } \\
\text { Corresponde al } \% \text { del curso con notas iguales o } \\
\text { superiores a } 18 / 30 ; 12 / 20 ; 30 / 50 \text { respectivamente. } \\
\% \text { de alumnos con nota superior al } 70 \% \text { de la nota total. } \\
\text { Corresponde al } \% \text { del curso con notas iguales o } \\
\text { superiores a } 21 / 30 ; 14 / 20 ; 35 / 50 \text { respectivamente. }\end{array}$}} \\
\hline $\mathrm{P}>.7$ & $\mathrm{P}>.7$ & & \\
\hline $\mathrm{P}>.8$ & $\mathrm{P}>.8$ & \multirow{2}{*}{\multicolumn{2}{|c|}{$\begin{array}{l}\text { \% de alumnos con nota superior al } 80 \% \text { de la nota total. } \\
\text { Corresponde al } \% \text { del curso con notas iguales o } \\
\text { superiores a } 24 / 30 ; 16 / 20 ; 40 / 50 \text { respectivamente. } \\
\% \text { de alumnos con nota superior al } 90 \% \text { de la nota total. } \\
\text { Corresponde al } \% \text { del curso con notas iguales o } \\
\text { superiores a } 27 / 30 ; 18 / 20 ; 45 / 50 \text { respectivamente. }\end{array}$}} \\
\hline $\mathrm{P}>.9$ & $\mathrm{P}>.9$ & & \\
\hline \multicolumn{4}{|c|}{ Medidas de dispersión } \\
\hline \multicolumn{2}{|c|}{$\frac{\text { NOMBRE }}{\text { DESVIACIÓN }}$} & & CONCEPTO \\
\hline \multicolumn{2}{|c|}{$\begin{array}{l}\text { DESVIACIÓN } \\
\text { ESTÁNDAR }\end{array}$} & SIGMA & $\begin{array}{l}\text { Raíz cuadrada de media de los cuadrados de } \\
\text { las diferencias de notas con respecto al } \\
\text { promedio }\end{array}$ \\
\hline \multicolumn{2}{|c|}{$\begin{array}{c}\text { DESVIACIÓN } \\
\text { NTERCUARTÍLICA }\end{array}$} & DIQ & $\begin{array}{l}\text { Diferencia entre los valores del cuartil3 y el } \\
\text { cuartill (Limites del } 50 \% \text { central) }\end{array}$ \\
\hline \multicolumn{4}{|c|}{ Otras medidas de la distribución } \\
\hline \multicolumn{2}{|c|}{ NOMBRE } & SÍMBOLO & CONCEPTO \\
\hline \multicolumn{2}{|c|}{$\begin{array}{l}\text { COEFICIENTE DE } \\
\text { ASIMETRÍA }\end{array}$} & ASIM. & $\begin{array}{l}\text { Cociente de la media de los cubos de las } \\
\text { desviaciones respecto del producto del } \\
\text { promedio y el cubo de la desviación típica y } \\
\text { describe el lado más extendido respecto al } \\
\text { promedio. Si es positiva la distribución se } \\
\text { extiende hacia el lado derecho y es negativa } \\
\text { cuando se alarga en la dirección opuesta. }\end{array}$ \\
\hline \multicolumn{2}{|c|}{ CURTOSIS } & CURT. & $\begin{array}{l}\text { Momento } 3 \text { que mide si la distribución es } \\
\text { elevada o aplanada en comparación con la } \\
\text { distribución normal. Es leptocúrtica si lleva el } \\
\text { signo positivo y platocúrtica si es negativo. }\end{array}$ \\
\hline
\end{tabular}




\begin{tabular}{|c|c|c|c|c|c|c|c|c|c|c|c|}
\hline $\begin{array}{r}\mathrm{CO} \\
\mathrm{CON} \mathrm{I}\end{array}$ & & $\mathrm{LAC}$ & tós & סמתח & $\begin{array}{r}\mathrm{CL} \\
\mathrm{RADA}\end{array}$ & $\begin{array}{l}\text { ADR } \\
\text { ENT } \\
{[C O S}\end{array}$ & $\begin{array}{l}n .^{\circ} \\
\text { DE EI }\end{array}$ & $\begin{array}{l}\text { PROME } \\
\text { DISTRI }\end{array}$ & $\begin{array}{l}\text { DIO D } \\
\text { BUCI }\end{array}$ & ÓN DE & $\begin{array}{l}\text { AD } \\
\text { IOTAS }\end{array}$ \\
\hline MEAN & Q1 & $\mathrm{Q} 2$ & Q3 & $\mathrm{P}>6$ & P>7 & P> 8 & $\mathrm{P}>9$ & SIGMA & DIO & ASIM & CURT \\
\hline+ & + & + & + & + & + & + & + & $?$ & $?$ & $?$ & $?$ \\
\hline
\end{tabular}

\section{CUADRO n. ${ }^{\circ}$ 4: ENCUESTA DE OPINIÓN A DOCENTES Y ALUMNOS}

Este es un sondeo de opiniones sobre la evaluación a los docentes por parte de los alumnos. Agradecemos su aporte.

Marque su condición de docente o de alumno y los años en la Facultad:

\begin{tabular}{|l|ll|}
\hline $\begin{array}{l}\text { Ind Profesor con años como } \\
\text { docente universitario en la Facultad }\end{array}$ & Ind Alumno del__ nivel (semestre) \\
\hline
\end{tabular}

Marque X en la casilla [n] correspondiente a su más sentida opinión.

1. Considera que las evaluaciones al docente por los alumnos es un instrumento válido para medir la calidad del docente.

\begin{tabular}{|c|c|c|}
\hline $\begin{array}{c}\text { [nd Sí, en la mayoría de } \\
\text { casos }\end{array}$ & [nd Son bastante válidas & [nd Rara vez son válidas \\
\hline
\end{tabular}

2. Considera que los alumnos realizan la evaluación a los docentes en forma reflexiva y objetiva.

\begin{tabular}{|c|c|c|}
\hline $\begin{array}{l}\text { [n] Sí, en la mayoría de } \\
\text { casos }\end{array}$ & $\begin{array}{l}\text { [nd Son bastante } \\
\text { reflexivas y objetivas }\end{array}$ & $\begin{array}{l}\text { [nd Rara vez son } \\
\text { reflexivas y objetivas }\end{array}$ \\
\hline
\end{tabular}

3. Considera que existe una reciprocidad entre notas del profesor a los alumnos y las evaluaciones que éstos dan al profesor, esto es, a mejores notas mejores evaluaciones.

\begin{tabular}{|c|c|c|}
\hline $\begin{array}{c}\text { [nd No, en la mayoría de } \\
\text { casos }\end{array}$ & $\begin{array}{l}\text { [nd Hay bastante } \\
\text { reciprocidad en ello }\end{array}$ & $\begin{array}{l}\text { Ind Hay un exceso de } \\
\text { reciprocidad en ello }\end{array}$ \\
\hline
\end{tabular}




\begin{tabular}{|c|c|c|c|c|c|c|c|c|c|}
\hline \multicolumn{10}{|c|}{$\begin{array}{c}\text { TABLA n. }{ }^{\circ} \text { l: RESUMEN DE INDICADORES I } \\
\text { Y } \% \text { DE LA NOTA MÁXIMA }\end{array}$} \\
\hline & \multicolumn{3}{|c|}{$\begin{array}{c}\text { ANO 2006-2007 2 } \\
\text { S }\end{array}$} & \multicolumn{3}{|c|}{$\begin{array}{c}\text { AÑO 2007-2008 } 1^{\circ} \\
\mathrm{S}\end{array}$} & \multicolumn{3}{|c|}{$\begin{array}{c}\text { AÑO 2007-2008 2 } \\
\text { S }\end{array}$} \\
\hline MEDIDA & S 30 & S 20 & S 50 & S 30 & S 20 & S 50 & S 30 & S20 & S 50 \\
\hline Moda & 27.0 & 20.0 & 42.0 & 27.0 & 20.0 & 43.0 & 27.0 & 20.0 & 43.0 \\
\hline Promedio & 24.1 & 16.1 & 40.3 & 24.0 & 16.0 & 39.4 & 23.9 & 15.8 & 39.7 \\
\hline Desy. estándar & 4.0 & 3.3 & 6.1 & 4.3 & 3.2 & 7.6 & 4.2 & 3.5 & 6.3 \\
\hline Cuartil 1 & 22.0 & 14.1 & 36.0 & 21.5 & 14.0 & 35.0 & 21.5 & 13.9 & 35.0 \\
\hline Cuartil 2 & 25.0 & 17.0 & 41.0 & 25.0 & 16.5 & 41.0 & 24.9 & 16.4 & 41.0 \\
\hline & 27.0 & 19.0 & 45.0 & 27.0 & 18.4 & 45.0 & 27.0 & 18.2 & 45.0 \\
\hline Asi & -1.1 & -1.0 & -0.8 & -1.1 & -0.9 & -1.5 & -1.0 & & -0.6 \\
\hline Curtosis & 1.6 & 0.7 & 0.5 & 3.1 & 0.8 & 3.9 & 1.3 & 1.7 & 0.2 \\
\hline \multicolumn{10}{|c|}{$\begin{array}{l}\text { VALOR EXPRESADO EN \% DE LA NOTA MÁXIMA } \\
\end{array}$} \\
\hline & \multicolumn{3}{|c|}{$\begin{array}{c}\text { AÑ O 2006-2007 } 2^{\circ} \\
\text { S }\end{array}$} & \multicolumn{3}{|c|}{$\begin{array}{c}\text { ANO 2007-2008 } 1^{\circ} \\
\text { S }\end{array}$} & \multicolumn{3}{|c|}{$\begin{array}{c}\text { ANO 2007-2008 20 } \\
\text { S }\end{array}$} \\
\hline MEDIDA & $\mathbf{S 3 0}$ & S 20 & S5O & S 30 & S20 & S5O & S 30 & S20 & S5O \\
\hline Moda & $90 \%$ & $100 \%$ & $84 \%$ & $90 \%$ & 100 & $86 \%$ & $90 \%$ & 100 & $86 \%$ \\
\hline Promedio & $80 \%$ & $81 \%$ & $81 \%$ & $80 \%$ & $80 \%$ & $79 \%$ & $80 \%$ & $79 \%$ & $79 \%$ \\
\hline Desy. estándar & $13 \%$ & $17 \%$ & $12 \%$ & $14 \%$ & $16 \%$ & $15 \%$ & $14 \%$ & $18 \%$ & $13 \%$ \\
\hline Cuartil 1 & $73 \%$ & $71 \%$ & $72 \%$ & $72 \%$ & $70 \%$ & $70 \%$ & $72 \%$ & $70 \%$ & $70 \%$ \\
\hline Cuartil 2 & $83 \%$ & $85 \%$ & $82 \%$ & $83 \%$ & $83 \%$ & $82 \%$ & $83 \%$ & $82 \%$ & $82 \%$ \\
\hline Cuartil 3 & $90 \%$ & $95 \%$ & $90 \%$ & $90 \%$ & $92 \%$ & $90 \%$ & $90 \%$ & $91 \%$ & $90 \%$ \\
\hline Asimetría & $-4 \%$ & $-5 \%$ & $-2 \%$ & $-4 \%$ & $-5 \%$ & $-3 \%$ & $-3 \%$ & $-6 \%$ & $-1 \%$ \\
\hline Curtosis & $5 \%$ & $4 \%$ & $1 \%$ & $10 \%$ & $4 \%$ & $8 \%$ & $4 \%$ & $9 \%$ & $0 \%$ \\
\hline
\end{tabular}

\begin{tabular}{|c|c|c|c|c|c|c|}
\hline \multicolumn{7}{|c|}{ TABLA n. ${ }^{\circ}$ 2: INDICADORES COMPARADOS DE NOTAS S30 y S20 } \\
\hline SEMESTRE: & \multicolumn{2}{|c|}{$2006-2$} & \multicolumn{2}{|c|}{$2007-1$} & \multicolumn{2}{|c|}{$2007-2$} \\
\hline NOTAS SOBRE: & S30 & S20 & S30 & S20 & S30 & S20 \\
\hline Promedio & 24.10 & 16.10 & 24.00 & 16.00 & 23.90 & 15.80 \\
\hline Promedio / Máximo & $80 \%$ & $81 \%$ & $80 \%$ & $80 \%$ & $80 \%$ & $79 \%$ \\
\hline Mediana - Q2 & 25.00 & 17.00 & 25.00 & 16.50 & 24.90 & 16.40 \\
\hline Mediana / Máximo & $\mathbf{8 3} \%$ & $\mathbf{8 5} \%$ & $83 \%$ & $83 \%$ & $\mathbf{8 3} \%$ & $82 \%$ \\
\hline Desviación estándar & 4.00 & 3.30 & 4.30 & 3.20 & 4.20 & 3.50 \\
\hline Desviación Intercuartílica & 5.00 & 4.90 & 5.50 & 4.40 & 5.50 & 4.30 \\
\hline Coeficiente de Variación & $17 \%$ & $20 \%$ & $18 \%$ & $20 \%$ & $18 \%$ & $22 \%$ \\
\hline Desviación Intercuartílica / Q2 & $20 \%$ & $29 \%$ & $22 \%$ & $27 \%$ & $22 \%$ & $26 \%$ \\
\hline
\end{tabular}




\begin{tabular}{|c|c|c|c|}
\hline \multicolumn{4}{|c|}{$\begin{array}{c}\text { TABLA n. }^{\circ} \text { 3: INDICADORES DE LA DISTRIBUCIÓN } \\
\text { DE LAS EVALUACIONES A DOCENTES }\end{array}$} \\
\hline MEDIDA & 2006-2 & 2007-1 & 2007-2 \\
\hline Moda & 100.00 & 93.36 & 93.75 \\
\hline Promedio & 89.40 & 89.48 & 89.38 \\
\hline Desviación estándar & 9.03 & 8.63 & 9.65 \\
\hline Cuartil 1 & 86.31 & 86.72 & 86.79 \\
\hline Cuartil 2 & 92.00 & 91.74 & 92.64 \\
\hline Cuartil 3 & 95.65 & 95.72 & 95.78 \\
\hline Asimetría & -1.63 & -1.52 & -1.94 \\
\hline Curtosis & 3.11 & 2.40 & 4.66 \\
\hline Mínimo & 37.77 & 51.86 & 37.77 \\
\hline Máximo & 100.00 & 100.00 & 100.00 \\
\hline
\end{tabular}

\begin{tabular}{|c|c|c|c|c|c|c|c|c|c|c|c|c|c|}
\hline ÑOS EXA & No & Q1 & Q2 & Q3 & DIQ & MEAN S & SIGMA & ASIM. & CURT. & $P>.6$ & $P>7$ & $P>.8$ & \\
\hline $062 S 20$ & 315 & $6 \%$ & & & $5,6 \%$ & $-2,5 \%$ & $46 \%$ & $3,5 \%$ & $-3,6 \%$ & $-2,6 \%$ & $-3,2 \%$ & $-2,5 \%$ & \\
\hline $071 \mathrm{~S} 20$ & 368 & $10 \%$ & $1 \%$ & & & $10 \%$ & & & & & & $-14 \%$ & \\
\hline $072 S 20$ & 295 &, $1 \%$ & $-12,2 \%$ & $8 \%$ & $12,8 \%$ & & & & $-1,5 \%$ & $-16,6 \%$ & & & \\
\hline 0062 S30 & 315 & $0,5 \%$ & $4,5 \%$ & $8,3 \%$ & $6,5 \%$ & $3,2 \%$ & $5,8^{\circ}$ & 0,4 & $1,8 \%$ & $-3,7 \%$ & $-4,4$ & $\%$ & \\
\hline $071 \mathrm{~S} 30$ & 36 & & & & & & & & & & & & \\
\hline $0072 \mathrm{~S} 30$ & 295 & & & & & & & & & & & & \\
\hline $.0062 S 50$ & 315 & & & & & & & & -3 & & & & \\
\hline $0071 \mathrm{~S} 50$ & 368 & & & & & & & & & & & & -11 \\
\hline 0072 S50 & 95 & $2,8 \%$ & $-0,2 \%$ & , & $11,9 \%$ & $0,7 \%$ & $5,1 \%$ & $-1,2 \%$ & $-6,9 \%$ & $-7,6 \%$ & $-4,1 \%$ & $-4,2 \%$ & $-2,6 \%$ \\
\hline
\end{tabular}




\begin{tabular}{|c|c|c|c|c|c|c|c|c|c|c|c|c|c|c|}
\hline \multicolumn{15}{|c|}{ TABLA n. ${ }^{\circ}$ 5: CORRELACIÓN POR GRUPOS DE LA NOTA S20 CON INDICADORES } \\
\hline & & & Q1 & Q2 & Q3 & DIQ & MEAN & SIGMA & ASIM. & CURT. & $P>6$ & P>.7 & $P>.8$ & $P>.9$ \\
\hline & INF & & & & & & $7 \%$ & & &, $3 \%$ & $3,1 \%$ & & & \\
\hline & MED & & & & & & & & & & & & & \\
\hline 062520 & SUP & & & 12, & & & & & & & & & & \\
\hline 062520 & $\pi$ & 315 & $\%$ & $-2,4$ & 0 , & & 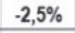 & & & & & & & -1, \\
\hline 20071 & INF & 122 & & & & & & & & & & & & \\
\hline 2007 & MED & 124 & & & & & & & & & & & & \\
\hline $0071 \mathrm{S2}$ & SUP & & & & & & & & & & & & & \\
\hline $20071 \mathrm{~S}$ & $T T$ & 36 & -1 & -10 , & & & & & & & & & & \\
\hline & INF & & & & & & & & & & & & & \\
\hline 2007 & MED & 96 & & & & & & & & & & $0 \%$ & & \\
\hline $20072 \mathrm{~S}$ & SUP & 100 & & & & & & & & & & $\%$ & & $8,8 \%$ \\
\hline 072 S20 & $\pi$ & 295 & $\%$ & $\%$ & $-8,8 \%$ & & $-12,1 \%$ & $8,2 \%$ & $5,5 \%$ & $-1,5 \%$ & $-16,6 \%$ & $-15,9 \%$ & $-12,0 \%$ & $3,9 \%$ \\
\hline
\end{tabular}

\begin{tabular}{|c|c|c|c|c|}
\hline \multicolumn{5}{|c|}{$\begin{array}{c}\text { TABLA n. }^{\circ} \text { 6: } \text { OPINIONES DE ALUMNOS Y PROFESORES SOBRE LAS } \\
\text { EVALUACIONES A DOCENTES (EAD) }\end{array}$} \\
\hline \multirow[t]{2}{*}{ OPINION DE ALUMNOS(A) Y PROFESORES (P) } & \multicolumn{2}{|c|}{$\mathbf{A}=72$} & \multicolumn{2}{|c|}{$\mathbf{P}=\mathbf{2 0}$} \\
\hline & n. ${ }^{\circ}$ & $\%$ & n. $^{0}$ & $\%$ \\
\hline \multicolumn{5}{|c|}{ ¿LAS EAD SON VÁLIDAS PARA MEDIR LA CALIDAD DEL DOCENTE? } \\
\hline SÍ EN LA MAYORÍA DE LOS CASOS & 16 & $22 \%$ & 3 & $15 \%$ \\
\hline SON BASTANTE VÁLID & 10 & & 7 & $35 \%$ \\
\hline RARA VEZ SON VÁLIDAS & 46 & $64 \%$ & 10 & $50 \%$ \\
\hline \multicolumn{5}{|c|}{ ¿LAS EAD SE REALIZAN EN FORMA REFLEXIVA Y OBJETIVA? } \\
\hline SÍ EN LA MAYORÍA DE LOS CASOS & 14 & $19 \%$ & 2 & $10 \%$ \\
\hline SON BASTANTE & 12 & 17 & 3 & $15 \%$ \\
\hline RARA VEZ SON REFLEXIVAS Y OBJETIVAS & 46 & $64 \%$ & 15 & $75 \%$ \\
\hline \multicolumn{5}{|c|}{ ¿HAY RECIPROCIDAD ENTRE NOTAS Y EVALUACIONES? } \\
\hline NO EN LA MAYORÍA DE LOS CASOS & 33 & $46 \%$ & 3 & $15 \%$ \\
\hline HAY BASTANTE RECIPROCID & 34 & $47 \%$ & 7 & $35 \%$ \\
\hline HAY UN EXCESO DE RECIPROCIDAD EN ELLO & 5 & $7 \%$ & 10 & $50 \%$ \\
\hline
\end{tabular}




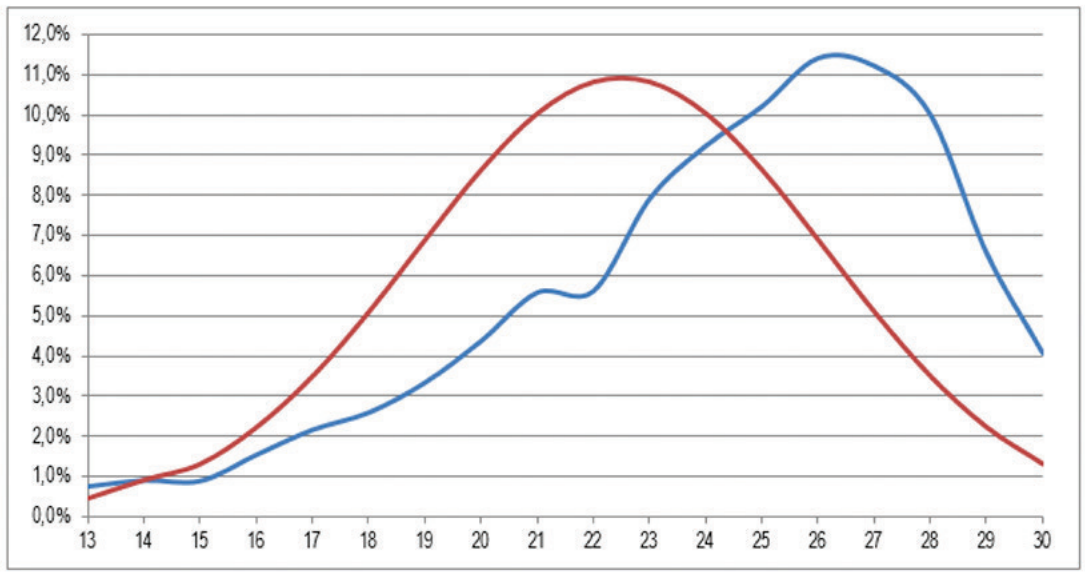

Gráfico n. ${ }^{\circ}$ 1. Notas $\$ 30$ comparadas con distribución normal

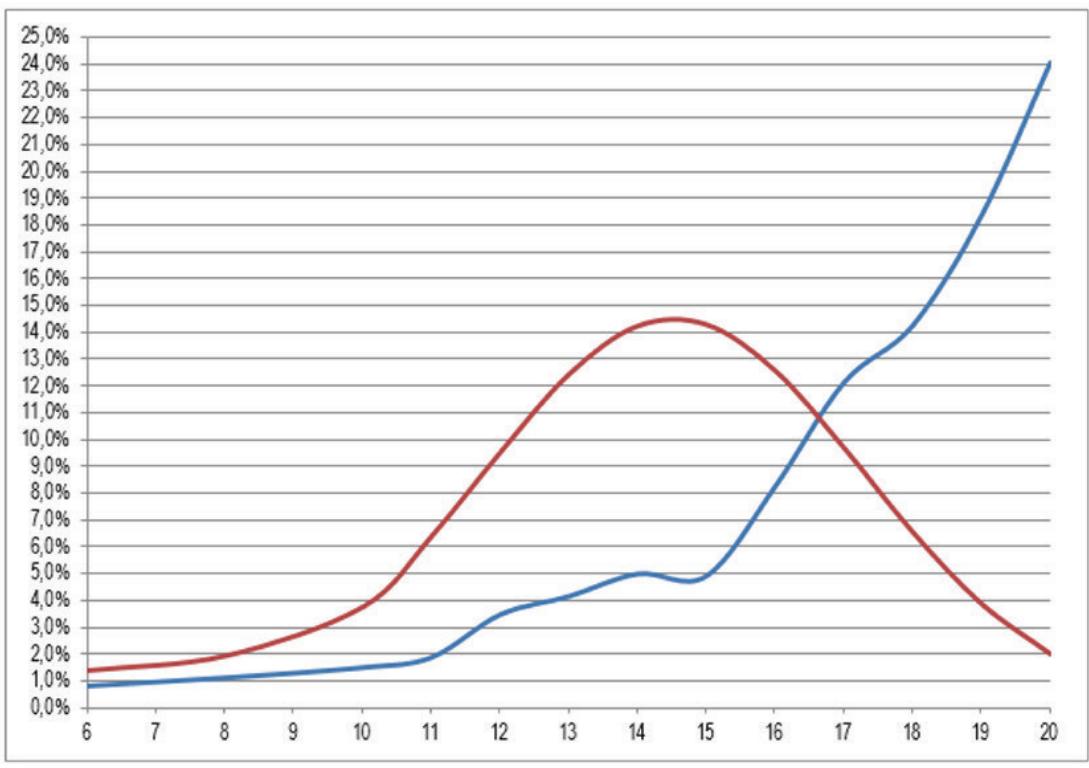

Gráfico n. ${ }^{\circ} 2$. Notas $\$ 20$ (examen final) versus distribución normal 
Revista PUCE. ISSN 1012-389X. Núm, 102

3 NOV 2015-3 MAYO 2016. CAGIGAL, PP. 169-198

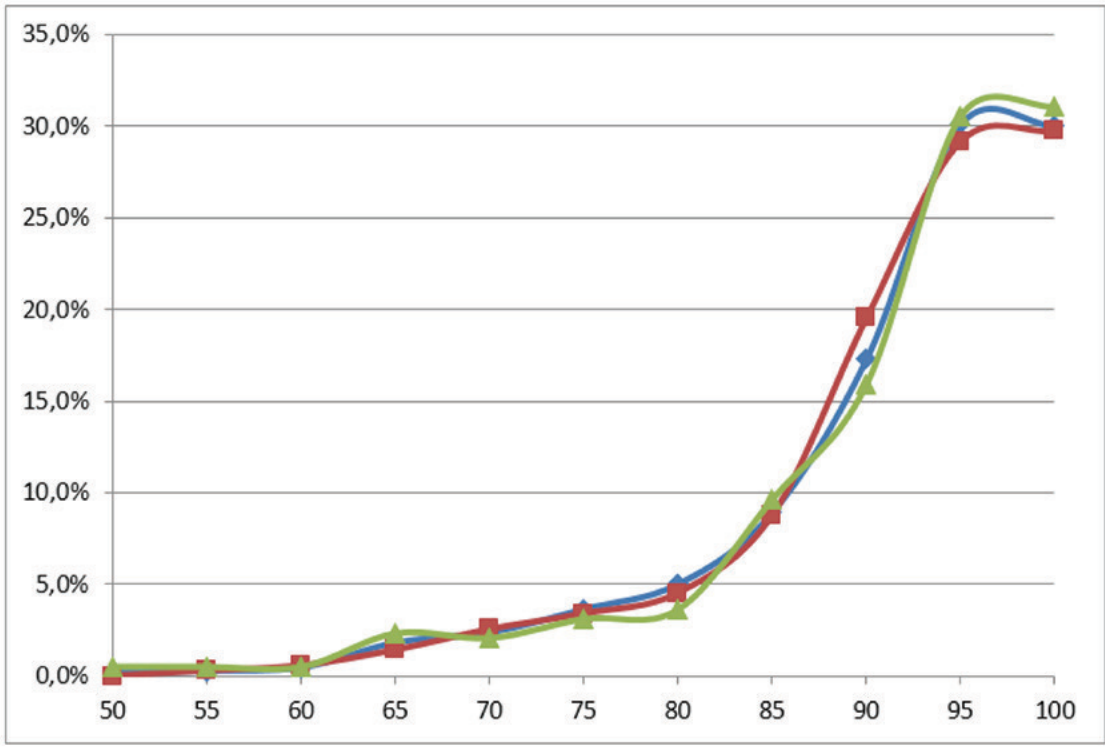

Gráfico n. ${ }^{\circ}$ 3. Distribución de las evaluaciones a docentes 


\section{BIBLIOGRAFÍA}

\section{Revistas}

Baldwin, T., \& Blattner, N. (2003). Guarding against potential bias in student evaluations. College Teaching, 51, 27-31.

Cabezas, C. y Mancheno, P. (2008). “Estudio de Factores de la Personalidad que influyen en un alto desempeño docente en la Pontificia Universidad Católica del Ecuador (PUCE)", Revista de la PUCE, n. ${ }^{84}, 9-20$.

Cashin, W. E. (1988). Student ratings of teaching. A summary of research (IDEA Rep. n.. 20), Kansas State University, Division of Continuing Education.

Cashin, W. E. and Downey, R.G. (1992). “Using Global Student Rating Items for Summative Evaluation." Journal of Educational Psychology, 84(4), 563-572.

Centra, J. (2015). Will teachers receive higher students evaluations by giving higher grades and less coursework? ETS, SIR II. Recuperado de http://www.ets.org/ Media/Products/StudentEval.pdf

Centra, J.A. and Creech, F.R. (1976)."The Relationship between Student, Teacher, and Course Characteristics and Student Ratings of Teacher Effectiveness." (Project Rep. n. ${ }^{\circ}$ 76-1). Princeton, NJ: Educational Testing Service.

Feldman, K.A. (1978). "Course Characteristics and College Students' Ratings of Their Teachers and Courses: What We Know and What We Don't." Research in Higher Education, 9, 199-242.
Feldman, K.A. (1978). "Course Characteristics and College Students' Ratings of Their Teachers and Courses: What We Know and What We Don't." Research in Higher Education, 9, 199-242.

Greenwald, A. and Gillmore, G. (1997). "Grading Leniency is a Removable Contaminant of Student Ratings." American Psychologist, 52, 1209-17.

Krautmann, A.C. and Sander, W. (1999). "Grades and Student Evaluations of Teachers." Economics of Education Review, 18, 59-63.

Kulik, J. A. (2001). "Student Ratings: Validity Utility and Controversy." New Directions for Institutional Research, 109, 9-25. Recuperado de http://deepblue.lib.umich. edu/bitstream/2027.42/34805/1/1ftp. pdf

Marsh, H.W. (1982). "Factors Affecting Students' Evaluations of the Same Course Taught by the Same Instructor on Different Occasions." American Educational Research Journal, 19(4), 485-497.

Marsh, H.W. (1983). "Students' Evaluations of University Teaching: Research Findings, Methodological Issues, and Directions for Future Research." International Journal of Educational Research, 11, 253-388.

McDonald, R., Johnson, R. (2003) Grade Distribution and its impact on CIS Faculty evaluations: 1992-2002, Information System Education Journal, Vol. 1 n. 42. 
Recuperado dehttp://www.isedi.org/ $1 / 42$

Miron, M. and Segal E. (1986). Student Opinion of the Value of Student Evaluations. Higher Education, Vol. 15, No. $3 / 4$ (1986), pp. 259-265. Recuperado de http:// www.jstor.org.stable/3446689

Naftulin, D. Ware, J., and Donnelly, F. (1973). The Doctor Fox Lecture: A Paradigm of Educational Seduction,.Journal of Medical Education, vol. 48, p. 630-635. Recuperado de http://www.er.uqam.ca /nobel/r30034/PSY4180/Pages/Naftulin.html

Seldin, P. (1993a). "How Colleges Evaluate Professors: 1983 versus 1993." American Academy of Higher Education Bulletin (oct.): 6-8, 12.

Remmers, H.H. and G.C. Brandenburg (1927). 'Experimental data on the Purdue Rating Scale for Instructors," Educational Administration and Supervision, 13, 519527. Manhattan, KS: Kansas State University

Rodin, M. and Rodin, B. (1972). "Student Evaluations of Teachers." Science, 177, 11641166.

Rosovsky, R. and Hartley, M. Evaluation and the Academy: Are We Doing the Right Thing? Grade Inflation and Letters of Recommendation. American Academy of Arts and Sciences, 2002

Sojka, J., Gupta, A. K., \& Deeter-Schmelz, D. R. (2002). Student and faculty perceptions of student evaluations of teaching. College Teaching, 50, 44-49.

\section{Revistas}

\section{Fuentes secundarias}

Aleamoni, L.M. and Hexner, P.Z. (1980). "A Review of Research on Student Evaluation and a Report on the Effect of Different Sets of Instructions on Student Course and Instructor Evaluation." Instructional Science, 9, 67-84.

Bosshardt, W. and Broder, J. Comparing Student and Instructor Evaluations of Teaching (2001). The Journal of Economic Education, Vol. 32, n. ${ }^{\circ}$ 1, 3-17.

Daniel E. Ho Timothy H. Shapiro. Evaluating Course Evaluations: An Empirical Analysis of a Quasi-Experiment at the Stanford Law School, 2000-2007, March 31, 2008

Eley, M. and Stecher, E. (1997). "A Comparison of Two Response Scale Formats Used in Teaching Evaluation Questionnaires." Assessment and Evaluation in Higher Education, 22(1), 65-79.

Ellis, L., Burke, D.M., Lomire, P., and McCormack, D.R. (2003). "Student Grades and Average Ratings of Instructional Quality: The Need for Adjustment." Journal of Educational Research, 97(1), 35-40.

Esperanza E. \& Covadonga Villasol, Sobre la opinión que los alumnos tienen de la efectividad de la docencia, Universidad Politécnica de Madrid. Revista Iberoamericana de Educación (ISSN: 1681-5653)

Feldman, K. A. (1989). "Instructional Effectiveness of College Teachers as Judged by 
Teachers Themselves, Current and Former Students, Colleagues, Administrators, and External (Neutral) Observers." Research in Higher Education, 30, 137 189.

Koon, J., \& Murray, H. S. (1996). Using multiple outcomes to validate student ratings of overall teacher effectiveness. Journal of Higher Education, 66, 61-81.

Kulik, J.A. and McKeachie, W.J. (1975). "The Evaluation of Teachers in Higher Education." Review of Research in Education, 3, 210-240.

Marsh, H.W. and Roche, L.A. (1997). "Making Students' Evaluations of Teaching Effectiveness Effective." American Psychologist, 52(11), 1187-1197

Maslow, A.H. and Zimmerman, W. (1956). "College Teaching Ability, Scholarly Activity and Personality." Journal of Educational Psychology, 47, 185-189.

Murray, H.G. (1983). "Low-Inference Classroom Teaching Behaviors and Student Ratings of College Teaching Effectiveness." Journal of Educational Psychology, 71, 856-865.

Powell, R. W. (1977). Grades, learning, and student evaluation of instruction. Research in Higher Education, 7, 193-205.

Rayder, N.F. (1968). "College Student Ratings of Instructors." Journal of Experimental Education, 37, 76-81.

Reardon, M. and Waters, L.K. (1979). "Leniency and Halo in Student Ratings of College
Instructors: A Comparison of Three Rating Procedures with Implications for Scale Validity." Educational and Psychological Measurement, 39(1), 159-162.

Remmers, H. H. (1927). The Purdue Rating Scale for Instructors. Educational Administration and Supervision, 6, 399406.

Rodin, M. and Rodin, B. Evaluation of Teaching. (1973). Journal of Economic Education, Vol.5, No 1, pp. 5-9. Recuperado de http://www.jstor.org.stable/1182829

Shapiro, E.G. (1989). Effect of instructor and class characteristics on student's class evaluations. Research in Higher Education. 31: 135.148.

Souce, B. The Development of Teacher Appraisal: A Recent History (2000). The British Journal of Educational Studies, Vol. 48, No. 1 pp. 22-37. Recuperado de http://www.jstor.org./stable/1555845

Tang, T.L.P. (1997). "Teaching Evaluation at a Public Institution of Higher Education: Factors Related to the Overall Teaching Effectiveness." Public Personnel Management, 26(3), 379-389.

Vasta, R., \& Sarmiento, R. F. (1979). Liberal grading improves evaluations but not performance. Journal of Educational Psychology, 71, 207-211.

Williams, W. M., and Ceci, S. J. (1997)." How I'm Doing? Problems with Student Ratings of Instructors and Courses." Change, 29(5), 13-23. 
Revista PUCE. ISSN 1012-389X. Núm, 102

Young, P., et al. (1999). "Student Evaluation of Faculty: Effects of Purpose on Pattern." Journal of Personnel Evaluation in Education, 13(2), 179-190.

\section{Libros}

Downie N. y Heath, R. (1973) Métodos estadísticos aplicados, Harper and Row Publishers Inc., México.

Neter, J., Kutner, M. H., Nachtsheim, C. J. Wasserman, W. (1996) Applied linear regression models ( $3^{a}$ ed). Irwin Co., Chicago. 

FILOSOFÍA 


\section{SOBRE LA CONCEPCIÓN BERGSONIANA DE "INTUICIÓN" \\ Y LAS CONSECUENCIAS PARA LA COMPRENSIÓN DE LA CIENCIA Y LA METAFÍSICA (UNA COMPARACIÓN CON KANT)}

ABOUT THE BERGSONIAN CONCEPT OF "INTUITION" AND THE CONSEQUENCES FOR THE UNDERSTANDING OF SCIENCE AND METAPHYSICS (A COMPARISON WITH KANT)

RUTH GORDILLO R.

Recibido 15 de marzo de 2016 Aceptado 8 de abril de 2016 



\section{SOBRE LA CONCEPCIÓN BERGSONIANA DE "INTUICIÓN" Y LAS CONSECUENCIAS PARA LA COMPRENSIÓN DE LA CIENCIA Y LA METAFÍSICA (UNA COMPARACIÓN CON KANT)}

Ruth Gordillo R. ${ }^{1}$

\section{RESUMEN}

El filósofo francés Henri Bergson señala una importante crítica a Kant desde la formulación del concepto de intuición, fundamental en la constitución de la teoría kantiana. Este artículo parte de la definición bergsoniana de dicho concepto además del de duración como condición de posibilidad para el conocimiento. La comparación con la definición de intuición sensible del kantismo y las consecuencias que dicha comparación supone para la compresión de ciencia y metafísica, serán el objeto central de este trabajo.

Palabras clave: intuición, evolución, conocimiento, ciencia, metafísica

\section{ABSTRACT}

French philosopher Henri Bergson formulates an important critique against Kant using the concept of intuition, an essential element in Kantian epistemology. This article considers the bergsonian definition of the concept of intuition in addition to duration as a necessary condition for knowledge. The central aim of this article is a comparison of the definition of sensible intuition in Kantian philosophy and its consequences for the understanding of science and metaphysics.

Key words: intuition, evolution, knowledge, science, metaphysics

\footnotetext{
1 Pontificia Universidad Católica del Ecuador, Facultad Eclesiástica de Ciencias Filosófico-Teológicas, Escuela de Filosofía, Quito, Ecuador (rgordillo@puce.edu.ec).
} 
Es relativo el conocimiento simbólico por conceptos preexistentes, que va de lo fijo a lo moviente pero no el conocimiento intuitivo, que se instala en lo moviente y adopta la vida misma de las cosas.

Esta intuición alcanza un absoluto.

H. Bergson

\section{INTRODUCCIÓN}

La delimitación del tema de este ensayo surge de la relación, muy trabajada ya a lo largo de la historia de la filosofía del s. XX, entre Kant y Bergson. Las posturas más ampliamente aceptadas por los herederos de Kant dentro del neopositivismo lógico y matematicista se pueden resumir en la crítica de Bertrand Russell, especialmente formuladas en la Historia de la filosofía occidental (1946), en el capítulo correspondiente a Bergson, donde entiende que su filosofía contiene un aspecto negativo muy importante, cual es, el carácter no intelectualista, carácter que le lleva a desarrollar una serie de tesis sobre el conocimiento humano y la ciencias, plagadas de errores. Sin embargo, es innegable el significado del filósofo francés en lo que tiene que ver con las consideraciones fundamentales respecto de la condición del sujeto en los actos cognitivos que, además de los aspectos atinentes al funcionamiento del cerebro, admite procesos importantes que permitieron la consolidación de tendencias y teorías en el siglo XX, especialmente en autores franceses posestructuralistas. En este contexto, el ensayo de Maurice Merleau-
Ponty, "Bergson haciéndose" (1960), da cuenta de esta influencia y, por ello, servirá para determinar las relaciones que se establecen en el proceso cognitivo bergsoniano y que enlazan los conceptos de metafísica y ciencia a partir de la noción de intuición; en la misma perspectiva, la comparación con Kant -que de suyo resulta obvia- completará el propósito de este ensayo. Esta relación entre los dos autores no es nueva y ha dado lugar a innumerables textos, quizás por ello la vigencia de las consecuencias e implicaciones preña una parte importante de las teorías filosóficas contemporáneas que se desarrollan en torno a sujeto y a sus problemáticas.

Además, es necesario hacer referencia a la crítica al kantismo que realiza Bergson para entender el punto de partida de las formulaciones que construye en torno a los procesos del conocimiento y, además, para entender cómo, desde ellas, concibe tanto a la metafísica como a la ciencia. En este sentido, la tesis de este ensayo se define en los siguientes términos: Bergson determina una búsqueda respecto del acto de la 
cognición más allá de la fundamentación kantiana que parte de la formulación del a-priori, en esta búsqueda, la intuición se concibe de manera diferente en los dos autores, al igual que las consideraciones sobre la metafísica y los corolarios para la ciencia. El desarrollo de esta afirmación supondrá abordar el concepto de intuición bergsoniano que remite al de duración y que será trabajado con relación a la categoría de intuición del kantismo, a partir de ello será posible marcar los límites entre los dos filósofos con relación a las concepciones de ciencia y de metafísica.

\section{INTUICIÓN Y DURACIÓN}

La definición de duración de Bergson y las categorías a-priori del entendimiento de Kant marcan una diferencia fundamental en la posibilidad y naturaleza del conocimiento que, en primera instancia, remite a la explicación que el filósofo francés busca respecto del origen del a-priori, aspecto que no está planteado en Kant. En sentido bergsoniano, una vez que se supera la generalización que el lenguaje realiza a partir de las percepciones, es posible acceder a los datos inmediatos de la conciencia.

El primer concepto bergsoniano que deviene fundamental para el trabajo de este punto es el de intuición. Hay que diferenciar percepción de intuición de la realidad como tal; esta categoría distingue entre la "la unidad en la que se piensa"y"la unidad convertida en cosa" después de ser pensada (Bergson, 2011: 62). Tal diferencia no da cuenta de dos formas de concebir de la conciencia, sino de dos estados de la conciencia; en esta medida, el primer problema que aparece es el de la conformación de la unidad con relación a la multiplicidad; dilucidar la forma en que cada una se constituye es el punto nodal de su reflexión, de allí la cuidadosa explicación de la definición de número. De esta explicación, es importante destacar lo siguiente: Bergson (2011, págs. 60 - 61) dice que al pensar la unidad aisladamente se piensa en la indivisibilidad pero, cuando se pasa a la siguiente unidad, ella se objetiva, se hace cosa y, obviamente, se piensa la multiplicidad. Ahora bien, ¿qué es lo que se pone de manifiesto en este paso de una unidad a otra? No otra cosa que la posibilidad de determinar los múltiples estados de la conciencia que, además, explican las diversas formas de concebir el mundo y, al mismo tiempo, de concebir el proceso interno de la conciencia. Desde la exposición de concepto de número, pasa a la exposición de la intuición de los objetos materiales. La condición epistemológica para ello se da tanto en la multiplicidad del mundo de las cosas como en la mul- 
tiplicidad de los hechos de la conciencia. La diferencia con la conceptualización de los objetos materiales, que remiten a un número, radica en que los hechos de la conciencia, es decir, los hechos internos, no pueden utilizar unidades -números- sin antes haber realizado una representación simbólica (2011: 65). El aporte de Bergson se entiende en el intento de profundizar en los procesos de la conciencia como ámbito del conocimiento, en esta perspectiva, considera una complejidad que no se resuelve, como en Kant, apelando a los límites de la razón pura respecto de posibilidad del conocimiento, sino desde el trabajo de los conceptos de espacio y tiempo. Vale decir que estos conceptos no son considerados categorías a-priori, al menos no en el mismo sentido de la filosofía kantiana.

Para Kant (2006:1 17), la intuición se define como la relación inmediata del conocimiento con el objeto; sin embargo, la intuición está ligada a la sensibilidad que es la capacidad de receptividad de un objeto que, además, afecta al sujeto. La intuición sensible es la categoría kantiana que define la forma en que el sujeto conoce los datos que provienen del objeto, el resultado de este proceso es el fenómeno compuesto de materia -aquello que proviene de la sensación y que se da a-posteriori- y, de forma - dada a-priori, por tanto, presente en toda sensación-. Es determinante la naturaleza a-priori de las categorías de espacio y tiempo que constituyen la condición de posibilidad de la intuición sensible. En las Sección primera de la Estética trascendental de la Crítica de la razón pura, Kant expone las características a-priori de las dos categorías; de la exposición surge el carácter lógico del apriori en términos generales en la medida que espacio y tiempo tienen una función ordenadora de las percepciones de los sentidos, entiéndase en el mismo sentido, y con más fuerza, la formulación de las doce categorías del entendimiento que hacen posible la segunda representación que se opera sobre el fenómeno -definido por Kant como la primera representación que surge de la intuición sensible y de los datos que ella capta del objeto-. Quiere decir que la condición del proceso de conocimiento se rige, fundamentalmente, por estructuras lógicas, propias de la racionalidad inapelable del sujeto. De igual forma, para Bergson, hay una exigencia lógica en la aceptación de ciertas propiedades del mundo físico; en el Essai sur les donnés immédiates de la conscience (1889), respecto de la impenetrabilidad de los cuerpos dice, "...une propieté de ce genre, purement négaive, ne saurait nous être révélée par les sens..."2 (2011: 65), entonces ¿de dónde surge la certeza

2 "...una propiedad de este género, puramente negativa, no podría sernos revelada por los sentidos..." (Bergson, 1999: 69). 
de esta creencia? Obviamente es una necesidad lógica, concluirá más adelante. La cuestión se vuelve sobre la necesidad de marcar la diferencia entre Kant y Bergson.

Para Kant, las categorías a-priori, tanto de la intuición sensible como del entendimiento, son condiciones estructurales que condicionan y posibilitan el conocimiento, sea del mundo físico, sea del mundo de los objetos ideales. Bergson asume que, al admitir la impenetrabilidad de los cuerpos como propiedad del mundo físico, se ha reconocido "la solidarité des notions de nombre et d'espace", lo que equivale a "énoncer une propiété du nombre, pultôt que de la matière."3 (2011: 66) Esta misma forma de comprensión la extiende a las cosas de la conciencia pero, señala, que ellas requieren primero, de una representación simbólica en el espacio que, en términos de la comparación que se ha formulado entre los dos autores, es imposible en Kant. En las dos formulaciones, el proceso corresponde al sujeto y, en términos amplios, no al mundo físico. Subsiste, además, el interés, tanto de uno como de otro filósofos, por explicar cómo es posible conocerse a sí mismo. Para Kant, en el ámbito de la razón pura, ello significa conocer los procesos del entendimiento, procesos que llama psíquicos o internos. En el $\S 6$ de la Crítica de la razón pura (1787) bajo el título "Consecuencias de estos conceptos"-se refiere a la exposición de los conceptos de espacio y de tiempo-, dice:

b) El tiempo no es otra cosa que la forma del sentido interno, esto es, del intuirnos a nosotros mismos y nuestro estado interno. Pues el tiempo no puede ser una determinación de fenómenos externos. No se refiere ni a una figura ni a una posición, etc., sino que determina la relación entre las representaciones existentes en nuestro estado interior (2006: 76-77).

Por detrás de la capacidad de representación que poseen los sujetos, está, para Bergson, una comprensión dualista de la materia: Io físico y lo psíquico; sin embargo, los dos elementos están relacionados.

La explicación de la opción bergsoniana para explicar la dualidad materia-psiquismo, desborda el proceso del conocimiento. Quizás el libro Matière et mémoire (1896), Bergson da pistas sobre una sui generis comprensión del dualismo que subsiste en su filosofía y que, para B. Russell, valió para considerarlo irracionalista. El asunto no es discutir si Bergson es o no irracionalista, sino entender qué significado tiene una postura que marcó la historia de la filosofía en el s. XX. De allí podrá definirse su distancia

\footnotetext{
3 "la solidaridad de las nociones de número y de espacio"... "enunciar una propiedad del número, más que de la materia." (Bergson, 1999: 70).
} 
con las concepciones y posturas respecto de la ciencia y, por otro lado, los posibles aportes a la filosofía francesa. La crítica de Russell sostiene, de manera particular, la explicación del sentido que para Bergson tiene el concepto de evolución, utilizado para definir tanto los procesos del conocimiento como para fundamentar su postura espiritualista que, para el filósofo inglés, está acompañada de un irracionalismo poco aceptable para quien se refiere a la ciencia; queda claro que la medida para decidir sobre Bergson será la ciencia y su imponente corpus.

Ahora bien, Bergson entiende que la realidad del sujeto es de naturaleza psicológica, de manera que cada vez el estado interno del sujeto puede cambiar; ese cambio no se reduce a formas biológicas, sino que está sujeto a un impulso que permite que el cuerpo siga en movimiento; en tal sentido la evolución es evolución creadora. En la obra L'évolution créatrice (1907), Bergson señala que

...la théorie de la connaissance et la théorie de la vie nous paraissent inséparables l'une de!'autre. Une théorie de la vie qui ne s'accompagne pas d'une critique de la connaissance est obligée d'accepter, tels quels, les concepts que l'entendement met à sa disposition : elle ne peut qu'enfermer les faits, de gré ou de force, dans des cadres préexistants qu'elle considère comme définitifs. ${ }^{4}$ (2009, p.9).

Quiere decir que el conocimiento no produce un saber en el sentido tradicional, esto es, el conocimiento del mundo exterior a partir de ciertas estructuras puramente racionales del sujeto, sino que busca dar cuenta de una realidad más rica cuya profundidad solo puede ser producto de un acto de creación. Este acto será el punto de escisión de la filosofía bergsoniana con el kantismo. Lo que resta, en este punto, es configurar los límites de la evolución creadora, como parámetro de la crítica a la concepción racionalista de Kant; en este contexto, la crítica de Russell tiene gran importancia, aun cuando es posible señalar que lejos del irracionalismo, Bergson determina la posibilidad de entender cómo el sujeto se constituye en el acto de conocer, no solamente desde la inteligencia, sino desde aspectos profundos, postulados como psíquicos. De esta manera, el dualismo de la tradición racionalista se corrige, ya no es más res cogitans y res extensa, sino vida -que se entiende como cuerpo y psiquismo-y materia. El replanteamiento tendrá otro tipo de consecuencias en la concepción del sujeto pero, fundamentalmente, otros supuestos tanto epistémicos como metafísicos.

\footnotetext{
${ }^{4}$... la teoría del conocimiento y la teoría de la vida nos parecen inseparables una de otra. Una teoría de la vida que no se acompañe de una crítica del conocimiento está obligada a aceptar, al pie de la letra, los conceptos que el entendimiento pone a su disposición: no puede sino encerrar los hechos, de grado o por fuerza, en cuadros preexistentes que considera como definitivos (Bergson, 1963: 436-437).
} 
Para determinar estos supuestos es necesario remitirse a la definición de evolución : "L'évolution doit donc comporter à tout moment une interprétation psychologique quien est, de notre point de vue, la meilleure explication, mais cette explication n'a de valeur et même de signification que dans le sens rétroactif. $»^{5}$ (Bergson, 2003: 39). La vida concebida con relación a esta forma de entender la evolución, es, sin lugar a dudas, una vida que desborda la teleología de la tradición filosófica moderna accesible solamente desde la racionalidad de la ciencia positiva; la inteligencia se comprende como el resultado de "...l'évolution au cours du trajet... II faut substituer à l'intelligence proprement dite la réalité plus compréhensive dont lintelligence nést que le rétrécissement." ${ }^{\prime 6}$ (2003: 39-40). El supuesto de realidad es sui generis, parecería integrar el sujeto, en tanto vida e inteligencia, al mundo exterior; tal forma de integración, que no es la única en la filosofía, implica la relación del sujeto con el mundo en el tiempo y en el espacio. Cuando Bergson aborda esta relación, aparecen claramente las notas que caracterizarán su postura frente a las del
Kant y del positivismo lógico desde el cual escribe Russell. Asimismo, bosquejará los aportes a la filosofía francesa del s. XX en los términos que se sustraen a las concepciones tradicionales y que se ubican en el camino del desgarramiento formulado por Merleau-Ponty en el texto sobre Bergson.

Russell (1946: 820) sostiene que para Bergson,

Evolution is not primarily explicable by adaptation to environ meat; adaptation explains only the turns and twists of evolution, like the windings of a road approaching a town through hilly country. But this simile is not quite adequate; there is no town definite goal, at the end the road along which evolution travels. ${ }^{\text {? }}$

El concepto de evolución así entendido, se distancia de la posibilidad de seguir la pista de un proceso cuya ley fundamental es la adaptación al medio; aún más, la ausencia de una finalidad que lleve a algo esencialmente nuevo en el mundo, concluye Russell; quiere decir que Bergson se ubica en una com-

\footnotetext{
5 "La evolución - dice Bergson- debe, pues, implicar en todo momento una interpretación psicológica, que es, desde nuestro punto de vista, la mejor explicación, aunque esta explicación no tiene valor ni incluso significación más que en el sentido retroactivo." (Bergson, 1963: 482).

6"... evolución en el curso de su trayectoria... Es preciso sustituir la inteligencia propiamente dicha por la realidad más comprensiva, de la cual la inteligencia no es más que su reducción." (Bergson, 1963: 482-483).

7 "La evolución no es primordialmente explicable por la adaptación al medio; la adaptación explica solamente los giros y vueltas de la evolución, como las vueltas de una carretera que se aproxima a una ciudad atravesando un campo montañoso. Pero este símil no es del todo adecuado; no hay una ciudad, una meta definidas al final del camino por donde marcha la evolución."
} 
prensión mecanicista y teleológica que, sumada a la categoría de creación, resulta extraña a la ciencia; queda asumir un pensamiento creador, tal y como lo hacen los artistas: "As against both these views, though with more sympathy for teleology than for mechanism, Bergson maintains that evolution is truly creative, like the work of an artist."8 (Russell, 1946: 820) El término sobre el que Russell regresa para desarrollar el análisis, es el de trabajo de un artista. ¿Qué tiene de problemática esta tesis? Basta recordar el impacto que propuestas como la de Nietzsche y Heidegger tuvieron en la filosofía de la ciencia de corte positivista. La reacción de Russell resulta, por decirlo de algún modo, natural. Sin embargo, los supuestos epistémicos son distintos, Bergson asume una concepción de la realidad que no es ajena a la voluntad, hay un carácter desiderativo en la conformación de la realidad desde el conocimiento; lo que llama vital está dado en relación a lo querido (2003: 175). Si bien puede pensarse que esto querido, ligado a la voluntad (no entendida en términos kantianos, sino más bien relacionada con aspectos profundos del sujeto no totalmente definibles), da cuenta de una postura irracional, es importante considerar que en la concepción bergsoniana están presentes elementos provenientes, no exclusivamente de las ciencias, sino de teorías como el psicoanálisis, presente en la época con gran fuerza. ${ }^{9}$ El trabajo de profundización en las estructuras del sujeto, deja una impronta en la filosofía de Bergson que es reconocida por filósofos como Merleau-Ponty: (1964: 224)

Las conciliaciones, las celebraciones,
no tendrían que hacernos olvidar el
camino que Bergson, solo, trazó y del
cual nunca renegó, esta manera di-
recta, sobria, inmediata, insólita, de re-
hacer la filosofía, de buscar lo profun-
do en la apariencia y lo absoluto más
allá de nuestros ojos, en fin, con los
mejores modos, el espíritu de descu-
brimiento que es la fuente primera del
bergsonismo.

El trabajo del filósofo francés sería, de acuerdo con Merleau-Ponty, una suer-

\footnotetext{
8 "Frente a ambas miradas, pero con más simpatía por la teleología que por el mecanicismo, Bergson mantiene que la evolución es verdaderamente creativa, como el trabajo de un artista."

${ }^{9}$ La discusión que se ha mantenido sobre la posible relación entre estos autores parece decidir que, primero, hay elementos comunes en los estudios que les llevaron a hacer sus respectivas propuestas, por ejemplo, los estudios sobre las afasias presentes en la formulación de la teoría freudiana de manera fundamental -en el texto de 1891 Las afasias-y que le sirvió para diferenciar a los neuróticos con sintomatología pero sin daño neurológico de pacientes que presentaban afasias a partir de un daño anatómico. De igual modo, en la obra de Bergson el tema aparece especialmente en Materia y memoria, texto en el que, además, admite el inconsciente, aunque, es necesario aclarar, no tiene el mismo sentido que en el freudismo; segundo, hay que entender que el trabajo de Bergson es fundamentalmente filosófico, no así el de Freud cuyo interés está dado en el campo de lo psíquico desde una perspectiva positivista que se alejaba de las consideraciones metafísicas.
} 
te de apertura hacia un horizonte del todo nuevo que reformula los parámetros de la filosofía desde el análisis de "los principios de mecánica de los que se servía sin rigor Spencer"10 (1964: 225); el resultado de este punto de partida lo llevó a la formulación del concepto de duración que concibe de manera distinta al tiempo. Antes de abordar este concepto queda por definir lo que, con relación a lo tratado en estas páginas, entenderá por intuición, de esta definición será posible deducir la posibilidad de la metafísica y los límites de la ciencia.

El carácter psicologista que surge de la comprensión bergsoniana del proceso del conocimiento, habla de una intuición no intelectual, a diferencia de Kant; esta tesis implica una compleja estructura explicable desde consideraciones fisiológicas y psíquicas, vinculadas a la forma en que la filosofía ha tratado los procesos de la percepción. En la conferencia "La percepción del cambio" dictada en 1911, en Cambridge, dice que el filosofar se aparta de la acción para especular, para trabajar con conceptos; en el campo de la percepción de las cosas, en tanto quedan aspectos sin explicarse, los filósofos se han visto obligados a"... compléter la perception par la conception, -celle-ci devant combler les intervalles entre les données des sens ou de la conscience et, par là, unifier et systématiser notre connaissance des choses."11 (Bergson, 1969: 83). La explicación bergsoniana tomará estos aspectos con el fin de profundizar en el conocimiento que está limitado por los datos de lo que denomina, las percepciones naturales; este será el campo propio de la filosofía, más cercano a las artes que a las ciencias. ¿En qué sentido?, en tanto el artista es capaz de "extender las facultades de percibir"; aun sin saberlo puede dar cuenta de una realidad que está reducida por la percepción corriente más bien ligada a una cierta practicidad (Bergson, 1969: 84 - 85). Esta forma profunda de percibir remite a una comprensión más completa de la realidad definida como intuición solamente en la medida que se liga a la duración interior, es decir "a la visión directa del espíritu por el espíritu" (1969: 19). Aun antes de entrar en la explicación y análisis del concepto de duración, la diferencia con Kant es notable. Aquello que Bergson niega a la intuición, en tanto intelectual, define la condición de posibilidad del conocimiento para Kant. La diferencia

\footnotetext{
${ }^{10}$ Para fines del s. XIX, la importancia del mecanicismo en la perspectiva teórica de Spencer, radicó en la necesidad de explicar, desde las leyes de la ciencia natural, los procesos humanos, biológicos, psíquicos y sociales. El darwinismo social que se le atribuye, surgió de temas similares a los tratados por Bergson. El interés fue el mismo pero los supuestos no.

11 “...completar la percepción por la concepción, debiendo esta colmar los intervalos entre los datos de los sentidos o de la conciencia, y con ello unificar nuestro conocimiento de las cosas." (Bergson, 1972: 109).
} 
reside en el supuesto de realidad del que parte Bergson, para él, la realidad es movimiento y la intuición lo capta; desde esta forma de comprensión -no solo la filosofía kantiana, sino la de Platón y, por extensión en gran medida la filosofía occidental-, la realidad se halla atrapada en lo inmóvil; de allí que la intuición, tal como la formula el filósofo de Königsberg, sea puramente intelectual, aun cuando esté ligada a la sensibilidad. El concepto de intuición, dentro del sistema bergsoniano, terminará de consolidarse con relación al de duración.

El segundo concepto determinante en el sistema bergsoniano es el de duración que, en términos generales, tiene, al menos, dos formas de entenderse, como duración pura, que es inextensa con relación al tiempo -considerado de manera sui generis, como se verá más adelante--, y como duración ligada al espacio. Para hacer la distinción entre ellas, Bergson se remite al concepto de número y a su proceso de constitución; la razón que funda la elección de este concepto en particular tiene quever con que "... il devient aisé de faire la part exacte du sujectif et de l'objectif dans l'idée de nombre."12 (2011: 63) En función del interés de este artículo, subjetivo y objetivo son términos que permitirán desarrollar la relación entre la perspectiva del filósofo francés y la de Kant respecto de la postura de cada uno con relación a la ciencia y su delimitación de la metafísica; en el mismo orden, lo que se afirma para el concepto de número, permitirá distinguir a los conceptos referidos a objetos de la experiencia sensible, a partir de la distinta concepción de la multiplicidad, tema que ya se ha abordado con relación al concepto de intuición pero que requiere ser precisado. Ahora bien, en el proceso que permite formular el concepto de número se distinguen dos formas de concebir la unidad: la primera es provisional y la segunda es definitiva; aquélla reside en la multiplicidad constitutiva de la unidad de la representación producto de lo que llama el "acto simple de la percepción" de la inteligencia; esta se formará "añadiéndose a sí misma" (Bergson, 2011:60). El problema que ve el autor en la provisionalidad de la representación de la unidad, en este caso remitida al concepto de número, exige entender lo que implica la forma simple de concebir de la mente; sin embargo, la posibilidad de la representación de lo real, esto es, referida a la duración, halla su sustento en la provisionalidad que permite mantener la divisibilidad de las unidades que conforman un número cualquiera; la unidad entendida como definitiva, en cambio, concluye en la indivisibilidad. Este asunto, sin duda complejo, le lleva a trabajar el proceso de elaboración de

12 “. .. resulta fácil el cómputo de lo subjetivo y de lo objetivo en la idea de número." (Bergson, 1999, pág. 67). 
los conceptos que no tienen un sustrato en la materialidad. Estos serán los que se revisarán más tarde con relación a la concepción kantiana; las conclusiones de esta comparación, permitirán delimitar el sentido y alcance del concepto de duración bergsoniano en el orden de la comprensión del concepto de intuición.

Bergson sostiene que las cosas deben percibirse por la duración. En el texto citado en el párrafo anterior, el autor considera que la posibilidad de la representación que realiza la conciencia reside en el carácter aislado de las impresiones que son captadas por los sentidos; en esta medida la representación consiste en la constitución de una unidad a partir de la yuxtaposición de los elementos distintos (2011: 56). La concepción de la multiplicidad que se había explicitado para el caso del concepto de número va a encontrar dos determinaciones en tanto, «Quand nous affirmons que le nombre est un, nous entendons par là que nous le représentons dans sa totalité par une intuition simple et indivisible de l'esprit: cette unité renferme donc une multiplicité, puisque c'est l'unité d'un tout». ${ }^{13}$ (2011: 59-60 ) El asunto que aquí interesa remite a la manera de concebir la intuición; en efecto, la intuición, una vez ligada a la duración, puede captar el mo- vimiento como continuidad que trae siempre algo nuevo; una vez establecida la relación intuición-duración, Bergson asume que la intuición, a partir de la percepción de la continuidad, «...elle voit, elle sait que l'esprit tire de lui-même plus qu'il n'a, que la spiritualité consiste en cela même, et que la réalité, imprégnée d'esprit, est création." ${ }^{14}$ (1969: 21) Ahora bien, el espíritu, en tanto actúa sobre sí mismo e impregna a la realidad con su naturaleza, se constituye en la condición para afirmar que la realidad es creación del espíritu a través de la intuición ligada a la duración. Las consecuencias de esta forma de concebir el proceso de la percepción, superado por una intuición creadora de realidad, determinan el alejamiento de la perspectiva kantiana; aun más, dan cuenta de una doble definición de intuición, intuición intelectual e intuición creadora. Esta última permite desvelar el cambio, es decir, el tiempo, que se halla cubierto por el espacio y por las percepciones que se dan en él. Estas percepciones desembocan en las conceptualizaciones producto de un acto del intelecto puro, como en el caso de Kant; quedan, en esta medida, alejadas de la realidad temporal que es el objeto de la búsqueda bergsoniana y que se define como, "...la création continue d'imprévisible nouveauté qui semble se

13 "Cuando afirmamos que el número es uno, entendemos por ello que nos lo representamos en su totalidad por una intuición simple e indivisible de la mente: esta unidad encierra, pues, una multiplicidad, porque es la unidad de un todo." (Bergson, 1999: 64).

14 "... ve y sabe que el espíritu extrae de sí mismo más de lo que tiene, que la espiritualidad consiste en eso mismo, y que la realidad, impregnada de espíritu, es creación." (Bergson, 1972: 33). 
poursuivre dans l'univers."15 (Bergson, 1969: 56).

Desde esta perspectiva, la realidad está constituida por materia y espíritu, parecería que este espíritu está en el sujeto que conoce y que, en cuanto material, forma parte del universo. Ahora, este ser vivo, que es el hombre, « ... dure essentiellement; il dure, justement parce qu'il élabore sans cesse du nouveau et parce qu'il n'y a pas d'élaboration sans recherche, pas de recherche sans tâtonnement. $»^{16}$ (Bergson, 1969: 57). Hay una conciencia que está impelida a la indagación que no solamente encuentra algo ya dado en la realidad, sino que la constituye fundamentalmente. De esta formulación surge el sentido del concepto de duración y, de forma consistente con él, la definición de cambio en términos de evolución creadora.

Veamos, si la duración aparece ligada a la temporalidad, la concepción de espacio, en la perspectiva kantiana, ha contribuido, según Bergson, a sustentar una forma de percepción que impide llegar a la realidad en su constitución verdadera. En el apartado de la Crítica de la razón pura, "Estética trascendental", anota el filósofo francés, el espacio tiene consistencia propia independiente- mente de su contenido (2011: 69-70). ¿Qué se sigue de esta concepción? Podría decirse que un olvido del análisis de la naturaleza del espacio, olvido que toca a las ciencias de manera directa y que desemboca en el empirismo o en el nativismo. El corolario de estas posturas aleja el trabajo, tanto filosófico como científico, de la búsqueda de la realidad en cuanto movimiento. Aun cuando hay intentos por reintegrar el espacio a los contenidos, estos, no se han alejado del presupuesto kantiano de la sensibilidad trabajando con categorías a-priori (2011: 70-71). Vale decir que la comprensión de la realidad como movimiento, solo será posible si se logra integrar el espacio al proceso de percepción del movimiento donde hay que"... distinguer entre la perception de l'étendue et la conception de

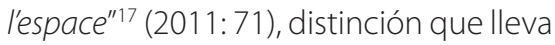
a abandonar la idea de un espacio homogéneo, resultado de un acto de la inteligencia $y$, por tanto, reducible al espacio de la geometría. Bergson, en cambio, en términos de la duración, sostendrá que la percepción del cambio, en el espacio integrado al tiempo, se dificulta porque la duración no solo se da en el sujeto sino en el mundo exterior; tal dificultad responde a la forma de percepción mediada por el lenguaje -que espesa el velo y esconde el movi-

\footnotetext{
15 "... la creación continua de imprevisible novedad que parece proseguirse en el universo." (Bergson, 1972: 89).

16 "... dura esencialmente: dura justamente porque elabora sin cesar algo nuevo y porque no existe elaboración sin búsqueda, ni búsqueda sin tanteos." (Bergson, 1972: 89).

17 "... distinguir entre la percepción de la extensión y la percepción del espacio..." (Bergson, 1999: 74).
} 
miento- y, además, por la acción de la inteligencia. La propuesta de la filosofía bergsoniana es ir más profundo en la búsqueda de la realidad donde el cambio se entiende como un conjunto de estados tanto de las cosas como de la conciencia percipiente. La duración es duración-cualidad determinada por momentos heterogéneos, pero no divisibles, que subyace a la percepción de estados homogéneos surgidos de la concepción de un espacio también homogéneo y desligado de sus contenidos, dentro del cual es posible la división de momentos y estados. La distancia con Kant es evidente, Russell la recoge cuando señala que Bergson no distingue "... the act of knowing and the object known..." aún más, "The distinction which Bergson has in mind in the above is not, I think, the distinction between the imaging as a mental occurrence and the thing images as an object."18 (1946: 836). Quiere decir que Bergson, efectivamente, no parte de la distinción entre sujeto y objeto que realiza el racionalismo ilustrado y que está presente en
Kant; al contrario, como dice MerleauPonty, Bergson procura un saber absoluto de lo absoluto pero de manera extraña pues, "no conocemos todos nuestros recuerdos, ni tampoco toda la densidad de nuestro presente", el contacto con uno mismo es, según Bergson, "coincidencia parcial". Luego, el saber absoluto es inherente al yo. A diferencia del racionalismo, de corte kantiano, MerleauPonty (1964: 225) sostiene que lo novedoso es dar a la filosofía no un yo pienso dentro de la inmanencia, sino "un ser uno mismo" cohesionado aunque, al mismo tiempo, desgarrado. Aquí radica la herencia que asumirá, en gran medida, la filosofía francesa a partir de la década de los 60.

Queda, entonces, retomar la segunda parte de este trabajo, esto es, la delimitación entre ciencia y metafísica, como resultado de las consideraciones que Bergson hace respecto del proceso de conocimiento del mundo; hacerlo implicará poner en relación las tesis de Bergson y las de Kant.

\section{CONSECUENCIAS: CIENCIA Y METAFÍSICA}

Antes de abordar este último apartado, vale señalar que en la filosofía de Bergson se pueden diferenciar dos mo- mentos respecto de la crítica a Kant. En lo que sigue, el texto fundamental para determinar la postura del francés, será $L a$

\footnotetext{
18 ". . el acto del conocimiento y el objeto conocido..." "La distinción que Bergson tiene en mente aquí, no es, yo pienso, la distinción entre el imaginar como suceso mental y la cosa imaginada como objeto."
} 
introducción a la metafísica (1903). Fréderic Worms, (2001) dice que la relación entre los dos autores tiene su fundamento en el problema del entendimiento que, por otra parte, sustenta la conformación del concepto de intuición, vale aclarar. La tesis de Worms se resume en lo siguiente: primero, Bergson asume la independencia del entendimiento en el proceso del conocimiento, independencia formulada por Kant; segundo, esta independencia no es total para el filósofo francés, de serlo, se abriría una diferencia insalvable entre el pensamiento y la realidad; $y$, finalmente, el límite de la independencia del entendimiento, se desplaza, en la filosofía bergsoniana hacia una comprensión que dispara la diferencia entre la forma de entender la intuición y la metafísica que cada uno postula (2001: 461). En este contexto, al poner a Bergson y Kant frente a frente para determinar la distancia que los separa, es lícito anotar que la comparación se recoge en este artículo, parte del texto sobre la metafísica (1903). Sin embargo, no serán abordados ni L'Énergie espirituelle (1919) ni Les deux sources de la morale et de la religión (1932); esta aclaración es necesaria en el orden otras lecturas que profundizan en la relación que nos ocupa.

La intención de Bergson es delimi- tar la metafísica desde la ciencia de la conciencia, en este enunciado se marca la diferencia con Kant; la pregunta obvia es, ¿en qué medida la ciencia de la conciencia, como la concibe Bergson, se aleja de la concepción kantiana de ciencia? La respuesta determinará la concepción de metafísica de cada uno de los autores. El punto de partida del filósofo francés es la forma en que la conciencia percibe el movimiento real, es decir, la duración. En el apartado anterior se ha definido el concepto de duración, en esta segunda parte, se trabajará a partir del ensayo aparecido en 1903 en la Revue de Métaphysique et de Morale, titulado "Introducción a la metafísica"; en el Prólogo de este ensayo, Bergson parte de la necesidad de plantear un giro en las concepciones del criticismo kantiano y del dogmatismo que dominaban en esos momentos: "Depuis cette époque, nous avons été amené à préciser davantage la significaction des termes métaphysique et science."19 (1969: 98). La metafísica se dirige al conocimiento de lo absoluto entrando en la cosa, la ciencia, dice, gira en torno a la cosa y es, por tanto, el conocimiento de lo relativo. Pero, esa cosa a la que se dirigen metafísica y ciencia es fundamentalmente movimiento, entendido como duración pura que "...exclut toute idée de juxtaposition, d'extério- rité réciproque et d'étendue. ${ }^{\prime 20}$ Con lo cual dice

\footnotetext{
19 "Desde entonces nos hemos visto obligados a precisar la significación de los términos metafísica y ciencia." (Bergson, 1960: 7).

20 "...excluye toda idea de yuxtaposición, de exterioridad recíproca y de extensión."
} 
más adelante, se advierte que el conocimiento del mundo exterior está determinado por el trabajo de la conciencia que es capaz de captar la movilidad pura, toda vez que se libera del espacio que contiene al movimiento. De esta manera, el sujeto tiene, a la vez,"... une image plus fidèle de notre développement dans la durée. $»^{21}$ (1969: 102) Interioridad y exterioridad se manifiestan en el mismo acto cognoscente que ha clausurado la diferencia entre el mundo exterior y los procesos internos a partir de la noción de duración. En la clausura se afirma la continuidad y la unidad del ser, podría concluirse. Con ello, Bergson afirma que la intuición da la pauta para afirmar que la duración es constitutiva del sujeto y de la totalidad del ser (1969: 103).

A partir de ello, surgen dos cuestiones: ¿qué es el conocimiento? y, ¿qué le corresponde a la ciencia y qué a la metafísica? La conciencia conoce pero no hay dos momentos iguales, luego, cada vez se conoce algo distinto; asimismo, absoluto e infinito se identifican en la medida que, la intuición o simpatía lo captan en la duración; no así el análisis que se remite a los elementos ya conocidos del objeto. En este punto la distancia con Kant es notable pues, "Analyser consiste donc à exprimer une chose en fonction de ce qui n'est pas elle... se conti- nue donc à l'infini. Mais l'intuition, si elle est possible, est un acte simple. 122 (Bergson, 1969: 100). El análisis remite a la ciencia positiva, precisamente a la ciencia que Kant trata de fundamentar. En Los principios metafísicos de la ciencia de la naturaleza (1991), el filósofo alemán define la ciencia como un sistema que reúne la totalidad de conocimientos ordenados por principios enlazados empírica o racionalmente; esta distinción se traduce en dos grupos de ciencias: en el primero está la matemática cuya certeza es apodíctica y la metafísica o filosofía pura, en el segundo están la química y la psicología. (1991: 3-5) Tanto matemática como metafísica se constituyen de igual manera, pero la primera lo hace a través de conceptos construidos intuitivamente, $y$ la segunda, por simples conceptos. Ahora bien, en cuanto al segundo grupo de ciencias, Kant sostiene que la ciencia natural supone una metafísica de la naturaleza en la medida en que ". . la existencia no se puede representar en ninguna intuición a-priori..." (1991: pág. 6), por lo que la metafísica de la naturaleza tratará de las leyes generales que posibilitan el concepto de naturaleza o de cosa que es dada empíricamente; de ello se sigue que, para Kant, conocer la cosa apriori, es "... conocerla por su simple posibilidad..." es decir que, conocer los objetos naturales implica, además de las

\footnotetext{
21 "... una imagen más fiel de nuestro desarrollo en la duración" (Bergson, 1960: 14).

22 "Analizar consiste expresar una cosa en función de lo que no es... se prolonga hasta el infinito. La intuición, si ella es posible, es un acto simple" (Bergson, 1960: 11).
} 
leyes dadas por la metafísica de la naturaleza, conocimientos que surgen fuera del pensamiento (1991: 7). En el ámbito de la ciencia, Kant no podría entender el trabajo de la intuición sensible desligado de las categorías a-priori; con ello, la intuición es algo completamente diferente, tanto en su definición como en su proceso, de lo señalado Bergson. Aún más, las categorías a-priori se definen, dentro de la filosofía kantiana, como determinaciones de nuestra conciencia que imitan las funciones lógicas de los juicios, son, por tanto, "... simples formas de los juicios en tanto que aplicadas a las intuiciones... siempre sensibles." (1991: 11). La objeción de Bergson se da en términos de la duración que capta el movimiento y el cambio permanente que produce; en tal sentido, el conocimiento se enfoca en el mundo, no de las cosas y del doble aspecto que les asigna Kant -empírico y referido al noúmeno-, sino de la movilidad pura. El resultado del conocimiento no se ciñe al concepto, lo sobrepasa, llega a la esencia del mundo porque da cuenta también de la vida interior y de su propio movimiento:

La vie intérieure est tout cela à la fois, va- riété de qualités, continuité de progrès, unité de direction. On ne saurait la représenter par des images.

Mais on la représenterait bien moins encore par des concepts, c'est-à-dire par des idées abstraites, ou générales, ou simples. Sans doute aucune image ne rendra tout à fait le sentiment original que j'ai de lécoulement de moi-même... À celui qui ne serait pas capable de se donner à lui-même l'intuition de la durée constitutive de son être, rien ne la donneraitjamais, pas plus les concepts que les images. ${ }^{23}$ (Bergson, 1969: 102).

La vida interior así concebida implica, según Russell, que"...the time here spoken of is not mathematical time, the homogeneous assemblage of mutually external instants. Mathematical time, according to Bergson, is really a form of space; the time which is of the essence of life is what he calls duration."24 (1946: 823). En la misma línea de Russell Kant considera que en el espacio no hay nada móvil y el tiempo es"... la forma real de la intuición interna" (2006: 82), no tiene en sí cambio alguno; las dos categorías están ligadas a la experiencia en tanto condiciones que la posibilitan.

\footnotetext{
23 "La vida interior es todo esto a la vez variedad de cualidades, continuidad de progreso, unidad de dirección. No podría representársela por imágenes.

Pues menos aún se la representaría por conceptos, esto es, por ideas abstractas, o generales, o simples. Sin duda ninguna imagen expresará completamente el sentimiento original que yo tengo de la fluencia de mí mismo... Al que no sea capaz de darse a sí mismo la intuición de la duración constitutiva de su ser, nada se la dará jamás, ni los conceptos ni la imágenes." (Bergson, 1960: 15).

24 "...el tiempo del que aquí se habla no es el tiempo matemático, la reunión homogénea de instantes mutuamente externos. El tiempo matemático, de acuerdo a Bergson, es realmente una forma del espacio; el tiempo que es la esencia de la vida es lo que él llama duración."
} 
El concepto que completa el sistema bergsoniano, según Russell, es el de memoria; es en ella donde se muestra la duración, en tanto en la memoria el pasado se mantiene en el presente. Entonces se determina que "Duration is the very stuff of reality, which is perpetual becoming, never something made."25 (1946: 824). En la memoria confluyen mente y materia, pero ello implica una problemática que recae sobre la acción del sujeto que se halla en tensión al tratar de reunir el pasado que está deslizándose, en un todo que es el presente, dice Russell. Pero lo que resulta realmente problemático en este punto, es la oposición que Bergson plantea entre memoria y percepción pura; esta última, en el acto de conocer, se convierte casi en materia; pues, la percepción sin memoria no logra captar la duración. Estas consideraciones, sin embargo, dan cuenta del interés del filósofo francés por los procesos del cerebro que se ocupan, según dice, solo de dar paso a lo útil, de lo cual resulta un sujeto que fluctúa entre esos procesos y los de la memoria; el sistema bergsoniano se dirige a dilucidar los contenidos de la duración, mismos que remiten a la realidad verdadera. La explicación de la oposición entre memoria y percepción se da con relación a otra oposición más fundamental, la que se da entre instinto e intelecto. Podría decirse que el instinto constituye a la intuición y el intelecto está en el orden de la percepción. En este contexto Bergson señala que el intelecto da cuenta del espacio en tanto que la intuición del tiempo, de este modo, el mundo de las cosas se diluye y solo quedan las acciones.

En Matière et mémoire( ), Bergson se refiere a la diferencia con Kant :

Limpuissance de la raison spéculative, telle que Kant l'a démontrée, n'est peutêtre, au fond, que l'impuissance d'une intelligence asservie à certaines nécessités de la vie corporelle et s'exerçant sur une matière qu'il a fallu désorganiser pour la satisfaction de nos besoins. Notre connaissance des choses ne serait plus alors relative à la structure fondamentale de notre esprit, mais seulement à ses habitudes superficielles et acquises, à la forme contingente quill tient de nos fonctions corporelles et de nos besoins inférieurs. ${ }^{26}$ (2012 : 205).

\footnotetext{
25 "La duración es el verdadero tejido de la realidad, que está perpetuamente deviniendo y nunca es algo hecho."

${ }^{26}$ La impotencia de la razón especulativa, como Kant lo ha demostrado, no es, en el fondo, más que la impotencia de una inteligencia esclavizada por ciertas necesidades de la vida corporal y ejerciéndose sobre una materia a la que ha necesitado desorganizar para la satisfacción de nuestras necesidades. Nuestro conocimiento de las cosas ya no sería entonces relativo a la estructura fundamental de nuestro espíritu, sino solamente a sus hábitos superficiales y adquiridos, a la forma contingente que se atiene a nuestras funciones corporales y de nuestras necesidades inferiores (Bergson, 2013: 194).
} 
Con ello quiere significar que la razón especulativa kantiana no logra determinar los aspectos que dan cuenta de la realidad en movimiento; de hecho Kant postula mediaciones entre las cosas y el conocimiento, estas mediaciones son los fenómenos, producto de una forma de interpretar las relaciones del sujeto con el mundo exterior, interpretación en la que el espacio y el tiempo devienen como formas puras de la intuición sensible; esta caracterización del espacio y el tiempo tienen un interés especulativo y no vital, que termina por colocar el problema del conocimiento en el idealismo. Las consecuencias del idealismo alcanzan tanto al proceso del conocimiento como a la ciencia: "Qu'on y regarde de près: on verra que l'écueil de tout idéalisme est là; il est dans ce passage de l'ordre qui nous apparaît dans la perception à l'ordre que nous réussit dans la science - ou, s'il s'agit plus particulièrement de l'idéalisme kantien, dans le passage de la sensibilité à l'entendement. » ${ }^{27}$ (Bergson, 2012: 255). La crítica de Bergson no alcanza solamente al kantismo sino también al racionalismo y al empirismo; en la Introducción a la metafísica (1960), cuando trabaja el concepto de análisis, señala que este ha sido confundido con la ciencia y la metafísica. Los términos de la confusión se hallan en la psicología experimental que busca determinar es- tados psicológicos para dar cuenta del yo. Este camino resulta en una inconsistencia pues, se busca, a través del análisis, la interioridad del sujeto que, como se ha visto, solo puede ser captada por la intuición, intuición que se opone al análisis. Ahora bien, estas críticas le permiten a Bergson delimitar la metafísica que sostiene tanto a empiristas como a racionalistas y que consiste en ir de los conceptos a la realidad, más aún, el problema de esta metafísica consiste en la aplicación de procedimientos, dirigidos a encontrar conocimientos de utilidad práctica, en la búsqueda de lo real (Kant I., 1991: 36). Resulta interesante que, al igual que Kant, Bergson encuentre que la forma de constituir conocimientos de la metafísica es compartida por las ciencias y que, en ello, la ciencia halla su principal problema. Sin embargo, en eso mismo que deviene como similar, puede determinarse una diferencia entre los dos filósofos; a saber, para Kant, el concepto de metafísica se formula sintéticamente a partir de principios y de la investigación en la razón pura y en sus leyes; este trabajo, sin embargo, se sustenta en un ejercicio previo que muestra lo que se debe hacer para tener una ciencia de la realidad, es decir, define un método cuyo momento central será analítico, en este sentido dice,"... se parte delo que se investiga... y se asciende a las

\footnotetext{
${ }^{27}$ Miremos esto de cerca: se verá que el escollo de todo idealismo está ahí; está en el pasaje del orden que nos aparece en la percepción al orden que obtenemos en la ciencia -o si se trata del idealismo kantiano, en el pasaje de la sensibilidad al entendimiento (Bergson, 2013: 235).
} 
condiciones que... lo posibilitan." (Kant, 1980: 72) El error para Kant, en la metafísica anterior, ha sido no poner en cuestión la razón y sus límites para obrar correctamente; es necesaria la filosofía trascendental que precede a la metafísica y a la ciencia, tanto a la matemática pura, como a la ciencia natural; estas ciencias teóricas representan los objetos en la intuición a partir de las categorías a-priori. (1980: 76) Toda esta empresa supone el trabajo de la razón como fuente y posibilidad del conocimiento. Para Bergson, el error de Kant está en atribuir a la intuición categorial, fundamentada solamente en la razón y en su carácter lógico, la condición y posibilidad de la metafísica y de la ciencia. Este error se traduce en la pérdida del objeto de la ciencia que confunde"...l'appareil logique de la science pour la science même, oubliant l'intuition d'où le reste a pu sortir." 28 (1969: 118) Aquello que permite delimitar el campo de la ciencia del campo de la metafísica es la intuición pero, en cada autor, la intuición se define en un contexto distinto.

\section{CONCLUSIONES}

Dentro de los límites de este artículo, la relación que se ha construido entre Bergson y Kant, en parte mediante Russell y Merleau-Ponty, ha centrado la discusión en los alcances del concepto de intuición que el filósofo francés define respecto del criticismo kantiano. El trabajo de Russell, profundamente arraigado en la tradición positivista, entiende que Bergson se ubica en una suerte de irracionalismo negador de los principios del conocimiento y del trabajo científico; Merleau-Ponty, al contrario, determina que el bergsonismo abre una nueva ruta para la ciencia en la medida que introduce en el entendimiento potencias complementarias que permiten al sujeto adentrarse en el ámbito del mundo que Kant había vedado para la razón pura.

En la línea de esta reflexión es posible dilucidar el sentido de la duración, categoría que permite a Bergson considerar la realidad en movimiento y, al sujeto con la capacidad de conocerla en su verdad. Esta concepción tiene consecuencias tanto en el plano del conocimiento como en el de la ontología. La realidad deviene dinámica, imposible de ser captada por el entendimiento racional; en el proceso que esto implica, la inteligencia actúa a profundidad superando a la intuición que solo capta el mundo material. En este punto, la inteligencia deviene creadora pues hay otra

28 "... el aparato lógico de la ciencia por la ciencia misma... olvidando la intuición de donde todo ha podido salir." (Bergson, 1960: 38 -39). 
intuición, que es capaz de atrapar la esencia de lo real, esto es su movimiento. De esta manera, el entendimiento que en Kant actúa a-priori, con estructuras lógico-formales para aprehender el mundo exterior, queda limitado al dato sensible sin dar cuenta de la esencialidad que presupone Bergson.

La representación del cambio y del movimiento, en la filosofía bergsoniana, llevará a un orden distinto para definir espacio y tiempo, distinto al orden kantiano que los define como a-priori, es decir, como condiciones de toda percepción posible. Bergson dirá que entre nosotros y el cambio hay un velo, el tiempo es el cambio, la verdad de lo real $y$, el espacio es el velo que cubre la verdad. Esta distancia entre los dos filósofos da a la ciencia y a la metafísica condiciones de posibilidad que resultan diversas; en la filosofía bergsoniana la metafísica es posible pero desde el conocimiento que surge de la intuición que capta el absoluto, dado en términos de movimiento; en la filosofía kantiana, la posibilidad de construir conocimiento a-priori, que reside en el entendimiento del sujeto y, el análisis de los límites de la razón, harán posible la metafísica.

Este aspecto importante para los dos autores gira en torno a la ciencia y su naturaleza. Kant fundamenta la ciencia en la capacidad del sujeto de construir juicios sintéticos a-priori cuya certeza es apodíctica, entiende así, que la ciencia por excelencia es la Matemática. Bergson, crítico de la concepción kantiana de entendimiento -excesivamente independiente de la realidad verdadera- dirá que la ciencia es el resultado del pensamiento creador que remite a los actos de la conciencia no fundados en los datos de los sentidos sino la actividad propia de la realidad. 


\section{BIBLIOGRAFÍA}

Bergson, H. (1960). Introducción a la metafísica. México: UNAM.

Bergson, H. (1963). La evolución creadora. Madrid: Aguilar.

Bergson, H. (1969). Le pensée et le mouvant Essais et conféfences. Paris: Les Presses Universitaires de France.

Bergson, H. (1972). El pensamiento y lo moviente. Buenos Aires: La Pléyade.

Bergson, H. (1999). Ensayo sobre los datos inmediatos de la conciencia. (J. M. Palacios, Trad.) Salamanca: Sígueme.

Bergson, H. (14 de Octubre de 2003). L'évolution créatrice. Québec, Canadá.

Bergson, H. (2011). Essai sur les données immédiates de la conscience (9 ed.). Paris: PUF.

Bergson, H. (2012). Matière et mémoire (9 ed.). Paris: PUF.
Bergson, H. (2013). Materia y memoria. Buenos Aires: Cactus.

Kant, I. (1980). Prolegómenos a toda metafísica futura. Buenos Aires: Aguilar.

Kant, I. (1991). Principios metafísicos de la ciencia de la naturaleza. Madrid: Tecnos.

Kant, I. (2006). Crítica de la razón pura. (P. Ribas, Trad.) México: Taurus.

Merleau-Ponty, M. (1964). Signos. Barcelona: Seix Barral.

Russell, B. (1946). History of Western Philosophy. s.c.: Unwin Brothers Limited.

Worms, F. (2001). L'intelligence gagnée par l'intuition. Les études philosophiques, 453464. 


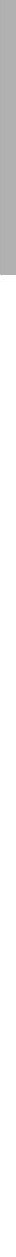




\title{
LA ARQUEOLOGÍA BÍBLICA: UNA CIENCIA HERMENÉUTICA ENTRE HISTORIA Y TOLDOT
}

\author{
BIBLICAL ARCHAEOLOGY: \\ A QUEST OF HISTORY \\ BETWEEN HISTORIA AND TOLDOT
}

STÉPHANE VINOLO

Recibido 15 de marzo de 2016

Aceptado 8 de abril de 2016 



\title{
LA ARQUEOLOGÍA BÍBLICA: UNA CIENCIA HERMENÉUTICA ENTRE HISTORIA Y TOLDOT
}

\author{
Stéphane Vinolo ${ }^{1}$
}

\section{RESUMEN}

La arqueología bíblica es sin duda una ciencia cuyas implicaciones políticas son fundamentales. Al querer esta establecer el estatuto histórico del texto bíblico, se encuentra en el centro de muchos debates académicos desde su surgimiento hasta hoy en día. Sin embargo, mostramos aquí que el carácter histórico del relato bíblico se debe recontextualizar dentro de varios significados posibles de la palabra Historia. Si bien las tradiciones griegas y romanas vinculan el concepto de historia con la verdad, el mundo hebreo, pensando a la Historia como toldot, la vincula con el sentido. Esta diferencia entre verdad y sentido dentro del concepto de Historia nos permite cuestionar los límites de la arqueología bíblica y establecer lo que podemos razonablemente esperar de esta.
Palabras clave: arqueología bíblica, Historia, sentido, Toldot, verdad.

\section{ABSTRACT}

From its early beginnings, biblical archaeology has suffered from political use and abuse. By questioning or establishing the historical reality of biblical characters and events, it is still today at the centre of several academic debates. It is demonstrated here that most of the misunderstandings of these debates lie in a confusion of what History means. Even though we know that in the ancient Greek and Roman worlds, the concept of historia was strongly linked with the one of truth, in the Hebraic and biblical worlds the concept of toldot was related to the ones of sense and meaning. This difference between truth and sense within the concept of History helps us establish the scope and limits of biblical

1 Pontificia Universidad Católica del Ecuador, Facultad Eclesiástica de Ciencias Filosófico-Teológicas, Quito, Ecuador (svinolo@puce.edu.ec). 
archaeology, precising what is to be expected from it.

La arqueología bíblica presenta en su mismo nombre una paradoja que hace de esta una ciencia aparte, o como mínimo, una disciplina cuyas fronteras siempre amenazan extenderse más allá de lo que la epistemología autoriza. Efectivamente, podemos preguntarnos: ¿por qué los arqueólogos investigando yacimientos cuyos nombres hacen referencia a espacios geográficos mencionados en la Biblia necesitan precisar de manera explícita que hacen arqueología específicamente bíblica, ya que por ejemplo ningún arqueólogo especialista de Grecia o del Imperio romano siente la necesidad de precisar que hace arqueología en referencia a la Historia de la guerra del Peloponeso de Tucídides (Tucídides, 2005) o a la Historia de Roma de Polibio (Polibio, 2008)? La simple existencia de una disciplina que precisa su carácter bíblico cuestiona la especificidad de esta, ya que los arqueólogos cuyas investigaciones se desarrollan en el campo histórico de la antigüedad griega o romana hacen simplemente arqueología, sin más precisión. No podemos dejar de notar entonces que la Biblia no se considera como cualquier otro libro a la hora de hacer arqueología por el simple hecho
Key words: biblical archaeology, History, sense, Toldot, truth.

que se precisa que se hace arqueología específicamente bíblica. Si bien la arqueología bíblica se somete a muchos de los criterios científicos de la arqueología y respeta en gran parte su epistemología, podemos sospechar que la Biblia pesa de forma muy fuerte sobre las interpretaciones que los arqueólogos hacen de sus descubrimientos ya sea de forma positiva o de forma negativa. Nuestra sospecha se puede fundamentar en hechos académicos muy simples que revelan cierto malestar académico frente a la arqueología bíblica. Podemos notar, por ejemplo, que en el ámbito universitario, la revista académica The Biblical Archaeologist, creada por G. Ernest Wright y publicada entre los años 1938 y 1997 cambió su nombre a Near Eastern Archaeology en 1998 para evitar esas acusaciones y mantenerse de manera estricta en el campo de la investigación científica.

Debemos sin embargo notar que existen dos actitudes muy diferentes o dos usos muy distintos, que los arqueólogos pueden hacer de la Biblia, lo que nos llevaría a presentar dos concepciones muy diferentes de la arqueología bí-

\footnotetext{
${ }^{2}$ http://www.asor.org/pubs/nea/ [Consultado el 15 de febrero 2016, 21h38]
} 
blica. Podemos imaginar una visión minimalista de la arqueología bíblica. Esta visión conocida como "Escuela de Copenhague", ya que dos de sus mayores representantes -Niels Peter Lemche y Thomas L. Thompson- eran académicos en la universidad de Copenhague, defiende la idea según la cual la Biblia relata los mitos fundadores de varias religiones monoteístas, pero que en muy pocos casos estos mitos se pueden corroborar con evidencias arqueológicas para pasar del estatuto de mito al de Historia. Al contrario, existe la posición maximalista que consiste en afirmar el carácter sumamente histórico de la Biblia ${ }^{3}$ apoyándose sobre los descubrimientos que parecen confirmar lo que relata la Biblia. Este debate entre las dos posiciones no fuera tan complicado ni tan vigoroso si la arqueología no fuera una ciencia profundamente hermenéutica. Si bien es verdad que toda ciencia conlleva cierta hermenéutica, ya que no existen hechos de por sí, y que cada hecho debe ser establecido (por no decir construido) mediante un proceso interpretativo que le da sentido dentro de una teoría general o de un paradigma global (Kuhn, 1962), es aún más perceptible en lo que se refiere a la arqueología ya que cada rastro de civilizaciones pasadas puede ser interpretado de manera radicalmente diferente dependiendo del paradigma dentro del cual se decida interpretarlo y darle sentido.

Más aún, la complejidad del debate alrededor de la arqueología bíblica proviene del hecho de que el paradigma dentro del cual los arqueólogos maximalistas interpretan los datos arqueológicos es un paradigma absoluto ya que se basa en una fe que no puede ser cuestionada - en cuanto es una fe - desde un punto de vista científico. Si este debate surgiera entre dos paradigmas científicos, estaríamos en una situación epistemológica común en la cual varios paradigmas luchan por imponerse, tal como podemos verlo por ejemplo en el caso del debate entre el paradigma corpuscular de la luz y el paradigma ondulatorio de esta. Sin embargo, este no es el caso en la arqueología bíblica a la hora de determinar cuál de la interpretación maximalista o minimalista es la correcta. Para la separación radical, que yace entre las dos órdenes que son la ciencia y la fe, ninguna ciencia refutará jamás la fe, y toda fe que espera razones científicas para creer es una mala $\mathrm{fe}^{4}$. Si bien los paradigmas científicos se refutan los unos a los otros de manera bastante fácil y consensual, y que hemos podido pasar en física del paradigma newtoniano al paradigma de la física de Einstein, estos saltos de paradigmas son mucho más complicados en lo que se re-

\footnotetext{
${ }^{3}$ Para ver una oposición concreta de estas dos posiciones sobre el caso específico del tamaño de la Jerusalén antigua, podremos leer el artículo de Tuland (Tuland, 1967).

${ }^{4}$ Para la separación radical de la fe y de la razón, y de la separación de las órdenes, podremos leer las obras de Blaise Pascal y particularmente su éxtasis místico del 23 de noviembre 1654, conocido como el Memorial.
} 
fiere a la arqueología bíblica ya que el carácter sagrado (y por lo tanto absoluto) del paradigma bíblico permite e impone un uso político ${ }^{5}$ de la arqueología y una línea de interpretación para algunos incuestionable.

Quisiéramos entonces preguntarnos aquí en este trabajo lo que se puede esperar de la arqueología bíblica y los límites de dicha ciencia localizándola entre Historia y mitología. Pero notemos de inmediato que el establecer límites a un campo disciplinario no es querer destruirlo ni minimizarlo, sino al contrario cercarlo con fronteras dentro de las cuales podemos apreciar el despliegue de toda su fuerza científica.

\section{¿QUÉ ME ESTÁ PERMITIDO ESPERAR?}

Sin duda alguna, la arqueología bíblica presenta elementos cuyos descubrimientos concuerdan perfectamente con los que nos relatan los textos bíblicos, o como mínimo presentan una adecuación tan probable que fácilmente entendemos en qué medida algunos arqueólogos fueron tentados por la interpretación maximalista de la arqueología bíblica. Para tomar un ejemplo históricamente muy lejano, podemos pensar aquí en el relato del diluvio tal como aparece en el Antiguo Testamento. En diversas excavaciones realizadas en las ciudades de Ur, Uruk, pero también de Shuruppak, Nuppur o Lagash, Sir Leonard Wooley, a finales de los años 1920, se encontró una capa de rastros que evidencia la presencia de una civilización (que data del 3000 al $2500 \mathrm{aC}$ ) por debajo de una capa de lodo de dos metros y medio de profundidad. Al extenderse esta capa de lodo sobre varios kilómetros, esto podría dejarnos pensar que estas civilizaciones fueron sumergidas de forma rápida y casi homogénea por un gran flujo de agua y lodo que les sorprendió al llegar a ellos de manera muy rápida y masiva (Wooley, 1929). A raíz de este hecho geológico incontrastable, algunos arqueólogos interpretaron esto como una posible prueba de la realidad del diluvio tal como nos los cuenta la Biblia. Tendríamos aquí, con estas excavaciones, una adecuación perfecta entre la arqueología y la Biblia. Sin embargo, bien vemos el papel que la interpretación juega en este caso, y podemos entender cómo la interpretación minimalista y maximalista se oponen en el caso de la arqueología bíblica. Para quien quisiera proponer una interpretación mini-

\footnotetext{
${ }^{5}$ No afirmamos aquí que el uso político de la arqueología es el triste privilegio de la arqueología bíblica, ya que por ejemplo el caso de las falsificaciones del yacimiento de Iruña-Veleia en el País Vasco español nos lleva a pensar que toda arqueología es política. Sin embargo, tal vez la arqueología bíblica sea el campo de la arqueología en el cual el uso político de los datos aparece de la manera más fuerte y evidente.
} 
malista del relato bíblico, se podría al contrario hacer del diluvio una simple estructura antropológica, ya que muchas culturas, incluso muchas para las cuales no disponemos de ningún rastro arqueológico que nos deje pensar en la realidad de un diluvio, presentan elementos vinculados a diluvios y grandes inundaciones en sus mitologías. De la misma manera que muchas mitologías presentan dioses que salen de las aguas o Dioses que bajan del cielo, podríamos pensar que la destrucción por el agua es una estructura antropológica fundamental de las sociedades humanas ${ }^{6}$. Recordemos aquí que la mitología incaica presenta un diluvio generado por el dios Viracocha, que la mitología de la religión Mexica dispone de una diosa -Chalchiuhtlicue- del agua que también generó un diluvio. Podríamos encontrar de la misma manera diluvios en las mitologías Pascuense o Kawésqar, es decir en regiones muy alejadas de la región en la cual se redactó la Biblia. Salvo que pensemos en la coexistencia de diluvios en todos los espacios geográficos del planeta, podemos cuestionar el simple hecho que busquemos un vínculo entre el relato bíblico del diluvio y un diluvio real. Al contrario, en una visión estructuralista de los textos y de los colectivos humanos podríamos al contrario evidenciar que por el vínculo fundamental y evidente que tiene el agua con la vida, la generación y la producción ${ }^{7}$, podemos imaginar que también haya sido vinculada por simple razones antropológicas, con la muerte y la destrucción. Sería fácil entonces imaginar que la destrucción por el agua es un elemento mitológico más que histórico (Girard, 2008) ya que parece ser una estructura mitológica casi universal o, por lo menos, que aparece en muchas regiones del planeta y en culturas muy diversas.

Sin embargo, si tal posición se puede defender para algunos puntos como el del diluvio bíblico, la arqueología bíblica presenta elementos que no podemos dejar de vincular con el relato bíblico y simplemente rechazar en estructuras antropológicas fundamentales. Si bien hemos visto que el diluvio es un tema demasiado genérico en la mitología para afirmar de manera segura la adecuación del relato bíblico con los rastros arqueológicos, otros elementos arqueológicos evidencian un vínculo muy fuerte con el relato bíblico. Este es el caso por ejemplo del descubrimiento hecho por la arqueóloga Eilat Mazar de la Universidad Hebrea de Jerusalén (Mazar, 2008) que pretende haber descubierto el túnel (conocido como "tsinnor") con el cual el Rey David pudo conquistar a Jerusalén, túnel mencio-

\footnotetext{
${ }^{6}$ Dentro de este paradigma estructuralista fundamental podremos ver las obras de Claude Levi-Strauss. Todas las interpretaciones estructurales de mitos por Lévi-Strauss han sido reunidas en los cuatro volúmenes de Mythologiques (Lévi-Strauss, 2009).

${ }^{7}$ Ya sea de manera biológica o agrícola.
} 
nado en el segundo libro del profeta Samuel (cf., 2 Samuel, 5, 6-8). En este caso, incluso los que hacen arqueología bíblica según la posición minimalista, bien deben acordar que el túnel parece exactamente mencionado en la Biblia y que la interpretación minimalista se encuentra frente a una verdadera dificultad a la hora de darle otro sentido que su sentido bíblico. De la misma manera, algunos piensan que el túnel supuestamente creado por Ezequías fue encontrado y permite entender cómo la ciudad de Jerusalén se abasteció de agua potable mientras las tropas de Asiria, dirigidas por el rey Senaquerib, avanzaban sobre ella después de haber destrozado a varias otras ciudades. Este túnel, que lleva agua desde la fuente del Gijón hasta la piscina de Siloé, presenta rastros muy precisos como la inscripción de Siloé que nos permite incluso entender el porqué el túnel no está cavado de manera recta sino sinusoidal ya que los obreros que lo excavaron se guiaban con el sonido que hacía cada equipo a cada lado de la excavación (Sneh et al., 2008). Una vez más en este caso, parece que la arqueología confirma de forma muy precisa los relatos bíblicos ${ }^{8}$.
Esta adecuación que parece darle toda su legitimidad a la lectura maximalista de la arqueología bíblica no se limita al Antiguo Testamento. Este es también el caso para el Nuevo Testamento y de manera paradigmática para la Pasión de Cristo. La arqueología bíblica parece revelarnos con una gran precisión los tres últimos días de la vida de Cristo. De esta manera, no solo Cristo aparece obviamente en los manuscritos cristianos, sino además en algunos manuscritos no-cristianos 9 , pero sobre todo, muchos rastros arqueológicos de los cuales disponemos hoy en día parecen estar en adecuación con el relato bíblico de sus últimos días. Así por ejemplo, existe en el British Museum de Londres, bajo la referencia British Museum Syriac MS additional 14.658, una carta redactada en asirio en la cual un nombrado Mara Bar Serapion ${ }^{10}$ le dice a su hijo que debe absolutamente seguir con su camino hacia la sabiduría ya que todos los que se han hecho culpables de maltratar y perseguir a los sabios conocieron un destino funesto ya que sus imperios cayeron los unos tras los otros. Para darle ejemplos a su hijo de este vínculo entre maltrato de los sabios y caída

\footnotetext{
${ }^{8}$ Cf., 2 Crónicas, 32, 30: Ezequías fue también quién cegó la salida superior de las aguas del Guijón y las desvió por un canal subterráneo hacia la parte occidental de la ciudad de David."

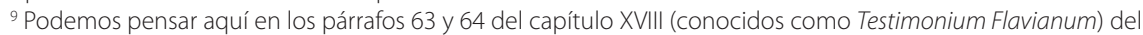
libro Antiquitates ludaicae escrito por Flavio Josefo en los cuales aparece de forma explícita el nombre de Jesús de Nazaret (Josefo, 1997).

${ }^{10}$ Dada la importancia de la mención de la crucifixión de Cristo fuera de la literatura cristina, los estudios acerca de esta carta son muy numerosos. El lector podrá ver por ejemplo el artículo completo de Annette Merz y Teun Tieleman (Merz, Tieleman, 2008).
} 
de los imperios, Mara Bar Serapion toma entonces en esta carta los ejemplos de la muerte de Sócrates que precipitó la caída de Atenas, la de Pitágoras y de los habitantes de Samos, y sobre todo y por fin el ejemplo de los judíos y de la muerte de Cristo. Así tenemos testimonios de la existencia de Cristo no solo en el mundo cristiano -lo que podría parecer sospechoso o lo que podría ser interpretado como una manera de afirmar la verdad del cristianismo dentro del mismo cristianismo, lo que epistemológicamente no nos permitiría afirmar dicha existencia histórica- sino además fuera de él, lo que apoya de manera muy fuerte su probable existencia histórica (Van Voorst, 2000). Pero más allá de textos, la arqueología también nos provee rastros arquitecturales que podrían confirmar la existencia histórica de Cristo y de cierta parte del relato del Nuevo Tes- tamento. Desde 1968, el Padre italiano Virgilio Corbo estuvo excavando por debajo de una pequeña iglesia bizantina octogonal y descubrió lo que podría ser la casa de Pedro ya que encontró inscripciones cristianas que manifiestan la presencia de lo que podríamos pensar hoy como el cristianismo primitivo (Corbo, 1968). Así, algunos puntos que nos revela la arqueología bíblica nos permiten sospechar que muchos de los relatos de la Biblia tienen algún fundamento histórico, ya que la descripción de muchas guerras, de invasiones pero también de ciudades y lugares corresponden con los datos que nos proporciona la arqueología. Gracias a estos casos innegables, los intérpretes maximalistas podrían encontrar los fundamentos epistemológicos de su maximalismo así como cierta legitimidad de este.

\section{LOS DIVINOS LÍMITES DE LA ARQUEOLOGÍA BÍBLICA}

Sin embargo, en cierto sentido que vamos a precisar, sería un error el pensar que la Biblia es un libro de historia, y sería un error aún más grande el querer basar su fe en lo que la arqueología bíblica nos pueda revelar. Podemos entonces cuestionar los fundamentos del paradigma maximalista en arqueología bíblica. Primero porque bien vemos que la arqueología bíblica, por ser una ciencia sumamente hermenéutica, presenta un límite epistemológico. Si bien la existencia de muchos lugares y eventos descritos por la Biblia está confirmada por la arqueología, un problema epistemológico muy profundo surge a la hora de determinar la existencia de individuos en concreto, y peor aún a la hora de determinar si el sentido histórico de estos individuos se encuentra reflejado en el sentido que la Biblia les da. Podemos fácilmente ilustrar esta dificultad epistemológica con ejemplos lejanos a la arqueología bíblica. Podemos 
ver que el Moscú descrito por Dostoievski en sus obras es casi perfecto: su ambiente histórico es exactamente el que describen las novelas de Dostoievski. Los lugares están muy bien descritos, las tiendas están ubicadas tal como los estipulan los textos, y los monumentos históricos reflejan a la perfección la ciudad rusa. Más aún, todos los conflictos evocados por Dostoievski, los juegos políticos y sociales son elementos que se dieron históricamente. Sin embargo, a pesar de estas precisiones, a pesar de que podamos encontrar en Moscú lo esencial del marco que Dostoievski no da a ver en sus obras, nadie podría mostrar, ni nadie pensaría seriamente que los personajes de Dostoievski que se desempeñen dentro de este marco histórico existieron. Así, el mostrar la adecuación intra-textual y extra-textual de un marco dentro del cual están situadas las acciones de un texto no basta para garantizar la existencia de los personajes de esta acción. Pero más allá del problema entre los personajes y el marco dentro del cual se desenvuelven, el problema puede ser extendido al sentido de existencia de los mismos personajes. Podemos perfectamente imaginar que rastros arqueológicos nos demestren la existencia de algún personaje histórico sin que este tenga el sentido que le da cierto texto. Conocemos muchos casos de esta divergencia entre verdad histórica y sentido intra-textual de un personaje en el campo de la filosofía. Es así el caso de todos los personajes creados por Platón: Sócrates, Alcibíades, Gorgas o Protágoras. Sabemos por la arqueología, así como por fuentes textuales, que cada uno de ellos existió históricamente, y dado que varios de ellos ocuparon un papel histórico de gran importancia en Grecia, disponemos de muchas fuentes para corroborar su existencia y entender quiénes fueron. Hay así una realidad histórica innegable de cada uno de ellos. Sin embargo, también sabemos gracias a estudios precisos realizados a lo largo del siglo XX, que sus existencias históricas están muy lejos de la manera de la cual Platón los presenta y los utiliza. Así, Gregory Vlastos (Vlastos, 1991) pudo mostrar que el Sócrates de Platón no es el Sócrates histórico, aunque Sócrates haya existido. De la misma manera, la gran helenista Jacqueline de Romilly (Romilly, 1995) mostró que el Alcibíades histórico no es el Alcibíades tal como lo presenta Platón. Este trabajo y este análisis se podrían realizar para cada uno de los personajes de Platón ya que al no ser un historiador, Platón no pretende presentar a sus personajes de manera histórica, sino dándoles el sentido que permite explicar el triunfo de Sócrates en cada uno de los diálogos, y presentar una oposición filosófica radical entre ellos y Sócrates. Hay así una ruptura hermenéutica entre lo intra-textual y lo extra-textual, a pesar que puedan tener un referente común. 
Podemos entonces concluir con dos afirmaciones de estas reflexiones en lo que se refiere a las diferentes posiciones intelectuales en arqueología bíblica. Primero, el hecho que la arqueología bíblica confirme la existencia histórica del marco en el cual se desempeñan los personajes de la Biblia no nos permite deducir la existencia histórica de estos personajes. Segundo, aunque se pueda llegar a demostrar la existencia histórica de los personajes de la Biblia, en ningún caso esto demostraría que el sentido histórico que tuvieron es el sentido que la Biblia describe o que la Biblia les da. Para utilizar el vocabulario creado por Deleuze (Deleuze \& Guattari, 1991, 60-81), podemos decir que la arqueología bíblica podrá, en el mejor de los casos, demostrar la existencia histórica de tal o tal persona, podrá tal vez certificar la existencia con una probabilidad que se acerque al cien por ciento; sin embargo, no podemos y no debemos esperar de ella que valide los personajes conceptuales de la Biblia; es decir, que valide el sentido que estos personajes tienen en los textos.

Esta oposición entre verdad histórica y sentido intra-textual no nos debe llevar a condenar a la arqueología bíblica. Al contrario, toda ciencia se define por sus límites, por lo que no puede hacer, y mientras más tenga claras sus fronteras, más precisa y eficiente puede ser dentro de sus límites ${ }^{11}$. Notemos así, por ejemplo, que cuando la física abandona la pregunta "por qué" para limitarse a la pregunta "cómo", es cuando realiza sus avances más espectaculares en la explicación de fenómenos a lo largo del siglo XVII. Igualmente, cuando abandonamos el sueño de conocer a las cosas tales como son para limitarnos a los objetos tales como puede conocerlos el entendimiento humano, la ciencia moderna presenta sus mayores avances. De esta manera, establecer sus límites para una ciencia no es construirse como ciencia pobre, sino al contrario reforzar sus posibilidades y ampliar el nivel de certeza accesible dentro de ciertas fronteras. Según el paradigma maximalista de la arqueología bíblica, muchos creyentes podrían ver en este límite de la arqueología bíblica una razón de abandonar su fe ya que buscan en la arqueología razones de creer, con pruebas de la existencia de tal acontecimiento histórico. Tal vez por esta razón, la crítica de la arqueología bíblica puede ser percibida como una agresión por parte de muchos creyentes. Esto sería un error muy grande, y se debería poder trabajar de forma racional y razonable en arqueología bíblica ya que los maximalistas no deberían olvidar que la fe, en su etimo-

\footnotetext{
${ }^{11}$ Podremos ver en los textos de Descartes en qué medida es un proceso de reducción del objeto de la ciencia moderna que le permitió avanzar de manera tan rápida y eficiente (Descartes, 1984). Y para entender en qué medida esta reducción determina toda una nueva ontología que nos hace pasar de la cosa al objeto, el lector podrá ver el libro clásico de Jean-Luc Marion (Marion, 2008).
} 
logía latina de fides (es decir confianza), supone cierta ignorancia y supone la incertidumbre. Quien supiera que Dios existe o quien habría podido, tal como lo soñaron varios filósofos desde Anselmo a Leibniz, demostrar la existencia de Dios, dejarían de inmediato de creer para saber. Paradójicamente, un acto de fe solo puede existir en un estado epistemológico débil, es decir en un estado que no encuentre raíces racionales que lo garanticen ${ }^{12}$. No tenemos fe de que la tierra gire alrededor del sol, lo sabemos, por lo que no demostramos ninguna confianza incondicional en los astros al afirmar el heliocentrismo. Sabemos calcular sus trayectorias y prever los eclipses. Por lo tanto, nuestro conocimiento elimina todo tipo de confianza en ellos. Al contrario, nuestra fe en Dios necesita, para manifestarse como confianza infinita y no como saber, padecer de cierta incertidumbre. A la diferencia de la apertura incondicional hacia una alteridad que supone la confianza en el caso de la fe, el conocimiento siempre presenta cierta clausura del sujeto sobre sí mismo, aunque sea en el hecho que los objetos del saber siempre son objetos para un sujeto. Así, la crítica epistemológica de la posición maximalista en arqueología bíblica no se presenta bajo ninguna circunstancia como cuestionamiento de la fe ni de la religión; al contrario, al establecer otra vez las fronteras, tal vez permita, como lo vamos a ver ahora, clarificar el estatuto epistemológico de la Biblia y de los textos de manera general en un sistema religioso. Para esto, necesitamos regresar a las raíces judías del cristianismo e interrogar la posición maximalista de la arqueología bíblica desde un punto de vista judío.

\section{TOLDOT: LA BIBLIA COMO LIBRO DE HISTORIA MÁS ALLÁ DE LAS HISTORIAS}

Hemos opuesto más arriba en este trabajo, la descripción de la verdad histórica al relato del sentido que le damos a eventos cuya realidad histórica no importa. Podríamos encontrar aquí una de las posibles oposiciones entre Historia y mitología. Esta oposición de la verdad y del sentido nos permite introducir com- plejidad en nuestro trabajo puesto que ambas nociones juegan un papel muy importante en la arqueología bíblica dado que no hay arqueología bíblica sin alguien (o una teoría) que le dé sentido a los hechos o rastros considerados como verdaderos. Al haber en la arqueología una parte de búsqueda de la ver-

\footnotetext{
12 Para una conceptualización brillante de esta oposición entre el conocimiento que siempre requiere el concepto de Dios creado por la metafísica y la fe en Dios, podremos ver el libro de Jean-Luc Marion (Marion, 2010).
} 
dad y una parte de donación de sentido, bien vemos que esta disciplina se debe pensar al cruce de la Historia y de la mitología. Sin embargo, las relaciones entre Historia y mitología no se deben limitar a lo que nosotros percibimos de ellas ya que lo que solemos entender por "Historia" en las lenguas romances está sumamente determinado por la herencia común del latín y del griego, de la misma manera que lo que sucede para la palabra mitología. Es interesante notar para nuestra problemática que tanto la palabra mitología como la palabra historia provienen del vocabulario griego y están entonces completamente determinadas (aunque sea de manera inconsciente) por el pensamiento griego. Pero el hebreo, lengua en la cual deberíamos leer el pentateuco y darle sentido, proviene de otra herencia, liberada de las determinaciones griegas y romanas, 0 más bien dicho todavía no determinadas por una herencia griega y romana. Por lo tanto, tal vez podamos afirmar que la Biblia es un libro de Historia y no de historias, si es que entendemos por Historia otra cosa que lo que las resonancias griegas nos dejan oír en esta palabra. Esto nos permitirá precisar el estatuto de la Biblia y por lo tanto también el de la arqueología bíblica.

Una de las primeras apariciones de la palabra historia en los textos se en- cuentra en el título de la obra de Heródoto que ocupa para muchos el papel originario de la historiografía. El opus que reúne los nueve libros de su Historia de las guerras médicas se titula efectivamente historia (Heródoto, 2011). Sin embargo, esta palabra en griego se debería o, por lo menos, se podría traducir por investigación o exploración, tal como lo vio perfectamente su traductor francés $^{13}$. Si aceptamos que Historia en este contexto griego signifique investigación o exploración de los hechos, bien vemos que se relaciona de forma fundamental con la intención de relatar los hechos tal como se desarrollaron en la realidad, es decir que se relaciona con la verdad. La preocupación de la adecuación entre eventos intra-textuales y eventos extratextuales se puede legítimamente llamarse preocupación por la verdad. Efectivamente, recordemos aquí que en el ámbito griego, la verdad se define de forma muy precisa como la adecuación de una proposición y de una realidad: "Así [...] similarmente las oraciones son verdaderas según sean las cosas reales." (Aristóteles, 1999, 9, 19a, 166) Esta definición de la verdad como adecuación tiene un impacto directo sobre la definición de la historia que por lo tanto se define como búsqueda de la verdad, en este sentido preciso de adecuación del discurso con los eventos reales, o de lo intratextual y de lo extratextual. En este

\footnotetext{
${ }^{13}$ Notemos que de hecho el último traductor francés de la obra de Heródoto decidió darle como título: L'enquête (es decir, literalmente, la investigación). Cf. (Heródoto, 1985).
} 
sentido deberíamos establecer una frontera epistemológica casi hermética entre historia y mitología usando el criterio de la relación con la realidad de los eventos transcurridos. Cuando la historia se preocupa de los referentes extratextuales y por lo tanto de la verdad, la mitología podría entenderse como pura relación de sentido intratextual, sin necesidad que este sentido tenga alguna referencia extra-textual.

Sin embargo, esta diferencia solo es posible a condición de que aceptemos la definición griega de la verdad y de su impacto sobre la definición de la Historia. Pero, lo que los hebreos entienden por Historia no está enmarcado dentro de los conceptos que acabamos de describir ya que en hebreo historia se dice toldot y que por razones cronológicas obvias, no proviene de la tradición griega. Así, cuando hablamos de Historia en el mundo griego o en el mundo hebreo, hablamos de dos disciplinas radicalmente diferentes, que deben entonces ser analizadas de manera distinta. La Historia tal como la entienden los hebreos, es decir la Historia como Toldot y no como historia proviene de una raíz hebrea que significa "generar" o "produ-

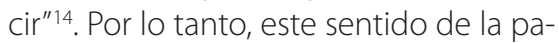
labra Historia no está vinculado con la visión de la Historia como "relato de los eventos" ni con la verdad en su definición griega, sino con la producción de sentido y la dirección que se debe tomar como pueblo judío. Más allá de una adecuación, es un problema de dirección que encontramos en la palabra Toldot. Cuando los judíos nos dicen entonces que la Torah es un libro de Historia, no lo entienden en el sentido griego de historia sino en el sentido hebreo de toldot. Nos es fácil entender esto ya que la Torah nunca pretendió darnos una definición griega del pueblo judío sino una definición judía del pueblo judío. Tomemos dos ejemplos para aclarar este punto de lo que puede ser una versión judía de la Historia en oposición a su versión griega. Esto permitirá aclarar en qué medida y en qué sentido se puede decir que la Biblia es un libro de Historia. Hagámoslo con un ejemplo filológico y con otro que nos lleva al corazón de la arqueología bíblica.

Todos conocemos el texto de Génesis en el cual se relata la creación de la mujer, que es la base de veinte siglos de machismo occidental:

Entonces el Señor Dios hizo caer sobre el hombre un profundo sueño, y cuando este se durmió, tomó una de sus costillas y cerró con carne el lugar vacío. Luego, con la costilla que había

\footnotetext{
14 "[...], le terme utilise par la Bible pour désigner l'Histoire au sens d'historia n'a pas du tout la même racine que cette première série de termes. Il s'agit du mot toldot, qui vient de la même racine que léda, lalédet, naissance, naître, et que l'on traduit généralement par histoire qui n'est que son sens second, toldot signifiant littéralement engendrement. » (Dureau, 2001, 95).
} 
sacado del hombre, el Señor Dios formó una mujer y se la presentó al hombre. El hombre exclamó: «iEsta sí que es hueso de mis huesos y carne de mi carne! Se llamará Mujer, porque ha sido sacada del hombre». Por eso el hombre deja a su padre y a su madre y se une a su mujer, y los dos llegan a ser una sola carne (Génesis, 2, 21-24).

Si aceptamos la concepción griega de lo que significa Historia y de su correlación con cierta visión de la verdad, los judíos nos recuerdan con razón en sus interpretaciones que esto no puede ser una Historia ya que todos vemos y sabemos que la mujer no proviene del hombre sino que tanto hombres como mujeres provienen del útero de las mujeres, más aún cuando sabemos que en hebreo Adam es un plural y que por lo tanto el Adam del cual nos habla la Biblia no es un hombre sino el mismo colectivo humano ${ }^{15}$. Si leemos entonces este texto con los conceptos griegos en la mente, estamos condenados a decir que son textos mitológicos y relegarlos en el campo de la fe de cada uno sin que ninguna ciencia pueda intentar aclararnos estos puntos. Si aceptamos entonces la dicotomía griega entre Historia y mitología, sin duda alguna la Biblia está más cerca de la mitología que de la Historia. Pero si aceptamos leer el texto con el concepto hebreo de Historia, es decir toldot, se aclara el sentido del texto más allá de su realidad factual. Este texto no nos dice la verdad de la relación hombre-mujer sino el sentido de esta relación para los judíos, sentido que es el siguiente. Recordamos que en la Biblia, todo lo que no está creado a partir del hombre está a su disposición: vegetales, animales y mundo inorgánico están a disposición del hombre ya que al no provenir de él han sido creado de cierta forma para él. Sin embargo, al provenir de la misma materia que la del hombre, la mujer goza de la misma dignidad que él frente a Dios y frente a la Creación, es decir frente a lo absoluto. Bien vemos aquí la diferencia entre Historia y toldot, entre producción de verdad y producción de sentido, y podemos medir las consecuencias radicalmente diferentes que tienen estas lecturas en lo que se refiere a la arqueología bíblica. Para los judíos, ya que Génesis nos da la dirección hermenéutica en la cual se desarrolla la humanidad (y no su verdad entendida como adecuación de un discurso y de una realidad extra-textual), podemos preguntarnos la legitimidad de investigaciones arqueológicas al respeto y lo que podrían aportar a esta creación de sentido.

Pero tomemos un ejemplo que generó debates al interior de la misma arqueología bíblica para precisar las consecuencias de la oposición entre historia

\footnotetext{
${ }^{15}$ Para una magistral interpretación filosófica y filológica de la Torah podremos ver el libro de Josy Einsenberg y Armand Abécassis (Einsenberg \& Abécassis, 2004).
} 
y toldot: el caso complicado del Éxodo. Todos conocemos el libro famoso de los arqueólogos Finkelstein y Silberman que produjo un gran debate en la arqueología bíblica (Finkelstein \& Silberman, 2001) y más allá en el mundo académico. Tal como lo preguntan estos dos arqueólogos: ¿sería posible que lo que nos cuenta el segundo libro de la Biblia tenga alguna realidad histórica? Si bien disponemos de rastros arqueológicos -sobre todo pinturas- que nos indican la presencia de semitas en las tierras de Egipto, ¿qué podemos decir del Éxodo como tal? Según piensen los arqueólogos, este éxodo se hubiera producido alrededor del siglo XIII aC ya que aparece el pueblo de Israel en un jeroglífico -y uno soloegipcio. Podemos entonces bien imaginar que la arqueología bíblica apoya de manera muy fuerte la presencia de semitas en el Egipcio antiguo. Sin embargo, esta interpretación se enfrenta a problemas muy complicados a la hora de evaluar la realidad del Éxodo como tal. Efectivamente, tal como lo señala el libro de Finkelstein y Silberman, ¿cómo imaginar que una presencia de casi cuarenta años en el desierto del Sinaí, presencia de centenas de miles (600 000) de personas, no haya dejado ni el mínimo rastro que podamos encontrar hoy en día? Si tomamos a la arqueología bíblica en serio cuando nos aporta rastros a favor de la historicidad de la Biblia, también debemos tomarla en serio cuando pone en peligro esta misma his- toricidad. Y en lo que se refiere al Éxodo, estos dos arqueólogos plantean problemas que cuestionan a la Biblia como historia en su sentido griego. ¿Cómo imaginar que la huida de 600000 personas de un imperio que contaba con 3 millones de ciudadanos no haya producido consecuencias tremendas en el mismo imperio egipcio? Si Éxodo fuese un relato histórico en el sentido griego de la Historia, deberíamos encontrar rastros de este en el desierto del Sinaí, así como en las consecuencias que hubiera producido en el mismo imperio egipcio. Sin embargo, no encontramos ni lo uno ni lo otro. Notemos además que en este caso no podemos ni siquiera invocar un problema de cronología para salvar la historicidad griega del Éxodo, ya que cualquiera que sea el siglo en el cual se haya producido este éxodo, hubiera tenido que dejar algún rastro sobre el recorrido de las centenas de miles de hebreos y hubiera tenido que tener un impacto muy fuerte en el imperio egipcio.

Sin embargo, bien vemos una vez más que el cuestionamiento del carácter histórico del Éxodo solo es posible y concebible dentro de cierta concepción de la Historia, la concepción griega. Pero el tomar la perspectiva judía sobre el concepto de historicidad de la Biblia nos puede ayudar a avanzar en nuestras interpretaciones y precisar lo que se puede esperar de la arqueología bíblica. Es notable que si bien el libro de Finkels- 
tein y Silberman tuvo repercusiones fuertes en la arqueología bíblica y en la política que la utiliza, no tuvo casi ningún impacto en lo que se refiere a la teología judía. A pesar de los múltiples debates políticos, ningún rabino se escandalizó de la tesis defendida por este libro. Los rabinos, con su silencio, nos ayudan a entender cuál es el estatuto histórico de la Biblia para los judíos y lo que nos quieren decir cuando nos dicen que la Biblia es un libro de Historia. Los rabinos nos ayudan a entender en qué medida el relato del Éxodo tiene una función interpretativa según lo que requiere el concepto de Historia pensado como toldot, fuera de la tradición griega. Efectivamente, para los rabinos del Talmud, la función del Éxodo es la de hacernos entender cómo pasamos del hebraísmo al judaísmo (Abécassis, 2003) y por lo tanto el explicarnos como el judaísmo se presenta como relevo del hebraísmo, podríamos casi decir como Aufhebung del hebraísmo si aceptamos con Derrida que Aufhebung se debería traducir por relevo. Podemos entonces leer al Éxodo como toldot del pueblo judío (Historia como generación del pueblo judío), ha- ciéndonos entender que el pueblo judío únicamente puede liberarse de las leyes humanas que le oprimen (las leyes egipcias de faraón) si se somete a las leyes divinas reveladas en el Sinaí. De esta manera, el Éxodo no nos dice la verdad del pueblo judío (verdad entendida como adecuación de un discurso con una realidad) sino su sentido: el pueblo judío es un pueblo que solo puede existir mientras se somete a los mandamientos de Dios. De hecho, es notable para esta interpretación que en el judaísmo nada es sagrado de por sí: ni instrumentos, ni palabras, ni gestos, ni siquiera una tierra. Lo sagrado solo puede ser tal si el uso que se hace de él respeta las leyes divinas. Así, la arqueología bíblica que se focaliza sobre los rastros del Éxodo no podría, por definición, ni confirmar ni infirmar este, ya que se trata de sentido y no de la verdad del pueblo judío, de toldot y no de historia. El Éxodo nos daría entonces mucho más el sentido que la verdad del pueblo judío que es un pueblo que solo puede existir como pueblo judío en cuanto aplica, esté en donde esté, las leyes divinas que lo definen como pueblo.

\section{CONCLUSIÓN}

Podemos entonces imaginar, gracias a esta articulación de historia y to-dot, que coexisten en la Biblia y en los textos sagrados dos capas de interpretación articuladas como un palimpsesto hermenéutico ${ }^{16}$, lo cual nos permite pre-

${ }^{16}$ En este sentido, no es totalmente un azar, que uno de los más grandes filósofos judíos del siglo XX, Emmanuel Levinas, describa a su propia filosofía como un palimpsesto que se articula entre Atenas y Jerusalén: "La pre- 
cisar lo que podemos esperar de la arqueología bíblica. Algunos puntos de la Biblia sin duda plantean el marco histórico dentro del cual se desarrollan los eventos importantes, y este marco puede y debe ser estudiado por los arqueólogos para revelarnos el contexto preciso en el cual fueron redactados los textos. Así, la presencia de semitas en Egipto parece incontrastable, asimismo la crucifixión de un judío llamado leshoua en la parte oriental del imperio romano, en una región bajo la responsabilidad de un tal Pilates ${ }^{17}$. Sin embargo, más allá de la interpretación histórica de muchos eventos, podemos pensar con los rabinos que existen en la Biblia algunos textos cuyo único objetivo es el de darnos el sentido de la aventura humana más que su verdad; así, por ejemplo, el del Éxodo o el del Génesis. En estos casos la arqueología bíblica no nos es de ninguna ayuda para poder entender los textos ya que va más allá de sus capacidades epistemológicas.

Sin embargo ya que no podemos hacer a priori la diferencia entre estos dos tipos de texto (los que apuntan a la verdad y los que apuntan al sentido), el gran valor de la arqueología bíblica tal vez sea el de poder aclarar este punto, y el permitirnos distinguir entre los textos que se deben leer según la concepción griega de la Historia, de los textos que debemos interpretar según la concepción hebrea de toldot. Así al limitar el campo de investigación de la arqueología bíblica y sus pretensiones (sobre todo las de los defensores de la posición maximalista en arqueología bíblica que esperan encontrar en ella una confirmación y una justificación de su fe), ampliamos en realidad sus horizontes ya que más allá de su propia especificidad arqueológica, podemos hacer de ella una meta-ciencia que nos permite distinguir los textos que deben ser leídos con los ojos del historiador de los textos que deben ser interpretados con los ojos del creyente. Su valor no se limita entonces a aumentar nuestros conocimientos en arqueología ya que gracias a ellos encuentra un valor para los filósofos, los teólogos, antropólogos y cualquier ser humano que quiera encontrar posibles salidas del laberinto hermenéutico que representa la Biblia.

gunta tiene un alcance más general: las sagradas escrituras leídas y comentadas, en Occidente, ¿han inclinado la escritura griega de los filósofos o sólo están unidas a ellos teratológicamente? ¿Filosofar es descifrar en un palimpsesto una escritura oculta? " (Levinas, 2009, 129). Para una interpretación de la filosofía como palimpsesto en Levinas podremos ver el estudio de Benny Levy (Levy, 2009).

${ }^{17}$ Escribimos aquí "un tal Pilates" sin desprecio ninguno, solo queremos marcar que la arqueología bíblica no nos puede demostrar (ya que no entra dentro de sus competencias) que el Pilates histórico es el Pilates bíblico, ya que si la primera nos revela su verdad, la segunda solo se ocupa de su sentido. 


\section{BIBLIOGRAFÍA}

Abécassis, A. (2003). L'univers hébraïque-Du monde païen à l'humanisme biblique. Paris : Albin Michel.

Aristóteles (1999). De Interpretatione. Madrid: Tecnos.

Corbo, V. (1968). The house of St. Peter at Capharnaum: a preliminary report of the first two campaigns of excavations, April 16-June 19, Sept. 12-Nov. 26, Franciscan Print Press.

Deleuze, G. \& Guattari, F. (1991). Qu'est-ce que la philosophie? (2a. ed.). Paris: Editions de Minuit.

Descartes, R. (1984). Reglas para la dirección del espíritu. Madrid: Alianza.

Dureau, Y. (2001). Histoire des hommes et histoire divine dans l'œuvre de Shakespeare, Etude de deux pièces. En M. Viallon-Schoneveld (Ed.). L'Histoire et les historiens au XVIIe siècle (pp. 95-108). Saint Etienne : Publications de I'Université de Saint Etienne.

Einsenberg, J. \& Abécassis, A. (2004). Bible ouverte. Paris : Albin Michel.

Finkelstein, I. \& Silberman, N. (2001). The Bible Unearthed:Archaeology's New Vision of Ancient Israel and the Origin of Its Sacred Texts. New York: Free Press.

Girard, R. (1972). La violence et le sacré. Paris : Grasset.

Heródoto. (1985). L'enquête, traducción francesa de Andrée Barguet. Paris : Folio classique.

Heródoto. (2011). Los nueve libros de la Historia. Madrid: Ediciones Edaf.

Josefo, F. (1997). Antiguedades Judias. Madrid: Ediciones Akal.

Kuhn, T. (1962). The structure of scientific revolutions. Chicago: University of Chicago Press.

Lévi-Strauss, C. (2009). Mythologiques. Paris: Plon.

Levinas, E. (2009). El humanismo del otro hombre. Madrid: Siglo Veintiuno Editores.

Levy, B. (2009). Lévinas: Dieu et la philosophie, Séminaire de Jérusalem, 27 novembre 1996 - 9 juillet 1997. Paris : Verdier.

Marion, J-L. (2008). Sobre la ontología gris de Descartes. Madrid: Escolar y mayor. 
Marion, J-L. (2010). Dios sin el ser. Vilaboa: Ellago ediciones.

Mazar, E. (2008). Preliminary Report on The City of David Excavations 2005 at the Visitors Center Area. Jerusalén: Shalem Press.

Merz, A. \& Tieleman, T. (2008). The letter of Mara Bar Serapion: some comments on its philosophical and historical context. En A. Houtman (Ed.). Empsychoi Logoi. Religious Innovations in Antiquity. Studies in Honour of Pieter Willem van der Horst (pp. 107-134). Leiden: Brill.

Polibio. (2008). Historia de Roma. Madrid: Alianza Editorial.

Romilly, J. (1995). Alcibiade, les dangers de l'ambition. Paris : Fallois.

Sneh, A., Weinberger, R., Shalev, E. (2010). The Why, How, and When of the Siloam Tunnel Reevaluated. Bulletin of the American Schools of Oriental Research (359), 57-65.

Tucídices. (2005). Historia de la Guerra del Peloponeso. Madrid: Ediciones Cátedra.

Tuland, C. (1967). ZB in Nehemiah 3: 8 , A reconsideration of Maximalist and Minimalist Views. University Seminar Series, (5), 158-180.
Vlastos, G. (1991). Socrates, Ironist and Moral Philosopher. Cambridge: Cambridge University Press.

Van Voorst, R. (2000). Jesus outside the New Testament, an introduction to the ancient evidence. Cambridge: Eerdmans Publishing.

Woolley, L. (1929). Ur of the Chaldees. London: Ernest Benn Limited. 


\section{LENGUA Y LITERATURA}




\section{iFULL LINDO!: ACERCA DEL USO DE FULL EN EL HABLA DE ECUADOR}

\section{FULL LINDO!: THE USE OF FULL IN ECUADORIAN SPANISH}

\section{ANA ESTRELLA-SANTOS}





\section{¡FULL LINDO!: ACERCA DEL USO DE FULL EN EL HABLA DE ECUADOR}

\section{Ana Estrella-Santos ${ }^{1}$}

\section{RESUMEN}

Full es un anglicismo ampliamente usado en español, especialmente en expresiones como full-time y full-equipped. Otros usos, sin embargo, están restringidos diatópica y diastráticamente. El objetivo de este trabajo es analizar todos los usos de full en el habla de Ecuador, poniendo especial énfasis en su uso como intensificador (full linda y full bien) que es el menos estudiado. Para ello, se han hecho 45 encuestas directas a informantes quiteños de entre 18 y 26 años, se han analizado dos horas de grabaciones a jóvenes del mismo rango de edad, se ha hecho una búsqueda sistemática de ejemplos en Internet, y se han utilizado los corpus de la Academia de la Lengua para constatar los diferentes usos a lo largo de Hispanoamérica. Este estudio ha encontrado que el uso de full, en el registro informal, es general entre los jóvenes de Ecuador. Además, en el caso de las perífrasis de intensificación, full está reemplazando a bien, y, en esos contextos, full no pierde su significado inicial de 'lleno'y, por lo tanto, se evitan las expresiones como "full poco" o "full vacío". Desde el punto de vista pragmático, este uso de full funciona como distintivo del habla juvenil. Los otros usos -"a full" como locución adjetival y full como adjetivo- son también propios de la oralidad y del registro informal pero el rango de edad de quienes lo usan frecuentemente es mayor entre 18 y 54 años.

Palabras clave: intensificador, full, habla del Ecuador, dialectología, pragmática, anglicismo

\section{ABSTRACT}

Full is an Anglicism widely used in Spanish, especially in expressions like full-time and full-equipped. Other uses, however, are restricted geographically and diastratically. The aim of this paper is to analyze all the uses of full in Ecuadorian Spanish, with particular emphasis

1 Pontificia Universidad Católica del Ecuador, Facultad de Comunicación, Lingüística y Literatura, Quito, Ecuador (atestrellla@puce.edu.ec). 
on its use as an intensifier (full linda and full bien) that has not been thoroughly studied. To this end, we have: a) analyzed 45 surveys that were given to quiteños between 18 and 26 years old; b) examined two hours of recordings of subjects of the same age range; c) explored the Internet to look for examples of full; and d) researched the Corpus of the Academy of Spanish Language in order to verify the different uses of this word throughout Latin America. This study determined that young Ecuadorians are using full in the informal register. In addition, when full is used as an intensifier in periphrasis, full is replacing bien, and, in these contexts, full does not lose its original meaning of 'having no empty space' and, therefore, expressions as "full poco" or "full vacío" are rarely used. Pragmatically, this use of full functions as a distinctive trait within urban youth speech. Other uses - " a full" and full as an adjective - are also characteristic of spoken and informal register but the age range of those who frequently use it is broader: between 18 and 54.

Key words: intensifier, full, Ecuadorian Spanish, dialectology, pragmatics, Anglicism.

\section{INTRODUCCIÓN}

El objeto de este trabajo es analizar full en el habla de Ecuador. Para ello se describen sus usos en expresiones como full-time y full-equipped, como adjetivo, en locuciones adjetivales y adverbiales y como intensificador en perífrasis adjetivales y adverbiales (full linda y full bien). Todos estos aspectos se analizarán en este artículo; así, en primer lugar, se describirán su extensión y su uso a lo largo de Hispanoamérica. Después, se explicarán los usos en las locuciones adjetivales y cuando funciona como un adjetivo. Por último se estudiarán las características semánticas de su uso como intensificador, que es un fenó- meno relativamente nuevo y poco estudiado, descrito en el Diccionario de Americanismos (DA) para Ecuador, Colombia, Venezuela y Perú. Hay que apuntar que en el Corpus del Nuevo Diccionario Histórico del Español (CDH), full se encuentra ya en 1908, en una publicación de Perú ("pasara un auto a todo full"), y, aunque los diversos usos aquí descritos, solo aparecen a partir de la década del 80 del siglo pasado, podemos considerar que full en el español no es un fenómeno reciente, aunque como veremos, algunos de sus usos, sobre todo con el significado de'muy'y'mucho', sí lo son. 


\section{MATERIALES Y MÉTODOS}

Para la recogida de datos se hizo teniendo en cuenta cuatro métodos: a) 45 encuestas directas a 23 hombres y 22 mujeres que viven en Quito y cuyas edades oscilan entre 18 y 26 años. En estas encuesta se preguntó específicamente si usaban o no full y cómo lo usaban. Se pidió además un ejemplo². b) Un análisis de 2 horas de grabaciones. Estas grabaciones se hicieron con sujetos de edades similares (18 a 26 años). Aquí se les pidió que hablaran en grupo libremente. c) La búsqueda de ejemplos del uso de full en la red de Internet. Esta búsqueda no se centró solo en Ecuador sino también en otros países. d) La búsqueda en los diccionarios y corpus de la Academia: Diccionario de la Real Academia de la Lengua (DRAE), Diccionario de Americanismos (DA), Diccionario Panhispánico de Dudas (DPD), en el Corpus de Referencia del Español Actual (CREA), el Corpus del Español del Siglo XXI (CORPES) y el Corpus del Nuevo Diccionario Histórico del Español (CDH).

\section{EL USO DE FULL COMO PRÉSTAMO INTEGRAL}

El préstamo, entendido como la transferencia integral de un elemento léxico extranjero (Gómez Capuz, 2009), es un proceso frecuente de ampliación léxica. En Hispanoamérica y España se usan muchas expresiones con full, aun cuando su traducción podría ser muy sencilla. Por ejemplo, full-time, recogida en el DRAE, cuyo significado es"con dedicación exclusiva", no tiene ninguna marca diatópica, por lo cual se supone del español estándar. La primera vez que aparece en el CDH es en un texto de Bioy Casares, de Argentina, en 1962 ("quieren ocuparnos full time").
EI DPD añade, además, half-time ('con media jornada') y part-time ('con dedicación parcial o no exclusiva') y, aunque explica que hay formas equivalentes en español, no da consejos sobre su uso preferente. La Fundéu (2016) en cambio sí recomienda sus correspondientes en español. Esto da cuenta de la extensión de estas expresiones.

Otros préstamos similares que hemos encontrado en Ecuador, pero que también son frecuentes en otros países latinoamericanos y en España son full equipped, full edition, full frame, full $H D$. En el CREA para Ecuador solo hay

\footnotetext{
2 Para evitar la distancia entre entrevistador e informante, estas encuestas fueron hechas por los estudiantes del cuarto semestre de la materia de Lingüística, de la carrera de Comunicación de la PUCE, entre marzo y mayo del 2014.
} 
tres ocurrencias de full: una en la que es parte del título de una película y las otras dos son: full color y full equipo (refiriéndose a completamente equipadas). En el CORPES, en una búsqueda sin restricción geográfica, full HD aparece 84 veces; full speed, full caché, full service, 10 veces cada uno. Hay también cuatro ocurrencias de préstamos parciales como, full equipado, full color, full de ases o de reyes (para el juego de cartas).

\section{La locución adjetival ${ }^{3}$ a full}

La locución a full es frecuente en gran parte de Hispanoamérica. Aunque el DA considera que la restricción diatópica es Ecuador, Perú, Bolivia, Argentina, Paraguay y Uruguay, una búsqueda sistemática en las redes sociales, permite constatar que hay ejemplos de otros países como México y Venezuela. Según el DA, semánticamente esta locución tiene dos acepciones: si se refiere a una persona significa "muy ocupada o atareada" y, si no, es sinónimo de 'lleno'.

La primera acepción podría considerarse como una ampliación semántica de la primera. En el inglés estándar, full como adjetivo significa 'lleno', pero no significa nunca'muy ocupado'. Algunos enunciados en inglés con este significado son: "I'm packed today", "Today is packed for me" o "Today is jam-packed".

En el CORPES hay ejemplos de Ar- gentina, Ecuador, México y Uruguay. En el corpus recogido de las encuestas y en las grabaciones encontramos "Estoy a full" (estoy muy ocupado); "La fiesta estaba a full" (La fiesta estaba llena/a rebosar).

\section{La locución adverbial a full}

Ninguna de las dos acepciones recogidas por el DA en el apartado anterior servirían para explicar el uso de esta locución (recogida en las entrevistas) cuando modifica a un verbo: "Hablamos a full". En este caso significa "hasta el límite de las fuerzas o posibilidades". En el CORPES también se encuentran algunos ejemplos: "apoyarnos a full", "vivir la democracia a full" (Argentina), "trabajar a full" (Chile), "parece estar trabajando a full" (Uruguay).

\section{Full como adjetivo}

El DA proporciona dos acepciones de full como adjetivo (además de 'mucho' que se describe en la siguiente sección). La primera es 'lleno' que tiene las siguientes marcas diatópicas: Estados Unidos, México, República Dominicana, Puerto Rico, Colombia, Venezuela, Ecuador, Perú, Chile y Bolivia. En nuestro corpus hemos encontrado "estoy full", "el vaso está full de agua", "está full de canguil".

\footnotetext{
${ }^{3}$ Las categorías gramaticales que se usan en este artículo son las que consigna el DA bajo el lema full.
} 
La segunda acepción del DA se considera solo para Ecuador: "referido a una habitación, completamente amueblada". Esta acepción realmente no parece ser general en nuestro país, a pesar de que esté en el DA. Se hicieron 50 encuestas para preguntar sobre este punto ninguno de los encuestados dijo que entendiera "la habitación está full" como "completamente amueblada". Todos consideraron que significaba que estaba 'repleta' o 'muy llena'. Una búsqueda exhaustiva en la internet tampoco dio cuenta de este uso.

\section{Full como 'mucho' y'muy'}

El DA considera que, como equivalente a'muy'y'mucho', solo se usa en Colombia, Venezuela, Perú y Ecuador. Además, diastráticamente lo restringe al habla juvenil. En el habla de Ecuador, aunque hay algunas personas de mediana edad (entre 35 y 45) que lo usan, lo normal es que sea una característica de los jóvenes. Nuestras encuestas fueron hechas en Quito, pero el análisis de las redes sociales nos permitió ver que es un fenómeno que se da en todo Ecuador. No hay una restricción geográfica.

Al igual que ocurre con 'mucho', full, antepuesto al sustantivo, actúa como adjetivo con el significado de 'abundante': "full agua en las calles", "full hambre", "full comida", "me dijeron que iban a ir full personas a esa fiesta","fueron full gente al concierto", "tengo full calor", "hay full tráfico", "tengo full deberes".

Full también equivale a mucho cuando funciona como adverbio, con el significado de 'abundantemente o intensamente': "me gusta full esta comida", "trabajamos full", "comí full". En el CORPES, aparte de los países señalados en el DA, hay ejemplos de México ("andamos full'").

Full antepuesto a los adjetivos y adverbios es similar a 'muy' y sirve para construir el grado superlativo: muy pequeño es equivalente a pequeñísimo. De la misma manera full pequeño significaría pequeño en un grado superlativo. Así, al igual que 'muy', modifica la intensidad de la cualidad denotada por el adjetivo (full linda/muy linda) y cualifica a los adverbios (full bien/muy bien).

Cuando está antepuesto a los adjetivos, convive también con la perífrasis bien + adjetivo. Hay pues, tres formas para intensificar el valor de los adjetivos:

$$
\begin{aligned}
& \text { muy + adjetivo: muy linda } \\
& \text { bien + adjetivo: bien linda } \\
& \text { full + adjetivo: full linda }
\end{aligned}
$$

Entre estas tres formas no hay una alternancia libre, puesto que se usa en registros diferentes. También, desde el punto de vista semántico hay matices que los hacen distintos. 
Las diferencias entre muy y bien en perífrasis con un adjetivo han sido extensamente analizadas por Serradilla Castaño (2006) quien considera que la perífrasis bien + adjetivo es utilizada sobre todo en el habla coloquial, en lengua oral y"preferentemente por las mujeres $y$, dentro de este grupo, entre las de un nivel cultural más bajo, es decir, en aquellos casos en los que la presión de la norma es más débil" (p. 218). Puesto que no tenemos un estudio similar en Ecuador, consideramos que estos datos coinciden con lo que intuitivamente vemos en el habla ecuatoriana, aunque habría que contrastar con lo que Serradilla Castaño (2006) apunta en relación con el estrato de edad, quien encuentra que los jóvenes de entre 18 y 34 usan más la perífrasis bien + adjetivo que los de la generaciones mayores. En Ecuador, entre los jóvenes de niveles culturales bajos y altos, y especialmente en las ciudades, hay una tendencia a preferir la forma full + adjetivo como superlativo. La forma bien+ adjetivo se usa menos en este socioestrato. Esta perífrasis tiene una restricción de registro, ya que se considera coloquial o informal. De hecho, algo que la autora ha observado es que durante las exposiciones de los estudiantes universitarios (de edades entre 18 a 22 años), cuando alguien decía sin querer full ("esta parte es full interesante", "fue full difícil encontrar información"), el resto de la clase se reía ya que encontraba chocante este uso en una situación formal.
En las entrevistas se preguntó sobre el grado de intensificación. Las respuestas siempre fueron que full + adjetivo tenía un grado mayor que muy + adjetivo y que muchos no decían nunca bien + adjetivo. Algo similar ocurre cuando va antepuesto a un adverbio (full bien): funciona como muy, pero tiene la restricción de registro (es informal) y de edad (lo usan mayoritariamente los jóvenes). Al igual que ocurre con 'muy', full puede reduplicarse para intensificar su sentido "full, full rápido".

En los dos casos en los que es equivalente a muy (como intensificador de un adjetivo," full mala" o de un adverbio, "full mal") hay un matiz adicional. Veamos los siguientes ejemplos:
(1)Ya no deseo más, estoy full lleno
(2) El concierto estuvo full bien
(3) Full bacán
(4) Esa cosa está full berreada
(5) Full mal
(6) Full poco
(7) Full escaso
(8) Full vacío

Del análisis de las respuestas dadas en las 45 encuestas y de las grabaciones, se desprende que, en general, full, cuando modifica a los adverbios o adjetivos, tiene una connotación de cantidad positiva. Es decir, a diferencia de muy que es neutra en este sentido, full no suele ser el intensificador de adver- 
bios o adjetivos que signifiquen una pequeña o nula cantidad. Por ejemplo, en (6), (7) y (8) dos informantes explicaron que no usarían esas formas porque no tiene ninguna relación con el significado de full. Para uno de ellos, este tipo de uso era "ignorante". Otra informante explicó que una vez dijo full poquito y se sintió mal. Estas respuestas salieron espontáneamente, sin que hubiera una pregunta específica acerca de este uso restringido. Sin embargo cuando se hizo una encuesta específica con 50 informantes, el 90\% explicó que nunca usarían las formas (6), (7) y (8). En relación con otras connotaciones como características positivas (linda, interesante, fácil) o negativas (difícil, feo, asqueroso), el uso es indiferente.

Esta restricción indica que full mantiene su valor semántico de'lleno'que es lo que significa en inglés. De hecho, el Merriam Webster Dictionary (n.d.), apunta que full viene del antiguo germánico fol, del latín plenus, y este del griego plèrēs. En inglés puede funcionar como el adverbio very (muy): They knew full well they had lied to me, pero incluso en esto casos, el sentido de completamente, no se ha perdido. Además es una forma que funciona en frases hechas, generalmente con well. En el habla estándar se prefiere el adverbio fully. Full no se usa en enunciados como full difficult, full good.

\section{¿Por qué se usa full?}

Dejando de lado el préstamo integral en expresiones que se transfieren directamente del inglés del tipo full-time, y que no tienen restricción de registro ni de edad, los otros usos descritos en este artículo se consideran coloquiales y propios de la oralidad. La perífrasis a full y full como 'lleno' tienen un uso más extendido y en relación con la edad ya que es común entre los de 18 a 34 y los de 35 a 54. Es menos usada a partir de los 55.

La revisión de las grabaciones del habla juvenil de Quito permitió ver que full reemplaza a bien. No hubo en el corpus analizado ningún caso en el que se usara bien como perífrasis de intensificación, pero sí hubo ejemplos del uso de muy. El uso como intensificador (ya sea como adjetivo o como adverbio) tiene, por lo tanto, una restricción muy clara en relación con la edad. Es difícil analizar la necesidad de esa intensificación. ¿Qué le aporta al hablante full que no tengan ya bien o muy? Sin duda, full actúa como un distintivo del habla juvenil. Un 73\% de los entrevistados consideró, además, que este era un uso propio de los ecuatorianos. Aunque, como hemos visto, esto no es verdad, desde el punto de vista pragmático funciona también como una particularidad diatópica. Rodríguez (2002) citado por Jørgensen y López (2007) considera que el habla juvenil se caracteriza por "una selección 
que tiene que ver con el distinto grado de inseguridad y competencia lingüística en los grupos de edad inferior. Así son los jóvenes los que exhiben un mayor empleo de muletillas y un estilo verbal menos cualitativo" (p. 2). La inse- guridad lingüística, por lo tanto, crea un espacio para identificarse como grupo y marcar las diferencias con las generaciones mayores. Además, está el hecho de que el uso de vocablos en inglés tienen una marca positiva (Zimmerman, 2002).

\section{CONCLUSIONES}

El uso de full es general entre los jóvenes de Ecuador. Aunque algunos usos como los préstamos integrales o la locución a full, se empezaron dar en las personas que actualmente tienen entre 30 y 50 años; los otros usos, especialmente como intensificador, son más recientes. Este no es un fenómeno exclusivo del Ecuador y su uso pudo haberse propagado desde otros lugares como Colombia que goza de una apreciación lingüística positiva. Además, la televisión puede haber jugado un papel importante en esta irradiación, debido a la gran cantidad de programas colombianos que se trasmiten en los canales abiertos de Ecuador. El análisis que se ha realizado ha permitido ver los diferentes significados y usos que se da a full. Además, se ha visto que, en el caso de las perífrasis de intensificación, el full está reemplazando a bien. Además, es importante resaltar que, en esos contextos, full no pierde su significado inicial de 'lleno' $y$, por lo tanto, se evitan las expresiones "full poco" o"full vacío". Puesto que el uso como intensificador es relativamente reciente, es difícil saber si se trata de un fenómeno efímero o si, como en los otros casos (full como lleno y la locución a full), se va mantener como una marca coloquial y oral del español de ciertas regiones. 


\section{BIBLIOGRAFÍA}

Asociación de Academias de la Lengua Española (2010). Diccionario de americanismos. Madrid: Santillana. Disponible en http://lema.rae.es/damer

Fundéu BBVA - Fundación del español urgente (2015). Disponible en http:// www.fundeu.es/

Gómez Capuz, J. (2009, julio). El tratamiento del préstamo lingüístico y el calco en los libros de texto de bachillerato y en las obras divulgativas. TONOS. Revista Electrónica de Estudios Filológicos 17. Disponible en https://www.um.es/tonosdigital/znum 17/secciones/tritonos-1-librosdetexto.htm

Jørgensen, A. M. y López, J.A. (2007, agosto). Los marcadores del discurso del lenguaje juvenil de Madrid. Revista Virtual de Estudos da Linguagem - ReVEL. 5 (9). Disponible en www.revel.inf.br

Merriam Webster Dictionary (n.d.). Disponible en: http://www.merriam-webster .com/dictionary

Real Academia Española (2014). Corpus del nuevo diccionario histórico del español $(\mathrm{CDH})$. [en línea]. Disponible en: http://www.rae.es.
Real Academia Española (2014). Banco de datos (CORPES XXI), Corpus del español del siglo XXI [en línea]. Disponible en: http://www.rae.es/recursos/banco dedatos/corpes-xxi.

Real Academia Española (2014). Banco de datos (CREA). Corpus de referencia del español actual [en línea]. Disponible en: http://www.rae.es.

Real Academia Española (2014, 23a ed.). Diccionario de la lengua española (DRAE). Madrid: Espasa-Calpe. Disponible en http://lema.rae.es/

Serradilla Castaño, A. (2006). "BIEN" + adjetivo como perífrasis de superlativo en español. Particularidades semánticas y sintácticas. Verba 33: 215-233. Disponible en http://hdl.handle.net/10347/ 3461

Zimmermann, K. (2002). La variedad juvenil y la interacción verbal entre jóvenes. En: F. Rodríguez. El lenguaje de los jóvenes, Barcelona: Ariel. 

MEDICINA 


\section{APLICACIÓN DEL TEST DE FUKUDA PARA IDENTIFICACIÓN DE}

ALTERACIONES PROPIOCEPTIVAS EN PACIENTES PRE Y POSQUIRÚRGICOS DE EXTRACCIÓN DEL TERCER MOLAR, EN EL HOSPITAL
"PABLO ARTURO SUÂREZ"

USE OF THE FUKUDA TEST TO IDENTIFY PROPRIOCEPTIVE ALTERATIONS IN PATIENTS BEFORE AND AFTER THIR MOLAR REMOVAL SURGERY IN PABLO ARTURO SUAREZ HOSPITAL

SUSANA ARGÜELlO P. CRISTINA DÍAZ C. ADRIÁN RUBIO

Recibido 15 de marzo de 2016 Aceptado 8 de abril de 2016 



\title{
APLICACIÓN DEL TEST DE FUKUDA PARA IDENTIFICACIÓN DE ALTERACIONES PROPIOCEPTIVAS EN PACIENTES PRE Y POSQUIRÚRGICOS DE EXTRACCIÓN DEL TERCER MOLAR, EN EL HOSPITAL "PABLO ARTURO SUÁREZ"
}

\author{
Susana Argüello P. ', Cristina Díaz C. ${ }^{2}$, Adrián Rubio ${ }^{3}$
}

\section{RESUMEN}

El presente estudio se realizó en los meses de julio-agosto de 2015, en el área de cirugía maxilofacial del hospital "Pablo Arturo Suárez", con el objetivo de determinar si existe una variación en cuanto a la propiocepción en pacientes que son extraídos los terceros molares, por medio de la aplicación del Test de Fukuda.

La investigación ejecutada fue de tipo exploratoria, prospectiva, observacional y longitudinal. La muestra obtenida fue de 30 pacientes entre 16 a 56 años, de los cuales 13 son hombres y 17 mujeres. Los criterios de inclusión fueron que tuviesen al menos dos terceros mo- lares uno a cada lado y que no presentasen patologías vestibulares, otitis, y alteraciones en la propiocepción por enfermedades del sistema nervioso. Se comprobó que existe una diferencia significativa $(p<0,013)$ en el desplazamiento en centímetros después de la extracción de los terceros molares, pero no existe una diferencia significativa en los grados de los giros.

Palabras clave: articulación temporomandibular, Propiocepción, Terceros molares, Test de Fukuda.

\section{ABSTRACT}

This study used the test Fukuda to

\footnotetext{
1 Pontificia Universidad Católica del Ecuador, Facultad de Enfermería, Quito, Ecuador (smarguello@puce.edu.ec).

2 Pontificia Universidad Católica del Ecuador, Facultad de Enfermería, Quito, Ecuador (acdiaz@puce.edu.ec).

${ }_{3}^{3}$ Pontificia Universidad Católica del Ecuador, Facultad de Enfermería, Quito, Ecuador (adrian_rb@hotmail.com).
} 
determine some variation in proprioception in patients whose third molars were removed in the area of maxillofacial surgery at Pablo Arturo Suarez' hospital conducted in the months of July-August 2015.

The research was exploratory, prospective, observational and longitudinal. The sample included 30 patients aged 16-56 years, 13 of whom were men and 17 women; the inclusion criteria was that they had two third molars on each side, which caused vestibular diseases, otitis, and proprioception alterations with nervous system diseases. This research found a significant difference ( $p$ $<0.013$ ) in the displacement in centimeters after removal of third molars, but there were no significant difference in the degrees of turns.

Keyword: temporomandibular joint, proprioception, third molars, Fukuda test.

\section{INTRODUCCIÓN}

La propiocepción hace referencia a la capacidad del cuerpo de detectar el movimiento y posición de las articulaciones. Es importante en los movimientos comunes que realizamos diariamente $y$, en especial, en los movimientos deportivos que requieren una coordinación especial.

Los trastornos temporomandibulares no solo se pueden asociar debido a su cercanía con la posición de la mandíbula y del cráneo, sino también con la columna cervical, torácica, lumbar, la musculatura supra e infrahioidea, los hombros que funcionan como una unidad biomecánica. Por lo tanto, los cambios en cualquiera de estos componentes podrían desencadenar alteraciones en el sistema estomatognático (Montero y Denis, 2013).
Una alteración a nivel de la articulación temporomandibular (ATM) puede aparecer a cualquier edad y en cualquier circunstancia de la vida, ya que las posibilidades son diversas y van desde un simple golpe en la zona, hasta el aparecimiento de nuevas estructuras óseas (tercer molar).

Son muchos los pacientes que sufren de inestabilidad, mareos, cefaleas, jaquecas, vértigo, dolores de columna cervical, lumbalgias o ciáticas repetitivas, entre otras patologías, que acuden a consulta a la unidad de cirugía maxilofacial del hospital "Pablo Arturo Suárez", y que debido a la falta de coordinación y conocimiento no se remite al área de rehabilitación física del hospital "Pablo Arturo Suárez" para efectuar un trabajo interdisciplinario. 
El test de Fukuda es un estudio de equilibrio dinámico que evalúa la descompensación lateral e hipertonía de un individuo, en el que se pide al paciente que con los ojos cerrados y los brazos extendidos a $90^{\circ}$ hacia al frente realice una marcha modo soldado (en su propio terreno) de 50 pasos alrededor de un minuto; si la persona se mantiene en el mismo sitio, la prueba es negativa y si existen giros mayores a $30^{\circ} \mathrm{o}$ el paciente avanza más de dos metros al cabo de los 50 pasos, es positiva. El lado de la desviación se le considerará hipofuncional (Bri$\cot B, 2008)$.
A pesar de algunas evidencias en contra, la mayoría de las investigaciones demuestran que los disturbios musculares posturales son más frecuentes en pacientes con trastornos temporomandibulares y establecen algún tipo de correlación entre el tipo de oclusión, la existencia de signos y síntomas de los trastornos temporomandibulares, dimensiones craneofaciales y el desequilibrio postural (Montero 2012); por lo cual se realiza esta investigación para determinar por medio de la aplicación del test de Fukuda la variación de la propiocepción previa y posterior a la extracción del tercer molar en los pacientes del área de cirugía maxilofacial del hospital "Pablo Arturo Suárez".

\section{HIPÓTESIS}

Existe una mejoría en la propiocepción de pacientes de la unidad de cirugía maxilofacial del hospital "Pablo Arturo
Suárez" luego de la extracción de los terceros molares.

\section{OBJETIVOS}

Identificar, por medio de la aplicación del test de Fukuda, la variación de la propiocepción, posterior a extracción del tercer molar en pacientes del área de cirugía maxilofacial del hospital "Pablo Arturo Suárez".

\section{MATERIALES Y MÉTODOS}

Es un estudio tipo exploratorio, prospectivo, observacional, longitudinal. El grupo de estudio son los pacientes que han sido sometidos a extracción de los terceros molares, quienes fueron evaluados luego de siete días de la extracción.
El estudio fue realizado en 30 pacientes entre las edades de 16 y los 56 años, que tuvieron al menos dos terceros molares uno a cada lado, que no presentaban alteraciones en la propiocepción como consecuencia de alguna patología 
base como síndrome de Menier, Otitis, inicios de Parkinson, además de patologías asociadas a problemas vestibulares.

Para el género femenino, el promedio de edad es 23.7 años ( $\mathrm{DE}=9.4$ años), con un valor mínimo de 16 y un máximo de 56. Para el género masculino, el promedio de edad es 24.22 años ( $D E=11.51$ años), con un valor mínimo de 16 y un máximo de 51.

Para realizar el test de Fukuda el paciente se ubicaba en un sitio con el menor ruido posible, descalzo, con los ojos cerrados, marcha con una altura del muslo a $45^{\circ}$, la cabeza en posición neutra, los maxilares en posición de reposo (sin con- tacto dental), los brazos a 90 grados de flexión. Se filmó la ejecución de la prueba.

Las variables estudiadas fueron las siguientes: diferencia del desplazamiento en cm del test de Fukuda pre- y posextracción de los terceros molares y variación de los grados de giro del test de Fukuda pre-y poscirugía.

El Análisis estadístico se lo realizó sobre la base de medidas de tendencia central, de dispersión, y prueba " $T$ " de comparación de medias relacionadas, usando las herramientas informáticas de Microsoft Excel versión 2010 y SPSS versión 23.

\section{RESULTADOS}

Tabla 1. Medidas de tendencia central y dispersión de los parámetros del Test de Fukuda

\begin{tabular}{|l|c|c|c|c|}
\hline Media & $\begin{array}{c}\text { Desplazamiento } \\
\text { preextracción } \\
(\mathrm{cm})\end{array}$ & $\begin{array}{c}\text { Desplazamiento } \\
\text { posextracción } \\
(\mathrm{cm})\end{array}$ & $\begin{array}{c}\text { Grados de } \\
\text { desviación } \\
\text { preextracción }\end{array}$ & $\begin{array}{c}\text { Grados dé } \\
\text { desviación } \\
\text { posextracción }\end{array}$ \\
$\begin{array}{l}\text { Desviación estándar } \\
\text { Mínimo }\end{array}$ & 39,3 & 31,3 & 55,6 & 52,5 \\
Máximo & 10 & 17,9 & 38,3 & 37,8 \\
\hline
\end{tabular}

En la tabla 1 se observa que existe disminución del desplazamiento en la aplicación del test de Fukuda, después de la extracción de los terceros molares. La media de desplazamiento precirugía es de $39.33 \mathrm{~cm}$ y poscirugía es de 31.3 $\mathrm{cm}$. Existe una diferencia entre datos máximos pos y pre de $20 \mathrm{~cm}$. El dato máximo de distancia recorrida antes de la extracción es de $110 \mathrm{~cm}$, y después de la cirugía el dato máximo es de $90 \mathrm{~cm}$. 
Otro parámetro del test de Fukuda son los grados de desviación, los cuales en la tabla 1 no presentan un gran cambio antes y después de la cirugía de los terceros molares. La media posextracción es de $52.5^{\circ}$ y preextracción es de
55.6 . La diferencia entre datos máximos pos y pre de $5^{\circ}$. El dato máximo de grados de desviación antes de la extracción es de $130^{\circ}$, y después de la cirugía el dato máximo es de $125^{\circ}$.

Tabla 2. Prueba de muestras relacionadas de la distancia de desplazamiento pre- y posextracción del tercer molar

\begin{tabular}{|l|c|c|c|c|c|}
\hline & \multicolumn{2}{|c|}{$\begin{array}{c}\text { Diferencias relacionadas } \\
95 \% \text { Intervalo de confianza } \\
\text { para la diferencia }\end{array}$} & Media & Desv. est. & Sig. (bilateral). \\
\cline { 2 - 5 } & $\begin{array}{l}\text { Inferior } \\
\text { Superior }\end{array}$ & $-14,2$ & -8 & 16,5 & 0,013 \\
\hline $\begin{array}{l}\text { Diferencia entre } \\
\text { distancia posextracción y } \\
\text { distancia preextracción. }\end{array}$ & $-1,8$ & -8 & & \\
\hline
\end{tabular}

En la tabla 2 de la prueba estadística de diferencias relacionadas, entre la distancia posextracción y preextracción de los terceros molares existe un $\mathrm{p}<0,05$ (0.013), concordando con la tabla 1, que se observaba una disminución de la distancia poscirugía. Existe una media de $8 \mathrm{~cm}$ de la diferencia entre la distancia pos- y preextracción de los terceros molares. El menor dato de la diferencia entre distancia pos- y preextracción de los terceros molares es de -1.8 y el máximo dato es de $-14,2$.

Tabla 3. Prueba de muestras relacionadas de los grados de desviación pre- y posextracción del tercer molar

\begin{tabular}{|c|c|c|c|c|c|}
\hline & \multicolumn{2}{|c|}{$\begin{array}{l}\text { Diferencias relacionadas } \\
95 \% \text { Intervalo de confianza } \\
\text { para la diferencia }\end{array}$} & \multirow[t]{2}{*}{ Media } & \multirow[t]{2}{*}{ Desv. est. } & \multirow[t]{2}{*}{ Sig. (bilateral). } \\
\hline & Inferior & Superior & & & \\
\hline $\begin{array}{l}\text { Diferencia entre grados de } \\
\text { desviación posextracción } \\
\text { y preextracción. }\end{array}$ & $-9,8$ & $-16,2$ & $-3,2$ & 34,8 & 0,62 \\
\hline
\end{tabular}


En la tabla 3 de la prueba estadística de diferencias relacionadas, entre los grados de desviación posextracción y preextracción de los terceros molares existe un $\mathrm{p}>0,05$ (0.622), concordando con la tabla 1, que se observaba que no existe una disminución considerable de los grados de desviación poscirugía.
Existe una media de $-3.2^{\circ}$ de la diferencia entre los grados de desviación post- y preextracción de los terceros molares. El menor dato de la diferencia entre los grados de desviación pos- y preextracción de los terceros molares es de $-9.8^{\circ}$ y el máximo dato es de $-16,2^{\circ}$.

\section{DISCUSIÓN}

El mantenimiento de la postura está dado por el sistema nervioso central y periférico, el tono muscular, la propiocepción, el sistema vestibular, el sistema visual, la alineación estructural. Si algunos de estos elementos se encuentran alterados la postura se modifica (Toussaint, Y. 2008).

El test de Fukuda evalúa la propiocepción en la postura, y si existe una disfunción periférica, el paciente se desvía más de 30 grados desde el eje sagital. Además, los valores de vaivén lateral amplios y permanentes sugieren una patología central (Schneider D, 2011).

El mencionado test se realiza con el cierre de los ojos; pues sin visión, es casi imposible pisar en el mismo lugar y no desviarse $30^{\circ}$. Estudios del test de Fukuda con estímulos visuales del uso de gafas de realidad virtual corroboran que no existen modificación en los resultados del test, pero la influencia vestibular con pruebas calóricas de irrigación en el oído sí modifican los resultados del test de Fukuda aumentando los grados de desviación hacia el oído estimulado (Marques B, 2014).

Se han realizado estudios modificando el test para determinar si los factores de ritmo impuesto, de doble tarea, o con el cuello doblado influyen en los grados de desviación, y se ha observado que con la cervical flexionada se aumentaron los grados de desviación (Toussaint, Y. 2008).

La aplicación del test de Fukuda con verificación craneocorpografía digital, en pacientes con síndromes cervicales agudos, presenta variación en los grados de desviación (Alpini, D. 2013).

Recientemente se han relacionado alteraciones oclusales funcionales con enfermedades posturales, en su mayoría sobre una base clínica. Sin embargo, algunos aspectos anatómicos y fisiológicos son todavía desconocidos. Sujetos 
con una mala oclusión de clase II al ser evaluados en plataformas de equilibrio, presentan una postura con alteración en la cadena muscular anterior, mientras que los sujetos con una mala oclusión clase III presentan una postura con alteración en la cadena muscular posterior (Nobili A, Adversi R. 2006).

El uso prolongado de aparatos bucales tipo MORA induce a algunas fluctuaciones en la actitud postural dinámica al ser evaluados con el Test Fukuda. Los efectos de retroalimentación son graduales después de retirar la férula mandibular (Milani, RS. 2011).
En este estudio se observa en la tabla 1 y 3 que existe una variación significativa en el test de Fukuda después de extraer el tercer molar en el parámetro de desplazamiento pero no en la desviación en grados. Sin embargo, las limitaciones que tiene esta investigación se deben al tiempo de ejecutada la segunda prueba de Fukuda, pues el paciente todavía estaba en el proceso de desinflamación propia de la intervención quirúrgica, por lo que se hacen necesarias evaluaciones luego de un tiempo más prolongado para evaluar la variación de la propiocepción en el tiempo.

\section{CONCLUSIONES}

Esta investigación demuestra que la mala posición de los terceros molares puede alterar la propiocepción, que en última instancia es necesaria para mantener un adecuado control postural, por lo cual se precisa la extracción de estos molares, no solo con el objetivo de mejorar estéticamente la mordida, sino también para que la información propioceptiva que envía la ATM al sistema nervioso central pueda ser la correcta, para que este elabore las respuestas motoras adecuadas que determinan un adecuado equilibrio corporal.

A la extracción de los terceros molares existe una disminución de las alteraciones propioceptivas, específicamente en el desplazamiento longitudinal, mientras que las desviaciones en grados son poco significativas. 


\section{BIBLIOGRAFÍA}

Alpini D. (2004). Evaluation of head-to-trunk control in whiplash patients using digital CranioCorpoGraphy during a stepping test. Gait and Posture. 22 (4) 308-316. Recuperado de: http://www. gaitposture.com/article/S09666362(04)00202-4/abstract.

Bricot B. (2008). Postura normal y postura patológica. Revista IPP, 1 (2). 1-13.

Marques B. (2010). Influencia de la estimulación vestibular y visual en fracción de banda para caminar. Springer link. 183 (4) 457 -463. Recuperado de: http://link.springer.com/article/10.100 7\%2Fs00221-007-1063-4.

Milani RS. De Perière D. Lapeyre L. Pourreyron L. (2000). Relationship between dental occlusion and posture. Cranio. 18(2)34 - 127. Recuperado de: http:// www.ncbi.nlm.nih.gov/pubmed/1120 2823.

Montero J. Denis. (2013). Los trastornos temporomandibulares y la oclusión dentaria a la luz de la posturología moderna. 50 (2). Recuperado de: http://scielo.sld.cu /scielo.php?pid=S0034750720130004 00008\&script=sci_arttext\&tlng=pt.
Nobili A, Adversi R. (2006). Relationship between posture and Occlusion: a clinical and experimental investigation. Cranio 14(4):85 - 274. Recuperado de: http:// www.ncbi.n/m.nih.gov/pubmed/9110 621.

Schneider D (2011). Cranio-corpo-graphy. A neurootological screening test. Acta Otorhinolaryngol Belg. 45(4). Recuperado de: http://www.ncbi.nlm.nih.gov /pubmed/1767670.

Toussaint Y. (2008). What are the factors responsible for the deviation in stepping on the spot? 435 (1) 60 - 64. Recuperado de: http://www.sciencedirect.com/sci ence/article/pii/S030439400800181X. 


\title{
TECNOLOGÍAS EN INFORMACIÓN Y COMUNICACIÓN SANITARIA
}

\author{
SANITARY INFORMATION \\ AND COMMUNICATION TECHNOLOGIES
}

MIRIAM ELENA BUITRÓN

ENRIQUE GEA MARÍA VERÓNICA GARCÍA 



\title{
TECNOLOGÍAS EN INFORMACIÓN Y COMUNICACIÓN SANITARIA
}

\author{
Miriam Elena Buitrón Vega' ${ }^{1}$ Enrique Gea-Izquierdo 1,2, \\ María Verónica García-Oquendo 3
}

\section{RESUMEN}

La cibersalud, conocida como eSalud, consiste en el uso de las tecnologías de la información y la comunicación en la salud, y otras áreas como la educación y la investigación. La salud es uno de los sectores en los que el uso de las TIC ha penetrado en forma intensiva, usándose en casi todos los ámbitos desde las políticas, la planificación, la información, la investigación, la promoción, prevención, diagnóstico, hasta el tratamiento y rehabilitación de la salud. La confluencia de la ciencia y tecnología, junto con otras prestaciones, transforman la eSalud en un sistema complejo con orientación hacia la salud integral, más allá de la interconexión entre sus componentes. Hay avances sobre la aplicación de las TIC en la salud en el Ecuador, pero pese a las po- tencialidades para mejorar el acceso y calidad de los servicios, estas no han sido completamente explotadas o implementadas en el país. El uso de las TIC en salud enfrenta un complejo marco legal; la autoridad y actores que intervienen en el proceso regulatorio son múltiples, lo cual implica ventajas y limitaciones para su utilización y desarrollo.

Palabras clave: eSalud, tecnologías de la información y comunicación, marco legal.

\section{ABSTRACT}

E-Health is the use of information and communications technology in health and other areas such as education and research. Health is one of the sectors in which the use of ICT has penetrated

\footnotetext{
1 Pontificia Universidad Católica del Ecuador, Facultad de Medicina, Quito, Ecuador (mebuitron@gmail.com). 'Pontificia Universidad Católica del Ecuador, Facultad de Medicina, Quito, Ecuador.

2Universidad de Málaga, Cátedra de Seguridad y Salud en el Trabajo, Málaga, España (enriquegea@yahoo.es).

${ }_{3}^{3}$ Pontificia Universidad Católica del Ecuador, Facultad de Psicología, Quito, Ecuador (mvgarcia@puce.edu.ec).
} 
intensively. It is said to be found in almost all areas from policy, planning, information, research, advocacy, prevention, diagnosis to treatment and rehabilitation of health. In health, the convergence of science and technology with other advances, make e-health in a complex field whose challenge is the provision of comprehensive health and not merely the possibility of interconnecting their components. There is progress in implementing health in Ecuador, but despite the potential of ICT to improve access and quality of health services, these have not been fully exploited or implemented in the country. The use of ICT in health faces a complex legal framework, authority and actors involved in the regulatory process are multiple, which implies advantages and limitations for application and development.

Key words: eHealth, information and communication technologies, legal framework.

\section{INTRODUCCIÓN}

Hasta principios del siglo XX la práctica médica se realizaba con pocos recursos, que consistían principalmente en la formación profesional como médico o doctor y su maletín. Generalmente, la casa, la habitación del enfermo era el lugar utilizado para el diagnóstico, tratamiento y recuperación del paciente con el apoyo de familiares y vecinos; los hospitales eran destinados a aquellos enfermos de escasos recursos económicos.

La medicina evolucionó significativamente, concomitantemente al desarrollo de la física, la fisiología, la ingeniería, la microbiología, etc. que fueron aplicadas al diagnóstico y tratamiento de las enfermedades. El descubrimiento de los Rayos X de W.K. Roentgen, en 1895; el electrocardiograma por Willem Einthoven, en 1903; y el desarrollo de los hos- pitales que dejaron de ser receptores de pacientes pobres y pasaron a ser instituciones para todos los miembros de la sociedad fueron innovaciones significativas para la medicina en el siglo pasado.

En las últimas décadas la innovación tecnológica ha cambiado rápidamente cada una de las facetas de nuestra forma de vida, modificando las relaciones personales que se trasladan a un ambiente no presencial o virtual (Torres Velandia \& García Ponce de León, 2008). Además, hay una preocupación creciente por diversas instancias en el uso de las TIC en salud (Ramos, 2006) y por ende en sus implicaciones en aspectos políticos y sociales. Este trabajo es una aproximación a las aplicaciones, los beneficios y el marco normativo que rige en el Ecuador. 


\section{MÉTODO}

El trabajo es de carácter descriptivo, en donde se realizó un estudio documental con énfasis en la aplicación de las TIC en Salud y un análisis del marco legal vigente en el Ecuador, así como de ciertos organismos internacionales y regionales como Organización Panamericana de la Salud y Comunidad Andina de Naciones.
Se identificaron las principales normas vigentes referentes a salud, telecomunicaciones y TIC, y se analizaron las reglamentaciones fundamentales. Se examinaron contenidos de textos político-normativos de los principales documentos legislativos, como la Constitución (2008), Plan Nacional para el Buen Vivir (PNBV), leyes, decretos y acuerdos.

\section{EL SECTOR SALUD Y LAS NUEVAS TECNOLOGÍAS}

Según la Organización Mundial de la Salud (OMS), la cibersalud, conocida como eSalud', consiste en el uso eficaz y seguro de las tecnologías de la información y la comunicación en la salud y otros ámbitos como los servicios médicos, la vigilancia, el registro sanitario, la educación y la investigación en materia de salud. (Organización Panamericana de la Salud/Organización Mundial de la Salud, 2011) Su evolución ha permitido el desarrollo de otras ramas como son la salud móvil (mHealth) que mediante el uso de dispositivos inalámbricos (teléfonos móviles, equipos de monitorización de pacientes, asistentes personales digitales y otros aparatos) apoyan la práctica de la medicina, la decisión clínica y la salud pública.

Eysenbach (2001) define a ehealth como un campo emergente resultante de la unión de la informática médica, la salud pública y los negocios. La eSalud involucra la interacción del software, hardware, telecomunicaciones e internet. Por una parte el uso de las TIC sirve para apoyar y habilitar servicios de atención médica y otras acciones de salud, mientras que por otra la interoperabilidad proporciona la capacidad a los sistemas y a las organizaciones para comunicarse, intercambiar datos, compartir e integrar información, conocimiento y procesos de manera fácil, segura y fluida, comúnmente haciendo uso de estándares y prácticas de trabajo comunes y compatibles.

Sin duda las TIC permiten ordenar los procesos y flujos de información, la comunicación y coordinación entre cen-

${ }^{1} \mathrm{O}$ eHealth en su terminología en inglés. 
tros prestadores, asegurando información oportuna y de calidad para la atención de salud. También permite reflexionar sobre la forma en que se entrega la atención en salud, el modo en que los profesionales y las instituciones se relacionan con los pacientes. Por tanto, los beneficios de estas nuevas tecnologías, tanto en la medicina como en la salud pública, son múltiples. De hecho, facilita la accesibilidad de los pacientes al sistema de salud, eliminando barreras geográficas, orientando que la prestación de servicios a través de telemedicina no requiera el traslado de los pacientes a los centros sanitarios. La implantación de las nuevas tecnologías de telemedicina podría ser una estrategia para mejorar el modelo actual de prestación de servicios de salud, sustituyendo la lógica de tratar enfermedades por la atención integral cuyo interés es el paciente, planteamiento tanto más necesario cuanto que la población envejece y el número de personas que requieren atención crónica va en aumento. (Rabanales Sotos, Párraga Martínez, Lopez-Torres, Prétel \& Navarro Bravo, 2011) Además, permiten obtener una amplia información de una manera rápida y sencilla mejorando la eficacia y racionalizando el gasto del sistema de salud.

\section{APLICACIÓN DE LAS TIC EN SALUD}

La aplicación de las TIC se realiza en un amplio rango de aspectos que afectan el cuidado de la salud, relacionada no solamente con la atención médica que requieren las personas en forma individual sino incluyendo los servicios de salud, la salud pública y la formación de profesionales y los pacientes. En la prevención, diagnóstico, tratamiento y rehabilitación de pacientes se podría decir que las TIC son aplicables en todos los campos médicos; esto ha dado lugar el desarrollo de la telemedicina que, actualmente, incluye distintos servicios: cirugía, teleradiología, teleconsultas, telefotografía y diagnóstico remoto por imagenología digital térmica.
(Sainz de Abajo, Rodrigues, García Salcines, Burón Fernandez, López Coronado \& de Castro Lozano, 2011) La telemedicina es una herramienta que puede servir para eliminar las barreras geográficas, sociales o culturales. Su aplicación permite proveer atención sanitaria sin importar dónde se encuentre el paciente y el profesional de la salud. (Avella Martínez \& Parra Ruiz, 2013)

Teniendo en cuenta el papel fundamental de las TIC en la salud, la convergencia de distintos elementos como la ciencia y tecnología, la informática, las telecomunicaciones y servicios de alto valor agregado como el internet convier- 
ten a la eSalud en un campo complejo cuyo reto es la provisión de salud integral y no solamente la posibilidad de interconectar los componentes del sistema de salud. De hecho hay que considerar no solo las necesidades de infraestructura tecnológica sobre la que debe funcionar sino la interoperabilidad que permite el intercambio de datos y formas de pensar diferentes. (Carnicero \& Fernández, 2012)

Además, la salud es un tema sensible, dependiendo de las características del sistema de cada país la aplicación de las TIC tendrá un impacto mayor o menor en cada uno de sus componentes. Entendemos como sistema de salud a las instituciones, las personas y los recursos implicados en la prestación de atención de salud a todos los individuos. (Organización Mundial de la Salud, 2003)

Por lo tanto, para la aplicación de las TIC hay que tener en cuenta factores como: el hecho que el sector salud tiene un alto grado de regulación por parte del gobierno o los profesionales de la salud; altamente fragmentado, coexisten los servicios públicos, privados, tradicionales o alternativos donde participan muchos actores y culturas diversas; la gestión es fundamentalmente pública; y el financiamiento es a través de impuestos $u$ otros mecanismos, agentes financieros, quienes recaudan fondos y los asignan a proveedores o compran servicios a nivel nacional y otros niveles que financian directa e indirectamente.

\section{LAS TIC EN EL SECTOR SANITARIO DE ECUADOR}

Tal como ocurre en muchos países el sistema de salud ecuatoriano está fragmentado y segmentado. La prestación de servicios se da principalmente por el subsector público conformado por el Ministerio de Salud Pública (MSP) y las instituciones de la seguridad social: Instituto Ecuatoriano de Seguridad Social (IESS), Instituto de Seguridad Social de las Fuerzas Armadas (ISSFA) e Instituto de Seguridad Social de la Policía Nacional (ISSPOL) para trabajadores, militares y policías respectivamente. Adicionalmente, participan los servicios de salud de las municipalidades e instituciones públicas como prefecturas y otros ministerios.

El sector privado con fines de lucro lo constituyen profesionales de la salud que actúan individual o colectivamente en corporaciones que prestan servicios a quienes pueden pagar; además, está el sector privado sin fines de lucro en las que se encuentran organizaciones de la sociedad civil y de servicio social que actúan independientemente. 
El sistema de salud tiene múltiples financiadores, el MSP se financia por rentas del Estado; el sistema de seguridad social por las cotizaciones de los trabajadores, de los empleadores y el Estado; los sistemas privados a través de aseguradoras o pago directo de aquellas personas con capacidad de pago, u Organizaciones no Gubernamentales (ONG) para los más pobres. Al MSP le corresponde el ejercicio de la rectoría, así como la responsabilidad de la aplicación, control y vigilancia del cumplimiento de la Ley Orgánica del Sistema Nacional de Salud (LOSNS) y las normas dictadas para su vigencia.

En el país hay esfuerzos por incorporar a las TIC. En los últimos años las políticas han mejorado ostensiblemente respecto el acceso a internet; en diversas instancias encargadas de la salud a nivel institucional hay acciones para incorporar a las TIC, pero las cosas no son tan simples. Respecto a la telemedicina, también conocida como telesalud existen proyectos pilotos en zonas alejadas, considerando que pese a que la tecnología para la telemedicina puede ir desde el uso de la simple red telefónica hasta los enlaces satelitales, pasando por el intercambio de señales de video y las teleconferencias remotas para trabajo en grupos; su utilización no se extiende a todo el país. (Universidad Técnica Particular de Loja, 2012).
El desarrollo de la comunicación virtual ha permitido la formación del personal sanitario en distintas modalidades y reflexionar en lo relativo a la forma en que se entrega la salud, ideando otros mecanismos de interacción con los pacientes. También informar a la ciudadanía sobre temas de salud y prevención haciendo uso de webcast y podcast. No cabe duda de que las TIC pueden revolucionar la atención de salud a través de proyectos que fusionen la tecnología Near Field Communication (NFC) y la ingeniería informática (Barrera-Jaramillo \& Gea-Izquierdo, 2013).

Por otro lado, respecto a la planificación, organización, gestión de los servicios y sistemas de salud a través de la información por internet y tecnologías relacionadas existen aplicaciones tan diversas como la historia clínica electrónica, la gestión farmacológica, los sistemas de información y gestión administrativa, la gestión de los recursos requeridos así como también los sistemas para la vigilancia de salud pública. Hasta el momento su uso es limitado, aunque hay esfuerzos por implementar la historia clínica electrónica en todo el país. El MSP ha integrado el Sisalud (Solución Informática para la Gestión Integral de Salud) en 116 centros de salud desde septiembre del 2013 y se prevé que 151 centros estatales contarán con el sistema en el 2016. (Vance, 2015). 
En un sistema de salud, la definición de políticas y programas a nivel nacional e internacional y la toma de decisiones, debe basarse en información que posibilite definir necesidades y los efectos de las políticas. Así mismo, se necesita establecer indicadores que permitan medir y garantizar la salud de calidad, acceso universal, continuidad asistencial y seguridad de los pacientes. (Indarte \& Pazos Gutiérrez, 2011) Si bien existen varias iniciativas a nivel nacional que se orientan hacia el gobierno en línea, al menos por el momento esto no es completo, por ejemplo los grandes prestadores del sistema el MSP y el IESS mantienen autonomía en la información y gestión de servicios.

Pese a las potencialidades de las TIC para mejorar el acceso y calidad de los servicios de salud, estas no han sido completamente explotadas o implementadas en el país, a pesar de que como lo vemos en el siguiente acápite, hay un marco legal extenso y favorable para su aplicación y desarrollo en salud.

\section{MARCO LEGAL \\ PARA LA APLICACIÓN DE LAS TIC EN EL ECUADOR}

El Estado nacional establece el marco legal y también los mecanismos de gestión y/o control necesarios para el funcionamiento de las TIC en el sector salud. Cobra especial importancia la función del MSP, sus respectivas dependencias, institutos y entidades descentralizadas así como determinados actores dentro del marco de la informática, la comunicación y la interoperabilidad entre otros.

En el ámbito internacional de la salud, la Organización Panamericana de la Salud (OPS) estableció la Estrategia y Plan de Acción sobre eSalud, siendo el Ecuador país signatario debería tomar en consideración los criterios orientadores para una política de salud y TIC. El propósito del plan es contribuir al desarrollo sostenible de los sistemas de salud de los Estados miembros. Con su adopción se busca mejorar el acceso y la calidad, proponiendo cuatro acciones estratégicas: garantizar y promover la formulación, ejecución y evaluación de políticas de información y públicas eficaces, integradas y sostenibles sobre el uso e implementación de las tecnologías de las comunicaciones en el ámbito sanitario; mejorar la salud pública a través del uso de herramientas y metodologías; fomentar y facilitar la colaboración horizontal entre los países para el desarrollo de una Agenda Digital en Salud para la región; y gestión del conocimiento, formación en alfabetización digital y tecnologías de la información y la comunicación. (Organización Panamericana de la Salud/Organización Mundial de la Salud, 2011) 
En el ámbito regional, la Comunidad Andina referente a las TIC es la que establece las normas que regulan el proceso de integración y liberalización del comercio de servicios de telecomunicaciones, mediante las cuales se fomenta la flexibilidad del mismo, a fin de alcanzar la creación de un Mercado Común Andino de Servicios, contribuyendo así a la inclusión de la Subregión Andina. (Decisión 462, 1999) Asimismo, desarrolló el Manual para la Producción de Estadísticas de Tecnologías de la Información y la Comunicación de la Comunidad Andina. (Resolución 1415, 2011)

Desde el 2002, la agenda nacional de conectividad es la política de Estado que "constituye una síntesis de los elementos políticos, ideológicos y tecnológicos, globales y locales para mejorar el acceso al uso de las tecnologías de la información para el fortalecimiento de la democracia y el buen gobierno, la promoción de los derechos humanos, [...] el desarrollo de la salud y educación, la promoción de la igualdad de género y la promoción de la diversidad cultural, ... " (Jurado, 2006), favoreciendo la aplica- ción de las TIC en el país. No obstante, la institucionalización de una estrategia transversal como es el caso de la Sociedad de la Información, es un proceso de gran complejidad. Tratándose de un tema nuevo, sus efectos están sobre un amplio espectro en diferentes autoridades del sector público, ciencia y tecnología, autoridades sectoriales para negocios-e, gobierno-e, formación-e y eSalud. (Hilbert, Bustos \& Ferraz, 2005)

Las autoridades y actores que intervienen en el proceso regulatorio nacional en materia de TIC está compuesto fundamentalmente por las siguientes normas:

1. La Constitución del Ecuador 2008 instituye el Sumak Kawsay o Buen Vivir como principio ético, que introduce cambios fundamentales en el país. Esta Constitución instaura un nuevo marco referencial para el manejo conceptual e institucional de la salud así como para las TIC y otros ámbitos relacionados, según se contempla en la tabla 1. 
Tabla 1. Marco Constitucional: Salud, TICs y otros ámbitos relacionados

\begin{tabular}{|c|c|c|c|}
\hline SALUD & TICS & $\begin{array}{l}\text { PROPIEDAD DE LOS } \\
\text { DATOS PERSONALES } \\
\text { Y SEGURIDAD }\end{array}$ & $\begin{array}{l}\text { CIENCIA Y } \\
\text { TECNOLOGÍA }\end{array}$ \\
\hline $\begin{array}{l}\text { - El artículo } 32 \text { estable- } \\
\text { ce que la salud es un } \\
\text { derecho que garantiza } \\
\text { el Estado, cuya realiza- } \\
\text { ción se vincula al ejerci- } \\
\text { cio de otros derechos, } \\
\text { entre ellos al de agua, } \\
\text { alimentación, educa- } \\
\text { ción, cultura física, tra- } \\
\text { bajo, seguridad social, } \\
\text { ambientes sanosy otros } \\
\text { que sustentan el buen } \\
\text { vivir. El Estado garan- } \\
\text { tizará este derecho } \\
\text { mediante políticas } \\
\text { económicas, sociales, } \\
\text { culturales, educativas y } \\
\text { ambientales. }\end{array}$ & $\begin{array}{l}\text { - Elartículo } 16 \text { establece } \\
\text { que todas las personas } \\
\text { en forma individual o } \\
\text { colectiva tienen dere- } \\
\text { cho a: acceso universal a } \\
\text { las TIC; la creación de } \\
\text { medios de comunica- } \\
\text { ción social; acceso en } \\
\text { igualdad de condicio- } \\
\text { nes al uso de las fre- } \\
\text { cuencias del espectro } \\
\text { radiolectrónico para la } \\
\text { gestión de estaciones } \\
\text { de radio y televisión pú- } \\
\text { blicas, privadas y comu- } \\
\text { nitarias, y a bandas libres } \\
\text { para la explotación de } \\
\text { redes inalámbricas. Asi- } \\
\text { mismo, el artículo } 261 \\
\text { expone que el Estado } \\
\text { central tendrá compe- } \\
\text { tencias exclusivas sobre } \\
\text { [...] el espectro radioe- } \\
\text { léctrico y el régimen ge- } \\
\text { neral de comunicacio- } \\
\text { nes y telecomunicacio- } \\
\text { nes. } \\
\text { - Superintendencia de } \\
\text { Telecomunicaciones, ar- } \\
\text { tículo } 213 \text {, es el orga- } \\
\text { nismo técnico de vigi- } \\
\text { lancia, auditoría, inter- } \\
\text { vención y control de las } \\
\text { actividades económicas, } \\
\text { sociales y ambientalesy }\end{array}$ & $\begin{array}{l}\text { - El artículo } 92 \text { estipula } \\
\text { que toda persona, por } \\
\text { sus propios derechos o } \\
\text { como representante le- } \\
\text { gitimado para el efecto, } \\
\text { tendrá derecho a cono- } \\
\text { cer de la existencia y a } \\
\text { acceder a los documen- } \\
\text { tos, datos genéticos, } \\
\text { bancos o archivos de } \\
\text { datos personales e in- } \\
\text { formes que sobre sí } \\
\text { misma, o sobre sus } \\
\text { bienes, consten en enti- } \\
\text { dades públicas o priva- } \\
\text { das, en soporte material } \\
\text { o electrónico. Así mis- } \\
\text { mo, tendrá derecho a } \\
\text { conocer el uso que se } \\
\text { haga de ellos, su finali- } \\
\text { dad, el origen y destino } \\
\text { de información perso- } \\
\text { nal. }\end{array}$ & $\begin{array}{l}\text { - El artículo } 385 \text { men- } \\
\text { ciona que el sistema na- } \\
\text { cional de ciencia, tecno- } \\
\text { logía, innovación y sa- } \\
\text { beres ancestrales, en el } \\
\text { marco del respeto al } \\
\text { ambiente, la naturaleza, } \\
\text { la vida, las culturas y la } \\
\text { soberanía, tendrá como } \\
\text { finalidad: desarrollar } \\
\text { tecnologías e innova- } \\
\text { ciones que impulsen la } \\
\text { producción nacional, } \\
\text { eleven la eficiencia y } \\
\text { productividad, mejoren } \\
\text { la calidad de vida y con- } \\
\text { tribuyan a la realización } \\
\text { del buen vivir. }\end{array}$ \\
\hline
\end{tabular}

Fuente: Constitución, 2008 
2. Plan Nacional para el Buen Vivir, la mayor jerarquía de la norma constitucional se completa en este caso con la herramienta normativa de planificación. El PNBV 20132017, cuyo objetivo 11 se refiere a "asegurar la soberanía y la eficiencia de los sectores estratégicos para la transformación industrial y tecnológica", concreta estos lineamientos obligatorios de política pública dentro del Estado. El objetivo 11.3 específicamente señala la necesidad de democratizar la prestación de servicios públicos de telecomunicaciones y de TIC, [...] y profundizar su uso y acceso universal. (Secretaría Nacional de Planificación y Desarrollo, 2013)

3. Ley del Sistema Nacional de Registro de Datos Públicos, artículo 1, tiene como objeto garantizar la seguridad jurídica, organizar, regular, sistematizar e interconectar la información, así como la eficacia y eficiencia de su manejo, su publicidad, transparencia, acceso e implementación de nuevas tecnologías.

a. Respecto a la accesibilidad y confidencialidad, el artículo 6 establece que son confidenciales los datos de carácter personal, tales como: ideología, afiliación política o sindical, etnia, estado de salud... b. El artículo 12 se refiere a los medios tecnológicos: el Estado, a través del ministerio sectorial con competencia en las telecomunicaciones y en la sociedad de la información, definirá las políticas y principios para la organización y coordinación de las acciones de intercambio de información y de bases de datos entre los organismos e instancias de registro de datos públicos... (Ley del Sistema Nacional de Registro de Datos Públicos, 2010)

4. Ley de Comercio Electrónico y Mensajes de Datos: provee instrumentos jurídicos que permiten el uso de medios electrónicos de intercambio tales como la firma electrónica, a fin de promover el uso de las TIC para el desarrollo del comercio y la provisión de servicios de administración pública. (Ley n. ${ }^{\circ}$ 2002-67, 2002)

5. Ley Especial de Telecomunicaciones Reformada: tiene por objeto normar en el territorio nacional la instalación, operación, utilización y desarrollo de toda transmisión, emisión o recepción de signos, señales, imágenes, sonidos e información de cualquier naturaleza por hilo, radioelectricidad, medios ópticos u otros sistemas electro- 
magnéticos. (Ley Especial de Telecomunicaciones Reformada, 1992)

6. Reglamento General a la Ley Especial de Telecomunicaciones Reformada: tiene como finalidad esta blecer las normas y procedimientos generales aplicables a las funciones de planificación, regulación, gestión y control de la prestación de servicios de telecomunicaciones... el internet se encuentra catalogado como servicio de valor agregado. (Decreto Ejecutivo 1790, 2001)

7. Ley Orgánica de Salud: establece la responsabilidad del MSP, mediante el artículo 6, de participar con el organismo competente, en la investigación y el desarrollo de la ciencia o tecnología en salud, salvaguardando la vigencia de los derechos humanos y respetando los principios bioéticos. (Ley n. ${ }^{\circ} 67$, 2006)

8. LOSNS: en el artículo 29 establece que el MSP, con el apoyo del Consejo Nacional de Salud y la participación de la FUNDACYT, ${ }^{2}$ impulsará una política de investigación orientada a las prioridades nacionales y al desarrollo y transferencia de tecnologías [...]. Evaluará y racionalizará el uso de los recursos tecnológicos para su optimización nacional y promoverá el intercambio científico y tecnológico entre las instituciones del sector. (Ley n. ${ }^{\circ}$ 2002-80, 2002)

9. El Ministerio de Telecomunicaciones y de la Sociedad de la Información, artículo 2 de su creación, es responsable de formular, dirigir, coordinar y evaluar las políticas, planes y proyectos para la promoción de la Sociedad de la Información y del Conocimiento y las Tecnologías de la Información y Comunicación. (Decreto Ejecutivo 8, 2009)

a. El Consejo Nacional de Telecomunicaciones (CONATEL) como ente de administración y regulación de las telecomunicaciones es el organismo que se encarga de la regulación, administración y creación de políticas, [...] en el Ecuador. Además, promueve el uso de las TIC para garantizar el acceso de todos los ecuatorianos a la Sociedad de la Información y fomenta el acceso y uso de internet, así como sus aplicaciones en el ámbito social como educación y salud. (Decreto Ejecutivo 8, 2009)

i. Reglamento a la prestación de servicios de valor agregado (internet): establece las nor-

${ }^{2}$ Actual SENESCYT 
mas y procedimientos aplicables a la prestación de servicios de valor agregado así como los deberes y derechos de los prestadores de servicios de sus usuarios. (Reglamento a la prestación de servicios de valor agregado, 2002)

10. El Ministerio de Salud Pública como Autoridad Sanitaria Nacional, es la entidad encargada de establecer las políticas, normar, regular y vigilar la salud de la población ecuatoriana.

a. El Manual de la Gestión Organizacional por Procesos establece la rectoría, regulación, planificación, coordinación, control y gestión de la Salud Pública ecuatoriana a través de la gobernanza, [...] y desarrollo de la ciencia y tecnología y la articulación de los actores del sistema, con el fin de garantizar el derecho a la salud.

i. El objetivo 8: incrementar el desarrollo de la ciencia y la tecnología según las prioridades sanitarias de la salud.

ii. El artículo 20, expone que la Gestión Estratégica tiene co mo misión: dirigir, implementar, administrar y evaluar la gestión de procesos, tecnolo- gías de la información y comunicaciones [...]

iii. La Dirección Nacional de Tecnologías de la Información y Comunicaciones tiene como misión proponer, implementary administrar políticas, normas y procedimientos que optimicen la gestión y administración de las TIC, [...] así como el soporte tecnológico institucional. (Ministerio de Salud Pública, 2012)

11. Política, Modelo y Plan Nacional Telemedicina/Telesalud: tiene como finalidad fortalecer el modelo de atención en salud relacionando el primer nivel de atención con los niveles superiores: secundario hospitales básicos-como terciario -hospitales especializados-. (Ministerio de Salud Pública del Ecuador/Proceso de Ciencia y Tecnología en Salud, 2010)

Debido a la interacción de varios elementos no se precisan otras normativas que sin duda tienen relación con las TIC, como la Ley n. ${ }^{\circ} 7$ de Derechos y Amparo del Paciente, la Ley Orgánica de la Defensoría del Pueblo, la Ley Orgánica de Defensa del Consumidor que proporcionan el marco legal a los proveedores del servicio de internet, y la Ley de Propiedad Intelectual entre las más importantes. 


\section{VENTAJAS Y LIMITACIONES DEL MARCO LEGAL}

La Constitución del Ecuador 2008 es garantista de derechos, constituye un cambio fundamental en el tema tratado y sin duda un avance para alcanzar la justicia y la equidad. El buen vivir visualiza al ser humano el centro estableciendo una relación diferente con el Estado, el mercado y la naturaleza. La salud, el acceso a las TIC, la propiedad de los datos personales y seguridad son derechos fundamentales garantizados por Estado, que al ser considerados como tales constituyen mandatos constitucionales que obligan a la implementación de políticas públicas, cuyos lineamientos se establecen en el PNBV. Asimismo, la ciencia y la tecnología tienen como finalidad la realización del Buen Vivir superando la visión de desarrollo supeditado al mercado. Por otro lado la recuperación de la rectoría proporciona el marco para el cambio institucional que debería regir en este campo configurando un escenario favorable para el desarrollo de las TIC y su aplicación en el ámbito de la salud.

La mayor jerarquía de la norma constitucional supone una obligación y proporciona el sustento jurídico sobre el cual se desarrollan leyes, reglamentos, normas, y demás cuerpos legales que actúan en el intersticio de la informática, la comunicación, la tecnología y la salud.
La Ley de Comercio Electrónico promueve el uso de la firma electrónica que norma el uso en la administración pública, es decir tiene relevancia en salud, aunque su origen está en el ámbito comercial.

En el caso de la Ley Especial de Telecomunicaciones y su reglamento con las modificaciones respectivas, mencionado con anterioridad, establecen la normativa general en el territorio nacional de aspectos relacionados con la comunicación. No obstante, su expedición se realizó antes de la vigencia de la Constitución.

La Ley Orgánica de Salud fomenta la ciencia y tecnología, constituyendo el marco general vigente que asociado a la LOSNS se refiere específicamente a las TIC y favorece su aplicación en la salud. Cabe resaltar que también estas leyes son previas a la norma constitucional vigente.

La ley del Sistema Nacional de Registro de Datos Públicos abarca los distintos momentos de atención a los pacientes o la gestión de los servicios que deben ser tratados con la debida confidencialidad y privacidad. El proceso de garantizar la protección de la información y los sistemas informáticos no es una actividad exclusivamente referida al 
campo de lo técnico; no en vano el respeto de la privacidad del paciente es un vínculo de confianza que se instaura entre él y la persona que lo atiende e involucra prácticas y actitudes referidas al uso de las tecnologías asociadas. (Torres \& Petrizzo, 2015)

Si bien la legislación vigente asegura la confidencialidad y privacidad de la información en salud, solo unos pocos países disponen de legislación específica que aborde la privacidad en la medicina aplicable en todos los ámbitos de la atención sanitaria, tal como se practica hoy en día, ya sea cara a cara o a través de las TIC. (Organización Mundial de la Salud, 2013)

Adicionalmente, es importante considerar que el MSP y el Ministerio de Telecomunicaciones, entre otros, son instancias sectoriales encargadas de la aplicación de las TIC en salud. EI MSP es la autoridad sanitaria nacional establecida tanto en la Constitución como en las Leyes, la diversidad de prestadores de servicios públicos y privados que si bien reconocen esta autoridad mantienen autonomía administrativa y financiera, lo cual implica que en muchos aspectos no hay la interoperabilidad entre los sistemas informáticos de los diferentes componentes del sistema de salud. El desarrollo de la Sociedad de la Información no puede reducirse a la adaptación de adelantos técnicos y a la creación de infraestructuras; si bien son cuestiones claves, los esfuerzos que se realicen en este sentido serán insuficientes sino se complementan con la educación, la cultura de la innovación en las empresas, los ajustes institucionales y regulatorios, y fundamentalmente, con el fomento de la investigación en TIC en la frontera de los avances actuales. (Ministerio de Telecomunicaciones y de la Sociedad de la Información, 2014)

\section{CONCLUSIONES Y RECOMENDACIONES}

La Constitución de 2008 ratifica el derecho a la salud y eleva a derecho el acceso a las TIC. Los mandatos legales obligan a implementar políticas públicas sobre asuntos determinados como de interés general y requiere un esfuerzo interinstitucional.

La ley o las normativas que tienen por objeto la regulación de materias in- formáticas y de comunicación en salud vigentes no obstaculizan las iniciativas que pueden desarrollar las instituciones para optimizar su aplicación. Sin embargo, requieren una actualización y articulación más detallada que permita compatibilizar los principios y garantías de la Constitución como sujetos de derechos, superando una visión de usuarios o clientes de servicios de salud o 
tecnologías y protegiendo la confidencialidad y seguridad de la información individual que garantice las libertades ciudadanas.

Los registros electrónicos se utilizan básicamente para actividades administrativas como registrar pacientes, citas, sistemas de gestión de medicamentos, personal, etc. Por ello, es necesario realizar un esfuerzo para la armonización técnica y normativa que facilite el intercambio de información al menos entre los servicios del MSP y la seguridad social pública.

Las voluntades por incorporar las TIC en todo tipo de aspectos en salud, aún incidiendo directamente en la calidad de servicios a los que accede la población, disminuyen brechas geográficas y económicas, no siendo una característica obligatoria en los servicios de salud tanto públicos como privados.

El uso de las TIC en salud enfrenta un prolijo marco legal. La autoridad y actores que intervienen en el proceso regulatorio son múltiples, producto de la complejidad del campo de acción, existiendo orientaciones en el ámbito internacional y regional. El reto está en favorecer la aplicación de las TIC, superando las restricciones legales y jurisdiccionales, que implica la interacción de la salud, la informática y las telecomunicaciones. 


\section{BIBLIOGRAFÍA}

Avella Martínez, L. Y. \& Parra Ruiz, P. (2013). Tecnologías de la Información y la Comunicación (TICS) en el Sector Salud. (Tesis de maestría, Universidad Nacional de Colombia). Recuperado de http://www.bdigital. unal .edu.co/11172/1/laurayanethavellamartinez. 2013.pdf

Barrera-Jaramillo, J. \& Gea-Izquierdo, E. (2013). La Tecnología NFC (Near Field Communication) en los servicios de salud. III Congreso Internacional Sobre Usos y Buenas prácticas con TIC. Málaga: Universidad de Málaga.

Carnicero, J. \& Fernández, A. (2012). Manual de Salud Electrónica para directivos de servicios y sistemas de salud. Santiago de Chile: Naciones Unidas.

Constitución de la República del Ecuador. (2008). Quito, Ecuador.

Decreto Ejecutivo 1790. (2001). Reglamento General a la Ley Especial de Telecomunicaciones Reformada- última modificación. Quito, Ecuador, 13 de octubre de 2011.

Decreto Ejecutivo 8. (2009). Registro Oficial n. ${ }^{\circ}$ 10. Quito, Ecuador, 24 de agosto de 2009.

Decisión 462. (1999). Normas que regulan el Proceso de Integración y Liberalización del Comercio de Servicios de Telecomunicaciones en la Comunidad Andina. Gaceta Oficial del Acuerdo de Cartagena n. 444. Cartagena, Colombia, 1 junio de 1999.

Eysenbach, G. (2001). What is e-health. Journal or Medicine Internet Research. Journal of Medical Internet. Recuperado de http:// www.jmir.org/2001/2/e20/doi10.2196/jmir. 3.2.e20

Hilbert, M., Bustos, S. \& Ferraz, J. C. (2005). Estrategias nacionales para la sociedad de la información en America Latina y el Caribe. CEPAL.

Indarte, S. \& Pazos Gutiérrez, P. (2011). Estándares e interoperabilidad en salud electrónica. Chile: CEPAL.

Jurado, R. (2006). Diagnóstico de las políticas de TIC en el Ecuador. Quito: FLACSO, Sede Ecuador.

Ley del Sistema Nacional de Registro de Datos Públicos, Ley s/n § Suplemento del Registro Oficial n. 162 (2010).

Ley n. 2002-67, Ley de Comercio Electrónico, Firmas Electrónicas y Mensajes de Datos § Registro Oficial n. ${ }^{\circ}$ 557-S (2002).

Ley Especial de Telecomunicaciones Reformada § Registro Oficial n. 992 (1992).

Ley n. ${ }^{\circ}$ 67, Ley Orgánica de Salud § Registro Oficial Suplemento n. ${ }^{\circ} 423$ (2006).

Ley n. ${ }^{\circ}$ 2002-80, Ley Orgánica del Sistema Nacional de Salud (2002).

Ministerio de Salud Pública. (2012). Estatuto Orgánico Sustitutivo de Gestión Organizacional por Procesos del MSP. Acuerdo Ministerial Registro Oficial n. 279.

Ministerio de Salud Pública del Ecuador/Proceso de Ciencia y Tecnología en Salud. (2010). Política, Modelo y Plan Nacional de Telemedicina/Telesalud. 
Ministerio de Telecomunicaciones y de la Sociedad de la Información. (2014). Tecnologías de la Información y Comunicaciones para el Desarrollo. Recuperado de http:// www.telecomunicaciones.gob.ec/wp-content/uploads/2015/09

Organización Mundial de la Salud. (2003). Informe de la Salud en el Mundo 2003. Forjemos el Futuro. Ginebra.

Organización Mundial de la Salud. (2013). Regímenes jurídicos de la cibersalud: informe basado en las conclusiones de la segunda encuesta mundial sobre Cibersalud. Ginebra.

Organización Panamericana de la Salud/Organización Mundial de la Salud. (2011). 51. ${ }^{\circ}$ Consejo Directivo. Estrategiay Plan de Acción sobre eSalud. Washington DC, EUA.

Rabanales Sotos, J., Párraga Martínez, I., Lopez-Torres, J., Prétel, F. \& Navarro Bravo, B. (2011). Tecnologías de la Información y Comunicaciones:Telemedicina. Revista Clínica de Medicina Familiar, 31 (5), 42-48.

Ramos, V. (2006). Las Tic en el sector de la salud. Research gate. Recuperado de https://www.researchgate.net/publication/2 168792_Las_TIC_en_el_sector_de_la_salud

Resolución 1415. (2011). Manual para la Producción Estadística de Tecnologías de la Información y Comunicación de la Comunidad Andina. Gaceta Oficial del Acuerdo de Cartagena n. ${ }^{\circ} 1951$.

Reglamento a la prestación de servicios de valor agregado. (2002). Resolución 071-03 CONATEL.
Sainz de Abajo, B., Rodrigues, J., García Salcines, E., Burón Fernandez, J., López Coronado, M. \& de Castro Lozano, C. (2011). M-Health y T-Health. La Evolución Natural del E-Health. Revista eSalud. Recuperado de dialnet-MHealthYTHealthLaEvolucionNaturalDeIEHealth-3407842.pdf

Secretaría Nacional de Planificación y Desarrollo. (2013). Plan Nacional para el Buen Vivir 2013-2017.

Torres Velandia, S. \& García Ponce de León, O. (2008). Redes de investigación y universidad pública. Revista Digital Universitaria, 9(2). Recuperado de http://www.revista. unam.mx/vol.9/num2/art06/int06.htm

Torres, J. \& Petrizzo, M. (2015). Sofware: programas libres y de código abierto en la Administración Pública. En D. Vila-Viñas, \& X. Barandiaran (Edits.), Buen Conocer/Flok Society Modelos sostenibles y políticas públicas para una economía social del conocimiento común y abierto en el Ecuador. Quito: IAEN-CIESPAL.

Universidad Técnica Particular de Loja. (2012). Manual de procesos y protocolos del proyecto "Telesalud UTPL Tutupaly". Recuperado de http://esalud.utpl.edu.ec/sites/default/files/publicaciones/manual_telesalud_r ural.pdf

Vance, C. (2015). Historia clínica electrónica se extiende por el país. Redacción Médica. Recuperado de http://www.redaccion medica.ec/noticia/medicos-tienen-historiaclinica-electronica-8663 

SOCIOLOGÍA 


\section{LA ARQUITECTURA DE LAS ORGANIZACIONES EN EL SIGLO XXI}

\section{ARCHITECTURE OF THE ORGANIZATIONS \\ IN THE CENTURY XXI}

PETER JOSÉ SCHWEIZER 



\section{LA ARQUITECTURA DE \\ LAS ORGANIZACIONES EN EL SIGLO XXI}

Peter José Schweizer ${ }^{1}$

\section{RESUMEN}

Este artículo se propone analizar la arquitectura de las organizaciones necesaria para el siglo XXI y orientado a las personas, al ambiente, ajustada a las decisiones políticas y adecuadas a la administración. Propone la humanización en el proceso productivo y destaca la importancia de las universidades en ese proceso de cambio.

Palabras clave: organizaciones, medio ambiente, planificación, administración
ABSTRACT:

This article intends to discuss the architecture of the organizations for the 21 st century and is oriented to people, the environment; it is also adjusted to proper administration and political decisions. It proposes the humanization of the production process and highlights the importance of universities in this process of change.

Key words: organization, environment, planning, administration

\section{INTRODUCCIÓN}

La aplicación del término arquitectura en el campo de estudios de las organizaciones merece una explicación previa. En su origen, arquitectura significa una concepción de un espacio que se realiza a través de una determinada construcción estética y funcional, con áreas delimitadas y destinadas a cubrir funciones sociales y/o necesidades humanas. Las organizaciones a que se hace aquí referencia pueden ser las productivas $u$ otras como es el caso de las uni-

\footnotetext{
'Pontificia Universidad Católica del Ecuador. Facultad de Arquitectura. Quito, Ecuador (pschweizer604@yahoo.com.br).
} 
versidades y sus facultades para la formación de dirigentes, líderes, profesionales en distintos campos.

La arquitectura, como una de las más antiguas manifestaciones de la cultura humana, nos ha enseñado, a lo largo de los siglos, la importancia de que espacios construidos deben ser creados y diseñados en función de las necesidades y de las aspiraciones humanas. Asimismo, las organizaciones deben dejar de buscar adaptar las personas a sus objetivos y pasar a atender las necesidades humanas y, siempre que sea posible, sus aspiraciones.

Bajo el título de"arquitectura organizacional" han sido presentadas contribuciones destacadas que, por ejemplo, la definieron como"el arte de modelar el espacio organizacional para satisfacer necesidades y aspiraciones humanas"2. Esta definición aún es incompleta dado que la arquitectura de las organizaciones puede comprender, además de la propia "arte de modelar", algo que antecede a esa arte que es el propio principio de la razón que define el sentido y la finalidad de una organización. La arquitectura organizacional, además de ser un arte, comprende, también la existencia de una ciencia que permite hacer del "espacio organizacional" una expresión de la historia del conocimiento y de las expe- riencias humanas. Finalmente, la arquitectura organizacional también demanda un conocimiento instrumental que presupone la existencia de la técnica. A través de esa técnica son establecidas las bases para la construcción operacional de una organización específica y son realizadas las modificaciones que esta demanda a lo largo del tiempo.

En el presente estudio se pretende ampliar la definición de arquitectura de las organizaciones hacia la "filosofía, el arte, la ciencia y la técnica de crear y operar espacios organizacionales para atender las necesidades y aspiraciones sociales y humanas". Esta visión de las organizaciones, más integral u "holística", permite señalar algunos enfoques nuevos para el siglo XXI. Vivimos una nueva era que demanda de modificaciones cualitativas en el funcionamiento de la sociedad humana, en armonía con los requerimientos ambientales y las propuestas para el desarrollo sustentable. Por supuesto, demanda cambios sustantivos en la formación de los profesionales en las universidades.

Actualmente la sociedad se encuentra frente a una importante encrucijada de la historia en la cual la humanidad necesita urgentemente redefinir cómo pretende convivir con la naturaleza, con las necesidades de pro-

${ }^{2}$ Nadler, David A. y otros (1994). Arquitetura organizacional: chave para a mudanca empresarial. Río de Janeiro: Editora Campus. 
ducción y consumo y consigo misma en el futuro inmediato. La devastación a que fueron sometidos los territorios, acompañada de la contaminación sin precedentes de los ríos y océanos, así como del aire, y el aumento de la pobreza y de la miseria, demandan reflexiones sobre el nuevo rol que deberán cumplir las organizaciones, entre ellas las universidades, para cambiar, de forma considerable, este panorama en los próximos años.

Otro tipo de devastación está vinculado al ámbito de la convivencia humana. Convivencia de las personas en las escalas familiar, comunitaria, urbana, regional, nacional e internacional, que después de dos guerras mundiales, evolucionó marginalmente hacia una situación mejor para las personas, dados los desequilibrios ambiental y de distribución de los ingresos. Es lo esperado después de tantos ejercicios de irracionalidad, sea en búsqueda desmesurada de la ganancia en las ventajas individuales, realizados por la humanidad en el pasado siglo y principios del presente.

Al mismo tiempo en que ocurría la devastación aquí referida, las organizaciones eran creadas y han sido sistemáticamente destruidas en nombre del mercado, de la producción masiva y de la búsqueda de un consumo sin límites. Esto solo ha logrado agravar las relaciones de los seres humanos con la natura- leza y con sus propias sociedades. En el campo de las organizaciones el problema más evidente que se puede observar, sin que se busque comprender sus causas reales, es el desempleo crónico que lleva a millones de personas a la marginalidad y a muchos países al caos y preocupantemente más grave en los extractos de la población joven.

Aparentemente eliminado el maniqueísmo político que venía operando las relaciones internacionales durante casi medio siglo, fue ganando cuerpo una concepción denominada neoliberal que exacerbó aún más la propuesta de un mercado sin fronteras y de la producción masiva con agresión creciente a la naturaleza. La nueva propuesta, imposición dominante de un mundo manejado exclusivamente por un concepto de mercado sin fronteras, solo logra abreviar aún más el tiempo de existencia de los recursos naturales no renovables y la reducción de aquellos que podrían ser renovables y que se pierden ante el desperdicio y la irracionalidad en su uso.

La búsqueda de una función que sea esencial y al mismo tiempo sustentable para las organizaciones, en el siglo $X X I$, es el objetivo de estas reflexiones que estarán orientadas hacia una propuesta de una nueva arquitectura de las organizaciones que contemple un proceso de producción restringido a un nivel cualitativo de suficiencia y un mer- 
cado delimitado por su propia esencia. ${ }^{3}$ Lo fundamental que debe ser proyectado consiste en el hecho de una nueva arquitectura de las organizaciones capaz de concebir organizaciones para que sean subsidiarias y complementarias a las necesidades humanas y no al contrario, como está ocurriendo hasta los días presentes.

Merece enfatizarse que cuando hablamos hoy de "organizaciones" normalmente esto se refiere a un tipo de entidad social dirigida hacia la consecución de finalidades productivas. Significa una unidad de transformación de materia prima o de informaciones en productos acabados o servicios, en la forma de un bien concreto o también de información. En este documento el término"organización" gana una acepción más amplia, de acuerdo con lo propuesto por el sociólogo brasileño Alberto Guerreiro Ramos en su libro "La nueva ciencia de las organizaciones". ${ }^{4}$

En efecto, en un encuentro promovido por la Fundación Getúlio Vargas (Río de Janeiro), en septiembre de 1982, a propósito de la vida y obra del profesor Guerreiro Ramos, uno de los participantes aclaró de forma explícita cual es el concepto sustantivo de organización: "la organización a la que él (Guerreiro Ramos) se refiere no es solo la organización formal o economicista. Es mucho más que eso, es el orden de la vida humana asociada, es la organización de las interacciones humanas. ${ }^{5}$ De esa forma, y para los propósitos de este artículo, el concepto de organización trasciende a los límites productivos y a las relaciones meramente funcionales.

\section{ARQUITECTURA DE LAS ORGANIZACIONES Y LAS PERSONAS}

El trabajo generado en cualquier organización, por ejemplo en una universidad, es realizado por personas y, por lo menos por definición, debería estar dirigido a ellas. Esta es la razón por la cual la relación entre la concepción, el proyecto (estructuras, sistemas y procesos), así como el funcionamiento de las organizaciones, y las personas que las operarán, merecen ser evaluados, y muy probablemente, rediseñados. Las universidades de nuestros días, aprisionada por sus conceptos funcionales y procesos internos, termina por capacitar profesionales para los paradigmas del pasado y en algunos casos se cierran

\footnotetext{
${ }^{3}$ Ramos, Alberto Guerreiro (1981). A nova ciência das organizações: uma reconceituação das riquezas das nações. Río de Janeiro. Editora Fundação Getúlio Vargas.

${ }^{4}$ Ramos, Alberto Guerreiro (1981). Op. Cit.

${ }^{5}$ Resende, Ubiratan Simões. Cuarto Panel - "A teoria da delimitação dos sistemas sociais". Revista de Administração Pública-RAP. Río de Janeiro, FGV, abril - junio de 1983.
} 
para los cambios demandados por nuevos requerimientos para el bienestar de la sociedad.

La universidad necesita transformar su estructura piramidal de poder en una estructura horizontal, interdisciplinar, en que el saber pueda transitar de un campo para el otro sin limitaciones, para formar un profesional con una visión holística. Un profesional que tenga la capacidad de operar y participar activamente de la transformación del mundo como lo indica seguidamente el Papa Francisco al proponer la "construcción de puentes" incluso para el conocimiento y saber humano.

En la actualidad, la concepción estructural y operacional de la arquitectura de las organizaciones tiene como finalidad adecuar las personas al trabajo que estas les exigen. Las personas, conjunto de individuos, de acuerdo con esta concepción, corresponden solamente a un componente del mecanismo organizacional junto con las máquinas, los equipos, los sistemas y las instalaciones requeridas por la operación. Por constituirse en la parte más compleja y de difícil estandarización, a pesar de los esfuerzos que para este fin se realizan a través del entrenamiento de contenido conductual, el individuo viene perdiendo sistemáticamente su posición en pro de las máquinas. El profesor, por ejemplo, pasa a ser un operador de computadora y poco más. La sustitución de personas, en las organizaciones, por mecanismos y sistemas, ha permitido al capital una autarquización para liberarse de legislaciones e instituciones como los sindicatos, que se proponen defender las personas y los trabajadores de las organizaciones que los utilizan.

Además, esta situación ha minado progresivamente uno de los fundamentos del actual sistema productivo: las relaciones capital - trabajo. Sin opciones, o mejor dicho, con cada vez menos opciones de empleo, la fuerza motriz de las economías, las personas, tienen solo dos salidas: convertirse en generador de capital o alienarse del mercado de trabajo, o sumándose a una creciente cantidad de personas "desajustadas" a los requerimientos del mercado de trabajo. La primera alternativa se expresa en los movimientos por la creación de micro y pequeñas empresas. A su vez, la segunda, que en realidad representa la propia "falta de alternativa", viene alienando personas del mercado, ya sea en el medio rural, en los minifundios de subsistencia, y también en las ciudades, principalmente en las grandes, donde el aumento del número de personas en situación de pobreza o extrema pobreza genera hoy una marginalidad consolidada y orgánica, poco reactiva o mismo inerte a las principales políticas de desarrollo económico y social. 
La mayoría de los que actualmente diseñan las organizaciones las proyectan en términos de un organigrama formal y un concepto de proceso productivo en el cual las unidades de trabajo están asociadas, así como se definen las tareas que deben cumplir. Una universidad, de esa forma, tiene que ofrecer conocimientos (normalmente científicos, artísticos y técnicos) y diplomas que correspondan a ellos. No obstante, esto no permite identificar las personas que componen tales unidades y carreras en términos de sus personalidades, sus relaciones propias y relaciones con el poder, la iniciativa individual, el compromiso de cada uno con los objetivos de la organización, además de otros factores que expresan el grado de complejidad del desempeño humano en un mundo globalizado.

Los modelos clásicos de concepción de las organizaciones, cerrados e inflexibles, mecanicistas u orgánicos, están siendo sustituidos por una visión de la organización como un sistema de interacción entre personas. Sin embargo, la idea de un ser humano limitado solamente a un factor o componente de la producción, no permitió, hasta hoy, una evolución práctica en el rumbo de una nueva arquitectura capaz de "diseñar" y concebir sistemas organizacionales en bases sociales.

La máquina se convirtió y es cada vez más importante que aquellas personas que las organizaciones aún están obligadas a mantener se subordinan incondicionalmente temerosos de la siempre presente y creciente amenaza del desempleo. Es exactamente el desempleo que hoy afecta desde el trabajador hasta el más alto ejecutivo con sofisticada formación profesional y académica, además de afectar el funcionamiento político de las entidades que los representan, que ya no luchan por mejores condiciones para el trabajador, sino apenas por mantener el empleo en las condiciones impuestas por el empleador.

En realidad, la modernidad y el avance tecnológico representaron un retroceso importante en las condiciones que se le impusieron al trabajador que pasó a ser considerado como parte de una clase privilegiada solamente por disponer y poder mantener algún tipo de empleo el mismo que sea con una remuneración decreciente.

\section{LA ARQUITECTURA DE LAS ORGANIZACIONES Y EL DESAFÍO AMBIENTAL}

El progresivo agotamiento de los recursos naturales no renovables y la ex- tinción de parte de los recursos renovables consumidos por los excesos huma- 
nos, como es el caso de muchas especies de árboles y animales que ya no existen por la explotación extensiva realizada en siglos pasados, constituye un testimonio vivo de la forma irracional como vienen operando las organizaciones.

En este contexto se observa la existencia de una cantidad significativa de organizaciones productivas, como es el caso de las industrias contaminantes y fraccionadoras del ambiente natural y cultural. Esto lleva a afirmar que la ecuación del mercado: producir mucho y de mala calidad, con obsolescencia acelerada o programada y al costo ambiental que fuera necesario para maximizar la ganancia, debe ser frenada y revista en sus fundamentos. Hoy ya se observan movimientos en esa dirección. Las universidades, en ese contexto, tienen gran importancia en la creación de una conciencia colectiva tanto local como planetaria.

Los excesos de confianza en el proceso técnico asociado al laissez-faire hace que las clases dirigentes mundiales consideren que el problema del agotamiento de los recursos naturales no renovables pueda ser satisfactoriamente superado a través de la sustitución de nuevas fuentes de energía, nuevas tecnologías y modernos medios que se adecuarán "naturalmente" al conjunto de las necesidades humanas erróneamente caracterizadas como "demandas del mercado".

Ya en los años 1970 ya nos alertaba el profesor y sociólogo Alberto Guerreiro Ramos sobre el hecho que"en los centros de investigación de vanguardia predomina el consenso que la modernización y el desarrollo son inseparables de las prácticas predatorias, nocivas a la vida humana y a las funciones autorregulables del ambiente natural". ${ }^{6}$

Sin embargo, en el último final de siglo ya no existía indicador que la humanidad, a través de las clases dirigentes, esté imponiendo límites a los procesos de "modernización"y de lo que se entiende por desarrollo. Este sigue siendo la meta final a alcanzar para la superación de los males crónicos que nos afectan de forma creciente, entre los cuales se destacan el aumento del desempleo y de la violencia contra el ambiente y, más que todo, en contra del ser humano.

El desarrollo que los países de América Latina han perseguido en los últimos años es resultante de las concepciones tradicionales, concepciones todavía mecanicistas sobre el funcionamiento del sistema económico. Las deformaciones que fueron y se están acumulando a lo largo del camino,

\footnotetext{
${ }^{6}$ Guerreiro Ramos, Alberto. "Límites de la Modernización". Artículo publicado en: Jornal do Brasil. Río de Janeiro, mayo 20 de 1979.
} 
hacen con que muchos filósofos modernos pierdan las esperanzas en la racionalidad humana como medio capaz de revertir el funcionamiento del proceso productivo y, consecuentemente, de la concepción y el funcionamiento de las organizaciones. Por lo tanto, es urgente revisar la arquitectura de las organizaciones presentes para poder evaluar efectivamente las repercusiones del funcionamiento destructivo y desintegrador sobre el ambiente natural y cultural tanto en el campo cuanto en la ciudad.

\section{ARQUITECTURA DE LAS ORGANIZACIONES Y LA DECISIÓN POLÍTICA}

Cualquier intento de cambio del panorama existente hoy en América Latina requiere voluntad, movilización social y decisión política. Aquí se entiende por política el arte y la ciencia de dirigir las relaciones sociales y tomar decisiones en una organización privada o gubernamental.

En la actualidad los países en desarrollo, como los de América Latina, están buscando insertarse de forma inconveniente en el ambiente de la denominada globalización que ha sido difundida como un nuevo paradigma para alcanzar el progreso económico y social. El mundo es ahora visto como un mercado global y los países pierden sistemáticamente su identidad en función del capital sin fronteras y sin ningún tipo de compromiso nacional, regional y mucho menos social.

Además, el ciudadano, el individuo, continúa siendo el mismo, vinculado a la familia, a su comunidad local y a todos los valores que siguen orientando sus relaciones sociales. El hecho de tener acceso a canales de televisión de otros países o a la red de Internet, así como el acceso a productos importados de otros países, transforma al ser humano en un consumidor mundial automáticamente incorporado a través de la globalización. Esa globalización aún no significa, al nivel de vida y cotidianidad de las personas, alteraciones sustanciales en lo relacionado con el aumento de cultura y de ingresos y menos aún de mejoras en las condiciones de vida material o espiritual. Un panorama de inseguridad física y económica está generando una creciente desconfianza en las organizaciones, especialmente en aquellas de carácter político que deberían representar una concentración de fuerzas para mejorar la vida individual y colectiva.

Una nueva arquitectura de las organizaciones debe ser el fruto de una propuesta, ambientalmente factible y de 
políticas concebidas en función de las personas y no de los componentes económicos y comerciales que hoy predominan. Esto para que no se pierda el tenue convencimiento en las cualidades de la democracia, tan discutidas en nuestros países en función de resultados todavía poco convincentes. La economía debe subordinarse a los requerimientos políticos y sociales de toda la sociedad y no en la dirección inversa, como predomina en los días actuales.

\section{ARQUITECTURA DE LAS ORGANIZACIONES Y LA ADMINISTRACIÓN DEL SIGLO XXI}

Una nueva arquitectura para las organizaciones que conforme un marco de referencia para la acción humana en este siglo XXI debe considerar algunos principios generales que sometemos a consideración de los que tienen interés en el tema.

\section{Una estrategia centrada en las perso- nas}

\section{- Proponer la planeación con las per- sonas y no para las personas}

Hasta hoy se ha planificado para la construcción de obras físicas, para la construcción de las ciudades, para las regiones, para los países, para las empresas, para atender el mercado. Sin embargo, olvídase de planificar con las personas afectadas. Discursos vacíos sobre una planificación participativa no han logrado obtener resultados concretos para el beneficio de la población en nuestros países. Solamente han escamoteado y legitimado decisiones "de arriba hacia abajo" justificadas bajo el pretexto de una eficiencia técnica, sin demostrar una real eficacia humana y social.

También en las universidades se hace necesario planificar no solamente con los profesores o solo con los dirigentes, pero también con los alumnos y con la participación de representantes de la población local (lo que significa una efectiva práctica de participación comunitaria).

La racionalidad ha sido limitada a la del "mercado", desconociéndose el valor humano, las necesidades de sustentabilidad de la humanidad y de su ambiente natural. El mejor ejemplo de eso ha sido el desempleo al cual han sido sometidas millones de personas en todo el mundo, además de otros millones de personas que jamás tuvieron acceso a un empleo formal, ni urbano ni mucho menos rural.

La planificación con las personas significa, en las organizaciones de este siglo, oír a los interesados y afectados en 
las acciones del gobierno o de las empresas, en la discusión de los asuntos relevantes y en la toma de decisiones que puedan afectar sus vidas. Existen precedentes importantes que nos permiten garantizar la factibilidad de este procedimiento como una posible práctica operacional.

\section{- El proyecto como referencia funda- mental para las iniciativas humanas}

La existencia previa de proyectos centrados en las personas y sustentables ambientalmente debe ser un requerimiento básico para las organizaciones del futuro. Hasta el presente el proyecto ha tenido como foco la rentabilidad de las iniciativas apoyada en las relaciones de costo-beneficio económico; la construcción de elementos físicos; el retorno para los financiadores. Sin embargo el proyecto no se transformó en un recurso organizacional para garantizar a la sociedad la concreción de iniciativas capaces de lograr que la vida humana pueda ajustarse al medio natural que la rodea y le da sustancia. Refiérase no solamente a los proyectos de arquitectura e ingeniería como también a los proyectos económicos y sociales.

El desconocimiento de las organizaciones formales en relación con miles de personas condenadas a una vida de pobreza extrema en asentamientos humanos precarios, en las ciudades (en tu- gurios, invasiones y otros) y en las áreas rurales, demuestra la inexistencia de proyectos que consideren a la población como un todo y no solamente a los grupos privilegiados como se ha hecho hasta ahora. Las universidades tienen también en este caso un papel destacado en la formación de un saber demandado por ese campo orientado al bienestar social.

\section{- La optimización en el uso de la ener- gía y la eliminación de los desechos}

Uno de los aspectos característicos de la sociedad centrada en el mercado ha sido el mal uso de la energía y la creciente generación de desechos. Esto último se convirtió en un requerimiento puesto que del desperdicio pasó a depender la producción de nuevos bienes para la población mundial que tiene acceso a ellos. Entre más rápido un objeto es eliminado y se hace obsoleto, más posibilidades existen para que el denominado mercado se amplíe con nuevas demandas que generen más lucro para las organizaciones privadas que lo producen.

En el caso de la energía ya existe un embrión de conciencia en algunas organizaciones, en distintas partes del mundo, que el manejo de los recursos energéticos en este siglo no debe estar subordinado a la ganancia de las empresas sino a la atención global de la pobla- 
ción, sin que sean afectadas las condiciones ambientales actuales y futuras, condiciones de las cuales dependerán todas las nuevas generaciones.

- Hacer de la satisfacción personal de sus necesidades esenciales (físicas, sicológicas y espirituales) el foco del proceso productivo

La reducción del ser humano a la simple condición de "consumidor"en un mundo considerado apenas como un "mercado globalizado" hizo que la dimensión humana se diluyera. De esta manera, quedaron visibles solo las necesidades biológicas capaces de ser manipuladas psicológicamente a través de la propaganda en donde el comportamiento humano no difiere del animal. Las Universidades son parte de las organizaciones que puede cambiar esta visión deformada que nos ha sido impuesta.

Una nueva arquitectura de las organizaciones centrada en la persona, una Universidad centrada en el alumno, no como consumidor sino como ser integrado de forma holística a la naturaleza, hará que se transformen las relaciones locales, nacionales y mundiales. La satisfacción del ser humano estará armonizada con los requerimientos ambientales globales existentes.

\section{- Construir escenarios de futuro sus- tentables}

Es cada vez más importante planificar mirando hacia el futuro y analizando sus requerimientos básicos o esenciales. Para ello, es necesario la elaboración de escenarios que permitan analizar la posible evolución de situaciones que afectarán a las personas y la estructura ambiental con la cual conviven y de la cual dependen. Las universidades tienen que mirar hacia el futuro y para qué tipo de profesionales la sociedad podrá requerir y no más quedarse estática formando profesionales que no tendrán, al graduarse, ninguna inserción en la sociedad, sea como emprendedores o como empleados, públicos o privados.

\section{Fortalecer la condición del ser hu- mano y del conocimiento humano}

\section{- Sustituir el entrenamiento por la ca- pacitación}

En pasado siglo los seres humanos fueron "entrenados", es decir, mecánicamente condicionados y ajustados para cumplir rutinas predeterminadas donde la inteligencia ha sido sustituida por el ajuste a las tareas (enfoque comportamental) demandadas por las máquinas.

El ser humano no debe recibir un entrenamiento conductual de la misma 
forma como se adiestran animales. Debe ser capacitado para realizar trabajos de interés personal y social. Debe ser despertado hacia un sentido de responsabilidad y solidaridad con sus semejantes, con su comunidad y con la naturaleza, de manera que se armonice con ella en una convivencia sustentable. Las universidades forman personas con un conocimiento universal capaces de aprender y no solo formar técnicos operacionales, hasta porque estos últimos ya no son los mismos, considerándose la multiplicidad de opciones tecnológicas hoy a disposición de las organizaciones permanentemente sumergidas en procesos de cambio.

\section{- Desarrollar nuevos talentos}

Los seres humanos tienen una capacidad increíble de adaptación, de percepción y creatividad que merece ser estimulada no solo para el desarrollo personal, sino principalmente para el desarrollo social y global, en distintos ámbitos organizacionales.

Se avecina una nueva era en la cual no bastan los conocimientos especializados. Es imprescindible promover conocimientos en sintonía con la naturaleza, conocimientos que sean capaces de despertar talentos que tengan condiciones de desarrollar nuevos conocimientos filosóficos, científicos y artísticos y que contribuyan sustantivamente al progreso de la humanidad. Las universidades tienen, sin duda, una responsabilidad primordial en ese aspecto.

\section{- Priorizar una educación holística}

Este es, indudablemente, el campo en el cual es notoria la regresión humana. La educación formal estuvo más orientada al cumplimiento de determinadas rutinas que a la preparación de las personar para la vida, para la convivencia social democrática, para el uso de la creatividad y para lograr la efectiva inserción productiva.

Miseria y segregación, guerras y destrucción ambiental han llegado a niveles nunca antes observados en el mundo, haciendo del ser humano solamente un espectador de las noticias sobre conflictos y sobre ese proceso de desagregación del ambiente físico y del ambiente cultural. Sin una reversión en el ámbito educativo, campo que merece ser repensado completamente, no se logrará alcanzar, una arquitectura organizacional humanizada planteada en este texto.

\section{- Remplazar la competencia por la co- operación}

En el final de siglo XX, cuando la competencia fue llevada a los extremos, fue posible verificar que la disputa en el violento proceso de competitividad pro- 
fesional generó resultados desastrosos en términos humanos y sociales.

Es pues importante determinar una forma de promover la cooperación en la cual los valores humanos sean estimulados, permitan sumar, fortalecerse y no tengan que anularse en una disputa febril por el éxito y por la riqueza material ni mucho menos por destacadas posiciones profesionales.

Una sociedad más justa podrá formarse ahora, con más conciencia política, ecológica y social, con base en la práctica efectiva de la cooperación a nivel individual y social así como en el ámbito de las naciones.

\section{- Reducir controles y fortalecer las responsabilidades}

La herencia de experiencias totalitarias del pasado siglo generó una visión y concepción de que lo fundamental está en la existencia de mecanismos de control para que las personas funcionen como máquinas que garanticen la producción. Esto solo significa que sean eficientes y permitan las ganancias en las empresas. La contribución humana quedó reducida al trabajo asalariado que hoy se encuentra en crisis en todo el mundo en la medida en que las máquinas sustituyen progresivamente el trabajo que realizaban las personas.

Para fortalecer la condición de ser humano será indispensable que este asuma crecientes responsabilidades, individuales y colectivas, para que no sea solamente dependiente de organizaciones públicas y privadas como empleado, sino que sea actor activo en el proceso de construcción de una sociedad mundial solidaria. Se requiere, pues, que cada persona asuma la posición de líder en ese proceso en el cual son actores y no, como en el pasado, espectadores.

Que las universidades amplíen los conocimientos y los espacios para que eso pueda ocurrir. Los desafíos e incertidumbres son muchas pero una cosa es segura: el rol de una universidad, con una arquitectura modificada y ajustada a los requerimientos de esta nueva Era, es sin duda una pieza fundamental en la medida que apunte para los caminos que conducen al futuro, con individuos, organizaciones y sociedades sustancialmente diferentes de lo que se dispone en los días presentes. 


\section{BIBLIOGRAFÍA}

Nadler, David A. y otros (1994). Arquitetura organizacional: chave para a mudanca empresarial. Rio de Janeiro: Editora Campus.

Guerreiro Ramos, Alberto (1981).'A nova ciência das organizações: uma reconceituação das riquezas das nações. Rio de Janeiro. Editora Fundação Getúlio Vargas.

Resende, Ubiratan Simões. Cuarto Panel - "A teoria da delimitação dos sistemas sociais". Revista de Administração Pública - RAP. Rio de Janeiro, FGV, 1983.

Guerreiro Ramos, Alberto. "Límites de la Modernización". Artículo publicado en Jornal do Brasil. Rio de Janeiro, 1979.
Pesca de Acosta, Claudia Adriana y Tovar, Lioval Moreno (2003) - "Una Arquitectura Organizacional Inteligente". Publicado en la Revista Universitaria de Investigación. Caracas.

Guerreiro Ramos, Alberto (1972). "Models of Man and Administrative Theory". Publicado en American Society for Public Administration. Washington. USA.

Guerreiro Ramos, Alberto (1983). "A Nova Ignorância e o Futuro da Administração Publica na América Latina" publicado em la Revista de Administração Publica. Rio de Janeiro. 


\section{SEGURIDAD ALIMENTARIA Y SU RELACIÓN CON FACTORES SOCIECONÓMICOS: CASO FAMILIA DE PRODUCTORES DE QUINUA DE LA PARROQUIA SAN ISIDRO, CANTÓN ESPEJO, PROVINCIA DEL CARCHI}

FOOD SECURITY AND ITS RELATIONSHIP WITH SOCIOECONOMIC FACTORS:

CASE QUINOA PRODUCERS, CANTON ESPEJO, CARCHI PROVINCE

PRISCILA MALDONADO P. 



\title{
SEGURIDAD ALIMENTARIA Y SU RELACIÓN CON FACTORES SOCIECONÓMICOS: CASO FAMILIA DE PRODUCTORES DE QUINUA DE LA PARROQUIA SAN ISIDRO, CANTÓN ESPEJO, PROVINCIA DEL CARCHI
}

\author{
Priscila Maldonado P.
}

\section{RESUMEN}

En la actualidad muchas comunidades rurales de Ecuador sufren de escasez de alimentos que componen la canasta familiar básica. De tal manera que la Organización de Naciones Unidas para la Agricultura y Alimentación (FAO) conceptualiza a la seguridad alimentaria como la suficiencia permanente de alimentos a los que tiene derecho la población para llevar una vida sana y activa. Si bien este concepto se lo conoce desde 1996 por falta de estrategias claras y precisas no se lo ha podido desarrollar.

Esta investigación analizó la relación que existe entre los factores socieconómicos y la seguridad alimentaria de 78 familias que se dedican a la produc- ción de quinua como principal actividad económica, tomando como premisa el estudio realizado en Risalda Colombia donde la línea base nutricional en menores de 5 años evidenció que los niños del campo no se beneficiaban por ser hijos de familias productoras de alimentos; por el contrario en algunos municipios varios niños presentaban las cifras más altas de desnutrición crónica en un porcentaje de 28,6\% (Martínez J. , 2009).

Los resultados nos permiten establecer que no todos los indicadores socioeconómicos se relacionan con la seguridad alimentaria medida con el instrumento ELCSA.

Palabras clave: quinua, disponibilidad, autoconsumo, indicadores

${ }^{1}$ Pontificia Universidad Católica del Ecuador, Facultad de Enfermería, Quito, Ecuador (bpmaldonado@puce.edu.ec). 


\begin{abstract}
Today many rural communities in Ecuador suffer from food shortage that makes up the basic family basket. Therefore, the United Nations Food and Agriculture Organization (FAO) conceptualizes food security as permanent sufficiency of food, which should be the right of people to be able to live a healthy and active life; although this concept has been known since 1996 due to lack of clear and precise strategies it has not been able to be developed.
\end{abstract}

This research analyzed the relation between socioeconomic factors and food security of 78 families dedicated to the production of quinoa as the main economic activity, taking as its premise the study in Risalda Colombia where the nutritional baseline in children under 5 years showed that rural children did not receive any benefit for being children of farming families. However some children in some municipalities had the highest rates of chronic malnutrition in a percentage of $28.6 \%$ (J. Martinez, 2009).

The results allow us to establish that not all economic indicators are related to food security meassured with the ELCSA instrument.

Keys words: Quinoa, availability, consumption, indicators

\section{INTRODUCCIÓN}

En América Latina y el Caribe la Seguridad Alimentaria ha tenido un notable impulso en los últimos diez años; varios elementos han favorecido el proceso de cambio en torno a una institucionalidad que promueve la protección de los derechos económicos, sociales y culturales, especialmente el derecho a la alimentación adecuada y suficiente.

El compromiso del Ecuador por garantizar seguridad alimentaria en la población nace en la Cumbre Mundial de la Alimentación celebrada en el año 1996, en la cual Ecuador se comprome- tió a desarrollar procesos que permitan garantizar un entorno político, social y económico propicio para reducir el número de personas con hambre en el país; aplicar políticas que tengan como objetivo erradicar la pobreza; adoptar políticas y prácticas participativas para el desarrollo alimentario; y construir planes de acción con todos los niveles de gobierno en cooperación para combatir el hambre. Estos acuerdos constan en el Decreto Ejecutivo n. ${ }^{\circ} 1039$ el 9 de enero de 1998, que declara a la Seguridad Alimentaria de la población ecuatoriana como Política de Estado. 


\section{SOBERANÍA ALIMENTARIA}

Actualmente el término Soberanía Alimentaria está en construcción, este dependerá de la situación de cada país o localidad; en sus inicios en 1996 fue impulsado por La Vía Campesina, en el contexto de la Cúpula Mundial sobre la Alimentación (CMA) realizada en Roma por la FAO. En este evento el debate oficial giraba en torno de la noción de la seguridad alimentaria, reafirmándola como "El derecho de toda persona a tener acceso a alimentos sanos y nutritivos, en consonancia con el derecho a una alimentación apropiada y con el derecho fundamental de no pasar hambre". Sin embargo, la Organización Mundial del Comercio (OMC) enfocó este principio a la liberalización del comercio de alimentos, motivo que generó controversia con las organizaciones campesinas.

En el Plan Nacional del Buen Vivir 2013-2017 se enuncia acerca de la Soberanía Alimentaria que esta se sustenta en el reconocimiento del derecho a la alimentación sana, nutritiva y culturalmente apropiada, para lo cual es importante incidir tanto en las condiciones de producción y distribución como en el consumo de alimentos. La Soberanía Alimentaria implica recuperar el rol de la sociedad para decidir: qué producir, cómo producir, dónde producir y para quién producir (SENPLADES, 2009).

\section{ESCALA LATINOAMERICANA Y CARIBEÑA DE SEGURIDAD ALIMENTARIA (ELCSA)}

La Escala Latinoamericana y Caribeña de Seguridad Alimentaria (ELCSA) pertenece a la categoría de las escalas de medición de inseguridad alimentaria que se basan en la experiencia en los hogares con esta condición (Tapajós, Quiroga, Pereira, \& Pinto, 2010). La ELCSA es un instrumento que ha demostrado ser muy eficaz y además cuenta con un alto grado de confiabilidad. Esto se debe al enfoque inclusivo y multisectorial que se siguió para el desarrollo, validación, y diseminación del uso de la escala, su metodología es simple, ya que cuenta con quince preguntas de carácter dicotómico, donde sus respuestas son: "sí" o "no". Estas preguntas están dirigidas al jefe/a de familia o a la persona encargada de preparar los alimentos en hogares conformados por adultos e integrantes menores de 18 años. Las primeras ocho preguntas están destinadas a medir solamente el grado de inseguridad alimentaria en hogares que no se encuentren conformados por menores de 18 años; en caso de tener integrantes menores de 18 años; en el hogar se deben responder las 15 preguntas (SESAN 
\& FAO, 2011). El período de referencia para las preguntas son los tres meses previos a la aplicación de la encuesta (Melgar, 2011).

\section{Tabla 1. Categorías de Inseguridad Alimentaria según el número de respuestas positivas en la encuesta ELCSA}

\begin{tabular}{|lcc|}
\hline CATEGORÍA & $\begin{array}{c}\text { NÚMERO DE RESPUESTAS POSITIVAS } \\
\text { Hogares con menores } \\
\text { de } 18 \text { años }\end{array}$ & $\begin{array}{c}\text { Hogares sin menores } \\
\text { de18 años }\end{array}$ \\
\hline Seguridad Alimentaria & 0 & 0 \\
Inseguridad Leve & $1-5 / 15$ & $1-3 / 8$ \\
Inseguridad Moderada & $6-10 / 15$ & $4-6 / 8$ \\
Inseguridad Severa & $11-15 / 15$ & $7-8 / 8$ \\
\hline
\end{tabular}

Fuente: SESAN \& FAO, 2011

Elaborado por SESAN \& FAO, 2011

\section{MATERIALES Y MÉTODOS}

Esta investigación se basa en un estudio observacional, mediante estadística descriptiva. El corte es de tipo transversal, como fuentes primarias se aplicaron encuestas de condiciones de vida, dentro de las cuales se indagó: el acceso a electricidad, al agua potable, al alcantarillado, discapacidad, analfabetismo, principal rama de actividad, nivel de instrucción, número de horas trabajadas, tipo de vivienda, número de personas por vivienda, vía de acceso principal a la vivienda, material del piso, ingreso familiar mensual promedio, procedencia del agua, destino de la producción, suficiencia del consumo de alimentos. Para establecer el grado de Seguridad Alimentaria se aplicó la Encuesta de la Escala Latinoamericana y Caribeña de
Seguridad Alimentaria (ELCSA), mediante criterios como: seguridad, inseguridad leve, inseguridad moderada e inseguridad severa.

Para la selección de la muestra se consideró a los productores de quinua con una producción máxima de 10 quintales anuales del producto y que tengan niños menores de 5 años como miembros de familia. Estos criterios totalizaron una muestra de 78 productores dividido en las comunidades de Carlisama ( $\mathrm{N}=23)$, Puchues ( $N=14)$ San Isidro ( $N=21)$ Chitacaspi $(\mathrm{N}=20)$.

El análisis de datos se realizó mediante la prueba estadística no paramétrica Chi Cuadrado de Pearson aplicando 
el programa estadístico IBM SPSS Statis- Machines Corp. IBM, 2012). tics versión 21.0 (International Business

\section{RESULTADOS}

Se analizaron varios indicadores establecer que 8 indicadores tienen resocieconómicos relacionados con el lación. nivel de seguridad alimentaria y se pudo

\section{Tabla 2. Resultados de la relación de indicadores socioeconómicos y el grado de seguridad alimentaria}

\begin{tabular}{|lr|}
\hline $\begin{array}{l}\text { Indicadores asociados relacionas } \\
\text { con el grado de Seguridad Alimentaria }\end{array}$ & Correlación \\
\hline Acceso a electricidad & $\left(X^{2}=1,88 ; p=0,59\right)$ \\
Acceso al agua potable & $\left(X^{2}=4,25 ; p=0,02\right) *$ \\
Acceso al alcantarillado & $\left(X^{2}=3,58 ; p=0,031\right)$ \\
Discapacidad & $\left(X^{2}=1,88 ; p=0,59\right)$ \\
Analfabetismo & $\left(X^{2}=3,71 ; p=0,29\right)$ \\
Principal rama de actividad & $\left(X^{2}=22,85 ; p=0,52\right)$ \\
Nivel de instrucción & $\left(X^{2}=16,14 ; p=0,37\right)$ \\
Número de horas trabajadas & $\left(X^{2}=16,38 ; p=0,01\right) *$ \\
Tipo de vivienda & $\left(X^{2}=16,53 ; p=0,01\right) *$ \\
Número de personas por vivienda & $\left(X^{2}=12,24 ; p=0,02\right) *$ \\
Vías de Acceso principal a la vivienda & $\left(X^{2}=11,27 ; p=0,04\right)$ \\
Material del piso & $\left(X^{2}=7,96 ; p=0,92\right)$ \\
Ingreso familiar mensual promedio & $\left(X^{2}=11,21 ; p=0,02\right) *$ \\
Procedencia del agua & $\left(X^{2}=7,19 ; p=0,61\right)$ \\
Destino de la producción & $\left(X^{2}=8,260 ; p=0,02\right) *$ \\
Suficiencia del consumo de alimentos & $\left(X^{2}=92,24 ; p=0,00\right) *$ \\
\hline Señala asociación relación entre el indicador socioeconómico \\
y el grado de seguridad alimentaria &
\end{tabular}

Al calcular la relación entre el acceso a servicios básicos y el grado de seguridad alimentaria se pudo determinar lo siguiente: El acceso a electricidad no tiene relación con el grado de seguridad alimentaria ( $\left.X^{2}=1,881 ; p=0,598\right)$, en cuanto al acceso de agua potable se establece que existe relación estadística $\left(X^{2}=4,255 ; p=0,023\right)$; respecto al acceso al alcantarillado existe relación estadística $\left(X^{2}=3,584 ; p=0,031\right)$. Figura 1 . 
En los hogares cuyos miembros tienen más acceso al mercado laboral presentan menor probabilidad de inaccesibilidad a una cantidad suficiente de alimentos, esto dependerá de cómo esté reconocido económicamente ese trabajo. Según Álvarez si un adulto en el hogar tiene trabajo remunerado, la probabilidad que el hogar sufra de inseguridad alimentaria se reduce en un 2,8\% a nivel rural.

En un estudio realizado por Rojas (2014)se establece que los hogares en los cuales los miembros de familia ganan menos de 10 dólares al día, sobrellevan un alto grado de inseguridad alimentaria severa; esta situación disminuye cuando las familias perciben mayores ingresos. Figura 2.

Respecto a la tenencia de vivienda, en el estudio de caso realizado por Rose (1998) en Estados Unidos, se determinó que los hogares que poseen vivienda propia, tienen menor probabilidad de sufrir inseguridad alimentaria, en cambio Calero en un estudio sobre Seguridad Alimentaria y Nutricional en Ecuador, establece que según la ECV 2005-2006 apenas el 40,6\% de los hogares que no acceden a una cantidad suficiente de alimentos poseen vivienda propia, uno de los factores a los cuales se atribuye este fenómeno es a la utilización del ingreso familiar en el pago por la vivienda, colocando como segunda opción la alimentación familiar.
En el 2004 se reportaron varios estudios realizados en diversos países que aportan información acerca de la relación entre tener derechos de propiedad de la tierra con el acceso a créditos y a montos de créditos superiores cuando existe la garantía de la tierra; además se estableció la correlación entre la desigualdad de la propiedad de la tierra y el grado de pobreza en regiones como el Sur de Asia, Sur de África y América Latina. Figura 3.

Respecto al número de personas que componen el hogar y considerando que la seguridad alimentaria se fundamenta en garantizar el acceso a los alimentos a todos los miembros del hogar, mientras mayor es la cantidad de miembros de la familia más recursos alimentarios se necesitan para satisfacer las necesidades energéticas.

Según Calero los hogares que presentan mayores indices de inseguridad alimentaria son más numerosos, tienen mas niños menores de cinco años y una gran proporción de miembros dependientes. Existe asociación estadísticamente significativa entre el número de integrantes de un hogar y el grado de seguridad alimentaria $\left(X^{2}=12,244 ; p\right.$ $=0,02)$. Figura 4 .

En un estudio realizado sobre seguridad alimentaria en el departamento de Antioquia en Colombia, se encontró 
que el promedio de integrantes de los hogares fue similar en la zona urbana $(4,6 \pm 2,1)$ y rural $(4,7 \pm 2,1)(p>0,05)$. En este estudio tanto en el área urbana como rural, los hogares tienden a ser más pequeños, incluso en población de pequeños productores de alimentos para el autoconsumo. Esto implica que la población rural asume algunas conductas similares a la urbana, como por ejemplo, la planificación familiar y la determinación de tener menos hijos. El hecho de que los hogares sean pequeños, la producción de alimentos para el autoconsumo mejorará las condiciones de seguridad alimentaria, ya que se representa en mayor disponibilidad per cápita de alimentos por miembro de familia.

El autoconsumo de alimentos cultivados representa una ventaja para la población, pues contribuye a que exista seguridad alimentaria, ya que las familias tienen mayor disponibilidad y accesibilidad de alimentos, y no implica un costo extra, lo que se traslada en beneficios a la economía familiar.

En un estudio realizado por la FAO (2008) respecto al incremento de precios de los alimentos y la respuesta de los hogares, se estableció que de nueve paises en desarrollo cerca del $75 \%$ de hogares rurales son compradores netos ${ }^{2}$ de alimentos.
El Banco Mundial (2007) realizó un estudio sobre la "Insuficiencia Nutricional en Ecuador", en los resultados obtenidos se determinó que los niños pertenecientes a familias de pequeños agrícultores a nivel rural presentan un estado nutricional deficiente; según el estudio esto se atribuye al aislamiento de estas zonas y al incremento en la cadena de intermediarios, que provocan encarecer a los alimentos.

Se puede establecer que existe asociación entre el destino de la producción de alimentos con el grado de seguridad alimentaria $\left(X^{2}=8,260 ; p=0,022\right)$.

Según los resultados obtenidos, 44 de 78 familias que venden toda la producción de cultivos, padecen de inseguridad alimentaria, los datos emitidos por Alvear en su estudio Seguridad y Soberanía en Ecuador denotan que el cambio de patrones alimentarios contribuye a la revalorización de cultivos tradicionales altamente nutritivos, ocasionando deficiencias alimentarias como la desnutrición y subnutrición. Figura 5.

El autoconsumo tiene una repercusión importante en la seguridad alimentaria nutricional en los hogares; en un estudio realizado en la ciudad de Fómeque, sobre autoconsumo y seguridad alimentaria, se constató que el autocon-

\footnotetext{
${ }^{2}$ Comprador neto. Se considera comprador neto cuando el valor de los productos básicos producidos en el hogar es menor que la cantidad que consume.
} 
sumo tenía una participación que osciló entre el $21-82 \%$ del costo de la canasta básica y representó el 43\% del ingreso familiar del agricultor .

Otro indicador importante es la suficiencia alimentaria; esta se calcula a través de la kilocalorías totales consumidas en el hogar dividido para las kilocalorías requeridas según la hoja de balance de alimentos de cada país; el valor resultante se lo transforma a porcentaje y se determina si es suficiente, insuficiente o crítica. Entre los factores que afectan a la suficiencia alimentaria están el empleo, los ingresos promedio, la pobreza y la desigualdad.

En los resultados se puede observar que 55 de las 78 familias encuestadas presentan insuficiencia alimentaria; al relacionar este indicador con el grado de seguridad alimentaria se establece una asociación estadística $\left(X^{2}=92,24\right.$; $p=0,00)$. La suficiencia alimentaria es un dato real reportado por la población al estar vinculada con el grado de seguridad alimentaria medida por la ELCSA se puede obtener un panorama real de la percepción con la situación.

La suficiencia alimentaria es un indicador de extrema relevancia para la seguridad alimentaria, ya que es el indicador más directo para relacionar la deficencia calórica consumida con la requerida por cada miembro de las familias de productores. Figura 6.

Para visualizar en qué lugar de inseguridad alimentaria se encuentran los productores de quinua se realizó una comparación a nivel nacional e internacional.

La Figura 7 muestra claramente que los países considerados desarrollados presentan bajos niveles de inseguridad alimentaria. A medida que se acerca a lo local se incrementa el riesgo de inseguridad alimentaria. Canadá tan solo presenta un $12 \%$ de inseguridad alimentaria, comparado con Antioquia en Colombia que presenta el $80 \%$ de inseguridad; en la parroquia de Sigchos el porcentaje es del 91 \% y por último de las familias productoras de quinua con un $73 \%$, si bien el universo de estudio no es el mismo, se pueden trasponer los resultados para una interpretación, ya que se utiliza el mismo instrumento de medición.

La comparación más real se realiza al tomar los datos de Antioquia y de la familia de productores de quinua de San Isidro, ya que los dos universos dedican su actividad principal a la producción de alimentos, ahí se puede evidenciar la similitud de los datos. 


\section{CONCLUSIONES}

A partir del análisis de los indicadores socieconómicos de las familias de productores de quinua de San Isidro, se pudo establecer que cuentan con servicios básicos y con un nivel de instrucción medio, indicadores relevantes para medir la calidad de vida de una población.

Respecto al ingreso se concluye que tan solo el $15 \%$ de 78 familias encuestadas; acceden a ingresos que permiten cubrir los costos de una canasta básica, en cuanto a las horas destinadas para trabajo el $73 \%$ de los jefes de hogar, trabajan 40 o más horas; esto revela que las horas trabajadas no son bien remuneradas acorde con la resolución del Ministerio del Trabajo que considera el salario mínimo vital en USD 340.

Las familias encuestadas están ubicadas en la zona rural, esta condición se relaciona con el bajo porcentaje de hogares que disponen de vías de acceso en buenas condiciones, este dato limita la disponibilidad de recursos alimentarios en la población.

Indicadores relacionados con las condiciones del hogar como material del piso, cocina exclusiva y material de construcción, denotan el grado de pobreza que tiene una población; en la presente investigación estas no fueron relevantes, ya que los hogares disponían de buenos recursos.

Uno de los indicadores relevantes en este estudio es el destino de la producción de alimentos, el 72,2 \% se reservan para la venta y tan solo un $24,1 \%$ entre venta y consumo, analizando estos valores con la suficiencia alimentaria se evidencia el cambio de patrones alimentarios, las familias destinan los recursos que adquieren de la venta de sus productos a la compra de alimentos que no aportan significativamente a su dieta.

Según la investigación realizada, la inseguridad alimentaria en los hogares de productores de quinua presenta una asociación con el acceso al agua potable, tipo de vivienda, total de horas destinadas al trabajo, vías de acceso, ingreso familiar promedio y suficiencia en el consumo de alimentos.

La Seguridad Alimentaria y Nutricional (SAN) determina en gran medida la calidad de vida de la población de un país y aglutina diversos aspectos de las políticas de Estado, como la educación, la salud, la cultura, el ambiente, la alimentación y nutrición y el acceso a saneamiento básico, entre otros. 


\section{Anexos}

Figura 1. Relación de seguridad alimentaria con los servicios básicos

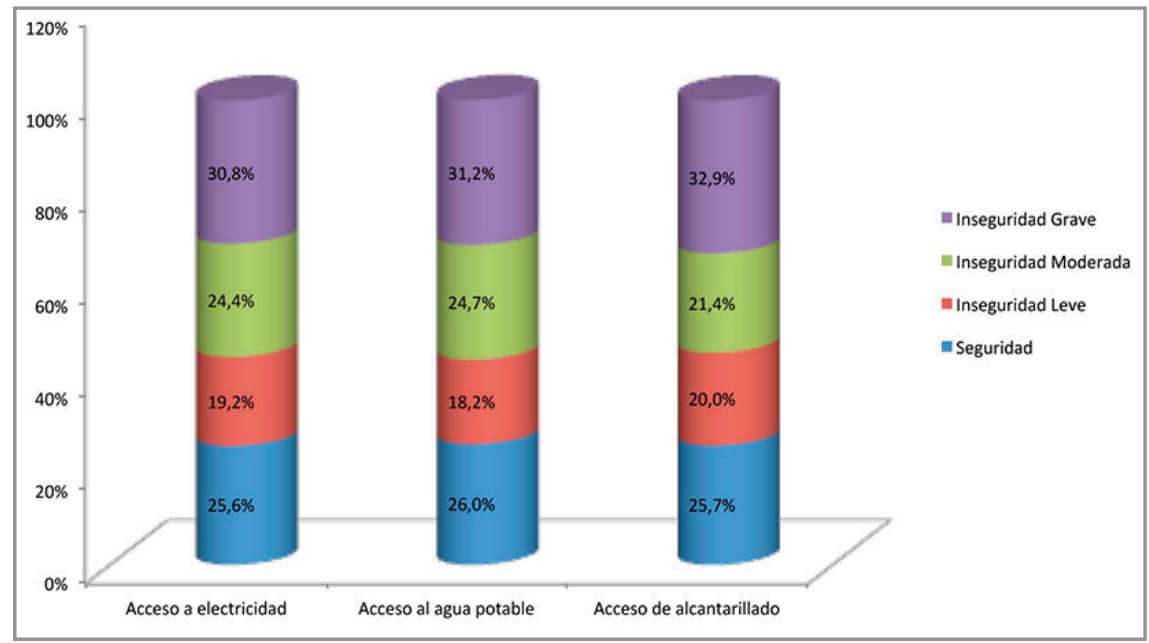

Fuente: Investigación Directa, Encuesta Elaborado por Priscila Maldonado

Figura 2. Relación de seguridad alimentaria con las horas trabajadas por el jefe de hogar

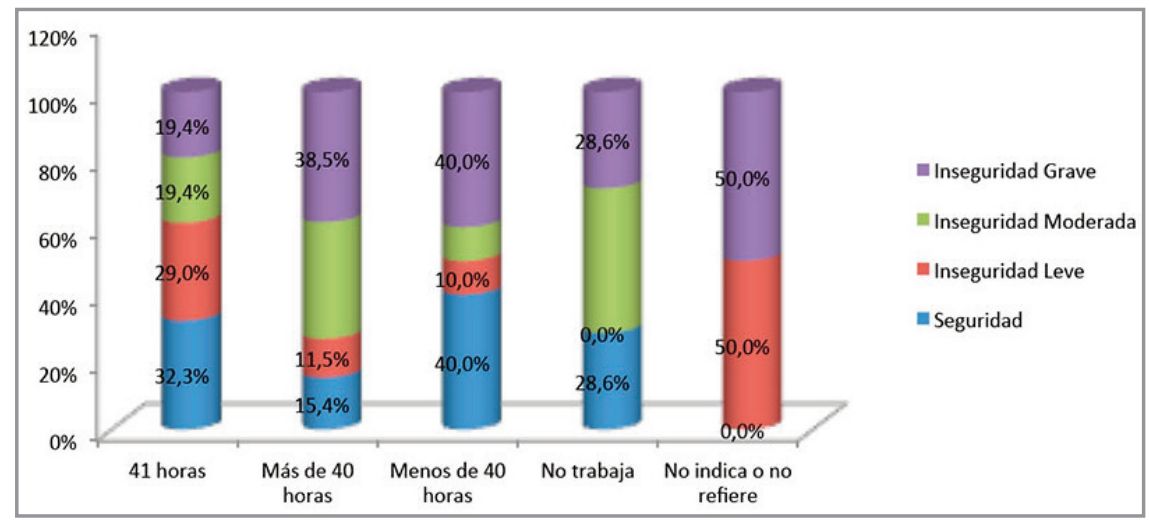

Fuente: Investigación Directa, Encuesta Elaborado por Priscila Maldonado 
Figura 3. Relación de seguridad alimentaria con la tenencia de la vivienda

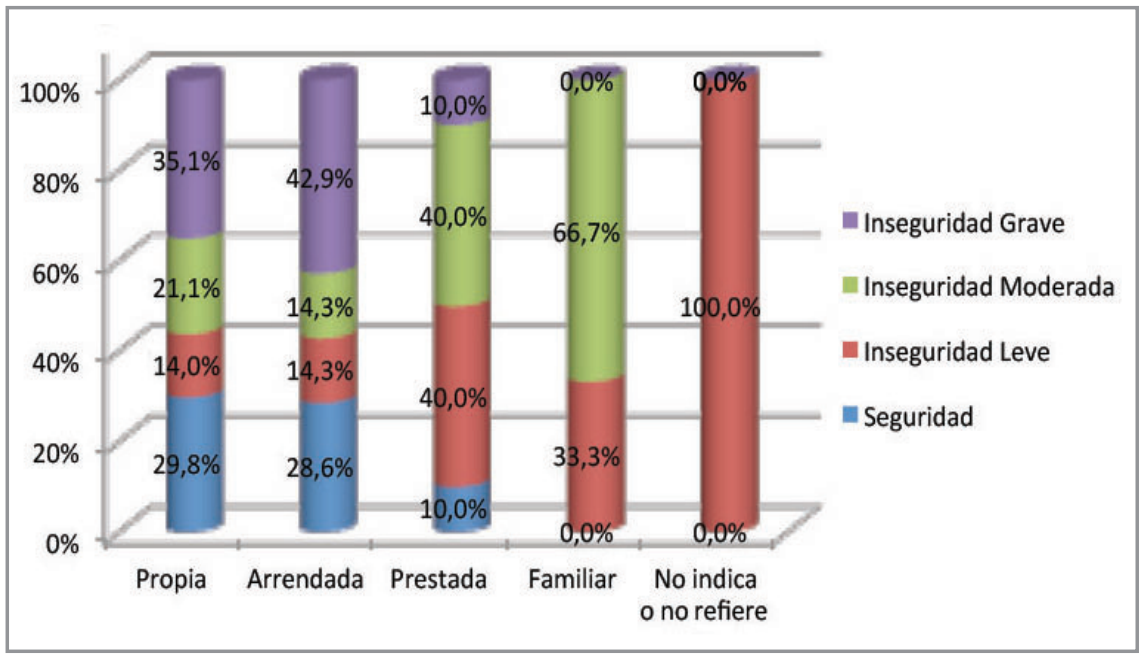

Fuente: Investigación Directa, Encuesta Elaborado por Priscila Maldonado

Figura 4. Relación de seguridad alimentaria con el número de personas por vivienda

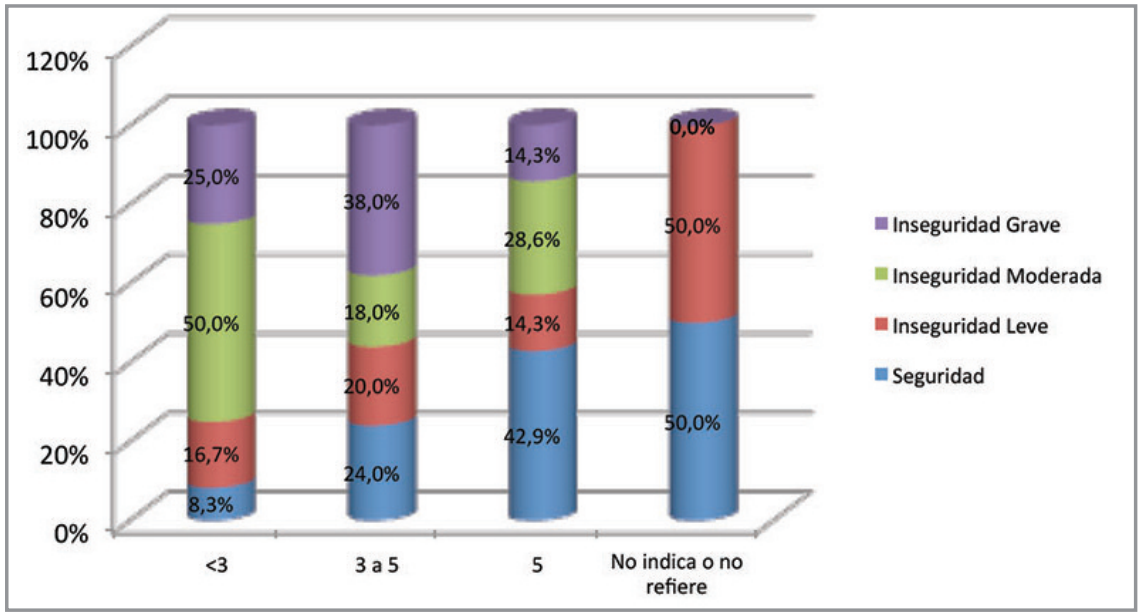

Fuente: Investigación Directa, Encuesta Elaborado por Priscila Maldonado 
Figura 5. Relación de seguridad alimentaria con el destino de la producción de alimentos

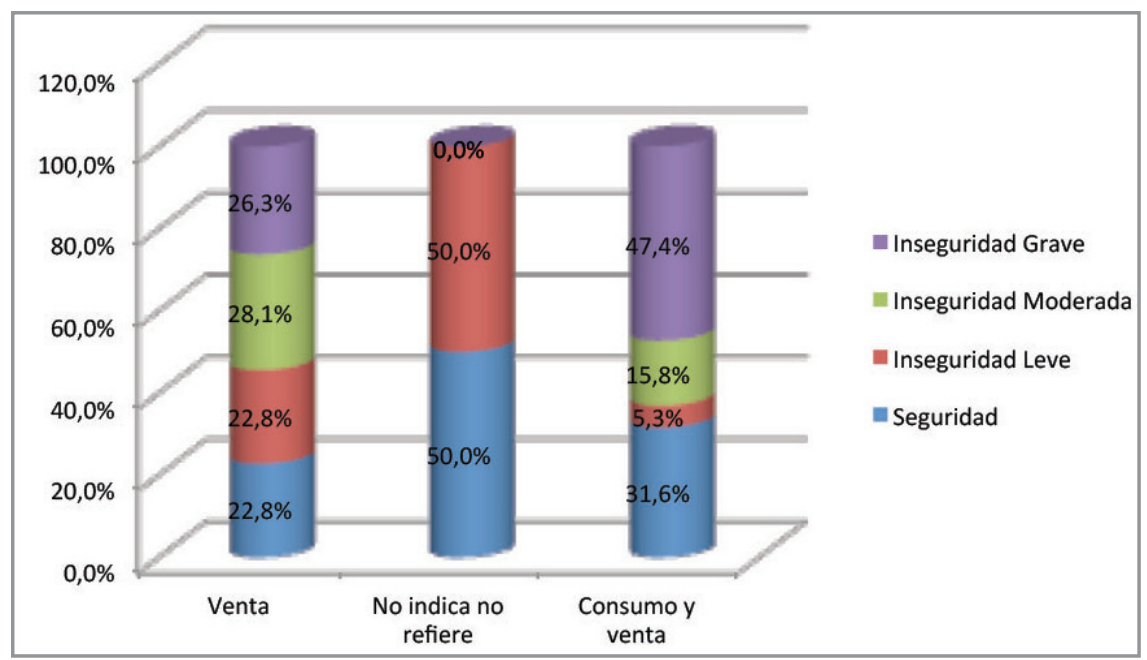

Fuente: Investigación Directa, Encuesta Elaborado por Priscila Maldonado

Figura 6. Relación de seguridad alimentaria con la suficiencia alimentaria

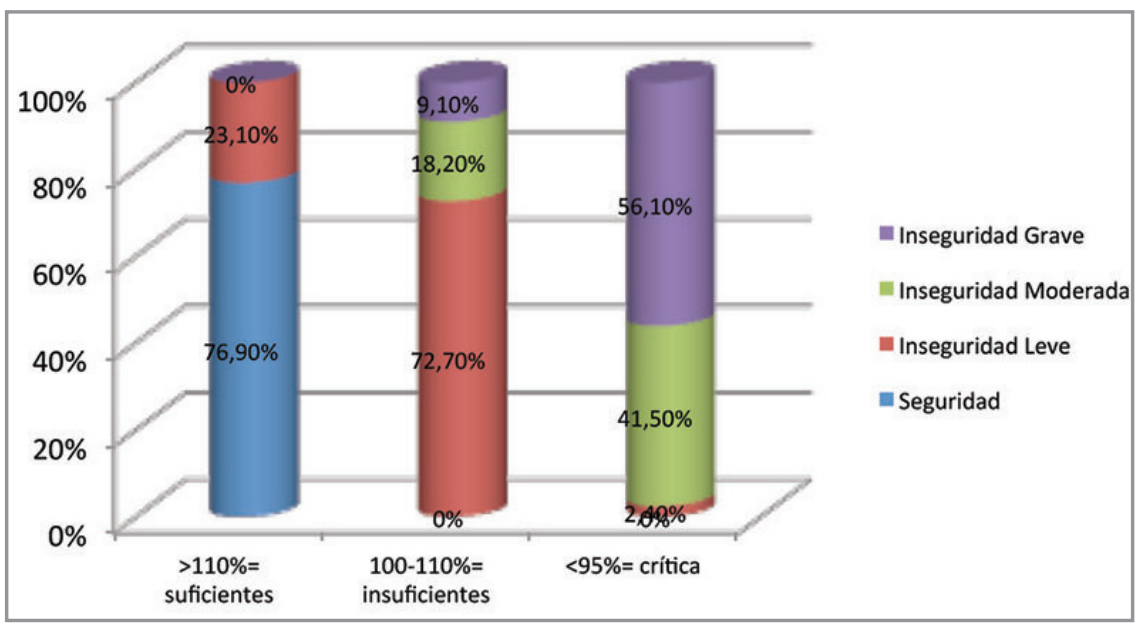

Fuente: Investigación Directa, Encuesta Elaborado por Priscila Maldonado 
ReVista PUCE, ISSN 1012-389X. NúM, 102

Figura 7. Comparación del nivel de seguridad alimentaria en varias localidades

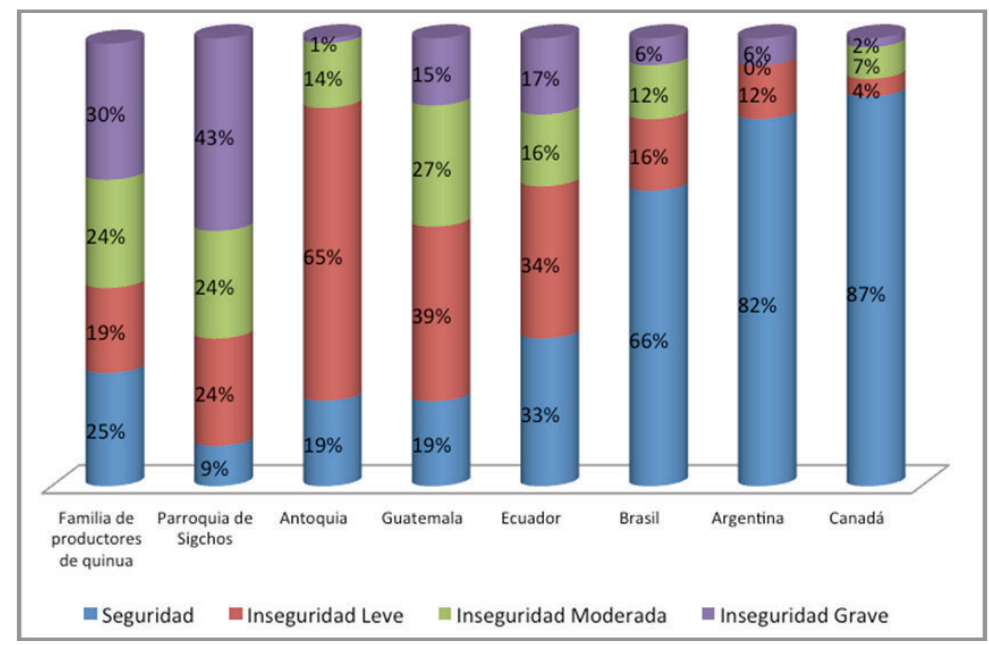

Fuente: Burns, (2004), (Tarasuk, 2012), (FAO, 2002), (Salvia, 2010), (Rojas, 2014) Elaborado por Priscila Maldonado 


\section{BIBLIOGRAFÍA}

Álvarez, M., Mancilla, L., \& Cortéz, J. (2007). Caracterización Socioeconómica y de Seguridad Alimentaria de Los Hogares Productores De Alimentos Para El Autoconsumo, Antioquia-Colombia. Mérida: AGROALIMENTARIA.

Alvear, J. (2012). La Seguridad y Soberanía Alimentaria en el Ecuador. Quito: Aries.

Calero, C. (Octubre de 2011). La Seguridad Alimentaria en Ecuador desde un enfoque de accesibilidad alimentaria. Quito, Pichincha, Ecuador: Abya-Yala.

FAO. (2004). Políticas de desarrollo agrícolas: conceptos y principios. Departamento de Cooperación Técnica. Roma: FAO.

Melgar, H. (2011). Prevalencia de la inseguridad alimentaria en el hogar de Guatemala. Guatemala: FAO.
Menchú, M., \& Santizo, M. (2002). Propuesta de indicadores para la vigilancia de la seguridad alimentaria y nutricional. Guatemala: INCAP/OPS/OMS.

OBSAN-R. (2008). Observatorio Regional de Seguridad Alimentaria y Nutricional, Información de Coyuntura sobre el Alza del Precio de. PRESANCA.

Samaniego, J. (2010). La institucionalidad de la Soberanía y Seguridad Alimentaria en el Ecuador. En M. d. Social, Seguridad Alimentaria y Nutricional del Ecuador (págs. 231 - 241). Ecuador: Aries. 


\section{PERFIL DE LOS DESEMPLEADOS ECUATORIANOS UN ANÁLISIS MULTIDIMENSIONAL}

\section{PROFILE OF THE UNEMPLOYED ECUADORIANS}

A MULTIDIMENSIONAL ANALYSIS

ANA PAREDES

MARISOL SARMIENTO

EFSTATHIOS STEFOS

Recibido 15 de marzo de 2016 Aceptado 8 de abril de 2016 



\title{
PERFIL DE LOS DESEMPLEADOS ECUATORIANOS UN ANÁLISIS MULTIDIMENSIONAL
}

\author{
Ana Paredes ${ }^{1}$ \\ Marisol Sarmiento ${ }^{2}$ \\ Efstathios Stefos ${ }^{3}$
}

\section{RESUMEN}

El objetivo del estudio es investigar el perfil de los desempleados ecuatorianos, para lo cual se realizó un análisis estadístico descriptivo y multidimensional. El estudio utilizó datos de la Encuesta Nacional de Empleo, Desempleo y Subempleo del 2014. El porcentaje de desempleo en hombres y mujeres es muy similar; $49.36 \%$ y $50.64 \%$ respectivamente. El mayor porcentaje de desempleados tienen instrucción media (33.97 \%) y superior universitaria (21.76\%). El 75.90\% de los desempleados viven en el área urbana. $43.90 \%$ de los desempleados son jóvenes. El $81.37 \%$ encuentran sin trabajo por falta de oportunidades. El que no tiene trabajo, en su mayoría, ve mermada el autoestima y el $27.92 \%$ tiene depresión.

Palabras clave: desempleo, análisis estadístico multidimensional

\section{ABSTRACT}

The aim of the study is to investigate the profile of unemployed Ecuadorians, for which a descriptive and multidimensional statistical analysis was realized. The study used data from the National Survey of Employment, Unemployment and Underemployment of 2014. The unemployment rate in men and women is very similar; $49.36 \%$ and

\footnotetext{
${ }^{1}$ Pontificia Universidad Católica del Ecuador, Facultad de Ciencias Exactas y Naturales, Quito, Ecuador (aparedes667@puce.edu.ec).

2 Pontificia Universidad Católica del Ecuador, Facultad de Ciencias Exactas y Naturales, Quito, Ecuador (nsarmiento842@puce.edu.ec).

${ }^{3}$ Pontificia Universidad Católica del Ecuador, Facultad de Ciencias Exactas y Naturales, Proyecto Prometeo, Quito, Ecuador (estefos@aegean.gr).
} 
$50.64 \%$ respectively. The educational level of the majority of the unemployed persons is secondary education (33.97\%) and higher education (21.76\%). 75.90\% of the unemployed live in urban areas and $43.90 \%$ of them are young. $81.37 \%$ of the unemployed persons are out of work due to lack of opportunities. The majority of the unemployed persons have low self-esteem and $27.92 \%$ suffer from depression.

Key words: unemployment, multidimensional statistical analysis

\section{INTRODUCCIÓN}

El presente trabajo contribuye a tener una visión actual de los desempleados ecuatorianos en lo concerniente a sexo, edad, estado civil, nivel de instrucción, raza, tiempo que no han trabajado, razón de desempleo, entre otras variables (Papapostolou \& Stefos, 2013).

Mejorar la calidad de vida es la aspiración de todo ser humano; la manera más segura de lograrlo es contar con un empleo que sea legalmente establecido y remunerado. Trabajar es un derecho y un deber social. Sin embargo, no todos los ciudadanos pueden ejercer este de- recho. Las tasas de desempleo varían cada semestre y generalmente no presentan porcentajes bajos.

El objetivo de este estudio es investigar el perfil de los desempleados ecuatorianos, para lo cual se realiza un análisis estadístico descriptivo y multidimensional con el fin de mostrar las frecuencias y los porcentajes de las variables y los principales criterios de diferenciación y clasificación en grupos de las personas investigadas. Los métodos empleados son el análisis factorial y el análisis jerárquico (Sarmiento Sarmiento et al, 2016).

\section{METODOLOGÍA}

El estudio utilizó datos de la Encuesta Nacional de Empleo, Desempleo y Subempleo de 2014 (INEC, 2014). En el marco del presente estudio, se realizaron un análisis descriptivo y un análisis estadístico multidimensional. El análisis descriptivo muestra las frecuencias y los porcentajes de las variables que estudia la investigación (Athanasiadis, 1995).
El análisis estadístico multidimensional se utiliza con el fin de mostrar las principales y más importantes criterios de diferenciación y la clasificación en grupos de las personas investigadas. Los métodos que utiliza son el análisis factorial de correspondencias múltiples que muestra los criterios de diferenciación y la agrupación jerárquica que define los 
grupos de las personas debido a sus características comunes (Stefos et al, 2011).

El método de análisis factorial de correspondencias múltiples se utiliza con el fin de encontrar cómo las personas se diferencian según sus respuestas. Este método investiga la correlación de las variables de la encuesta de forma simultánea. Los ejes factoriales son los criterios de diferenciación que expresan las oposiciones de las respuestas de las personas.
El análisis jerárquico muestra los grupos de las personas de acuerdo a sus respuestas y características comunes. Este método también presenta un gráfico de clasificación que conecta estos grupos (Papapostolou et al, 2013).

Se utilizó el software SPAD v.4.5 para el análisis de los datos, ofrecido por la Facultad de Humanidades de la Universidad del Egeo. 


\section{ANÁLISIS DESCRIPTIVO}

Tabla 1: Área de residencia de los desempleados ecuatorianos

\begin{tabular}{|lcr|}
\hline & n. $^{\circ}$ & $\%$ \\
\hline Urbana & 1430 & 75.90 \\
Rural & 454 & 24.10 \\
Total & 1884 & 100.00 \\
\hline
\end{tabular}

$75.90 \%$ de los ecuatorianos que están desempleados viven en el área urbana y $24.10 \%$ viven en el área rural (Tabla 1, Gráfico 1).

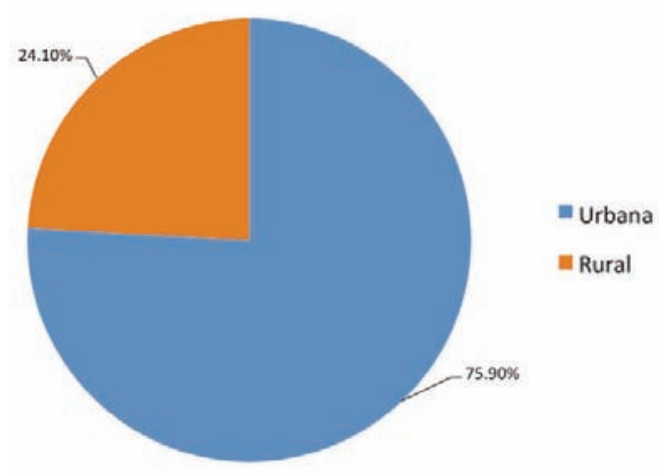

Gráfico 1: Área de residencia de los desempleados ecuatorianos 
Tabla 2: Sexo de los desempleados ecuatorianos

\begin{tabular}{|lcc|}
\hline & n. $^{\circ}$ & $\%$ \\
\hline Hombres & 930 & 49.36 \\
Mujeres & 954 & 50.64 \\
Total & 1884 & 100.00 \\
\hline
\end{tabular}

El $49.36 \%$ de los ecuatorianos que se encuentran desempleados son hombres y el $50.64 \%$ son mujeres (Tabla 2, Gráfico 2).

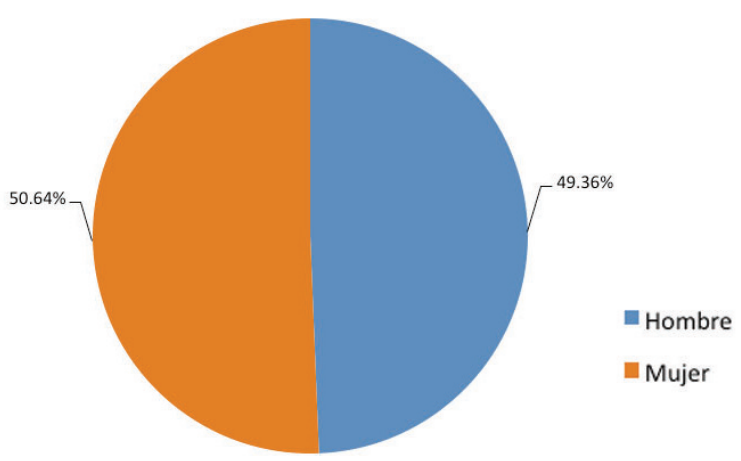

Gráfico 2: Sexo de los desempleados ecuatorianos 


\section{Tabla 3: Edad de los desempleados ecuatorianos}

\begin{tabular}{|lcr|}
\hline Edad & $\mathbf{n .}^{\circ}$ & \multicolumn{1}{c|}{$\%$} \\
\hline$[15,25)$ & 827 & 43.90 \\
{$[25,35)$} & 529 & 28.08 \\
{$[35,45)$} & 249 & 13.22 \\
{$[45,55)$} & 155 & 8.23 \\
{$[55,65)$} & 88 & 4.67 \\
{$[65,75)$} & 29 & 1.54 \\
{$[75,85)$} & 7 & 0.37 \\
Total & 1884 & 100.00 \\
\hline
\end{tabular}

El $43.90 \%$ de los ecuatorianos desempleados son personas jóvenes que se encuentran entre los 15 y 24 años de edad, $28.08 \%$ son personas entre los 25 y 34 años de edad, $13.22 \%$ son personas entre los 35 y 44 años de edad, $8.23 \%$ son personas entre los 45 y 54 años de edad, $4.67 \%$ tienen edades comprendidas entre 55 y 64 años, $1.54 \%$ son personan entre 65 y 74 años de edad y el $0.37 \%$ tienen edades entre 75 y 84 años (Tabla 3, Gráfico 3).

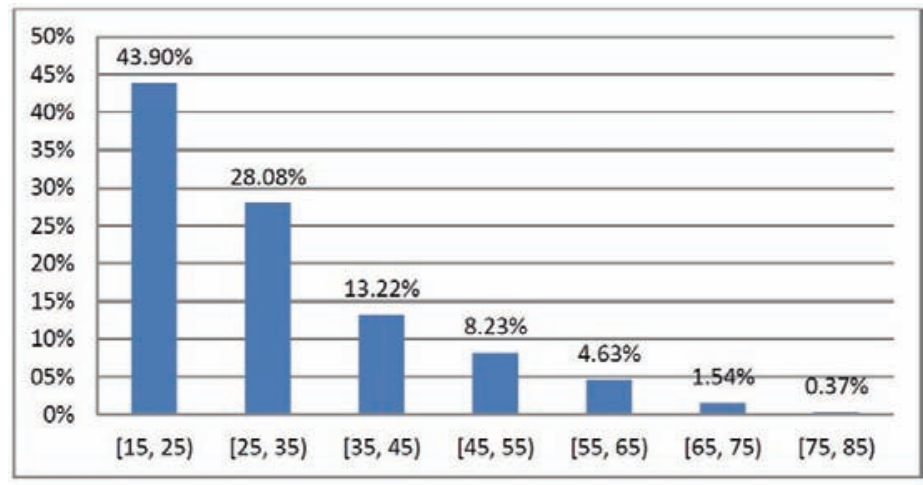

Gráfico 3: Edad de los desempleados ecuatorianos 
Tabla 4: Estado civil de los desempleados ecuatorianos

\begin{tabular}{|lcr|}
\hline & n. & \multicolumn{1}{c|}{$\%$} \\
\hline Casado(a) & 352 & 18.68 \\
Separado(a) & 136 & 7.22 \\
Divorciado(a) & 44 & 2.34 \\
Viudo(a) & 27 & 1.43 \\
Unión libre & 300 & 15.92 \\
Soltero(a) & 1025 & 54.41 \\
Total & 1884 & 100.00 \\
\hline
\end{tabular}

$18.68 \%$ de las personas son casadas, $7.22 \%$ son separadas, $2.34 \%$ son diencuentran en unión libre y 54.41 \% son vorciadas, $1.34 \%$ son viudos, $15.92 \%$ se

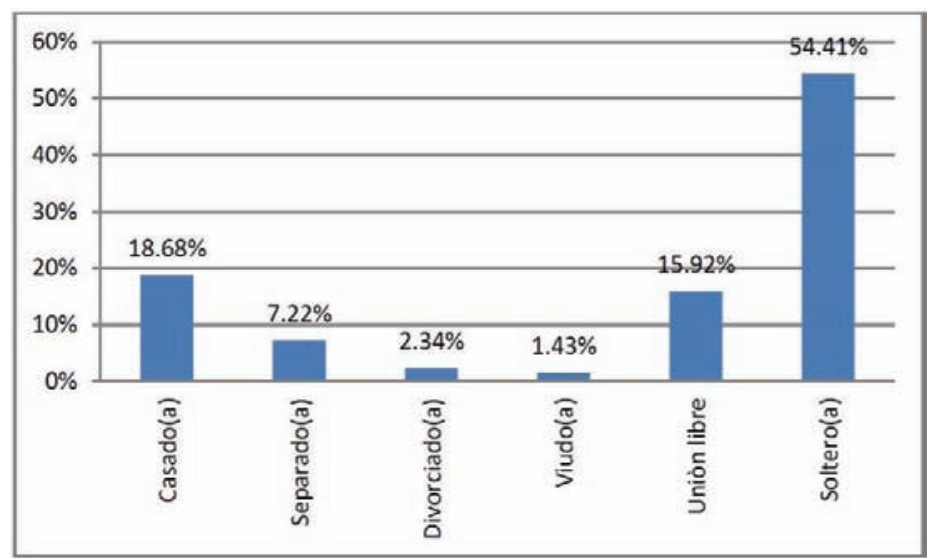

Gráfico 4: Estado civil de los desempleados ecuatorianos 
PERFIL DE LOS DESEMPLEADOS ECUATORIANOS.

UN ANÁLISIS MULTIDIMENSIONAL

Tabla 5: Asiste a clases

\begin{tabular}{|lcr|}
\hline & n. $^{\circ}$ & \multicolumn{1}{c|}{$\%$} \\
\hline Sí & 125 & 6.63 \\
No & 1759 & 93.37 \\
Total & 1884 & 100.00 \\
\hline
\end{tabular}

$6.63 \%$ de los desempleados ecuatorianos asiste a clases y $93.37 \%$ no asiste a clases (Tabla 5, Gráfico 5).

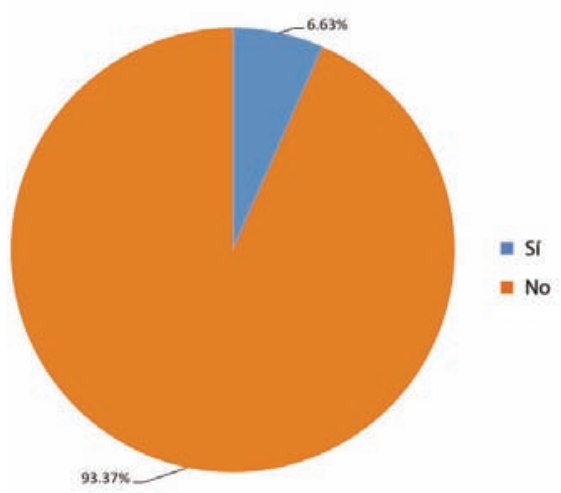

Gráfico 5: Asiste a clases 
Tabla 6: Nivel de instrucción

\begin{tabular}{|lcr|}
\hline & n. $^{\circ}$ & \multicolumn{1}{c|}{$\%$} \\
\hline Ninguno & 18 & 0.96 \\
Centro de alfabetización & 4 & 0.21 \\
Primaria & 299 & 15.87 \\
Educación Básica & 103 & 5.47 \\
Secundaria & 640 & 33.97 \\
Educación Media & 370 & 19.64 \\
Superior no universitario & 29 & 1.54 \\
Superior Universitario & 410 & 21.76 \\
Posgrado & 11 & 0.58 \\
Total & 1884 & 100.00 \\
\hline
\end{tabular}

$0.96 \%$ de las personas ecuatorianas desempleadas no poseen ningún nivel de instrucción, $0.21 \%$ se educaron en centros de alfabetización, $15.87 \%$ de las personas poseen instrucción Prima- ria, $5.47 \%$ Educación Básica, $33.97 \%$ Secundaria, 19.64 \% Educación Media, $1.54 \%$ Superior no universitario, $21.76 \%$ Superior universitario y $0.58 \%$ Posgrado (Tabla 6, Gráfico 6).

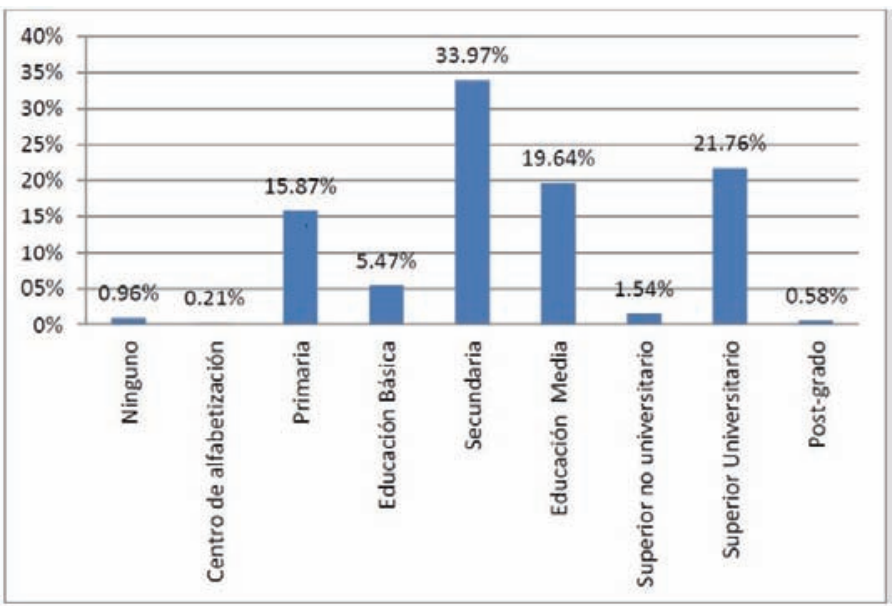

Gráfico 6: Nivel de instrucción 


\section{Tabla 7: Idioma que hablan}

\begin{tabular}{|lcc|}
\hline & $\mathrm{n}^{\circ}$ & $\%$ \\
\hline Solo lengua indígena & 1 & 0.05 \\
Lengua indígena y español & 77 & 4.09 \\
Solo español & 1768 & 93.84 \\
Español e idioma extranjero & 36 & 1.91 \\
Idioma extranjero & 1 & 0.05 \\
No habla & 1 & 0.05 \\
Total & 1884 & 100.0 \\
\hline
\end{tabular}

$0.05 \%$ hablan sólo lengua indí- idioma extranjero, 0.05 \% idioma extrangena, $4.09 \%$ lengua indígena y español, jero (Tabla7, Gráfico 7). 93.84 \% sólo español, $1.91 \%$ español e

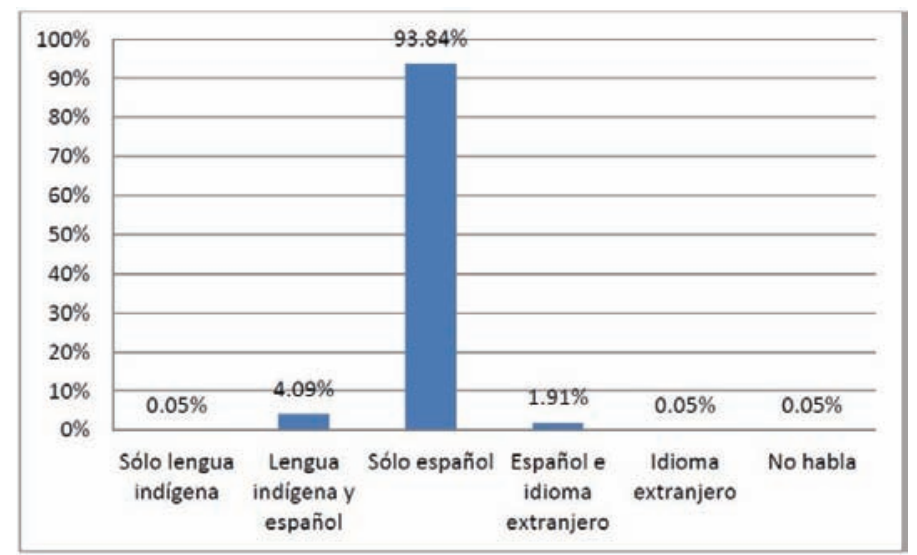

Gráfico 7: Idioma que hablan 
Tabla 8: Cómo se considera

\begin{tabular}{|lcc|}
\hline & $\mathbf{n .}^{\circ}$ & $\%$ \\
\hline Indígena & 104 & 5.52 \\
Afroecuatoriano & 74 & 3.93 \\
Negro & 49 & 2.60 \\
Mulato & 18 & 0.96 \\
Montubio & 48 & 2.55 \\
Mestizo & 1557 & 82.64 \\
Blanco & 34 & 1.80 \\
Total & 1884 & 100.0 \\
\hline
\end{tabular}

$5.52 \%$ se consideran indígena, mestizo, y $1.80 \%$ blanco (Tabla 8, Gráfico $3.93 \%$ afroecuatoriano, $2.60 \%$ negro, 8).

$0.96 \%$ mulato, $2.55 \%$ montubio, $82.64 \%$

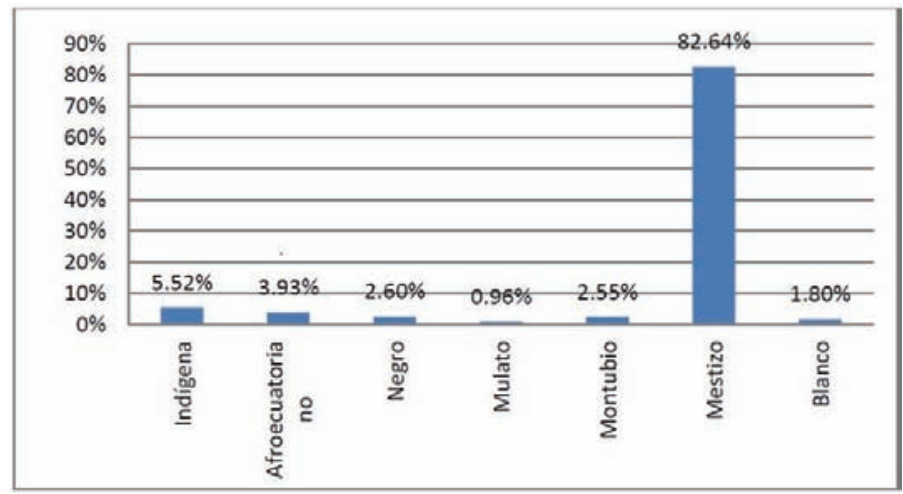

Grafico 8: Cómo se considera 


\section{Tabla 9: Buscó trabajo el mes anterior}

\begin{tabular}{|lrr|}
\hline & n. & \multicolumn{1}{c|}{$\%$} \\
\hline Acudir a sitios de contratación temporal & 118 & 6.26 \\
Hablar con amigos o parientes & 504 & 26.75 \\
Buscar en la prensa o radio & 94 & 4.99 \\
Acudir a agencias de empleo & 88 & 4.67 \\
Tratar de establecer su propio taller, negocio & 29 & 1.54 \\
Asistir a entrevistas & 86 & 4.56 \\
Colocar carteles en tiendas o negocios & 4 & 0.21 \\
Buscar por Internet & 98 & 5.20 \\
Enviar hoja de vida & 374 & 19.85 \\
Otra gestión & 10 & 0.53 \\
No realizó ninguna gestión & 479 & 25.42 \\
Total & 1884 & 100.00 \\
\hline
\end{tabular}

$6.26 \%$ acudió a sitios de contratación temporal, $26.75 \%$ hablo con amigos o parientes $4.99 \%$ buscó en la prensa o radio, $4.67 \%$ acudió a agencias de empleo, $1.54 \%$ trató de establecer su propio taller, negocio, el $4.56 \%$ asistió a entrevistas, $0.21 \%$ colocó carteles en tiendas o negocios, $5.20 \%$ buscó por Internet, $19.85 \%$ envió hoja de vida, $0.53 \%$ realizó otra gestión y el 25.42 \% no realizó ninguna gestión (Tabla 9, Gráfico 9).

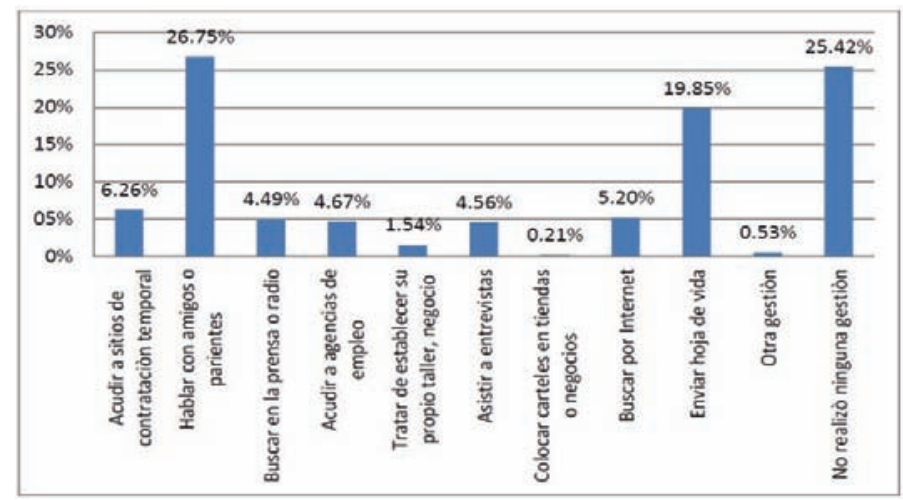

Gráfico 9: Buscó trabajo el mes anterior 


\section{Tabla 10: Meses que busca trabajo}

\begin{tabular}{|lcr|}
\hline & $\mathbf{n}^{\circ}$ & \multicolumn{1}{c|}{$\%$} \\
\hline 1 & 522 & 27.71 \\
2 & 290 & 15.39 \\
3 & 166 & 8.81 \\
4 & 73 & 3.87 \\
5 & 61 & 3.24 \\
6 & 93 & 4.94 \\
7 & 17 & 0.90 \\
8 & 29 & 1.54 \\
9 & 11 & 0.58 \\
10 & 18 & 0.96 \\
11 & 7 & 0.37 \\
12 & 30 & 1.59 \\
13 & 88 & 4.67 \\
NA & 479 & 25.42 \\
Total & 1884 & 100.00 \\
\hline
\end{tabular}

$27.71 \%$ buscó trabajo durante $1 \quad 0.58 \% 9$ meses, $0.96 \% 10$ meses, $0.37 \%$ mes, $15.39 \% 2$ meses, $8.81 \% 3$ meses, 11 meses, $1.59 \% 12$ meses, $4.67 \% 13$ 3.87 \% 4 meses, $3.24 \% 5$ meses, $4.94 \%$ meses (Tabla 10, Gráfico 10). 6 meses, $0.90 \% 7$ meses, $1.54 \% 8$ meses,

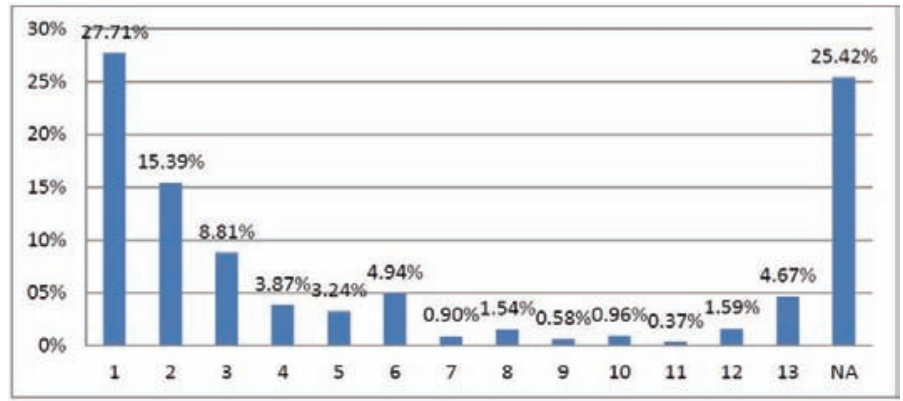

Gráfico 10: Meses que busca trabajo 


\section{Tabla 11: Razón por la que no buscó trabajo}

\begin{tabular}{|lcc|}
\hline & $\mathbf{n .}^{\circ}$ & $\%$ \\
\hline Trabajo ocasional & 25 & 1.33 \\
Tiene trabajo para empezar inmediatamente & 12 & 0.64 \\
Espera respuesta a una gestión & 30 & 1.59 \\
Espera respuesta de un empleador & 52 & 2.76 \\
Espera cosecha o temporada de trabajo & 19 & 1.01 \\
Piensa que no le darán trabajo & 93 & 4.94 \\
No cree poder encontrar & 248 & 13.16 \\
NA & 1405 & 74.58 \\
Total & 1884 & 100.00 \\
\hline
\end{tabular}

$1.33 \%$ de los desempleados ecua- dor, $1.01 \%$ espera cosecha o temporada torianos no buscaron trabajo porque de trabajo, $4.94 \%$ piensa que no le tiene trabajo ocasional, $0.64 \%$ tiene tra- darán trabajo, $13.16 \%$ no cree poder enbajo para empezar inmediatamente, contrar, $74.58 \%$ no responde (Tabla 11, $1.59 \%$ espera respuesta a una gestión, Gráfico 11).

$2.76 \%$ espera respuesta de un emplea-

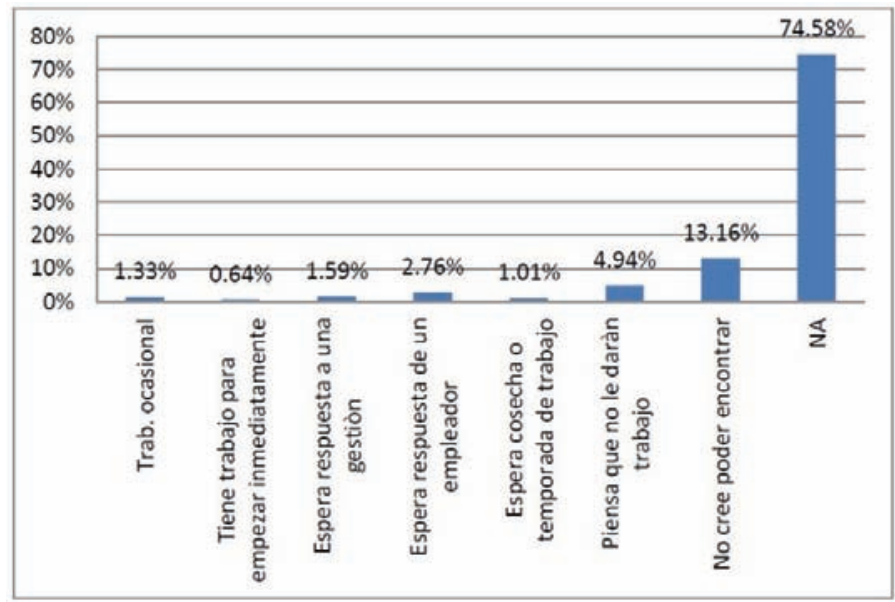

Gráfico 11: Razón por la que no buscó trabajo 
Tabla 12: Trabajó anteriormente

\begin{tabular}{|lcr|}
\hline & n. & \multicolumn{1}{c|}{$\%$} \\
\hline Sí & 1250 & 66.35 \\
No & 634 & 33.65 \\
Total & 1884 & 100.00 \\
\hline
\end{tabular}

El 66.35 \% sí trabajó anteriormente, y el 33.65 \% no (Tabla 12, Gráfico 12).

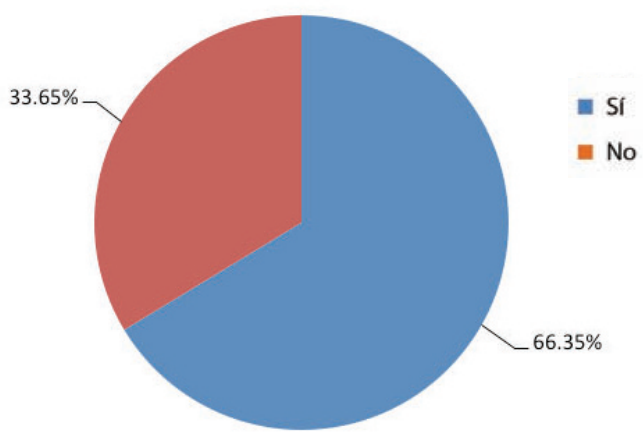

Gráfico 12: Trabajó anteriormente 
Tabla 13: Motivos por los que dejó de trabajar

\begin{tabular}{|lcc|}
\hline & $\mathbf{n .}^{\circ}$ & $\%$ \\
\hline Liquidación empresa & 73 & 3.87 \\
Despido intempestivo & 167 & 8.86 \\
Renuncia voluntaria & 276 & 14.65 \\
Supresión partidas & 14 & 0.74 \\
Terminación contrato & 398 & 21.13 \\
Fue mal en el negocio & 75 & 3.98 \\
Terminó ciclo agrícola & 99 & 5.25 \\
Se jubiló o pensionaron & 4 & 0.21 \\
Otro & 144 & 7.64 \\
NA & 634 & 33.65 \\
Total & 1884 & 100.0 \\
\hline
\end{tabular}

$3.87 \%$ de los ecuatorianos desem- das; $21.13 \%$ terminaron su contrato; pleados dejaron de trabajar por liquida- $3.98 \%$ les fue mal en el negocio; $5.25 \%$ ción empresarial; 8.86 \% por despido porque terminó el ciclo agrícola y $0.21 \%$ intempestivo; 14.65 \% por renuncia vo- por jubilación (Tabla 13, Gráfico 13). luntaria; $0.74 \%$ por supresión de parti-

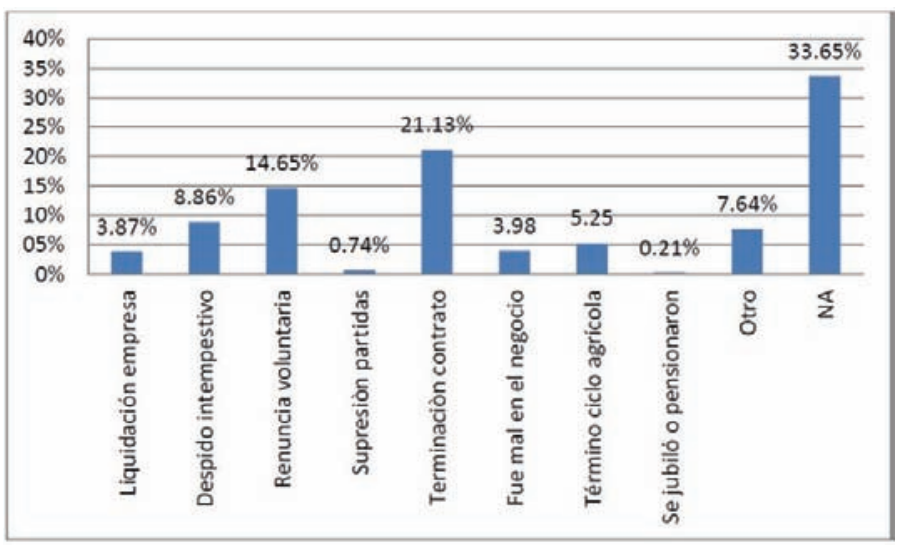

Gráfico 13: Motivos por los que dejó de trabajar 


\section{Tabla 14: Número de meses que no trabaja}

\begin{tabular}{|lcr|}
\hline & $\mathrm{n}^{\circ}$ & $\%$ \\
\hline 1 & 275 & 14.60 \\
2 & 211 & 11.20 \\
3 & 149 & 7.91 \\
4 & 75 & 3.98 \\
5 & 74 & 3.93 \\
6 & 92 & 4.88 \\
7 & 18 & 0.96 \\
8 & 51 & 2.71 \\
9 & 26 & 1.38 \\
10 & 31 & 1.65 \\
11 & 4 & 0.21 \\
12 & 50 & 2.65 \\
13 & 194 & 10.30 \\
14 & 634 & 33.65 \\
Total & 1884 & 100.00 \\
\hline
\end{tabular}

$14.60 \%$ de los desempleados $0.96 \%$ no trabajan 7 meses; $2.71 \%$ no ecuatorianos no trabajan durante 1 mes; trabajan 8 meses; $1.38 \%$ no trabajan $11.20 \%$ no trabajan durante 2 meses; 9 meses; $1.65 \%$ no trabajan 10 meses; $7.91 \%$ no trabajan durante 3 meses; $0.21 \%$ no trabajan 11 meses; $2.65 \%$ no $3.98 \%$ no trabajan durante 4 meses; trabajan 12 meses; $10.30 \%$ no trabajan $3.93 \%$ no trabajan durante 5 meses; 13 meses y $33.65 \%$ no trabajan durante 4.88 \% no trabajan durante 6 meses; 14 meses (Tabla 14, Gráfico 14).

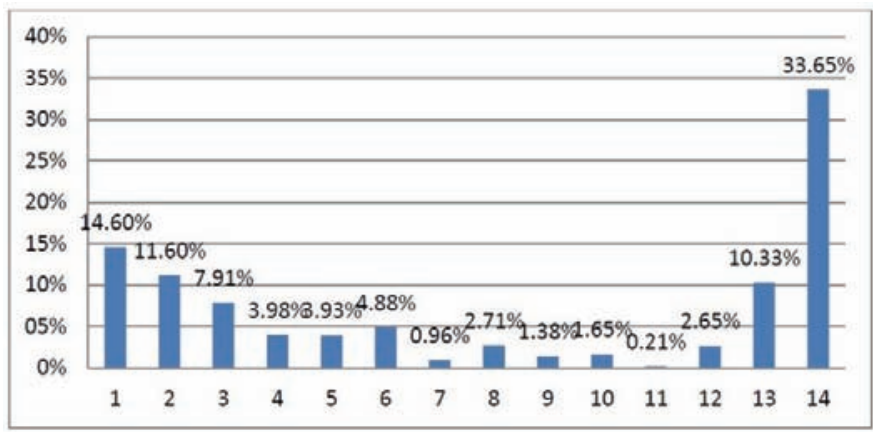

Gráfico 14: Número de meses que no trabaja 
Tabla 15: Se encuentra sin trabajo por

\begin{tabular}{|lcr|}
\hline & $\mathbf{n}^{\circ}$ & $\%$ \\
\hline Falta de oportunidades en la actualidad & 1533 & 81.37 \\
Resultado de sus errores del pasado & 108 & 5.73 \\
Motivos personales / familiares & 237 & 12.58 \\
Fenómenos / desastres naturales & 6 & 0.32 \\
Total & 1884 & 100.0 \\
\hline
\end{tabular}

$81.37 \%$ de los ecuatorianos se en- $\quad 12.58 \%$ por motivos personales y $0.32 \%$ cuentra sin trabajo por falta de oportu- $\quad$ se encuentran sin trabajo por fenómenidades; 5.73 \% no tienen trabajo como nos / desastres naturales (Tabla 15, Gráresultado de sus errores del pasado; fico 15).

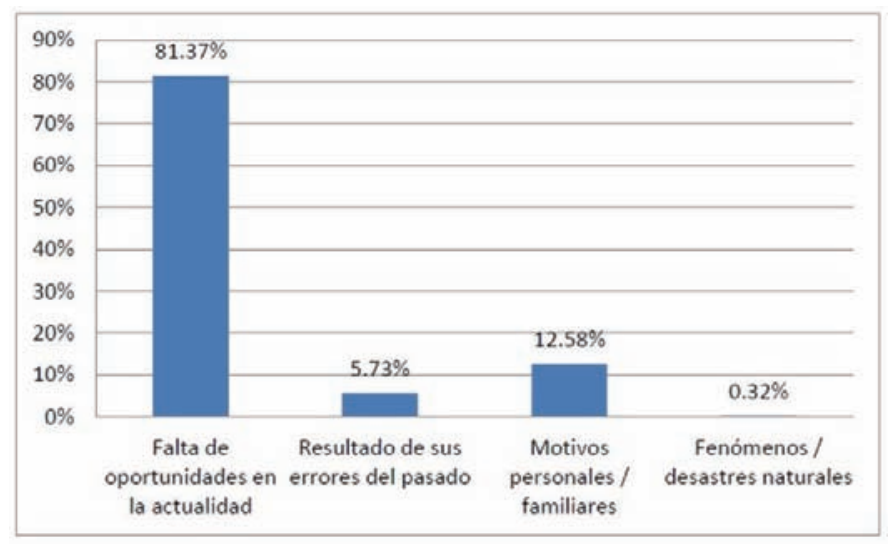

Gráfico 15: Se encuentra sin trabajo por 
Tabla 16: Tiene deterioro de sus habilidades

\begin{tabular}{|lcc|}
\hline & n. & $\%$ \\
\hline Sí & 626 & 33.23 \\
No & 1258 & 66.77 \\
Total & 1884 & 100.0 \\
\hline
\end{tabular}

$33.23 \%$ de los ecuatorianos que se lidades y $66.77 \%$ respondieron que no encuentran desempleados respondie- tienen deterioro de sus habilidades ron que sí tienen deterioro de sus habi- (Tabla 16, Gráfico 16).

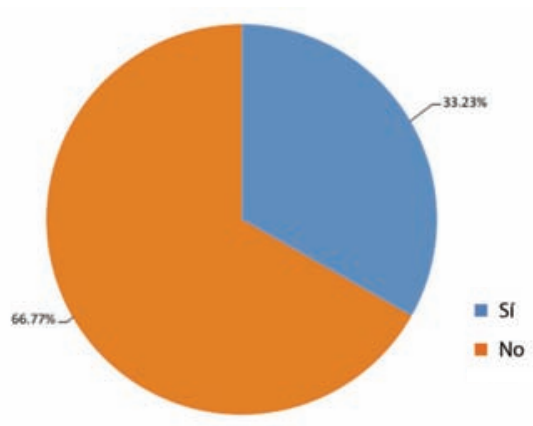

Gráfico 16: Tiene deterioro de sus habilidades 
PERFIL DE LOS DESEMPLEADOS ECUATORIANOS.

UN ANÁLISIS MULTIDIMENSIONAL

\section{Tabla 17: Tiene disminución de su autoestima}

\begin{tabular}{|lcr|}
\hline & n. $^{\circ}$ & \multicolumn{1}{c|}{$\%$} \\
\hline Sí & 964 & 51.17 \\
No & 920 & 48.83 \\
Total & 1884 & 100.00 \\
\hline
\end{tabular}

$51.17 \%$ de los ecuatorianos des- nución de su autoestima (Tabla 17, Gráempleados si tienen disminución de su fico 17).

autoestima y $48.83 \%$ no tienen dismi-

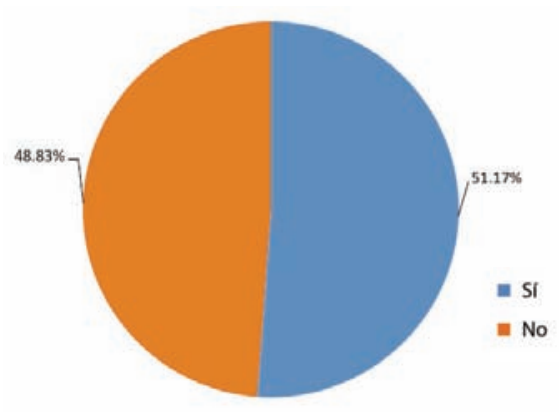

Gráfico 17: Tiene disminución de su autoestima 
Revista PUCE, ISSN 1012-389X. Núm, 102

3 Nov 2015-3 mayo 2016. Paredes, SARmiento, Stefos, pr. 325-368

Tabla 18: Tiene depresión

\begin{tabular}{|lcr|}
\hline & n. & \multicolumn{1}{c|}{$\%$} \\
\hline Sí & 526 & 27.92 \\
No & 1358 & 72.08 \\
Total & 1884 & 100.00 \\
\hline
\end{tabular}

$27.92 \%$ de los desempleados no tienen depresión (Tabla 18, Gráfico ecuatorianos tienen depresión y $72.08 \%$ 18).

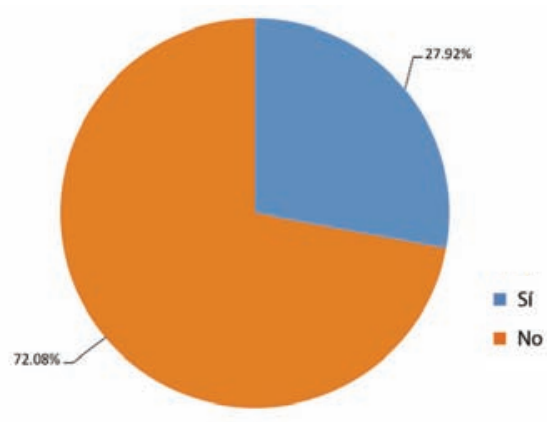

Gráfico 18: Tiene depresión 
Tabla 19: Tiene falta de superación personal y profesional

\begin{tabular}{|lcc|}
\hline & n. $^{\circ}$ & $\%$ \\
Sí & 776 & 41.19 \\
No & 1108 & 58.81 \\
Total & 1884 & 100.0 \\
\hline
\end{tabular}

$41.19 \%$ de los ecuatorianos de- falta de superación personal y profesiosempleados tienen falta de superación nal (Tabla 19, Gráfico 19). personal y profesional, $58.81 \%$ no tienen

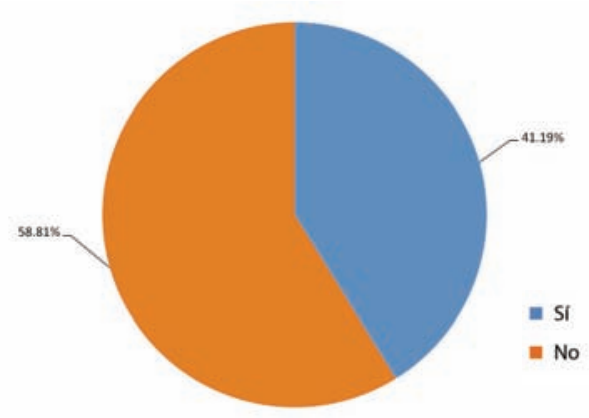

Gráfico 19: Tiene falta de superación personal y profesional 
Tabla 20: Por ser desempleado ha tenido que gastar ahorros

\begin{tabular}{|lcr|}
\hline & n. $^{\circ}$ & \multicolumn{1}{c|}{$\%$} \\
\hline Sí & 1035 & 54.94 \\
No & 849 & 45.06 \\
Total & 1884 & 100.00 \\
\hline
\end{tabular}

El $54.94 \%$ de ecuatorianos por ser ahorros, y el $45.06 \%$ no ha tenido que desempleado ha tenido que gastar sus gastar ahorros (Tabla 20, Gráfico 20).

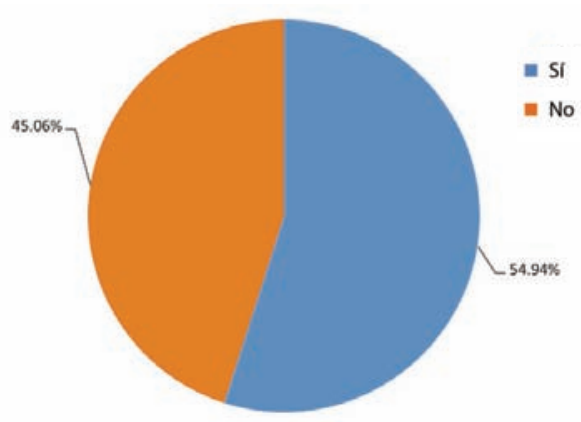

Gráfico 20: Por ser desempleado ha tenido que gastar ahorros 
Tabla 21: Por ser desempleado ha tenido que vender bienes

\begin{tabular}{|lcr|}
\hline & n. & $\%$ \\
Sí & 222 & 11.78 \\
No & 1662 & 88.22 \\
Total & 1884 & 100.0 \\
\hline
\end{tabular}

El 11.78\% de ecuatorianos por ser bienes, y el $88.22 \%$ no (Tabla 21, Grádesempleados han tenido que vender fico 21).

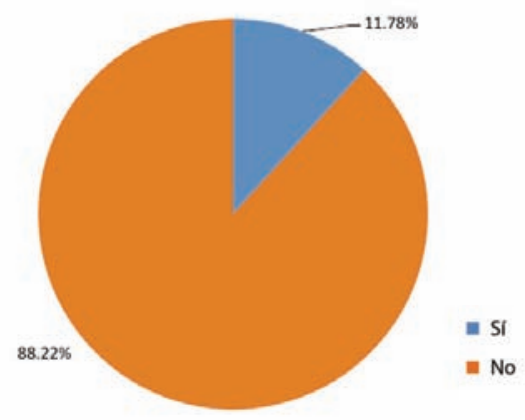

Gráfico 21: Por ser desempleado ha tenido que vender bienes 
Tabla 22: Por ser desempleado ha tenido que endeudarse

\begin{tabular}{|lcr|}
\hline & n. $^{\circ}$ & \multicolumn{1}{c|}{$\%$} \\
\hline Sí & 673 & 35.72 \\
No & 1211 & 64.28 \\
Total & 1884 & 100.00 \\
\hline
\end{tabular}

El 35.72\% por ser desempleado ha ha tenido que endeudarse (Tabla 22, tenido que endeudarse, y el $64.28 \%$ no Gráfico 22).

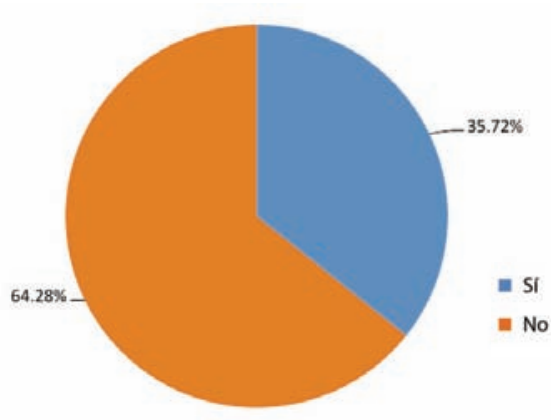

Gráfico 22: Por ser desempleado ha tenido que endeudarse 
Tabla 23: Por ser desempleado ha tenido que comprar productos baratos

\begin{tabular}{|lcc|}
\hline & n. $^{\circ}$ & $\%$ \\
\hline Sí & 1109 & 58.86 \\
No & 775 & 41.14 \\
Total & 1884 & 100.0 \\
\hline
\end{tabular}

El $58.86 \%$ de ecuatorianos por ser nido que comprar productos baratos desempleado ha tenido que comprar (Tabla 23, Gráfico 23). productos baratos, el $41.14 \%$ no ha te-

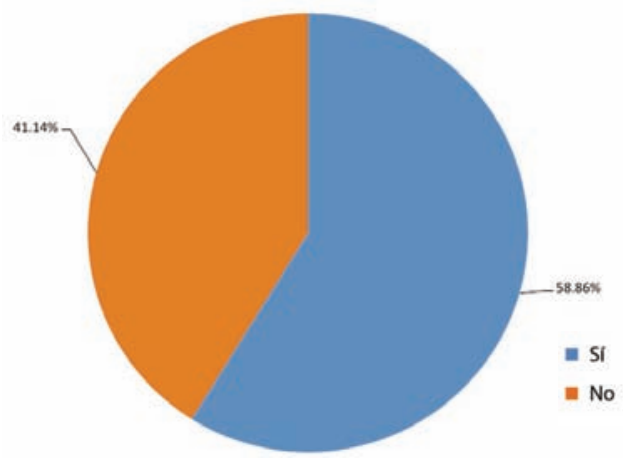

Gráfico 23: Por ser desempleado ha tenido que comprar productos baratos 
Tabla 24: Por ser desempleado ha disminuido el consumo de alimentos

\begin{tabular}{|lcc|}
\hline & n. $^{\circ}$ & $\%$ \\
\hline Sí & 929 & 49.31 \\
No & 955 & 50.69 \\
Total & 1884 & 100.0 \\
\hline
\end{tabular}

El $49.31 \%$ de ecuatorianos por ser disminuido el consumo de alimentos desempleado ha disminuido el con- (Tabla 24, Gráfico 24). sumo de alimentos, y el $50.69 \%$ no han

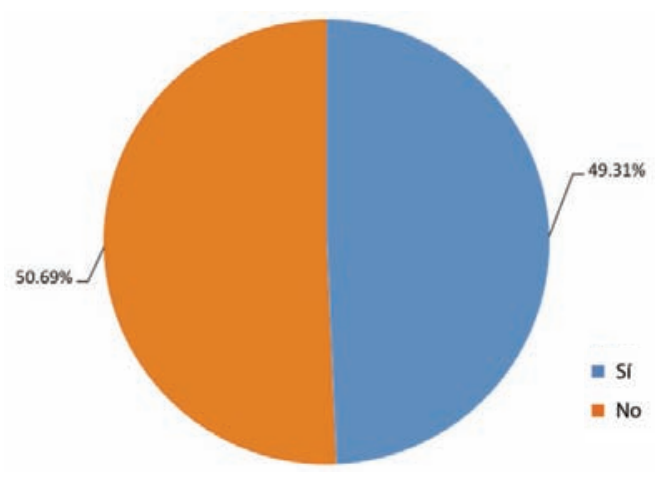

Gráfico 24: Por ser desempleado ha disminuido el consumo de alimentos 
Tabla 25: Por ser desempleado ha disminuido la compra de vestido

\begin{tabular}{|lcr|}
\hline & n. $^{\circ}$ & \multicolumn{1}{c|}{$\%$} \\
\hline Sí & 1122 & 59.55 \\
No & 762 & 40.45 \\
Total & 1884 & 100.00 \\
\hline
\end{tabular}

El $59.55 \%$ por ser desempleado $40.45 \%$ no ha disminuido la compra de ha disminuido la compra de vestido, y el vestido (Tabla 25, Gráfico 25).

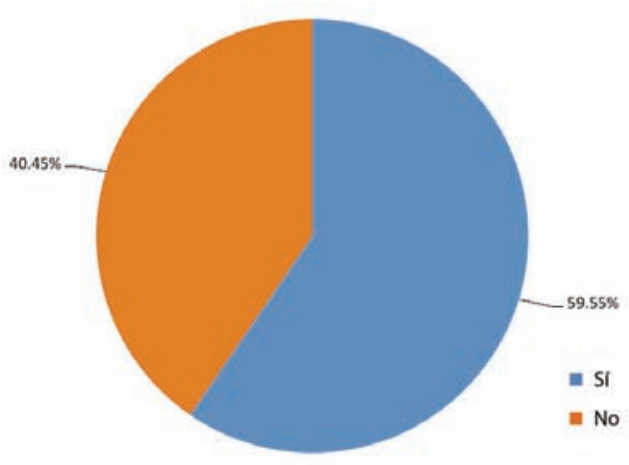

Gráfico 25: Por ser desempleado ha disminuido la compra de vestido 
Tabla 26: Por ser desempleado cambió a estudiantes de establecimientos

\begin{tabular}{|lcr|}
\hline & n. $^{\circ}$ & $\%$ \\
\hline Sí & 162 & 8.60 \\
No & 1722 & 91.40 \\
Total & 1884 & 100.00 \\
\hline
\end{tabular}

$8.60 \%$ de los desempleados ecua- ron de establecimiento (Tabla 26, Grátorianos cambiaron a estudiantes de es- fico 26). tablecimientos y $91.40 \%$ no les cambia-

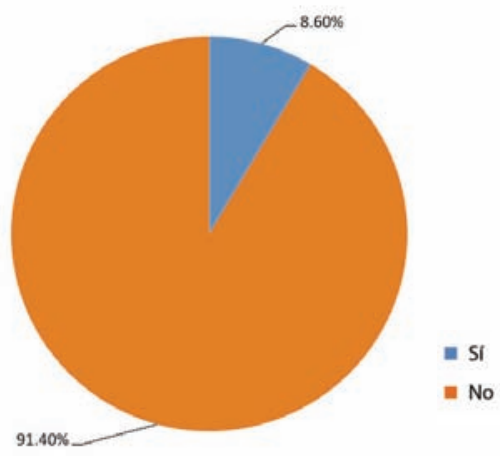

Gráfico 26: Por ser desempleado cambió a estudiantes de establecimientos 
PERFIL DE LOS DESEMPLEADOS ECUATORIANOS.

UN ANÁLISIS MULTIDIMENSIONAL

Tabla 27: Está embarazada o en periodo de lactancia

\begin{tabular}{|lcr|}
\hline & n. $^{\circ}$ & \multicolumn{1}{c|}{$\%$} \\
\hline Sí & 60 & 3.18 \\
No & 834 & 44.27 \\
NA & 990 & 52.55 \\
Total & 1884 & 100.00 \\
\hline
\end{tabular}

$3.18 \%$ de las mujeres ecuatorianas pondieron a esta pregunta (Tabla 27, desempleadas están embarazadas; $44.27 \%$ Gráfico 27).

no están embarazadas y $52.55 \%$ no res-

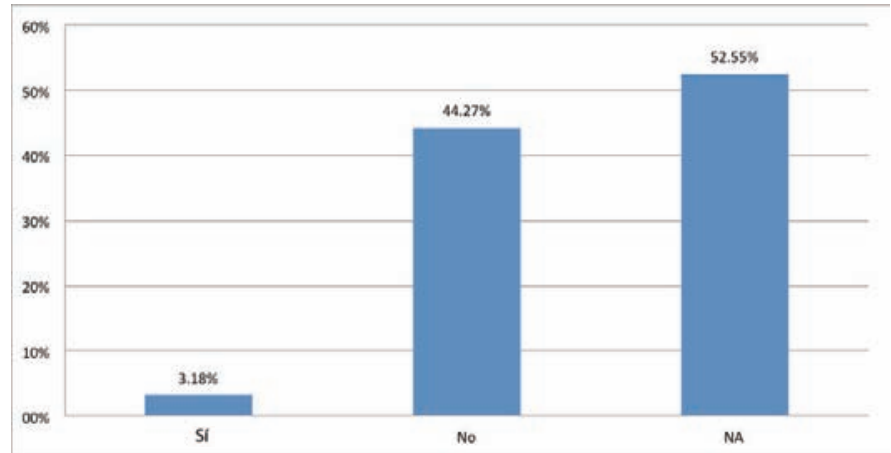

Gráfico 27: Está embarazada o en periodo de lactancia 


\section{Tabla 28: Tiene teléfono celular activado}

\begin{tabular}{|lcc|}
\hline & n. & $\%$ \\
Sí & 1346 & 71.44 \\
No & 520 & 27.60 \\
NA & 18 & 0.96 \\
Total & 1884 & 100.0 \\
\hline
\end{tabular}

$71.44 \%$ de los ecuatorianos de- celular activado y $0.96 \%$ no respondiesempleados tienen teléfono celular ac- ron esta pregunta (Tabla 28, Gráfico 28). tivado; $27.60 \%$ no tienen teléfono

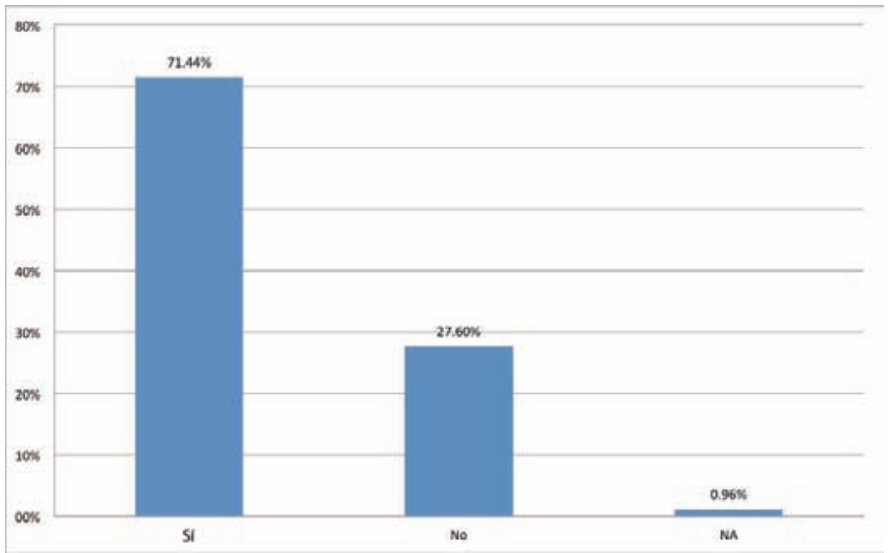

Gráfico 28: Tiene teléfono celular activado 
Tabla 29: En los últimos 12 meses ha usado computador

\begin{tabular}{|lcr|}
\hline & n. & \multicolumn{1}{c|}{$\%$} \\
\hline Sí & 1225 & 65.02 \\
No & 641 & 34.02 \\
NA & 18 & 0.96 \\
Total & 1884 & 100.00 \\
\hline
\end{tabular}

$65.02 \%$ de los desempleados usado computadory $0.96 \%$ no responecuatorianos han usado computador en dieron esta pregunta (Tabla 29, Gráfico los últimos 12 meses; $34.02 \%$ no han 29).

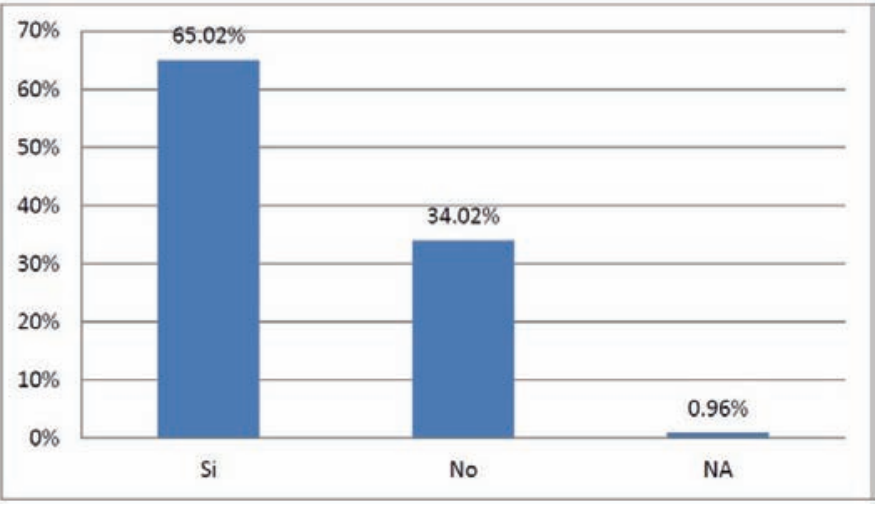

Gráfico 29: En los últimos 12 meses ha usado computador 
Tabla 30: En últimos 12 meses ha usado internet

\begin{tabular}{|lcr|}
\hline & n. $^{\circ}$ & \multicolumn{1}{c|}{$\%$} \\
Sí & 1215 & 64.49 \\
No & 651 & 34.55 \\
NA & 18 & 0.96 \\
Total & 1884 & 100.00 \\
\hline
\end{tabular}

El $64.49 \%$ de ecuatorianos en últi- $\quad 34.55 \%$ no ha usado internet (Tabla 30, mos 12 meses ha usado internet, el Gráfico 30).

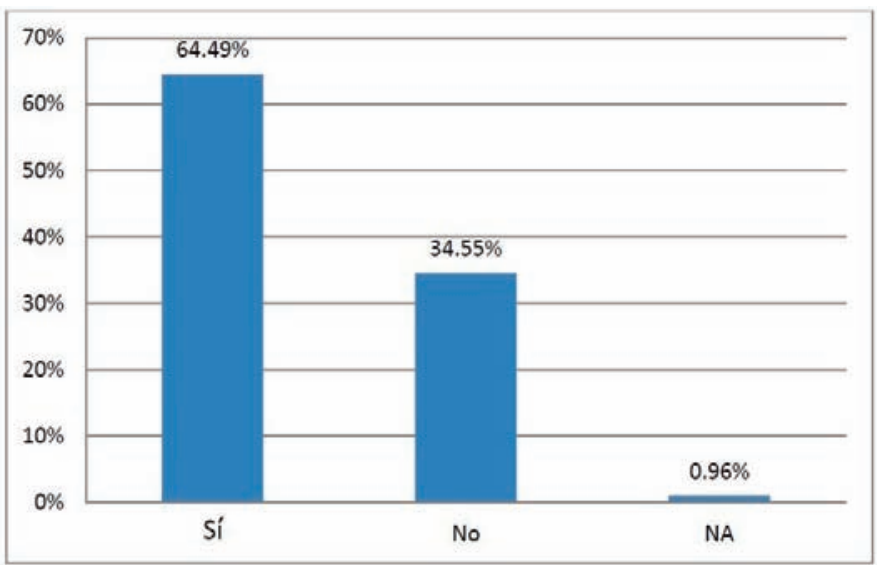

Gráfico 30: En últimos 12 meses ha usado internet 
Tabla 31: En los últimos 12 meses ha asistido a algún curso de capacitación

\begin{tabular}{|lcr|}
\hline & n. & \multicolumn{1}{c|}{$\%$} \\
\hline Sí & 136 & 7.22 \\
No & 1729 & 91.77 \\
NA & 19 & 1.01 \\
Total & 1884 & 100.00 \\
\hline
\end{tabular}

$7.22 \%$ en los últimos 12 meses sí curso de capacitación (Tabla 31, Gráfico ha asistido a algún curso de capacita- 31). ción, y el $91.77 \%$ no ha asistido a algún

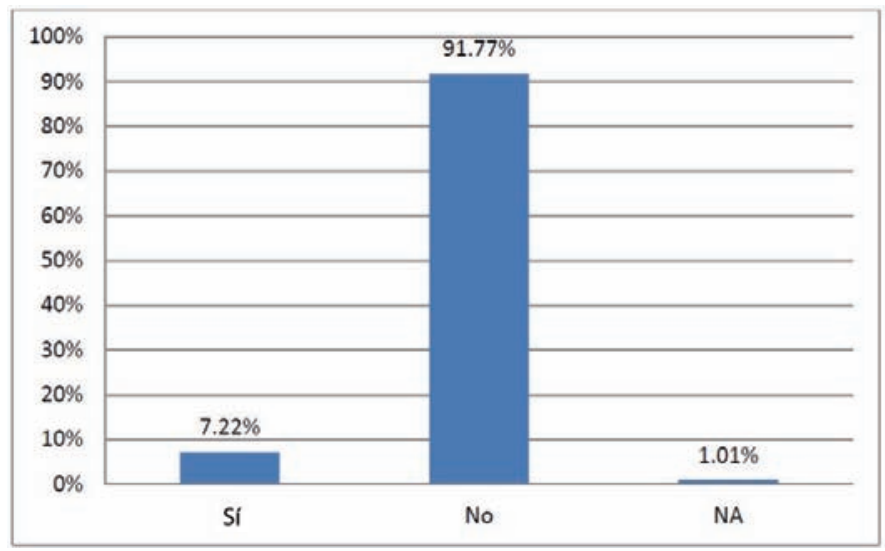

Gráfico 31: En los últimos 12 meses ha asistido a algún curso de capacitación 
Tabla 32: Región natural

\begin{tabular}{|lcc|}
\hline & n. $^{\circ}$ & $\%$ \\
\hline Sierra & 808 & 42.89 \\
Costa & 692 & 36.73 \\
Amazonía & 374 & 19.85 \\
Insular & 10 & 0.53 \\
Total & 1884 & 100.0 \\
\hline
\end{tabular}

El $42.89 \%$ de desempleados ecua- amazonía y $0.53 \%$ a la región insular torianos pertenecen a la región natural (Tabla 32, Gráfico 32).

Sierra, $36.73 \%$ a la Costa, $19.85 \%$ a la

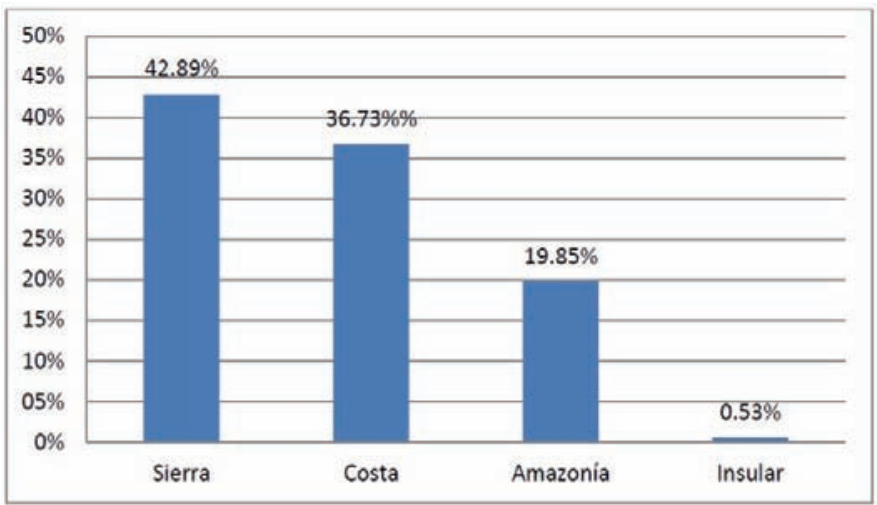

Gráfico 32: Región natural 
PERFIL DE LOS DESEMPLEADOS ECUATORIANOS.

UN ANÁLISIS MULTIDIMENSIONAL

Tabla 33: Condición de actividad nueva

\begin{tabular}{|lcc|}
\hline & n. $^{\circ}$ & $\%$ \\
\hline Desempleo abierto & 1405 & 74.58 \\
Desempleo oculto & 479 & 25.42 \\
Total & 1884 & 100.0 \\
\hline
\end{tabular}

$74.58 \%$ de los desempleados dieron que son desempleados ocultos ecuatorianos respondieron que son de- (Tabla 33, Gráfico 33). sempleados abiertos y $25.42 \%$ respon-

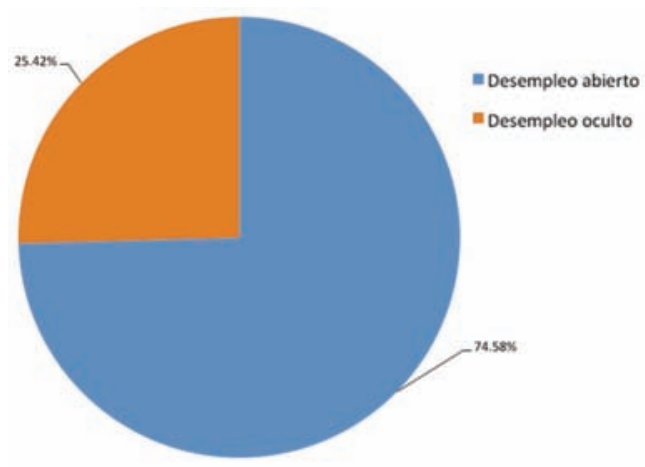

Gráfico 33: Condición de actividad nueva 


\section{ANÁLISIS FACTORIAL DE CORRESPONDENCIAS MÚLTIPLES}

El método de análisis factorial de correspondencias múltiples se utilizó para encontrar cómo las personas que participaron en la encuesta son diferenciadas según sus respuestas (Stefos \& Koulianidi, 2016). Los criterios que diferencian a las personas son los siguientes:

Primer criterio de diferenciación (porcentaje de inercia 6.35\%)

En el primer eje, por un lado, hay personas que trabajaron anteriormente, son desempleados abiertos y buscaron trabajo el mes anterior hablando con amigos. Por otro, hay personas que no buscaron trabajo el mes anterior, su condición de actividad nueva es desempleo oculto, su edad está comprendida entre 15 y 25 años y su estado civil es soltero(a).
Segundo criterio de diferenciación (porcentaje de inercia $5.44 \%$ )

En el segundo eje, por un lado, hay personas que son desempleados abiertos y respondieron que la razón por la cual no buscaron trabajo es porque trabajan ocasionalmente. Por otro, hay personas que pertenecen al área urbana de la región natural de la Amazonía y buscan trabajo los últimos 4 meses.

\section{Tercer criterio de diferenciación} (porcentaje inercia $3.72 \%$ )

En el tercer eje, por un lado, hay hombres que no trabajaron durante el último mes, en los últimos 12 meses no han usado internet ni computadora y tienen un nivel de instrucción primaria. Por otro, hay mujeres que durante los últimos 12 meses han usado internet y computadora y su nivel de instrucción es superior.

\section{ANÁLISIS JERÁRQUICO}

El análisis jerárquico llevó a cinco grupos de 1884 personas que se muestran en la figura 1 (Benzécri, 1992).

\section{Primer grupo (639 personas, $33.91 \%$ de la muestra)}

Los ecuatorianos del primer grupo trabajaron anteriormente y respondieron que son desempleados abiertos. En los 12 últimos meses han usado internet y computadora. Su trabajo terminó por contrato y su nivel de instrucción es superior.

\section{Segundo grupo (339 personas, $17.99 \%$ de la muestra)}

Los ecuatorianos del segundo grupo en los últimos 12 meses no han usado internet ni computadora. Este grupo tiene un nivel de instrucción pri- 
maria. Buscaron trabajo el mes anterior hablando con amigos y su condición de actividad nueva es desempleo abierto.

Tercer grupo (88 personas, $4.67 \%$ de la muestra)

Los ecuatorianos de este grupo se consideran indígenas y el idioma que hablan es la lengua indígena. Pertenecen al área rural de la región natural de la amazonía y no tienen teléfono celular activo.

Cuarto grupo (364 personas, $19.32 \%$ de la muestra)

Los ecuatorianos del cuarto grupo respondieron que no trabajaron ante- riormente por 14 meses. Su condición de actividad nueva es desempleado abierto, su edad está comprendida entre 15 y 25 años y su estado civil es soltero(a).

Quinto grupo (454 personas, $24.09 \%$ de la muestra)

El quinto grupo está formado por ecuatorianos que no buscaron trabajo el mes anterior. Su condición de actividad nueva es desempleo oculto y respondieron que la razón por la cual no buscaron trabajo es porque no creen poder encontrarlo o piensan que no les darán. Este grupo no trabajó anteriormente.

Quinto grupo

454 personas

$24.09 \%$ de la muestra

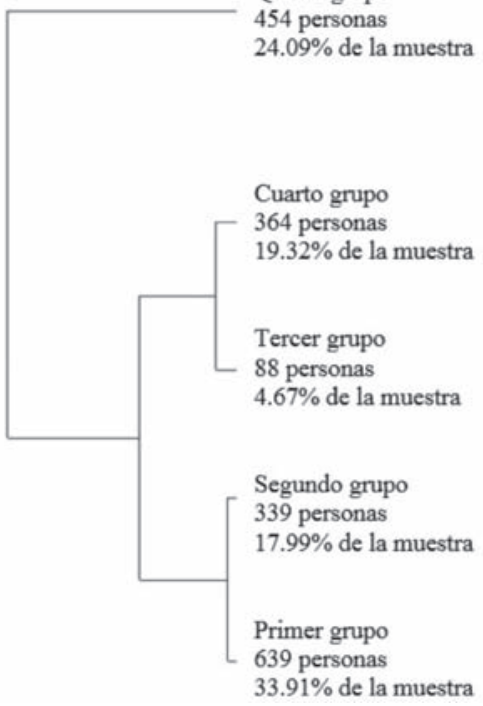

Figura 1: El gráfico de clasificación 
Estas diferencias de los grupos se mostraron en la Figura 2 donde el gráfico del Análisis de Correspondencias (nivel factorial 1×2) presenta los centroides de los cinco grupos en los dos ejes.
También, define las diferencias y las similitudes entre las personas de los cinco grupos (Stefos \& Papapostolou, 2013).

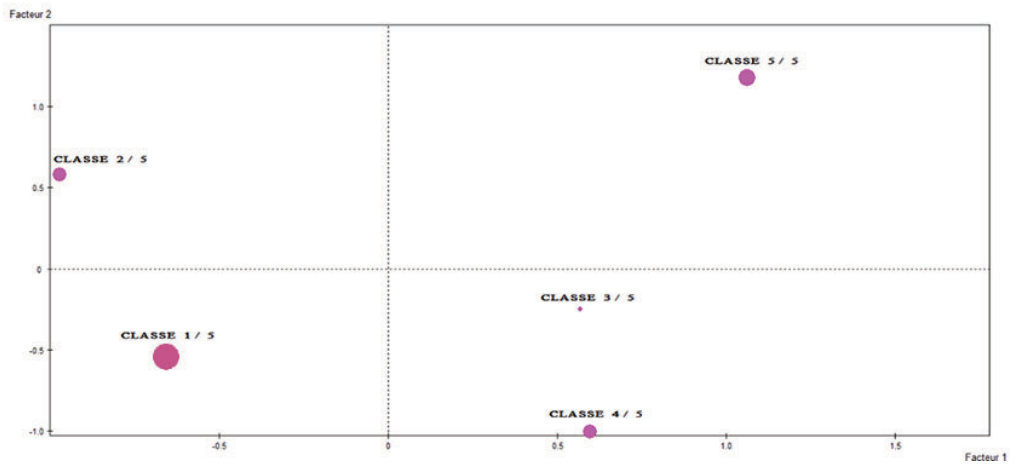

Figura 2: Análisis de correspondencias

\section{CONCLUSIONES}

En este estudio se investigó el perfil de los desempleados ecuatorianos tomando como referencia una muestra de 1884 personas de la encuesta realizada por el INEC; para lo cual se desarrolló un análisis estadístico descriptivo y multidimensional con el fin de mostrar las frecuencias y los porcentajes de las variables y los principales criterios de diferenciación y la clasificación en grupos de las personas investigadas. Los métodos empleados fueron el análisis factorial de correspondencias múltiples y el análisis jerárquico (Koulianidi \& Stefos, 2015).
Los resultados que sobresalen en el estudio descriptivo y son confirmados por el análisis factorial hacen referencia al sexo, nivel de instrucción, raza, área de residencia, edad, motivos por los que se encuentra sin trabajo, uso de tecnología y condición de actividad nueva (Stefos \& Efstathiou, 2013; Olivier, 2008).

El porcentaje de desempleo en hombres y mujeres es muy similar: $49.36 \%$ y $50.64 \%$ respectivamente. El mayor porcentaje de desempleados tienen instrucción media (33.97\%) y superior universitaria (21.76\%). La raza con mayor desem- 
pleo es la mestiza (82.64 \%), el $75.90 \%$ de los desempleados viven en el área urbana; $43.90 \%$ de los desempleados son jóvenes. El 81.37 \% encuentran sin trabajo por falta de oportunidades. El 71.44 $\%$ tiene teléfono celular activado, el 65.02 $\%$ usa computadora e internet y $74.58 \%$ respondieron que su condición de actividad nueva es desempleado abierto.

El 93.37\% no asisten a clases, apenas el 33.9 7\% llega a la secundaria. La mayoría habla español. El $26.75 \%$ habló con amigos y parientes en busca de un trabajo, el $27.71 \%$ ha buscado un mes trabajo, y el $66.35 \%$ sí ha trabajado anteriormente.

El no tener trabajo, a la mayoría, le disminuye el autoestima, el $27.92 \%$ tiene depresión (Stefos, 2015). Una gran parte de desempleados ha tenido que comprar productos baratos, ha disminuido la compra de vestido; pero no ha disminuido el consumo de alimentos, ni se han cambiado de establecimiento de estudio. 


\section{BIBLIOGRAFÍA}

Athanasiadis, I. (1995). Correspondence Analysis and Hierarchical Classification (pp. 5156). Athens: New Technologies Editions.

Benzécri, P. (1992). Correspondence Analysis Handbook. New York: Dekker.

Instituto Nacional de Estadística y Censos - INEC (2014). Encuesta Nacional de Empleo, Desempleo y Subempleo - ENEMDU, 2014. Quito, Ecuador.

Koulianidi, G. \& Stefos, E. (2015). Consequences of Dietary Habits and Endocrine Disruptors in School Performance of Children Aged 10-12 in Greece. American Journal of Food Science and Nutrition. Vol. 2, No. 6, 2015, pp. 113-120.

Papapostolou, I., Papapostoulou, K. \& Stefos, E. (2013). Educational Research. From Qualitative to Quantitative analysis. p.178. Rhodes: Evdimos Editions.

Papapostolou, I. \& Stefos, E. (2013). Qualitative analysis on pedagogical research. Methodological approaches. In I. Papapostolou (Ed.), Educational activities. Teaching Interventions in Secondary Education. pp.244-251. Rhodes: Evdimos Editions.

Sarmiento Sarmiento, N.M., Paredes Proaño, A.M. \& Stefos, E. (2016). Deaths by Suicide in Ecuador: A Quantitative Data Analysis. Review of European Studies; Vol. 8, No. 1; 2016. pp. 145-156.
Stefos, E. \& Koulianidi, G. (2016). Nutrition Data Analysis Using R: Applications in Higher Education. Health Sciences Research. Vol. 3, No. 1, 2016, pp. 10-16.

Stefos, E. (2015). Causes of Death of Indigenous Ecuadorians. International Journal of Clinical Medicine Research. Vol. 2, No. 6, 2015, pp. 65-70.

Stefos, E. \& Efstathiou, I. (2013). Quantitative analysis of the data of the School of Trianta during the period of 1906-1916. In I. Papapostolou (Ed.), Educational activities. Teaching Interventions in Secondary Education. pp.29-57. Rhodes: Evdimos Editions.

Stefos, E. \& Papapostolou, I. (2013). Research Methodology. Processes and suggestions. p.406. Rhodes: Evdimos Editions.

Stefos, E., Athanasiadis I., Gialamas, B. \& Tsolakidis, C. (2011). The Use of New Technologies and the Project Method in Teaching Statistics: A Case Study in Higher Education. HMS i JME, Volume 3. 2010-2011. pp.84-100.

Olivier, M. (2008). The analysis of quantitative data, Transl. Athanasiadis, I. (pp.86-88). Athens:Topos. 


\title{
DISEÑO METODOLÓGICO PARA LA VALORACIÓN ECONÓMICA DE LOS SERVICIOS AMBIENTALES DE LA RESERVA ECOLÓGICA "HOLA VIDA"
}

\author{
METHODOLOGICAL DESIGN \\ FOR THE ECONOMIC VALUATION \\ OF THE ENVIRONMENTAL SERVICES \\ "HOLA VIDA" ECOLOGICAL RESERVE
}

JOSÉ GAVIDIA B. TERESA PALACiOS C.

CARMEN YAURI B. 



\section{DISEÑO METODOLÓGICO PARA LA VALORACIÓN ECONÓMICA DE LOS SERVICIOS AMBIENTALES DE LA RESERVA ECOLÓGICA "HOLA VIDA"}

José Gavidia B. ${ }^{1}$, Teresa Palacios C. ${ }^{2}$, Carmen Yauri B. ${ }^{3}$

\section{RESUMEN}

Los servicios ambientales que presta un bosque son incalculables y carecen de un mercado, es decir, no tienen un valor económico relacionado con cada uno de ellos, por tal motivo, son explotados de manera incontrolada sin prever las consecuencias que ello conlleva.

La importancia de establecer un valor económico a los servicios ambientales provenientes de los bosques, no solo radica en representar en cifras monetarias cuánto significarían las pérdidas de uno u otro recurso natural; sino más bien, representar la necesidad de mantener el equilibrio ecológico con respecto al cuidado y manejo de los recursos naturales, mediante la implementación de medidas que contribuyan al logro de un desarrollo sostenible que permita el balance entre la actividad económica y el desarrollo de la sociedad.

En Ecuador existen muy pocos estudios sobre la valoración de los servicios ambientales en Reservas Ecológicas; es por ello que la presente investigación sugiere un valor económico representativo a los principales bienes y servicios ambientales presentes en la Reserva Ecológica "Hola Vida", a través de métodos que incluyen la valoración contingente, costo de viaje, valoración basada en costes y costo de oportunidad.

La propuesta metodológica para la valoración de servicios ambientales, concentra elementos para obtener resultados relevantes, como parte de un mecanismo que permita encontrar el

1 Ministerio del Interior, Comandancia General de Policía Nacional, Quito, Ecuador (jlg_luis@yahoo.com).

2 Universidad Central del Ecuador, Facultad de Ingeniería, Minas, Petróleos y Ambiental, Quito, Ecuador (tere saalejandrap3@gmail.com).

3 Ministerio del Ambiente, Facilitadora socio-ambiental, Quito, Ecuador (c.yauri.facilitador.mae@gmail.com). 
valor de los principales bienes y servicios ambientales evaluados y a su vez, promuevan una concienciación ambiental dentro la sociedad que visita este importante recurso natural.

Palabras clave: bienes y servicios ambientales, Reserva Ecológica, valoración económica, ecosistemas, economía ambiental, recursos naturales, equilibrio ecológico.

\section{ABSTRACT}

The environmental services provided by a forest are incalculable and lack of a market, it does not have an economic value related to each of them, for that reason, they are exploited in an uncontrolled manner without considering the consequences that such action entails.

The importance of establishing an economic value to environmental services from forests lies not only in representing in monetary figures how much the loss of any natural resoucer would mean, but rather represent the need to maintain the Ecological balance regarding the care and management of natural resources by implementing measures that would contribute to achieving sustainable development that the balance between economic activity and the development of society allow.

In Ecuador there are very few studies on environmental valuation services in ecological reserves; it is for this reason that the current research suggests an economic value representative to the main environmental goods and services existing in the Ecological Reserve "Hola Vida," through methods that include the contingent valuation, cost of travel, valuation based on costs and opportunity cost.

The methodology for the valuation of environmental services focuses to obtain precise data elements as part of a mechanism to find the value of the main environmental goods and services evaluated and in turn, promote environmental awareness within society that visit this important natural resource.

Key words: environmental goods and services, Ecological Reserve, economic valuation, ecosystems, environmental economy, natural resources, ecological balance.

\section{INTRODUCCIÓN}

Los recursos naturales son parte fundamental en el progreso y desarrollo del ser humano, su agotamiento, dete- rioro y sus efectos no son claros y al no existir un mercado donde los bienes ambientales puedan ser intercambiados, no 
es posible obtener una curva de demanda; ello ha motivado el desarrollo de distintas técnicas para estimar sus beneficios o para valorar el daño que produce un deterioro ambiental, cuantificando hasta donde está dispuesto a sacrificar la sociedad en pos de una mejor calidad de vida (Gorfinkiel D, 1999).

El comportamiento actual de la sociedad en cuanto a la sobreexplotación de recursos naturales, ha generado cambios significativos sobre los diferentes ecosistemas agotando su capacidad de resistencia y poniendo en peligro la biodiversidad, lo cual, a su vez, ha provocado la extinción de numerosas especies a un ritmo acelerado, con graves consecuencias sobre la biósfera.

Este proceso de cambio, se evidencia en la cantidad y calidad de servicios y bienes ambientales que se obtienen en la actualidad.

"Hola Vida" es una Reserva Ecológica, ubicada al suroeste de la provincia de Pastaza, a 850 metros sobre el nivel del mar y cubre una superficie de 2,25 $\mathrm{km}^{2}$ (225 hectáreas) lo que representa el $0,04 \%$ del territorio de la parroquia Pomona. Desafortunadamente, la Reserva no cuenta con un análisis económico de los servicios ambientales que presta por su existencia a la sociedad. La falta de cuantificación del valor ambiental que posee un determinado lugar, impide que los recursos ambientales y los ecosistemas sean gestionados de forma óptima; además, cabe señalar que en economía los bienes que tienen un precio nulo se pueden consumir infinitamente, situación que propicia el inadecuado manejo de los recursos naturales; bajo este contexto, se prevé la necesidad de una valoración económica que nos permita dar a conocer a la sociedad, el costo ambiental que implica la pérdida de ecosistemas, de acuerdo con su grado de agotamiento y deterioro, así como, los efectos que ello genera sobre los niveles de producción, la salud humana o el bienestar social.

Los ecosistemas son dinámicos y se caracterizan por su complejo conjunto de plantas, animales y comunidades de microorganismos que conviven en un ambiente e interactúan como una unidad funcional. Los bienes y servicios del ecosistema son los productos de las funciones y atributos del mismo; $y$ desde el punto de vista antropocéntrico, estas funciones solo se convierten en servicios, una vez que los humanos las reconocen como parte de su sistema social y generan valores.

La economía ambiental busca cuantificar, en términos monetarios, los bienes y servicios ambientales sobre el entorno de las actividades económicas humanas, por lo que se precisa diseñar una metodología que permita valorar 
servicios ambientales no evaluados dentro de la Reserva Ecológica "Hola Vida", para resaltar el valor ecológico y cultural; y a su vez, establecer medidas de con- servación y manejo que garanticen la existencia de los recursos naturales para las futuras generaciones.

\section{OBJETIVOS}

- Diseñar una metodología que permita valorar servicios ambientales no evaluados dentro de la Reserva Ecológica "Hola Vida", para resaltar el valor ecológico y cultural.

- Realizar el levantamiento de línea base de la Reserva.

- Identificar los principales servicios ambientales potencialmente valorables.

- Determinar los costos ambienta- les asociados a cada uno de los servicios identificados.

- Determinar los beneficios de la valoración económica de los principales servicios ambientales.

- Proponer alternativas o mecanismos de sostenibilidad para la provisión de los servicios ambientales dentro de la reserva, desde el punto de vista económico y ecológico.

\section{METODOLOGÍA}

El área de estudio comprende la delimitación de la Reserva en cuadrantes, su tamaño se definió en base al FIA (Forest Inventory and Analysis) que muestrea parcelas de una hectárea (aproximadamente 2.5 acres), con el fin de garantizar la cobertura y calidad de la información a procesar, al tratarse de bosques (McRoberts, Tomppo, \& http:, 2015).

Los puntos principales de estudio fueron definidos a través de un muestreo sistemático que utiliza una cuadrí- cula fija o una matriz, para asignar parcelas en un patrón regular de 1 hectárea.

Según el tamaño de la muestra debe estar definida en función de la intensidad de muestreo, que establece los parámetros: área de bosque, área de parcela, intensidad de muestreo 2 \%, y número de parcelas.

El procedimiento para definir el número de parcelas consiste en lo siguiente: 
- Héctareas de bosque $(A)=225$ hectáreas

- Área de parcela (a) $=1$ hectárea

- Intensidad de muestreo requerida (i) = $2 \%$
- Número de hectáreas $(\mathrm{N})=225$

$$
\mathrm{n}=\mathrm{N} * \mathrm{i}
$$$$
n=225 * 0.02
$$

$\mathrm{n}=5$ parcelas

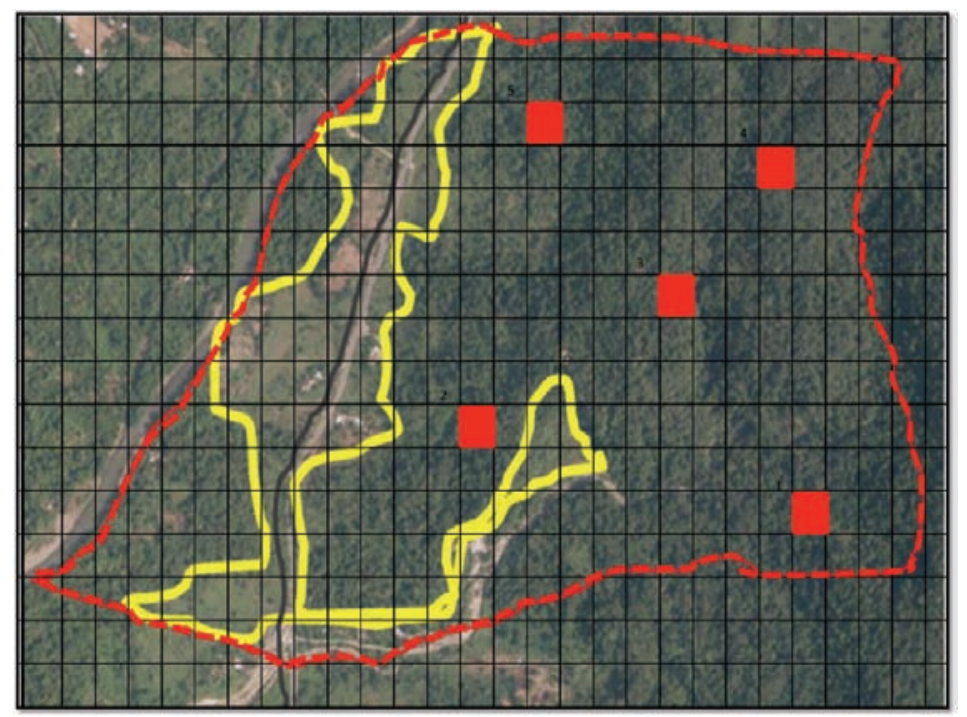

Figura 1. Sitios de muestreo

Se definieron 5 parcelas de 1 hectárea, las cuales fueron una muestra representativa para un bosque con características homogéneas, donde el diámetro a la altura del pecho de las especies boscosas, es superior a $15 \mathrm{~cm}$.

Para el desarrollo del siguiente trabajo se emplearon dos metodologías:
Metodología para la valoración de servicios ambientales: concentra elementos para mejorar los resultados y obtener datos más precisos, como un mecanismo que permita encontrar el valor de los bienes y servicios ambientales en la Reserva Ecológica "Hola Vida".

Para valorar las funciones ecológicas, en términos de bienes y servicios, en la reserva se han estimado cuatro fases: 
- Fase I: Identificación de bienes y servicios generados por la Reserva Ecológica Hola vida.

- Fase II: Jerarquización de los bienes y servicios con potencial para ser valorados económicamente.

- Fase III: Selección de los principales bienes y servicios ambientales a valorar.

- Fase IV: Determinación del valor económico de los bienes y servicios seleccionados.

\section{Metodología de Valoración Con-}

tingente: se ha convertido en una herramienta cada vez más popular para estimar cambios en el bienestar de las personas, especialmente cuando estos cambios involucran bienes no mercadeables cómo la naturaleza; se realizó con ayuda de un sistema informático software EViews 8, que es un programa sencillo para el análisis de datos econométricos, en este caso se utiliza, para conocer la disposición a pagar de las personas por conservar la reserva. Los resultados fueron analizados sobre una base de 300 individuos encuestados en la Reserva Ecológica "Hola Vida" (HANEMANN, 1984) (DUCCI, 1988) y (ARDILA, 1993).

El estudio consideró las siguientes variables:
- PRSI: Variable dependiente de naturaleza binaria. Representa la probabilidad de responder SI (=1) a la Disposición a Pagar-DAPag o No $(=0)$ de otra forma.

- PH: Precio hipotético ofertado sobre el que compara el entrevistado su disposición a pagar-DAPag.

- INGr: Ingreso familiar mensual.

- EDAD: Del jefe de familia o grupo. Toma el valor de 1 si está dentro de lo que se considera PEA y 0 de cualquier otra forma.

- EDUC: Educación del Jefe de Familia o Grupo. 1 si es educación superior o 0 de cualquier otra forma.

- PREO: Interés por mejorar el bien ambiental. 1 si es así, 0 de cualquier forma diferente.

- OCUP: Ocupación. Si pertenece a la clase de dependencia ( $=1$ ) y 0 en caso contrario.

Los siguientes modelos incrementales de utilidad se basaron en (HANEMANN, 1984) (DUCCI, 1988) y (ARDILA, 1993). 


\section{MATERIALES Y EQUIPOS UTILIZADOS}

Los materiales y equipos necesarios que fueron utilizados en el trabajo de campo son los siguientes:

- Encuestas

- Cámara fotográfica

- GPS

- Sonómetro
- Escala de Ringelmann

- Cinta métrica

- Computador portátil

- Cartas Topográficas

- Botas de caucho

- Poncho de agua

- Guantes

\section{RESULTADOS Y DISCUSIÓN}

Entre los principales bienes y servicios ambientales que presta la Reserva Ecológica, se determinó un total de USD \$13.371.919,03 dólares, proporcionados por el cálculo de los diferentes recursos valorados, en función de la alta disponi- bilidad de información y métodos de valoración aplicados de acuerdo con la metodología compuesta para la valoración económica de los bienes y servicios ambientales en la Reserva Ecológica "Hola Vida".

\section{Tabla 1. Valoración económica tołal de los servicios ambientales de la Reserva Ecológica "Hola Vida"}

\begin{tabular}{|c|c|}
\hline $\begin{array}{l}\text { SERVICIO AMBIENTAL VALORADO DENTRO DE LA } \\
\text { RESERVA ECOLÓGICA HOLA VIDA }\end{array}$ & $\begin{array}{c}\text { VALOR } \\
\text { ESTIMADO\$ }\end{array}$ \\
\hline $\begin{array}{l}\text { Valor estimado de volumen de madera existente en } \\
\text { la Reserva Ecológica }\end{array}$ & $10 \cdot 889.719,99$ \\
\hline Valor del recurso hidrico (año) & $2 * 154.224,16$ \\
\hline \multicolumn{2}{|l|}{ Valoración costo de oportunidad } \\
\hline Artesanias (año) & $1.800,00$ \\
\hline Alimentación (año) & $12.775,00$ \\
\hline Hospedaje (año) & $9.125,00$ \\
\hline \multicolumn{2}{|l|}{ Costo de viaje } \\
\hline Ingreso de turistas (año) & $5.400,00$ \\
\hline Almacenamiento de Carbono & $298.874,88$ \\
\hline VALORACIÓN ECONÓMICA TOTAL & $13.371 .919,03$ \\
\hline
\end{tabular}

Elaborado por José Luis Gavidia, 2015 
Luego de valorar los principales bienes y servicios ambientales identificados en la reserva, se pudo determinar que el volumen de madera existente representa el $81,44 \%$ de los ingresos totales calculados; mientras que el recurso hídrico es el 16,11\%; seguido por el almacenamiento de carbono con el 2,24\% y los otros servicios valorados representando el 0,22\%.

A partir de estos resultados, se debe considerar que el recurso hídrico y almacenamiento de carbono, generan en el largo plazo mayores beneficios económicos ya que, el recurso de volumen de madera existente en la reserva, únicamente se podría aprovechar una sola vez y se tendría que reforestar para su uso consecuente. Sin embargo, es necesario resaltar que su regeneración llevaría años, en tal sentido, se considera un recurso finito y de consumo limitado.

El carbono acumulado en la Reserva Ecológica "Hola Vida", es de 166,04 ton/ha promedio, considerando que es un bosque secundario homogéneo. Los beneficios económicos que presenta el servicio ambiental de captura de carbono y la conservación del bosque en la Reserva Ecológica "Hola Vida", permitiría la preservación e incremento de la biodiversidad existente y la reducción de las emisiones de $\mathrm{CO}_{2}$.

Tabla 2. Reportes de estimaciones de biomasa aérea y carbono, en el trópico

\begin{tabular}{|c|c|c|c|c|}
\hline Tipo de bosque & $\begin{array}{c}\text { Biomas } \\
\text { (tha) }\end{array}$ & $\begin{array}{c}\text { Carbono } \\
\text { (t/ha) }\end{array}$ & Fuente & \\
\hline Tropical de Montano* & 290 & 145 & Adams, 1997 & \\
\hline Tropical premontano húmedo* & 284 & 142 & Golley, et al., 1975 & \\
\hline Tropical montano húmedo* & 428 & 214 & Brun, 1976 & \\
\hline $\begin{array}{l}\text { Tropical premontano muy } \\
\text { húmedo* }\end{array}$ & 456 & 228 & $\begin{array}{l}\text { Greenland and } \\
1960\end{array}$ & Kowal, \\
\hline Tropical Húmedo (América)* & 546 & 273 & Folster. 1989 & \\
\hline Tropical Secundario (América) & 310 & 155 & Folster, 1989 & \\
\hline Subtropical secundario (Ecuador) & 255 & 128 & Fehse et al., 1999 & \\
\hline Tropical húmedo cerrado* & 192 & 96 & Brown et al., 1989 & \\
\hline Tropical Húmedo* (América) & 340 & 170 & Brown et al., 1989 & \\
\hline Bosque secundario (Ecuador) & 223 & 112 & López et al., 2002 & \\
\hline Bosque secundario (Ecuador) & 332 & 166 & Gavidia, 2015 & \\
\hline
\end{tabular}

Fuente: (López, Koning, Paredes, \& Benítez, 2002), Modificado por José Luis Gavidia, 2015

La valoración económica de los bienes y servicios ambientales es una herramienta esencial, que permitirá demostrar la importancia de los ecosistemas en el desarrollo de la vida; debido a ello, es necesario utilizar un denominador común que es el dinero, de modo que facilite la toma de decisiones de carácter político en base a fundamentos más amplios. 


\section{MODELO}

\section{Disposición a pagar-DAPag 1}

Last updated: 12/12/15 - 10:35

Modified: $1300 / /$ dap2 $=-(c(1)+c(3) *$ ing $) / c(2)$

\section{Tabla 2. MODELO INCREMENTAL 2 - DISTRIBUCIÓN LOGIT PRSI, PH, ING}

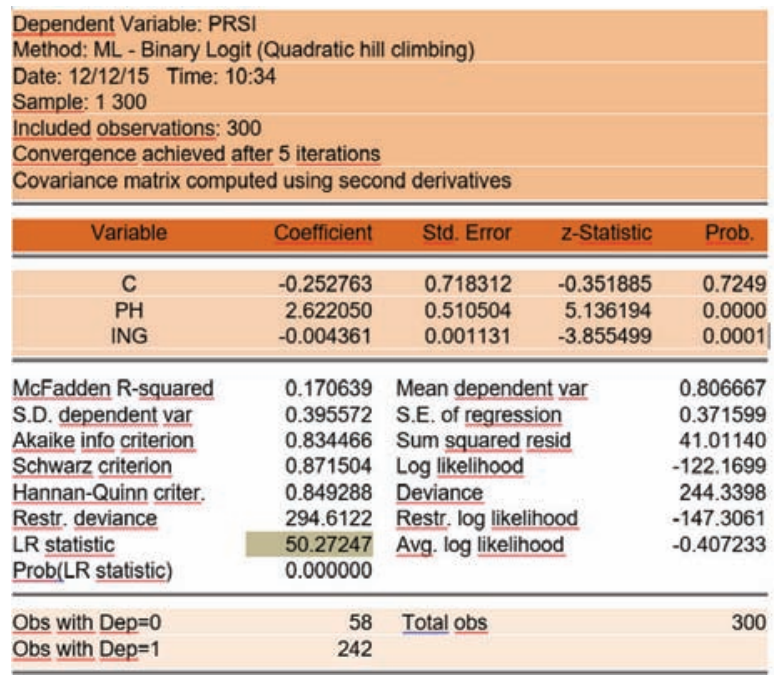

Elaborado por José Luis Gavidia, 2015

El resultado del estudio señala que la población encuestada apoya a la conservación de un entorno natural y paisajístico como es la Reserva Ecológica "Hola Vida"; de los 300 encuestados el $81 \%$ apoya su conservación y estaría de acuerdo en realizar un pago mensual para conservar el recurso y el $19 \%$ no está de acuerdo con pagar un valor para su conservación, pero si les gustaría que se conserve el lugar.
El método empleado para el presente análisis es la Valoración Contingente, que permite conocer las preferencias de los consumidores respecto de determinado bien ambiental y así obtener un valor económico, que para el presente caso determina una disponibilidad de pago de USD \$0,87 ctv. de dólar por individuo de acuerdo con el análisis realizado en DAPag 1, que es el valor medio como disponibili- 
dad a pagar por disfrutar de los beneficios potenciales de los servicios que ofrece la Reserva Ecológica "Hola Vida".

Al presente estudio se ha incluido un Plan de Manejo Ambiental, por cuanto es un instrumento de planificación, mediante el cual se proporciona una guía de medidas, prácticas y acciones e indicadores orientados a aprovechar de manera sostenible los recursos naturales dentro de la Reserva.

\section{CONCLUSIONES}

Los servicios ambientales proporcionados por la Reserva Ecológica "Hola Vida" están en función de su dinámica natural, por cuanto está conformada por un conjunto de bosques naturales y fuentes hídricas que proporcionan innumerables beneficios no solo desde el punto de vista económico para la población local, sino también, desde el punto de vista ecológico como regulador de gases efecto invernadero, almacenamiento de carbono, entre otros.

La valoración de los servicios ambientales se ha convertido en una herramienta estratégica que permitirá direccionar la gestión y manejo sostenible de los recursos naturales dentro de la Reserva.

Entre los principales bienes y servicios ambientales que presta la Reserva Ecológica, se determinó un total de USD \$13.371.919,03 dólares, proporcionados por el cálculo de los diferentes recursos valorados, en función de la alta disponibilidad de información y métodos de valoración aplicados de acuerdo con la metodología compuesta para la valoración económica de los bienes y servicios ambientales en la Reserva Ecológica "Hola Vida".

Los beneficios económicos que presenta el servicio ambiental de captura de carbono y la conservación del bosque en la Reserva Ecológica "Hola Vida", permitiría la preservación e incremento de la biodiversidad existente y la reducción de las emisiones de $\mathrm{CO}_{2}$.

La valoración económica de los bienes y servicios ambientales es una herramienta esencial, que permitirá demostrar la importancia de los ecosistemas en el desarrollo de la vida; debido a ello, es necesario utilizar un denominador común que es el dinero, de modo que facilite la toma de decisiones de carácter político en base a fundamentos más amplios.

El resultado del estudio señala que la población encuestada apoya a la conservación de un entorno natural y paisajístico como es la Reserva Ecológica 
"Hola Vida", de los 300 encuestados el $81 \%$ apoya su conservación y estaría de acuerdo en realizar un pago mensual para conservar el recurso y el 19\% no está de acuerdo con pagar un valor para su conservación pero sí les gustaría que se conserve el lugar, el método empleado para el presente análisis es la Valoración Contingente, que permite conocer las preferencias de los consumidores res- pecto a determinado bien ambiental y así obtener un valor económico, que para el presente caso determina una disponibilidad de pago de USD \$ 0,87 ctv. dólar por individuo de acuerdo con el análisis realizado en DAPag 1, que es el valor medio como disponibilidad a pagar por disfrutar de los beneficios potenciales de los servicios que ofrece la Reserva Ecológica Hola Vida. 


\section{BIBLIOGRAFÍA}

Alpízar, F. (2004). Curso Valoración económica del ambiente. Tema1: Introducción y medidas del bienestar. Costa Rica: CATIE. p. 11-13.

ARDILA, S. (1993). Guía para la utilización de modelos econométricos en aplicaciones del método de valoración contingente. BID, diciembre, 1-24.

DUCCI, J. (1988). Metodología de cuantificación de beneficios. Saneamiento ambiental de Montevideo, Uruguay. Anexo Técnico.

HANEMANN, W. M. (1984). Welfare evaluations in contingent valuation experiments with discrete responses. Amer. J. of Agr. Econ. 66(1), 332-341.

López, M., Koning, F. d., Paredes, H., \& Benítez, P. (2002). Estimación de carbono en biomasa de bosques secundarios y plantaciones forestales en el Noroccidente de Ecuador. Investigación de bosques tropicales. Quito, Ecuador: Institute of soil Science and Forest.

McRoberts, R., Tomppo, E., \& http:, R. C. (8 de octubre de 2015). Diseños de muestreo de las evaluaciones forestales nacionales. Obtenido de Diseños de muestreo de las evaluaciones forestales nacionales.: http://www.fao.org/fileadmin/ user_upload/national_forest_assessment/images/PDFs/Spanish/KR2_ES_ _4_.pdf
Ortiz, E., \& Carrera, F. (2002). Inventarios forestales para bosques latifoliados en América Central. Turialba Costa Rica: Centro agronómico tropical de investigación y enseñanza.

Pascó-Font, A. (29 de julio de 1997). Valoración de los recursos naturales y políticas para la promoción del desarrollo sostenible de la Amazonía (en línea). Obtenido de http://www.idrc.ca/library/ document/101488

Uclés, D. (2006). El valor económico del medio ambiente. España 6p.

UICN. (2012). Un análisis del impacto de las resoluciones de la UICN en los esfuerzos internacionales de la conservación. Unión internacional para la conservación de la naturaleza, 12.

WINDEVOXHEL. (1992). Valoración económica parcial de los manglares de la región II de Nicaragua. Citado en la tesis Valoración económica de bienes y servicios ambientales en sistema agrícolas de San Migue, Petén, Guatemala. Costa Rica: Tesis Mag. Sc CATIE Turrialba. 
TEOLOGÍA 



\section{LA TEOLOGÍA DE LA LIBERACIÓN DEL ECUADOR}

LIIDERES, PRINCIPIOS Y ESTILO DE IGLESIAS

\section{ECUADORIAN LIBERATION THEOLOGY LEADERS, PRINCIPLES AND STYLE OF THE CHURCHES}





\title{
LA TEOLOGÍA DE LA LIBERACIÓN DEL ECUADOR LÍDERES, PRINCIPIOS Y ESTILO DE IGLESIAS
}

\author{
Boris Tobar Solano'
}

\section{RESUMEN}

Este artículo aborda la historia de la teología de la liberación en Ecuador, vivida y testimoniada por pastores emblemáticos de las comunidades eclesiales, que con su labor dignificaron la vida de los indígenas, de los pobres, de las mujeres y del conjunto de las personas que participan de la vida comunitaria. En primer lugar se aproxima a la práctica de Leonidas Proaño quien desde su opción por los indios, construyó una teología de la solidaridad y dignificación de la persona. En segundo lugar recuerda la práctica de pastores como Mons. Luna Tobar, Gonzalo López y Padre José Carollo, quienes hicieron y vivieron su opción por los pobres desde los principios de solidaridad-liberación. En tercer lugar, visibiliza la práctica pastoral de colectivos eclesiales, que en tiempos de globalización, se convierten en sujetos históricos apasionados por la vida, y por la diversidad como mujeres, ecologistas y pueblos profundos, que desde su fe caminan comprometidos en el cuidado de la vida.

Palabras clave: teología, indios, pobres, iglesia, CEB.

\section{ABSTRACT}

This article approaches the history of Liberation Theology in Ecuador, lived and witnessed by emblematic ministers of ecclesial communities, whose work dignified the life of indigenous people, the poor, the women and everyone who takes part of community life. First, it remarks the practice of Mgr. Leonidas Proaño, who from his "option for the indians" built a theology of solidarity and personal dignification. Then, it recalls the practice of other ministers as Mgr. Luna Tobar, Gonzalo Lopez and Father Jose Carollo, who took and lived

${ }^{1}$ Pontificia Universidad Católica del Ecuador, Escuela de Trabajo Social, Quito, Ecuador (cbtobar@puce.edu.ec). 
their "preferential option for the poor" from the principles: solidarity-liberation. In the end, it shows the pastoral work of the base ecclesial communities, which in times of globalization, became historical subjects passionate about life and di-

En la voz de Francisco, la Iglesia Católica ha retomado la palabra profética que denuncia la injusticia de un sistema idolátrico que solo piensa en la reproducción del capital y olvida el cuidado de la vida, por eso, con su palabra, estilo de vida y otros signos como la canonización de Mons. Óscar Romero, el Papa Francisco de hecho ha rehabilitado filones de la teología de la liberación nacida en suelo latinoamericano. En este marco, el artículo aborda la historia de la teología liberadora vivida y testimoniada por comunidades comprometidas de la Iglesia del Ecuador para recuperar sus principios y convicciones, y desde allí, entrar en sintonía con la espiritualidad que anima a Francisco, primer Papa latinoamericano.

La teología de la liberación del Ecuador (TLE), en primera instancia, está ligada a la figura de Leonidas Proaño Villalba, obispo de la provincia de Chimborazo, lugar geográfico que hacia finales de los años 50 registra la mayor población indígena del país y al mismo tiempo la mayor explotación y miseria que grupo humano puede haber vivido versity, as women, environmental activists and "deep people", walking committed by their faith to care life.

Key words: theology, indian, poor, church. CEB.

en Ecuador. Proaño, gracias a la formación de una iglesia viva, comunitaria, logró un giro fundamental en la vida de las comunidades indígenas que hoy se han convertido en un sujeto histórico con palabra propia. Luego, la TLE, se enriquece con la práctica y testimonio de un puñado de obispos, como Alberto Luna Tobar, Gonzalo López Marañón, muchos religiosos y religiosas, pero sobre todo del trabajo de laicas y laicos de las Comunidades Eclesiales de Base (CEB) campesinas y urbano-marginales que trabajan por la defensa de su dignidad, la gestión comunitaria y una vivencia de fe comprometida con la transformación social. Los inicios de los noventa con todo el peso del contexto mundial "desencantador" la TL sufrió un nuevo impulso en Ecuador, ligado a las palabra resistencia, esperanza, vida para los pueblos, para la Pachamama, para las mujeres y otros actores emergentes, que desde la práctica, reflexión y sueños que aporta la teología se abren a seguir a Jesús el predicador del Reino, al Dios de la vida y a Espíritu que aletea en los diversos colectivos eclesiales que asumen el reto de ser y construir comuni- 
dades de vida, con rostro femenino, ecológico, migrante, étnico, generacional, incluyente y diverso.

Además, la teología ecuatoriana no es una reflexión académica, sistematizada, organizada por tratados. Es una teología pastoral nacida de la palabra y escritos cercanos de pastores, teólogos, laicos y laicas que tienen como interlocutor a comunidades concretas, y como marco referencia la realidad de negación, pobreza y exclusión que atraviesa la historia del Ecuador contemporáneo y que la iglesia liberadora ha sabido acompañar y sigue acompañando.

Este artículo desarrolla tres momentos claves de la práctica y reflexión de la TL en el Ecuador, cada uno se corresponde con una determinada época de la realidad ecuatoriana: el primero de opción por los indios, que se centra en la Iglesia del Chimborazo y en el trabajo pastoral de Leonidas Proaño, cuya práctica eclesial se condensa en la expresión "hay que caminar con los dos pies, uno en la iglesia y otro en la organización social"; es una teología que se mueve por los principios solidaridad, dignificación- organización. El segundo momento de práctica de la opción por los pobres, que surge de las CEB, sobre todo en las barriadas populares de la ciudad y el campo, movidos por los principios de solidaridad-liberación. El tercer momento de diversidad de sujetos históricos articulado por principios como resistencia, pasión por la vida, y diversidad que se descubre en la práctica de muchas organizaciones eclesiales y sociales, que desde la acción y reflexión comunitaria creyente, profundizan la identidad de sus luchas orientadas al mejoramiento de la calidad de vida de diversos actores sociales y el cuidado de la gran casa.

En cada momento histórico se presenta el contexto socio-económico, el ambiente eclesial, los principios y características de la teología y prácticas pastorales, la tensión con la iglesia jerárquica, los símbolos bíblico-teológicos inspiradores, la pedagogía popular que acompaña el trabajo evangelizador, la organizaciones eclesiales y sociales que nacen y se inspiran en la $T L$, y por último, se evalúa los logros y retos de cada momento.

\section{LA TEOLOGÍA DE LA SOLIDARIDAD, ILA OPCIÓN POR LOS INDIOS!}

La teología liberadora surgió en Ecuador en un contexto de vigencia de una institución llamada hacienda, organización económica productiva semi- feudal fundada en el trabajo agrario de los indígenas, en condiciones de explotación y maltrato, que a cambio reciben un minifundio o parcela de terreno para 
sembrar maíz, papas, un poco de trigo o cebada. Dentro de ese territorio "la señora de la hacienda" enseña "la doctrina cristiana" a los indígenas ¡Qué contradicción! El Dios de los pobres había sido vaciado de sentido en la práctica y discurso de la iglesia jerárquica para hacerlo funcional a la estructura económico social y despersonalizar a los indios y campesinos. Alienación lo llamaba Marx. Más aun, la connivencia entre el poder económico y la iglesia se expresaba en la edificación del templo, dentro de los límites de la hacienda, con lo que el presbítero queda prisionero del territorio simbólico-geográfico.

En este ambiente histórico-eclesial Leonidas Proaño es nombrado obispo de la provincia de Chimborazo en 1954 y comienza por conocer la realidad de la gente; en una conversación con sus sacerdotes recordaba los primeros pasos de su práctica pastoral "Yo anduve por toda la diócesis viendo quiénes eran los indios, dónde vivían, cómo vivían, y también cómo lloran los indios". Es decir, viendo y sintiendo esa realidad desde su formación teológica, pero sobre todo desde su sensibilidad humana, Proaño empieza a desarrollar una evangelización centrada en la figura del Buen Samaritano (LC. 10, 25-37) que se encontró con el "indio que había sido molido a golpes en su caminar por la historia" sí, molido a golpes por la historia de opresión de la colonia española y luego por el régimen político republicano que a semejanza de los ladrones de la parábola habían robado los bienes del caminante $y$, también a semejanza de algunos, neosacerdotes y neolevitas, religiosos que por llegar temprano al rito no se detuvieron a auxiliar la miseria de los indios, sino que muchas veces bendijeron al dueño de hacienda. Este encuentro desata una relación de recuperación y dignificación del pueblo indígena que en primera instancia encuentra en la palabra y práctica de Proaño y, progresivamente en muchos pastores y laicos comprometidos del Chimborazo, una Iglesia solidaria, sanadora, restauradora de su dignidad, que con el paso de tiempo, permitió que los indígenas se conviertan en sujeto colectivo con identidad y agenda ético-política propia.

En medio de esta emergencia pastoral renovadora, acontece el Concilio Vaticano II, que posibilita el "giro copernicano" a la teología, que entiende que la Iglesia no es la sociedad perfecta más allá del juego de la historia, sino que es el Pueblo de Dios y está llamado a ser signo de los valores del Reino. La tarea de la Iglesia según el documento conciliar Gaudium et Spes es ser solidaria con el mundo "los gozos y las esperanzas, las tristezas y las angustias de los hombres de nuestro tiempo, sobre todo de los pobres y de cuantos sufren, son los gozos y las esperanzas, tristezas y angustias de los discípulos de Cristo". Incluso en este espíritu, 
cerca de 40 pastores latinoamericanos entre los que se cuenta L. Proaño, al finalizar el Concilio firmaron el Ilamado Pacto de las Catacumbas, en la Catacumba de Santa Domitila, "pacto propuesto por Dom Helder Cámara, en quese comprometían a vivir de modo sencillo, renunciar a la riqueza, renunciar a títulos de poder, apoyar a las personas que se comprometan con los pobres y trabajadores"

En este sentido el principio articulador del primer momento de la teología de la liberación del Ecuador es la categoría solidaridad con el negado en su condición de persona, de allí que en los primeros años el discurso teológico se hablara en la Iglesia de Riobamba de hominización, es decir, humanizar al negado en su condición humana, dignificar al hombre en sentido genérico. Pero para sacar adelante la tarea humanizadora, Proaño construyó un discurso teológico sencillo, pedagógico, pastoral cargado de contenido, como tierra, comunidad, organización, educación, que constituyen al mismo tiempo las características de su teología.

En primera instancia es necesario que la comunidad indígena tenga la tierra en sus manos, que precisamente estaba en manos de los hacendados, incluso en manos de la misma Curia de Riobamba, que por cierto fue la que comenzó a devolver la tierra a sus legítimos dueños, los indios. El valor de la tierra, de la Pachamama, quizás es el primer aprendizaje que recibe de la cultura indígena Mons. Proaño, pues para el indio la tierra es fuente de vida e identidad, más aún en la sociedad agraria ecuatoriana de finales de los años 50 y comienzos de los 60, por eso se constituyó en leitmotiv de sus reflexiones, en sus homilías y en su práctica. No es extraño que sus escritos sencillos estén salpicados de citas bíblicas en torno a la tierra. Cultiva la vivencia comunitaria, tan arraigada en la cultura indígena y que es al mismo tiempo un signo fundamental de la fe cristiana, por eso, en 1977 como fruto de su vivencia y manifiesto utópico publicó el libro Creo en el hombre y la comunidad. Proaño también entendió que la fe en Jesús abre al trabajo por la justicia, más aún en una sociedad tan inequitativa, injusta y excluyente como la del Chimborazo para quienes los indios solo eran una fuerza de trabajo. Por ello, decía el Obispo," Hay que caminar con los dos pies, uno en la comunidad y otro en la organización"; no es de extrañar que desde el inicio de su tarea evangelizadora la iglesia de Riobamba empezara a tejer la organización indígena, no solo como fuerza interna, que ya la tenía, sino como fuerza para canalizar demandas sociales y políticas que se concretaron en décadas subsiguientes. Hay una característica más de esta teología, es teología popular, por eso su aliada fue la pedagogía de Paulo Freire; muy tempranamente, en 1962, Riobamba empezó a 
escuchar una nueva radio, "Escuelas Radiofónicas Populares" cuyas motivaciones para crearla definen el horizonte teológico: "Organizar campañas de alfabetización por radio y por otros medios audiovisuales. Instruir a las clases populares en las materias fundamentales para su desarrollo. Incorporar al campesino indígena a la cultura y a la vida social y económica de la nación, mediante su educación integral y estimulando su propio esfuerzo". Un libro que condensa la articulación entre fe, política y educación popular es Concienciación, Evangelización y Política, que Proaño publica en 1974.

La Teología de Proaño encarnada en la vida, había tomado partido, construir humanidad en los indígenas, dejando de lado la construcción de la Catedral, decisión que le trajo como consecuencia la antipatía de la gente urbana citadina que lo empezó a llamar "obispo de los indios" tampoco dejó indiferente a la jerarquía eclesial que veía en la pastoral del Chimborazo un brazo del comunismo ateo, por ello no es de extrañar que algún obispo preocupado por la doctrina y no de la vida del pueblo, en los años 70, denunciara a Proaño ante el Vaticano, que se hizo presente en 1973 con un Visitador Apostólico quien "durante una misa campal que celebró en el patio de las Escuelas Radiofónicas, Juanita (Males) dio este testimonio, que parece una página de los Hechos de los Apóstoles. Se acercó al Visitador. Le entregó una bufanda. "Entregarás esto, le dijo, al Papa Pablo; pero no sacarás a Taita Obispo: porque con él, ojo está aprendiendo a ver, oreja está aprendiendo a oír, boca está aprendiendo a hablar, pie nomás todavía no camina" Testimonio que conmovió al visitador y entendió el papel evangelizador de Proaño.

Este primer período profético de la teología de la liberación ecuatoriana se puede sintetizar en la misma poesía de Proaño hecha canción en los años 80.

Mantener siempre atentos los oídos/ al grito de dolor de los demás/y escuchar su pedido de socorro /es solidaridad, solidaridad, solidaridad. /Entregar por amor hasta la vida/es la prueba mayor de la amistad, les vivir y morir con Jesucristo / la solidaridad.

\section{LA TEOLOGÍA DE LA LIBERACIÓN. iLA OPCIÓN POR LOS POBRES!}

En América Latina la teología de la liberación eclosionó apoyada por el magisterio de la Iglesia, en concreto, del
Concilio Vaticano II, de la Encíclica Populorum Progressio y las Asambleas de la Iglesia Latinoamericana de Medellín 
1968 y Puebla 1979 y de la vida marcada por las luchas y esperanzas de cambio que se estaba generando en varios países del continente. Ecuador también se vio influenciado por aquel momento Kairológico, con algunas señales de identidad específicas.

Si el primer momento de la teología de la liberación en el Ecuador estuvo marcado por la hacienda como modo de producción, el segundo momento se caracteriza por dos hechos históricos: el primero, la reforma agraria que se inicia en el año 1963, como una forma de erradicar formas precarias de producción e incorporar al Ecuador al capitalismo. Este hecho está acompañado de luchas por la tierra encabezados por indígenas y campesinos que por la vía jurídica o económica buscan contar con un pedazo de tierra para sus labores agrícolas, pero rápidamente descubrieron que la tierra no era suficiente; eran necesarios otros recursos y estrategias para poder producir y mantener una economía de sobrevivencia. El segundo, el comienzo de la producción petrolera en 1972, que permitió el desarrollo de infraestructura y una incipiente industria nacional inspirada en las políticas de la CEPAL. Efectivamente, Quito y Guayaquil son las primeras ciudades beneficiarias del llamado progreso. Esta nueva realidad hizo que los indígenas y campesinos sin tierra o con tierras semiproductivas se sientan atraídos por "las luces de la ciudad", migran a los centros urbanos, pero al no tener lugar en ellas, se asientan primero en tugurios, y luego por vía de invasiones forman barrios periféricos sin servicios básicos, marcados por la pobreza y por la manipulación de políticos oportunistas que ven en los migrantes pobres "masas manipulables" de acuerdo con sus intereses.

Es en este ambiente de pobreza urbana y de luchas campesinas donde emergen nuevas experiencias eclesiales inspiradas en el magisterio latinoamericano y la praxis evangelizadora de Leonidas Proaño. Teoría y práctica eclesiales que abrieron la ruta a otras Iglesias locales. Por eso, a finales de los años 60 y comienzos de los 70 aparecen nuevos lugares teológicos inspirados por la teología de la liberación en el país. En concreto, zonas misioneras amazónicas con fuerte presencia de comunidades indígenas como Sucumbíos, con la figura de Mons. Gonzalo López Marañón, la provincia de Orellana, el Coca, donde el trabajo misionero se asocia a los Capuchinos y al nombre de Mons. Alejandro Labaka, que tendrán como reto la evangelización de comunidades indígenas en medio de los intereses de grandes empresas petroleras que ven en los pueblos indios un obstáculo para sus ambiciones. Además, en la región costera, en las provincias de Los Ríos y El Oro, el grupo misionero vasco, también inspirado por esos documentos y la práctica eclesial de la iglesia del Chimborazo, posicionó en sus escenarios geográfico-so- 
ciales un horizonte teológico liberador, Mons. Jesús Martínez fue un referente.

Luego, hacia finales de los años 70 y la década del 80, la espiritualidad liberadora se hace presente en la ciudad de Quito, sobre todo, en la zona sur donde surge un fuerte movimiento de comunidades eclesiales de base que articulan fe y vida, iglesia y compromiso social; hasta hoy está viva la presencia espiritual del padre José Carollo, de Graciano Mazón y de la Hna. Rosa Zúñiga animadores emblemáticos de "la Quito Sur". En la provincia del Azuay, se realiza un fuerte trabajo evangelizador en las comunidades campesinas y urbanas que genera el despertar ético entre grupos populares y en la misma sociedad azuaya. Las figuras de José Luis Caravias S.J., Hernán Rodas, Fernando Vega y Mons. Luna Tobar se asocian al trabajo liberador de esta provincia.

La práctica pastoral de este momento histórico tiene identidad teológica:

Posicionamiento del Dios liberador de Éxodo 3,7-14, que es capaz de ver, escuchar, sentir y comprometerse con la liberación de un pueblo esclavo al que le promete liberarlo del poder del Faraón y dar una tierra para que vivan como hermanos. En las reuniones de centenares de CEB, los textos bíblicos donde aparece la figura del Dios liberador, son leídos y releídos en la Biblia latinoamericana, pues, encuentran en Yavé la figura simbólica de la justicia y en el faraón la figura diabólica del poder político-económico generador de injusticia.

Se descubre la figura del Jesús histórico, humano, cercano a las necesidades y aspiraciones del pueblo pobre, pero sobre todo la centralidad de Reino de Dios, como don y tarea a construir. No cabe ya el discurso religioso de "salvar el alma" por medio de la confesión del credo y la participación en la liturgia, es necesario trabajar apasionadamente por hacer presente entre nosotros el Reino de justicia y paz y el resto vendrá por añadidura. Por ello, se supera la dicotomía entre lo espiritual y lo material, entre lo religioso y lo político, superando también esa equivocada interpretación de la expresión "Mi reino no es de este mundo", pues el Reino de Dios irrumpe en el mundo, en la sociedad con la presencia liberadora de Jesús, dando vista a los ciegos, libertad a los cautivos, y anunciando el año de gracia del Señor (LC. 4, 16-20).

Surge un nuevo modo de ser Iglesia inspirado en el documento conciliar Lumen Gentium, que comprende a la comunidad cristiana como Pueblo de Dios, con la tarea fundamental de ser signo y fermento del Reino. Ese nuevo rostro de Iglesia tiene nombre propio, Comunidades Eclesiales de Base, campesinas, indí- 
genas, urbanas, populares, cuyos miembros son pobres y gente comprometida con la causa de los pobres, unidos por la fe en Jesucristo, sus necesidades comunes y su ideal de vivir como hermanos en una sociedad que se la sueña más justa y solidaria. Es una Iglesia viva, ministerial, con animadores comunitarios que frecuentemente son personas sencillas con poca educación formal pero con gran sabiduría vital y vivencia de fe. Animadores de la pastoral de la salud en zonas donde muchas veces el Estado está ausente y la Iglesia, desde la solidaridad y la autogestión comunitaria crea boticas populares y acompaña a los hermanos enfermos. Ministros de la solidaridad, que desde el compartir y la creatividad apoyan a las personas y familias más necesitadas de la comunidad. Cantores y músicos que en las celebraciones expresan estéticamente su fe. Educadores populares que concientizan a la comunidad de lo que acontece en la compleja realidad. Incluso en algunas comunidades más vulnerables surgen defensores de derechos humanos y ministros que impulsan la autogestión comunitaria.

Las CEB, alimentan su espiritualidad liberadora en reuniones semanales donde acompañadas por un animador o animadora refuerzan su compromiso con el Reino de Dios, y en su barrio celebran, cantan y comparten un café. En las reuniones la biblia es leída, fijándose más en el espíritu del texto que en la letra, para descubrir el plan de Dios y despertar la conciencia solidaria de la comunidad. Además se cuenta con guías bíblicas como Vivir como hermanos y Cristo Compañero de J. Luis Caravias, Círculos bíblicos de Carlos Mesters, y un sinnúmero de folletos escritos por agentes de pastoral con claridad pedagógica y lenguaje sencillo que sirven de pauta para ver la realidad de pobreza, juzgar la realidad a la luz de las Escrituras, es decir, descubrir la novedad de Jesús, los ideales y problemas de las comunidades neotestamentarias y asumir pequeños compromisos comunitarios.

Este espíritu y teología, se fortalecen en los encuentros anuales de las CEB, en donde agentes de pastoral y miembros de comunidades de las iglesias del Chimborazo, Sucumbíos, Coca, Quito Sur, Azuay, Los Ríos, El Oro, entre otras, hacen análisis de coyuntura, comparten el caminar de sus iglesias locales y delinean compromisos comunes. Junto a esta práctica, son emblemáticos los equipos de reflexión de comunidades de Vida Religiosa inserta en medios populares (CRIMPO), que se convirtieron en espacios de revisión de vida y de producción teológica.

La teología de la liberación, no solo que inspira un conjunto de convicciones y prácticas de renovación intraeclesial, sino que desde dentro de las 
comunidades generan un nuevo tejido social liberador como: organizaciones barriales que buscan mejorar las condiciones de vida, comités de solidaridad con Centroamérica que fueron significativos en las ciudades de Quito, Cuenca, Riobamba, Lago Agrio; organizaciones de derechos humanos como la Comisión Ecuménica de Derechos Humanos que se comprometen con la práctica de denuncia y defensa de los derechos de las personas; organizaciones indígenas nacidas y animadas por Proaño, López Marañón, misioneros capuchinos, misioneros salesianos y desde luego, por el trabajo de comunidades religiosas femeninas como Lauritas, Esclavas del Sagrado Corazón entre otras; organizaciones de educación popular, que generan procesos que permiten pasar de una conciencia mágica o ingenua a una conciencia crítica propuesta por Paulo Freire y acogida en centros de formación como Santa Cruz Riobamba o la parroquia Cristo Resucitado de Quito, donde permanentemente llegan educadores, teólogos, biblistas que aportan en la toma de conciencia de la realidad, el cultivo de la espiritualidad Reino-céntrica y el compromiso con la historia.

A nivel jerárquico eclesial, este tiempo es de sensibilidad de algunos pastores que movidos por los documentos fundantes del Magisterio de la Iglesia latinoamericana como Medellín y Puebla, permiten una renovación teológica de los agentes de pastoral e invitan a un compromiso menos ritual y más solidario con los pobres. De este sector eclesial surgieron varias organizaciones, sobre todo ONGs que impulsan programas y proyectos de desarrollo para los pobres.

Otros obispos desde una intencionalidad incluso no muy entendida por ellos mismos, pero apelando a que la Iglesia es de todos, promovieron la emergencia de nuevos movimientos eclesiales de tipo pentecostal, que desde un cierto dualismo de cuerpo-alma, santopecador, iglesia-mundo formaron grupos altamente emotivos, donde la acción del Espíritu Santo se confunde con el nivel de mayor o menor emotividad de las personas, que se reconocen pecadores individualmente pero no reconocen las estructuras de pecado. Sociológicamente, los líderes de este movimiento, por lo regular son comerciantes, movidos por la teología de la bendición y políticamente alineados a sectores conservadores, por eso en época de elecciones pedían a sus miembros votar por los candidatos de partidos tradicionales. También auspiciaron movimientos "liturgocéntricos", que usando recursos altamente afectivos logran cohesionar grupos cuya preocupación fundamental es la celebración litúrgica y el estudio literal de la biblia. Sin duda, estos y otros movimientos emotivos y biblio-céntricos son críticos de la teología de la liberación; por eso, en sus reuniones es muy común es- 
cuchar aclaraciones sobre la opción preferencial por los pobres proclamada por la Iglesia en las Conferencias de Medellín y Puebla, con expresiones como "la opción de la Iglesia es por los pobres, pero no solo por los pobres materiales sino también por los pobres espirituales".

Un tercer sector muy conservador ligado a intereses económicos y de prestigio, no toleró la teología de la liberación y la combatió desde sus espacios, acusando a los obispos como Leonidas Proaño de comunista. Impulsaron, o al menos toleraron, a la organización Tradición, Familia y Propiedad, que en la siguiente época de la TLE se transformará en "Heraldos del Evangelio". Desde luego, también auspiciaron el fortalecimiento de la Prelatura del Opus Dei y la creación de nuevas CEB de carácter emotivo-ritual en sectores populares y campesinos.

En los años 80, particularmente entre 1984 y 1988 desde el Estado se realizó una persecución sistemática a laicas -laicos, religiosas- religiosos comprometidos con los pobres, que eran vistos por el gobierno de turno como grupos de comunistas infiltrados en la Iglesia. Elina Guarderas, recordando la presencia de la mujer en la iglesia y la sociedad dice:

En Cotopaxi como CRIMPO logramos el respeto, que no nos vieran como las "monjitas", sino como mujeres comprometidas con el pueblo, y se logró mucho, desgraciadamente duró poco tiempo porque tuvimos que salir por distintas circunstancias, algunas expulsadas por los gobiernos, por la represión militar, Alma Montoya fue tomada presa la había cogido la Brigada Patria y yo fui amenazada de muerte, el gobierno fue muy represor, yo tuve que salir, viví una de las dificultades a nivel espiritual terriblemente grande y dolorosa, me sentí como el asalariado que deja a las ovejas ahí y huye.

La TLE por medio de sus figuras emblemáticas crea una atmósfera que invita al compromiso con los más pobres, con la justicia, con la liberación del país. Esa atmósfera cuenta con lugares geográficos concretos, donde se vive y sueña con el Reino histórico y hace que jóvenes, intelectuales, obreros, organizaciones y sectores críticos de la sociedad tiendan puentes de diálogo con esta nueva Iglesia. No es casualidad que en ciudades y provincias que antes eran muy conservadoras, por la presencia de una práctica pastoral liberadora, empezaran a legitimar discursos y opciones político-sociales más comprometidas con los sectores populares.

En síntesis la teología liberadora del Ecuador en este segundo momento posiciona al pobre social y económico como sujeto histórico, capaz no solo de ser objeto de la bondad paternalista de la Iglesia sino de ser actor que camina movido por la utopía del Reino anunciado por Jesús de Nazaret. Por eso, en 
casi todas las CEB es común escuchar la canción "Un pueblo que camina por el mundo/ gritando ven Señor. / Un pueblo que busca en esta vida/la gran liberación/.
Los pobres siempre esperan el amanecer/ de un día más justo y sin opresión/los pobres hemos puesto la esperanza en ti/libertador".

\section{LAS TEOLOGÍAS DE LIBERACIÓN ¿LA OPCIÓN POR LAS VÍCTIMAS!}

La caída del socialismo real, la pérdida electoral del movimiento sandinista en Nicaragua y el triunfo económico del Consenso de Washington con su agenda neoliberal, fueron acontecimientos externos que al parecer dejaba sin piso histórico viable a la luchas enmancipatorias de los pueblos de América Latina. No hay alternativas, el futuro es más de lo mismo se escuchaba con frecuencia en la voz de los ideólogos criollos del neoliberalismo. En este marco internacional de utopías ausentes, la teología de la liberación sufrió un revés que amenazaba su supervivencia como reflexión crítica desde la fe. Inclusive algunas comunidades religiosas y misioneros se desencantaron de América Latina y salieron de sus lugares de evangelización. Sin embargo, como la realidad de pobreza y exclusión se agudizó en esta geografía, la teología de la liberación tercamente sigue su fidelidad al Reino, porque mientras los sistemas generen pobreza y exclusión y haya comunidades de fe que reflexionen sobre su realidad seguirá existiendo teología de la liberación. Además, la TL en este período incorpora nuevos actores, nuevas hermenéuticas, nuevas herramientas de análisis como la antropología cultural y replantea los horizontes de liberación más contextuales.

A nivel nacional, como fruto de la aplicación de las políticas neoliberales, la disminución del tamaño del Estado y la desinversión en las áreas de educación, salud y vivienda la pobreza crece. En los años noventa, Ecuador aparece con un 60\% de su población en condiciones de pobreza. Como consecuencia, muchos migran a los países del norte como Estados Unidos y España. La deuda externa se convierte en el peor obstáculo para el desarrollo humano, es más, se convierte en el modo de garantizar la dependencia del país frente al capital financiero representado por los organismos internacionales de crédito como el FMl y Banco Mundial. Además, en medio de la crisis emergen nuevos actores sociales con demandas locales, regionales y globales y postulan la resistencia al neoliberalismo.

Pastores, religiosos y teólogos, sensibles a la nueva realidad entienden que esta se constituye en el lugar teológico desde el cual Dios habla, se reflexiona 
comunitariamente la vida desde la fe y se construye la nueva savia de la teología de la liberación. En los años 90 se dan encuentros, reuniones, cursos, pronunciamientos para entender desde la fe, la misión de la iglesia en estas nuevas circunstancias.

Los principios que guían la teología y práctica evangelizadora de la liberación, en este nuevo período, son resistencia, vida y diversidad. La Resistencia a los nuevos proyectos de globalización de la economía, que se alimenta desde la experiencia bíblica de los Macabeos, que frente a la invasión cultural griega resisten apelando a sus valores religiosos y desde la cultura profunda que inspira la vivencia y práctica los pueblos y comunidades. El principio vida cobra sentido, pues frente a los proyectos de muerte que empobrecen, excluyen, y poco a poco matan no solo la vida individual sino colectiva de comunidades, se posiciona el Dios apasionado de la vida. Al mismo tiempo se descubre la urgencia del cuidado de la vida de la gran oikos. El principio diversidad, emerge porque no basta con identificar a los pobres, estos pobres tienen rostro propio, indígenas, afroecuatorianos, campesinos, pobladores, mujeres, migrantes, que son víctimas de la exclusión, y que al mismo tiempo, reclaman participación en la sociedad y en la Iglesia. Es decir, se construye una teología con hermenéuticas específicas.
Los rasgos de identidad de la teología liberadora son los siguientes:

- Es una teología que incorpora lo étnico, que no era la preocupación principal en la fase anterior, pero que dada la nueva realidad fue objeto de tematización desde la teología, en muchos casos, desde la categoría "semillas del Verbo", y otras cercanas como inserción, inculturación, encarnación e interculturalidad pasan a ser palabras clave para la comprensión del nuevo momento teológico. Cerca del quinto centenario del "descubrimiento" de América, la reflexión histórico-teológica va por deslegitimar la celebración de los 500 años de conquista y colonización, donde nuevamente el movimiento indígena es protagonista, pues afirma que no hay nada que celebrar, por el contrario, consideran que es tiempo de recordar 500 años de resistencia y de proyectar la agenda social para las nuevas décadas. En 1990 sucede un acontecimiento histórico, el levantamiento indígena, acontecimiento que tiene que ser leído simbólicamente, pues es el acto de mayor trascendencia político-cultural que realiza el movimiento. Es su visibilización pública como indios, no para mendigar al poder sino para exigir sus derechos frente al Estado, no para conquistar el poder sino como forma de construir el poder.

- En esta misma línea se ubica la reflexión teológica realizada en las co- 
munidades afro-descendientes, fruto de un largo proceso de evangelización y dignificación realizado por los misioneros combonianos, quienes desde su opción de acompañar la evangelización de las comunidades negras, sobre todo en la provincia de Esmeraldas, descubren en las páginas de la biblia la presencia y ausencia de los negros y en diálogo entre el pasado y el presente, de cultura a cultura, de fe a fe, comprenden la misión de los pueblos afroecuatorianos hoy.

- Es una teología de la liberación con rostro de mujer que, en primer término, en la primera y segunda fase de la TLE son las protagonistas de las comunidades eclesiales, las que forman parte de equipos pastorales, las que animan, las que cantan en la liturgia, las que tienen a su cargo ministerios de la caridad y la catequesis, pero, no obstante, son las que sufren el peso de las estructuras patriarcales de la sociedad y a veces en la misma Iglesia, por eso, en la tercera fase son las mismas mujeres las que desde su propia mirada y lectura de las fuentes de la teología sistematizan su teología y la escriben. Desde su visión teológica y con la agenda liberadora empiezan a realizar encuentros, cursos de formación, reuniones en donde conversan sobre su situación de mujer, visibilizan las formas patriarcales de dominación del varón en la casa y la sociedad. Leen la biblia desde su condición, visibilizan el rostro ma- terno de Dios, rescatan el protagonismo de las mujeres dentro de la historia de la salvación. Es más, afirman que la práctica y palabra de Jesús es el canon para interpretar los textos tanto del primer como segundo testamentos, sobre todo de las cartas paulinas que si no se hace una lectura Cristo-céntrica de ellas, se puede justificar y reforzar formas patriarcales de organización social y eclesial. Además, se incluyen los talleres y ceremonias rituales para restaurar a las mujeres víctimas de la sociedad androcéntrica.

Según Margarita María Pinos una de las contribuciones del momento actual de la reflexión teológica feminista en América Latina, "es la recuperación de una cosmovisión holística donde la humanidad se descubre como parte de un todo, integrada a la energía vital de la naturaleza. El eco feminismo reafirma elementos fundamentales de las teologías ancestrales indígenas." Es así que en el Taller que realizan las mujeres en Riobamba, inician con un ritual a través del que expresan su resistencia a la discriminación y exclusión como etnia y como mujeres, alli se resignifican y se recrean.

Es una ecoteología del cuidado de la vida en todas sus formas. Esta emerge sobre todo entre agentes pastorales de la cuenca amazónica, de las provincias de Orellana y Sucumbíos, zona altamente biodiversa, donde habitan pueblos profundos en autoaislamiento, pero que al mismo tiempo es la fuente de explotación petrolera que causa la contamina- 
ción del suelo, del agua y atenta contra el frágil equilibrio ecológico amazónico. Desde finales del siglo XX y comienzos del XXI, se cultiva una teología y espiritualidad de la creación, del Dios de la vida, presente en todas las formas de vida. En la misión capuchina de la Amazonía se busca vivir"la relación fraterna entre todos los seres, porque antes de pensar en Dios, la realidad nos descubre y demuestra que todos los seres estamos conectados, por eso debemos cultivar una espiritualidad de la fraternidad entre los seres". El texto de Génesis dos, que narra la relación armónica entre la humanidad y la naturaleza y define la misión del jardinero en la frase"cultivar y cuidar el huerto" $(G n 2,15)$ es inspirador para la tarea evangelizadora y para la espiritualidad de las comunidades. Esta teología ha permitido el diálogo con los nuevos actores y con las organizaciones sociales. Hay que recordar que en fase anterior de la TLE, monseñor Labaka y la hermana Inés Arango por la defensa de los pueblos que habitan en la gran oikos amazónica paradójicamente fueron lanceados por un grupo de waoranis que defendían su casa.

Esta práctica pastoral liberadora que en fidelidad a Jesús optó por unos sujetos concretos, modeló un nuevo tipo de organización eclesial y creó también un nuevo modo de hacer reflexión teológica, recibió la censura al interior de la jerarquía católica, la misma que se visibilizó en la "intervención" del Vaticano en la Iglesia de Sucumbíos. Aceptó la renuncia de Mons. Gonzalo López el 30 de octubre de 2010 por límite de edad, y para borrar todo el trabajo liberador nombró como Administrador Apostólico al P. Rafael Ibarguren Schindler, bajo el argumento que "La visión pastoral llevada adelante por usted (Mons. Gonzalo) no siempre era conforme con la exigencia pastoral de la Iglesia" por lo que "el nuevo Administrador Apostólico tendrá que organizar el Vicariato e implantar de manera diferente todo el trabajo pastoral"

Asimismo, algunos líderes de las CEB y organizaciones eclesiales fuertes en la segunda época, en las década de los noventa y comienzos del siglo XXI, frente a la urgencia de atender las necesidades básicas de cuidado infantil, educación, salud, constituyeron ONGs de asistencia social, lo que en primer lugar es una respuesta inmediata en favor de la población, "dar de comer al hambriento y de beber al sediento", pero luego, desmoviliza a las CEB que pierden capacidad de articulación en función del horizonte teológico liberador y se reducen a ser administradores de los pequeños proyectos de subsistencia, línea teológica que hoy también ha cobrado fuerza en la reflexión de la teología del desarrollo, la cooperación internacional, etc.

Sin embargo, las teologías de liberación desde rostros y hermenéuticas específicas, ha hecho que las organizacio- 
nes eclesiales laicales sigan fortaleciendo la interlocución con organizaciones feministas, étnicas, ecologistas, juveniles, alterglobalizadoras que descubren en la espiritualidad liberadora unos valores fundamentales que inspiran sus luchas y aportan para la construcción de la agenda ético-social para nuevas décadas, siempre mirando al frente y en fidelidad a los excluidos.

En conclusión, la teología de la liberación ecuatoriana en sus tres etapas sin duda que encuentra en Leonidas
Proaño el referente de mayor significación e inspiración. Tiene como fortaleza ser vivida, hablada y escrita por pastores, religiosos y teólogos que caminan con las comunidades. Es una teología reinocéntrica, que busca la dignificación de la persona, cultiva la solidaria entre los pobre. Está comprometida con rostros específicos e inspira las prácticas de defensa y cuidado del ambiente. Estos principios, para alegría de las CEB, están presentes en el discurso y espiritualidad del Papa Francisco, que sin duda ha rehabilitado la Teología Latinoamérica. 
Revista PUCE, ISSN 1012-389X. Núm, 102

\section{BIBLIOGRAFÍA}

Aciprensa. (10 de febrero de 2013). El Papa nombra administrador apostólico para Sucumbíos Ecuador. Aciprensa, pág. 1.

Concilio Vaticano II. (1965). Gaudium et Spes. Vaticano : BAC.

Educación, M. d. (1989). Monseñor Proaño. Su mensaje en anécdotas. Documento de trabajo 7. Campaña Nacional de Alfabetización Monseñor Leonidas Proaño. Quito: Ministerio de Educación.

García, J. (15 de Mayo de 2015). La teologia de la liberación en la misión capuchina de Orellana (B. Tobar, Entrevistador).

Moreno, J. (1987). La Iglesia en Ecuador. Riobamba (desde 1962). En CEHILA. Sígueme 1987. En E. Dussel, Historia General de la Iglesia en América Latina VIII. Perú, Bolivia y Ecuador. Salamanca: Sígueme.
Obispos, reunidos en el Vaticano II. (1965). El pacto de las Catacumbas . (pág. 2). Vaticano: Iglesia. cl Conferencia Epispocal de Chile.

Pineda, C. (2013). Tesis maestría "Mujeres y teología de la liberación en Riobamba y Quito: los decenios de 1970 y 1980". Programa de maestría en historia. Quito: Universidad Andina.

Vera, A. S. (4 de mayo de 2015). La práctica pastoral de Mons. Proaño (B. T. Solano, Entrevistador). 


\title{
LOGOS Y VERDAD INTRODUCCIÓN A LA PERSPECTIVA CRISTOLÓGICA DE LA VERDAD
}

\author{
LOGOS AND TRUTH \\ INTRODUCTION TO THE CHRISTOLOGICAL \\ PERSPECTIVE OF TRUTH
}

AGUSTÍN GARCELLS SUÁREZ

Recibido 15 de marzo de 2016 Aceptado 8 de abril de 2016 



\section{LOGOS Y VERDAD \\ INTRODUCCIÓN A LA PERSPECTIVA CRISTOLÓGICA DE LA VERDAD}

Agustín Garcells Suárez

\section{RESUMEN}

El presente ensayo constituye una introducción a la perspectiva cristológica de la "verdad" en el pensamiento cristiano. En este sentido, se realiza primeramente un recorrido entre las tradiciones helénica, hebrea y cristiana, con el objetivo de demostrar la relación existente entre el Logos y la cuestión de la "verdad", tanto desde el punto de vista filosófico, como teológico. En segundo lugar, se efectúa un análisis de la relación Logos-Verdad, teniendo en cuenta su connotación cristológica, triadológica, soteriológica, antropológica y cosmológica.

Palabras clave: logos, verdad, cristología, antropología, cosmología.

\section{ABSTRACT}

This essay constitutes an introduction to the Christological perspective of "truth" in Christian thought. In this sense, a journey between Hellenic, Hebrew, and Christian traditions is first established to show the relationship between Logos and the question of "truth", both from a philosophicaland theological point of view. Second, the relationship between Logos and Truth is analyzed, considering their Christological, triadological, soteriological, anthropological, and cosmological connotations.

Key words: logos, truth, christology, anthropology, cosmology.

1 Pontificia Universidad Católica del Ecuador, Facultad de Arquitectura, Diseño y Artes, Quito, Ecuador (agustingarcells79@gmail.com). 


\section{LOGOS Y VERDAD. INTRODUCCIÓN A LA PERSPECTIVA CRISTOLÓGICA DE LA VERDAD}

\begin{abstract}
Pilato entonces le dijo: ¿Así que tú eres rey? Jesús respondió: Tú dices que soy rey. Para esto yo he nacido y para esto he venido al mundo, para dar testimonio de la verdad. Todo el que es de la verdad escucha mi voz. Pilato le preguntó: ¿Qué es la verdad? (Jn 18: 37, 38).
\end{abstract}

Para Poncio Pilatos la "verdad" constituye un concepto abstracto y este parece ser el motivo que la conversación finalice con su pregunta retórica. Lo cierto es que hoy día resulta imposible asegurar con certeza si de esta manera pretendía ironizar a Cristo, o simplemente confesar su ignorancia o rechazo. Transcurre el instante más decisivo de la Economía Divina y el Logos de Dios Encarnado se encamina hacia su pasión voluntaria, pero antes ha decidido revelar una particularidad específica de su naturaleza. Consideramos que la frase "Para esto yo he nacido y para esto he venido al mundo (...)"tiene como objetivo aquí, señalar un rasgo concreto del Logos Encarnado: el "testimonio de la verdad".

No hay dudas que la "verdad" constituye aquí una noción ambivalente, es decir, el "testimonio" de Cristo: la Encarnación, la Pasión, la Muerte y la Resurrección del "Theánthropos". Además, parece consistir también en la ma- nifestación en cuanto tal de la segunda persona de la Trinidad y su carácter mediador, conforme a lo dicho por el propio Cristo en 14, 6: "Yo soy el camino, y la verdad, y la vida; nadie viene al Padre sino por -a través de-mí,, una frase que complementa maravillosamente lo dicho con anterioridad, pero de la cual Pilatos no tuvo nunca conocimiento.

La conversación con Pilatos continúa haciendo referencia también a los destinatarios de esta "verdad", de este "testimonio". Aquel que es capaz de "pertenecer a" $y$ "concordar con" esta "verdad", dice Jesús que "escucha su voz" (áxoúcı), "obedece" sus preceptos. Es decir que Cristo invita al ser humano a participar de esta "verdad" en la medida que este reproduce su propio testimonio (de Cristo) de la verdad o, ¿por qué no?, de sí mismo (de Cristo), en virtud de la ambivalencia que ha sido sugerida. Parece que para el pensamiento cristiano, la "verdad" constituye el propio Cristo y, al mismo tiempo, la experiencia de Cristo entre sus discípulos, aquel célebre"Con Cristo he sido crucificado, y ya no soy yo el que vive, sino que Cristo vive en mí (...)" (Ga 2: 20), según el apóstol san Pablo.

El diálogo de Jesús con el "hegémono" resulta decisivo para este estudio. 
El "desconcierto" de Pilatos, más allá de su posible tono irónico, traiciona ciertas concepciones ontológicas de la verdad romana, claramente contrapuestas al nuevo imaginario cristiano ${ }^{2}$. En primer término aparece en Occidente, por primera vez, la comprensión judía del "Dios de la Verdad": "En tu mano encomiendo mi espíritu; tú me has redimido, oh SEÑOR, Dios de verdad" (Sal 31: 5)³. Vale la pena señalar que el sentido de la conversación de Pilatos con Cristo, tanto si ocurrió realmente o no - de hecho, algunos la consideran apócrifa ${ }^{4}$ - fue rescatado, primero verbalmente y después por escrito en los evangelios canónicos de la Iglesia, y de ahí se extendió entre los cristianos por todo el imperio romano durante los siguientes siglos, determinando de manera decisiva el pensamiento occidental. Luego, está el concepto de "verdad" como persona, la idea de un Dios personal, -“(...) mi corazón y mi carne cantan con gozo al Dios vivo" (Sal 84: 2.) ${ }^{5}$ - que había existido desde la era del Antiguo Testamento, a través de un imaginario más o menos antropomórfico. Sin embargo, con Jesucristo y el misterio de la Encarnación esta idea se convertiría en un callejón sin salida para la ideología greco-romana y sus años de consagración al pensamiento abstracto.

Entonces, la contradicción de este diálogo se debe a la aparición de un nuevo concepto ontológico de la "verdad". Las palabras de Juan:"Porque la ley fue dada por medio de Moisés; la gracia y la verdad fueron hechas realidad por medio de Jesucristo" (Jn 1: 17), excluyen cualquier perspectiva óntico-ética de la verdad, lo cual nos permite afirmar que Jesús es la "verdad" en sí misma. Así queda claro que esta "verdad" no es ajena al Logos de Dios, ni una hipótesis conquistada gradualmente por él ${ }^{6}$, sino una particularidad de su naturaleza,

\footnotetext{
${ }^{2}$ Algunos autores, como Moloney, rechazan la perspectiva filosófica de este diálogo: "La pregunta de Pilato es un rechazo despectivo de la palabra de Jesús y no la expresión de una búsqueda de índole filosófica, por mucho que durante siglos se haya utilizado este pasaje de ese modo" (2005: 482).

${ }^{3}$ La misma frase se emplea también para referirse al Espíritu Santo en Juan 14, 17: "(...) es decir, el Espíritu de verdad, a quien el mundo no puede recibir, porque ni le ve ni le conoce, pero vosotros sí le conocéis porque mora con vosotros y estará en vosotros".

${ }^{4}$ Es el caso de Bultmann:"(...) la narración de la historia de la pasión fue retocada con algunos detalles que presuponen una previa orientación sobre los acontecimientos de aquella noche."Y más específico, lo referente a la conversación de Cristo y Pilatos: "También la historia de la pasión, que es donde Juan se encuentra más próximo a los sinópticos, ha sido totalmente reelaborada por él. (...) Han sido totalmente reelaborados el diálogo ante el sanedrín y ante Pilato $(. . .)^{\prime \prime}(1981: 131,421)$ Raymond Brown lo advierte también en 1999: 1248, teniendo en cuenta que los sinópticos aseguran que el juicio ocurrió en público, mientras que Juan insiste en una conversación privada entre Cristo y Pilatos, no quedando claro de qué manera pudo acceder a los detalles de esta. Además, el contenido de la conversación se corresponde más con el contexto joánico, posterior a los acontecimientos históricos.

${ }^{5}$ La idea de que se trata de una entidad viva y autoconsciente es lo que sugiere su condición de persona.

${ }^{6}$ En este caso nos referimos al Cristo de Nikos Kazantzakis en la novela La Última Tentación, donde la "verdad"
} 
razón por la cual el evangelista se atreve a decir también que: "Y el Verbo se hizo carne, y habitó entre nosotros, y vimos su gloria, gloria como del unigénito del Padre, lleno de gracia y de verdad" (Jn 1: $14)^{7}$. Donde el adjetivo "Ileno"-pleno-

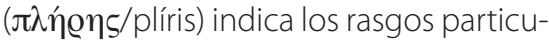
lares que conforman al Logos según sus naturalezas, o que se manifiestan a partir

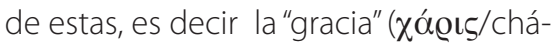
ris) y la "verdad" ( $\dot{\lambda} \lambda \hat{\eta} \theta \varepsilon \iota \alpha / a l i ́ t h e i a), ~ q u e$ son percibidos o experimentados por los hombres como "su gloria" ( $\delta$ ó $\xi \alpha$ / dóxa) y que desde una perspectiva hermenéutica más amplia los consideramos idénticos, como demostraremos más adelante.

En este punto nos interesa dialogar también con la posición del filósofo Martin Heidegger, donde el ser humano se entiende como destinatario por excelencia de la "verdad". Esto es destinatario activo y no pasivo, es decir "receptor" o como la palabra "destino" parece sugerir también. Dentro de la tradición cristiana se insiste no pocas veces en esta cuestión: el hombre no constituye un espectador de la"verdad" sino que participa de esta como ente activo, tiene una expe- riencia de la "verdad" en la medida que también es "hacedor" de la "verdad". Lo cual no significa que él es el autor, "hacedor", valga la redundancia, de este Logos, sino en el sentido de "imitatio Dei". Así lo confirma el versículo: "Pero el que practica la verdad viene a la luz, para que sus acciones sean manifestadas que han sido hechas en Dios" (Jn 3: 21.) $)^{8}$. De esta manera, cuando "viene" hacia la "luz", hacia el propio Logos, experimenta, "practica" -en griego se utiliza el partici-

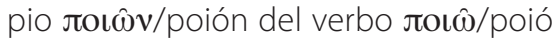
(hacer) - esta "verdad" como "gloria llena de gracia y de verdad"y por eso el evangelista dice: "Santifícalos en la verdad; tu palabra es verdad" (Jn 17: 17). Donde la "verdad" viene a constituir una forma de "gracia" o la "gracia" misma y no un concepto abstracto, porque no es posible "ser santificado a partir de", o "en", algo abstracto, en virtud del mencionado carácter personal de Dios. Algo que refuerza la idea de que esta "verdad" es una experiencia, que por cierto en una manera diríamos precristiana, encontramos también en la filosofía de Parménides y su tautológica sentencia, no pocas veces

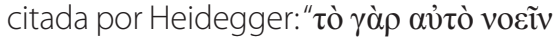

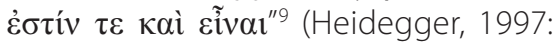

acerca de su identidad parece más bien, el descubrimiento "progresivo" del propio Cristo. Por otro lado está la cuestión en Marcos del "secreto mesiánico", pero en este otro caso el asunto es una decisión consciente y personal, la de mantener en secreto su identidad, en virtud de la Economía Divina y su oportuna revelación.

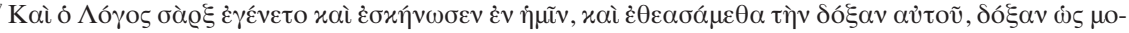

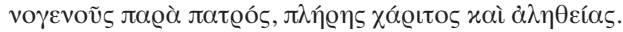

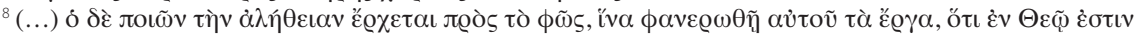

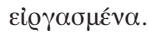

${ }^{9}$ Esto es, según el consenso general "porque este (mismo) comprender es lo mismo que ser", pero también nos aventuramos con la versión, y se aceptan cuestionamientos, "porque conocer eso mismo (es decir, el ser) es lo mismo que ser". 
233). Sin embargo, debemos aclarar que para el presocrático la "verdad" nunca habría podido tratarse de una persona. Otro ejemplo proveniente de la filosofía presocrática sería el de Heráclito ${ }^{10}$, del cual nos ocuparemos más adelante en profundidad. Pero, parece que el antecedente más prominente viene de la tradición hebrea, donde no existe exactamente la palabra "verdad", sino la palabra, "aemet", que significa tanto "verdad" como "fe", "creencia". La "fe" para los hebreos requiere el conocimiento personal, la relación con el objeto. El «daat Elohim», es decir, el "conocimiento de Dios" que solo es posible si existe una estrecha relación, comunicación y comunión, con la Deidad (Kaimakis, 2007: 15).

Esta "verdad", que consiste en la experiencia humana del Logos de Dios, y al mismo tiempo, en el propio Logos de Dios, es también significativa desde el punto de vista soteriológico:"(...) el cual quiere que todos los hombres sean salvos y vengan al pleno conocimiento de la verdad" (2 Tm 2: 4) $)^{11}$. Donde la expre-

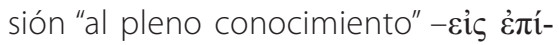
$\gamma v \omega \sigma v v-$, primero tiene una significación ontológica puesto que describe con precisión la experiencia del martirio de Cristo en cada persona y segundo, es un punto de referencia fundamental para la teleología y la soteriología cristiana. También hay que añadir que el uso del sustantivo " $\gamma v \tilde{\omega} \sigma ı /$ gnosis" y sus derivados no tiene ninguna relación con la herejía conocida como gnosticismo, advertencia que tiene validez para todo el Evangelio de Juan (Brown, 1999: 64-77). Esto significa que la palabra "verdad", aunque describe una particularidad "esencial" del Logos de Dios, no describe su esencia en cuanto tal, la cual permanece inaccesible al entendimiento y la experiencia humanos, razón que nos permite hablar de una experiencia de la "verdad" en cada cristiano sin que esto constituya ni gnosticismo, ni panteísmo: "Y conoceréis - $\gamma v \omega \dot{\sigma \varepsilon} \sigma \theta \varepsilon$ - la verdad, y la verdad os hará libres" (Jn 8: 32) 12. Además, esta "libertad" desde una perspectiva ontológica puede considerarse también como "esencia" de toda verdad, elemento que podemos identificar también en el pensamiento filosófico de Martin Heidegger ${ }^{13}$, pero también en la teología de Rudolf Bultmann ${ }^{14}$, tomando en cuenta que existió una estrecha relación entre el filósofo y el teólogo alemanes y que este último habría reconocido vehemente la influencia de las concepciones heideggerianas en su obra.

\footnotetext{
10 Se trata de la influencia del pensamiento helénico en san Juan, según el teólogo bíblico, Raymond Brown, 1999: 64-77.

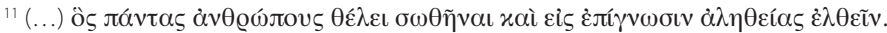

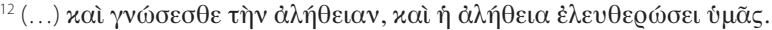

${ }^{13}$ En concreto Heidegger, M. (1952). De la esencia de la verdad, Revista Cubana de Filosofía Vol. II/10 pp. 5-22.

${ }^{14}$ Bultmann, Teología del Nuevo Testamento, 1981.
} 
El hecho que esta "verdad" no se identifica con la esencia divina, nos lleva de vuelta al pensamiento de Santo Tomás de Aquino, pero no teológicamente sino desde un punto de vista más bien "antropológico", porque el Escolástico parece entender la "verdad" a través del concepto de «operatio» (adequatio intelectus et rei) (Heidegger, 1997: 234). Entonces, deberíamos preguntarnos en qué sentido y cómo es esta "verdad" teológicamente. Y para hacer esto, sin sucumbir en la trampa del "gnosticismo", tendremos que referirnos también a cuestiones cristológicas y triadológicas.

A continuación, está también el papel que juega esta "verdad" dentro de la creación y la renovación del ser humano: "(...) y os vistáis del nuevo hombre, el cual, en la semejanza de Dios, ha sido creado en la justicia y santidad de la verdad" (Ef 4: 24) ${ }^{15}$. Aquí la justicia entendida en el sentido de "justicia divina" y en oposición a la "justicia humana" tiene también un significado ontológico, mientras que el característico "santidad" denota la santidad del Logos, lo cual sustenta todavía más la idea que la "verdad" es una persona. Por su parte, el determinante preposicional de contenido dog-

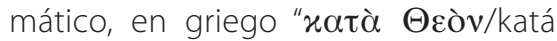
Theón" -conforme a Dios, en la semejanza de Dios-, se refiere a la "semejanza" del hombre con su creador, y supone que esta "vestimenta" del nuevo hombre no es más que la "restauración", es decir, su resurgimiento en Cristo, y este último como "verdad primigenia".

Tenemos entonces, a un ser humano creado a imagen de la Deidad, "en" o "con" la "verdad" que es Cristo mismo, por lo tanto, parece que la "verdad" es también un elemento esencial en lo referente a la creación del hombre y su llamada escatológica: "En el ejercicio de su voluntad, Él nos hizo nacer por la palabra de verdad, para que fuéramos las primicias de sus criaturas" (St 1: 18) ${ }^{16}$. Cuestión que no descarta tampoco que el resto de los seres o entes hayan sido creados "en verdad", solo que el hombre, evidentemente, tiene prioridad entre toda la naturaleza. Por lo tanto en este tercer punto, en lo que respecta al tema de la "verdad" cristiana, vale la pena poner de relieve que esta también se manifiesta en toda la creación en general, conforme a lo que dice el apóstol:

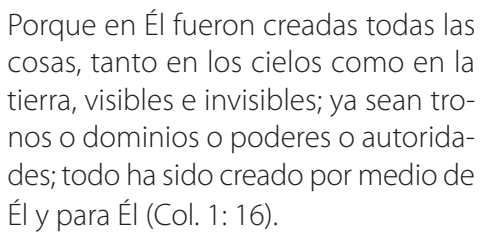

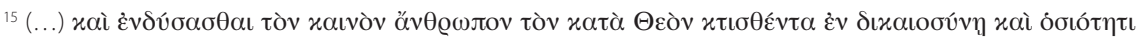
$\tau \tilde{\eta} \varsigma$ $\dot{\alpha} \eta \eta \varepsilon i ́ \alpha \varsigma$.

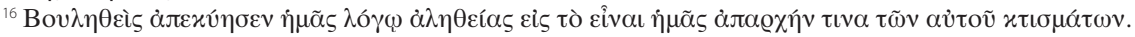


Hasta ahora hemos tratado de averiguar qué es, o mejor quién es esta "verdad" cristiana. Esta "verdad" puede ser constatada en tres niveles fundamentales: el Cristológico, el Antropológico y el Cosmológico -el Soteriológico no lo desarrollamos independiente- mente, considerando que se encuentra contenido en los tres que acabamos de mencionar-. Sin embargo, queda por profundizar un poco más en el cómo es, o cómo se manifiesta esta"verdad", cuestión que desarrollaremos a continuación.

\section{TRIADOLOGÍA DE LA “VERDAD”}

El uso del término "logos" se remonta a la época de Heráclito (siglo $V$ a. C). Este filósofo considera que existe una especie de enfrentamiento antitético y que el Universo, esto es el equilibrio cósmico, constituye el resultado de esta tensión de elementos contrarios, los cuales expone a partir de todo tipo de niveles de complejidad. $O$ al menos, esto es lo que es posible inferir de su fragmentada obra. Sin embargo, lo que más nos interesa en el contexto de nuestra investigación es la concepción de un elemento estable, cuya función, según el filósofo, es reguladora:

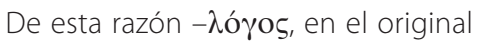
griego- (Lypourles, 1999: 72) ${ }^{17}$, que existe siempre, resultan desconocedores-àgúvetol- los hombres, tanto antes de oírla como tras haberla oído a lo primero, pues, aunque todo transcurre conforme a esta razón, se asemejan a inexpertos teniendo como tienen experiencia de dichos y hechos (...) (Bernabé, 2008: 129).

De este pasaje se deduce en primer lugar, que el Universo es un orden determinado por el Logos y en segundo lugar, que existe una estrecha relación entre Logos y"verdad". Esto es la "verdad" como " $\dot{\alpha} \lambda \eta \dot{\eta} \theta \varepsilon \iota \alpha$ ", sustantivo griego compuesto por el prefijo privativo " $\dot{\alpha}^{\prime \prime} y$ el sustantivo" $\lambda \eta \dot{\theta} \theta \eta /$ lithi" -olvido- o el verbo

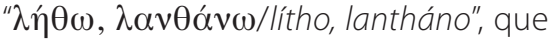
significa olvidar, ocultarse ${ }^{18}$. Esta última concepción, por supuesto, no se identifica completamente con la cuestión cristiana que se ha manejado hasta ahora, teniendo en cuenta que la noción presocrática de la verdad constituye una abstracción, pero sí es un argumento sólido en lo que respecta al impacto del pensamiento filosófico griego en el judaísmo y el cristianismo (Brown, 1999: 69, 1635).

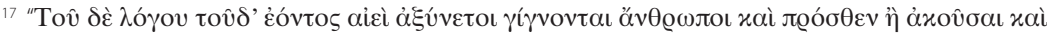

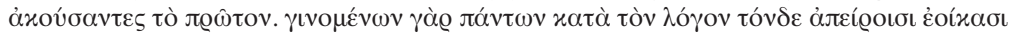

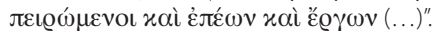

${ }^{18}$ Para profundizar en esta idea consultar Heidegger, 1997: 233-250.
} 
Pero al volver a la sentencia de Heráclito, el conocimiento humano del ente depende del grado de experiencia previa del Logos. Para los filósofos presocráticos la "verdad" es el ente en sí mismo y por eso para Heráclito entre Logos y "verdad" existe una estrecha relación. Además, la imposibilidad de experimentar el ente en cuanto tal -más allá de sus implicaciones cosmológicas (Matsoukas, 2001: 118) - presupone para el ser humano una ruptura o "corrupción" a nivel ontológico. De aquí la distinción de los seres humanos en "conocedores" $y$ "desconocedores", cuestión que Heidegger desarrolla brillantemente en su célebre tratado Ser y Tiempo:

Al $\lambda$ óros y a aquel que lo dice y comprende, Heráclito contrapone los

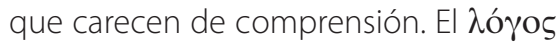

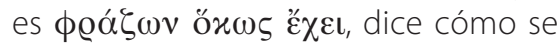
comporta el ente. En cambio, para los que no comprenden, queda oculto,

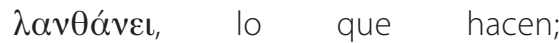

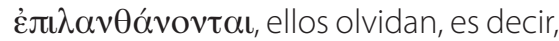
vuelve a hundírseles en el ocultamiento. Por consiguiente, al $\lambda$ ó $\gamma$ os le es inherente la no-ocultación, la $\dot{\alpha}-\lambda \eta \dot{\theta} \theta \varepsilon \iota \alpha$. La traducción de este vocablo por la palabra "verdad"y, sobre todo, las determinaciones conceptuales teoréticas de esta expresión, encubren el sentido de la comprensión prefilosófica que subyacía para los griegos "como cosa obvia" en el uso del término $\dot{\alpha} \lambda \hat{\eta} \theta \varepsilon \iota \alpha$ " (Heidegger, 1997: 240).

Esta percepción presocrática del Logos tendrá en lo que sigue una influencia significativa sobre otras corrientes filosóficas de la antigüedad griega, como es el caso del estoicismo, que ejerció no poca influencia sobre el pensamiento judeo-cristiano. ${ }^{19}$ En este caso resulta crucial la obra de Filón de Alejandría (25 a. C.), principal representante de la escuela filosófica judeo-cristiana de Antioquía. Para muchos estudiosos, como Brown, resulta imposible conocer qué tan profunda o decisiva fue la influencia del pensamiento griego en la teología, por ejemplo, del evangelista Juan. Lo cierto es que hubo, sin dudas, intercambios y préstamos entre el pensamiento griego y semítico, de ahí la existencia de una problemática y terminología "helenísticas". En el caso del apóstol Pablo resultan evidentes, pero esto no nos permite juzgar si se trató de elementos lo suficientemente determinantes. Sin embargo, en este estudio lo que nos interesa es considerar cómo fueron interpretados estos conceptos helénicos por las futuras, entiéndase posteriores, generaciones de teólogos. En otras palabras, si realmente el pensa-

\footnotetext{
${ }^{19}$ Sin embargo, el teólogo Raymond Brown no parece convencido del carácter decisivo de esta relación. Considera que la terminología helénica fue utilizada por los primeros cristianos y evangelistas con el objetivo de facilitar la divulgación del mensaje evangélico en las regiones griegas y no porque resultaran verdaderos deudores de la filosofía helénica (Brown, 1999: 1635).
} 
miento cristiano post neotestamentario presenta alguna continuidad en lo que respecta a la relación Logos-Verdad y cuán consistente es esta. Si se puede verificar esta continuidad podríamos demostrar incluso, en contra de lo que piensa Heidegger, que existe un concepto paralelo de la "verdad" en el Oriente cristiano, que tiene que ver mucho más con las nociones grecorromanas que el filósofo alemán utiliza e intenta recuperar aparentemente, en sus conocidos trabajos, concepción de la "verdad" que de alguna manera daba ya por perdida.

En el siglo I, Justino el Mártir, concibe la teoría del Logos Espermático, la cual tendría en lo que sigue una relevancia diacrónica. Para San Justino, la persona del Logos se manifiesta en la historia desde mucho antes de la Encarnación. Este Logos no Encarnado, fue experimentado por todos los profetas del Antiguo Testamento y "puso su morada" entre ellos (Matsoukas, 2010: 217). Sin embargo, lo más audaz de esta teología es que considera que el Logos no Encarnado se reveló también fuera del contexto semita, es decir, en la filosofía griega. Antes de ser bautizado, Justino fue educado en el paganismo helénico, era un filósofo erudito que, después de convertirse al cristianismo, intentó correlacionar la todavía joven cristología con la antigua pero vigente aún, teoría del Logos de Heráclito:
(...) y los que vivieron conforme al Logos son cristianos, a pesar de que fueron considerados ateos; como entre los griegos, Sócrates, Heráclito y otros como ellos; y entre los bárbaros, Abraham, Ananías, Azarías, Misael, Elías, y muchos otros (...) (Justino Mártir, PG 6, 397C.).

Esta teoría tiene una aceptación unívoca dentro de los círculos de pensamiento cristianos, tanto en Oriente como en Occidente. Sin embargo, resulta contradictorio que no se aplique en todos los contextos culturales. Por ejemplo, la Iglesia Griega suele comprender la teoría de Justino dentro de los límites del pensamiento filosófico precristiano. Lo que significa que con el advenimiento de Cristo y en lo adelante, el Logos Espermático dejaría de manifestarse en todo contexto exocristiano o exoeclesiástico, tanto religioso, como sociocultural. Una comprensión como esta se encuentra abiertamente opuesta a la enseñanza cristiana, la cual puede resumirse maravillosamente con las palabras del apóstol Pablo:

Porque en Dios no hay acepción de personas. Pues todos los que han pecado sin la ley, sin la ley también perecerán; y todos los que han pecado bajo la ley, por la ley serán juzgados; porque no son los oidores de la ley los justos ante Dios, sino los que cumplen la ley, esos serán justificados. Porque 
cuando los gentiles, que no tienen la ley, cumplen por instinto los dictados de la ley, ellos, no teniendo la ley, son una ley para sí mismos, ya que muestran la obra de la ley escrita en sus corazones, su conciencia dando testimonio, y sus pensamientos acusándolos unas veces y otras defendiéndolos, en el día en que, según mi evangelio, Dios juzgará los secretos de los hombres mediante Cristo Jesús (Rm 2: 11-15).

Afortunadamente, la teología contemporánea parece haber superado, o estar superando, esta problemática, y con el paso del tiempo comienzan a predominar las opiniones de nuestros teólogos más audaces:

Cristo es también el punto donde se encuentran Occidente y Oriente, las religiones de la Biblia y las religiones exo-bíblicas. Sin embargo, la catolicidad de la revelación cristiana, su propio milagro, aquel que fue predicado por los Padres, abarca todas las tradiciones sin truncarlas en absoluto, sino elevando su verdadera esencia como su propia verdad (Evdokimov, 1972: 428). ${ }^{20}$

Es por eso que el Logos Cristiano es ecuménico, porque se encuentra abierto a cualquier perspectiva espacio- temporal:"(...) la riqueza del Logos no Encarnado, revelada en la historia del pueblo elegido, no se limita solo al contexto histórico, sino que se extiende a lo largo de toda la historia" (Matsoukas, 2010: 73).

Sin embargo, lo que más interesa dentro del marco de nuestra investigación es que la Iglesia habría aceptado desde muy temprano que existía una relación entre su enseñanza y la cultura griega. En este punto es importante destacar que esta relación no es superficial, sino que gracias a la teoría del Logos Espermático puede considerarse como esencial. Hecho que se confirma en el caso del Logos como un elemento que regula (a) el equilibrio cosmológico y (b) el equilibrio antropológico. De esta manera puede sustentarse el vínculo indisoluble entre el Logos y la "verdad". Pero para Heráclito, la "verdad" consiste en el desencubrimiento del ente en cuanto tal, mientras que para los cristianos la "verdad", este Logos, es la segunda persona de la Santa Trinidad, y aquí las dos líneas parecen separarse porque -y aquí reside la clave de la diferencia- para Heráclito es impensable identificar al Logos con una persona. Sin embargo, todavía tenemos que ver lo que implica el hecho de la Persona del Logos, de Cristo, y cuál es su relación con el Cosmos, para que constituya la "verdad" el ente en cuanto tal, no parece impedir que en

\footnotetext{
${ }^{20}$ Los textos en griego en el original han sido traducidos directamente por el autor de este ensayo, con las correspondientes aclaraciones entre paréntesis.
} 
este contexto cristiano consista al mismo tiempo en una persona (Cristo) también.

La obra de San Juan Damasceno (680-749) es considerada por la tradición oriental como una sinopsis de la enseñanza cristiana, de la recta doctrina. En su Exposición Exacta de la Fe Ortodoxa, presenta desde el comienzo una definición del Logos que justifica su relación con la "verdad" (Juan Damasceno, PG 94, 801 C). Según este teólogo, el Dios de los cristianos no es "a-lógico", no carece

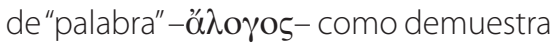
plenamente la tradición semítica. Este Logos de Dios es en sí mismo una persona, es "en-hipóstato", nacido de Dios Padre, sin principio ni fin y por ello consustancial al Padre: "(...) uno (con el Padre) según su naturaleza, distinto (al Padre) según el sujeto, la persona" (PG 94, 804 B). Sin embargo, el Logos -entiéndase también discurso, palabra, razón- perfecto de un Dios perfecto no puede constituir otra cosa que la "verdad" absoluta. Aquí, la "verdad" se aleja notablemente de la percepción escolástica tomista adequatio intelectus et rei (Santo Tomás de Aquino, 2001: c.16 a.1, 225.). Esto no pasa desapercibido para Santo Tomás. El escolástico tiene claro que Dios, por naturaleza, no tiene necesidad de efectuar semejante adecuación, no obstante:

Aun cuando en el entendimiento divino, no hay composición ni división, sin embargo, por su inteligencia simple todo lo juzga y todo lo complejo lo conoce. Así, en su entendimiento está la verdad (2001, c.16 a.5 228).

De lo cual podemos inferir que el propio concepto tomista adequatio intelectus et rei se encuentra limitado, tiene una dimensión antropocéntrica, pero no por eso está privado de una dimensión teocéntrica y por tanto logo-cristo-céntrica de la "verdad". Pero esto constituye el objeto de estudio de otro trabajo.

Por su parte, este Logos-verdad, continúa el Damasceno, no está desprovisto de Espíritu, que es en-hipóstato también. El Espíritu Santo procede del Padre, "descansa" en el Hijo y al mismo tiempo (al Hijo) lo revela, lo manifiesta: "(...) el que da testimonio conjunto

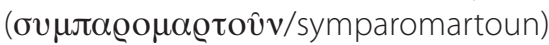
del Logos y que manifiesta su acto" (Juan Damasceno, PG 94, 805 B). Constituye la tercera persona de la Trinidad, con las mismas características de las otras hipóstasis, pero diferente en lo que respecta al sujeto. Por lo tanto, tenemos a un único Dios Trino, Padre, Hijo y Espíritu Santo, donde el Hijo-Logos, constituye la "verdad" absoluta de toda "verdad". El Padre, como resultado de sus particularidades, es la "causa" originaria de esta

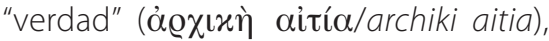
mientras el Espíritu Santo "co-efectúa"

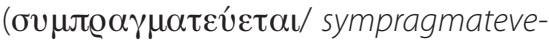
tai) esta "verdad", la culmina o concluye en el sentido de "perfección" (Matsoukas, 
2010: 95). Dentro de la Trinidad, conforme a su "economía", la "verdad absoluta", el Logos de Dios, "lleva a cabo la tarea de la revelación de su presencia, no encarnada y encarnada, en la naturaleza y la historia, para la salvación del hombre" (95). Y como acertadamente completa en este segmento el teólogo griego Nikos Matsoukas, no para beneficio de sí mismo (del Logos), sino de un tercero: el ser humano. De este modo también queda diferenciado lo que constituye la Santísima Trinidad según su existencia eterna, de su manifestación histórica, es decir "económica".

\section{CRISTOLOGÍA DE LA “VERDAD”}

Y el Logos de Dios se hizo carne. Acontecimiento que tenía como objetivo cumplir con algo muy específico también, es decir, con la encarnación de la "verdad absoluta"21. En este sentido el teólogo ruso Pavel Evdokimov ha escrito también:"(...) el amor del Filántropo sobrepasa infinitamente la visión soteriológica, llegando hasta el extremo impactante de la Encarnación, que ocurriría incluso sin (la necesidad de) la caída" (1972: 80).

Entonces esta "verdad" se hizo

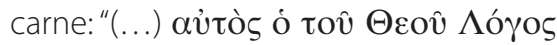

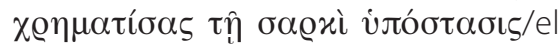
mismo Logos de Dios devino hipóstasis a través de la carne" (Damasceno, PG 94, 985 C). Y esto de tal manera que después de la "unión" resulta imposible distinguir la naturaleza humana de la divina, sin que el resultado de esta unión se tratase de una tercera naturaleza compuesta. Por lo tanto, inmediata- mente después de la "unión" nombramos como "Cristo" a toda su hipóstasis, su persona y existencia, y no a una de sus dos naturalezas, la humana o la divina. Así, después de la "unión" no es posible referirse a esta segunda persona de la Trinidad sin tomar en cuenta su naturaleza humana, como símbolo y presunción real de la "Alianza" entre lo divino y lo humano. En el presente estudio, esto también significa que se trata de una Alianza entre la "verdad" y el hombre, lo que a su vez indica que esta "verdad" tenía un destino antropológico muy específico.

Esta "verdad" encarnada tiene dos voluntades y dos energías, cada una correspondiente con su naturaleza. Sin embargo, es imposible distinguir entre ellas como consecuencia de esta "unión" incomprensible e imperceptible de las dos naturalezas:

\footnotetext{
21 "Es inherente a su deseo eterno e inexpresable convertirse en hombre y hacer de su humanidad teofanía y residencia suyas" (Evdokimov, 1972: 80).
} 
(...) la paradoja del cristianismo radica en el equilibrio entre la trascendencia radical de Dios en sí mismo (que es en esencia "oculto") y su inmanencia según economía (cuando se manifiesta a través de sus energías y la gracia de la Encarnación, donde la filantropía supera su propia trascendencia)" (Evdokimov, 1972, 20).

Por lo tanto, existe una concordancia absoluta entre las voluntades y las energías en lo que respecta a la finalidad esencial de la Encarnación, o sea la salvación del hombre: "(...) porque según ambas naturalezas su voluntad y su acto persiguen nuestra salvación" (Damasceno, PG 94, 1036 A).

Como en esta persona, que después de la "unión"y como consecuencia de esta fue llamado Cristo, es imposible separar las dos naturalezas, podemos añadir que nació, creció, sufrió, fue crucificado, murió y resucitó al tercer día, conforme a las Escrituras y el Credo; solo que todo esto en virtud de su naturaleza humana porque cada naturaleza conservó sus particularidades: "(...) lo uno brilla por sus milagros, lo otro se somete al ultraje" (PG 94, 993 C). Pero como consecuencia de la paradoja de la existencia de una sola hipóstasis con dos naturalezas, es que la tradición cristiana afirma que Dios también, es decir la naturaleza divina, fue crucificada, murió y resucitó, cuestión que pasa a ser el eje central, paradójico, de esta tradición:
(...) porque uno y el mismo es él, que es también esto y aquello, o sea, Dios y Hombre, y al mismo corresponden sus identidades divina y humana; porque la naturaleza divina realizaba milagros no sin la participación de la carne y la carne realizaba lo más bajo no sin la naturaleza divina" (PG 94, 1057 C).

En este modo irrepetible de existencia, conocido como Cristo, la "verdad" y la "humanidad", o sea, toda la naturaleza divina y toda la naturaleza humana, se encuentran inseparables en una sola persona. Esta "verdad" se encarnó y realizó en un solo ser, geográfica e históricamente determinado: en la tierra del pueblo de Israel, y por un período de aproximadamente treinta y tres años. Este marco espacio-temporal del "suceso Cristo" tiene un significado soteriológico evidente, ya que se refiere (a) a la Tierra Santa ${ }^{22}$, el pueblo elegido por Dios, y (b) al Evangelio de Cristo, predicación, crucifixión y resurrección del hijo de Dios y el Hombre. Visto desde esta perspectiva, ni un solo hecho de la vida de Cristo parece carecer de sentido, ni se encuentra forzado por las circunstancias, sino que es voluntario y filantrópico, teniendo en cuenta que su objetivo constituye la salvación del ser humano.

Esta salvación depende directamente de la siguiente paradoja "existencial": Porque en el momento que padecía la

\footnotetext{
22 Ex 19:6: "(...) y vosotros seréis para mí un reino de sacerdotes y una nación santa".
} 
carne, la naturaleza divina se encontraba unida a esta, permaneciendo impasible y llevando a cabo la pasión salvadora, y en el momento que actuaba la divinidad del Logos, se encontraba unida a esta su santa mente, meditando y conociendo todo aquello que ocurría" (PG 94, 1057 C).

Gracias a esta hipótesis, incluso una cuestión como la de la Pasión, sinónimo de la corrupción de la carne, resulta ser un elemento activo de renovación. Porque la voluntad de Dios era que este hombre se convirtiera en vencedor, dice el Damasceno (PG 94, 1072 B). Y por eso es que la "verdad" se hace humana, porque solo si asumía esta naturaleza podría salvarla: "(...) тò

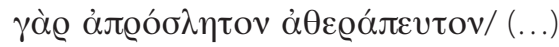
porque lo que no se asume no se salva (cura)" (PG 94, 1072 C). Por lo tanto, la naturaleza humana a causa de esta "unión" con el Logos-Verdad fue "dei- ficada" por participación, si se tiene en cuenta que Cristo asumió, con excepción del pecado, todas las pasiones humanas incluida la más peculiar: la muerte. Y por eso concluye el santo: "(...) por lo tanto nos regaló valentía para enfrentar a la muerte" (PG 94, 1073 C), al sugerir que la muerte en la Cruz constituye el auténtico camino de la salvación. Porque, según la tradición, después que Jesús murió, su alma, permaneciendo unida hipostáticamente a la naturaleza divina, descendió al Hades con el objetivo de liberar a los que se encontraban presos en él. Y de nuevo regresó del Hades, como Dios con toda su grandeza, pero también como un hombre, recapitulando la naturaleza humana completa, ofreciendo la posibilidad de resurrección: "(...) él llegó a ser para nosotros principio de la resurrección, de la incorruptibilidad y de la apatía" (PG 94, 1100 C)

\section{ANTROPOLOGÍA ECLESIOLÓGICA Y COSMOLOGÍA DE LA "VERDAD"}

El célebre teólogo Nikos Matsoukas propuso el término "antropología eclesiológica" (Matsoukas, 2010: 501), al tener en cuenta que el cristianismo, por encima de todo, concibe al hombre como miembro de un conjunto orgánico. Más allá de su potencial como ser independiente o persona en el sentido filosófico, el hombre es un miembro de la Iglesia o del Cuerpo Místico de Jesucristo ${ }^{23}$, como también reconoce la tradición. Siguiendo la misma lógica, podemos confirmar que aquello que constituye el hombre ontológicamente,

\footnotetext{
23 "Ahora bien, vosotros sois el cuerpo de Cristo, y cada uno individualmente un miembro de él". (1 Co 12:27). "Ahora me alegro de mis sufrimientos por vosotros, y en mi carne, completando lo que falta de las aflicciones de Cristo, hago mi parte por su cuerpo, que es la iglesia (...)". (Col 1:24).
} 
pero con el sentido de un "devenir" o un "hacerse", se efectúa dentro de los límites de lo que conocemos como Iglesia:"(...) la constitución del ser y del buen-ser

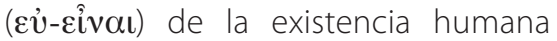
depende de esta relación"(501).

La tradición del Antiguo Testamento describe la creación del hombre de una manera muy diferente a las demás criaturas. Para ello utiliza una serie de antropomorfismos entre los que se destacan el siguiente: la creación del hombre con las propias manos de Dios $^{24}$. Recurso que no puede interpretarse literalmente, sino respecto a su profundo significado espiritual, o como ilustra poéticamente el teólogo alemán Gerard von Rad:"(...) Dios tomó en este caso una decisión particular y solemne en lo profundo de su corazón" (1971: 194). Esta decisión divina se encuentra conectada con el objetivo, es decir, la dimensión teleológica-soteriológica de la creación del Hombre, la criatura más importante. Tampoco podemos pasar por alto la constitución, el modo y el cómo de esta creación, una hipótesis a la que el texto bíblico responde de forma muy abstracta, pero que ha sido estudiada bastante por los Padres de la Iglesia y la teología contemporánea.
San Juan Damasceno describe al hombre como un ser compuesto de dos elementos: 1) el "alma" invisible o inmaterial, el soplo divino y 2) el elemento visible o material, el "cuerpo", que fue creado del polvo, del barro. Ninguna otra criatura presenta semejante constitución, ni remite de modo tan directo a su creador, dice Von Rad (1971, 194). Este soplo divino consiste en la naturaleza lógica y autodeterminada, la "imagen divina". Por su parte, la "semejanza" reside en la posibilidad que tiene este ente particular de igualarse, no por naturaleza, sino por participación, con aquello que el Damasceno denominó "la virtud divina":"(...) la semejanza en lo posible a la virtud" (PG, 94, 920 B). Estos dos pilares de la teología cristiana, incluso antes de ser meditados por los Padres de la Iglesia, en la era del Antiguo Testamento, se referían ya al hombre como una entidad psicosomática y no privilegiaban a ninguno de los dos elementos ${ }^{25}$.

Esta entidad humana fue creada, por naturaleza, ajena al pecado (Damasceno, PG, 94, 924 A). No se descarta que, por decisión propia, es decir, por el libre albedrío el ser humano no pueda pecar, como ocurrió exactamente. Con la caída del "primer hombre", la posibilidad de

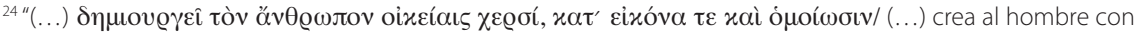
sus propias manos, según imagen y semejanza". (Damasceno, PG, 94, 920 B)

25 "se refieren al hombre entero y no tan solo a su naturaleza espiritual, sino también, y a veces en primer lugar, al esplendor de su aspecto corporal, a la dignidad, majestad y la gloria con que Dios le adornó $(S a l$ 8, 6). Ez 28, 12 habla aún más explícitamente de la «perfecta hermosura» del primer hombre". (von Rad, 1971: 194), Algo parecido encontramos también en Kaimakis, 2007: 26.
} 
"igualarse" a Dios se convirtió en una "utopía". Esto significa que el "primer hombre" no constituye ningún modelo antropológico, sino el otro extremo de una dialéctica basada en la Encarnación de Cristo. La Antropología Cristiana no puede entenderse sino en la perspectiva de esta relación «dialéctica», entre la caída del viejo Adán y la Encarnación del Logos de Dios en Cristo, el nuevo Adán. La peculiaridad de esta "theanthropología" es que no depende, como otros modelos antropológicos, de una teoría del hombre, que a menudo conduce a un ideologismo metafísico o ético (Yfantis, 2010: 93.), sino de la persona de Cristo, que es el principio y el final de esta dialéctica, donde el hombre, Adán, fue creado a imagen y semejanza de Jesucristo, según el pensamiento patrístico oriental (92).

Siguiendo esta lógica, se puede designar como libre albedrío a la "libertad"y a la semejanza como "verdad", si se tiene en cuenta que el fundamento de la primera constituye la "libertad absoluta" en el sentido ontológico, y la esencia de la segunda es la experiencia de Cristo, de la "verdad absoluta". Sin embargo, no existe la una independiente de la otra, sino conectadas a partir de un esquema de forma-contenido: "La libertad es la forma de la verdad, su cómo, y la verdad es el contenido de la libertad, su qué" (Evdokimov, 1972: 79). Por lo tanto, el hecho que este hombre esté llamado a imitar a Cristo, a tener una experiencia de la "verdad", es posible solo si es completamente libre, incluso para negarlo, de la misma manera que ya lo hicieron nuestros antepasados, y lo hacemos cada uno de nosotros en nuestra lucha espiritual cotidiana. Solo que esta "libertad absoluta" ya está restringida por el objetivo de cada "libre elección", que constituye al mismo tiempo el contenido de esa elección, es decir la "verdad": "La todavía negativa o vacía libertad de soy libre de deviene la libertad positiva de soy libre para" (79). Donde ese "devenir" presupone la existencia de un camino de crucifixión, lleno de fracasos y triunfos.

El significado de la Encarnación del Logos no está determinado por la caída de Adán, ni por nuestra predisposición al pecado. Pavel Evdokimov, sustenta sus reflexiones en los descubrimientos más audaces de los Padres de la Iglesia, dice que si meditamos en el plan de la Divina Providencia se puede afirmar incluso que "Dios creó el mundo para hacerse hombre en él y que el hombre se hiciera dios en él por la gracia, participando en los términos de la vida divina" (80). La participación en los "términos de la vida divina" no significa estar en contacto con la esencia de Dios, sino una experiencia de su Divina Energía Increada, como enseña Gregorio Palamás (1296-1359). Esta experiencia suele clasificarse, según la 
Filocalia, en tres niveles: purificación, iluminación y deificación. La experiencia de la purificación o catarsis podríamos definirla como una liberación de las pasiones, ya sea morales o físicas, mientras que con la iluminación y la deificación nos referimos a dos maneras de experimentar, por los seres humanos, la "Divina Luz Increada". La primera como una experiencia interior y la segunda a través de toda la unidad psicosomática del hombre. La experiencia de la deificación o glorificación (glorificatio) no consiste en una"inyección exterior de lo divino" (Romanidis, 2004: 30), sino en una plena restauración ontológica del ser humano, que, en estado de glorificación, participa de la gracia divina bañado por la luz divina. Según el teólogo ruso Vladimir Lossky:

La luz increada es transmitida al ser humano completo y le hace vivir en comunión con la Santísima Trinidad. Esta es la comunión con Dios, según la cual los justos finalmente serán transformados a través de la luz divina y resplandecerán como el sol" (2004: 214).

Se trata de una restauración que se lleva a cabo dentro de un conjunto más amplio que denominamos Iglesia, que se fundamenta por medio de la participación en los misterios o sacramentos y que implica, en última instancia, una restauración de todo el Cosmos también:
Aquel que ve, ve la luz de la divinidad atravesar toda la creación. Este es el significado de la frase Dios está presente en todo lugar, así como del verso del himno angelical plenos están el cielo y la tierra de tu gloria" (Romanidis, 2004: 30).

$Y$ aquella persona que consigue experimentar lo antedicho se conoce y reconoce como "santo" por la "comunidad de creyentes", que lo proclama como "amigo de la Santa Trinidad". Es en esta perspectiva que se comprende por qué el santo constituye una "teología viva" (Evdokimov, 1972: 79), por cuanto constituye la comunión orgánica entre el ser humano y la "verdad absoluta".

Este ser humano "recapitulado", "contempla que todo el entorno natural que le rodea es iluminado y penetrado por la Luz", dice el padre Romanidis (2004: 30). Esta "Luz" no consiste en otra cosa que el Logos de Dios, la "verdad absoluta". La narración del Génesis nos presenta un mundo que ha sido creado a través del Logos, es decir "en verdad": "Y crea según concibe la idea, y esa idea se vuelve acto, que se completa a través del Logos y se perfecciona por el Espíritu" (Damasceno, PG, 94, 865A). Es un mundo que, según el relato bíblico, inmediatamente después de su creación, fue reconocido por su Creador como "bello y bueno" ( $x \alpha \lambda$ ós). Utilizando el discurso antropomórfico, la fuente sacerdotal se refiere también a la per- 
fección del mundo primitivo y a la ausencia del mal. Por su parte, la tradición completa haciendo referencia a la procedencia de esta creación:"(...) produce y crea el universo de la nada, lo invisible y lo visible..." (PG, 94, 864C-865A).

Sin embargo, según el axioma, nada procede de la nada (Nihil ex nihilo fit). Obviamente, la raíz de esta problemática radica en la definición del concepto no-ser ( $\mu$ ò óv), una vez que las generaciones de teólogos comienzan a identificarlo con el cero absoluto (Matsoukas, 2010: 501). La narración del Génesis, sin embargo, nos dice que Dios antes de la creación se encontró con un específico escenario primordial, una materia preexistente, caótica y desordenada, en hebreo tohuwabohu (von Rad, 1982: 58), la cual puso en orden a través del Logos. De dónde proviene esta materia primordial y si tiene que ser de este modo, qué es y cómo es con exactitud, queda todavía por responder.

Nikos Matsoukas sugiere que la referida materia se encuentra mediada por las Energías Divinas Increadas de la Trinidad, siguiendo las teorías de Gregorio Palamás:

Por lo tanto, la creación desde el noser, significa principalmente, que el origen de la realidad creada procede, no de la Esencia Divina, sino a través de la Energía Divina Increada (2010: 151).

Sin embargo, no nos dice en qué o que consiste la Energía Divina propiamente, sino que depende o se deriva de la misma (148). No parece conveniente identificar a las Energías Divinas de Dios con este caos al que nos referíamos anteriormente. Lo más seguro es que la concepción de este tohuwabohu se remonta a una antigua interpretación que evolucionó a partir de las fuentes del Génesis. Una interpretación que incluso a la fecha del Código Sacerdotal (538-450 a. C.) se encontraba bajo la influencia de las concepciones de los cananeos, los antiguos vecinos de la nación hebrea.

La frase $\dot{\varepsilon} \xi$ oủx öv $\omega \omega v^{26}$ no aparecerá en las escrituras hasta el período helenístico, en el segundo libro de los Macabeos, escrito por un judío helenista, claramente influenciado por las teorías del mundo filosófico helénico (Matsoukas, 2010: 150). No podemos subestimar, sin embargo, el impacto de esta concepción, porque sin duda resulta el comienzo de esta problemática, más allá de la innegable importancia histórica dentro de la literatura cristiana. Por lo tanto, lo importante aquí, lo que puede responder la teología con preci-

\footnotetext{
${ }^{26} 2$ M 7: 28: "Te ruego, hijo, que mires al cielo y a la tierra y, al ver todo lo que hay en ellos, sepas que a partir de la nada lo hizo Dios y que también el género humano ha llegado así a la existencia".
} 
sión, es que el Cosmos constituye"heterousios", esto es hetero-sustancial, respecto a la única entidad auto-existente: Dios. Esto significa que este cosmos no es independiente ni auto-determinado. Por el contrario, proviene del Creador y con precisión, no de su esencia, sino de la Energía Divina Increada, en las palabras de Gregorio Palamás. Es por eso que este mundo consiste en el "no-ser", porque no proviene de la esencia de Dios, a diferencia de este último que se hace llamar "el que es" (Ex 3: 14).

Sin embargo, existe lo ente, aunque de una forma distinta a la del Dios auto-existente. Las características fundamentales de lo ente, en cuanto creación, son las siguientes: En primer lugar que es finito y en segundo lugar, que "se extiende", "transcurre"

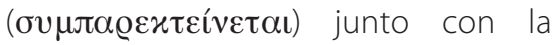
"temporalidad", según lo especificado por Matsoukas (2010: 158). La "eternidad" de Dios difiere radicalmente de la "finitud" del Cosmos que "co-existe" de manera "pre-eterna" en Dios, pero en forma de "logos demiúrgicos", "voluntades" o "paradigmas" de la Voluntad Divina (156). El Logos de Dios consiste en la expresión de estas formas y por eso constituye también la "verdad absoluta", a la cual nos hemos estado refiriendo en todo el texto.

La finalidad de esta creación, como ya hemos señalado, es que Dios llegara a ser hombre en ella, para la salvación y la "deificación" del género humano. Sin embargo, la peripecia del ser humano no es independiente al destino del Cosmos en general: "Maldita será la tierra por tu causa" (Gn 3: 17). Con la caída, la naturaleza se convierte en una amenaza para el hombre, no solo porque este se encuentra de repente indefenso ante ella, sino porque esta queda transformada de manera sustancial. Por esto, de la misma manera que la perspectiva del ser humano es la "deificación", en el caso de la naturaleza debe haber también un cambio radical, una restauración en su condición originaria:"La verdad de la naturaleza consiste en llegar a ser hyperfysis, el hyper este significa teomorfa y teofora conforme a sus orígenes" (Evdokimov, 1972: 79). Y esto en sí mismo constituye una finalidad preeterna, no como consecuencia de la caída, sino porque el hombre fue llamado a convertirse en dios por participación, así también la naturaleza se salva y deviene teofora. Aquí cada ente, y no solo el hombre, están llamados a peregrinar hacia Cristo con el objetivo de la "recapitulación" ontológica. Una "recapitulación" que presupone la identificación del Cosmos con los "logos demiúrgicos", "voluntades" o "paradigmas" de la Voluntad Divina: "Siguiéndole, cada ente recapitulado en Cristo, es restaurado y conducido hacia su estado de integridad, hacia el status naturae integrae» (119). 
A manera de conclusión, podemos afirmar que la "verdad" para el pensamiento teológico cristiano no constituye solamente una teoría, sino también, y con mayor propiedad, una persona, una entidad con una forma específica y única de existencia, conocida como Cristo. En respuesta a un enfoque metodológico más estricto, esta "verdad" se ha podido confirmar dentro de tres áreas fundamentales del conocimiento teológico:

1) La Cristológica y Trinitaria, donde sus particularidades se verifican (a) antes de la "unión", o sea en la Segunda Persona de la Santísima Trinidad y las expresiones espermáticas del Logos, de acuerdo con la teoría específica de San Justino
Mártir y (b) después de la Encarnación en la persona de Jesucristo el "Theántropos", en sus dos naturalezas, en su nacimiento, predicación, pasión, muerte y resurrección.

2) La antropológica eclesiológica, donde se considera al ser humano como miembro del Cuerpo Místico de Cristo: la Iglesia. Aquí, este hombre es llamado a participar de esta "verdad", a constituirse en "hacedor" ( experimenta el martirio de Cristo, la crucifixión, la "deificación" y la "recapitulación" ontológica.

3) La cosmológica, donde se verifica la perspectiva de esta "verdad" en el Cosmos, su papel esencial en cuanto a la creación y la salvación del mundo caído. 


\section{BIBLIOGRAFÍA}

Bernabé, A. (ed.) (2008). Fragmentos Presocráticos, Madrid: Alianza Editorial.

Brown, R. (1999). El Evangelio según San Juan, Madrid: Cristiandad.

Bultmann, R. (1981). Teología del Nuevo Testamento. Salamanca: Sígueme.

Evdokimov, P. (1972). H Orthodoxía, Thessaloniki: B. Regopoulou.

Heidegger, M. (1972). El Seryel Tiempo, Santiago de Chile: Editorial Universitaria.

Juan Damasceno, Ekdosis Akribis tis Orthodoxou Pisteos, PG 94

Justino Mártir, Apologia A Hyper Christianon, PG 6, 397C.

Kaimakis, D. (2007). Themata Palaiodiathikikis Theologias, Thessaloniki: Vanias.

Lossky, V. (2004). H Thea tou Theou, Prebeza: I. M. Nikopoleos,
Lypourlis, D. y otros (eds.) (1999). Archaioi Syngrapheis 8, Athina: Zetros.

Matsoukas, N. (2001). Historia tis Philosophias, Thessaloniki: Pournaras.

Matsoukas, N. (2010). Dogmatiki kai Symboliki Theologia, Thessaloniki: Pournaras.

Moloney, F. J. (2005). El Evangelio de Juan. Navarra: Verbo Divino.

Romanidis, I. S. (2004). Pateriki Theologia, Thessaloniki: Parakatathiki.

Santo Tomás De Aquino (2001). Suma Teológica, Madrid: Biblioteca de Autores Cristianos.

Von Rad, G. (1971). Teología del Antiguo Testamento, Barcelona: Biblioteca Estudios Bíblicos.

Yfantis, P. Ar. (2010). Klisi, Poreia, Metochi. H Pneumatiki Ontologia tis Christianikis Hagiotitas, Athina: Armos. 


\section{LA VERDAD DE LA ESCRITURA: ENTRE TEOLOGIA DOGMÁTICA Y EXÉGESIS}

THE TRUTH OF THE SCRIPTURE:

BETWEEN DOGMATIC THEOLOGY AND EXEGESIS

DAVID DE LA TORRE

Recibido 15 de marzo de 2016 Aceptado 8 de abril de 2016 



\title{
LA VERDAD DE LA ESCRITURA: ENTRE TEOLOGÍA DOGMÁTICA Y EXÉGESIS
}

\author{
David de la Torre
}

\section{RESUMEN}

Cada domingo, como lo hicieron nuestros padres, los cristianos de distintas confesiones nos reunimos para leer el texto que narra las acciones y las palabras de Jesús. Este texto es venerado como Palabra de Dios y así canonizado, sin cesar, en la liturgia eucarística. Pero, la relación con él difiere mucho de una confesión a otra y también en el interior de una misma confesión. Uno de los malos entendidos, más grave, en esa relación que tenemos con la Escritura, es el historicismo, es decir, juzgar el texto a partir de los resultados de la ciencia histórica, imaginando que la verdad de esa palabra radica en ser la radiografía exacta de hechos acontecidos y palabras proferidas en el pasado. Si bien el referente histórico es esencial en una religión de encarnación, tenemos que afirmar que la Escritura cristiana, justamente por ser testimonio de la Verdad encarnada en la historia, no puede reducirse a la simple crónica neutra de la vida de Jesús. Es necesario abandonar toda tentación fundamentalista y todo riesgo de doble verdad, y recordar que los evangelios son un testimonio de fe de las primeras comunidades cristianas, cuya experiencia fundadora les obligó a inventar un lenguaje "poietico" capaz de expresar la Verdad inscrita en la historia de Jesús, para que todos los hombres aproximándose a ese texto, puedan descubrir la verdad de su propia existencia a la luz de la Verdad que es el Logos, único exégeta del Padre.

Palabras clave: Evangelio, Exégesis, Método histórico-crítico, Ficción, Verdad.

\section{ABSTRACT}

Every Sunday, as our fathers in faith did,

1 Pontificia Universidad Católica del Ecuador, Facultad de Ciencias Filosofico-Teológicas, Quito, Ecuador (ddelatorre"puce.edu.ec). 
Christians of different confessions gather to read the text that narrates the actions and words of Jesus. This text is revered as the Word of God and thus canonized, unceasingly in the framework of Eucharistic liturgy. But, the relationship with the text differs a lot, not only from one confession to another, but also within the same confession. One of the worst misunderstandings in that relationship that we have with the Scripture is historicism, that is to say; judging the text based on the results of the historical science, imagining that the truth of such word is the exact radiography of events and words uttered in the past. Even though, the historic referent is essential in the context of a religion of incarnation, we have to say that the Christian Scripture, precisely a testimony of the Truth incarnated in history cannot be reduced to a simple neutral chronicle of the life of Jesus. It is necessary to abandon every fundamentalist temptation and every risk of a double truth, and remember that the gospels are testimony of faith of the early Christian communities, whose founding experiences forced them to invent a "poietic" language capable of expressing the Truth engraved in the history of Jesus of Nazareth to enable all men approaching to this text discover the truth of their own existence through the light of the Truth which is the Logos, the only exegete of the Father.

Key words: Gospels, exegesis, historicalcritical method, fiction, Truth.

\section{INTRODUCCIÓN}

Los textos evangélicos que leemos en cada celebración eucarística son, para todos los cristianos, Palabra de Dios. No solo reconocemos que el personaje central de esas narraciones es el Hijo de Dios, sino que esa palabra tiene algo que decirnos a los hombres y mujeres de este siglo. El protestantismo evangélico ha contribuido a hacer del interés por la Biblia una de las grandes constantes de nuestra época. Los católicos buscan conocer la Biblia, sin embargo, los cursos bíblicos que se ofrecen son en general una arqueología del texto bíblico. Nos hacen creer que la verdad del texto se encuentra en su exacta reproducción completa de la historia, reduciéndola a una simple crónica del pasado. Entonces, es necesario que nos preguntemos qué es en definitiva el texto bíblico, para poder así discernir cuál es la hermenéutica adecuada que honre el hecho de que la Palabra de Dios no es un texto, sino una persona, Jesús. 


\section{EXÉGESIS Y DOGMÁTICA: ¿CRÓNICA DE UN DIVORCIO ANUNCIADO?}

En enero de 1988, el cardenal J. Ratzinger pronunció en Nueva York una conferencia sobre las relaciones entre exégesis y teología; comenzaba su intervención haciéndose eco de la obra de $\mathrm{V}$. Soloviev, La Historia del Anticristo, en donde el Anticristo para seducir a los creyentes se presenta como un gran teólogo y sobre todo como un pionero de la exégesis histórico-crítica:

En la Historia del Anticristo de Vladimir Soloviev, el enemigo escatológico del Redentor se hace valer, en particular, ante los creyentes por el hecho de haber conquistado su doctorado de Teología de Tübingen y haber escrito una obra exegética por la que es reconocido como un pionero en este campo. jEl Anticristo, un famoso exegeta! A través de esta paradoja, Soloviev -hace cerca de cien años- pretendía sacar a la luz la ambigüedad que caracteriza el método de la exégesis bíblica. Es casi ya un truismo hablar hoy de la crisis que conoce el método crítico histórico. Sin embargo, comen- zó con un inmenso optimismo² (Ratzinger, 2000: 76).

Este inicio provocante, incluso injusto respecto a la exégesis histórico-critica, nos pone frente al conflicto de interpretación que marca las relaciones entre la teología dogmática y la exégesis histórico-critica. Este conflicto de interpretación no data de hoy, es omnipresente desde hace dos siglos en la reflexión teológica. Lo que es nuevo es que después de un período en el que las antinomias entre estas dos disciplinas parecían haber sido superadas, las tensiones reaparecen. $Y$ reaparecen con tanta fuerza que este conflicto de interpretación, que en muchos aspectos ha sido saludable, corre el riesgo de transformarse actualmente en un franco divorcio. La indiferencia mutua entre la exégesis y la teología puede hacer muchas más devastaciones para la probidad intelectual de la fe cristiana que la discusión más partisana ${ }^{3}$ (Ratzinger, 2000).

2 J. Ratzinger, 2000: 76. El nombre de Vladimir Soloviev (1853-1900) es citado cada vez con más autoridad en el actual debate filosófico y religioso. Juan Pablo II le cita en su encíclica Fe y razón (número 74) como ejemplo de un pensador que ha sabido establecer una relación fecunda entre la filosofía y la fe cristiana. Nacido en Moscú, fue profesor en la Universidad de Moscú y luego en la de San Petersburgo, cargo que tuvo que abandonar por motivos políticos. Sus primeros trabajos se centraron en la metafísica, pero a continuación prevalecieron en él las preocupaciones religiosas. En 1884 escribió "Los fundamentos espirituales de la vida", obra que contiene la Leyenda del Anticristo, narración de estilo autobiográfico, en la que se narra la venida del Anticristo y su derrota por obra del segundo Concilio de Jerusalén.

3 « La separación entre la exégesis y el dogma es ahora total. La Escritura se ha convertido en una palabra del pasado que todo el mundo se esfuerza a su manera de traer al presente (...) Yendo a la deriva, la 
Tanto en el mundo protestante como en el católico, existe la tentación de renunciar a la crítica, esperando así salvar la fe.

J. Ratzinger señalaba, en su conferencia, algunos riesgos de una exégesis histórico-crítica que con todos sus métodos se convirtió, según él, en una verdadera muralla que bloquea a todo "no iniciado" el acceso a la Biblia. Y denunciaba el hecho que los propios iniciados "no leían" más la Biblia ya que estaban demasiado ocupados en decorticarla en pedazos a partir de los cuales supuestamente había sido compuesta. J. Ratzinger incriminaba el desinterés por lo sobrenatural en una exégesis en la cual la hipótesis "Dios" se había vuelto inútil para interpretar el texto bíblico y la multiplicación de hipótesis no hacía más que conducirnos a una "selva de contradicciones".

El más prudente de los teólogos dogmáticos busca una teología lo más independiente posible de la exégesis. ¿Pero qué valor puede tener una teología cortada de sus propios fundamentos? Esta es la razón por la que un enfoque radical, que se llama el "fundamentalismo", comenzó a ganar partidarios que estigmatizan como falsa en sí misma y absurda toda aplicación del método histórico-crítico a la Palabra de Dios. Quieren regresar a la pureza literal de la Biblia, tomarla tal como se pre- senta y tal como lo comprende el lector ordinario (Ratzinger, 2000: 69-70).

Ante la amenaza del fundamentalismo, una tarea se imponía a los ojos de J. Ratzinger: tener en cuenta los innegables descubrimientos del método histórico y, al mismo tiempo, superar sus límites abriéndolo sobre una hermenéutica pertinente. Solo así será posible escuchar verdaderamente el texto bíblico que me suministra un mensaje que no viene de mí mismo y que es Palabra de Vida para el hombre de hoy. El reto es entonces encontrar esta "hermenéutica pertinente".

La tarea que J. Ratzinger asigna a los teólogos y a los exegetas es sin duda necesaria pero, pensando en los cristianos de hoy, no solo por el riesgo del fundamentalismo, sino para evitar que la "doble verdad" se instale entre los cristianos, eso que E. Troeltsch llamaba "la esquizofrenia de los cristianos" en el mundo moderno. En efecto, es como si para los cristianos existiera una "causalidad de domingo" donde, por ejemplo, Jesús resucita a Lázaro, y una "causalidad de los días laborables" donde Lázaro muerto desde hace más de tres días estaría para siempre en su tumba ya que nadie puede volver a la vida luego de haber muerto. ¿Esta escisión de la conciencia

fe se reduce a una especie de filosofía de la vida que cada uno, según sus posibilidades intenta deducir de la Biblia. El dogma, al cual se le negó su fundamento en la Escritura, ya nada significa. La Biblia, que fue separada del dogma, se ha convertido en un documento del pasado; y por lo tanto, pertenece al pasado». J. Ratzinger, 2000: 76. 
puede superarse? ¿La teología puede abandonar la "conciencia pública" de la verdad, para permanecer encerrada en su propia verdad? Si fuera el caso, la fe cristiana se volvería pura y simplemente una secta al margen de la sociedad. Si deja de ser un potencial crítico para el futuro común de la humanidad, se pierde en el relativismo de la sociedad moderna, en donde cada uno puede creer lo que quiera a condición de aceptar que el otro tenga el mismo derecho.

En la búsqueda de una comprensión de la realidad que no esté basada en el arbitrario de nuestras preconcepciones, J. Ratzinger, después de haber hecho un breve cuestionamiento de algunas formas de exégesis (materialistas, feministas, psicológicas...), hace una crítica enérgica de las preconcepciones positivistas de la exégesis histórico-crítica y de su supuesta "inocencia dogmática"4 (Barthes, 1957). En efecto, insertos en historias no estamos nunca al principio del proceso que conduce a la verdad. En todo hombre hay, irreducible al conocimiento y sin común medida con él, una posición adoptada sobre el significado de la realidad tomada como un todo, es decir, una fe que guía sus pensamientos y sus opciones.
Necesitamos una "autocrítica" de la exégesis histórica que pueda prolongarse en una crítica de la razón histórica y que sea pues la continuación y el desarrollo de las críticas kantianas de la razón y del juicio [... ] la autocrítica del método histórico debería comenzar por una lectura diacrónica de sus propias conclusiones; debería así romper incluso con el deseo ilusorio de querer alcanzar esta certeza casi científica con la cual, hasta ahora, se presentaron generalmente sus interpretaciones. De hecho, a la base del método históricocrítico se encuentra el esfuerzo por alcanzar, en el ámbito de la historia, un nivel de precisión metodológica y de certeza análoga a aquél que se alcanza en las ciencias de la naturaleza (Ratzinger, 2000: 77-78).

Pero, todo método invita a un cuestionamiento de sus preconcepciones críticas. Al igual que los seguidores de cualquier método, los exegetas no escapan a esta exigencia. Entre los desplazamientos importantes que los conciernen, J. Ratzinger señala el gran lugar tomado hoy por la reflexión acerca de la importancia del acto de lectura, del compromiso del lector en su relación al texto ${ }^{5}$ (Vidermann, 1977).

\footnotetext{
${ }^{4}$ « Las pruebas materiales siendo inciertas o contradictorias [...] se reconstituyen sin la sombra de una duda, los móviles y el encadenamiento de los actos; hacemos como los arqueólogos que van recogiendo viejas piedras en las cuatro esquinas del campo de excavaciones, y con su cemento moderno ponen de pie un delicado descanso de Sesostris, o aún más reconstituyen una religión muerta hace dos mil años sacando del viejo fondo de la sabiduría universal, que no es hecho sino de su sabiduría elaborada en las escuelas de la 3era. República ». R. Barthes, 1957: 53.

${ }^{5}$ «El texto se convierte en el lugar de una experiencia singular y privilegiada, de una recreación en donde
} 
Pero, denunciar la ilusión positivista de la exégesis histórico-crítica como lo hace J. Ratzinger no puede significar una identificación, sin más, entre las prácticas científicas y las preconcepciones "ideológicas" de los investigadores. En efecto, esta identificación hace también el juego del relativismo y olvida el carácter profundamente histórico de nuestra fe. Las prácticas científicas implican también una parte de racionalidad irreductible que no puede considerarse como nada y que permite que la ciencia avance. Del seno mismo del conflicto del cual la figura de Jesús era el objeto, la exégesis histórico-crítica ha surgido progresivamente como una auténtica disciplina intelectual. Al mismo tiempo, poco a poco se volvió imposible decir"absolutamente cualquier cosa" sobre Jesús. Sin duda cada exegeta aborda a Jesús en virtud de sus preconcepciones pero al final termina por tropezar con la resistencia que el texto neotestamentario opone a sus proyecciones idealizantes.
En efecto, quedarse en "una crítica de la razón crítica" sería por una parte olvidar el carácter histórico no solamente de la teología, sino de la propia fe, y por otra, menospreciar el trabajo titánico que hombres y mujeres han hecho, para abrir el camino hacia una lectura de la Biblia que pueda hacer oír hoy la Palabra de Dios en las ágoras de nuestras sociedades secularizadas 6 . Los métodos científicos no pueden reducirse a las preconcepciones de los investigadores, tienen una singularidad irreductible que permite a la ciencia avanzar. J. I. Marion denunciaba, hace algunos años, la tendencia actual a reducir la cuestión de la verdad a la cuestión "¿de dónde hablas?" con el fin de descalificar por principio toda posición. Tendencia que califica de "nihilista".

En el ámbito de la verdad, donde la situación ideológica se hace patente con respecto a las ciencias humanas y a las ciencias sociales: ¿cada doctrina debe someterse, prestamente, a una interroga-

cada lector puede convertirse en el centro, a condición de que quiera salir de esta pasividad que lo empobrece, donde se aísla del texto cuyo sentido se le escapa siempre en gran parte y necesariamente ya que establecido por el autor, pertenece únicamente al autor, el lector no tiene ningún lugar. Que el lector aprenda que no es el espectador maravillado o aburrido de una historia hecha en otro lugar con la que no tiene nada que ver. Que sepa solamente que el texto le habla de sí mismo y de su propia historia y enseguida aparecerá la pluralidad de sentidos posibles». S. Vidermann,1977: p. 43.

${ }^{6}$ P.-M. Beaude señala, por ejemplo, que el método crítico e histórico pone el creyente en harmonía con la cultura de su tiempo. «En la cultura contemporánea, la historiografía juega un papel decisivo. Es a través de ella que nuestra empresa maneja gran parte de su relación con el pasado. Prescindir del enfoque histórico-crítico es correr el riesgo de dejar que se diga cualquier cosa y se pierda la memoria [ ... ] El enfoque evita las trampas del fundamentalismo [ ... ] y permite desarrollar una teología dónde la salvación de Dios encuentre la historia según las leyes de una encarnación real de la Palabra » P.-M. Beaude, 1992 : 5. Cf. P. Gibert, 1995 : 371-384. J. Zumstein, 1994: 51-67. 
ción sobre aquel o aquellos que la sostienen (como es la cuestión siniestramente célebre: ¿de dónde hablas?), que hace explícitamente el salto sobre la verdad misma, de hecho o de teoría7 (Marion, 1992: 14).

Además, los exegetas de hoy son cada vez más sensibles a estos cuestionamientos, aunque siguen desconfiando de las críticas que podrían hacer creer que la exégesis histórico-crítica habría cumplido su tiempo ya sea porque otros métodos comienzan a sustituirla o, más socarronamente, porque se asemejaría a "la montaña que concibió un ratón".

Si era saludable criticar las preconcepciones de nuestras exégesis y también de nuestras teologías, nos parece que un malentendido radical sigue envenenando nuestra exégesis y nuestra teología. No pretendo silenciar la desconfianza recíproca entre teólogos y exegetas, pero nos cuesta calificarla de "separación total"8 (Ratzinger, 2000). Nos parece que hoy por hoy asistimos a la búsqueda sincera de los unos y de los otros por encontrar un punto de equilibrio, intelectualmente aceptable que los haga servidores de la Palabra y no simplemente descifradores de un texto.

Queremos, en las páginas que siguen, buscar un camino de reflexión desplazando la cuestión de la relación dogmática-exégesis a un cuestionamiento de nuestra manera ampliamente historicista de acercarnos aún hoy a la Escritura. Tenemos que tomar conciencia de la humanidad de la escritura como "ficción", como "obra literaria", único camino para hacer acceder la singularidad del recuerdo y la particularidad del acontecimiento al universal, capacidad que genera una complicidad con el dogma. Sin olvidar que no hay ni Escritura ni Dogma fuera de la paradidosis de la Iglesia que vuelve viva a las comunidades que los forjó, que los produjo y que los porta. Las primeras comunidades no extrajeron su Escritura y su Dogma de un acto de exuberante imaginación, como lo pretendían los grupos gnósticos, sin ninguna relación con lo real, sino de la práctica de una auténtica anamnesis de su Señor Resucitado en la confesión de fe de que Él es, no solo la última palabra del Padre, sino su Palabra absoluta y definitiva.

\footnotetext{
7 J.-L. Marion, 1992: 14. Marion analiza también lo que pasó con los otros dos trascendentales -lo bueno y lo bello- en el régimen nihilista de nuestro pensamiento actual. Y sostiene la oportunidad que representa el cristianismo para la razón proclamando una verdad independiente del consenso. Sobre este tema volveremos más adelante.

${ }^{8}$ Cfr. J. Ratzinger, 2000:76.
} 


\section{EL LENGUAJE, CONSTRUCTOR DE LO REAL}

Lo dicho anteriormente nos hace tomar conciencia de la mediación lingüística, del grosor del tejido textual, de la carne del texto en la "nominación" de un acontecimiento dado. Esta toma de conciencia es primera con relación a la mediación comunitaria.

... la toma de conciencia de la distancia entre el texto y su referente, aquí presuntamente histórico, es función de la interpretación, es decir, de una lectura actualizada que, en el caso de los métodos históricos, desea comprobar qué tipo de vínculo se establece entre el texto propuesto, su contexto de producción y el "real" avizorado [... ] [ pero ] la historia es demasiado fragmentaria para apoyar la tarea que se le había asignado. Jesús no es domesticable por la ciencia, aunque esta tenía por objeto acuñarlo en su figura originaria, fuente de su universalidad presente [... ] la toma de conciencia de la ficción [es ] indispensable para una buena comprensión del camino de Jesús tal como lo reportan los Evangelios (Duquoc, 2000: 494,502).

En definitiva, lo que está aquí en juego es la toma de conciencia seria de la distancia considerable entre el referente histórico señalado y su consignación literaria. Una vez que el historicismo de nuestras cristologías contemporáneas ha sido denunciado y que el efecto de espejo entre el dato literario y lo real de lo que es invitado a señalar ha sido roto, hay que leer el texto evangélico como texto literario, construido; en consecuencia, creador de su efecto de sentido, y no como la simple trascripción escrita de las aventuras épicas de Jesús. "Lo que ocurre" no puede decirse sin la palabra que lo constituye en "acontecimiento", y, en consecuencia, lo manifiesta en la diferencia que le da sentido. El acontecimiento es distinto de $y_{;}$como W. Pannenberg lo ha señalado, está en relación con, solo así viene a ser significante. Hay entonces siempre un necesario desfase entre los relatos y lo que ha ocurrido. Esta distancia no nos permite decir que estos relatos sean "infrahistóricos" ya que rigen su relación con la historia de una manera diferente del historicismo. Su dificultad es justamente que se amasan a menudo de demasiada historia.

Un poco a la manera de esos documentales de historia que recogen en dos horas las imágenes demasiado verdaderas de una aventura auténtica. La película puede ser, a la vez, perfectamente objetiva recordando un pasado inevitable (ya que lo que se hizo no puede no haber sido hecho), y completamente construido en función incluso del historiador que lo firma y del mundo donde este vive. La "retrodicción" es un éxito cuando el lector- espectador se deja llevar por la imagen hacia el mundo de la historia. Por su parte, el colega de nuestro cineastahistoriador reconoce, cuando proceda, 
el valor objetivo de esta retrodicción imaginaria; pero al mismo tiempo, entiende inmediatamente todos los"desplazamientos de la historia" que se acumulan en el episodio representado. Puede entonces hacer estallar la película, para distinguir mejor la historia más allá de la imagen de la historia (Perrot, 1982: 56).

Como ya lo dijimos, a pesar de los seísmos que la exégesis histórico-crítica ha producido en nuestra fe, la mentalidad común sigue creyendo, como W. Pannenberg, por ejemplo, que entre todos los saberes actualmente disponibles, el saber histórico es el mejor, quizás el único apto para evaluar la verdad de las Escrituras ${ }^{9}$. Sostenemos firmemente esta convicción, por ejemplo, que el evangelio no es una leyenda piadosa. Para salir "bien parados" del debate público alrededor de la figura de Jesús, tenemos dos opciones: la primera, al igual que W. Pannenberg, animados por la idea de que los únicos testimonios verdaderos son aquellos cuya exactitud puede ser establecida por la ciencia de la historia, hacemos inconscientemente una selección liberadora entre lo que es "verdadero" y lo que es "mítico"; o la segunda, más conscientemente nos aferramos neuróticamente a la historicidad de cada relato con la esperanza que un día la ciencia histórica podrá confirmarlo todo, de la curación del ciego de naci- miento en Jerusalén hasta el ahogamiento de la piara de cerdos en el mar de Galilea. Pero, en los dos casos continuamos leyendo los evangelios como un manual historiográfico, un poco suavizado por el mito, pero historiográfico de todas maneras. En el pensamiento de W. Pannenberg, esto constituye una especie de principio "epistemológico" de nuestras cristologías que no solo determina el tipo de respuestas establecidas, sino, lo que es más grave, condiciona el tipo de preguntas que planteamos a los textos de la Escritura.

Si un tal marco epistemológico debe criticarse, no es en absoluto denegado de razón. No es simplemente el fruto de la ingenuidad de la gente sencilla, sino a menudo el fruto de una reflexión que se quiere teológica. Si la Biblia, el Antiguo Testamento (AT) y el Nuevo Testamento (NT) se presentan como una recopilación cuya intención explícita es dar testimonio de la alianza de Dios con los hombres y en consecuencia de la intervención de Este en la historia haciéndose un hombre de nuestra historia (Jesús de Nazareth que muere "bajo Poncio Pilato"), la primera cosa que es necesario reconocer es que no se honraría la Escritura, al menos, tal y como se da a sus lectores si se la recibiera a priori como una serie de fábulas sofisticadas o relatos míticos. La segunda

${ }^{9}$ En lo que se refiere a la teología historicista de W. Pannenberg Cfr. entre otros Pannenberg, W, 1967: 52 ss. 
epístola de Pedro lo pone ya de manifiesto: "ya que no es siguiendo fábulas sofisticadas que les dimos a conocer la potencia y la llegada de nuestro Señor Jesucristo, pero porque nos convertimos en testigos oculares de su majestad" (2 P 1,16).

Someter la verdad de las Escrituras al examen de la crítica histórica, es pues para muchos cristianos la única manera de tomar en serio esta pretensión del Libro de no ser una mitología. Lejos de poner en entredicho la dimensión histórica de "eso" de lo que hablan las Escrituras, me parece que otra vía puede abrirse delante de nosotros.

Es precisamente porque, entre otras cosas, un tal fundamento es reconocido y aceptado, que conviene preguntarse si el marco epistemológico del que acabamos de hablar y que criticamos en W. Pannenberg es el mejor adaptado para tratar la cuestión que se plantea respecto a la verdad de las Escrituras.

Una posibilidad se presenta: abandonar el combate en torno a la oposición entre el Jesús de la historia y el Cristo de la fe, y dirigirse hacia una interpretación que privilegia otro acceso a lo real, la ficción. El texto neotestamentario no es un reportaje de hechos diversos, susceptibles de ser el objeto de un informe policial, es el resultado de una elaboración literaria para sacar a la luz el sentido de los hechos, acontecimientos, palabras que caerían , sin esta puesta en escena, en la trivialidad, el mito o lo maravilloso. El texto entra en el orden de la ficción, separándose al mismo tiempo del mito, el cuento y la fábula. Es resultante de una voluntad individual o colectiva de evidenciar en el lenguaje lo que se tejía en lo cotidiano y eventual ocultándose al mismo tiempo. Los libros apócrifos orientan hacia esta dimensión sin honrarlo plenamente, y a veces pervirtiéndolo (Duquoc, 2000: 503).

Si la verdad anunciada por el NT considerado en su conjunto, es el propio Cristo, más exactamente que el hombre Jesús que se pretendió el Enviado es realmente Cristo y Señor, Hijo del Padre, cuya muerte y resurrección revelan que por Él y en Él la vida eterna se da a los hombres, se deduce fácilmente que las verdades de la ciencia histórica son completamente impotentes a sostenerlo o a refutarlo. El NT no es un libro histórico en el sentido moderno de esta palabra, es el testimonio, portado por la fe cristiana, del encuentro de un hombre que apareció en nuestra historia. Ahora bien, al poner a un lado la historia, incapaz de pronunciarse sobre la cuestión de fondo, no queremos poner en entredicho la eficacia del acontecimiento de Jesucristo en la historia ya que el NT es una interpretación auténtica de un acontecimiento histórico. Lo que nos interesa es hacer surgir otra cuestión compartida, o, al menos, que deberían tener en común la historia y la teología: ¿cómo los discursos en 
busca de la verdad asumen la diferencia radical que separa y distingue lo real de la realidad? Esta diferencia no es el fruto de una teoría metafísica particular, se impone en cuanto el lenguaje no es un simple instrumento del hombre, según la representación común del conjunto de la tradición filosófica, sino que debe ser reconocido como mediación, como fundación de lo humano (Chauvet, 1987).

En un esquema "instrumentalista" se cree que el sujeto está en una relación inmediata a lo real; y que este le corresponde en el espíritu de manera natural como una copia perfecta bajo la forma de imagen mental de representación o de concepto; y es eso que permite al sujeto comunicarse enseguida con otros, o comunicarse a sí mismo como a otro, lo real. Se tiene la pretensión de alcanzar la inmediación de la "cosa" como una presencia plena de sí a sí en un proceso de transparencia total.

El sujeto humano es colocado (al menos lógicamente) antes del lenguaje presuponiendo así un sujeto ideal que estaría fuera del lenguaje, por lo tanto, fuera de la mediación, es decir, finalmente fuera del cuerpo y fuera de historia ya que lo que regula la concepción instrumental del lenguaje, es la preconcepción que las mediaciones sensibles del lenguaje constituyen obstáculos a la verdad. Es precisamente esa preconcep- ción que se ha puesto en cuestión a través de la revolución epistemológica operada por las ciencias y la filosofía contemporánea del lenguaje. En lugar de ser obstáculo a la verdad, las mediaciones sensibles del lenguaje, del cuerpo, de la historia, del deseo, constituyen el medio mismo en el seno del cual el ser humano adviene a su verdad y, así, corresponde a la Verdad que lo solicita.

La comparación del lenguaje con un instrumento (...) debe llenarnos de desconfianza, como toda noción simplista con respecto al lenguaje. Hablar de instrumento, es poner en oposición el hombre y la naturaleza. El pico, la flecha, la rueda no están en la naturaleza. Son fabricaciones. El lenguaje está en la naturaleza del hombre, que no lo ha fabricado. Somos siempre propensos a esta imaginación ingenua de un período original en donde un hombre completo se descubriría un similar, también completo, y entre ellos, poco a poco el lenguaje se elaboraría. Eso es pura ficción. No vemos nunca al hombre separado del lenguaje y no lo vemos nunca inventándolo. No alcanzamos nunca al hombre reducido a sí mismo e ingeniándose a concebir la existencia del otro. Es un hombre hablante que encontramos en el mundo; un hombre hablante a otro hombre, y el lenguaje señala la definición misma del hombre ${ }^{10}$ (Benvéniste, 1996: 259).

${ }^{10}$ E. Benvéniste, 1996: 259. K. Rahner dice exactamente lo mismo: «Nuestra palabra es más que un pen- 
El lenguaje es contemporáneo del hombre, de la humanidad como tal; comienza con él, y con cada uno individualmente. Si el ser humano existió antes de haber inventado el fuego, el pico o la flecha, no pudo existir antes del lenguaje y en consecuencia, antes de la cultura. No hay sujeto sino hablante, y hablando a otro sujeto-hablante. Para poder "inventar" el lenguaje, hay que pensar en ello, pero, para poder hacerlo es necesario ya estar en el lenguaje. En ese sentido podemos decir que "el lenguaje señala a la definición misma del hombre" y que, como lo añade el mismo E. Benvéniste," es en y por el lenguaje que el hombre se constituye como sujeto". El mundo viene a nosotros siempre ya dicho, formateado en los discursos culturales. Es necesario romper con la falsa inocencia de un mundo dado, anterior al lenguaje y que supone a veces el recurso a la historia en teología. El lenguaje es "mediación", es decir, el medio matricial en el cual adviene el sujeto. Toda relación del sujeto a lo real, toda relación propiamente humana o significante es mediatizada, construida por el lenguaje, y de manera más amplia, por la cultura, y es precisamente construyendo lo real como "mundo" que el sujeto se construye como sujeto.

El "real" es así un efecto del lenguaje, lo que surge como otro y que este no puede ni simbolizar, ni representar completamente. Es más exactamente correlativo al lenguaje, dependiente de este por una relación que al mismo tiempo es de disyunción y de conjunción. Adviene, al borde extremo de este orden de "realidades" que construye, bajo forma de representaciones, el poder imaginario, simbólico, del lenguaje. "Imaginario" no significa ilusorio o falso ${ }^{11}$ (Perrot, 1982). Se designa así este orden de "re-

samiento: es un pensamiento encarnado. Admitida la doctrina escolástica de la unidad sustancial de cuerpo y alma, la palabra es más que una simple exteriorización sonora de un pensamiento que no precisa de este silbido animal para existir y del cual se sirve para señalarse, convencionalmente nada más, en esta bruta animalidad en que nosotros, «espíritus», nos vemos forzados a desenvolvernos. No, la palabra es la corporeidad en que primariamente existe, esculpiéndose, aquello que ahora pensamos y experimentamos. Mejor: la palabra es el pensamiento corpóreo (no solo la corporeidad del pensamiento), y por lo mismo es más que el pensamiento y originariamente anterior a él, como el hombre, uno y total, supera y antecede al alma y al cuerpo individualmente considerados». K. Rahner,1961: 332.

${ }^{11}$ "La narración transmisora de la palabra no es más que la exposición visual del movimiento de la palabra evocada. Tomemos el ejemplo de Mt 19,13-15. El relato, sumamente esquemático, que rodea la palabra («dejad a los niños; no les impidáis que se acerquen a mí») se limita a exponer visualmente el movimiento del logion: la palabra lleva en sí misma su propio relato. Por eso, no debemos decir precipitadamente, con Bultmann, que ese relato es pura invención. Otra forma de «visualización», más difícil de entender para un espíritu occidental, es la de la convicción de fe que se expresa en el lenguaje plástico del judeocristianismo. El relato de las tentaciones de Jesús, según Mt 4,1-11 o Le 4,1-13, nos ofrece un ejemplo notable a este respecto. En toda la vida de Jesús no hay nada más seguro históricamente que esas pruebas, si bien el relato las expresa en un lenguaje de imágenes para que cobren vida a los 
alidades" que el discurso construye pretendiendo hacerlos coincidir con la mayor exactitud posible a lo real mismo. En este sentido, todas las ciencias son imaginarias y lo son aún más ya que su pretensión de exactitud es mayor. No pudieron ni pueden desarrollarse de otra manera. No obstante, se vuelven "ilusorias" -por más exactos, verificables y eficaces que sean sus resultados- cuando trabajan olvidando completamente esta alteridad de lo real que escapa a toda forma de representación y simbolización absoluta.

Ahora bien, como lo vimos, este olvido es, en el fondo, el olvido del sujeto humano, puesto que es sobre él que lo real como efecto del lenguaje hace pesar todo su peso. Olvido de la división que lo constituye en sí mismo, encerrado desde antes de su nacimiento entre la carne y eso que lo representa en los significantes del lenguaje. Ya que la primera manifestación de lo real con la cual el sujeto choca es el propio cuerpo de carne, o más bien, la carne viva y mortal que, porque está vinculada íntimamente con el lenguaje, se erige radi- calmente en un otro al límite de este, pero que también con ese mismo lenguaje al que está ligada constituye el cuerpo, cuerpo del sujeto y alianza de carne y de

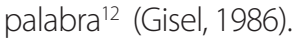

Si la exactitud es ilusoria porque olvida la división del sujeto, este último no es, sin embargo, impotente para acercarse a la división que lo constituye, ni condenado a discurrir en el olvido de lo real cuyo carácter extraño se impone a sí mismo como su parte más íntima. Habla en efecto. Y hablar es estar al borde de lo real, es, por el rodeo de las figuras, acercar y significar como absolutamente irrepresentable este real que, de ser tal, no podrá nunca decirse. Esta es la razón por la cual, si la verdad tiene algo que ver con lo real la literatura -la de todas las épocas y de todas las formas, oral o escrita- es seguramente mucho más apta y mejor armada que los discursos de la exactitud para aventurarse en la búsqueda de lo que, en realidad, no puede sino decirse de manera incompleta. No nos enfrentamos nunca a un universo físico que nos sería heterogéneo, sino a un

\footnotetext{
ojos del lector. Pero ese lenguaje no ha sido elegido arbitrariamente: está elaborado a partir de la Escritura. Otra forma es la de los relatos de milagro, que exponen la praxis cristiana mediante la anamnesis visualizada de las acciones salvadoras del Señor ». Ch. Perrot, 1982: 251.

12 « La distancia que [la Escritura] marca en relación con el acontecimiento del cual da testimonio no es reducible: no se puede ir antes de los textos para descubrir una verdad más pura, como despojada del peso de humanidad propio de todo testimonio. La distancia es al contrario elemento constitutivo del dato de la Escritura: irreductiblemente testimonio dado a eso que ella no es (pero que lo confiesa) y advenimiento de la humanidad verdadera. La verdad cristiana ignora así toda inmediatez de partida. Solo la diferencia entre el texto y la palabra así recordada debe permitir al texto ser revelación: reenviando a Dios ( Palabra) que ahí se dice, en el centro, pero indirectamente, de manera incógnita, y al hombre ahora suscitado como creyente y testigo». P. Gisel,1986: 66.
} 
mundo siempre lleno de significados, siempre ordenado, siempre socialmente arreglado. En ese sentido, las mediaciones sensibles, culturales e institucionales no son tampoco obstáculos que sería necesario descartar idealmente para ir hacia la verdad. Constituyen al contrario, incluso en sus ambi- güedades, el medio en el seno del cual el ser humano adviene a su propia verdad dejándose solicitar por la Verdad, siempre más grande.

El género literario elegido [llamado Evangelio] no privilegia ni lo que se nombra hoy como "Jesús de la historia" ni lo que se define por "Cristo de la fe", esta distinción, legitima en una interpretación crítica moderna, no tiene sentido en su redacción. Los evangelistas describen un itinerario que es invadido de un conflicto del que la muerte será la sanción. Se esfuerzan en significarlo literariamente como la revelación de lo que está en juego: la verdad difícil del vínculo al Dios de Israel. Para este objetivo, el reporte estricto del acontecimiento no tendría ningún efecto. La ficción era necesaria para la puesta en coherencia con lo que está en juego revelado en el proceso; movimientos, actos y discursos del Nazareno. La fe tenía que clasificar y construir, contar no según los criterios de los cronistas, sino según la fuerza evocadora de los novelistas. Leer así el texto permite escapar a menudo al imperialismo positivista del antiguo método histórico-crítico y a la decepción mítica de R. Bultmann (Duquoc, 2000: 504-505).
El texto evangélico debe leerse en su fuerza creativa y en sus potencialidades interpretativas. No se trata de establecer la lista de las respuestas que dirían una a una las verdades de la Escritura, se trata de responder a la verdad cuando esta viene a revelarse en la articulación de la letra y el cuerpo, de la escritura y el encuentro, de la ausencia y la presencia, de la espera y de la venida, de las figuras y de su realización. El Cristo de la fe no devalúa al Jesús de la historia y el Jesús de la historia no evacua como un a priori al Cristo de la fe.

La ficción salva el acontecimiento de su encierro en el hecho anecdótico, conecta los hechos de tal modo que, por construcción literaria, un sentido con valor universal, se da a leer. El referente al acontecimiento impide que la ficción se transforme en cuento o ceda a la imaginación mítica. Los relatos evangélicos se sitúan en este entredicho: el acontecimiento como horizonte necesario, imperceptible debido a su contingencia y su carácter no repetitivo y la construcción literaria como tentativa de generar un sentido a partir de la construcción de la trama de los hechos. El relato impone una estructura y libera un sentido.

La "crítica de las formas" nos volvió sensibles al hecho que los evangelios, tal como los conocemos hoy, no son una pura yuxtaposición azarosa de fuentes dispares sino el fruto de un verdadero 
trabajo de creación literaria, a partir, por supuesto, de fuentes independientes, pero que han sido retocadas por el autor del evangelio para hacerlas entrar en la intriga de su relato. Cristo nos ha sido narrado: citas, alusiones, aproximación tipológicas, reanudación de temas y figuras muestran la intensidad con la que, la construcción de la trama del acontecimiento Jesús, utiliza abundantemente la Escritura, para darle su riqueza semántica al texto evangélico, como por ejemplo, el Servidor Sufriente de Isaías, el Justo abandonado del SI. 22, el Señor del SI. 110, el Rey David y su tumba, el Hijo del hombre de Daniel, el nuevo Adán...

... los evangelios son "producciones eclesiales" que recogen materiales de épocas y medios diversos con el fin de responder mejor a las necesidades concretas de una iglesia determinada: Roma (Mc), Antioquía (Mt) y otros. ¡Son "textos vivos"! (Perrot, 1995: 33).

\section{LA ESCRITURA: UNA PALABRA ORIGINAL ( $U R W O R T$ )}

Nos olvidamos a menudo de leer los relatos evangélicos tal y como "fueron reescritos" por los evangelistas. Un vínculo literario es creado entre los acontecimientos relatados, las palabras referidas, los gestos escogidos y la aparición de un sentido para todo lector, individual y colectivo. En esta dialéctica entre el hecho contingente y la construcción literaria, el acontecimiento, incluso si es imperceptible en su singularidad, es decisivo para el sentido. Los autores de los primeros símbolos de fe, por ejemplo, lo habían comprendido al arraigar en la historia general del Imperio, por la mediación de una de sus autoridades, Poncio Pilatos, el asesinato judicial de Jesús de Nazareth. Un cambio de perspectiva es necesario.

Antes de hablar de fuentes y dependencia literaria, conv[iene] de aprehender los textos como textos, conjuntos en los cuales los temas pueden seguramente deri- var de fuentes variadas, pero deben sobre todo ser examinados en el papel que juegan. La "crítica literaria" sola no basta, ya que recurre sin cesar a las"intenciones" de modificaciones, que son hipotéticas a un grado muy alto (Léon-Dufour, 1971: 150).

El valor de los relatos evangélicos tal y como los conocemos no puede reducirse a ser la caja fuerte en la cual la verdad se oculta en forma de un texto primitivo y en consecuencia, histórico, que es necesario descubrir absolutamente. Seguramente, los esfuerzos para situar el Sitz im Leben - a pesar de todo lo que pueden tener de arbitrario- pueden ayudarnos a comprender mejor un texto, pero no podemos reducir nuestra comprehensión del texto a ello. Es necesario colocarnos frente a él como lectores y no como arqueólogos que con una fina brocha intentaran delicadamente remontar los siglos en busca de un 
texto primitivo que no pudiera ya ser comprendido, ya que no guarda con nosotros ninguna relación viva. Los vestigios aislados de los textos evangelios no pueden sino hacerse polvo. El hecho que incluso el trabajo más docto a nivel histórico o lingüístico sobre, por ejemplo, la reconstrucción de la fuente $Q$, o sobre la vida de Jesús, no podrá nunca ocupar el lugar de los evangelios en nuestras asambleas litúrgicas debe hacernos reflexionar. Este hecho no es la señal de la esquizofrenia cristiana denunciada por E. Troeltsch sino un revelador de lo que es la Escritura para la lógica del cristianismo.

Además, es necesario tomar en serio la especificidad del género literario de los evangelios. Marcos no solamente escribió un evangelio en vez de un manual de historia o de una novela biográfica de un héroe, sino que inventó el género. La manera de preguntar históricamente un documento varía según su "género literario". No leemos una novela como si se tratase de una recopilación de poemas. Y además, cada autor adapta o amplia los géneros ya existentes respetando, al mismo tiempo, un mínimo de reglas que facilitarán la comunicación con el lector. G.N. Stanton en su libro"Palabra de Evangelio?" (1997) supo expresar esta exigencia de una manera muy provocadora a partir del desconcierto que la llegada del Codex de los evangelios habría producido en la biblioteca de Éfeso:
En 110, se creaba una espléndida biblioteca en Éfeso a la memoria de Gaius Julius Celsus que fue gobernador de la provincia a partir de 105-107. La biblioteca de Celsio, nombre bajo el cual se la conoce ahora, [... ] es uno de los monumentos más impresionante de la antigua Éfeso. Contenía 12.000 rollos conservados en las repisas de nichos construidos en las paredes de la habitación central [.. en la generación que vio la apertura de esta biblioteca el cristianismo comenzaba a llamar la atención (a menudo crítica) de los medios "doctos" de la región. Es pues probable que ejemplares de algunos de los evangelios hayan llegado hasta la biblioteca. Esta llegada de los evangelios habría sido para los bibliotecarios un verdadero rompecabezas. ¿Dónde clasificarlos? ¡Se presentaban bajo la forma de un Codex (un libro) y se había concebido la biblioteca para albergar millares de rollos! [... ] los cuatro evangelios se habían unido juntos en un único Codex a mediados del siglo II (o quizá antes) [... ] el bibliotecario encargado de las adquisiciones se encontraba ante un problema aún más serio: ¿en qué sección colocar los evangelios? ¿En las historias, o novelas, o biografías, o tratados religiosos? La decisión del bibliotecario debía despertar en el lector una inquietud particular (Stanton, 1997:168).

En ese sentido es bueno recordar cómo los Padres llamaban a los relatos evangélicos. Con respecto a Marcos, Papias al referirse a "lo que decía el presbí- 
tero" habla de apomnemoneuo (acordarse) ${ }^{13}$ (De Césarée). Justino escribió: "Marcos, dicen, se acordaba de las Memorias de los Apóstoles (apomnemoneimata tu apostolôn) que se llaman Evangelios"14. Según Papias, el mismo Pedro no presentaba en su predicación el relato completo de las acciones de Jesús y su enseñanza: adaptaba las tradiciones, para responder a las necesidades de sus auditores. Al leer de cerca las observaciones de Papias, uno se da cuenta que ya reconoce la existencia de una distancia entre Marcos y la vida de Jesús: Marcos interpretó la enseñanza de Pedro; Pedro adaptó las tradiciones relativas a Jesús. Papias reconoce también explícitamente que Marcos no era un testigo ocular personal de la vida de Jesús. Pero, en la frase que sirve de prólogo al evangelio según Lucas, el autor destaca que se inspiró en el trabajo de estos antecesores que fundaron sus relatos sobre tradiciones transmitidas por testigos oculares que son a la vez Ministros de Palabra. En otros términos, los testigos oculares no aportan recuerdos "neutros" sobre los acontecimientos de la vida de Jesús. Sobre la base de su experiencia personal en el seno de la ekklesia, proclaman su significado transmitiendo una tradición interpretada.
Loveday Alexander recientemente estudió el prólogo de Lucas en su contexto del siglo I greco-romano y judío y hace notar la diferencia en el empleo de la expresión "testigo ocular" en griego y en el tiempo moderno. Para nosotros, un testigo ocular, en contexto judicial, es a menudo, inapreciable: se trata de alguien que se encontraba allí (en general por casualidad) en el momento en que un incidente se produjo. En cambio, la palabra griega no se emplea en este sentido. Una mejor traducción de lo mencionado por Lucas de "testigos oculares" podría ser: "los que tuvieron una experiencia personal, de primera mano, los que conocen los hechos de primera mano (Alexander, 1993: 116-125).

Es pues a un "trabajo de memoria" al que se dedicaban los evangelistas. El relato no es pues una pálida copia del original que sería la experiencia histórica o una débil y decepcionante imitación de la realidad de la que habla. Es el lugar de una operación poética necesaria, que refigurando la relación a la realidad, le permite dar sentido. Entre el creyente de hoy (o el simple lector) y la experiencia "viva" vivida por los apóstoles está el escrito, que pone orden a los hechos sin lo

\footnotetext{
${ }^{13}$ «Y el anciano decía lo siguiente: Marcos, que fue intérprete de Pedro, escribió con exactitud todo lo que recordaba, pero no en orden de lo que el Señor dijo e hizo. Porque él no oyó ni siguió personalmente al Señor, sino, como dije, después a Pedro. Este llevaba a cabo sus enseñanzas de acuerdo con las necesidades, pero no como quien va ordenando las palabras del Señor, más de modo que Marcos no se equivocó en absoluto cuando escribía ciertas cosas como las tenía en su memoria. Porque todo su empeño lo puso en no olvidar nada de lo que escuchó y en no escribir nada falso » Papias citado par Eusebio. Cf. Eusèbe de Césarée, Histoire ecclésiastique, I, 39, 15. Paris : SC 31, p. 156-157.

14 Justino. I Apologie CVI.
} 
cual la memoria no se haría y el sentido no se propondría. Volveremos a esto más adelante.

¿Pero se puede utilizar la palabra ficción? Es seguramente posible, a condición de descartar desde el principio un malentendido sobre el sentido de esta palabra. Hoy día, la ficción se pone más bien del lado de la historia inventada en oposición a la historia "seria". Se habla de ficción en la televisión para las series novelescas, se habla de las novelas en términos de literatura de ficción. Si entiendo la palabra "ficción" en el sentido de obra novelesca no es de gran ayuda para hablar de los evangelios.

Los evangelios no son novelas, cuentos imaginados para seducir al lector, a menudo con algo de color, para hacer buena impresión. Sólo el relato de la decapitación de Juan-Bautista entra en esta categoría (Mc 6,17-29 y Mt 14, 312). En la antigüedad, apenas se apreciaba este tópico común de los modernos, la ficción nos instruye sobre la condición humana. (Stanton, 1977: 171-172)

La novela, en efecto, es un género literario relativamente reciente, cuya aparición no remonta, en líneas generales, más allá del Renacimiento. P. Ricoeur comprende "la ficción" como el auxiliar indispensable de toda comprensión del tiempo, del hombre y de la historia. La etimología de la palabra"ficción" (del latín fingere: modelar en la arcilla) nos enseña que se trata de un trabajo de prefiguración, una manera de hacer eso que se quiere expresar, y sin lo cual no se puede expresar nada. La ficción viene a ser el hilo conductor gracias al cual se organiza la realidad, no para representarla (ilusión positivista) sino para presentarla, dejarla ver.

No se puede hablar de un género literario de ficción con respecto a los evangelios sino como literatura, producto de una operación poética (poièsis), de una construcción de la trama de la realidad. El hombre es, sin duda, un ser visitado, hecho por algo que le adviene. Pero, al mismo tiempo, hace y visita eso que le adviene. No hay realidad que no sea atravesada por su palabra y por su acción, y la palabra y la acción son "poiéticas", son un hacer, una creación. No en el sentido que inventen a partir de nada (incluso el artista no lo hace), sino en el sentido que hacen advenir todas las cosas al mundo del hombre.

Esta es la razón por la cual es, seguramente, preferible hablar de " poiética", para designar este poder "de moldear"la realidad reconocido a la obra literaria, un poco lo que K. Rahner llamaba Urwort, "palabra originaria".

Hay también palabras que, a través de una cosa particular, hacen traslucir lo infinito de toda realidad. Son como conchas en las cuales resuena el mar del infinito, por más pequeñas que 
puedan ser. Nos iluminan [...]. Tienen poder sobre nosotros porque son dones de Dios, no fabricaciones del hombre, aunque sea quizá por fabricaciones del hombre, que ellas han venido a nosotros. Las unas son claras porque son planas y sin misterio; bastan a la inteligencia; gracias a ellas uno se apodera de las cosas. Las otras pueden ser oscuras, porque evocan el misterio supraluminoso de las cosas. Suben del corazón y estallan en himnos. Abren las puertas para las grandes obras, y deciden sobre eternidades. Estas palabras que brotan del corazón, que se apoderan de nosotros, que unen por un encanto, las palabras que celebran y que son dadas, querría llamarlas palabras originales. Las otras, podrían llamarse palabras fabricadas, técnicas, las palabras utilitarias ${ }^{15}$ (Rahner, 1964: 269).

Por esta expresión, Urwort K. Rahner no designó simplemente palabras particulares, sino la palabra que saca las cosas de su oscuridad para llevarlas a la luz del hombre. Este poder de"representar" no es la capacidad de mostrar la simple y pálida copia de una realidad que seguiría siendo cada vez más rica que su imitación, sino la refiguración de esta realidad en la operación creativa que es la puesta en escena, el descubrimiento de la palabra original que no deja de velarse en el corazón de nuestras historias. Tal operación, lo vimos, produce una cons- trucción de la trama capaz de suscitar el trabajo de memoria. En el caso de los evangelios, es la experiencia de los apóstoles que habiendo vivido con Jesús de Nazareth, que por la transmisión de todo un material narrativo y figurativo es representado y accede por allí a una condición literaria que aporta la coherencia y lo inteligible, insertada, por el juego de prefiguraciones, en un desarrollo que tiene una lógica en conformidad con el querer misterioso de Dios.

¿Pero después de todo cuándo una historia es "verdadera"? Cuando, a través de los hechos o los personajes mencionados, se dice algo de la verdad profunda del hombre; cuando aquel o aquella que lo dice hace que su relato esté habitado por el peso de su experiencia y de la sabiduría común de su pueblo; cuando lleva a los lectores a hacer la verdad de su propia existencia; resumidamente, cuando los hechos singulares son elevados a un significado universal. La ficción, lo mismo que la historiografía, es capaz de dar testimonio de la verdad y de la complejidad de la historia y de los que hacen la historia. Dando vida al relato, la ficción da la facultad de entrar en el pensamiento de los protagonistas, de describir sus emociones, sus motivaciones y sus intenciones ocultas, de poner de relieve su evolución personal y relacionada. Gracias a la fic-

\footnotetext{
${ }^{15}$ Urwort, formado de Wort, palabra, y del prefijo Ur que significa lo que es a la vez totalmente primitivo, auténtico, profundo, cargado de misterio.
} 
ción, el autor puede introducir al lector en el designio secreto de Dios, denunciar los callejones sin salida donde lo precipitan las elecciones de su pueblo, describir la fineza de la estrategia con la cual pretende reorientar la historia. En el fondo, gracias a la ficción -a menudo más verdadera que la realidad- los autores de la Biblia presentan al lector una meditación sobre la complejidad de las motivaciones humanas y sobre la ambigüedad de los personajes, simplemente porque son dimensiones constitutivas de una determinada visión del hombre, creado por Dios y probando las consecuencias a veces felices, a veces austeras, del ejercicio de su libertad. Es quizá en eso que sus relatos afectan al lector en el corazón mismo de su historia, y hacen la historia. ¡La escritura es así una obra de vida, una obra de amor, una obra de verdad!

El amante que espera para mañana el regreso de la amada no escribe pero si no volvió ni al día siguiente ni los días siguientes, la primera carta señala la primera inquietud, la primera angustia. Es seguramente eso lo que pasó para los hombres de ese tiempo el primer evangelio escrito: una carta durante la separación, la señal de una cita pospuesta (Merejkovsky, 1974: 11).

\section{CONCLUSIÓN}

La poiética de los evangelios es capaz de testimoniar la verdad y la complejidad de la historia y de los que la hacen. Es quizás en eso que el relato evangélico toca al lector en el corazón mismo de su historia, y hace la Historia. Cada vez que el hombre es confrontado a su verdad la más profunda, indisociable de la Verdad, sea a partir de la experiencia del mal radical o de la bondad la más sublime ninguna construcción puramente histórica podrá expresarla con justeza.

J. Semprun hace referencia a un debate entre los supervivientes del campo de Buchenwald inmediatamente después de la liberación. Después de un debate agitado, donde cada participante experimenta la gravedad de la pregunta planteada: " ¿cómo hay que contar para que se nos comprendan?", ellos que habían probado en su carne el peso trágico de la realidad, llegan a la conclusión que "la verdad esencial de la experiencia no es transmisible... o más bien, ella solo lo es a través de la escritura literaria..." y que será necesario para ello, inventar un género literario propio ... ¿No es eso lo que los cristianos hicieron a fines del siglo I?

\footnotetext{
... sería necesario una ficción, pero ¿quien se atreverá? Mejor sería realizar una película de ficción hoy mismo, en la verdad de Buchenwald aún visible...
} 
La muerte aún visible, aún presente. No un documental, digo bien: una ficción... es impensable...

Hay silencio, pensamos en ese proyecto impensable. Bebemos a lentos tragos el alcohol de la vuelta a la vida.

- Si comprendo bien, dice Yves, nunca sabrán, los que no han estado! - Nunca realmente... Habrá los libros. Las novelas, preferiblemente. Los rela- tos literarios, al menos, que superarán el simple testimonio, que darán a imaginar, incluso si no dan a ver... Habrá quizá una literatura de los campos... yo digo bien: una literatura, no solamente un reportaje. (Semprun, 1994: 165-167). 


\section{BIBLIOGRAFÍA}

Alexander, L. (1993 ). The Preface to Luke's Gospel. Cambridge: CUP.

Barthes, R. (1957). Mythologies. Paris: Seuil.

Benvéniste, E. (1996). Problèmes de linguistique généralel. Paris : Gallimard.

Chauvet, L.-M. (1987). Symbole et Sacrement. Paris: Cerf (CF 144).

De Césarée, E. (1952). Histoire ecclésiastique. Paris: Cerf. (SC 31).

Duquoc, C. (2000). «Lintérêt théologique de la quête du Jésus historique». In: RSR 88/4, 492.

Gibert, P. (1995). «L'Exégèse Critique, témoin de l'incarnation ». In Ce Dieu qui vient (sous la dir. de R. Kuntzmann), Paris : Cerf (LD 159).

Gisel, P. (1986). Croyance Incarnée. Tradition-Ecriture-Canon-Dogme. Genève: Labor et Fides.

Léon-Dufour, X. (1971). Résurrection de Jésus et message pascal. Paris: Le Seuil.

Marion, J.-L. (1992). «L'Apologie de l'argument». In COMMUNIO XVII 2-3.
Merejkovsky, D. (1974). Jésus inconnu. Paris: Cerf.

Pannenberg, W. (1967). "Heilsgeschehen und Geschichte". In: Grundfragen systematischer Theologie. Göttingen.

Perrot, C. (1982). Jesús y la Historia. Madrid: Cristiandad.

Perrot, C. (1995). Jésus et l'Histoire. Paris: Desclée

Rahner, K. (1961). "Sacerdote y Poeta". In: Escritos de Teología III. Madrid:Taurus.

Ratzinger, J. (2000). L'Exégèse chrétienne aujourd'hui. Paris: Fayard.

Stanton, G. (1997). Parole d'évangile?. Paris: Cerf.

Semprun, J. (1994). Lécriture ou la vie. Paris: FolioGallimard .

Vidermann, S. (1977). Le Céleste et le Sublunaire. Paris: PUF.

Zumstein, J (1994). «Les enjeux de la méthode historico-critique», in Exégèse et Théologie, Paris : Cerf (LD 158 


\section{INSTRUCTIVO PARA PUBLICAR EN LA REVISTA PUCE}





\section{INSTRUCTIVO PARA PUBLICAR ARTÍCULOS EN LA REVISTA PUCE}

\section{Datos Generales}

Revista PUCE es una publicación de la Pontificia Universidad Católica del Ecuador en Quito, Ecuador que edita una revista cada seis meses (3 de mayo-3 noviembre). Esta revista da a conocer los resultados y análisis, frutos de la investigación en diferentes áreas del conocimiento. Los artículos postulados para la publicación en la Revista PUCE deben someterse a las siguientes instrucciones:

1. Exigencia de originalidad: los artículos publicados en la Revista PUCE tienen que ser originales e inéditos. No deben estar postulando para publicación simultáneamente en otras revistas u órganos editoriales. Por lo tanto, para que este apartado quede claro se hace firmar un documento de originalidad y cesión de derechos de autor a cada autor del artículo; de esta manera, los autores se comprometen a respetar la información académica de otros autores, a ceder los derechos de autor a la Revista PUCE, para que esta sea la única autorizada en editar formatos más no información y se evita que más de una revista publique el mismo artículo.

2. En la Revista PUCE se recibirán trabajos de docentes e investigadores de la Universidad, así como de autores externos a ella. Esto con la finalidad de ayudar a difundir el material científico no solamente de nuestra Universidad, sino también de investigadores externos.

3. Los artículos por publicarse en esta revista deberán principalmente estar escritos en español; sin embargo, bajo ciertos pedidos se pueden publicar también artículos en francés, inglés o portugués.

4. El Centro de Publicaciones de la Pontificia Universidad Católica entregará un documento de recepción cuando se hayan entregado los artículos. Es importante indicar que como la publicación de cada revista se realiza de acuerdo con cada Facultad de nuestra Universidad, este documento de recepción estará firmado por el Director del Centro de Publicaciones en su condición de editor.

5. Los decanos interesados en publicar artículos de su facultad deben entregar los artículos con un documento de entrega de artículos mediante el formato establecido por el Centro de Publicaciones. Este formato puede ser solicitado en el Centro de Publicaciones de la Pontificia Universidad Católica del Ecuador.

6. La convocatoria para presentar artículos será publicada en la página web de la Pontificia Universidad Católica del Ecuador y por medio de un email a cada decano/a de dicha facultad.

7. Firmar un documento en el cual indiquen que el artículo por publicarse es inédito y original, así como que este no ha sido publicado en ninguna otra revista ya sea virtual o impresa. En este documento también el autor se compromete a ceder su derecho 
de autor a la Revista PUCE, para que el artículo pueda ser editado, publicado y distribuido.

8. Para asegurar la calidad científica de los artículos presentados para su publicación, se realiza un proceso de evaluación de artículos los cuales pasan por tres fases: 1. Revisión por parte del Director/Editor y el Comité Editorial del Centro de Publicaciones para determinar si el tema, contenido de los artículos y formato de presentación se ajustan a los parámetros temáticos y formales. 2. Los artículos son enviados al Decano de la Facultad, quien designa dos o tres pares académicos, quienes anónimamente (modalidad de doble ciego) se encargan de realizar una evaluación a nivel del contenido científico del artículo según los parámetros del formato de dictaminación. Al final de este proceso, los miembros del Comité envían la plantilla completa donde se indica: a) el artículo aprobado para publicación; b) artículo no apto para publicación; c) artículo apto pero después de realizar las correcciones indicadas en el informe. Luego este informe es aprobado y firmado por el revisor. Esta información puede ser usada únicamente por el Director/Editor de la revista ya que el nombre de los revisores debe ser anónimo y bajo ninguna circunstancia sus nombres podrán ser revelados. 3. Revisión detallada del artículo por parte del Comité Editorial de la Facultad (personas no anónimas) para cerciorarse y asegurar al 100 \% el cumplimiento de los requisitos establecidos en la primera y segunda fase, para poder continuar con el proceso de edición. Una vez recibida la aprobación del artículo, este pasará a una revisión final para su futura aprobación, edición y publicación.

9. Con respecto al apartado 7, es importante indicar que el Comité Editorial constará de tres miembros que no pertenezcan a la universidad, para brindar apertura editorial y permitir una mejor selección de los artículos por publicarse. Igualmente los artículos entregados al Centro de Publicaciones pasarán por una revisión con especial istas en el área y que pertenecen a la Universidad, así como especialistas externos que evalúen la calidad científica de los trabajos.

10. El Director/editor de la revista firmará el documento de aceptación como representante del Centro de Publicaciones y su Comité.

\section{Portada}

11. Título del artículo con letras mayúsculas, en negrita y centrado. El título debe ir tanto en español como en inglés.

12. Debajo del título y centrado indicar los nombres de cada autor, de la siguiente manera: José Dávila P., Carla Casas, Francisco Chiriboga J.

13. Al final del nombre de cada autor, señalar un superíndice y mencionar al pie de página la afiliación del autor, es decir, lugar de trabajo, país, ciudad y dirección de correo electrónico de la siguiente manera: José Dávila P. ', Carla Casas L. ${ }^{2}$ \& Francisco Chiriboga J.3. y al pie de página indicar de la siguiente manera: Pontificia Universidad Católica del Ecuador, Facultad de Medicina, Quito, Ecuador (jdavila@hotmail.com). Si no se desea especificar el mail de todos los autores, se debe colocar el email de la persona encargada del artículo. 


\section{Resumen}

14. Se deberá presentar un resumen en español, claro y conciso, de todo el contenido.

15. Se deberá presentar un abstract en inglés, claro y conciso, de todo el contenido.

\section{Palabras clave}

16. Debajo del resumen se deben incluir 4 a 6 palabras clave que permitan al lector identificar el tema del artículo.

17. Debajo del abstract se deben incluir 4 a 6 palabras (key words) que permitan al lector identificar el tema del artículo.

\section{Texto}

18. El texto deberá estar escrito en formato Word, letra Times New Roman número 12, como fuente de texto y con espacio 1,5 de párrafo. Este formato no será mantenido durante la edición pero sí constará como requisito para la aprobación del artículo en la parte de formato.

19. Los subtítulos como introducción, materiales y métodos, resumen, entre otros, deberán ir en mayúsculas con negrita y alineados a la izquierda.

20. Las tablas y gráficos pueden ser ubicados entre el texto, si estos ayudan a explicar más sobre lo que se está refiriendo el autor, o al final, es decir, antes de la bibliografía.

21. Se recomienda mantener el orden del artículo como: título en español, título en inglés, nombre del autor, resumen, palabras clave, abstract, key words, introducción, objetivos, materiales y métodos, resultados, discusión, conclusiones, tablas y figuras, bibliografía, entre otros.

\section{Citas}

22. La forma de citar en los artículos se ha basado en el método APA (American Psychological Association), sexta edición, y ha sido modificado por el Centro de Publicaciones de la Pontificia Universidad Católica del Ecuador.

23. Las citas se usarán de la siguiente manera: (Aguirre, 2007) en el caso de un solo autor, para dos autores (Aguirre \& Pérez, 2007) o (Aguirre y Pérez, 2007), para más de dos autores (Aguirre et al., 2007). Estas citas irán entre el texto, y al pie de página solo se marcarán citas de internet y también datos explicativos sobre términos, autores, entre otros.

\section{Bibliogafía}

24. En caso de usar artículos o libros del mismo autor, estas citas deben tener un orden cronológico desde el más antiguo al más nuevo.

25. El formato para escribir la bibliografía será usada según el modelo APA (American Psychological Association), sexta edición:

Libro con un autor

Apellido del autor, inicial del nombre del autor (año de publicación). Nombre del 
libro en cursiva. Ciudad: Editorial. Ejemplo:

Flores de Fernández, R. (1965). Historia de la enfermería en Chile: Síntesis de su evolución educacional. Santiago: Universidad de Chile.

\section{Libro con más de un autor yedición}

Apellido del autor, inicial nombre. \& apellido del segundo autor, inicial del nombre (fecha de publicación). Nombre del libro en cursiva (número de la edición). Ciudad: Editorial. Ejemplo:

Hoffman, C.P. \& Lipkin, G.B. (1981). Simplified nursing (19a. ed.). Philadelphia: J.B. Lippincott.

\section{Libro sin autor o editor}

Título del libro en cursiva (número de edición) (año de publicación). Ciudad: Editorial. Ejemplo:

Merriam-Webster's collegiate dictionary (10a. ed.) (1993). Springfield: Merriam-Webster.

\section{Parte o capítulo de un libro}

Apellido del autor, inicial nombre del autor. \& apellido del segundo autor, inicial del nombre (año de publicación). Título del capítulo del libro. En apellido del autor del libro, inicial del nombre. Título del libro en cursiva. (número de edición., páginas). Ciudad: Editorial. Ejemplo:

O'Neil, J.M. \& Egan, J. (1992). Men's and women's gender role journeys; Methaphor for healing, transition and transformation. En B.R. Wainrib (Ed.). Gender issues across the life cycle (4a.ed., pp.107-123). Nueva York: Springer.

\section{Artículo de revista científica con un autor}

Apellido del autor, nombre del autor (año de publicación). Título del artículo. Nombre de la revista en cursiva, número de la revista (volumen), páginas. Ejemplo:

Prieto, A. (2001). Instrumento de evaluación de campos clínicos para la enseñanza profesional de enfermería (ECCE). Horizonte de Enfermería, 12 (1), 11 - 21.

\section{Artículo de revista científica con más de un autor}

Apellido del autor, inicial del nombre., apellido del segundo autor, iniciales., apellido del tercer autor, inicial del nombre., \& apellido del cuarto autor, iniciales. (año de publicación). Título del artículo. Nombre de la revista en cursiva, número de la revista (volumen), páginas. Ejemplo:

Kernis, M.H., Cornell, D.P., Sun, C.R., Berry, A., \& Harlow, T. (1993). There's more to selfesteem than whether it is high or low: The importance of stability of self-esteem. Journal of Personality and Social Psychology, 65 (6), 1190-1204. 
Si necesita el modo de como citar otro tipo de documento visite http://www. frvt.utn.edu.ar/pdfs/Citas_Bibliogr\%C3\%A1ficas_-_Normas_APA.pdf, ahí encontrará la forma adecuada de citar los documentos no explicados en este texto; sin embargo, no se olvide de revisar el instructivo de publicación de artículos en la revista PUCE, ya que el Centro de Publicaciones ha realizado ciertas modificaciones al manual del APA, para facilitar a los autores el manejo de citas y referencias bibliográficas.

\section{Figuras y tablas}

26. Las tablas deben llevar el texto explicativo en la parte superior y con letra en negrita.

27. Las figuras deben llevar el texto en la parte inferior y con letra en negrita.

28. La ubicación de tablas y figuras dependerá de qué tan explicativas sean. Si se trata de este tipo de tablas o figuras que son dentro del contexto al cual se están refiriendo, colocarlas en el texto, de lo contrario ubicarlas antes de la bibliografía.

29. Los cuadros y tablas deben estar en formato Word y las figuras pueden estar en formato JPG o Word.

30. Para tablas, cuadros, gráficos, se usarán palabras completas y se numerarán en orden; ejemplo:

Tabla 1: Lista de especies de la Estación Científica Yasuní

31. Si las imágenes son obtenidas de publicaciones anteriores, deben ser citadas.

32. Las imágenes por ningún motivo podrán ser modificadas en Photoshop, Ilustrator o cualquier otro software de diseño; la única modificación posible de realizar es el aumento o reducción del color y contrastes.

\section{Formas de envío}

33. Los artículos por publicarse deben ser enviados en CD y en impreso en formato Word.

34. Los artículos deben ser remitidos con una carta del Decano de la Facultad y con los artículos postulados para la publicación tanto en impreso como en digital, sin protección o candados.

35. En caso de ser un autor extranjero enviar una carta de solicitud y el artículo en digital vía email.

\section{Enviar Correspondencia:}

Revista PUCE/ Centro de Publicaciones

Pontificia Universidad Católica del Ecuador

Av. 12 de Octubre 1076 y Roca

Quito, Ecuador

Apartado 17-01-2184

Teléfono: 593022991711

publicaciones@puce.edu.ec 


\section{INSTRUCTIONS FOR PUBLISHINGARTICLES IN THE REVISTA PUCE (PUCE JOURNAL)}

\section{General Information}

Revista PUCE (the PUCE Journal) is a publication of the Pontifical Catholic University of Ecuador in Quito, Ecuador which edits a journal every three months (May 3 to November 3). This magazine informs of results and analysis, as products of research, in different areas of knowledge. Articles proposed for publication in "Revista PUCE" must follow the following instructions:

1. Originality: The articles published in "Revista PUCE" have to be original and unpublished. They must not be proposed for publication simultaneously in other journals or editorial media. Therefore, so that this part is clear, a document of author originality and property rights has to be signed by each author; in this way, the authors are committed to respecting the academic information of other authors, and to transfer author rights to the Revista PUCE, so that this be the only one authorized to edit formats and not information, avoiding that more than one journal publish the same article.

2. The works of professors and researchers from the University will be received, as well as from external authors. This is to help disseminate scientific material not only from our university, but rather from external researchers as well.

3. The articles to be published in this journal must mainly be written in Spanish; however, on specific request, articles can also be published in French, English, or Portuguese.

4. The Publications Center of the Pontifical Catholic University will deliver a reception document when the articles have been handed in. It is important to indicate that as publication of each magazine is done in accordance with each faculty of our university, this reception document will be signed by the Director of the Publications Center as the editor.

5. Deans interested in publishing articles from their faculty should hand in the articles with a document for article delivery by means of a format established by the Publications center. This format can be requested in the Publications Center of the Pontifical Catholic University of Ecuador.

6. The invitation for presenting articles will be published in the web page of the Pontifical Catholic University of Ecuador, and by means of an electronic mail to each dean of every faculty.

7. A document must be signed indicating that the article to be published is original and unpublished, and that it has not been published in any other journal, whether virtually or in print. As well, the author is committed to transferring his author rights to the Revista PUCE so that the article can be edited, published, and distributed.

8. In order to assure the scientific quality of the articles presented for publication, an article evaluation process is performed, passing through three phases: 1. Review by 
the Director/Editor and the Editorial Committee of the Publications Center to determine if the topic, article content and format presentation come to terms with thematic and formal parameters. 2. The articles are sent to the dean of the faculty, who will designate two or three academic pairs, and who anonymously (double blind modality) will be in charge of evaluating the scientific content level of the article, according to the parameters of the format adjudication.

8. At the end of this process, the Committee members send the complete template where is indicated the following: a) the article approved for publication; b) the article not apt for publication; c) the article apt, but after making the necessary corrections as mentioned in the report. Afterwards, this report is approved and signed by the copy editor. This information may be used only by the Director/Editor of the journal, since the names of the copy editors should be anonymous, and under no circumstances can their names be revealed. 3) There must be a detailed review of the article on the part of the Faculty Editorial Committee (non anonymous members) to verify and to be assured $100 \%$ of compliance with the requirements established in the first and second phases, in order to continue with the editing process. Once approval of the article has been received, it will pass to a final review for future approval, editing, and publication.

9. In regard to part 7, it is important to indicate that the Editorial Committee will have three members who do not pertain to the university, in order to provide editorial openness and permit a better selection of the articles to be presented. As well, the articles delivered to the Publications Center will pass through a review with specialists in the area and that belong to the university, just as in the case of external specialists, to evaluate the scientific quality of the works.

10. The Director/Editor of the Journal will sign the approval document as representative of the Publications Center and its Committee.

\section{Cover}

11. The article title will be in capital letters, in black, and centered. The title should be in both Spanish and English.

12. Under the centered title should be located the names of each author, in the following manner: José Dávila P., Carla Casas, Francisco Chiriboga J.

13. At the end of the name of each author, there should be a superscript, and the author's affiliation ought to be mentioned at the foot of the page; in other words, place of work, country, city and electronic mail address, in the following manner: José Dávila P. ', Carla Casas L. ${ }^{2}$, \& Francisco Chiriboga J. ${ }^{3}$, and at the foot of the page, in the following manner: Pontificia Universidad Católica del Ecuador, Facultad de Medicina, Quito Ecuador (jdavila@hotmail.com). If there is no wish to specify the electronic mail address of all the authors, the electronic mail address of the person in charge of the article should be located. 


\section{Summary}

16. In addition, a summary of all the content should be presented: clear and concise, both in Spanish and English.

17. The summary in Spanish and then the summary in English should be placed below the Key words (abstract).

\section{Key words}

14. Below the name of the author(s), from 4 to 6 words should be included referring to the type of content of the article, to facilitate the search.

15. These key words should be centered and be first in Spanish and then in English (key words).

\section{Text}

18. The text should be written in Word, with Times New Roman font number 12 as text source, and with paragraph spacing of 1.5. This format will not be maintained during the editing, but will be a requirement for article approval in said format.

19. The subtitles, such as the introduction, materials and methods, summary, among others, should be in capital letters in black and aligned to the left.

20. The tables and graphics can be located within the text, if they help to explain more regarding what the author is referring to, or at the end, in other words, after the literature cited.

21. It is recommended that order in the article be maintained, such as: the title in Spanish, the title in English, name of the author, key words, summary, abstract, introduction, objectives, materials and methods, results, discussion, conclusions, bibliography, tables and figures, among others.

\section{Citations}

22. The citation form in the articles is based on the APA method (American Psychological Association), sixth edition, and has been modified by the Publications Center of the Pontifical Catholic University of Ecuador.

23. Citations will be used in the following way: (Aguirre,2007) in the case of one author; for two authors, (Aguirre \& Pérez, 2007), or (Aguirre y Pérez, 2007); for more than two authors, (Aguirre et al., 2007). These citations will be within the text and at the foot of the page. Citations from Internet will be marked as well as explanatory citations regarding terms, authors, among others.

\section{Bibliography}

24. In case there are articles or books by the same author, these citations should be in chronological order from the oldest to the newest.

25. The format for writing the literature cited will be used according to the APA model (American Psychological Association), sixth edition. 
Book with one author

Author's last name, initials of the author's name (publication year). Book name in italics. City: Editorial.

For example: Flores de Fernández, R. (1965). Historia de la enfermería en Chile: Síntesis de su evolución educacional. Santiago: Universidad de Chile.

Book with more than one autor and edition

Author's last name, name initial. \& second author's last name, name initial (publication date). Book name in italics (edition number). City: Editorial.

For example: Hoffman, C.P. \& Lipkin, G. B. (1981). Simplified nursing (19a.ed.). Philadelphia: J.B. Lippincott.

Book without an author or editor

Book title in italics (edition number) (publication year). City: Editorial.

For example: Merriam-Webster's collegiate dictionary (10a. ed.) (1993). Springfield: Merriam-Webster.

\section{Book part or chapter}

Author's last name, author's name initials. \& second author's last name, name initials (publication year). Book chapter title. Last name of book author, name initials. Book title in italics. (edition number., pages). City: Editorial.

For example: O’Neil, J.M. \& Egan, J. (1992). Men's and women's gender role journeys; Metaphor for healing, transition and transformation. In B.R. Wainrib (Ed.). Gender issues across the life cycle (4a. ed., pp 107-123). New York: Springer.

Scientific journal article with one author

Author's last name, author's name (publication year). Article title. Journal name in italics, journal name (volume), pages.

For example: Prieto, A. (2001). Instrumento de evaluación de campos clínicos para la enseñanza profesional de enfermería (ECCE). Horizonte de enfermería, 12 (1), 11-21.

Scientific journal article with more than one author

Author's last name, name initials., second author's last name, initials., third author's last name, name initials., \& fourth author's last name, initials. (publication year). Article title. Journal name in italics, journal number (volume), pages.

For example: Kernis, M.H., Cornell, D.P., Sun, C.R., Berry, A., \& Harlow, T. (1993). There's more to self-esteem than whether it is high or low: The importance of stability of self-esteem. Journal of Personality and Social Psychology, 65 (6), 1190-1204.

If you need to know how to cite other kinds of documents, please visit http://www.frvt.utn.edu.ar/pdfs/Citas_Bibliogr\%C3\%A1ficas_-_Normas_APA.pdf There you will find the appropriate way to cite unexplained documents in this text; 
nevertheless, do not forget to review the instructions for article publication in the "Revista PUCE", since the Publications Center has made certain modifications in the APA manual to facilitate the authors in handling citations and bibliographic references.

\section{Figures and charts}

26. The tables should contain the explicative text in the upper part and with letters in black.

27. The figures should contain the text in the lower part and with letters in black.

28. The location of the tables and figures will depend on how explicative they are. If it is about the type of tables or figures that are within the context being referred to, place them in the text; otherwise, place them after the literature cited.

29. The charts and tables should be in Word and the figures can be in JPG format or Word.

30. For tables, charts, graphics, use complete words and number them in order; for example:

Table 1: List of species at the Yasuní Scientific Station

31. If the images are obtained from previous publications, they should be cited.

32. The images should not be modified in Photoshop, Illustrator, or any other design software for any reason; the only possible modification to be done is the increase or reduction of color and contrasts.

\section{Delivery modes}

33. The articles to be published should be sent in CD and in print in Word.

34. The articles should be sent with a letter from the dean of the faculty and with the proposed articles for publication, both in print and digitally, without any protection or padlocks.

35. If the author is a foreigner, please send a solicitude and the article digitally via electronic mail.

\section{For sending correspondence:}

Revista PUCE/Publications Center

Pontificia Universidad Católica del Ecuador

Av. 12 de octubre 1076 y Roca

Quito, ecuador

Apartado 17-01-2184

Teléfono: 593022991711

publicaciones@puce.edu.ec 

